QA: QA

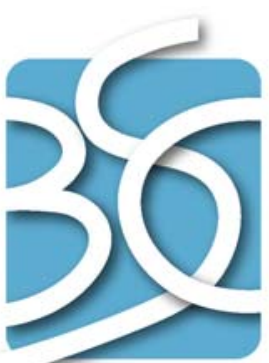

BECHTEL SAIC COMPANYLC

ANL-EBS-MD-000074 REV 01

August 2005

\title{
Analysis of Dust Deliquescence for FEP Screening
}

Prepared for:

U.S. Department of Energy

Office of Civilian Radioactive Waste Management

Office of Repository Development

1551 Hillshire Drive

Las Vegas, Nevada 89134-6321

Prepared by:

Bechtel SAIC Company, LLC

1180 Town Center Drive

Las Vegas, Nevada 89144

Under Contract Number

DE-AC28-01RW12101 


\section{DISCLAIMER}

This report was prepared as an account of work sponsored by an agency of the United States Government. Neither the United States Government nor any agency thereof, nor any of their employees, nor any of their contractors, subcontractors or their employees, makes any warranty, express or implied, or assumes any legal liability or responsibility for the accuracy, completeness, or any third party's use or the results of such use of any information, apparatus, product, or process disclosed, or represents that its use would not infringe privately owned rights. Reference herein to any specific commercial product, process, or service by trade name, trademark, manufacturer, or otherwise, does not necessarily constitute or imply its endorsement, recommendation, or favoring by the United States Government or any agency thereof or its contractors or subcontractors. The views and opinions of authors expressed herein do not necessarily state or reflect those of the United States Government or any agency thereof. 
QA: QA

Analysis of Dust Deliquescence for FEP Screening ANL-EBS-MD-000074 REV 01

August 2005 


\begin{tabular}{c|c|l} 
BSC & $\begin{array}{c}\text { Scientific Analysis Signature Page/ } \\
\text { Change History } \\
\text { Complete only applicable items. }\end{array}$ & Page iii \\
1. Total Pages: 274
\end{tabular}

\begin{tabular}{|c|c|c|c|}
\hline \multicolumn{4}{|c|}{$\begin{array}{l}\text { 2. Scientific Analysis Title } \\
\text { Analysis of Dust Deliquescence for FEP Screening }\end{array}$} \\
\hline \multicolumn{4}{|l|}{ 3. DI (including Rev. No.) } \\
\hline \multicolumn{4}{|c|}{ ANL-EBS-MD-000074 REV 01} \\
\hline & Printed Name & Signature & Date \\
\hline 4. Originator & C. Bryan & Chalar R. Buyror & $8 / 26 / 05$ \\
\hline 5. Checker & S. LeStrange & Susan helt & $8 / 26 / 05$ \\
\hline 6. QER & D. Svalstad & & \\
\hline 7. Responsible Manager/ Lead & W. Duffy & & \\
\hline 8. Responsible Manager & E. Hardin & & $8 / 26 / 05$ \\
\hline \multicolumn{4}{|l|}{ 9. Remarks } \\
\hline \multicolumn{4}{|c|}{$\begin{array}{l}\text { The originator of this document was the author of some sections, and integrated and coordinated inputs provided by several other } \\
\text { authors. The following BSC and National Laboratory personnel contributed to sections of the document: T. Breene (Summary of } \\
\text { talks by C. Steefel and J. Payer, Appendix E); R. Jarek (1, 4.1, 5, 6.4, 6.5, 7); C. Jove-Colon (4.1, Appendix B); S. Carroll (6.1); } \\
\text { J. Case (4.1, Appendix A); J. Kam (2, 3, 4, 6.2, 6.4.2, 6.4.4, 6.5); K. Mon (6.3, 6.4, and 6.5); B. Kirstein (6.4.2); H. Shaw (6.1); } \\
\text { Y. Tsang (Section 6.4); and Y. Wang (6.3). }\end{array}$} \\
\hline \multicolumn{4}{|c|}{$\begin{array}{l}\text { S. LeStrange checked the front matter and Sections } 1,2,5,6,6.1,6.2,6.3 \text {, and Appendix D; F. Caporuscio checked Sections } 3 \text {, } \\
\text { 6.4.1.2, 6.4.1.3, 6.4.4, 6.4.5, 6.5, and 7; W. Jaros checked Sections 1, 4, Appendices C, E, and G, and DIRS; J. Case checked } \\
\text { Sections 6.4, 6.4.1, 6.4.1.1, 6.4.2 and subsections, 8, and DIRS; J. Leem checked Appendices A and B; J. Kam checked Section } \\
\text { 6.4.3 and subsections, and Appendices A and F; B. Kirstein checked 4.1. }\end{array}$} \\
\hline \multicolumn{4}{|c|}{ Change History } \\
\hline 10. Revision No. & \multicolumn{2}{|c|}{ 11. Description of Change } & \\
\hline REV 00 & \multicolumn{2}{|c|}{ Initial Issue. } & \\
\hline REV 01 & \multicolumn{3}{|c|}{ DOE comment incorporation. Revision addresses CR 6366.} \\
\hline
\end{tabular}




\section{INTENTIONALLY LEFT BLANK}




\section{CONTENTS}

Page

ACRONYMS AND ABBREVIATIONS …..................................................................

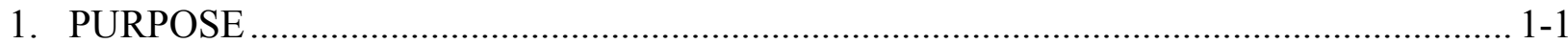

1.1 THE SCREENING APPROACH ............................................................. 1-1

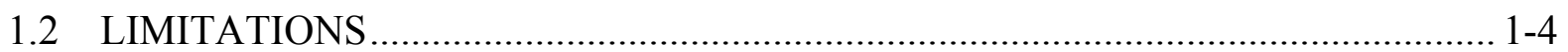

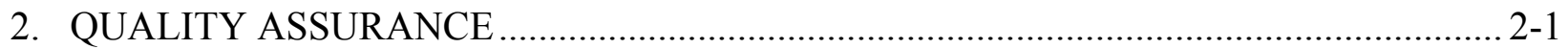

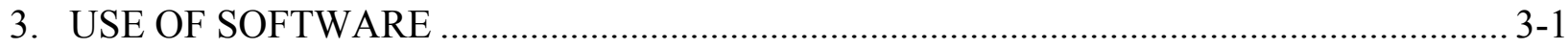

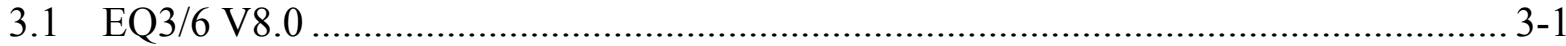

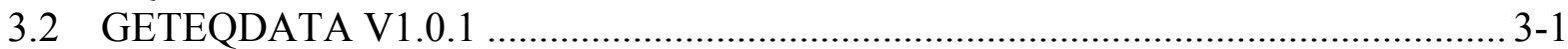

3.3 XTOOL V10.1 .......................................................................................... $3-1$

3.4 EXEMPT SOFTWARE USE .......................................................................... $3-2$

3.4.1 Microsoft Excel Versions 97, 2000, 2003 .............................................. 3-2

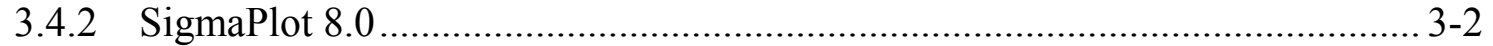

3.4.3 MathCad Version 11.2a ........................................................................ 3-2

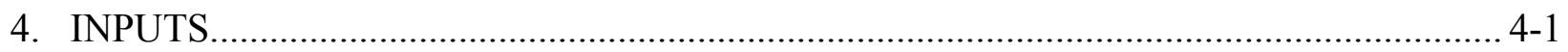

4.1 DIRECT INPUTS .................................................................................. $4-1$

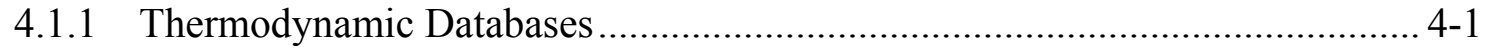

4.1.2 Parameters Describing Dust Deposition in Emplacement Drifts During Ventilation .................................................................................... 4-11

4.1.3 Dust Compositional Data Used to Estimate Brine Volume........................... 4-14

4.1.4 Data Supporting Stifling of Crevice Corrosion ......................................... 4-16

4.1.5 Dust Physical Data Used to Evaluate Retention Characteristics ................... 4-17

4.1.6 Input Data for Analysis of Grain-Grain Contacts, Oxygen Diffusion Properties, and Passive Current/Temperature Relationship........................ 4-17

4.1.7 Thermogravimetric Analysis Results for Ammonium Mineral Thermal Decomposition and Deliquescence of Mixed-Salt Assemblages at Elevated Temperatures................................................................................ 4-19

4.1.8 Input Data for Preclosure Temperature and Relative Humidity Analyses ..... 4-20

4.1.9 Dust Compositional Data Used to Evaluate Brine Reactions with Low-Solubility Dust Minerals and the Effects of Ammonium Decomposition................................................................... 4-26

4.1.10 Boiling Points for Saturated Aqueous Solutions of Pure Salts ...................... 4-29

4.1.11 Other Qualified Direct Input DTNs ............................................................. 4-30

4.1.12 Direct Inputs from Other Reports ......................................................... 4-30

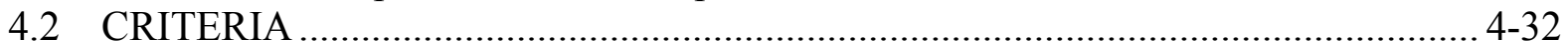

4.3 CODES, STANDARDS, AND REGULATIONS ........................................... 4-32

5. ASSUMPTIONS .......................................................................................................... $5-1$

5.1 UNIFORMITY OF DUST COMPOSITION..................................................... 5-1 


\section{CONTENTS (Continued)}

Page

6. SCIENTIFIC ANALYSIS DISCUSSION.

6.1 CAN MULTI-SALT DELIQUESCENT BRINES FORM AT

ELEVATED TEMPERATURE?

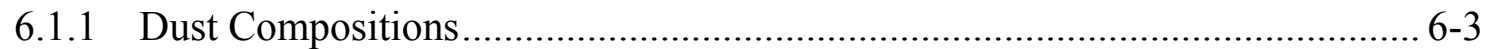

6.1.2 Analyses Based on Tunnel Dust Samples.................................................... 6-4

6.1.3 Composition of Atmospheric Aerosols................................................... 6-17

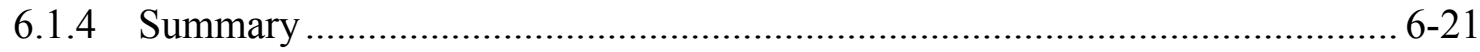

6.2 IF BRINES FORM AT ELEVATED TEMPERATURE, WILL

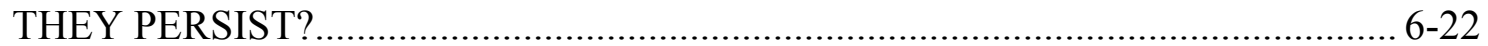

6.2.1 Thermogravimetric Studies of Acid-Gas Volatilization ................................ 6-23

6.2.2 Thermodynamic Analysis of Acid Degassing from Deliquescent Brines ...... 6-24

6.2.3 Scoping Evaluation of Degassing Efficiency ............................................. 6-40

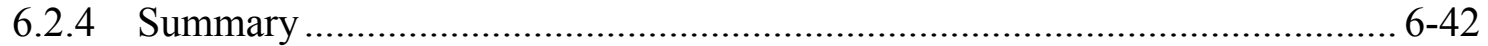

6.3 IF BRINES PERSIST, WILL THEY BE CORROSIVE? ....................................... 6-44

6.3.1 Predicted Initial Brine Compositions Are Noncorrosive .............................. 6-44

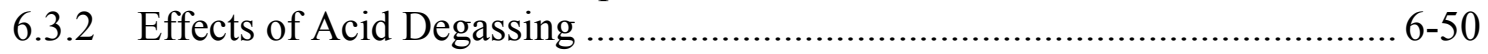

6.3.3 Reactions with Low-Solubility Dust Minerals ......................................... 6-51

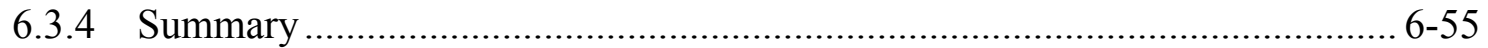

6.4 IF POTENTIALLY CORROSIVE BRINES FORM, WILL THEY INITIATE LOCALIZED CORROSION? ....................................................................... 6-56

6.4.1 Brine Volume Estimates from Deliquescence of Salts Originating as Atmospheric Aerosols..................................................................................... 6-56

6.4.2 Geometrical Analysis of Grain-Grain Contact............................................ 6-68

6.4.3 Retention of Brine in the Dust by Capillary Forces.................................... 6-78

6.4.4 Scale Limitations on Diffusion as Part of the Localized Corrosion Process .. 6-84

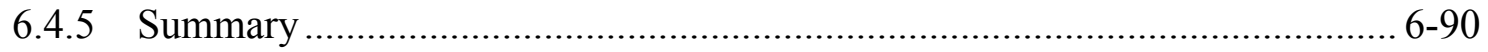

6.5 ONCE INITIATED, WILL LOCALIZED CORROSION PENETRATE THE

WASTE PACKAGE OUTER BARRIER? ......................................................... 6-92

6.5.1 Crevice Corrosion .................................................................................... 6-92

6.5.2 The Power Law for Propagation of Localized Corrosion .............................. 6-93

6.5.3 Will Corrosion Products Physically Sequester Brine?............................... 6-102

6.5.4 Will Corrosion Products Consume Brine Components $(\mathrm{Cl})$ ? ...................... 6-105

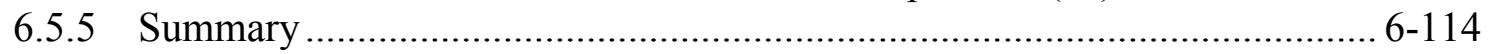

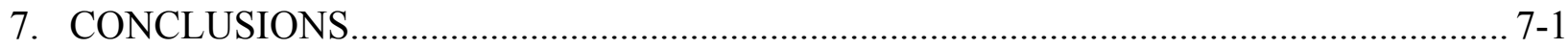

7.1 SUMMARY OF SCREENING ARGUMENTS ............................................... 7-1

7.1.1. Can Multi-Salt Deliquescent Brines Form at Elevated Temperature?

(Section 6.1) .............................................................................................. 7-2

7.1.2. If Brines Form at Elevated Temperature, Will They Persist? (Section 6.2) .... 7-2

7.1.3. If Brines Persist, Will They Be Corrosive? (Section 6.3) ............................... 7-3

7.1.4. If Potentially Corrosive Brines Form, Will They Initiate Localized Corrosion? (Section 6.4) ............................................................................ 7-3

7.1.5. Once Initiated, Will Localized Corrosion Penetrate the Waste Package Outer Barrier? (Section 6.5). 


\section{CONTENTS (Continued)}

Page

7.2 ADDRESSING ACCEPTANCE CRITERIA......................................................... 7-5

7.3 PRODUCT OUTPUT DTNS.............................................................................

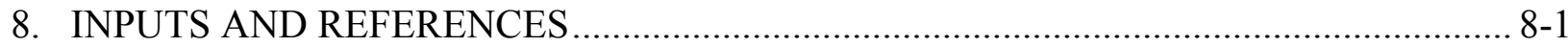

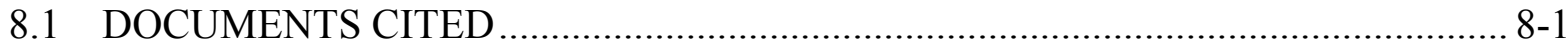

8.2 CODES, STANDARDS, REGULATIONS, AND PROCEDURES ......................... 8-15

8.3 SOURCE DATA, LISTED BY DATA TRACKING NUMBER ……………......... 8-17

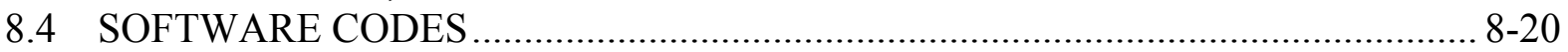

APPENDIX A: PRECLOSURE TEMPERATURE AND RELATIVE

HUMIDITY ANALYSIS................................................................. A-1

APPENDIX B: CALCULATIONS FOR AMMONIUM PITZER

DATABASE PARAMETERS ...............................................................

APPENDIX C: QUALIFICATION OF AIR PARTICULATE MATTER DATA

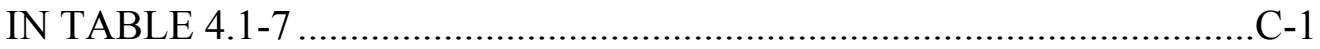

APPENDIX D: CORROBORATION OF THE SOLUBILITY OF OXYGEN IN

WATER FROM EPRI REPORT ………………………........................ D-1

APPENDIX E: SUMMARY OF MAY 2004 PRESENTATIONS TO THE

NUCLEAR WASTE TECHNICAL REVIEW BOARD.................................E-1

APPENDIX F: QUALIFICATION OF WATER-SOLUBLE CONCENTRATIONS

OF DUST SAMPLES ……………………………...........................

APPENDIX G: QUALIFICATION OF THE SOLUBLE SALT CONTENT

IN ATMOSPHERIC DUST SAMPLES COLLECTED IN

FORTYMILE WASH FROM 1985 TO 1989, REPORTED

IN REHEIS AND KIHL 1995 [DIRS 106653]

G-1 


\section{INTENTIONALLY LEFT BLANK}




\section{FIGURES}

Page

4-1. Predicted Deposition Velocities at 1 Meter as a Function of Particle Diameter and Density $4-14$

6-1. Schematic Illustration of Deliquescence and Evaporation ......................................... 6-1

6-2. Evolution of Temperature and $\mathrm{RH}$ on a Waste Package Surface ............................... 6-3

6.1-1. Deliquescence of the $\mathrm{NaCl}-\mathrm{KNO}_{3}-\mathrm{NaNO}_{3}$ System at Elevated Temperature............. 6-5

6.1-2. Decomposition of Dry Ammonium Chloride $\left(100\right.$ to $\left.250^{\circ} \mathrm{C}\right)$ and Ammonium Sulfate (100 to $200^{\circ} \mathrm{C}$ ) Salts Determined by Weight Loss Using a Thermogravimetric Analyzer

6.1-3. Arrhenius Plot for the Decomposition of $\mathrm{NH}_{4} \mathrm{Cl}$, Using Data for Mass Losses Less Than $10 \%$

6.1-4. Calculated Time for Complete Decomposition of $\mathrm{NH}_{4} \mathrm{Cl}$ and $\mathrm{NH}_{4} \mathrm{NO}_{3}$ Particles as a Function of Temperature

6.2-1. Evolution of the $\mathrm{NaCl}-\mathrm{KNO}_{3}$ Salt Assemblage ("A") at $126^{\circ} \mathrm{C}$ and $10^{-3.5}$ bar $p \mathrm{CO}_{2}$, as $\mathrm{HCl}$ and $\mathrm{HNO}_{3}$ Degas in a Swept-Away Gas Boundary Condition

6.2-2. Evolution of the $\mathrm{NaCl}-\mathrm{KNO}_{3}-\mathrm{NaNO}_{3}$ Salt Assemblage ("B") at $100^{\circ} \mathrm{C}$ and $10^{-3.5}$ bar $p \mathrm{CO}_{2}$, as $\mathrm{HCl}$ and $\mathrm{HNO}_{3}$ Degas in a Swept-Away Gas Boundary Condition.

6.2-3. Evolution of the $\mathrm{NaCl}-\mathrm{KNO}_{3}-\mathrm{NaNO}_{3}$ Salt Assemblage ("C") at $25^{\circ} \mathrm{C}$ and $10^{-3.5}$ bar $p \mathrm{CO}_{2}$, as $\mathrm{HCl}$ and $\mathrm{HNO}_{3}$ Degas in a Swept-Away Gas Boundary Condition ...... 6-34

6.2-4. Deliquescence RH as a Function of Temperature for Salt Assemblage A and the Dryout Assemblage That Forms during Acid Degassing....

6.2-5. Deliquescence RH as a Function of Temperature for Salt Assemblage B and the Dryout Assemblages That Form during Acid Degassing

6.2-6. Deliquescence RH as a Function of Temperature for Salt Assemblage $\mathrm{C}$ and the Dryout Assemblages That Form during Acid Degassing ....

6.2-7. Degassing Efficiency as a Function of Gas-Phase and Acid-Gas Removal Rates ..... 6-42

6.3-1. Comparison of Analysis Results with Dust Leachate Residues Included (Labeled as "Leachate + solid") with Calculations Using Only Leachate (Labeled as "Leachate only").

6.4-1. Normalized Dust Deposition Quantity at Waste Package Position in Emplacement Drift: (a) 66-m Turnout, $1 \mathrm{~g} / \mathrm{cm}^{3}$; (b) $105-\mathrm{m}$ Turnout, $1 \mathrm{~g} / \mathrm{cm}^{3}$; (c) $105-\mathrm{m}$ Turnout $2 \mathrm{~g} / \mathrm{cm}^{3}$ Density $6-60$

6.4-2. Dust Deposition Quantity on the Waste Package with: (a) 66-m Turnout, $1 \mathrm{~g} / \mathrm{cm}^{3}$; (b) $105-\mathrm{m}$ Turnout, $1 \mathrm{~g} / \mathrm{cm}^{3}$; (c) $105-\mathrm{m}$ Turnout $2 \mathrm{~g} / \mathrm{cm}^{3}$ Density 6-61

6.4-3. NV00-2000 Solute and Water Mass during Evaporation at Various Temperatures. 6-64

6.4-4. NV00 Solute and Water Mass during Evaporation at $70^{\circ} \mathrm{C}$................................... 6-65

6.4-5. Mass Fraction of Salts Associated with Contacting Grains, for the Two-Salt System (upper) and the Three-Salt System (lower).

6.4-6. Calculated Film Thickness When the Brine Formed by Two Salts in Contact Is Spread throughout the Dust, Coating All Grains

6.4-7. FIB Image Showing the Freshly Exposed Cross-Section of a Dust Particle with an Average Dimension of $\sim 5$ Microns 


\section{FIGURES (Continued)}

Page

6.4-8. Backscattered Electron SEM Image of Epoxy-Impregnated Dust (Image A)........... 6-80

6.4-9. Backscattered Electron SEM Image of Epoxy-Impregnated Dust (Image B) ........... 6-80

6.4-10. Confocal Three-Dimensional Images of Air-Deposited Dust ................................ 6-81

6.4-11. Drawing of Pore Areas and Perimeters for Over 800 Pores, Based on the SEM Image Presented in Figure 6.4-8 ...................................................................... 6-82

6.4-12. Pore Diameter Distribution Based on the Pore Analysis in Figure 6.4-11 ............... 6-83

6.4-13. Passivation Current $\left(i_{\text {pass }}\right)$ as a Function of Temperature ....................................... 6-87

6.4-14. Predicted Change in Dissolved $\mathrm{O}_{2}$ Concentration with Brine Layer Thickness

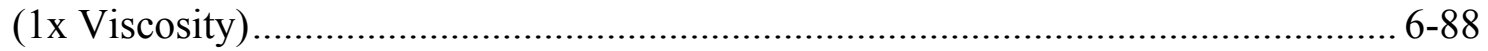

6.4-15. Predicted Change in Dissolved $\mathrm{O}_{2}$ Concentration with Brine Layer Thickness (10x Viscosity) .......................................................................................... 6-8

6.4-16. Predicted Change in Dissolved $\mathrm{O}_{2}$ Concentration with Brine Layer Thickness (100x Viscosity).

6.4-17. Optical Microscopic Images of Crevice Corrosion on an Alloy 22 Sample under a Pseudo Thin Film $(\sim 5 \mathrm{~mm})$ of Saturated $\mathrm{NaCl}$ Solution after 330 Hours at $105^{\circ} \mathrm{C}$ and $78 \%$ Relative Humidity.

6.5-1. Schematic Plot of Depth versus Time for Power Law Growth with Exponent Less Than One

6.5-2. Plot of Current versus Time during Constant Potential Testing of As-Welded Alloy 22 Prism Crevice Assembly Specimens

6.5-3. Plot of Depth versus Time during Constant Potential Testing of As-Welded Alloy 22 Prism Crevice Assembly Specimens

6.5-4. X-Ray Diffraction Patterns of "Rinsed" and "Unrinsed" Corrosion Products from the $\mathrm{CaCl}_{2}$ Brine Systems Aged with an Applied Polarizing Potential of $100 \mathrm{mV}$

6.5-5. Smoothed and Background Subtracted Diffraction Pattern of the "Rinsed" Sample Shown in Figure 6.5-4.

6.5-6. Published X-Ray Diffraction Peaks for a Ni:Cr LDH Phase, Formed at (a) High Supersaturation, (b) Low Supersaturation, and (c) after Hydrothermal Treatment.. 6-109

A-1. Range of Preclosure Waste Package Temperatures versus Relative Humidities for Various Conditions................................................................................... A-6

D-1. Corroboration of Polynomial Fit for Temperature-Dependent Oxygen Solubility

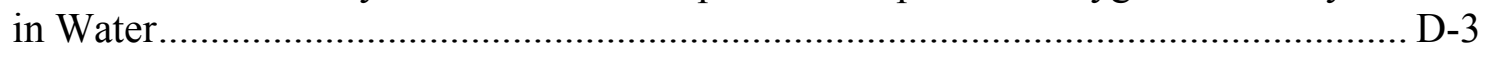

E-1. Periods in the Thermal Evolution of the Repository ….........................................2

E-2. $\quad \mathrm{RH}$ versus Mole-Fraction $\mathrm{NO}_{3}$ for $\mathrm{NaCl}-\mathrm{NaNO}_{3}$ System.........................................

E-3. Deliquescence and Stability of $\mathrm{CaCl}_{2}$ and $\mathrm{MgCl}_{2}$ Brines in TGA Experiments........... E-7

E-4. $\quad$ Fate of Acid Gas in the Drift Environment........................................................... E-8

E-5. THC Simulation of Acid-Gas Transport in the Drift and Near-Field: Waste Package above Boiling, Drift Wall below Boiling (No Condensation in the Drift)

E-6. $\quad$ THC Simulation of Acid-Gas Transport: Waste Package and Drift Wall below Boiling, Water Vapor Axially Transported from a Hotter Region (Condensation Occurs). E-10

E-7. Catholic University Distillation Experiment ........................................................ 12 


\section{FIGURES (Continued)}

Page

E-8. Long-Term Passive Corrosion Rates of Alloy 22 in Liquid and Vapor, to $90^{\circ} \mathrm{C}$.......E-15 E-9. $\quad$ Passive Corrosion Rates of Alloy 22 in the Presence of Nitrate in (a) Sodium-Chloride Brines and (b) Calcium-Chloride Brines .................................E-15

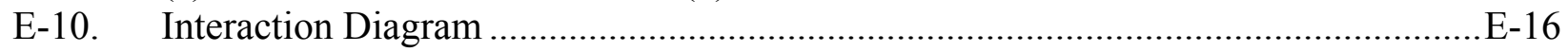

E-11. Expected Aqueous Solution Types .......................................................................... E-19

E-12. Possible Brine Composition Zones Related to Temperature and Relative Humidity during Cooldown after the Peak Temperature. 


\section{INTENTIONALLY LEFT BLANK}




\section{TABLES}

Page

3-1. Qualified Software Used in This Report.......................................................... 3-2

4.1-1. Input Pitzer Interaction Parameters.................................................................. 4-2

4.1-2. Input Mole Fraction Solubility Constants at 298.15 K ….......................................... 4-7

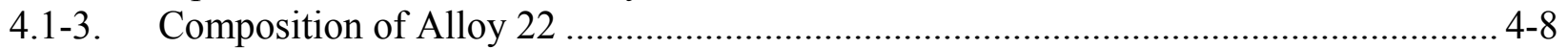

4.1-4. Thermodynamic Data for Ni:Cr and Ni:Fe LDH Phases ........................................... 4-9

4.1-5. Thermodynamic Data for Akaganeite................................................................ 4-11

4.1-6. Emplacement Drift Design and Operational Input Data............................................ 4-12

4.1-7. Airborne Particulate Measurement Inputs from Site 5, Annual Averages .................. 4-12

4.1-8. NADP/NTN Precipitation-Weighted Annual Mean Concentrations............................ 4-15

4.1-9. Fortymile Wash Dust Data................................................................................. 4-16

4.1-10. $\mathrm{NaNO}_{3}$ and Water Densities for Input to Brine Volume Calculation .......................... 4-16

4.1-11. Current versus Exposure Time for Alloy 22 Specimens Held at

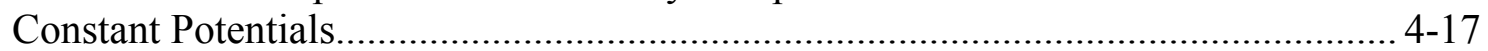

4.1-12. Emplacement Drift Geometries, Ventilation Flow Rate, Ventilation Duration........... 4-21

4.1-13. Waste Package Heat Decay ............................................................................ 4-22

4.1-14. Kays and Leung Parameters for Forced Convection ................................................ 4-23

4.1-15. Thermophysical Properties at the Repository Horizon ................................................ 4-24

4.1-16. Thermophysical Properties of Air........................................................................ 4-25

4.1-17. Bulk Chemical Compositions of Dust Samples from the ESF (wt \%) ...................... 4-26

4.1-18. Chemical Compositions of Dust Leachates ( $\mu \mathrm{g} / \mathrm{g}$ Dust) ………................................ 4-28

4.1-19. Boiling Points of Aqueous Solutions of Pure Salts ................................................. 4-29

6.1-1. Calculated Lifetimes of $\mathrm{NH}_{4} \mathrm{Cl}$ and $\mathrm{NH}_{4} \mathrm{NO}_{3}$ as a Function of Temperature............. 6-10

6.1-2. Effect of Ammonium Salt Decomposition on Predicted Brine Compositions ............ 6-13

6.1-3. Tunnel Dust Analyses That Include Ammonium .................................................... 6-13

6.1-4. Compositions of Brines Formed by Dust Deliquescence after Ammonium Salt

Decomposition: NADP/NTN Salts .................................................................... 6-16

6.1-5. Compositions of Brines Formed by Dust Deliquescence after Ammonium Salt

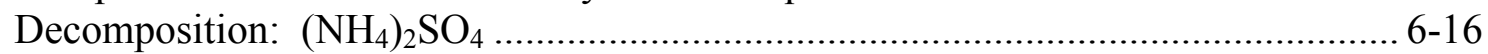

6.1-6. Generalized Aerosol Particle Properties as a Function of Size.................................. 6-17

6.2-1. Evolution of Single-Salt Systems by Acid Degassing .............................................. 6-27

6.2-2. Evolution of Multiple-Salt Assemblages by Acid Degassing.................................... 6-29

6.2-3. Predicted Initial and Final $\mathrm{pH}$ Values and Acid-Gas Partial Pressures for

Deliquescent Brines, at $p \mathrm{CO}_{2}=10^{-3.5} \mathrm{bar}$................................................................. 6-41

6.3-1. Target Composition of Standard Test Media Based on Evaporative

Concentration of a Dilute Carbonate-Type Water ...................................................... 6-45

6.3-2. Brines Formed by Dust Deliquescence and the Corresponding Corrosion

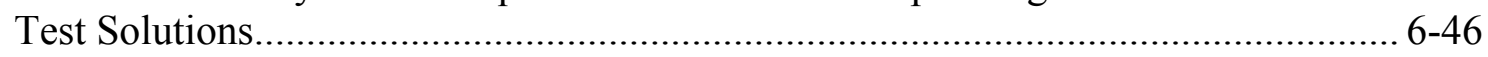

6.3-3. General Classification of the Brine Types and the Probabilities of Contact .............. 6-47

6.3-4. Test Temperatures and Durations Used in Autoclaves and Teflon Acid

Digestion Bombs................................................................................................... 6-50

6.4-1. Disposition of Representative Ventilation Dust in Average and Short Drifts ............ 6-62

6.4-2. Consideration of Smaller Particle Deposition in Average Drift .................................. 6-63

6.4-3. Analysis Values and Results for Atmospheric Dust Brine Volume ............................ 6-66 


\section{TABLES (Continued)}

Page

6.4-4. Maximum Brine Developed from Atmospheric Dust on Waste Package ................... 6-67

6.5-1. Summary of Data from Constant Potential Experiments .......................................... 6-96

6.5-2. Summary of Power Law Fit to Corrosion Stifling Data .......................................... 6-102

6.5-3. Calculations Illustrating Brine Sequestration in the Porosity of Corrosion

Products Using Hemispherical and Conical Breaches, and a Maximum

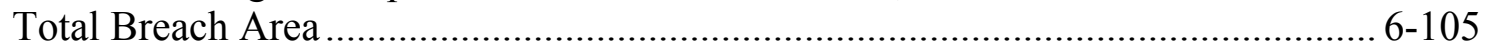

6.5-4. Thermodynamic Data for Ni:Cr and Ni:Fe LDH Phases ...................................... 6-109

6.5-5. Composition of Hypothetical Alloy 22 Solid Phase Added to data0.ypf.R2 2........... 6-110

6.5-6. EQ3/6 Files Used in Evaluating the Stability of LDH in Deliquescent Brines ........ 6-112

6.5-7. Results of Simulations of Experimental Corrosion Studies..................................... 6-113

6.5-8. Results of Simulations of Deliquescent Brine Assemblages ................................. 6-114

7.1-1. Decision Tree Propositions and Data Sources Considered............................................. 7-1

7.3-1. Product Output DTNs ..........................................................................................

A-1. Summary of Preclosure Maximum Temperature and Relative Humidity Results ...... A-5

A-2. $\quad$ Range of Rock Mass Thermal Conductivity ............................................................. A-6

B-1. Calculated Coefficients for the Molality-Based Pitzer Parameters Based on the

Mole-Fraction Model of Clegg et al. (1998 [DIRS 172815]) .........................................3-3

B-2. Corrected $\mathrm{NH}_{4} \mathrm{NO}_{3}$ Parameters at $298.15 \mathrm{~K}$ for Clegg et al.

(1998 [DIRS 172815]) Mole Fraction Model ...............................................................-4

B-3. Fitting Coefficients for Temperature Function of the Clegg et al.

(1998 [DIRS 172815]) Mole Fraction Model ..................................................................

C-1. Unqualified Airborne Particulate Matter Data Tracking Numbers................................

C-2. Qualified Airborne Particulate Matter Data Tracking Numbers....................................-2

C-3. Unqualified Airborne Particulate Matter Annual Averages from Site 5 ........................2-2

C-4. Qualified Airborne Particulate Matter Annual Averages from Site 5 ………….............

C-5. Airborne $\mathrm{PM}_{10}$ Measurement Descriptive Statistics .......................................................

C-6. Airborne TSP Measurement Descriptive Statistics.......................................................

D-1. Corroboration of EPRI Oxygen Solubility Prediction .............................................. D-2

E-1. X-Ray Diffraction Analysis of Salts Precipitated from Evaporated

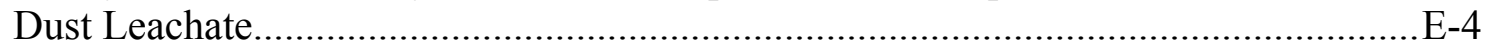

E-2. Salt Mineralogy Calculated with EQ3/6 ................................................................

E-3. Comparison of Soluble Ionic Ratios ( $\mathrm{mol} / \mathrm{mol})$ : Tunnel Dusts versus

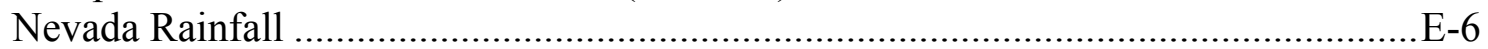

E-4. Alloy 22 Corrosion Rates in Concentrated Salt Brines at Elevated Temperatures,

Determined by Weight Loss in Autoclave Tests ........................................................

F-1. Tunnel Dust Analyses That Include Ammonium .....................................................F-1

F-2. Sample Splits for Leachate Analyses...................................................................

F-3. Results of Leaching of Dust and Rock Samples from the ESF ………......................F-3

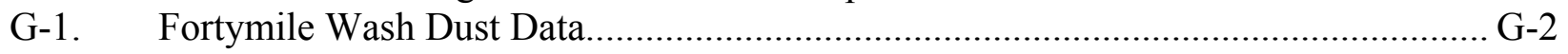




\section{ACRONYMS AND ABBREVIATIONS}

ASTM American Society for Testing and Materials

BSW basic saturated water

DHLW defense high-level radioactive waste

DTN data tracking number

ECRB Enhanced Characterization of the Repository Block

EPA Environmental Protection Agency

EPRI Electric Power Research Institute

ESF Exploratory Studies Facility

FEP feature, event, or process

FIB focused ion beam

IDPS in-drift precipitates/salts (model)

IED information exchange drawing

JCPDF Joint Committee Powder Diffraction File

LBNL Lawrence Berkeley National Laboratory

LDH layered double hydroxide

LLNL Lawrence Livermore National Laboratory

NADP/NTN National Airfall Deposition Program/National Trends Network

NWTRB Nuclear Waste Technical Review Board

$\mathrm{PM}_{10} \quad$ inhalable particulate matter $10 \mu \mathrm{m}$ or less in diameter

PWR pressurized water reactor

QA quality assurance

$\mathrm{RH} \quad$ relative humidity

SAW simulated acidic water

SCW simulated concentrated water

SDW simulated dilute water

SEM scanning electron microscope

SSC saturated silver chloride

SSW simulated saturated water

TDMS Technical Data Management System

TGA thermogravimetric analysis

THC thermal-hydrologic-chemical

TSP total suspended particles 


\section{ACRONYMS AND ABBREVIATIONS (Continued)}

TSPA-LA total system performance assessment for the license application

TWP technical work plan

USGS United States Geological Survey

XRD X-ray diffraction

YMP Yucca Mountain Project

YMRP Yucca Mountain Review Plan, Final Report 


\section{PURPOSE}

The purpose of this report is to evaluate the potential for penetration of the Alloy 22 (UNS N06022) waste package outer barrier by localized corrosion due to the deliquescence of soluble constituents in dust present on waste package surfaces. The results support a recommendation to exclude deliquescence-induced localized corrosion (pitting or crevice corrosion) of the outer barrier from the total system performance assessment for the license application (TSPA-LA).

Preparation of this report, and supporting laboratory studies and calculations, were performed as part of the planned effort in Work Package AEBM21, as implemented in Technical Work Plan for: Screening Evaluation for Dust Deliquescence and Localized Corrosion (BSC 2004 [DIRS 172804]), by Bechtel SAIC Company, LLC, and staff from three national laboratories: Sandia National Laboratories, Lawrence Livermore National Laboratory (LLNL), and Lawrence Berkeley National Laboratory (LBNL).

The analysis and conclusions presented in this report are quality affecting, as determined in the controlling technical work plan. A summary of background information, based on work that was not performed under a quality assurance program, is provided as Appendix E. In this instance, the use of unqualified information is provided for transparency and corroboration only, and is clearly separated from uses of qualified information. Thus, the qualification status of this information does not affect the conclusions of this report.

The acceptance criteria addressed in Sections 4.2 and 7.2 were changed from the technical work plan in response to review comments received during preparation of this report.

\subsection{THE SCREENING APPROACH}

This report presents arguments that localized corrosion of the waste package outer barrier caused by dust deliquescence can be excluded from TSPA-LA. The reason for this is that a suite of conditions must be met for deliquescence-induced localized corrosion to result in penetration of the outer barrier. To evaluate the likelihood that these conditions will be met, this report evaluates several processes, including the deposition of dust on the waste package, thermal decomposition and deliquescence of salts in the dust, processes affecting brine composition and stability, and processes controlling initiation and stifling of localized corrosion. Note that, although "stifling" has a specific meaning in corrosion literature, this report uses it in a more general sense to refer to any process that slows evolution of localized corrosion.

The technical basis for the screening arguments presented in Section 6 was developed throughout the calendar year 2004 and up to the completion date of this report. Public presentations on this topic by the Department of Energy during this time period consisted of presentations to the Nuclear Waste Technical Review Board (NWTRB) on May 19, 2004. Two key presentations from this series are summarized in Appendix E, as background information. In addition, representatives from the Electric Power Research Institute (EPRI) presented "Analysis of NWTRB's Scenario Regarding Localized Corrosion by Formation of High-Temperature Deliquescent Brine" at the same meeting, and this information is also used in the screening arguments documented in this report. The EPRI presentation is documented in a written report 
to the NWTRB (EPRI 2004 [DIRS 172825]), and in a published technical paper (Apted et al. 2005 [DIRS 172858]). The logical approach used in this report and described below is based on this foregoing work, with adjustments for current information on dust composition.

The screening analysis is presented using a logical framework approach, similar to that presented in the May 2004 EPRI report to the NWTRB (see Appendix E; see also EPRI 2004 [DIRS 172825]):

1) Can multiple-salt deliquescent brines form at elevated temperature? This is addressed in Section 6.1, which evaluates potential sources of dust and their thermal decomposition and deliquescence characteristics.

2) If brines form at elevated temperature, will they persist? Section 6.2 reviews experimental data on the behavior of $\mathrm{CaCl}_{2}$ and $\mathrm{MgCl}_{2}$ salts (which are not significant contributors to the corrosion environment), then uses thermodynamic calculations and scoping calculations to analyze the effects of brine degassing and reaction of brine with non-deliquescent minerals present in the dust on brine stability.

3) If deliquescent brines persist, will they be corrosive? The nitrate-chloride ratio for elevated temperature deliquescent brines is discussed in Section 6.3. Recent corrosion testing of Alloy 22 samples at temperatures up to $220^{\circ} \mathrm{C}$ is discussed in support of nitrate inhibition of localized corrosion at higher temperatures. Key chemical reactions that could modify the brines (i.e., acid degassing and reactions with silicate minerals) are evaluated with respect to possible changes in corrosivity.

4) If deliquescent brines are potentially corrosive, will they initiate localized corrosion? Should corrosive brines somehow form (e.g., in a micro-scale heterogeneous dust mixture), the quantity of soluble salts present determines the maximum brine volume on the waste package surface. Section 6.4 presents a bounding estimate of brine volume, then describes geometric constraints on grain-grain contacts in dust which further limit the volume of brine formed from multi-salt deliquescence. In addition, scale limitations on the oxygen fugacity gradients necessary for development of localized corrosion on exposed surfaces, due to the dimensions of brine films or droplets, are evaluated.

5) Once initiated, will localized corrosion penetrate the waste package outer barrier? If localized corrosion initiates it will be stifled (limited) by several processes discussed in Section 6.5: a) cathodic limitation due to formation of precipitates; b) decrease in the rate of localized corrosion with time, as corrosion products accumulate and diffusive transport becomes increasingly rate limiting; c) physical sequestration of brine in the porous corrosion products, leading to lapse of the continuous water film connecting the anodic and cathodic regions, which is necessary for localized corrosion to continue; and d) chemical sequestration of brine components (e.g., chloride) in corrosion products by substitution, ion exchange, or surface adsorption.

In accordance with $10 \mathrm{CFR}$ 63.114(e) and (f) [DIRS 173273], this report documents the exclusion arguments for one of the features, events, or processes (FEPs) catalogued in LA FEP List and Screening (DTN: MO0501SEPFEPLA.001 [DIRS 172601]), with wording as modified 
in Technical Management Review Board (TMRB) Decision Proposal (BSC 2005 [DIRS 174965]). Using these arguments, FEP 2.1.09.28.0A, "Localized Corrosion on Waste Package Outer Surface due to Deliquescence," will be screened out in this report on the basis of low consequence.

As stated in Yucca Mountain Review Plan, Final Report (NRC 2003 [DIRS 163274], p. 2.2-6), FEP screening is intended to reduce the burden of analysis and to focus the representation of the repository system on those FEPs that most affect compliance with the overall performance objectives. Based on 10 CFR 63.114(e) and (f) [DIRS 173273], FEP screening in general evaluates the effects on radiological exposures to the reasonably maximally exposed individual or radionuclide releases to the accessible environment. The effects are evaluated by examining whether they lead to any significant change to the expected annual dose. It is inferred for screening of FEP 2.1.09.28.0A that "insignificant" corresponds to a negligible effect relative to the dose standard.

The screening approach taken in this report has determined that there is no expectation that localized corrosion due to dust deliquescence could result in penetration of the waste package outer barrier during the first 10,000 years, and that the associated risk is insignificant. In accordance with 10 CFR 63.114(d) [DIRS 173273], the screening approach is a "risk-informed" argument for exclusion based on low consequence; a detailed quantification of the probability of waste package outer barrier penetration by localized corrosion resulting from dust deliquescence is not required. This approach is consistent with the definition of performance assessment in 10 CFR 63.2 [DIRS 173273], which requires that the consequences of all significant FEPs (i.e., with respect to "the dose incurred by the reasonably maximally exposed individual") be "weighted by their probability of occurrence."

The screening approach in this report provides multiple lines of reasoning, which taken individually provide support to the screening arguments, and taken together show that there is no expectation that localized corrosion caused by dust deliquescence could result in penetration of the waste package outer barrier, and that the associated risk is insignificant. The arguments presented here provide confidence that any dose consequence from this FEP will not materially affect compliance with the regulatory dose standard, consistent with 10 CFR 63.102(j) [DIRS 173273].

This analysis and its recommendation are consistent with the regulatory application of reasonable expectation (10 CFR 63.304 [DIRS 173273]). The postclosure performance objectives specified at 10 CFR 63.113 [DIRS 173273] are generally stated in unqualified terms, and it is not expected that complete assurance be presented that the requirements will be met. A reasonable expectation that the postclosure performance objectives will be met is the general standard required, on the basis of the record before the U.S. Nuclear Regulatory Commission.

The screening decision for FEP 2.1.09.28.0A (Section 7.1) is documented in Engineered Barrier System Features, Events, and Processes (BSC 2005 [DIRS 173781], Section 6.2.61) and Screening of Features, Events, and Processes in Drip Shield and Waste Package Degradation (BSC 2005 [DIRS 174995], Section 6.2.18). 
Clarifying the Scope of FEP 2.1.09.28.0A - The description of this FEP is given as follows (BSC 2005 [DIRS 174965]):

Salt-containing dust, which could accumulate on the waste package surface during the preclosure ventilation period, can absorb moisture from the drift atmosphere, even at low relative humidity, dissolving the salt and creating concentrated aqueous solutions. This deliquescence process may result in localized surface chemistry that could cause penetration of the waste package outer barrier by localized corrosion.

The exclusion arguments presented in this report address salt deliquescence, and the possibility that the resulting aqueous phase may persist on the waste package surface after it forms (i.e., earlier than predicted for seepage or condensation). The resulting aqueous chemistry is evaluated in terms of its corrosivity (i.e., whether it can initiate and sustain localized corrosion).

The exclusion arguments also consider the specifics of localized corrosion that may result from dust deliquescence, which establishes a link between dust deliquescence and repository system dose consequence, or risk. This is justified as the starting point for development of the exclusion arguments for dust deliquescence, because the TSPA-LA model for localized corrosion of the waste package outer barrier (Alloy 22) is the only model that needs an explicit representation of dust deliquescence as an input. General or uniform corrosion of the waste package outer barrier is already included in TSPA-LA and does not depend on the chemistry of the surface environment (BSC 2004 [DIRS 169984], Section 8.2). Stress corrosion cracking may result from mechanical damage, or residual stress from waste package fabrication, but, as represented in the TSPA-LA, is not directly related (as a cause or effect) to dust deliquescence. The scope of FEP 2.1.09.28.0A does not include waste form degradation or radionuclide transport. Thus, localized corrosion is the only potentially significant process, as represented in the TSPA-LA, that could result from dust deliquescence on the waste package, and this report addresses the limitations on initiation of localized corrosion and penetration of the outer barrier, in addition to brine characteristics, in evaluating risk from dust deliquescence.

It is noted that seepage can result in localized corrosion of the waste package outer barrier, if the drip shield ceases to perform its function of diverting seepage. This is implemented in TSPA-LA using the abstraction described in General Corrosion and Localized Corrosion of Waste Package Outer Barrier (BSC 2004 [DIRS 169984], Section 6.4.4). Also, while dust deliquescence may occur on drip shields, Titanium Grade 7 is not subject to localized corrosion, and the general corrosion rate used for TSPA-LA does not depend on the chemical environment (BSC 2004 [DIRS 169845], Sections 8.3 and 8.4).

\subsection{LIMITATIONS}

The analyses presented in this report are based on the current state of knowledge of expected dust and atmospheric aerosol compositions at Yucca Mountain. Temperature and RH conditions in the repository, gas-phase compositions, and airflow rates and potential dust deposition during the ventilation period are based on current model outputs and design specifications. For the current status of these inputs, there are no limitations on the use of this analysis. 


\section{QUALITY ASSURANCE}

As discussed in Technical Work Plan for: Screening Evaluation for Dust Deliquescence and Localized Corrosion (BSC 2004 [DIRS 172804], Section 8), the guidelines given in Quality Assurance Requirements and Description (DOE 2004 [DIRS 171539]) apply to the development of this document. The technical work plan (TWP) directs the work identified in work packages AEBM21 (EBS Modeling NFE) and AWPTA4 (Waste Package Environment). There were no variances from the planned activities. The methods used to control the electronic management of data are identified in Section 8.4 of the TWP (BSC 2004 [DIRS 172804]) and were implemented without variance. As directed in Section 4 of the TWP (BSC 2004 [DIRS 172804]), this report was prepared in accordance with LP-SIII.9Q-BSC, Scientific Analyses, and LP-3.15Q-BSC, Managing Technical Product Inputs, and reviewed in accordance with LP-2.14Q-BSC, Document Review.

The analysis and conclusions presented in this report are quality affecting, as determined in the controlling technical work plan (BSC 2004 [DIRS 172804]). A summary of background information, based on work that was not performed under a quality assurance program, is provided in Appendix E. This unqualified information is provided for transparency and corroboration only, and is clearly separated from uses of qualified information; its qualification status does not affect the conclusions of this report.

The work scope of this report involves conducting investigations or analyses of Engineered Barrier System components contained in Q-List (BSC 2005 [DIRS 174269]). In accordance with Q-List (BSC 2005 [DIRS 174269]), the waste packages and the drip shield are classified as "Safety Category" because they are important to waste isolation as defined in AP-2.22Q, Classification Analyses and Maintenance of the Q-List. The results of this report are important to the demonstration of compliance with the postclosure performance objectives prescribed in 10 CFR 63.113 [DIRS 173273]. 


\section{INTENTIONALLY LEFT BLANK}




\section{USE OF SOFTWARE}

Qualified software used in the development of this document was obtained from Software Configuration Management in accordance with LP-SI.11Q-BSC, Software Management. This software was used in the operating environments for which it was baselined.

Note that TOUGHREACT V3.2 (LBNL 2005 [DIRS 173862]) is cited as a reference in Appendix E of this report but was not used.

\subsection{EQ3/6 V8.0}

EQ3/6 V8.0 (BSC 2003 [DIRS 162228]) is a software package used to perform geochemical modeling computations, including fluid-mineral interactions and/or solution-mineral equilibria in aqueous systems, and reaction pathway modeling. It was installed and used on IBM-compatible computers using the Microsoft Windows 2000 operating system (see Table 3.3-1). This software was selected because it was the best software available for implementing calculations described in this report. Hereafter, the code will be referred to as EQ3/6, EQ3NR, or EQ6 depending on the specific use in the calculations described in later sections of this document. In accordance with LP-SI.11Q-BSC, the software was used only within the range of qualification. For this activity, the application of EQ3/6 V8.0 did not exceed the qualified ranges of pressure and temperature, of 0.01 to 85.8378 bars and 0 to $300^{\circ} \mathrm{C}$, respectively. (The qualification range for the EQ3/6 software is different from the qualification ranges for chemical databases used as input to the software, as discussed in Sections 4.1.1 and 6.) No additional macros or software routines were generated by this software.

\subsection{GETEQDATA V1.0.1}

GETEQDATA V1.0.1 (BSC 2002 [DIRS 173680]) is a software routine that operates as a Microsoft Excel (97 or 2000) macro to postprocess data found in EQ3/6 *.3o or *.6o output files. This program is used in this report to extract specified data from the EQ3/6 output files to generate lookup tables (Excel spreadsheet files). The program was run using the Windows 2000 operating system on a PC platform. This macro is limited by the EQ3/6 output data and performs a specific extraction of data as directed at run time. The use of this software is consistent with its intended use and within its documented qualification range (Jarek 2002 [DIRS 169567], Section 2.1), which is to postprocess the output files from EQ3/6 versions 7.2 or 8.0. Hereafter, the code will be referred to as GETEQDATA.

\subsection{XTOOL V10.1}

XTOOL V10.1 (LLNL 200 [DIRS 148638]) is baselined as a qualified software routine per LP-SI.11Q-BSC, and was obtained from Software Configuration Management and run on a Sun workstation using the SunOS 5.6.1 operating system. XTOOL V10.1 is used to extract time-history of data and generate graphical representations of the results given in the NUFT and MSTHAC v7.0 time-history files (which are files with the suffix: *.ext). XTOOL V10.1 is the only appropriate software for these tasks. Because this software is only used to extract data and generate graphical displays of data, there are no applicable qualification ranges or limitations of use. 
Table 3-1. Qualified Software Used in This Report

\begin{tabular}{|l|c|c|l|c|}
\hline $\begin{array}{c}\text { Software Name } \\
\text { and Version }\end{array}$ & $\begin{array}{c}\text { Software } \\
\text { Tracking Number }\end{array}$ & \multicolumn{1}{|c|}{ Platform } & \multicolumn{1}{c|}{ Range of Use } & $\begin{array}{c}\text { Reference } \\
\text { Number }\end{array}$ \\
\hline EQ3/6 V8.0 & $10813-8.0-00$ & $\begin{array}{l}\text { Windows 2000 } \\
\text { Professional }\end{array}$ & $\begin{array}{l}\text { Determined by the validity range of } \\
\text { input thermodynamic data for given } \\
\text { pressure and temperature. }\end{array}$ & [DIRS 162228] \\
\hline GETEQDATA V1.0.1 & $10809-1.0 .1-00$ & $\begin{array}{l}\text { Windows 2000 } \\
\text { Professional }\end{array}$ & $\begin{array}{l}\text { There are no limits on the use of } \\
\text { this program. }\end{array}$ & [DIRS 173680] \\
\hline XTOOL V10.1 & $10208-10.1-00$ & SUN O.S. 5.6.1 & $\begin{array}{l}\text { Since it is for postprocess results } \\
\text { only, there are no limits on the use } \\
\text { of this program. }\end{array}$ & [DIRS 148638] \\
\hline
\end{tabular}

\subsection{EXEMPT SOFTWARE USE}

\subsubsection{Microsoft Excel Versions 97, 2000, 2003}

Microsoft Excel is a commercial off-the-shelf software program used for this report on Windows 2000 operating systems. The computations performed using Excel use only standard functions and are documented in sufficient detail in this report to allow an independent technical reviewer to reproduce or verify the results by visual inspection or hand calculation without recourse to the originator. The formulas or algorithms used, and a listing of inputs to and outputs from the formulas or algorithms, are sufficiently documented to allow results to be reproduced. Therefore, this software is exempt from LP-SI.11Q-BSC. Excel is appropriate for its intended use because it offers the mathematical and graphical functionality necessary to perform and document the numerical manipulations used in this report.

\subsubsection{SigmaPlot 8.0}

SigmaPlot 8.0 is a commercial off-the-shelf software program used in this report. It was used on Windows 2000. No computations were performed for this report using SigmaPlot 8.0; therefore, this software is exempt from LP-SI.11Q-BSC. SigmaPlot 8.0 is appropriate for its intended use because it offers the graphical functionality necessary to perform and document the plots used in this report.

\subsubsection{MathCad Version 11.2a}

MathCad Version 11.2a is a commercial off-the-shelf software program that was used with Windows 2000 to develop information presented in Appendix A. The computations performed with MathCad use only standard functions and are documented in detail, within the MathCad files and in this document. The formulas or algorithms used, and a listing of inputs to and outputs from the formulas or algorithms, are sufficiently documented to allow results to be reproduced. Therefore, this software is exempt from LP-SI.11Q-BSC. MathCad Version 11.2a is appropriate for its intended use because it offers the mathematical and graphical functionality necessary to perform and document the numerical manipulations used in this report. 


\section{INPUTS}

\subsection{DIRECT INPUTS}

\subsubsection{Thermodynamic Databases}

Two qualified thermodynamic databases have been used as inputs to the EQ3/6 calculations presented in this report. These are listed below with their associated data tracking numbers (DTNs) and an accompanying description.

Data0.ypf.R0 (DTN: SN0302T0510102.002 [DIRS 162572]) - This database was developed in In-Drift Precipitates/Salts Model (BSC 2004 [DIRS 169863]). It contains parameters for a Pitzer activity-coefficient model, allowing simulation of concentrated brines, and is qualified for use up to $140^{\circ} \mathrm{C}$ (see BSC 2004 [DIRS 169863] for additional limits on the qualification). This database is used in an unmodified form for calculations of acid degassing and equilibrium with silicate minerals presented in Sections 6.2 and 6.3, respectively. The data0.ypf.R0 database (DTN: SN0302T0510102.002 [DIRS 162572]) is used in several calculations in this document. The in-drift precipitates/salts (IDPS) model itself was developed to evaluate the composition of aqueous solutions at varying stages of dilution or evaporation and is used directly in this report, within its range of validation, to evaluate the compositions of eutectic brines in Sections 6.1, 6.2, and 6.3 .

Data0.ypf.R1 (DTN: SN0504T0502404.011 [DIRS 173493])-This database is an expanded version of data0.ypf.R0 containing Pitzer parameters and thermodynamic data for a suite of transition metal and actinide solid and aqueous species not present in data0.ypf.R0. The data0.ypf.RI database is qualified for use at $25^{\circ} \mathrm{C}$ when used with the added transition-metal and actinide species (for other species it has the same status as data0.ypf.R0). It is not used directly in the calculations presented in this document. Instead, it provides the basis for a new database, data0.ypf.R2 (DTN: SN0504T0502205.008) developed for use in this document (and shown as output from this analysis). In addition to containing data0.ypf.R1 in its entirety, the data0.ypf.R2 update includes parameters to model high-ionic strength solutions involving ammonia and its protonated form, ammonium. This version of the database also contains data for several additional solid species, namely, ammonium salts, potential chloride-bearing corrosion phases, and a hypothetical Alloy 22 solid phase used in the analysis. The updated data0.ypf.R2 is used in Sections 6.1, 6.4, and 6.5, which deal respectively with ammonium minerals, brine volumes, and potential consumption of brine components by chloride-bearing corrosion phases. Input data used to develop the changes for data0.ypf.R2 are discussed in the following sections.

\subsubsection{Parameters Primarily for Ammonia and Ammonium in Solution}

First among the parameters added to data0.ypf. 22 are the ammonium nitrate $\left(\mathrm{NH}_{4}{ }^{+}-\mathrm{NO}_{3}{ }^{-}\right)$ temperature-dependent binary interaction parameters. These parameters required the refitting of data from the mole-fraction formalism of Clegg et al. (1998 [DIRS 172815]), as described in Appendix B. Also required for this calculation were the Debye-Hückel limiting law slopes reported by Clegg and Brimblecombe (1995 [DIRS 173820]). The results were then recast into the needed Pitzer database format, and included in Output DTN: SN0504T0502205.009 (Pitzer_database_NH4_additions.txt). 
The next category of Pitzer parameters did not require any modification from their original sources and were directly incorporated into the database, as shown in Output DTN: SN0504T0502205.009 (Pitzer_database_NH4_additions.txt). The parameters, their values, and their sources are listed in Table 4.1-1. Entries in the "Value" column correspond to the $25^{\circ} \mathrm{C}$ results for the interaction parameters and correlate to the "al" coefficient in the database file. Linear temperature dependence is shown in Table 4.1-1; "a4" is the linear temperature-dependent coefficient ( $\partial / \partial \mathrm{T})$. Refer to In-Drift Precipitates/Salts Model (BSC 2004 [DIRS 169863], Equation I-58 and Table I-3) for coefficient definitions and further information.

Table 4.1-1. Input Pitzer Interaction Parameters

\begin{tabular}{|c|c|c|c|}
\hline Pitzer Parameter & $\begin{array}{c}\text { Parameter } \\
\text { Name }^{a}\end{array}$ & Value & Source \\
\hline $\mathrm{NH}_{4}^{+}-\mathrm{Na}^{+}$ & $\theta$ & 0.00436 & Clegg and Whitfield 1995 [DIRS 172806], Table 6 \\
\hline $\mathrm{NH}_{4}^{+}-\mathrm{Mg}^{2+}$ & $\theta$ & 0.0124 & Clegg and Whitfield 1995 [DIRS 172806], Table 6 \\
\hline $\mathrm{NO}_{3}^{-}-\mathrm{HCO}_{3}^{-}$ & $\theta$ & 0.0414 & Meng et al. 1995 [DIRS 172808], Table 6 \\
\hline $\mathrm{NO}_{3}^{-}-\mathrm{CO}_{3}^{2-}$ & $\theta$ & 0.081 & Meng et al. 1995 [DIRS 172808], Table 6 \\
\hline $\mathrm{CO}_{2}(\mathrm{aq})-\mathrm{NH}_{4}^{+}$ & $\lambda$ & 0.01 & Meng et al. 1995 [DIRS 172808], Table 7 \\
\hline $\mathrm{NH}_{3}(\mathrm{aq})-\mathrm{NH}_{4}^{+}$ & $\lambda$ & 0.0 & Clegg and Brimblecombe 1989 [DIRS 172803], Table VI \\
\hline $\mathrm{NH}_{3}(\mathrm{aq})-\mathrm{Mg}^{2+}$ & $\lambda$ & -0.21 & Clegg and Brimblecombe 1989 [DIRS 172803], Table VI \\
\hline $\mathrm{NH}_{3}(\mathrm{aq})-\mathrm{Ca}^{2+}$ & $\lambda$ & -0.081 & Clegg and Brimblecombe 1989 [DIRS 172803], Table VI \\
\hline $\mathrm{NH}_{3}(\mathrm{aq})-\mathrm{Li}^{+}$ & $\lambda$ & -0.038 & Clegg and Brimblecombe 1989 [DIRS 172803], Table VI \\
\hline $\mathrm{NH}_{3}(\mathrm{aq})-\mathrm{Na}^{+}$ & $\lambda$ & 0.031 & Clegg and Whitfield 1995 [DIRS 172806], Table 7 \\
\hline $\mathrm{NH}_{3}(\mathrm{aq})-\mathrm{K}^{+}$ & $\lambda$ & $\begin{array}{l}\mathrm{a} 1=0.0454 \\
\mathrm{a} 4=-0.000141\end{array}$ & Clegg and Brimblecombe 1989 [DIRS 172803], Table VI \\
\hline $\mathrm{CO}_{2}(\mathrm{aq})-\mathrm{NO}_{3}^{-}$ & $\lambda$ & -0.0457 & Meng et al. 1995 [DIRS 172808], Table 7 \\
\hline $\mathrm{NH}_{3}(\mathrm{aq})-\mathrm{NO}_{3}^{-}$ & $\lambda$ & -0.01 & Clegg and Brimblecombe 1989 [DIRS 172803], Table VI \\
\hline $\mathrm{NH}_{3}(\mathrm{aq})-\mathrm{SO}_{4}{ }^{2-}$ & $\lambda$ & 0.138 & Clegg and Whitfield 1995 [DIRS 172806], Table 7 \\
\hline $\mathrm{NH}_{3}(\mathrm{aq})-\mathrm{CO}_{3}{ }^{2-}$ & $\lambda$ & 0.174 & Clegg and Whitfield 1995 [DIRS 172806], Table 7 \\
\hline $\mathrm{NH}_{3}(\mathrm{aq})-\mathrm{OH}^{-}$ & $\lambda$ & 0.103 & Clegg and Brimblecombe 1989 [DIRS 172803], Table VI \\
\hline $\mathrm{NH}_{3}(\mathrm{aq})-\mathrm{F}^{-}$ & $\lambda$ & 0.091 & Clegg and Brimblecombe 1989 [DIRS 172803], Table VI \\
\hline $\mathrm{NH}_{3}(\mathrm{aq})-\mathrm{Cl}^{-}$ & $\lambda$ & 0.0, defined & Clegg and Brimblecombe 1989 [DIRS 172803], Table VI \\
\hline $\mathrm{NH}_{3}(\mathrm{aq})-\mathrm{Br}^{-}$ & $\lambda$ & -0.022 & Clegg and Brimblecombe 1989 [DIRS 172803], Table VI \\
\hline $\mathrm{NH}_{3}(\mathrm{aq})-\mathrm{I}^{-}$ & $\lambda$ & -0.051 & Clegg and Brimblecombe 1989 [DIRS 172803], Table VI \\
\hline $\mathrm{Na}^{+}-\mathrm{K}^{+}-\mathrm{HCO}_{3}^{-}$ & $\psi$ & -0.003 & Harvie et al. 1984 [DIRS 118163], Table 2 \\
\hline $\mathrm{Na}^{+}-\mathrm{K}^{+}-\mathrm{CO}_{3}^{2-}$ & $\psi$ & 0.003 & Harvie et al. 1984 [DIRS 118163], Table 2 \\
\hline $\mathrm{NH}_{4}^{+}-\mathrm{Na}^{+}-\mathrm{Cl}^{-}$ & $\psi$ & -0.0031 & Clegg and Whitfield 1995 [DIRS 172806], Table 6 \\
\hline $\mathrm{NH}_{4}^{+}-\mathrm{Na}^{+}-\mathrm{SO}_{4}^{2-}$ & $\psi$ & -0.00363 & Clegg and Whitfield 1995 [DIRS 172806], Table 6 \\
\hline $\mathrm{NH}_{4}^{+}-\mathrm{Mg}^{2+}-\mathrm{Cl}^{-}$ & $\psi$ & -0.0249 & Clegg and Whitfield 1995 [DIRS 172806], Table 6 \\
\hline $\mathrm{NH}_{4}^{+}-\mathrm{Mg}^{2+}-\mathrm{SO}_{4}{ }^{2-}$ & $\psi$ & -0.0439 & Clegg and Whitfield 1995 [DIRS 172806], Table 6 \\
\hline $\mathrm{NH}_{4}^{+}-\mathrm{HCO}_{3}^{-}-\mathrm{SO}_{4}^{2-}$ & $\psi$ & 0.005424 & Meng et al. 1995 [DIRS 172808], Table 6 \\
\hline $\mathrm{NH}_{4}^{+}-\mathrm{HCO}_{3}^{-}-\mathrm{NO}_{3}^{-}$ & $\psi$ & 0.000559 & Meng et al. 1995 [DIRS 172808], Table 6 \\
\hline $\mathrm{NH}_{4}^{+}-\mathrm{HCO}_{3}^{-}-\mathrm{Cl}^{-}$ & $\psi$ & -0.001168 & Meng et al. 1995 [DIRS 172808], Table 6 \\
\hline $\mathrm{Na}^{+}-\mathrm{HCO}_{3}^{-}-\mathrm{NO}_{3}^{-}$ & $\psi$ & -0.007438 & Meng et al. 1995 [DIRS 172808], Table 6 \\
\hline $\mathrm{K}^{+}-\mathrm{HCO}_{3}^{-}-\mathrm{NO}_{3}^{-}$ & $\psi$ & 0.001373 & Meng et al. 1995 [DIRS 172808], Table 6 \\
\hline
\end{tabular}


Table 4.1-1. Input Pitzer Interaction Parameters (Continued)

\begin{tabular}{|l|c|c|l|}
\hline \multicolumn{1}{|c|}{ Pitzer Parameter } & $\begin{array}{c}\text { Parameter } \\
\text { Name }\end{array}$ & \multicolumn{1}{c|}{ Value } & Source \\
\hline $\mathrm{Na}^{+}-\mathrm{CO}_{3}{ }^{2-}-\mathrm{NO}_{3}{ }^{-}$ & $\psi$ & 0.0103 & Meng et al. 1995 [DIRS 172808], Table 6 \\
\hline $\mathrm{K}^{+}-\mathrm{CO}_{3}{ }^{2-}-\mathrm{NO}_{3}{ }^{-}$ & $\psi$ & 0.012 & Meng et al. 1995 [DIRS 172808], Table 6 \\
\hline $\mathrm{NH}_{3}(\mathrm{aq})-\mathrm{NH}_{4}{ }^{+}-\mathrm{SO}_{4}{ }^{2-}$ & $\zeta$ & -0.0092 & Clegg and Whitfield 1995 [DIRS 172806], Table 7 \\
\hline $\mathrm{NH}_{3}(\mathrm{aq})-\mathrm{Ca}^{2+}-\mathrm{Cl}^{-}$ & $\zeta$ & -0.008 & Clegg and Whitfield 1995 [DIRS 172806], Table 7 \\
\hline $\mathrm{NH}_{3}(\mathrm{aq})-\mathrm{K}^{+}-\mathrm{OH}^{-}$ & $\zeta$ & 0.0023 & Clegg and Whitfield 1995 [DIRS 172806], Table 7 \\
\hline
\end{tabular}

${ }^{a}$ For a discussion of these parameters, see BSC 2004 [DIRS 169863], Section I.4.

The temperature functional for $\mathrm{NH}_{3}(\mathrm{aq})$ interactions with itself was converted from the original data input from Clegg and Brimblecombe (1989 [DIRS 172803], footnote $a$ in Table VI). This equation is reproduced here:

$$
\lambda_{\mathrm{NH}_{3}, \mathrm{NH}_{3}}=0.033161-21.12816 / T+4665.1461 / T^{2}
$$

This equation is refit in an Excel spreadsheet (Output DTN: SN0504T0502205.009, NH3-Temp_Regress.xls) with the temperature functional currently used by EQ3/6, shown here as Equation 4-2 (input from data0.ypf.R0 in DTN: SN0302T0510102.002 [DIRS 162572]):

$$
x(T)=a 1+a 2 *(1 / T-1 / 298.15)+a 3 * \ln (T / 298.15)+a 4 *(T-298.15)
$$

Justification for the four sources cited in Table 4.1-1 is provided as follows:

Harvie et al. 1984 [DIRS 118163], Table 2-Description of Data: Pitzer interaction parameters as shown in Table 4.1-1. Qualification Status: Justified for intended use in this analysis. Extent to Which the Data Demonstrate the Properties of Interest: This work presents a comprehensive study involving the internally consistent retrieval of Pitzer parameters for major salt systems, including those relevant to consideration of dust deliquescence and identified in Table 4.1-1. This is the source for thermodynamic data of various salt solids adopted in the qualified thermodynamic database data0.ypf.R0 (DTN: SN0302T0510102.002 [DIRS 162572]). The objective of this article is to analyze data in existence up to its date of publication to model high ionic strength natural water systems at $25^{\circ} \mathrm{C}$. The specific results used as input here $\left(\mathrm{K} / \mathrm{Na}-\mathrm{CO}_{3}-\mathrm{HCO}_{3}\right.$ ternary interactions) are part of an extensive set of solubility data for the $\mathrm{Na}-\mathrm{K}-\mathrm{CO}_{3} \mathrm{HCO}_{3} \mathrm{H}_{2} \mathrm{O}$ system, which is used in a nonlinear least square evaluation of the parameters (Harvie et al. 1984 [DIRS 118163], p. 733). Harvie et al. (1984 [DIRS 118163]) determine their Pitzer interaction parameters by fitting two separate sets of experimental solubility data, and their resulting fits are very good (see Harvie et al. 1984 [DIRS 118163], Figure 10). Therefore, these data appropriately demonstrate the parameters of interest, which are the Pitzer ternary interaction parameters for the $\mathrm{Na} / \mathrm{K}-\mathrm{CO}_{3}-\mathrm{HCO}_{3}$ system. Qualification of Personnel: The authors have published extensively on the application of the Pitzer modeling approach to major salt systems using critically reviewed experimental data. Use and scrutiny of these data by the investigators provides appropriate confidence and has resulted in general acceptance of the data by the scientific community. Reliability of Data Source: These data were published in Geochimica et Cosmochimica Acta, which is a respected journal with a long record 
of publication. Its articles are peer-reviewed, i.e., reviewed by other experts in the pertinent technical field, including individuals with experience in the subject matter who typically use such information in the course of their work. Technical problems identified by the review process are either resolved prior to publication or the article is rejected. This process provides an appropriate level of confidence that the information is suitable for use in types of analyses for which it was intended.

Clegg and Brimblecombe 1989 [DIRS 172803], Table VI-Description of Data: Pitzer interaction parameters as shown in Table 4.1-1. Qualification Status: Justified for intended use in this analysis. Extent to Which the Data Demonstrate the Properties of Interest: This work presents a comprehensive treatment on ammonia solubility in a multicomponent aqueous system, which is generally consistent with the analysis of ammonia behavior in this report. Using results of multiple sources, including salt solubility and partial pressure (or partitioning) data, a comprehensive and consistent set of neutral ammonia to aqueous ion interaction parameters was developed. The results of this extensive analysis appropriately represent the Pitzer interaction parameters for ammonia-containing brines, for the chemical systems considered in this report. Qualification of Personnel: The authors, Drs. Simon L. Clegg and Peter Brimblecombe, have published extensively on the modeling of highly soluble salts with application to atmospheric chemistry and utilizing critically reviewed experimental data. Use and scrutiny of these data by the investigators provides appropriate confidence and has resulted in general acceptance of the data by the scientific community. Reliability of Data Source: These data were published in Journal of Physical Chemistry, which is a respected journal with a long record of publication. Its articles are peer-reviewed, i.e., reviewed by other experts in the pertinent technical field, including individuals with experience in the subject matter who typically use such information in the course of their work. Technical problems identified by the review process are either resolved prior to publication or the article is rejected. This process provides an appropriate level of confidence that the information is suitable for use in the types of analyses for which it was intended.

Clegg and Brimblecombe 1995, Table 8 [DIRS 173820]—Description of Data: Debye-Hückel limiting slope values as a function of temperature. These values are needed for use in the mole-fraction based model expressions for $\mathrm{NH}_{4} \mathrm{NO}_{3}(\mathrm{aq})$ given by $\mathrm{Clegg}$ et al. (1998 [DIRS 172815]) and described in Appendix B. The limiting slopes are calculated using a Chebychev polynomial expression and coefficients given in Table 8 of Clegg and Brimblecombe's (1995 [DIRS 173820]) study. Qualification Status: Justified for intended use in this analysis. Extent to Which the Data Demonstrate the Properties of Interest: This work presents a comprehensive treatment of the thermodynamic properties of sulfuric acid in a multicomponent aqueous system, along with providing the parameters for the temperature dependence of the Debye- Hückel limiting law slopes. These temperature parameter coefficients are a fitting of the Debye- Hückel limiting law slopes from 273.15 to $373.15 \mathrm{~K}$ with an 11-term Chebychev polynomial. The results of this analysis appropriately represent the Debye-Hückel limiting slope values used in the mole-fraction based model, and are required for the calculation of the thermodynamic properties of aqueous $\mathrm{NH}_{4} \mathrm{NO}_{3}$. Qualification of Personnel: The authors, Drs. Simon L. Clegg and Peter Brimblecombe, have published extensively on the modeling of highly soluble salts with application to atmospheric chemistry and utilizing critically reviewed experimental data. Use and scrutiny of these data by the investigators provides appropriate confidence and has resulted in general acceptance of the data by the scientific community. 
Reliability of Data Source: These data were published in Journal of Chemical Engineering Data, which is a respected journal with a long record of publication. Its articles are peer-reviewed, i.e., reviewed by other experts in the pertinent technical field, including individuals with experience in the subject matter who typically use such information in the course of their work. Technical problems identified by the review process are either resolved prior to publication or the article is rejected. This process provides an appropriate level of confidence that the information is suitable for use in the types of analyses for which it was intended.

Clegg and Whitfield 1995 [DIRS 172806], Tables 6 and 7-Description of Data: Pitzer interaction parameters as shown in Table 4.1-1. Qualification Status: Justified for intended use in this analysis. Extent to Which the Data Demonstrate the Properties of Interest: The authors of this source examined several types of experimental data to retrieve the Pitzer parameters adopted for inclusion in the database. They used results from multiple sources, including available thermodynamic data (e.g., calorimetric) validated against electrochemical data for seawater, to develop dissociation constants as functions of salinity and temperature. In this manner a consistent set of ammonium and neutral ammonia aqueous ion-interaction parameters was developed. These parameters and the supporting data are consistent with other thermodynamic data from Clegg's group used in this report, which helps to ensure that ammonium speciation calculations in this report are accurate. The data therefore demonstrate the properties of interest, which are ternary Pitzer interaction parameters for $\mathrm{NH}_{4}{ }^{+}$and $\mathrm{NH}_{3}(\mathrm{aq})$ in brines. Qualification of Personnel: The first author, Dr. Simon L. Clegg, has published extensively on the modeling of highly soluble salts with application to atmospheric chemistry and utilizing critically reviewed experimental data. Use and scrutiny of these data by the investigators provides appropriate confidence and has resulted in general acceptance of the data by the scientific community. Reliability of Data Source: These data were published in Geochimica Cosmochimica Acta, which is a respected journal with a long record of publication. Its articles are peer-reviewed, which provides appropriate confidence in the accuracy of the information as discussed above.

Clegg et al. 1998 [DIRS 172815], Table 1-Description of Data: Fitting parameters for determining the temperature dependence of $\mathrm{NH}_{4}{ }^{+}-\mathrm{NO}_{3}{ }^{-}$interaction parameters. Qualification Status: Justified for intended use in this analysis. Extent to Which the Data Demonstrate the Properties of Interest: This work presents a comprehensive treatment on ammonia solubility in a multicomponent aqueous system, which is generally consistent with the analysis of ammonia behavior in this report. Using results of multiple sources, including salt solubility and partial pressure (or partitioning) data, a comprehensive and consistent set of ammonium to aqueous ion interaction parameters was developed. These parameters and the supporting data are consistent with other thermodynamic data from Clegg's group used in this report, which helps to ensure that ammonium speciation calculations in this report are accurate.

There were some typographical errors identified in the source (Clegg et al. 1998 [DIRS 172815]): (1) the signs of the third and fourth terms on the right hand side of Equation 13 in this reference are incorrect, and (2) three parameter values for the $\mathrm{NH}_{4}{ }^{+}-\mathrm{NO}_{3}{ }^{-}$ion pair are incorrect as listed in Table 1. Corrections to these errors are discussed in detail in Appendix B of this report. Confirmation of the corrections was obtained as direct input, in the form of an email communication from Dr. Simon L. Clegg to Dr. Joseph Rard of LLNL, containing corroborating 
values for osmotic coefficients as discussed in Appendix B (Clegg 2004 [DIRS 174184]). The confirmatory information is justified for intended use because of its relevance to the properties of interest, and because the contributor was the principal author of the original work. Qualification of Personnel: Two of the authors, Drs. Simon L. Clegg and Peter Brimblecombe, have published extensively on the modeling of highly soluble salts with application to atmospheric chemistry and utilizing critically reviewed experimental data. Use and scrutiny of these data by the investigators provides appropriate confidence and has resulted in general acceptance of the data by the scientific community. Reliability of Data Source: This paper was published in Journal of Physical Chemistry, which is a respected journal with a long record of publication. Its articles are peer-reviewed, which provides appropriate confidence in the accuracy of the information as discussed previously.

Meng et al. 1995 [DIRS 172808], Table 6-Description of Data: Pitzer interaction parameters as shown in Table 4.1-1. Qualification Status: Justified for intended use in this analysis. Extent to Which the Data Demonstrate the Properties of Interest: The authors for this source conducted an evaluation of available information on thermodynamic properties for carbonate salts, and in some cases used solubility data from experiments. They critically examined the data and developed ternary Pitzer interaction parameters for carbonate species in a multicomponent saline solution. Because these data were thoroughly evaluated and pertain to ammonium and nitrate species interactions in multicomponent brine systems, they appropriately demonstrate the parameters of interest. Qualification of Personnel: One of the authors, Dr. John H. Seinfeld, has published extensively on the chemical modeling of aerosols with application to atmospheric chemistry. Use and scrutiny of these data by the investigators provides appropriate confidence and has resulted in general acceptance of the data by the scientific community. Reliability of Data Source: These data were published in Journal of Physical Chemistry, which is a respected journal with a long record of publication. Its articles are peer-reviewed, i.e., reviewed by other experts in the pertinent technical field, individuals with experience in the subject matter who typically use such information in the course of their work. Technical issues are raised during the review process and either resolved prior to publication or the article is rejected. This process provides an appropriate level of confidence that the data are suitable for use in the types of analyses for which it was intended.

\subsubsection{Database Parameters for Solids}

To simulate the behavior of ammonium in high ionic strength solutions, inclusion of ammonium salts is required. Also included are two layered double hydroxide (LDH) solids and a hypothetical Alloy 22 solid.

Ammonium Salts-Ten unique ammonium-containing salts are input from Clegg et al. (1998 [DIRS 172807], Table 3), and these are presented in Table 4.1-2. Seven ammonium salts from that source already exist in data0.ypf.R0 (DTN: SN0302T0510102.002 [DIRS 162572]), and where overlaps in data exist, comparisons were made (Output DTN: SN0504T0502205.009, AmmoniumSalts.xls) to increase confidence in the $\log (K)$ values. The $\ln \left({ }^{x} K\right)$ values at $298.15 \mathrm{~K}$ shown in Table 4.1-2 are expressed using the mole-fraction scale and are converted to the molal scale for use in this report (Output DTN: SN0504T0502205.009, AmmoniumSalts.xls). 
Table 4.1-2. Input Mole Fraction Solubility Constants at $298.15 \mathrm{~K}$

\begin{tabular}{|l|l|l|r|}
\hline \multicolumn{1}{|c|}{ Solid Phase } & \multicolumn{1}{c|}{$\operatorname{In}\left({ }^{x} \boldsymbol{K}\right)$} & \multicolumn{1}{c|}{ Solid Phase } & $\operatorname{In}\left({ }^{x} \boldsymbol{K}\right)$ \\
\hline$\left(\mathrm{NH}_{4}\right)_{3} \mathrm{H}_{\left(\mathrm{SO}_{4}\right)_{2}}$ & -26.04 & $\mathrm{NH}_{4} \mathrm{HSO}_{4}: \mathrm{NH}_{4} \mathrm{NO}_{3}$ & -17.49 \\
\hline $\mathrm{NH}_{4} \mathrm{HSO}_{4}$ & -11.43 & $\left(\mathrm{NH}_{4}\right)_{2} \mathrm{SO}_{4}: 2 \mathrm{NH}_{4} \mathrm{NO}_{3}$ & -23.67 \\
\hline $\mathrm{NaHSO}_{4}: \mathrm{H}_{2} \mathrm{O}$ & -12.29 & $\left(\mathrm{NH}_{4}\right)_{2} \mathrm{SO}_{4}: 3 \mathrm{NH}_{4} \mathrm{NO}_{3}$ & -29.37 \\
\hline $\mathrm{NaHSO}_{4}$ & -10.65 & $\left(\mathrm{NH}_{4}\right)_{2} \mathrm{SO}_{4}: \mathrm{Na}_{2} \mathrm{SO}_{4}: 4 \mathrm{H}_{2} \mathrm{O}$ & -28.00 \\
\hline $\mathrm{NaH}_{3}\left(\mathrm{SO}_{4}\right)_{2}: \mathrm{H}_{2} \mathrm{O}$ & -13.02 & $\mathrm{Na}_{2} \mathrm{SO}_{4}: \mathrm{NaNO}_{3}: \mathrm{H}_{2} \mathrm{O}$ & -19.28 \\
\hline
\end{tabular}

Source: Clegg et al. 1998 [DIRS 172807], Table 3.

The conversion to molal solubility is accomplished using the relation presented by the same authors in an associated paper (Clegg et al. 1998 [DIRS 172815], Equation 4). This input equation is shown here as Equation 4-3 and is implemented in AmmoniumSalts.xls (Output DTN: SN0504T0502205.009).

$$
{ }^{x} K={ }^{m} K\left(M_{1} / 1000\right)^{\left(v_{i, \mathrm{p}}-v_{i, \mathrm{r}}\right)}
$$

Terms in Equation 4-3 are defined as follows: ${ }^{x} K$ is the mole fraction solubility constant; ${ }^{m} K$ is the molal solubility constant; $M_{1}$ is the molar mass of the solvent $\left(\mathrm{g} \mathrm{mol}^{-1}\right) ; v_{i, \mathrm{r}}$ is the sum of stoichiometric numbers of the reacting liquid-phase solutes; and $v_{i, \mathrm{p}}$ is the equivalent sum for any products that are also solutes.

For the ammonium nitrate solid phase $\left(\mathrm{NH}_{4} \mathrm{NO}_{3}\right)$, temperature-dependent solubility was determined. Input for this consists of the $\ln \left({ }^{x} K\right)$ value from Clegg et al. (1998 [DIRS 172815], Table 2) for $\mathrm{NH}_{4} \mathrm{NO}_{3}(\mathrm{IV})$ of -5.5295 at $298.15 \mathrm{~K}$; this value is converted to $\log ^{m} K$ in the AmmoniumSalts.xls spreadsheet using Equation 4-3. The resulting value was converted to a natural $\log$ value (2.5036) and used in the spreadsheet Solids_j_NH4.xls, sheet "NH4NO3," cell B6 (Output DTN: SN0504T0502205.009), with one other input from Clegg et al. (1998 [DIRS 172815], Table 2) for solid phases $\mathrm{NH}_{4} \mathrm{NO}_{3}$ (III) and (IV): $\Delta_{\mathrm{r}} C_{p}{ }^{\circ}=-101.2$ $\left(\mathrm{J} \mathrm{mol}^{-1} \mathrm{~K}^{-1}\right.$ ). The transition temperature of $\mathrm{NH}_{4} \mathrm{NO}_{3}$ (III) to (IV) is at $305.38 \mathrm{~K}$ (Clegg et al. 1998 [DIRS 172815], Table 2), but these are adequately represented here as identical species because both their $\ln \left({ }^{x} K\right)$ and $\mathrm{r} H^{\circ}$ values are similar.

Clegg et al. 1998 [DIRS 172807]; Clegg et al. 1998 [DIRS 172815]; and Clegg 2004 [DIRS 174184]-Description of Data: Mole-fraction solubility constants as shown in Table 4.1-2, also the conversion equation for molal solubility (Equation 4-3), and author confirmation of corrections. Qualification Status: Justified for intended use in this analysis. Extent to Which the Data Demonstrate the Properties of Interest: These data appropriately represent solubility constants for ammonium salts, and stand out as the best available source because of the range of different salts parameterized, and because there are few such data published. Where applicable, comparison with similar parameters from data0.ypf.R0 (DTN: SN0302T0510102.002 [DIRS 162572]) shows differences that are within a factor of approximately 2. The $\log (K)$ values based on data from Clegg et al. (1998 [DIRS 172807]) are used instead of values for the same parameters from data0.ypf.R0 in this report, to maintain consistency in the use of information from the Clegg publications. 
Alloy 22 Composition-The composition of Alloy 22 is used in Section 6.5.4, which discusses the potential consumption of brine components by corrosion products. The major metal components in Alloy 22 are listed in Table 4.1-3; these nominal composition values are from an American Society for Testing and Materials (ASTM) publication (ASTM B575-99a [DIRS 147465]), are established fact, and thus do not require further justification for use. Also shown in Table 4.1-3 are atomic masses for the metals in Alloy 22. These values are from the qualified project thermodynamic database data0.ymp.R2 (DTN: MO0302SPATHDYN.000 [DIRS 161756]).

Table 4.1-3. Composition of Alloy 22

\begin{tabular}{|l|c|c|c|}
\hline \multicolumn{1}{|c|}{ Element } & Atomic Weight $^{\mathbf{a}}$ & wt \% in Alloy $^{\mathbf{b}}$ & $\begin{array}{c}\text { \# Moles, Assuming } \\
\mathbf{1 0 0} \mathbf{~ g / m o l e ~ A l l o y ~ 2 2 ~}\end{array}$ \\
\hline $\mathrm{Ni}$ & 58.6934 & 50.02 & 0.8522 \\
\hline $\mathrm{Cr}$ & 51.9961 & 22.5 & 0.4327 \\
\hline $\mathrm{Mo}$ & 95.94 & 14.5 & 0.1511 \\
\hline $\mathrm{Fe}$ & 55.845 & 6.0 & 0.1074 \\
\hline $\mathrm{W}$ & 183.84 & 3.5 & 0.0190 \\
\hline $\mathrm{Co}$ & 58.9332 & 2.5 & 0.0424 \\
\hline
\end{tabular}

a data0.ymp.R2 (DTN: MO0302SPATHDYN.000 [DIRS 161756]).

b ASTM B575-99a [DIRS 147465].

NOTE: $\quad$ ASTM refers to Alloy 22 as Alloy N06022. The values used here are the maximum allowed per the specification. Minor components of Alloy 22 (C, Si, V, P, and S, constituting $<1 \%$ of the total) are not shown. $\mathrm{Ni}$ is calculated as the remainder, after all components, including minor ones, are summed.

This input data set is used to calculate a hypothetical, simplified Alloy 22 composition and associated dissolution reaction, which were added to the data0.ypf.R2 database (Output DTN: SN0504T0502205.008). The compositional description is developed within Output DTN: SN0504T0502205.009 (LDH titration calcs.xls, sheet “Alloy-22 composition"). Description of this is provided in Section 6.5.4.2.

Layered Double Hydroxides - Layered double hydroxides are potential corrosion products from Alloy 22, and thermodynamic data for two of these phases, $\mathrm{Ni}$ : $\mathrm{Cr}$ and $\mathrm{Ni}$ :Fe $\mathrm{LDH}$, have been added in the form of $\log (K)$ values of dissociation reactions to the qualified Pitzer thermodynamic database data0.ypf.R2 for use in simulating the corrosion of Alloy 22 . The thermodynamic data and the associated dissociation reactions are listed in Table 4.1-4. The data were taken from studies by Boclair et al. (1999 [DIRS 172929], Table 1) and Boclair and Braterman (1999 [DIRS 172930], Table 2). These data are recast into dissolution reactions in a format compatible with the reactions in the EQ3/6 database; this is done in Output DTN: SN0504T0502205.009 (LDH titration calcs.xls, sheets "LDH_Cr-Ni" and "LDH_Fe-Ni") and described in Section 6.5.4.2. Other LDH species (e.g., containing Co, or molyb̄ate or tungstate in exchangeable sites) may possibly form, but thermodynamic data are unavailable.

Boclair et al. 1999 [DIRS 172929], Table 1; Boclair and Braterman 1999 [DIRS 172930], Table 2-Description of Data: $\log (K)$ solubility data for two Ni-bearing LDH phases (Table 4.1-4). Qualification Status: Justified for intended use in this analysis. Extent to Which 
the Data Demonstrate the Properties of Interest: The authors performed synthesis using a titration method to produce LDH phases with various transition metal cations and differing divalent:trivalent cation ratios. The authors developed solubility data based on the solution composition in equilibrium with these phases. They also conducted phase characterization for all the synthetic LDH phases, an important step in evaluating the measured solubility data for these compositionally variable phases. These data appropriately demonstrate the properties of interest because the solid phase characterization performed by the authors provides confidence in the derived solubility constants, because LDH phases are common mineral phases and common products of metal corrosion, and because these LDH phases contain the major components in Alloy 22 and are therefore relevant to the geochemical system on waste packages at Yucca Mountain. The following also justify the data from these sources for the intended use in this analysis. Qualifications of Personnel or Organizations Generating the Data: One of the authors of these papers, Paul Braterman, is a world-recognized authority on layered double hydroxides, and has published over a dozen articles on the synthesis and characterization of these materials. Reliability of Data Source: These data were published in Chemical Materials, which is a respected journal of the American Chemical Society. Its articles are peer-reviewed, i.e., reviewed by other experts in the pertinent technical field, individuals with experience in the subject matter who typically use such information in the course of their work. Technical issues are raised during the review process and either resolved prior to publication or the article is rejected. This process provides an appropriate level of confidence that the data are suitable for use in the types of analyses for which it was intended.

Table 4.1-4. Thermodynamic Data for Ni:Cr and Ni:Fe LDH Phases

\begin{tabular}{l}
\begin{tabular}{|l|l|l|l|}
\hline $\begin{array}{c}\text { Name in } \\
\text { data0.ypf.R2 }\end{array}$ & $\begin{array}{c}\text { Chemical } \\
\text { Formula }\end{array}$ & \multicolumn{1}{|c|}{ Dissociation Reaction } & log(K) \\
\hline Cr-Ni_LDH & $\mathrm{CrNi}_{2}(\mathrm{OH})_{6} \mathrm{Cl}$ & $\mathrm{CrNi}_{2}(\mathrm{OH})_{6} \mathrm{Cl} \rightarrow \mathrm{Cr}^{3+}+2 \mathrm{Ni}^{2+}+6 \mathrm{OH}^{-}+\mathrm{Cl}^{-}$ & -61.83 \\
\hline Fe-Ni_LDH & $\mathrm{FeNi}_{2}(\mathrm{OH})_{6} \mathrm{Cl}$ & $\mathrm{FeNi}_{2}(\mathrm{OH})_{6} \mathrm{Cl} \rightarrow \mathrm{Fe}^{3+}+2 \mathrm{Ni}^{2+}+6 \mathrm{OH}^{-}+\mathrm{Cl}^{-}$ & -59.49 \\
\hline
\end{tabular} \\
NOTES: Cr-Ni_LDH data from Boclair et al. 1999 [DIRS 172929], Table 1. \\
\multicolumn{4}{r}{ Fe-Ni_LDH data from Boclair and Braterman 1999 [DIRS 172930], Table 2. }
\end{tabular}

Akaganeite - Akaganeite is a polymorph of $\mathrm{FeOOH}$ (also known as $\beta-\mathrm{FeOOH}$ ), along with goethite and lepidocrocite, but with channels in its structure. These channels can accommodate anions such as $\mathrm{Cl}^{-}, \mathrm{NO}_{3}{ }^{-}$, and $\mathrm{F}^{-}$plus water (see Murray 1979 [DIRS 173260] and Flynn 1984 [DIRS 173253] for a general review on the properties of Fe(III) oxy-hydroxides). It forms preferentially to goethite in chloride-rich solutions, and contains up to several weight percent $\mathrm{Cl}$ (Cornell and Schwertmann 2003 [DIRS 173037], pp. 21, 499). It has been included here as a potential sink for brine chloride as Alloy 22, which contains iron, corrodes. The $\log (K)$ value of 3.05 for this phase was determined by Murray (1979 [DIRS 173260]), who corrected for ionic strength based on the evaluation of solubility data reported by Biedermann and Chow (1966 [DIRS 173269]) in $0.5 \mathrm{M} \mathrm{NaCl}$ solution. Murray (1979 [DIRS 173260]) cautions that this estimation should be regarded as an approximation. Very few studies have focused on the solubility of this phase (Biedermann and Chow 1966 [DIRS 173269]; Khoe and Robins 1989 [DIRS 173256]). A thermodynamic study by Laberty and Navrotsky (1998 [DIRS 173254]) of Fe oxy-hydroxides shows that akaganeite is less stable than goethite but more so than lepidocrocite on the basis of measured enthalpies of formation. Because the authors were attempting to evaluate the changes in enthalpy of formation due to structural differences only, 
the amount of chloride in the akaganeite phase used by Laberty and Navrotsky (1998 [DIRS 173254]) was kept to a minimum, and was reported as $\beta$-FeOOH $0.032 \mathrm{HCl}$. This is much lower than the values reported by Biedermann and Chow (1966 [DIRS 173269]) and Khoe and Robins (1989 [DIRS 173256]) of $\mathrm{Fe}(\mathrm{OH})_{2.7} \mathrm{Cl}_{0.3}$ and $\mathrm{Fe}(\mathrm{OH})_{2.5} \mathrm{Cl}_{0.5}$, respectively.

Solubility studies on ferric $\mathrm{Fe}$ hydroxide, $\mathrm{Fe}(\mathrm{OH})_{3}(\mathrm{~s})$, in electrolyte solutions of ionic strengths greater than 0.5 molal have been conducted by various authors (Liu and Millero 1999 [DIRS 168023]; Byrne et al. 2000 [DIRS 168006]; Byrne and Luo 2000 [DIRS 173255]; Liu and Millero 2002 [DIRS 173257]). An interesting observation by Byrne et al. (2000 [DIRS 168006]) is that, in a plot of $\log \left[\mathrm{Fe}^{3+}\right]$ versus $\mathrm{pH}$, the slope of the solubility boundary for $\mathrm{Fe}(\mathrm{OH})_{3}(\mathrm{~s})$ is less than 3, the value that would be expected from this phase's stoichiometry and its dissociation reaction:

$$
\mathrm{Fe}(\mathrm{OH})_{3}(\mathrm{~s})+3 \mathrm{H}^{+}=\mathrm{Fe}^{3+}+3 \mathrm{H}_{2} \mathrm{O}
$$

This observation is consistent with the slopes observed by Biedermann and Chow (1966 [DIRS 173269]) and Khoe and Robins (1989 [DIRS 173256]) in their studies. However, Byrne and Luo (2000 [DIRS 173255]) interpreted this observation as a dependence of the activity of $\mathrm{Fe}(\mathrm{OH})_{3}(\mathrm{~s})$ solid on $\mathrm{pH}$ instead of assigning a specific stoichiometry for hydroxyls and other balancing anions to the solid as in the two former studies. Given the adopted conventions for solution-mineral equilibria in the development of this thermodynamic database, it is difficult to reconcile the form in which the equilibrium solubility expression and evaluation of solubility data given by Byrne and Luo (2000 [DIRS 173255]) could be considered. These authors (Byrne and Luo 2000 [DIRS 173255]) described the nature of this $\mathrm{Fe}(\mathrm{OH})_{3}(\mathrm{~s})$ activity dependence on $\mathrm{pH}$ in terms of particle size of the solids. Although this has been described in other ferric Fe hydroxide precipitation studies, Byrne and Luo (2000 [DIRS 173255]) did not test for this possibility because the particle size of the resulting precipitates was not characterized in their study. Moreover, the authors did not identify the precipitated solids (e.g., by X-ray diffraction), nor did they analyze their composition after the experiments. Therefore, the solubility constants given by Murray (1979 [DIRS 173260]) based on the study by Biedermann and Chow (1966 [DIRS 173269]) are deemed more reliable and are selected for the akaganeite dissociation reaction with the phase stoichiometry of $\mathrm{Fe}(\mathrm{OH})_{2.7} \mathrm{Cl}_{0.3}$.

To further support the akaganeite stoichiometry adopted for this database, the study by Khoe and Robins (1989 [DIRS 173256]) advanced a composition of $\mathrm{Fe}(\mathrm{OH})_{2.5} \mathrm{Cl}_{0.5}$ based on the fits to solubility data as a function of $\mathrm{pH}$ in $1 \mathrm{M} \mathrm{KCl}$ solution. The differences in akaganeite stoichiometry are relatively small compared to the inherent uncertainties in the experimental measurements. The difference in solubility product between the studies by Biedermann and Chow (1966 [DIRS 173269]) and Khoe and Robins (1989 [DIRS 173256]) is $\sim 4 \log (K)$ units as given by the latter, which is rather large but still in reasonable agreement given the differences in the experimental methodology and inherent uncertainties in the determined phase composition. The study by Biedermann and Chow (1966 [DIRS 173269]) is the only one that confirms the phase identity as $\beta$-FeOOH (akaganeite) based on the X-ray diffraction data. Another factor for consideration of the work by Biedermann and Chow (1966 [DIRS 173269]) is that aging or equilibration time in this type of solubility experiment may play an important role, and that their study seems to be the only one that allowed equilibration times on the order of weeks. Therefore, the $\log (K)$ reported by Murray (1979 [DIRS 173260]), which is based on the 
solubility data of Biedermann and Chow (1966 [DIRS 173269]), is suitable for use and is selected as the direct input.

Murray 1979 [DIRS 173260], pp. 67 to 68-Description of Data: $\log (K)$ solubility for akaganeite. Qualification Status: Justified for intended use in this analysis. Extent to Which the Data Demonstrate the Properties of Interest: As discussed above, Murray (1979 [DIRS 173260]) considers the data reported by Biedermann and Chow (1966 [DIRS 173269]) in their evaluation of solubility for akaganeite. Biedermann and Chow (1966 [DIRS 173269]) confirm the phase identity as $\beta-\mathrm{FeOOH}$ (akaganeite) based on the X-ray diffraction data. Another factor for consideration of the work by Biedermann and Chow (1966 [DIRS 173269]) is that aging or equilibration time in this type of solubility experiment may play an important role, and that their study allowed equilibration times on the order of weeks. The $\log (K)$ value of 3.05 for this phase was determined by Murray (1979 [DIRS 173260]) and was corrected for ionic strength by the author based on the evaluation of solubility data reported by Biedermann and Chow (1966 [DIRS 173269]) in $0.5 \mathrm{M} \mathrm{NaCl}$ solution. Murray (1979 [DIRS 173260]) cautions that this estimate is an approximation. Considering the scarcity of solubility data for this phase and the careful experimental work of Biedermann and Chow (1966 [DIRS 173269]) (see discussion above), the $\log (K)$ value derived by Murray (1979 [DIRS 173260]) and adopted in this report is suitable for intended use. These data appropriately demonstrate the properties of interest because this phase has been observed as a common product of metal corrosion in the presence of electrolyte aqueous species such as $\mathrm{Cl}^{-}$and $\mathrm{NO}_{3}{ }^{-}$. This phase, along with other ferric iron oxy-hydroxide phases, is expected to form as a result of Alloy 22 corrosion, and is therefore relevant to the geochemical system on waste packages at Yucca Mountain. The following criteria also justify the data from Murray (1979 [DIRS 173260]) for the intended use in this analysis. Qualifications of Personnel or Organizations Generating the Data: The author, Dr. James W. Murray, is professor of chemical oceanography at the University of Washington. He has published more than a dozen articles on the distribution of metals in various aquatic environments. The article referenced for the solubility data selected for akaganeite is a review titled "Iron Oxides," published in the Mineralogical Society of America's volume on marine minerals (Vol. 6) in the Reviews in Mineralogy series. This series is a respected source of information for various topics related to mineralogy and is edited and reviewed by experts in the field.

Table 4.1-5. Thermodynamic Data for Akaganeite

\begin{tabular}{|l|c|c|c|}
\hline $\begin{array}{c}\text { Name in } \\
\text { data0.ypf.R2 }\end{array}$ & $\begin{array}{c}\text { Chemical } \\
\text { Formula }\end{array}$ & Dissociation Reaction & \multicolumn{1}{l|}{$(K)$} \\
\hline Akaganeite & $\mathrm{Fe}(\mathrm{OH})_{2.7} \mathrm{Cl}_{0.3}$ & Akaganeite $+2 \mathrm{H}^{+} \leftrightarrow \mathrm{Fe}^{3+}+0.3 \mathrm{Cl}^{-}+2.7 \mathrm{H}_{2} \mathrm{O}$ & $3.05 \pm 0.1$ \\
\hline
\end{tabular}

NOTE: $\quad$ Akaganeite data from Murray 1979 [DIRS 173260], pp. 67 to 68 . The author reports an uncertainty \pm 0.1 for the reported $\log (K)$ value based on the evaluation of solubility data.

\subsubsection{Parameters Describing Dust Deposition in Emplacement Drifts During Ventilation}

Inputs described here are used to calculate the dust deposition quantities brought in by ventilation (Section 6.4.1). Table 4.1-6 contains the emplacement drift input data and sources, and Table 4.1-7 provides dust measurement data from Site 5 that is qualified in Appendix C. Both of these tables are inputs to Deposition.xls in Output DTN: SN0508T0502205.016. The 
dust data from Site 5 were used because the data sets from Site 5 and Site 1 are the most complete, and Site 5 is more remote with respect to anthropogenic activities than Site 1.

Table 4.1-6. Emplacement Drift Design and Operational Input Data

\begin{tabular}{|c|c|c|}
\hline Description & Value (Units) & Source \\
\hline Ventilation duration & 50 years after final emplacement & BSC 2004 [DIRS 168489], Table 1 \\
\hline Nominal ventilation airflow rate & $15 \mathrm{~m}^{3} / \mathrm{s}$ & BSC 2004 [DIRS 168489], Table 1 \\
\hline Emplacement drifts length & $66,450 \mathrm{~m}$ & BSC 2003 [DIRS 165572], Table 8 \\
\hline Emplacement drift turnouts length & $11,148 \mathrm{~m}$ & BSC 2003 [DIRS 165572], Table 8 \\
\hline Number of emplacement drifts & $\begin{array}{l}\text { Panel 1: } 8 \\
\text { Panel 2: } 27 \\
\text { Panel 3: } 22 \text { West and } 19 \text { East } \\
\text { Panel 4: } 30\end{array}$ & BSC 2003 [DIRS 165572], Figure 5 \\
\hline Emplacement drift diameter & $5.5 \mathrm{~m}$ & BSC 2003 [DIRS 165572], Table 8 \\
\hline Turnout drift width & $26 \mathrm{ft}(8.0 \mathrm{~m})$ & BSC 2004 [DIRS 172801] \\
\hline Turnout drift height & $23 \mathrm{ft}(7.0 \mathrm{~m})$ & BSC 2004 [DIRS 172801] \\
\hline Turnout springline & $10 \mathrm{ft}(3.05 \mathrm{~m})$ (Height - radius) & $\begin{array}{l}\text { BSC } 2004 \text { [DIRS 172801] and IED } \\
\text { source specified (BSC 2004 } \\
\text { [DIRS 167736], Section C) }\end{array}$ \\
\hline Short turnout length & $238 \mathrm{ft}$ (curve) $+80 \mathrm{ft}$ (straight) & $\begin{array}{l}\text { BSC } 2004 \text { [DIRS 172801], and IED } \\
\text { source specified (BSC 2004 } \\
\text { [DIRS 167736]; see detail Panel 1) }\end{array}$ \\
\hline Turnout curve centerline radius & $200 \mathrm{ft}$ & $\begin{array}{l}\text { BSC } 2004 \text { [DIRS 172801], and IED } \\
\text { source specified (BSC 2004 } \\
\text { [DIRS 167736]; see detail Panel } 1 \\
\text { and note 2) }\end{array}$ \\
\hline Waste package diameter (21-PWR) & 66.9 in. $(1.70 \mathrm{~m})$ & BSC 2004 [DIRS 169062] \\
\hline
\end{tabular}

NOTE: IED = information exchange drawing.

Table 4.1-7. Airborne Particulate Measurement Inputs from Site 5, Annual Averages

\begin{tabular}{|c|c|c|c|}
\hline Year & $\mathrm{PM}_{10}\left(\mu \mathrm{g} / \mathrm{m}^{3}\right)$ & Total Particles $\left(\mu \mathrm{g} / \mathrm{m}^{3}\right)$ & Sources \\
\hline 1996 & 10 & 26 & $\begin{array}{l}\text { TM000000000001.084 [DIRS 121419] } \\
\text { TM000000000001.096 [DIRS 121421] } \\
\text { TM000000000001.097 [DIRS 121426] } \\
\text { TM000000000001.098 [DIRS 121429] }\end{array}$ \\
\hline 1997 & 9 & 20 & $\begin{array}{l}\text { TM000000000001.099 [DIRS 121435] } \\
\text { TM000000000001.105 [DIRS 121440] } \\
\text { TM000000000001.108 [DIRS 121442] } \\
\text { MO98PSDALOG111.000 [DIRS 119501] }\end{array}$ \\
\hline 1998 & 7 & 18 & MO0104SEPAMARQ.001 [DIRS 173790] \\
\hline 1999 & 8 & 23 & MO0104SEPAMARQ.002 [DIRS 173791] ${ }^{a}$ \\
\hline 2000 & 12 & NR & MO0104SEPAMARQ.003 [DIRS 173792] ${ }^{a}$ \\
\hline
\end{tabular}

${ }^{a}$ Refer to Appendix C for the qualification of these data sources (DTN: MO0505SEPAMARQ.004 [DIRS 173795] was also qualified in Appendix $C$ but not used in this report).

NOTES: $\quad$ NR $=$ not reported (total particulate sampling had been discontinued).

$\mathrm{PM}_{10}=$ Inhalable particulate matter $10 \mu \mathrm{m}$ or less in diameter. 
The analysis of dust deposition is based on the review article "Particle and Gas Dry Deposition: A Review," by Sehmel (1980 [DIRS 172607], Equation 1). The dry deposition velocity of a particle from the air is given as:

$$
v_{\mathrm{d}}=\frac{-F}{\chi}
$$

where $v_{\mathrm{d}}$ is the dry deposition velocity, a function of particle diameter; $F$ is the deposition flux; and $\chi$ is the airborne concentration.

Figure 6 from the article by Sehmel (1980 [DIRS 172607]), reproduced here as Figure 4-1, is used as input to determine the deposition velocity of specific size and density dust particles. For the purposes of the analyses in Section 6.4.1.1, the "roughness height," $\mathrm{z}_{0}$, is assumed to be $0.1 \mathrm{~cm}$; a value greater than "Level desert" $\mathrm{z}_{0}=0.03 \mathrm{~cm}$, and equivalent to "Snow surface, lawn to $1 \mathrm{~cm}$ " $z_{0}=0.1 \mathrm{~cm}$ (Sehmel 1980 [DIRS 172607], Table 6). This surface roughness value of $\mathrm{z}_{0}=0.1 \mathrm{~cm}$ is applied to both the invert and the waste package horizontal surface.

Sehmel 1980 [DIRS 172607] - Description of Data: Deposition function (Equation 4-5), and deposition velocity from Figure 6 of the source. Qualification Status: Justified for intended use in this analysis. Extent to Which the Data Demonstrate the Properties of Interest: This source contains a broad collection of experimental deposition rate results from many sources that are internally consistent. It also provides a general introductory theory, and associated rate equations, for particle deposition. These data appropriately demonstrate the property of interest, which is to express dust particle deposition as a simple function (Equation 4-5). Qualification of Personnel and Organization: G.A. Sehmel was with the Pacific Northwest National Laboratory at the time of the work in question. He has authored over 40 published works involving various material deposition processes and dating back to the mid-1960s. Prior uses of the data: This article has been cited over 350 times in scientific and engineering literature, demonstrating that it is accepted in the field of particle and gas deposition. 


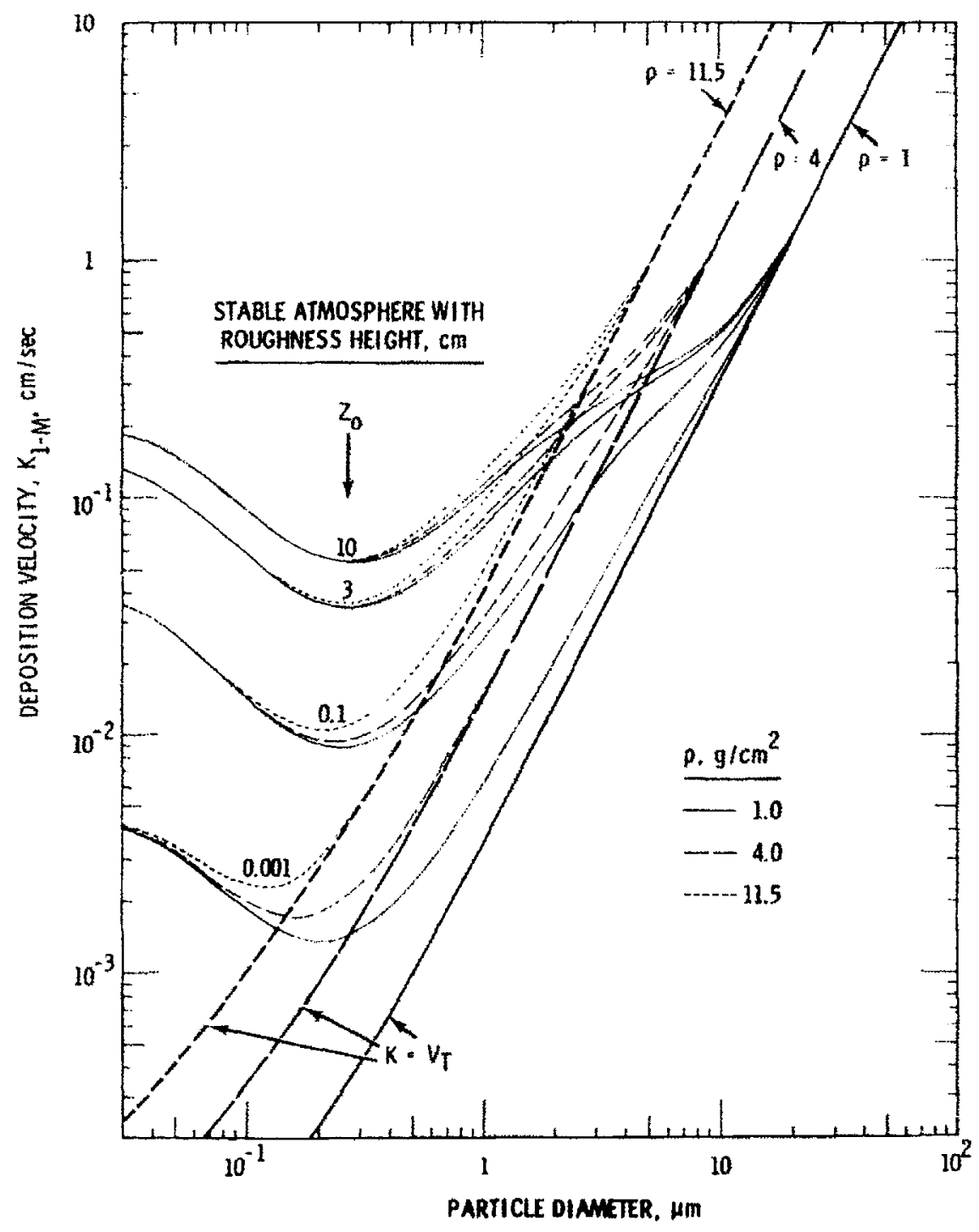

Source: Sehmel 1980 [DIRS 172607], Figure 6.

NOTE: The units given for $\rho$, density, in the graph above are incorrect, and should be $\mathrm{g} / \mathrm{cm}^{3}$.

Figure 4-1. Predicted Deposition Velocities at 1 Meter as a Function of Particle Diameter and Density

\subsubsection{Dust Compositional Data Used to Estimate Brine Volume}

Inputs described here are used to calculate the brine quantities that will form by dust deliquescence on waste packages (Section 6.4.1); these are inputs to NV00-dust.xls and EQ3/6 calculations in Output DTN: SN0508T0502205.016.

The primary inputs are from the National Atmospheric Deposition Program/National Trends Network (NADP/NTN) and their precipitation collection and chemical analyses. Table 4.1-8 shows the chemical information used as direct input. These are compositional data for the soluble components in dust, scavenged from the atmosphere by precipitation. The analyses represent only soluble inorganic components, and do not include carbonate/bicarbonate. 
In EQ3/6 simulations with these data, carbonate is fixed at equilibrium with atmospheric $\mathrm{CO}_{2}$ levels in the gas phase, and charge balancing is done on $\mathrm{H}^{+}$; hence, the $\mathrm{pH}$ values listed in Table 4.1-8 are used only as initial guesses in calculating the solution composition

Table 4.1-8. NADP/NTN Precipitation-Weighted Annual Mean Concentrations

\begin{tabular}{|c|c|c|c|c|c|c|c|c|c|}
\hline Year & $\begin{array}{c}\mathrm{Ca} \\
(\mathrm{mg} / \mathrm{L})\end{array}$ & $\begin{array}{c}\mathrm{Mg} \\
(\mathrm{mg} / \mathrm{L})\end{array}$ & $\begin{array}{c}\mathrm{K} \\
(\mathrm{mg} / \mathrm{L})\end{array}$ & $\begin{array}{c}\mathrm{Na} \\
(\mathrm{mg} / \mathrm{L})\end{array}$ & $\begin{array}{c}\mathrm{NH}_{4} \\
(\mathrm{mg} / \mathrm{L})\end{array}$ & $\begin{array}{c}\mathrm{NO}_{3} \\
(\mathrm{mg} / \mathrm{L})\end{array}$ & $\begin{array}{c}\mathrm{Cl} \\
(\mathrm{mg} / \mathrm{L})\end{array}$ & $\begin{array}{c}\mathrm{SO}_{4} \\
(\mathrm{mg} / \mathrm{L})\end{array}$ & $\mathrm{pH}(\mathrm{lab})$ \\
\hline 2000 & 0.48 & 0.044 & 0.013 & 0.059 & 0.26 & 1.14 & 0.09 & 0.46 & 5.44 \\
\hline 2001 & 0.66 & 0.068 & 0.042 & 0.113 & 0.69 & 2.15 & 0.16 & 1.01 & 5.55 \\
\hline 2002 & 1.21 & 0.137 & 0.055 & 0.263 & 1.01 & 3.24 & 0.36 & 1.35 & 6.38 \\
\hline
\end{tabular}

NADP/NTN 2000 [DIRS 172977]; 2001 [DIRS 172976]; 2002 [DIRS 173141]—Description of Data: Compositional data for leachate from precipitation collectors deployed at NADP sites in the Yucca Mountain region. Qualification Status: Justified for intended use in this analysis. Extent to Which the Data Demonstrate the Properties of Interest: These precipitation chemistries result from the capture and wash-out of dust and atmospheric aerosols by rain or snow. This type of data appropriately demonstrates the properties of interest, i.e., the soluble salt composition for atmospheric dust, because atmospheric aerosols are ubiquitous and always present (except when depleted by rain-out). Windblown surface dust may be present episodically, but atmospheric aerosols are effectively present at all times. Rain-out data are widely used to evaluate atmospheric dust composition. Further discussion of dust composition is provided in Section 6.1 of this report. Reliability of Data Source: The National Trends Network samples precipitation on a weekly basis and determines its ionic composition. A brief programmatic description is contained within an Atmospheric Environment article by Lamb and Bowersox (2000 [DIRS 173067]). Therein, on page 1661, it is stated that all samples are "sent to the Central Analytical Laboratory at the Illinois State Water Survey in Champaign Illinois, where they were analyzed for ten inorganic ions following rigorous quality assurance procedures." This laboratory follows guidelines published in Quality Assurance Plan Central Analytical Laboratory, 2002 (NADP 2002 [DIRS 173628]) and a general quality assurance (QA) program as summarized on the National Airfall Deposition Program's website (NADP 2005 [DIRS 173625]). Prior use of data: Also described in the article by Lamb and Bowersox (2000 [DIRS 173067]) is the collection of papers that appeared in the same journal issue presenting work based on these and other NADP/NTN data.

In addition to these chemistries, the soluble salt content of dust samples collected near the Yucca Mountain site at Fortymile Wash are used. These values come from a study by Reheis and Kihl (1995 [DIRS 106653], Table 2) and are listed in Table 4.1-9. 
Table 4.1-9. Fortymile Wash Dust Data

\begin{tabular}{|c|c|}
\hline Site (T) & Soluble Salt \% \\
\hline 1 & 12.2 \\
\hline 2 & 11.1 \\
\hline $3 a$ & 6.3 \\
\hline 4 & 12.4 \\
\hline 5 & 13.1 \\
\hline 6 & 7.9 \\
\hline
\end{tabular}

Source: Reheis and Kihl 1995 [DIRS 106653], Table 2.

Reheis and Kihl 1995 [DIRS 106653]-Description of Data: Average soluble salt fraction for dust collection sites near Yucca Mountain. Qualification Status: Qualified for use as direct input in this document (Appendix G).

Other Inputs Used to Estimate Brine Volume-Atomic weights needed to convert the $\mathrm{mg} / \mathrm{L}$ values in Table 4.1-8 to millimoles per liter were taken from the data0.ypf.R0 database file (DTN: SN0302T0510102.002 [DIRS 162572]). Also, the total pressure at the elevation of the repository of 0.89 bars (converted and rounded from the 89,112 Pa input from BSC 2004 [DIRS 169862], Appendix XIX) is used to determine the maximum possible relative humidity level supportable at temperatures greater than $100^{\circ} \mathrm{C}$.

$\mathrm{NaNO}_{3}$ brine density values are input to compare with estimated brine densities used to calculate brine volumes. Also, the density of water at $70^{\circ} \mathrm{C}$ is used to adjust the sodium nitrate density values to approximate them at $70^{\circ} \mathrm{C}$. All input values are in Table 4.1-10 and come from CRC Handbook of Chemistry and Physics (Lide 2000 [DIRS 162229]), which is a source of established fact.

Table 4.1-10. $\quad \mathrm{NaNO}_{3}$ and Water Densities for Input to Brine Volume Calculation

\begin{tabular}{|c|c|c|}
\hline \multicolumn{2}{|c|}{$\mathrm{NaNO}_{3}$ Solution Density at $20^{\circ} \mathrm{C}$} & \multirow{2}{*}{$\begin{array}{l}\text { Location in Lide } 2000 \\
\text { [DIRS 162229] }\end{array}$} \\
\hline wt \% & $\mathrm{g} / \mathrm{mL}$ & \\
\hline 12 & 1.0819 & \multirow[t]{5}{*}{ p. 8-78 } \\
\hline 14 & 1.0967 & \\
\hline 20 & 1.1429 & \\
\hline 30 & 1.2256 & \\
\hline 40 & 1.3175 & \\
\hline \multicolumn{2}{|c|}{ Water Density $(\mathrm{g} / \mathrm{mL})$} & \\
\hline At $20^{\circ} \mathrm{C}$ & 0.99821 & \multirow[t]{2}{*}{ p. 6-3 } \\
\hline At $70^{\circ} \mathrm{C}$ & 0.97778 & \\
\hline
\end{tabular}

\subsubsection{Data Supporting Stifling of Crevice Corrosion}

Although not initially implemented to obtain crevice corrosion stifling rate parameters, constant-potential experiments were conducted in a variety of de-aerated electrolytes with a nitrate-chloride ratio between zero and 100 (DTN: LL050200212251.125 [DIRS 173131]) at exposure temperatures between $80^{\circ} \mathrm{C}$ and $155^{\circ} \mathrm{C}$. These experiments were originally undertaken 
to test the validity of the use of the repassivation potential as a critical potential for crevice corrosion initiation. The data consist of measurements of current versus exposure time for specimens held at constant potentials. The specimens used were as-welded prism crevice assembly specimens with a total area of $14.06 \mathrm{~cm}^{2}$ with 24 creviced regions of equal area and a total creviced area of $1.50 \mathrm{~cm}^{2}$ (i.e., each crevice had an area of $1.50 \mathrm{~cm}^{2} / 24=6.25 \times 10^{-2} \mathrm{~cm}^{2}$ ). These data are used in this report to conduct a conservative quantitative analysis of the time exponent for crevice corrosion stifling in Section 6.5.2.1.

Table 4.1-11 lists the source of the current versus exposure time for Alloy 22 specimens held at constant potentials used in the analysis of stifling of crevice corrosion.

Table 4.1-11. Current versus Exposure Time for Alloy 22 Specimens Held at Constant Potentials

\begin{tabular}{|l|l|l|l|}
\hline \multicolumn{1}{|c|}{ Data Name } & \multicolumn{1}{|c|}{ Data Source } & \multicolumn{1}{c|}{ DTN } & \multicolumn{1}{c|}{$\begin{array}{c}\text { Data Use in } \\
\text { This Report }\end{array}$} \\
\hline $\begin{array}{l}\text { Current versus exposure time for Alloy 22 } \\
\text { specimens held at constant potentials }\end{array}$ & $\begin{array}{l}\text { Waste Package } \\
\text { Materials Testing }\end{array}$ & $\begin{array}{l}\text { LL050200212251.125 } \\
\text { [DIRS 173131] }\end{array}$ & Section 6.5.2.1 \\
\hline
\end{tabular}

\subsubsection{Dust Physical Data Used to Evaluate Retention Characteristics}

The potential for capillary retention of brines in dust on the waste package surface is evaluated in Section 6.4.3. Inputs to these calculations are two qualified LBNL DTNs:

- LB0503DUSTIMAG.001 [DIRS 173258] - ECRB Dust Characterization (Imaging)

- LB0503DUSTPCAP.001 [DIRS 173259] - ECRB Dust Pore Diameter Distribution and Capillary Pressure Characteristic Curves.

In addition, a single value for the surface tension of water at room temperature, $0.072 \mathrm{Newton} / \mathrm{m}$, is taken from Fundamentals of Heat and Mass Transfer (Incropera and DeWitt 1996 [DIRS 108184], Table A.6). This source is established fact, as described in Section 4.1.8.

\subsubsection{Input Data for Analysis of Grain-Grain Contacts, Oxygen Diffusion Properties, and Passive Current/Temperature Relationship}

Analysis of Grain-Grain Contacts-The geometrical analysis of grain-grain contacts in Section 6.4.2 requires information on coordination numbers that could occur. Klein and Hurlbut (1993 [DIRS 153700], p. 191) give the maximum coordination number as 12 for closest packing of equal-sized spheres. This source, Manual of Mineralogy, is considered to be established fact data. The analysis also refers to a calculated minimum coordination number of 4 , for rigid packing of equal spheres (Gardner 1995 [DIRS 173894], p. 88).

Gardner 1995 [DIRS 173894]—Description of Data: Minimum coordination number for a rigid packing of equal spheres. Qualification Status: Justified for intended use in this analysis. Extent to Which the Data Demonstrate the Properties of Interest: The source specifies the datum of interest, the minimum coordination number for a rigid packing of equal spheres. Reliability of Data Source: The datum is published in a widely circulated popular book, which is compiled from twenty columns published in the periodical Scientific American. This is 
considered a reliable source for such a simply stated mathematical result, used in this report to support the range for a parametric analysis. Qualification of Personnel and Organization: Martin Gardner is a well-published author of mathematical books and texts, and the source volume is published by the Mathematical Association of America, a professional group of national prominence with wide membership.

Inputs for evaluating $\mathrm{O}_{2}$ diffusion in brines formed by dust deliquescence (Section 6.4.4), are as follows:

- Diffusion coefficient $D_{0}$ for $\mathrm{O}_{2}$ in sodium chloride solution: $1.8 \times 10^{-5} \mathrm{~cm}^{2} / \mathrm{sec}$ (King et al. 1995 [DIRS 172836], Table A-1)

- Salting-out coefficient for $\mathrm{O}_{2}$ in concentrated brine treated parametrically in Section 6.4.4.

- Oxygen solubility $\left(\mathrm{mol} \cdot \mathrm{dm}^{-3}\right)=-1.4842 \mathrm{E}-14 \mathrm{~T}^{5}+2.8347 \mathrm{E}-11 \mathrm{~T}^{4}-2.1630 \mathrm{E}-08 \mathrm{~T}^{3}+$ $8.2524 \mathrm{E}-06 \mathrm{~T}^{2}-1.5759 \mathrm{E}-03 \mathrm{~T}+1.2078 \mathrm{E}-01$, based on a polynomial fit presented by EPRI (2004 [DIRS 172825], Figure 5-5).

King et al. 1995 [DIRS 172836], Table A-1-Description of Data: Diffusion coefficient for $\mathrm{O}_{2}$ in brine. Qualification Status: Justified for intended use in this analysis. Extent to Which the Data Demonstrate the Properties of Interest: The datum from this source, the diffusion coefficient of oxygen in solution, appropriately demonstrates the property of interest because it was measured in a brine (although diffusion coefficients do not vary greatly with solute concentration). Corroborating Data: The representative oxygen-diffusion coefficient value of $D_{0}=1.8 \times 10^{-5} \mathrm{~cm}^{2} / \mathrm{sec}$ at $25^{\circ} \mathrm{C}$ from this source is justified by a corroborating value of $2.0 \times 10^{-5} \mathrm{~cm}^{2} / \mathrm{sec}$ (Kear et al. (2004 [DIRS 172833], Table 6), which is very close for a parameter with intrinsic statistical uncertainty, such as a diffusion coefficient.

Parametric Range for $\mathbf{O}_{2}$ Salting-Out Coefficient-EPRI (2004 [DIRS 172825], pp. 5-6 to 5-7) presents literature values for the $\mathrm{O}_{2}$ salting-out factor in brine of 0.24 and 0.127 for saturated $\mathrm{NaCl}$ brine and $5 \mathrm{~mol} / \mathrm{L} \mathrm{CaCl}_{2}$ solution, respectively. Langmuir (1997 [DIRS 100051], Table 4.5) gives a value of 0.132 for $\mathrm{O}_{2}$ in $\mathrm{NaCl}$ solution at $25^{\circ} \mathrm{C}$. Because of uncertainty associated with this parameter in multi-salt deliquescent brines, the salting-out factor is treated parametrically in Section 6.4.4, using values of $0.05,0.1$, and 0.5.

Qualification of Oxygen Solubility Information from EPRI 2004 [DIRS 172825]-The information used from the referenced source by EPRI is the prediction of the solubility of oxygen in water as a function of temperature. This prediction is in the format of a 5 th order polynomial as a function of temperature, presented in Figure 5.5 of the cited document, and used in Section 6.4.4 of this report. The polynomial is corroborated by data from the handbook of Perry et al. (1984 [DIRS 125806]) in Appendix D to this report. The polynomial representation is also shown in Appendix D to be consistent with the oxygen solubility data in the Pitzer databases discussed in Section 4.1.1. For the intended application of predicting the solubility of oxygen, these sources predict the same solubilities. 
Porosity of Deposited Dust Layer-A value of $50 \%$ is used for the porosity of dust deposited on the surface of the waste package. This is based on a bulk dust density of $70 \mathrm{lb} / \mathrm{ft}^{3}$, or $1.12 \mathrm{~g} / \mathrm{cm}^{3}$, the midpoint of the range 57 to $83 \mathrm{lb} / \mathrm{ft}^{3}$ identified for "Dry Earth, Loose Density" by Hartman (1992 [DIRS 101970], Table E). Dust particles comprise mainly silicate, carbonate, nitrate, and sulfate minerals with densities ranging from approximately 2.1 to $2.7 \mathrm{~g} / \mathrm{cm}^{3}$ (Roberts et al. 1990 [DIRS 107105]); hence the bulk density of $1.12 \mathrm{~g} / \mathrm{cm}^{3}$ corresponds to porosity of 50 to $60 \%$. Values taken from Hartman (1992 [DIRS 101970], Table E) are established fact. Values taken from Roberts et al. (1990 [DIRS 107105]) come from a widely used mineralogy reference book, the Encyclopedia of Minerals, and are also established fact.

Passive Corrosion Current-The passive current temperature relationship described in Section 6.4.4 is a summary of a derivation in General Corrosion and Localized Corrosion of Waste Package Outer Barrier (BSC 2004 [DIRS 169984], Equations 6-28, 6-29, and I-3). The equation for current density $(i)$ can be derived as:

$$
i\left(\mathrm{na} / \mathrm{cm}^{2}\right)=\exp (C / T-C / 333.15) \cdot r_{0} \rho /(k \cdot E W)
$$

where $r_{0}(\mathrm{~nm} / \mathrm{yr})=s[\ln (1 /(1-p))]^{1 / b}$ (i.e., a Weibull Distribution) (BSC 2004 [DIRS 169984], Equations 6-28, 6-29, and I-3). In Equation 4-6:

$$
\begin{aligned}
E W= & \text { equivalent weight, } 23.28 \text { for Alloy } 22 \text { (ASTM G 102-89 } \\
& \text { [DIRS 163908], Table } 1, \text { listed by ASTM as N06022 Alloy) } \\
k= & \text { constant of } 3.27 \times 10^{-3} \mathrm{~mm} \mathrm{~g} /(\mu \mathrm{A} \mathrm{cm} \mathrm{yr)} \\
\rho= & \text { density, } 8.69 \mathrm{~g} / \mathrm{cm}^{3} \text { (Haynes International } 1997 \text { [DIRS 100896], p. 13) } \\
T= & \text { absolute temperature (Kelvin). }
\end{aligned}
$$

Based on the fitted model of temperature-dependent general corrosion used by the Yucca Mountain Project (YMP) (BSC 2004 [DIRS 169984], Section 6.4.3.4):

$$
\begin{aligned}
s & =8.88 \mathrm{~nm} / \mathrm{yr} \\
b & =1.62 \\
C & =-3,116.47 \mathrm{~K} \\
p & =\text { cumulative probability. }
\end{aligned}
$$

\subsubsection{Thermogravimetric Analysis Results for Ammonium Mineral Thermal Decomposition and Deliquescence of Mixed-Salt Assemblages at Elevated Temperatures}

An evaluation of the effects of ammonium mineral thermal decomposition on the dust salt assemblages is presented in Section 6.1, and is largely based on experimental work from the qualified DTNs: LL050205223121.048 [DIRS 174025] and LL050301723121.050 [DIRS 173175]. The journal article by Vyazovkin et al. (2001 [DIRS 172842]) has a detailed analysis of the thermal dissociation kinetics of ammonium nitrate, specifically the activation energy $\left(91.5 \pm 5.6 \mathrm{~kJ} \mathrm{~mol}^{-1}\right)$ and pre-exponential Arrhenius factor $\left(\log \left(A / \mathrm{min}^{-1}\right)=9.0 \pm 0.6\right)$ (Vyazovkin et al. 2001 [DIRS 172842], p. 964). This article is used as input for its isothermal 
kinetic rate law (Equation 6.1-1) and associated ammonium nitrate kinetic parameters (Section 6.1.2.3).

Vyazovkin et al. 2001 [DIRS 172842]—Description of Data: Rate law and parameters describing sublimation/dissociation kinetics of ammonium nitrate. Qualification Status: Justified for intended use in this analysis. Extent to Which the Data Demonstrate the Properties of Interest: This paper determines the thermal dissociation kinetics of ammonium nitrate using a thermogravimetric method, examining both the solid and liquid phases. Data were acquired isothermally and non-isothermally and used to determine the best fit for the parameters of a rate equation describing ammonium nitrate dissociation. The methodology adopted in this study provides a detailed characterization of the sublimation/vaporization kinetics, allowing for a thorough characterization of these two processes. These kinetic parameters are the property of interest used in this report as input, and include the kinetic rate law and parameters for decomposition of ammonium nitrate. Qualification of Personnel and Organization: Dr. Sergey Vyazovkin has published over fifty papers in the scientific literature within the past ten years. Most of his body of work is in the specific area of calorimetry and kinetics of thermally induced processes (e.g., decomposition, crystallization and degradation). Reliability of Data Source: These data were published in Chemical Materials, which is a respected journal of the American Chemical Society. Its articles are peer-reviewed, i.e., reviewed by other experts in the pertinent technical field, individuals with experience in the subject matter who typically use such information in the course of their work. Technical issues are raised during the review process and either resolved prior to publication or the article is rejected. This process provides an appropriate level of confidence that the data are suitable for use in the types of analyses for which it was intended.

Experimental confirmation of deliquescence of mixed salt assemblages at temperatures greater than $120^{\circ} \mathrm{C}$ is also discussed in Section 6.1, and is based on experimental data in the qualified DTN: LL041001423121.046 [DIRS 173688].

For Section 6.1.2.2, the file Boiling_temperatures_R1c-1.doc ("Figure 1") supplies information regarding the dryout temperature of the $\mathrm{NaCl}-\mathrm{KNO}_{3}$ assemblage being below $160^{\circ} \mathrm{C}$ (DTN: LL040901831032.008 [DIRS 173659]). Also, Figure 6.1-1 uses data boiling point measurement data from this same file (Boiling_temperatures_Rlc-1.doc, "Figure 3").

\subsubsection{Input Data for Preclosure Temperature and Relative Humidity Analyses}

Appendix A presents preclosure temperature and relative humidity analyses. Preclosure ventilation is analyzed to estimate the average waste package temperature at various times; individual waste package temperatures based on waste package output; partial pressure of water vapor based on meteorological data; and the relative humidity at individual waste packages. Preclosure temperature and relative humidity are not predicted by the multiscale model that describes postclosure conditions for TSPA-LA (BSC 2005 [DIRS 173944]); the analysis in Appendix A is an application of the validated analytical version of the ventilation model (BSC 2004 [DIRS 169862], Section 6.4.2) that describes a wider range of spatial and temporal variability than the original ventilation model output. 
With minor exceptions, the inputs summarized below are obtained from Ventilation Model and Analysis Report (BSC 2004 [DIRS 169862]). For other sources of engineering data used in the preclosure temperature and relative humidity analysis, information is provided in Appendix A to justify inputs for their intended use.

The analysis inputs for the ventilation model include the in-drift geometry and ventilation parameters; the waste package dimensions, thermal properties, and power decay; Kays and Leung parameters for forced air convection; and the thermophysical properties of the rock and air. In addition to these inputs, other analysis inputs, such as the saturated water-vapor pressure relationship for water, and meteorological data (temperature and relative humidity) are required to calculate the partial pressure of water.

\subsubsection{In-Drift Geometry and Ventilation Parameters}

Table 4.1-12 lists various in-drift geometric and preclosure ventilation parameters. This design information is used as input to the analysis described in Appendix A. These are the same as those presented in Ventilation Model and Analysis Report (BSC 2004 [DIRS 169862]). These qualified project design data do not require further justification for use.

Table 4.1-12. Emplacement Drift Geometries, Ventilation Flow Rate, Ventilation Duration

\begin{tabular}{|l|c|}
\hline \multicolumn{1}{|c|}{ Parameter } & Value \\
\hline Emplacement Drift Diameter $(\mathrm{m})$ & 5.5 \\
\hline Emplacement Drift Spacing $(\mathrm{m})$ & 81 \\
\hline Nominal Ventilation Airflow Rate Preclosure $\left(\mathrm{m}^{3} / \mathrm{s}\right)$ & 15 \\
\hline Ventilation Duration after Final Emplacement (years) & 50 \\
\hline
\end{tabular}

Source: BSC 2004 [DIRS 168489].

\subsubsection{Waste Package Dimensions and Properties}

The waste package dimensions are obtained from IED Waste Package Configuration [Sheet 1 of 1] (BSC 2005 [DIRS 173501], Table 1). The power source emissivity is 0.87, as obtained from Repository Multiple Waste Package Thermal Calculation (BSC 2001 [DIRS 156276], pp. 13 and 14). These qualified project sources do not require further justification for use.

\subsubsection{Waste Package Heat Decay}

The discrete waste package powers are used in estimating the preclosure waste-package temperatures. The discrete waste package powers are obtained from an information exchange drawing (IED) contained in IED Waste Package Decay Heat Generation [Sheet 1 of 1$]$ (BSC 2005 [DIRS 173705]). This IED presents the waste package thermal power time histories for a six-plus-two-half waste package series used in TSPA-LA. Also, it presents the average line load for this series of waste packages. These waste package powers and their sequence are the starting point for developing other waste package powers.

The IED (BSC 2005 [DIRS 173705]) presents the average line load for this series of waste packages. Table 4.1-13 shows the repository average lineal heat load as a function of time since waste emplacement. The design information presented in this table is used as input to the 
analysis described in Appendix A. These qualified project design data are the same as those used in Ventilation Model and Analysis Report (BSC 2004 [DIRS 169862]) and do not require further justification for use.

Table 4.1-13. Waste Package Heat Decay

\begin{tabular}{|c|c|c|c|}
\hline $\begin{array}{c}\text { Time Since } \\
\text { Emplacement } \\
\text { (yrs) }\end{array}$ & $\begin{array}{c}\text { Lineal Heat } \\
\text { Load } \\
(\mathrm{kW} / \mathrm{m}) \\
\end{array}$ & $\begin{array}{c}\text { Time Since } \\
\text { Emplacement } \\
\text { (yrs) }\end{array}$ & $\begin{array}{c}\text { Lineal Heat } \\
\text { Load } \\
(\mathrm{kW} / \mathrm{m}) \\
\end{array}$ \\
\hline 0.000001 & $1.45 \mathrm{E}+00$ & 26 & $8.525 \mathrm{E}-01$ \\
\hline 1 & $1.399 E+00$ & 27 & $8.382 \mathrm{E}-01$ \\
\hline 2 & $1.357 \mathrm{E}+00$ & 28 & $8.245 \mathrm{E}-01$ \\
\hline 3 & $1.321 \mathrm{E}+00$ & 29 & $8.114 \mathrm{E}-01$ \\
\hline 4 & $1.289 \mathrm{E}+00$ & 30 & 7.992E-01 \\
\hline 5 & $1.259 \mathrm{E}+00$ & 31 & $7.858 \mathrm{E}-01$ \\
\hline 6 & $1.232 \mathrm{E}+00$ & 32 & $7.730 \mathrm{E}-01$ \\
\hline 7 & $1.206 \mathrm{E}+00$ & 33 & $7.610 \mathrm{E}-01$ \\
\hline 8 & $1.181 \mathrm{E}+00$ & 34 & 7.493E-01 \\
\hline 9 & $1.157 \mathrm{E}+00$ & 35 & $7.381 \mathrm{E}-01$ \\
\hline 10 & $1.135 \mathrm{E}+00$ & 36 & $7.262 \mathrm{E}-01$ \\
\hline 11 & $1.110 \mathrm{E}+00$ & 37 & $7.150 \mathrm{E}-01$ \\
\hline 12 & $1.088 \mathrm{E}+00$ & 38 & $7.042 \mathrm{E}-01$ \\
\hline 13 & $1.068 \mathrm{E}+00$ & 39 & $6.938 \mathrm{E}-01$ \\
\hline 14 & $1.049 \mathrm{E}+00$ & 40 & $6.838 \mathrm{E}-01$ \\
\hline 15 & $1.033 \mathrm{E}+00$ & 41 & $6.733 \mathrm{E}-01$ \\
\hline 16 & $1.012 \mathrm{E}+00$ & 42 & $6.632 \mathrm{E}-01$ \\
\hline 17 & $9.934 \mathrm{E}-01$ & 43 & $6.535 \mathrm{E}-01$ \\
\hline 18 & $9.759 \mathrm{E}-01$ & 44 & $6.441 \mathrm{E}-01$ \\
\hline 19 & $9.595 \mathrm{E}-01$ & 45 & $6.351 \mathrm{E}-01$ \\
\hline 20 & $9.443 \mathrm{E}-01$ & 46 & $6.258 \mathrm{E}-01$ \\
\hline 21 & $9.267 \mathrm{E}-01$ & 47 & $6.169 \mathrm{E}-01$ \\
\hline 22 & $9.103 \mathrm{E}-01$ & 48 & $6.083 \mathrm{E}-01$ \\
\hline 23 & $8.950 \mathrm{E}-01$ & 49 & $6.000 \mathrm{E}-01$ \\
\hline 24 & $8.805 \mathrm{E}-01$ & 50 & $5.920 \mathrm{E}-01$ \\
\hline 25 & $8.666 \mathrm{E}-01$ & & \\
\hline
\end{tabular}

Source: BSC 2005 [DIRS 173705], Table 1.

\subsubsection{Kays and Leung Parameters for Forced Convection}

The Kays and Leung parameters for forced air convection were obtained from Kays and Perkins (1973 [DIRS 160782]). These parameters are also used in Ventilation Model and Analysis Report (BSC 2004 [DIRS 169862], Table 4-19). In the current report, the Kays and Leung parameters (Table 4.1-14) are used for the mixed convection correlation to calculate forced convection heat transfer coefficients. 
Table 4.1-14. Kays and Leung Parameters for Forced Convection

\begin{tabular}{|c|c|c|c|c|c|c|}
\hline & $\begin{array}{c}\text { Annulus } \\
\text { Radius } \\
\text { Ratio } \\
\left(r^{*}\right)\end{array}$ & $\begin{array}{c}\text { Reynolds } \\
\text { Number } \\
\text { (Re) }\end{array}$ & $\begin{array}{c}\text { Nusselt Number } \\
\text { - Inner Surface } \\
\text { Condition, Inner } \\
\text { Surface Heated } \\
\text { Alone } \\
\text { (Nuii) } \\
\end{array}$ & $\begin{array}{c}\text { Non-Dimensional } \\
\text { Temperature - Inner } \\
\text { Surface } \\
\left(\theta_{\mathrm{i}}\right)\end{array}$ & $\begin{array}{c}\text { Nusselt Number } \\
\text { - Outer Surface } \\
\text { Condition, } \\
\text { Outer Surface } \\
\text { Heated Alone } \\
\left(\mathrm{Nu}_{00}\right) \\
\end{array}$ & $\begin{array}{c}\text { Non- } \\
\text { Dimensional } \\
\text { Temperature } \\
\text { - Outer } \\
\text { Surface } \\
\left(\theta_{0}\right) \\
\end{array}$ \\
\hline \multirow{10}{*}{$\begin{array}{l}\text { Fluid } \\
\text { with } \\
\text { Prandtl } \\
\text { Number } \\
=0.700\end{array}$} & \multirow{5}{*}{0.2} & $1.00 \mathrm{E}+04$ & 38.6 & 0.412 & 29.4 & 0.063 \\
\hline & & $3.00 \mathrm{E}+04$ & 79.8 & 0.338 & 64.3 & 0.055 \\
\hline & & $1.00 \mathrm{E}+05$ & 196 & 0.286 & 165 & 0.049 \\
\hline & & $3.00 \mathrm{E}+05$ & 473 & 0.26 & 397 & 0.044 \\
\hline & & $1.00 \mathrm{E}+06$ & 1,270 & 0.235 & 1,070 & 0.04 \\
\hline & \multirow{5}{*}{0.5} & $1.00 \mathrm{E}+04$ & 30.9 & 0.3 & 28.3 & 0.137 \\
\hline & & $3.00 \mathrm{E}+04$ & 66 & 0.258 & 62 & 0.119 \\
\hline & & $1.00 \mathrm{E}+05$ & 166 & 0.225 & 158 & 0.107 \\
\hline & & $3.00 \mathrm{E}+05$ & 400 & 0.206 & 380 & 0.097 \\
\hline & & $1.00 \mathrm{E}+06$ & 1,080 & 0.185 & 1,040 & 0.09 \\
\hline
\end{tabular}

Source: Kays and Perkins 1973 [DIRS 160782].

Kays and Perkins 1973 [DIRS 160782] — Qualification Status: These are handbook data, and are established fact. This source is also referenced in the more recent handbook by Rohsenow et al. (1998 [DIRS 169241], reference number 263 in Chapter 5: "Forced Convection, Internal Flow in Ducts"). These data appropriately demonstrate the properties of interest, forced convection and internal flow in ducts, because these handbook parameters are widely applicable for describing flow behavior.

\subsubsection{Emissivity at the Drift Wall Surface}

The emissivity at the drift-wall surface is affected by the presence of Bernold-style surface sheets, which are described in a document by Michel (1999 [DIRS 163054]), and in Ground Control for Emplacement Drifts for LA (BSC 2004 [DIRS 170292]) and Longevity of Emplacement Drift Ground Support Materials for LA (BSC 2003 [DIRS 165425]). Bernold-style surface sheets (Michel 1999 [DIRS 163054]) are rock-bolted tightly to the drift wall to provide ground control for emplacement drifts, as described in Ground Control for Emplacement Drifts for LA (BSC 2004 [DIRS 170292]) and Longevity of Emplacement Drift Ground Support Materials for LA (BSC 2003 [DIRS 165425]). Because the Bernold surface sheets are in good mechanical contact with the surrounding rock, they are in reasonable thermal contact with the host rock as well. Thus, with respect to heat transfer in the drift, the influence of the Bernold surface sheets modifies the value of emissivity at the drift-wall surface, compared to the value for exposed rock. The Bernold-style surface sheets are Stainless Steel Type 316, which has an emissivity range of 0.52 to 0.66 (McAdams 1954 [DIRS 161435]). This is the same range evaluated as input to the multiscale thermohydrologic model (BSC 2005 [DIRS 173944], Section 5.3.2.7]). A value of 0.59 for Stainless Steel Type 316 falls at the midpoint of the range of emissivity of stainless steel. 
McAdams 1954 [DIRS 161435]-Qualification Status: This source is considered to be established fact and is suitable for its intended use in the preclosure temperature and relative humidity analysis. The value of the emissivity from this source is justified for this use because temperatures calculated by radiant heat transfer are proportional to the fourth root of the waste package heat flux rate. As discussed in Multiscale Thermohydrologic Model (BSC 2005 [DIRS 173944], Section 5.3.2.7), when peak temperatures occur at the drift wall, variations in drift wall emissivity result in small variations if drip shield temperature. These changes in emissivity are small compared to the influence of host-rock thermal conductivity uncertainty at the repository horizon during the preclosure period. Qualification of Personnel and Organization: The monograph written by McAdams (1954 [DIRS 161435]) is a prominent work in heat transfer and is listed in the McGraw-Hill Series in Chemical Engineering. The monograph was sponsored by the Committee on Heat Transmission of the National Research Council.

\subsubsection{Thermophysical Properties of the Stratigraphic Layers}

The analytical ventilation model uses thermophysical properties at the repository horizon (Table 4.1-15). The specific heat of the solids used for the Tptpll Unit at the repository horizon is $930 \mathrm{~J} /(\mathrm{kg} \mathrm{K})$ (DTN: SN0307T0510902.003 [DIRS 164196]). These are the same as those presented in Ventilation Model and Analysis Report (BSC 2004 [DIRS 169862]).

Table 4.1-15. Thermophysical Properties at the Repository Horizon

\begin{tabular}{|c|c|c|c|c|c|c|c|c|c|c|}
\hline \multirow{2}{*}{$\begin{array}{l}\text { Unit } \\
\text { (UZ } \\
\text { Layer) }\end{array}$} & \multicolumn{2}{|c|}{$\begin{array}{c}\text { Dry Bulk Thermal } \\
\text { Conductivity } \\
(\mathrm{W} / \mathrm{m} \cdot \mathrm{K})\end{array}$} & \multicolumn{2}{|c|}{$\begin{array}{c}\text { Wet Bulk } \\
\text { Thermal } \\
\text { Conductivity } \\
(\mathrm{W} / \mathrm{m} \cdot \mathrm{K})\end{array}$} & \multicolumn{2}{|c|}{$\begin{array}{c}\text { Dry Bulk Density } \\
\left(\mathrm{g} / \mathrm{cm}^{3}\right)\end{array}$} & \multicolumn{2}{|c|}{ Matrix Porosity } & \multicolumn{2}{|c|}{$\begin{array}{c}\text { Lithophysal } \\
\text { Porosity }\end{array}$} \\
\hline & Mean & $\begin{array}{l}\text { Std. } \\
\text { Dev. }\end{array}$ & Mean & $\begin{array}{l}\text { Std. } \\
\text { Dev. }\end{array}$ & Mean & $\begin{array}{l}\text { Std. } \\
\text { Dev. }\end{array}$ & Mean & $\begin{array}{l}\text { Std. } \\
\text { Dev. }\end{array}$ & Mean & $\begin{array}{l}\text { Std. } \\
\text { Dev. }\end{array}$ \\
\hline $\begin{array}{l}\text { Tptpll } \\
\text { (tsw35) }\end{array}$ & 1.2784 & 0.2511 & 1.8895 & 0.2484 & 1.9793 & 0.1381 & 0.1486 & 0.0340 & 0.0883 & 0.0540 \\
\hline \multirow[t]{2}{*}{$\begin{array}{l}\text { Unit } \\
\text { (UZ } \\
\text { Layer) }\end{array}$} & \multicolumn{2}{|c|}{$\begin{array}{c}\text { Dry Matrix } \\
\text { Thermal } \\
\text { Conductivity } \\
(\mathrm{W} / \mathrm{m} \cdot \mathrm{K})\end{array}$} & \multicolumn{2}{|c|}{$\begin{array}{c}\text { Wet Matrix } \\
\text { Thermal } \\
\text { Conductivity } \\
(\mathrm{W} / \mathrm{m} \cdot \mathrm{K})\end{array}$} & \multicolumn{2}{|c|}{$\begin{array}{l}\text { Solid Thermal } \\
\text { Conductivity } \\
(\mathrm{W} / \mathrm{m} \cdot \mathrm{K})\end{array}$} & \multicolumn{2}{|c|}{$\begin{array}{c}\text { Solid } \\
\text { Connectivity }\end{array}$} & & \\
\hline & Mean & $\begin{array}{l}\text { Std. } \\
\text { Dev. }\end{array}$ & Mean & $\begin{array}{l}\text { Std. } \\
\text { Dev. }\end{array}$ & Mean & $\begin{array}{l}\text { Std. } \\
\text { Dev. }\end{array}$ & Mean & $\begin{array}{l}\text { Std. } \\
\text { Dev. }\end{array}$ & & \\
\hline $\begin{array}{l}\text { Tptpll } \\
\text { (tsw35) }\end{array}$ & 1.3998 & 0.2640 & 2.0707 & 0.2455 & 2.6030 & 0.3413 & 0.8531 & 0.1130 & & \\
\hline
\end{tabular}

Source: DTN: SN0404T0503102.011 [DIRS 169129], ReadMe Summary.Doc, Tables 7-10 and 7-11.

\subsubsection{Atmospheric Pressure}

The atmospheric pressure calculation is $89,112 \mathrm{~Pa}$ (or $0.88 \mathrm{~atm}$ ), as determined in Ventilation Model and Analysis Report (BSC 2004 [DIRS 169862], Section 4.1.11, Appendix XIX). 


\subsubsection{Thermophysical Properties of Air}

Table 4.1-16 lists the thermophysical properties of air at one atmosphere, the total pressure at sea level, taken from Fundamentals of Heat and Mass Transfer (Incropera and DeWitt 1996 [DIRS 108184]).

Table 4.1-16. Thermophysical Properties of Air

\begin{tabular}{|c|c|c|c|c|c|c|c|}
\hline $\begin{array}{c}\text { Reference } \\
\text { Temperature } \\
\text { (K) } \\
\end{array}$ & $\begin{array}{l}\text { Density } \\
\left(\mathrm{kg} / \mathrm{m}^{3}\right)\end{array}$ & $\begin{array}{c}\text { Specific } \\
\text { Heat } \\
(\mathrm{kJ} / \mathrm{kg} \cdot \mathrm{K})\end{array}$ & $\begin{array}{c}\text { Viscosity } \\
10^{7}\left(\mathrm{~N} \cdot \mathrm{s} / \mathrm{m}^{2}\right)\end{array}$ & $\begin{array}{l}\text { Kinematic } \\
\text { Viscosity } \\
10^{6}\left(\mathrm{~m}^{2} / \mathrm{s}\right)\end{array}$ & $\begin{array}{c}\text { Thermal } \\
\text { Conductivity } \\
10^{3}(\mathrm{~W} / \mathrm{m} \cdot \mathrm{K}) \\
\end{array}$ & $\begin{array}{c}\text { Thermal } \\
\text { Diffusivity } \\
10^{6}\left(\mathrm{~m}^{2} / \mathrm{s}\right)\end{array}$ & $\begin{array}{l}\text { Prandtl } \\
\text { Number }\end{array}$ \\
\hline 250 & 1.3947 & 1.006 & 159.6 & 11.44 & 22.3 & 15.9 & 0.720 \\
\hline 300 & 1.1614 & 1.007 & 184.6 & 15.89 & 26.3 & 22.5 & 0.707 \\
\hline 350 & 0.9950 & 1.009 & 208.2 & 20.92 & 30.0 & 29.9 & 0.700 \\
\hline 400 & 0.8711 & 1.014 & 230.1 & 26.41 & 33.8 & 38.3 & 0.690 \\
\hline
\end{tabular}

Source: Incropera and DeWitt 1996 [DIRS 108184], Table A.4.

Incropera and DeWitt 1996 [DIRS 108184] -Qualification Status: The physical data in Table 4.1-16 are justified for use in this report. They are taken from a widely used textbook on heat transfer, Fundamentals of Heat and Mass Transfer. Extent to Which the Data Demonstrate the Properties of Interest: The data in Table 4.1-16 are essentially handbook data for common properties of air, which are appropriate descriptors of the physical behavior of air in preclosure ventilation (Appendix A). Reliability of Data Source: The information from this source is reliable because it has been in publication through five editions, and it is a widely used textbook on heat transfer.

\subsubsection{Thermophysical Properties of Water Vapor}

The properties of water vapor are used to estimate the saturated vapor pressure, as a function of temperature (Incropera and DeWitt 2002 [DIRS 163337], Table A.6, pp. 924 to 925). The properties are used in the analysis of preclosure ventilation (Appendix A) to account for water vapor as a partial component of the ventilation air.

Incropera and DeWitt 2002 [DIRS 163337]-Qualification Status: The data for saturation vapor pressure for water (steam tables) are justified for use in this report. They are taken from a widely used textbook on heat transfer, Fundamentals of Heat and Mass Transfer. Extent to Which the Data Demonstrate the Properties of Interest: The vapor pressure data used in the calculations supporting Appendix A are essentially handbook data, which are appropriate descriptors of the physical behavior of air in preclosure ventilation. Reliability of Data Source: The version of the source discussed here is the fifth edition. The information from this source is reliable and qualified for the intended use because it has been in publication through five editions, and it is a widely used textbook on heat transfer.

\subsubsection{Meteorological Temperature and Relative Humidity Data}

Two sets of data are used in the waste package temperature and relative humidity calculation for the preclosure analysis. Meteorological data were recorded at Site 9 from 1993 to 1997. The temperature and RH measurements are obtained from DTN: MO03119MET9397.000 
[DIRS 166207]. This information is used to determine the range of the partial pressure of water in the preclosure analysis. The second data set is from DTN: MO04019SUM9397.000 [DIRS 167054] and provides a summary calculation of the average temperature for thirty-day periods during the winter and summer at Site 9 from 1993 to 1997 . The average temperature measurements are $7^{\circ} \mathrm{C}$ in January for the winter and $31.2^{\circ} \mathrm{C}$ in July. These average temperatures are used to represent the inlet air temperatures for the winter and summer in the ventilation analysis.

\subsubsection{Dust Compositional Data Used to Evaluate Brine Reactions with Low-Solubility Dust Minerals and the Effects of Ammonium Decomposition}

The bulk chemical compositions of tunnel dust samples from the Exploratory Studies Facility (ESF), and the compositions of corresponding dust leachate samples, are inputs to calculations in Section 6.3.3 that evaluate the potential impact of reactions with low-solubility dust components on deliquescence brine compositions. These data, summarized in Tables 4.1-17 and 4.1-18, are used in Output DTN: MO0506SPAEQ36F.002 (DUST_LEACHATE_YW.xls) and are taken from the qualified DTNs: MO0209EBSDUST2.030 [DIRS 162557] and MO0207EBSDUSTS.020 [DIRS 162556].

A second set of dust leachate compositions, which include ammonium concentrations, are inputs to calculations in Section 6.1.2 that evaluate the potential impact of ammonium mineral decomposition on deliquescent mineral assemblages and brine compositions. These project data, from DTN: GS050408313000.001 [DIRS 173724], are presented and qualified for use in Appendix F.

Table 4.1-17. Bulk Chemical Compositions of Dust Samples from the ESF (wt \%)

\begin{tabular}{|l|l|l|l|l|l|l|l|l|l|c|}
\hline \multicolumn{1}{|c|}{ Sample } & $\mathrm{SiO}_{2}$ & $\mathrm{Al}_{2} \mathrm{O}_{3}$ & $\mathbf{M g O}$ & $\mathrm{CaO}$ & $\mathrm{Na}_{2} \mathrm{O}$ & $\mathrm{K}_{2} \mathrm{O}$ & $\mathbf{P}_{2} \mathrm{O}_{5}$ & $\mathbf{C l}$ & $\mathbf{F}$ & $\mathbf{S}$ \\
\hline $00574979 \mathrm{~A}$ & 68.6 & 13.6 & 0.59 & 2.67 & 3.18 & 4.21 & 0.040 & 0.0171 & 0.0443 & $<0.05$ \\
\hline $00574979 \mathrm{~B}$ & 63.5 & 13.4 & 1.24 & 4.16 & 2.55 & 3.75 & 0.077 & 0.0209 & 0.0744 & $<0.05$ \\
\hline $00574979 \mathrm{C}$ & 59.5 & 13.6 & 1.67 & 5.64 & 1.97 & 3.6 & 0.102 & 0.0175 & 0.097 & $<0.05$ \\
\hline $00574980 \mathrm{~A}$ & 70.9 & 12.6 & 0.46 & 1.14 & 2.74 & 4.31 & 0.047 & 0.058 & 0.0899 & $<0.05$ \\
\hline 00574980B & 68.2 & 13.1 & 0.76 & 2.12 & 2.58 & 3.86 & 0.087 & 0.059 & 0.101 & $<0.05$ \\
\hline 00574980C & 65.2 & 12.3 & 0.84 & 3.3 & 2.51 & 3.81 & 0.101 & 0.114 & 0.116 & $<0.05$ \\
\hline $00574981 \mathrm{~A}$ & 72.8 & 11.4 & $<0.10$ & 1.73 & 3.77 & 4.1 & 0.559 & 0.0399 & 0.424 & 0.13 \\
\hline $00574981 \mathrm{~B}$ & 68.2 & 11.5 & 0.19 & 2.42 & 3.61 & 4.12 & 1.847 & 0.0874 & 0.743 & 0.22 \\
\hline $00574981 \mathrm{C}$ & 66 & 11.8 & 0.43 & 2.75 & 3.24 & 4.19 & 0.958 & 0.144 & 0.335 & 0.2 \\
\hline $00574982 \mathrm{~A}$ & 71 & 12.6 & 0.38 & 0.64 & 3.4 & 4.41 & 0.021 & 0.1 & 0.108 & $<0.05$ \\
\hline $00574982 \mathrm{~B}$ & 69.8 & 12.5 & 0.48 & 1.05 & 3.11 & 4.24 & 0.029 & 0.119 & 0.104 & $<0.05$ \\
\hline $00574982 \mathrm{C}$ & 67.2 & 12.1 & 0.57 & 2.19 & 2.99 & 4.09 & 0.052 & 0.122 & 0.0948 & 0.06 \\
\hline $00574983 \mathrm{~A}$ & 67.4 & 15.1 & 0.28 & 1.15 & 4.15 & 5.83 & 0.089 & 0.0527 & 0.0805 & $<0.05$ \\
\hline $00574983 \mathrm{~B}$ & 65.5 & 13.5 & 0.44 & 2.02 & 3.49 & 4.88 & 0.073 & 0.139 & 0.107 & 0.05 \\
\hline $00574983 \mathrm{C}$ & 66.7 & 12.4 & 0.42 & 2.2 & 3.11 & 4.39 & 0.068 & 0.171 & 0.108 & 0.07 \\
\hline $00574984 \mathrm{~A}$ & 74.6 & 11.4 & 0.21 & 1.01 & 2.93 & 4.37 & 0.048 & 0.0621 & 0.031 & $<0.05$ \\
\hline $00574984 \mathrm{C}$ & 70.2 & 12.1 & 0.25 & 1.52 & 3.25 & 4.46 & 0.234 & 0.22 & 0.0568 & 0.06 \\
\hline $00574985 \mathrm{~A}$ & 70.8 & 12 & 0.31 & 1.62 & 3.19 & 4.43 & 0.034 & 0.13 & 0.0682 & 0.06 \\
\hline $00574985 \mathrm{~B}$ & 68.9 & 11.7 & 0.26 & 2.3 & 3.21 & 4.33 & 0.049 & 0.131 & 0.0759 & 0.08 \\
\hline
\end{tabular}


Table 4.1-17. Bulk Chemical Compositions of Dust Samples from the ESF (wt \%) (Continued)

\begin{tabular}{|c|c|c|c|c|c|c|c|c|c|c|}
\hline Sample & $\mathrm{SiO}_{2}$ & $\mathrm{Al}_{2} \mathrm{O}_{3}$ & MgO & $\mathrm{CaO}$ & $\mathrm{Na}_{2} \mathrm{O}$ & $\mathrm{K}_{2} \mathrm{O}$ & $\mathrm{P}_{2} \mathrm{O}_{5}$ & $\mathrm{Cl}$ & $\mathbf{F}$ & S \\
\hline $00574985 \mathrm{C}$ & 69 & 11.7 & 0.25 & 2.26 & 3.15 & 4.3 & 0.050 & 0.126 & 0.0757 & 0.07 \\
\hline $00574986 \mathrm{~A}$ & 73.7 & 12.3 & 0.12 & 1.04 & 3.3 & 4.8 & 0.017 & 0.0481 & 0.0402 & $<0.05$ \\
\hline 00574986B & 71.8 & 12 & 0.17 & 1.86 & 3.23 & 4.58 & 0.031 & 0.092 & 0.0454 & 0.05 \\
\hline $00574986 \mathrm{C}$ & 70.3 & 11.7 & 0.23 & 2.36 & 3.09 & 4.31 & 0.047 & 0.149 & 0.0542 & 0.07 \\
\hline $00574987 \mathrm{C}$ & 65.2 & 11.4 & 0.29 & 3.34 & 3.05 & 4.15 & 0.066 & 0.286 & 0.0711 & 0.11 \\
\hline $00574990 \mathrm{~A}$ & 70.5 & 13.9 & 0.15 & 1 & 3.77 & 5.44 & 0.055 & 0.0412 & 0.0466 & $<0.05$ \\
\hline 00574990B & 69.3 & 13.5 & 0.21 & 1.31 & 3.63 & 5.1 & 0.061 & 0.0872 & 0.0634 & $<0.05$ \\
\hline $00574990 \mathrm{C}$ & 68.1 & 12.9 & 0.22 & 1.64 & 3.54 & 4.84 & 0.067 & 0.169 & 0.0847 & 0.06 \\
\hline $00574991 \mathrm{~A}$ & 67.1 & 14.3 & 0.77 & 1.5 & 2.86 & 4.29 & 0.097 & 0.0961 & 0.136 & $<0.05$ \\
\hline 00574991B & 66.5 & 14 & 0.81 & 1.57 & 2.75 & 4.23 & 0.121 & 0.0903 & 0.141 & $<0.05$ \\
\hline $00574991 \mathrm{C}$ & 67.4 & 13.4 & 0.57 & 1.76 & 3 & 4.54 & 0.112 & 0.0845 & 0.125 & $<0.05$ \\
\hline $00574992 A$ & 73.7 & 12.8 & $<0.10$ & 0.96 & 4.25 & 4.73 & 0.015 & 0.0613 & 0.135 & $<0.05$ \\
\hline 00574992B & 73 & 12.8 & $<0.10$ & 1.12 & 4.24 & 4.74 & 0.016 & 0.0526 & 0.148 & $<0.05$ \\
\hline $00574992 \mathrm{C}$ & 71.8 & 12.6 & 0.11 & 1.52 & 4.03 & 4.66 & 0.033 & 0.0727 & 0.192 & $<0.05$ \\
\hline SPC00573607 & 61.3 & 10.4 & 0.7 & 6.71 & 3.25 & 3.77 & 0.100 & 0.09 & 0.112 & 0.1 \\
\hline SPC00573610 & 69.3 & 13 & 0.35 & 1.55 & 3.48 & 4.87 & 0.100 & 0.104 & 0.101 & $<0.05$ \\
\hline SPC00573611 & 66.5 & 12.7 & 0.46 & 1.94 & 3.3 & 4.54 & 0.100 & 0.117 & 0.116 & 0.05 \\
\hline SPC00573612 & 67.1 & 11.4 & 0.24 & 1.49 & 3.2 & 4.31 & 0.080 & 0.187 & 0.082 & 0.06 \\
\hline SPC00573614 & 66.8 & 11.3 & 0.27 & 2.18 & 3.15 & 4.16 & 0.090 & 0.151 & 0.075 & 0.07 \\
\hline SPC00573615 & 68.8 & 11.6 & 0.27 & 1.93 & 3.17 & 4.23 & 0.080 & 0.111 & 0.065 & 0.05 \\
\hline SPC00573616 & 65.8 & 11.3 & 0.32 & 2.01 & 3.07 & 4.15 & 0.090 & 0.149 & 0.074 & 0.08 \\
\hline SPC00573617 & 66.9 & 11.4 & 0.27 & 2.09 & 3.22 & 4.26 & 0.080 & 0.124 & 0.062 & 0.06 \\
\hline SPC00573618 & 70.4 & 11.7 & 0.31 & 2.58 & 3.19 & 4.52 & 0.080 & 0.067 & 0.039 & $<0.05$ \\
\hline SPC00573619 & 69 & 11.6 & 0.27 & 1.9 & 3.16 & 4.42 & 0.090 & 0.123 & 0.041 & $<0.05$ \\
\hline SPC00573620 & 75 & 12.3 & 0.17 & 0.97 & 3.37 & 4.71 & 0.070 & 0.026 & 0.025 & $<0.05$ \\
\hline SPC00573622 & 67.1 & 11.9 & 0.42 & 2.3 & 3.38 & 4.19 & 0.080 & 0.15 & 0.224 & 0.05 \\
\hline SPC00573623 & 67.9 & 12.6 & 0.5 & 1.45 & 3.12 & 4.26 & 0.090 & 0.129 & 0.09 & $<0.05$ \\
\hline SPC00573624 & 73.9 & 12.1 & 0.2 & 0.88 & 3.38 & 4.45 & 0.070 & 0.132 & 0.042 & $<0.05$ \\
\hline SPC00573625 & 64.3 & 12 & 0.46 & 2.04 & 3.1 & 4.29 & 0.100 & 0.198 & 0.091 & 0.06 \\
\hline SPC00573626 & 70.4 & 12.4 & 0.42 & 1.68 & 3.36 & 4.52 & 0.120 & 0.096 & 0.064 & $<0.05$ \\
\hline SPC00573627 & 70.6 & 11.9 & 0.31 & 1.52 & 3.2 & 4.43 & 0.190 & 0.166 & 0.046 & 0.05 \\
\hline SPC00573628 & 72.5 & 11.9 & 0.23 & 1.67 & 3.2 & 4.48 & 0.090 & 0.122 & 0.041 & $<0.05$ \\
\hline SPC00573629 & 73 & 11.8 & 0.26 & 0.92 & 3.19 & 4.42 & 0.090 & 0.086 & 0.032 & $<0.05$ \\
\hline SPC00573630 & 70.8 & 11.9 & 0.25 & 1.06 & 3.37 & 4.44 & 0.080 & 0.12 & 0.038 & $<0.05$ \\
\hline SPC00573631 & 68.4 & 11.9 & 0.26 & 1.27 & 3.36 & 4.39 & 0.070 & 0.167 & 0.043 & 0.06 \\
\hline SPC00573632 & 70 & 11.5 & 0.17 & 0.91 & 3.27 & 4.31 & 0.070 & 0.099 & 0.036 & $<0.05$ \\
\hline
\end{tabular}

Source: DTNs: MO0209EBSDUST2.030 [DIRS 162557] (samples that begin with 005749) and MO0207EBSDUSTS.020 [DIRS 162556] (samples that begin with SPC005736). 
Table 4.1-18. Chemical Compositions of Dust Leachates ( $\mu \mathrm{g} / \mathrm{g}$ Dust)

\begin{tabular}{|c|c|c|c|c|c|c|c|c|c|c|}
\hline Sample & $\mathrm{Ca}$ & Mg & K & $\mathrm{Na}$ & Si & $\mathrm{Cl}$ & $\mathbf{F}$ & $\mathrm{NO}_{3}$ & $\mathrm{SO}_{4}$ & $\mathrm{PO}_{4}$ \\
\hline 00574979A & 147 & 16.3 & 159 & 55.4 & 161 & 12 & 8 & 3.5 & 16 & 7.67 \\
\hline 00574979B & 91.7 & 9.47 & 127 & 46.4 & 96.5 & 12 & 4 & 10 & 16 & 14.10 \\
\hline 00574979C & 119 & 12.6 & 174 & 66 & 144 & 12 & 8 & 24 & 16 & 19.01 \\
\hline 00574980A & 270 & 34.3 & 193 & 115 & 169 & 76 & 18 & 220 & 220 & 11.65 \\
\hline 00574980B & 466 & 49.3 & 181 & 124 & 76.6 & 98 & 4 & 400 & 360 & 6.75 \\
\hline 00574980C & 1,080 & 80.1 & 206 & 195 & 176 & 154 & 12 & 640 & 840 & 7.05 \\
\hline $00574981 \mathrm{~A}$ & 772 & 44.1 & 280 & 188 & 33.4 & 74 & 8 & 116 & 3,800 & $3,160.00$ \\
\hline 00574981B & 1060 & 39.5 & 389 & 471 & 287 & 280 & 22 & 360 & 1,000 & 15.02 \\
\hline 00574981C & 2,340 & 130 & 389 & 392 & 42.8 & 320 & 8 & 1,760 & 4,600 & $4,380.00$ \\
\hline $00574982 A$ & 246 & 39.6 & 196 & 262 & 164 & 86 & 20 & 240 & 320 & 17.17 \\
\hline 00574982B & 458 & 64.1 & 244 & 339 & 51.6 & 118 & 4 & 520 & 520 & 14.41 \\
\hline $00574982 \mathrm{C}$ & 1,010 & 99.6 & 345 & 556 & 99.2 & 170 & 6 & 1,000 & 1,060 & 14.10 \\
\hline 00574983A & 262 & 23.7 & 281 & 296 & 94.9 & 114 & 12 & 198 & 380 & 17.78 \\
\hline 00574983B & 770 & 50.8 & 303 & 425 & 57.3 & 260 & 4 & 540 & 720 & 11.04 \\
\hline $00574983 C$ & 1,240 & 85.9 & 369 & 666 & 62.7 & 360 & 10 & 980 & 1,200 & 10.73 \\
\hline 00574984A & 335 & 49.4 & 339 & 265 & 87.3 & 128 & 10 & 220 & 440 & 166.19 \\
\hline 00574985A & 994 & 65.4 & 303 & 349 & 248 & 170 & 18 & 340 & 880 & 15.94 \\
\hline 00574985B & 1,260 & 52.4 & 333 & 461 & 181 & 168 & 22 & 480 & 1,180 & 24.84 \\
\hline $00574985 C$ & 1,030 & 54.7 & 275 & 480 & 130 & 166 & 22 & 500 & 1,220 & 22.08 \\
\hline 00574986A & 248 & 23.4 & 234 & 222 & 75.4 & 96 & 6 & 146 & 320 & 5.21 \\
\hline 00574986B & 806 & 38 & 220 & 292 & 131 & 170 & 12 & 300 & 740 & 9.51 \\
\hline 00574986C & 1,190 & 51.4 & 260 & 408 & 159 & 220 & 18 & 440 & 1,140 & 12.88 \\
\hline 00574987A & 1,290 & 84.6 & 257 & 201 & 21.8 & 188 & 8 & 600 & 5800 & $12,700.00$ \\
\hline 00574987B & 1,180 & 64.1 & 313 & 564 & 135 & 360 & 22 & 540 & 1,400 & 19.32 \\
\hline $00574987 \mathrm{C}$ & 1,280 & 70.5 & 288 & 570 & 143 & 320 & 24 & 520 & 1,480 & 19.01 \\
\hline 00574990A & 274 & 19.8 & 186 & 149 & 44.7 & 88 & 8 & 170 & 500 & 3.99 \\
\hline 00574990B & 434 & 25.9 & 151 & 186 & 38.9 & 102 & 6 & 220 & 760 & 7.05 \\
\hline 00574990C & 689 & 34.7 & 251 & 370 & 82.2 & 136 & 14 & 300 & 940 & 12.88 \\
\hline $00574991 \mathrm{~A}$ & 281 & 55.4 & 139 & 128 & 161 & 88 & 22 & 122 & 440 & 4.91 \\
\hline 00574991B & 319 & 56.8 & 114 & 121 & 79.4 & 76 & 4 & 156 & 520 & 7.05 \\
\hline 00574991C & 622 & 53.6 & 177 & 196 & 215 & 82 & 10 & 164 & 700 & 7.97 \\
\hline 00574992A & 122 & 10.3 & 155 & 171 & 57.4 & 98 & 8 & 70 & 116 & 5.52 \\
\hline 00574992B & 110 & 9.48 & 121 & 126 & 12.3 & 82 & 2 & 68 & 124 & 6.44 \\
\hline 00574992C & 305 & 19.8 & 173 & 187 & 60.2 & 166 & 6 & 150 & 280 & 10.12 \\
\hline SPC00573607 & 2,490 & 12.8 & 350 & 455 & 173 & 260 & 8 & 1,820 & 2,200 & 4.20 \\
\hline SPC00573610 & 430 & 19.4 & 221 & 304 & 89.2 & 162 & 24 & 220 & 640 & 4.40 \\
\hline SPC00573611 & 941 & 6.32 & 242 & 378 & 213 & 200 & 30 & 340 & 840 & 3.10 \\
\hline SPC00573612 & 630 & 28.3 & 231 & 388 & 95.1 & 154 & 10 & 340 & 1,060 & 5.50 \\
\hline SPC00573614 & 939 & 27.1 & 219 & 343 & 121 & 130 & 12 & 380 & 1,160 & 5.60 \\
\hline SPC00573615 & 863 & 25.9 & 220 & 369 & 134 & 162 & 12 & 380 & 740 & 6.50 \\
\hline SPC00573616 & 893 & 35.7 & 248 & 374 & 107 & 130 & 12 & 400 & 1480 & 5.60 \\
\hline SPC00573617 & 919 & 32.8 & 221 & 332 & 96.4 & 140 & 18 & 440 & 1180 & 6.10 \\
\hline SPC00573618 & 439 & 13.7 & 479 & 345 & 120 & 114 & 12 & 300 & 400 & 5.50 \\
\hline SPC00573619 & 635 & 43.6 & 214 & 397 & 100 & 200 & 24 & 420 & 720 & 10.90 \\
\hline
\end{tabular}


Table 4.1-18. Chemical Compositions of Dust Leachates ( $\mu \mathrm{g} / \mathrm{g}$ Dust) (Continued)

\begin{tabular}{|c|c|c|c|c|c|c|c|c|c|c|}
\hline Sample & $\mathbf{C a}$ & $\mathbf{M g}$ & $\mathbf{K}$ & $\mathbf{N a}$ & \multicolumn{1}{c|}{$\mathbf{S i}$} & $\mathbf{C l}$ & $\mathbf{F}$ & $\mathbf{N O}_{3}$ & $\mathbf{S O}_{4}$ & $\mathbf{P O}_{4}$ \\
\hline SPC00573620 & 226 & 10.6 & 101 & 157 & 79.1 & 56 & 4 & 82 & 162 & 3.60 \\
\hline SPC00573622 & 980 & 83.6 & 183 & 358 & 43.5 & 182 & 6 & 800 & 1,120 & 1.80 \\
\hline SPC00573623 & 638 & 79.7 & 193 & 431 & 46.6 & 180 & 6 & 580 & 980 & 3.50 \\
\hline SPC00573624 & 332 & 35.7 & 128 & 386 & 14.9 & 240 & 10 & 280 & 340 & 0.80 \\
\hline SPC00573625 & 974 & 79.1 & 260 & 617 & 58.7 & 300 & 8 & 680 & 1,340 & 3.20 \\
\hline SPC00573626 & 575 & 34.3 & 206 & 415 & 94.9 & 200 & 14 & 400 & 660 & 5.70 \\
\hline SPC00573627 & 394 & 53.4 & 237 & 511 & 65 & 260 & 32 & 420 & 1020 & 196.00 \\
\hline SPC00573628 & 480 & 34.8 & 142 & 287 & 61.2 & 160 & 8 & 380 & 620 & 40.20 \\
\hline SPC00573629 & 268 & 26.7 & 126 & 346 & 34.5 & 184 & 10 & 240 & 360 & 9.60 \\
\hline SPC00573630 & 392 & 42 & 149 & 344 & 27.9 & 196 & 8 & 280 & 480 & 4.60 \\
\hline SPC00573631 & 630 & 31.4 & 150 & 389 & 82.5 & 220 & 40 & 260 & 640 & 4.60 \\
\hline SPC00573632 & 229 & 18.9 & 101 & 262 & 42.3 & 220 & 8 & 114 & 300 & 5.00 \\
\hline
\end{tabular}

Source: DTNs: MO0209EBSDUST2.030 [DIRS 162557] (samples that begin with 005749) and MO0207EBSDUSTS.020 [DIRS 162556] (samples that begin with SPC005736).

\subsubsection{Boiling Points for Saturated Aqueous Solutions of Pure Salts}

The boiling points of saturated aqueous solutions of pure salts are used in Section 6.2.2.1 to analyze the effect of the simulated degassing of acid-gas species from single-salt brines. These values are from Kracek (1928 [DIRS 122125], pp. 369 to 373) and are given in Table 4.1-19. Use of these values is limited to identifying the approximate upper limit of temperature for analysis. The accuracy of these values at ambient pressure (they are for a reference condition of $1 \mathrm{~atm}$ total pressure) is discussed in Environment on the Surfaces of the Drip Shield and Waste Package Outer Barrier (BSC 2004 [DIRS 161237], Section 6.7.2.5), and found to be suitable for representing the influence of salt content on boiling point elevation, for the indicated salt systems.

Table 4.1-19. Boiling Points of Aqueous Solutions of Pure Salts

\begin{tabular}{|l|c|}
\hline Salt & Boiling Point $\left({ }^{\circ} \mathbf{C}\right)$ \\
\hline $\mathrm{KCl}$ (sylvite) & 108.6 \\
\hline $\mathrm{NaCl}$ (halite) & 108.67 \\
\hline $\mathrm{KNO}_{3}$ (niter) & 115.5 \\
\hline $\mathrm{NaNO}_{3}$ (soda niter) & 120.59 \\
\hline
\end{tabular}

Source: Kracek 1928 [DIRS 122125], pp. 369 to 373.

Kracek 1928 [DIRS 122125], pp. 369 to 373-Qualification Status: These handbook data are established fact. The data appropriately demonstrate the properties of interest, because these salt phases have been identified as likely components in dust deposited on the waste packages. 


\subsubsection{Other Qualified Direct Input DTNs}

Postclosure Temperature and Relative Humidity Conditions - The postclosure analysis data for Figures 6-2 and 6.2-4 through 6.2-6, in Output DTN: SN0508T0502205.015, come from the following DTNs and associated files:

- LL030808523122.035 [DIRS 166419], MSTHAC/mi_abstractions/OUTPUT/mi_P2e@r\#126:58:1.ext

Direct Input: average (or medium) temperature and RH waste package conditions

- LL030905931032.001 [DIRS 168767], MSTHAC_abstraction/MSTHAC_output/LI-lkt_P3@r\#61:46:1.ext Direct Input: hot temperature and dry RH waste package conditions

- LL030906331032.004 [DIRS 168768], MSTHAC_abstraction/MSTHAC_output/UI-hkt_P2e@r\#161:59:1.ext

Direct Input: cool temperature and humid $\mathrm{RH}$ waste package conditions.

The data were extracted using XTOOL (Section 3.3). Documentation of the development of these data is provided in Multiscale Thermohydrologic Model (BSC 2005 [DIRS 173944]).

DTN: LL050302823121.051 [DIRS 173608]-The files $3364 R$ and $3364 N R$ are used for Figures 6.5-4 and 6.5-5.

\subsubsection{Direct Inputs from Other Reports}

In-Drift Precipitates/Salts Model (BSC 2004 [DIRS 169863])-Table 6-3 of the IDPS model report is the source of the list of mineral suppressions used in most of the thermodynamic calculations performed in this report. Exceptions are noted in the thermodynamic modeling descriptions provided in Section 6. Table 7-8 of the IDPS model report provides the uncertainties for the predicted deliquescence RH values discussed in Section 6.2 of this report.

Environment on the Surfaces of the Drip Shield and Waste Package Outer Barrier (BSC 2004 [DIRS 161237])-Description of Data: The following information from this source is used as direct input:

- Table 6.7-11, classifying the three salt assemblages represented in tunnel dust (used in Sections 6.1, 6.2, and 6.3 of this report)

- Tables 6.7-21 through 6.7-23, for predicted deliquescence RH curves and dryout temperatures for the three-salt assemblages (Sections 6.1.2, 6.2.2, and 6.2.3)

- Section 6.7, as it describes the modeling method used for deliquescence and degassing (Section 6.2.2.2)

- Section 6.7.2.10, which summarizes the characteristics of tunnel dust samples (Section 6.1.1). 
Environment on the Surfaces of the Drip Shield and Waste Package Outer Barrier (BSC 2004 [DIRS 161237]) does not consider ammonium salts, degassing, or reaction of brine with non-deliquescent mineral phases in dust, which are addressed in this report. Environment on the Surfaces of the Drip Shield and Waste Package Outer Barrier (BSC 2004 [DIRS 161237]) is a cancelled document, but the geochemical analyses presented in it are still valid and are justified for use in this report. Qualification Status: Justified for intended use in this report. Extent to Which the Data Demonstrate the Properties of Interest: The data demonstrate the properties of interest because they are based on YMP-relevant dust samples collected in the Yucca Mountain underground, and the properties and classification of deliquescent salt assemblages presented in the cited document are also applicable to probable deliquescent brines formed by atmospheric dusts. Reliability of Data Source: The information from this source is reliable because the source is a QA:QA Yucca Mountain report, developed under the Yucca Mountain Quality Assurance Program. The report was cancelled because of the more complete analyses presented here. However, the cited document provides analyses of tunnel dust compositions and thermodynamic arguments which are fundamental and do not depend on the dust deliquescence screening argument. Hence, although the cited document does not reflect the screening decision for FEP 2.1.09.28.0A recommended by this report (Section 7.1), the analyses and classifications it presents are still valid for use in this report.

Engineered Barrier System: Physical and Chemical Environment (BSC 2004 [DIRS 169860]) - Description of Data: The following information from this source is used as direct input: (1) Tables 6.10-6 and 6.13-9 from the source are used for Table 6.3-2 (Brines Formed by Dust Deliquescence and the Corresponding Corrosion Test Solutions) of this report, to summarize the relationship between brines predicted to form by dust deliquescence, and corrosion test conditions; and (2) the argument from Section 6.15.1.1 of the source, that nitrate-chloride ratios in brines only increase with increasing temperature, is used in Sections 6.3.1 and 6.3.4 of this report. The cited version of Engineered Barrier System: Physical and Chemical Environment (BSC 2004 [DIRS 169860]) has been superseded; the dust analyses have been removed from newer versions, which reflect the screening argument for dust deliquescence as presented in this report. Qualification Status: Justified for intended use in this report. Extent to Which the Data Demonstrate the Properties of Interest: The data demonstrate the properties of interest because they are based on dust samples collected in the Yucca Mountain underground, and directly relate dust leachate compositions to solutions used in corrosion testing for the Yucca Mountain Project. Reliability of Data Source: The information from this source is reliable because the source is a QA:QA Yucca Mountain Report, developed under the Yucca Mountain Quality Assurance Program. The direct inputs from the superseded document are appropriate for use in this report because the reason for supersession was to update the source document to reflect the dust screening arguments presented here; the cited document provides analyses of tunnel dust compositions and thermodynamic arguments which are fundamental and do not depend on the dust deliquescence screening argument. Hence the cited direct inputs remain valid and appropriate for use in these screening arguments.

General Corrosion and Localized Corrosion of Waste Package Outer Barrier (BSC 2004 [DIRS 169984]) - In addition to the input discussed in Section 4.1.6, this source (BSC 2004 [DIRS 169984]) is referenced in this report for description of: general and localized corrosion data and modeling for Alloy 22 (Sections 6.1.2.4, 6.2.2.1, 6.3.1, 6.4.4, and 6.5.2.1); experimental data showing a deliquescent salt sample undergoing weight loss associated with degassing 
(Section 6.2.1); and potential beneficial effects of sulfate on initiation of localized corrosion (Section 6.1.2.3).

\subsection{CRITERIA}

Acceptance criteria from two sections of Yucca Mountain Review Plan, Final Report (YMRP) (NRC 2003 [DIRS 163274]) are relevant to this report: "Scenario Analysis" (NRC 2003 [DIRS 163274], Section 2.2.1.2.1) and "Quantity and Chemistry of Water Contacting Engineered Barriers and Waste Forms" (NRC 2003 [DIRS 163274], Section 2.2.1.3.3). These criteria are based on meeting the requirements of 10 CFR 63.114(a)-(c) and (e)-(g) [DIRS 173273]. The following criteria and subcriteria from the YMRP are addressed in this document (see Section 7.2):

- YMRP Section 2.2.1.2.1.3, Acceptance Criterion 2 (Screening of the List of Features, Events, and Processes is Appropriate) - Subcriteria (2) and (3), respectively dealing with the screening justification and technical adequacy, are addressed by this report.

- YMRP Section 2.2.1.3.3.3, Acceptance Criterion 1 (System Description and Model Integration are Adequate)-Subcriteria (1), (6), and (10), respectively dealing with incorporation of design features, physical phenomena, and couplings; ranges of environmental conditions; and likely modes for container corrosion; are addressed by this report.

These criteria are different from those identified in the TWP (BSC 2004 [DIRS 172804]), and were changed in response to review comments received during preparation of this report.

\subsection{CODES, STANDARDS, AND REGULATIONS}

The following codes, standards, and regulations apply to the work presented in this analysis:

- 10 CFR 63. 2005. Energy: Disposal of High-Level Radioactive Wastes in a Geologic Repository at Yucca Mountain, Nevada [DIRS 173273]

- Requirement PRD-002/T-015 (Requirements for Performance Assessment) of Project Requirements Document (Canori and Leitner 2003 [DIRS 166275], Section 3)

- ASTM B 575-99a. 1999. Standard Specification for Low-Carbon Nickel-MolybdenumChromium, Low-Carbon Nickel-Chromium-Molybdenum, Low-Carbon NickelChromium-Molybdenum-Copper, Low-Carbon Nickel-Chromium-MolybdenumTantalum, and Low-Carbon Nickel-Chromium-Molybdenum-Tungsten Alloy Plate, Sheet, and Strip [DIRS 147465]

- ASTM G 102-89 (Reapproved 1999). 1989. Standard Practice for Calculation of Corrosion Rates and Related Information from Electrochemical Measurements [DIRS 163908] 
- ASTM G 48-99a. 1999. Standard Test Methods for Pitting and Crevice Corrosion Resistance of Stainless Steels and Related Alloys by Use of Ferric Chloride Solution [DIRS 138917]

- ASTM G 5-94. 1994. Standard Reference Test Method for Making Potentiostatic and Potentiodynamic Anodic Polarization Measurements [DIRS 117479]. 


\section{INTENTIONALLY LEFT BLANK}




\section{ASSUMPTIONS}

\subsection{UNIFORMITY OF DUST COMPOSITION}

It is necessary to assume that the dust is compositionally homogeneous, regardless of particle size. Although some data exist to indicate that the smaller size fraction holds more soluble salt content, the lack of size-specific chemical data precludes utilizing this information. This assumption is conservative because salts in the small size fraction (on the order of $1 \mu \mathrm{m}$ and less) would be transported through the drift without depositing on the waste packages (see Table 6.4-2); thus, assuming compositional homogeneity maximizes the salt load deposited. 


\section{INTENTIONALLY LEFT BLANK}




\section{SCIENTIFIC ANALYSIS DISCUSSION}

Using the logical framework discussed in Section 1.1, this section evaluates the potential for localized corrosion caused by dust deliquescence to result in penetration of the waste package outer barrier. Because the presence of an aqueous phase is required for localized corrosion, a necessary first step is to evaluate the conditions in the repository under which deliquescence can occur. Therefore, this section considers the potential composition of deliquescent salts on the waste package surface and, after screening out ammonium salts for reasons discussed below, the deliquescent behavior of the multiple-salt systems predicted to be present.

Deliquescent minerals in drift dust are of consequence because of their ability to absorb water vapor from the air and form aqueous solutions (Figure 6-1). As long as the thermodynamic activity of water in an actual or potential solution is less than the relative humidity (expressed as a fraction) of the surrounding atmosphere, that solution will absorb water from the atmosphere until the activity of water in the solution and the relative humidity are equal. Campbell and Smith (1951 [DIRS 163817], p. 237) state, "It is clear that if the pressure of the aqueous vapor in the atmosphere is greater than that of the saturated solution of a salt, that salt will, on being placed in the air, form a solution: it will deliquesce." Where deliquescing minerals (salts) are present in the dust, the minerals will dissolve to form a small quantity of aqueous solution. As shown in Figure 6-1, the evaporative process is the reverse of deliquescence.

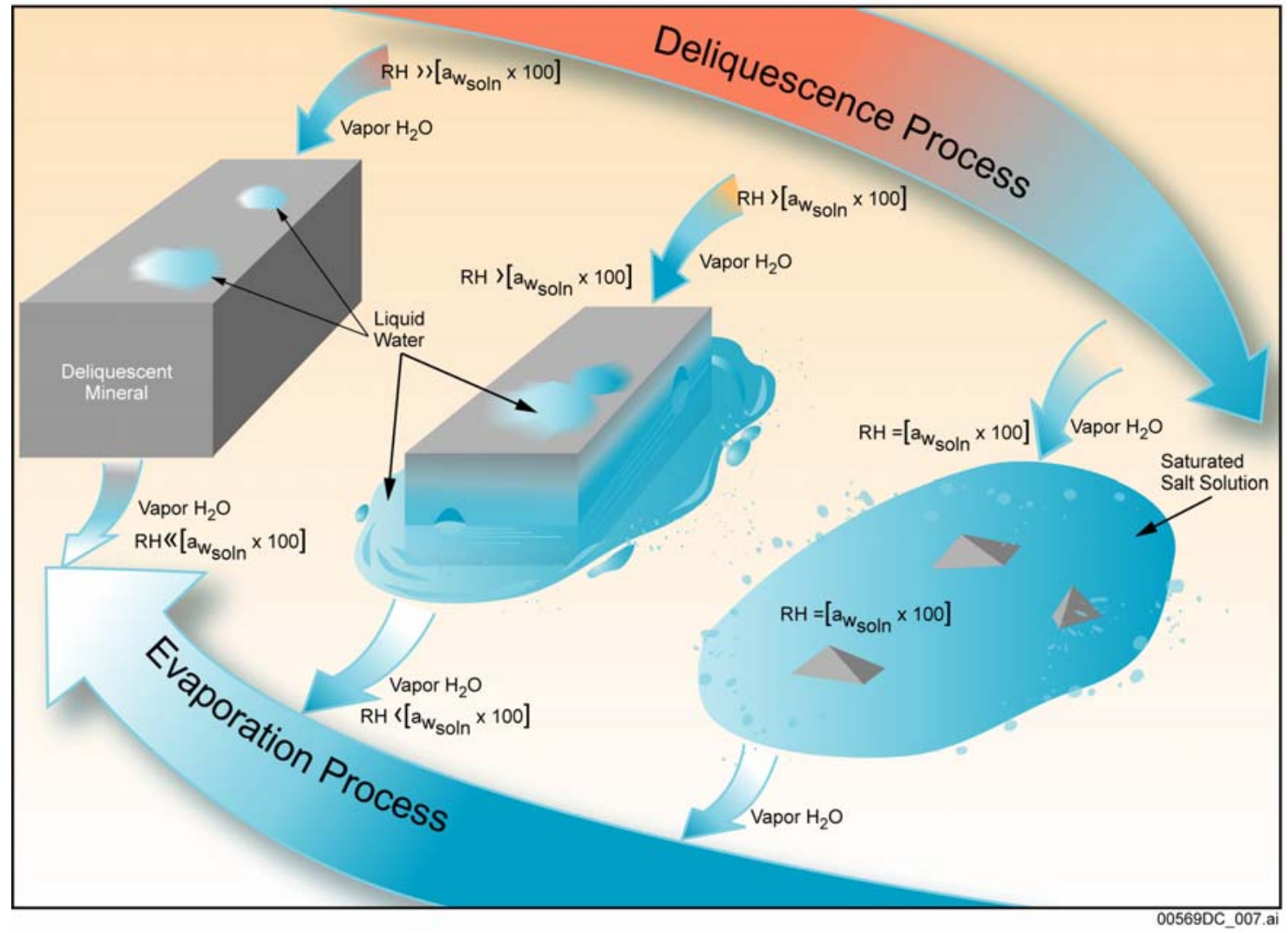

Figure 6-1. Schematic Illustration of Deliquescence and Evaporation 
The dust deliquescence processes are evaluated in the framework of the temperature-RH conditions predicted to occur in the drift during preclosure ventilation and for the few hundred to few thousand years after closure. Preclosure temperature-RH curves were determined by representing inlet air conditions ranging from the "average winter" (as represented by historical data for January) temperature of $7.0^{\circ} \mathrm{C}$ with a corresponding relative humidity of $62.2 \%$, to the "average summer" (as represented by historical data for July) temperature of $31^{\circ} \mathrm{C}$ with a corresponding relative humidity of 24\% (DTNs: MO04019SUM9397.000 [DIRS 167054] and MO03119MET9397.000 [DIRS 166207]). Calculation of these curves is documented in Appendix A. The published ventilation model describes the average waste package temperature with a fixed value of the inlet air temperature (BSC 2004 [DIRS 169862], Section 6.4). The analysis provided in Appendix A applies the analytical version of this model to a wider range of waste package heat output, and a wider range of inlet air conditions, for a more detailed description of the range of preclosure environments for dust deliquescence.

Following emplacement, waste package surfaces heat up until ventilation is initiated, after which waste packages cool to well below $100^{\circ} \mathrm{C}$, and the RH rises. Following closure, waste package surface temperatures will increase rapidly (in about 20 years) to the maximum value and then decrease slowly, taking approximately 70,700 , and 1,800 years to drop below $100^{\circ} \mathrm{C}$ for designated cool, median, and hot waste packages, respectively. Relative humidity will decrease during the 20-year temperature "ramp-up," and then slowly increase after each waste package evolves through its peak temperature. These conditions and those of preclosure are shown in Figure 6-2.

Note that in Figure 6-2 the temperature and RH ranges transition from the end of the preclosure ventilation period to the beginning of the postclosure period. The beginning and end points of this transition are valid model predictions of the ventilation and multiscale thermohydrologic models. Moisture removal from the rock by preclosure ventilation is not included in the multiscale model (BSC 2005 [DIRS 173944], Section 7.5.3), which affects the predicted recovery time for $\mathrm{RH}$ in the drifts. The timing of the transition in $\mathrm{RH}$ during the early postclosure response has been evaluated by comparing drift-wall matrix liquid saturation predicted using the multiscale approach and a three-dimensional thermal hydrology model (BSC 2005 [DIRS 173944], Section 7.5.4). The comparison shows that the multiscale thermohydrologic model (as represented in Figure 6-2) overestimates the RH for several hundred years following closure, which is a conservative result with respect to the availability of humidity for dust deliquescence at elevated temperature. 


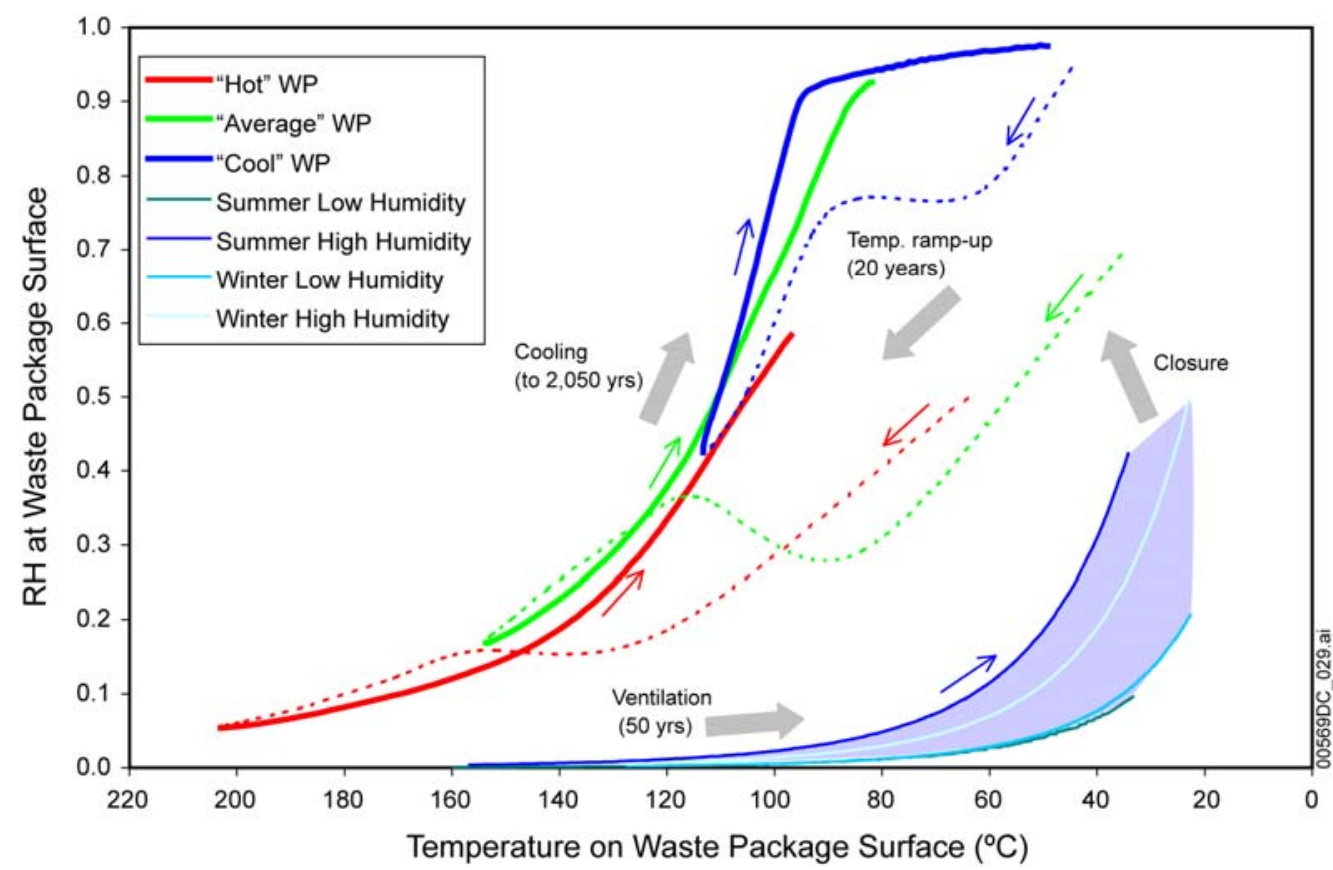

Source: Output DTN: SN0508T0502205.015. The spreadsheet Graph of Temperature and RH Conditions on the WP.xls contains the figure and data, as described in Section 4.1.11. See Appendix A for preclosure analysis.

NOTE: The 20-year temperature ramp-up is indicated by dotted lines. The cool-down curves are shown only to a maximum time of 2,050 years, the time step at which the surface of the "hot" waste package drops below $96^{\circ} \mathrm{C}$.

Figure 6-2. Evolution of Temperature and RH on a Waste Package Surface

\subsection{CAN MULTI-SALT DELIQUESCENT BRINES FORM AT ELEVATED TEMPERATURE?}

The conditions under which brines may form by dust deliquescence have been evaluated using both geochemical simulation and experimental testing. Geochemical simulation has been used to determine the salt assemblages in the dust that are likely to control the deliquescent behavior, and to estimate the conditions under which deliquescence occurs. Experimental testing of those assemblages has provided direct information on the deliquescence behavior of these salts.

Ammonium salts will decompose at relative humidities lower than those expected for brine deliquescence after repository closure. When this happens, these salts (mainly $\mathrm{NH}_{4} \mathrm{Cl}, \mathrm{NH}_{4} \mathrm{NO}_{3}$, and $\left(\mathrm{NH}_{4}\right)_{2} \mathrm{SO}_{4}$ ) release their anions as acid-gas species (Section 6.1.2.3), thus depleting the dust system in these components. Previous calculations of dust deliquescence (BSC 2004 [DIRS 169860]) did not include loss of ammonium salts prior to deliquescence. The effect of this process is evaluated here, and found to be of little consequence.

\subsubsection{Dust Compositions}

The analyses presented here are based on two sets of data. The first set comprises measured dust and dust leachate compositions based on tunnel dust samples collected from the Exploratory Studies Facility (Section 4.1.9). These samples are the basis for an evaluation of dust 
deliquescence documented in Environment on the Surfaces of the Drip Shield and Waste Package Outer Barrier (BSC 2004 [DIRS 161237]) and Engineered Barrier System: Physical and Chemical Environment (BSC 2004 [DIRS 169860], Section 6.10). That evaluation is based on incomplete chemical analyses of the dust leachates; more recent experimental work has identified ammonium as a significant component of the dusts, and the calculations presented in the reports cited above do not include ammonium.

It has also been recognized that samples of tunnel dust are probably not representative of dust that will be deposited during the ventilation period. The tunnel dust samples consist mostly of crushed rhyolite, generated by excavation and other support activities underground, and contain only a small amount (typically $<0.5 \%$ by weight; see BSC 2004 [DIRS 161237], Section 6.7.2.10, p. 6-65) of total soluble salts. However, dust deposited during ventilation will probably be more similar to atmospheric dusts and aerosols, with a greater soluble salt content (10 to 15\%; see Table 4.1-9) and different composition. The composition of potential atmospheric dusts is evaluated using measured rain-out data collected by the National Atmospheric Deposition Program at a Nevada sampling site (Section 4.1.3), which reflects contributions of both atmospheric aerosols and windblown dust in the Yucca Mountain area.

\subsubsection{Analyses Based on Tunnel Dust Samples}

In this section, the deliquescence behavior of dust on the waste package, as predicted by thermodynamic analysis and experimental studies of tunnel dusts and dust leachates, is presented, and the potential effects of ammonium in the dust are evaluated. Although the tunnel dusts are probably not representative of repository dust composition, as stated above, the following subsections show that the effects of ammonium salts are limited because they decompose. The same salt assemblages analyzed in the reports cited above (BSC 2004 [DIRS 161237]; BSC 2004 [DIRS 169860]) can then be used to represent multiple-salt deliquescence at elevated temperature.

\subsubsection{Thermodynamic Analysis Results}

In Environment on the Surfaces of the Drip Shield and Waste Package Outer Barrier (BSC 2004 [DIRS 161237], Table 6.7-11) three major assemblages of deliquescent salts are identified as controlling the deliquescence $\mathrm{RH}$ for tunnel dust, based on analysis of dust leachates (not including $\mathrm{NH}_{4}$ ). These salt assemblages were not directly observed in the dusts, but are inferred from a normative approach verified by simulation of evaporative evolution, and the analysis is representative of the soluble dust compositions with the exception of ammonia (see discussion in Section 6.1). The three assemblages are:

- Assemblage A: $\mathrm{NaCl}-\mathrm{KNO}_{3}$

- Assemblage B: $\mathrm{NaCl}-\mathrm{KNO}_{3}-\mathrm{NaNO}_{3}$

- Assemblage C: $\mathrm{NaCl}-\mathrm{KNO}_{3}-\mathrm{NaNO}_{3}-\mathrm{Ca}\left(\mathrm{NO}_{3}\right)_{2}$.

Simulations using the EQ3/6 V8.0 software code and Pitzer parameters developed for the in-drift precipitates/salts (IDPS) model (BSC 2004 [DIRS 169863]; as implemented in data0.ypf.R0 from DTN: SN0302T0510102.002 [DIRS 162572]) predicted that maximum temperatures of deliquescence at 0.90 bars for the first two assemblages would be $126.1{ }^{\circ} \mathrm{C}$ and $135.8^{\circ} \mathrm{C}$, 
respectively (BSC 2004 [DIRS 161237], Tables 6.7-21 and 6.7-22). Because of limitations in the available thermodynamic data for the calcium-nitrate system, the third assemblage was not explicitly modeled, and a boiling temperature of $155^{\circ} \mathrm{C}$ (slightly higher than the boiling temperature of a pure $\mathrm{Ca}\left(\mathrm{NO}_{3}\right)_{2}$ solution at 1 bar) was assumed (BSC 2004 [DIRS 161237], Table 6.7-23). However, the IDPS model uncertainties in the calculated deliquescence RH values at these higher temperatures or lower relative humidities are large (e.g., $\pm 15 \%$ for predicted RH values less than 40\%; BSC 2004 [DIRS 169863], Table 7-8) and correspond to large uncertainties in the predicted boiling temperatures for these assemblages. As discussed in the next section, experimental data acquired subsequently show that the predicted boiling (dryout) temperatures for these assemblages are too low.

\subsubsection{Results of Experimental Deliquescence Measurements}

Experimental work has been performed with the three salt assemblages described above to evaluate the potential for deliquescence at high temperatures and low relative humidities. Experimental work with the $\mathrm{NaCl}-\mathrm{KNO}_{3}$ assemblage at 1 bar confirmed that dryout occurred at temperatures below $160^{\circ} \mathrm{C}$, with the highest measured temperature at which deliquescent liquid was present being approximately $134^{\circ} \mathrm{C}$ (DTN: LL040901831032.008 [DIRS 173659], Boiling_temperatures_Rlc_1.doc, Figure 1). Deliquescence salt Assemblage B, the $\mathrm{NaCl}-\mathrm{KNO}_{3}-\mathrm{NaNO}_{3}$ assemblage, has also been examined experimentally. Boiling-point and short-term resistivity experiments suggest that $\mathrm{NaCl}-\mathrm{KNO}_{3}-\mathrm{NaNO}_{3}$ brine can form at temperatures in excess of $190^{\circ} \mathrm{C}$ (Figure 6.1-1). By inference, salt Assemblage $\mathrm{C}, \mathrm{NaCl}-\mathrm{KNO}_{3}-$ $\mathrm{NaNO}_{3}-\mathrm{Ca}\left(\mathrm{NO}_{3}\right)_{2}$, of which Assemblage $\mathrm{B}$ is a subset, must also deliquesce at temperatures greater than $190^{\circ} \mathrm{C}$.
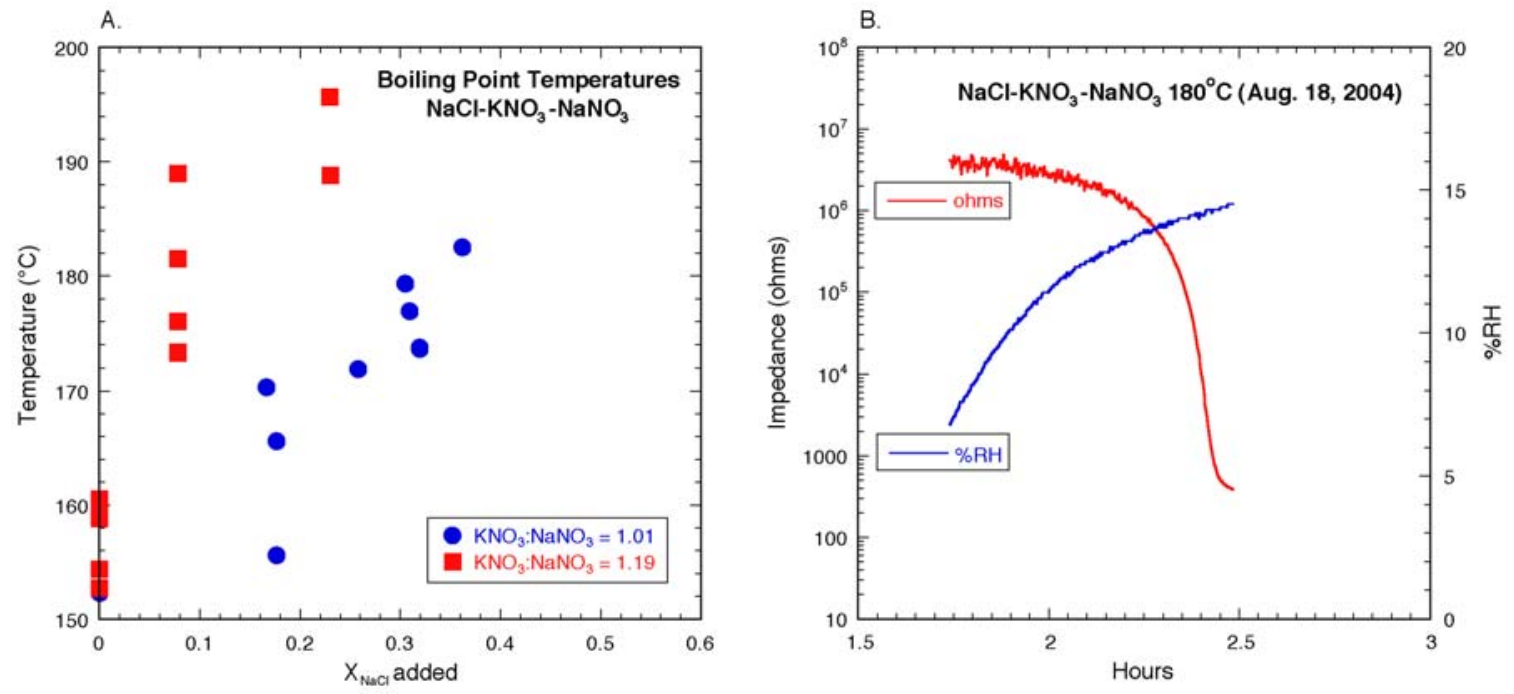

NOTES: A. Boiling point measurements at fixed $\mathrm{KNO}_{3}: \mathrm{NaNO}_{3}$ mole ratios versus the mole fraction of $\mathrm{NaCl}$ salt added; from DTN: LL040901831032.008 [DIRS 173659], Boiling_temperatures_R/c_1.doc, Figure 3.

B. Resistivity measurements show that this salt mixture deliquesces at $180^{\circ} \mathrm{C}$ (measured $\mathrm{RH}$ was not calibrated); from DTN: LL041001423121.046 [DIRS 173688], tab “18 Aug 04 kno3+nano3(nacl)_180C.”

Figure 6.1-1. Deliquescence of the $\mathrm{NaCl}-\mathrm{KNO}_{3}-\mathrm{NaNO}_{3}$ System at Elevated Temperature 


\subsubsection{Effects of Ammonium}

Ammonium salts (sulfate, nitrate, and chloride) are common components in atmospheric dust that may be entrained in the repository during the ventilation stage of repository operations. The EQ3/6 dust leachate modeling described in Engineered Barrier System: Physical and Chemical Environment (BSC 2004 [DIRS 169860]), and the deliquescent salt assemblages identified in Environment on the Surfaces of the Drip Shield and Waste Package (BSC 2004 [DIRS 161237], Table 6.7-11), are based on experimentally measured tunnel dust leachate compositions. More recent analysis of tunnel dust leachates shows that ammonium is present and that ammonium salts constitute a significant fraction of the salts present (Section 6.1.2.4). Further, it is expected that the relative abundance of ammonium will be greater in the atmospheric dusts deposited during preclosure ventilation than in tunnel dust samples collected to date. The following discussion evaluates the stability of ammonium salts in a repository environment and the likely effects of ammonium on the formation and composition of predicted deliquescent brines.

Experimental Decomposition of Ammonium Salts-This section demonstrates that ammonium nitrate and ammonium chloride are volatile, and decompose over short time periods at modestly elevated temperatures. Ammonium nitrate $\left(\mathrm{NH}_{4} \mathrm{NO}_{3}\right)$ decomposes to $\mathrm{HNO}_{3}$ and $\mathrm{NH}_{3}$ gases, while ammonium chloride $\left(\mathrm{NH}_{4} \mathrm{Cl}\right)$ decomposes to form $\mathrm{HCl}$ and $\mathrm{NH}_{3}$ gases. This suggests that all ammonium nitrate and chloride salts can be removed from bulk water analyses of dust leachates to estimate key salt assemblages for brine formation after the ventilation period because these salts will have decomposed to their gas components during preclosure or early postclosure history of the repository.

Ammonium nitrate decomposition is strongly dependent on temperature. Vyazovkin et al. (2001 [DIRS 172842]) determined the isothermal kinetics of decomposition of this compound between $147^{\circ} \mathrm{C}$ and $190^{\circ} \mathrm{C}$ (bracketing the $169.5^{\circ} \mathrm{C}$ melting temperature of $\mathrm{NH}_{4} \mathrm{NO}_{3}$ ), and found that the data were best fit with a rate law of the form:

$$
1-\left(1-\alpha_{N H 4 N O 3}(t, T)\right)^{1 / 2}=A \cdot t \cdot e^{-E_{a} / R T}
$$

where $T$ is the absolute temperature; $t$ is the time; $\alpha_{N H 4 N O 3}(t, T)=[1-\mathrm{M}(t) / \mathrm{M}(0)]$ is the fraction of $\mathrm{NH}_{4} \mathrm{NO}_{3}$ that has decomposed at time $\mathrm{t}$ at temperature $T ; \mathrm{M}(0)$ is the sample mass at $t=0$; and $\mathrm{M}(t)$ is the sample mass at time $t$. In this equation, $A=1 \pm_{0.7}^{3} \cdot 10^{9} \mathrm{~min}^{-1}$ (given in Vyazovkin et al. 2001 [DIRS 172842], p. 964, as $\left.\log _{10}\left(\mathrm{~A} / \mathrm{min}^{-1}\right)=9.0 \pm 0.6\right), E_{a}=91.5 \pm 5.6 \mathrm{~kJ} \mathrm{~mole}^{-1}$ (Vyazovkin et al. 2001 [DIRS 172842], p. 964), and $R=8.3144 \mathrm{~J}^{\mathrm{mole}}{ }^{-1} \mathrm{~K}^{-1}$ is the universal gas constant.

This form of the rate law corresponds to a contracting cylinder geometry. The same law was found to apply to both solid and molten $\mathrm{NH}_{4} \mathrm{NO}_{3}$.

Relevant literature data on the thermal decomposition kinetics of $\mathrm{NH}_{4} \mathrm{Cl}$ were not available. To determine the temperature dependence of the kinetics of this reaction, thermogravimetric analysis (TGA) data for reagent-grade, powdered $\mathrm{NH}_{4} \mathrm{Cl}$ were obtained at temperatures between $100^{\circ} \mathrm{C}$ and $250^{\circ} \mathrm{C}$, and at one atmosphere pressure in air. In these experiments, the mass loss as a function of time was measured at a constant temperature. Fractional mass losses varied from $<5 \%$ at the lowest temperatures to $100 \%$ (complete decomposition) at the higher 
temperatures and for the longer run times (hours) at intermediate temperatures. Experimental data can be found in DTNs: LL050205223121.048 [DIRS 174025] and LL050301723121.050 [DIRS 173175] and are plotted in Figure 6.1-2.
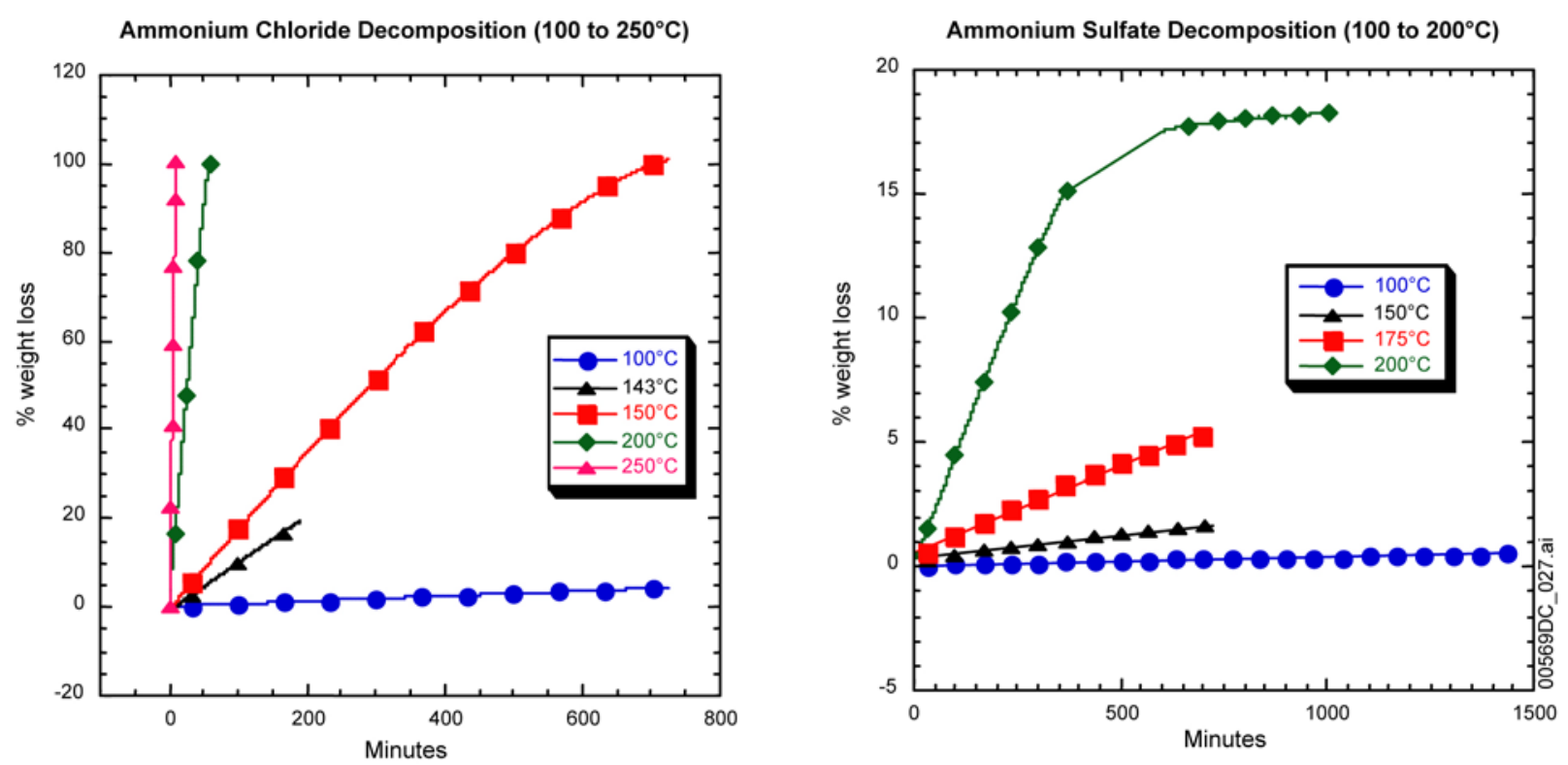

Source: DTNs: LL050301723121.050 [DIRS 173175] and LL050205223121.048 [DIRS 174025].

Figure 6.1-2. Decomposition of Dry Ammonium Chloride $\left(100\right.$ to $\left.250^{\circ} \mathrm{C}\right)$ and Ammonium Sulfate (100 to $200^{\circ} \mathrm{C}$ ) Salts Determined by Weight Loss Using a Thermogravimetric Analyzer

The calculations to extract decomposition rate parameters are documented in Output DTN: LL050600123121.052. The resulting data on mass as a function of time for each temperature were plotted as $\alpha(\mathrm{t}, \mathrm{T})=[1-\mathrm{M}(\mathrm{t}) / \mathrm{M}(0)]$ versus $\mathrm{t}$, where $\mathrm{t}=0$ it taken as the time at which the temperature stabilized at the run temperature, $\mathrm{M}(0)$ is the sample mass at $\mathrm{t}=0$, and $\mathrm{M}(\mathrm{t})$ is the sample mass at time $\mathrm{t}$. For fractional mass losses less than approximately $30 \%$, the resulting plots are linear, and the slope yields the decomposition rate (expressed in grams evaporating per gram of initial material per unit time). For larger mass losses, the $\alpha(t, T)$ versus $t$ plots show some deviation from linearity, but remain very close to linear over the entire range of mass loss.

Because the surface area of the samples must have been decreasing as samples decomposed, and because a number of plausible mechanisms for the kinetics of decomposition depend on the surface area, "initial" rates were calculated by limiting the analysis to "early-time" data (i.e., data for which it could be reasonably argued that the surface area involved in evaporation had not changed significantly from the initial surface area). Because it was not clear, a priori, what would constitute "early times," rates were calculated using data corresponding to 5\% mass loss, $10 \%$ mass loss, and 15\% mass loss. For comparison, rates were also calculated using all the available data (cut off, of course, at the point a sample had completely decomposed, if that occurred) at each temperature. For the $100^{\circ} \mathrm{C}$ run, less than $5 \%$ of the sample decomposed, so only one rate could be calculated from this experiment. Rates were determined by linear least 
squares with the constant term forced to be equal to zero (i.e., fractional mass loss $=0$ at time $=0$ ) using the regression analysis add-in of Microsoft Excel.

The resulting rate data were used to create linearized Arrhenius plots $(\ln ($ rate $)$ versus $1 / \mathrm{T})$, with the data fit to a straight line, again using the linear least-squares regression analysis add-in of Microsoft Excel. Separate plots and regressions were made for the 5\%, 10\%, and 15\% mass-loss cases, and for the "all data" case. The activation energies and pre-exponential factors obtained for the three candidate "initial rate" determinations were identical at $E_{a}=89 \pm 2 \mathrm{~kJ} / \mathrm{mole}$ and $\ln (\mathrm{A}$, minutes $)=18.9 \pm 0.5\left(\mathrm{~A}=\mathrm{e}^{18.9 \pm 0.5} \mathrm{~min}^{-1}=1.6 \pm \pm_{0.7}^{1.2} \cdot 10^{8} \min ^{-1} \quad[1\right.$ sigma errors $\left.]\right)$. Somewhat surprisingly, the Arrhenius parameters determined using all the data were essentially the same, at $88 \pm 2 \mathrm{~kJ} /$ mole and $\ln (\mathrm{A}$, -minutes $)=18.7 \pm 0.5$. As can be seen in Figure 6.1-3, which shows the data for the $10 \%$ mass-loss case, the linear fits to plots of $\ln$ (rate) versus $1 / \mathrm{T}$ were excellent, with $\mathrm{r}^{2}$ values of greater than 0.998 .

The data are thus consistent with a rate law for thermal decomposition of $\mathrm{NH}_{4} \mathrm{Cl}$ of the form:

$$
\alpha_{N H 4 C l}(t, T)=A \cdot t \cdot e^{-E_{a} / R T}
$$

where

$$
\begin{array}{lll}
T & = & \text { absolute temperature }\left({ }^{\circ} \mathrm{K}\right) \\
t & = & \text { time }(\min ) \\
\alpha_{N H 4 C l}(t, T) & = & {[1-\mathrm{M}(t) / \mathrm{M}(0)] ; \text { fraction of } \mathrm{NH}_{4} \mathrm{Cl} \text { decomposed at time } t \text { and }} \\
& & \text { temperature } T \\
A & =1.6 \pm_{0.7}^{1.2} \cdot 10^{8} \mathrm{~min}^{-1} \\
E_{a} & =89 \pm 2 \mathrm{~kJ} \mathrm{~mole}^{-1} \\
R & = & \text { gas constant }\left(8.3144 \mathrm{~J} \text { mole }^{-1} \mathrm{~K}^{-1}\right) .
\end{array}
$$

The activation energy determined here is significantly higher than the values determined by Schultz and Decker (1956 [DIRS 173682]) $(46.9 \mathrm{~kJ} / \mathrm{mol})$ and Chaiken et al. (1962 [DIRS 173681]) $(55.2 \mathrm{~kJ} / \mathrm{mol})$ for the decomposition of $\mathrm{NH}_{4} \mathrm{Cl}$ into a vacuum. However, Chaiken et al. (1962 [DIRS 173681]) note that rate function and the activation energy for $\mathrm{NH}_{4} \mathrm{Cl}$ decomposition at higher pressures (e.g., one atmosphere) is different from their measured value for a vacuum, possibly due to a change in the rate-limiting mechanism. 


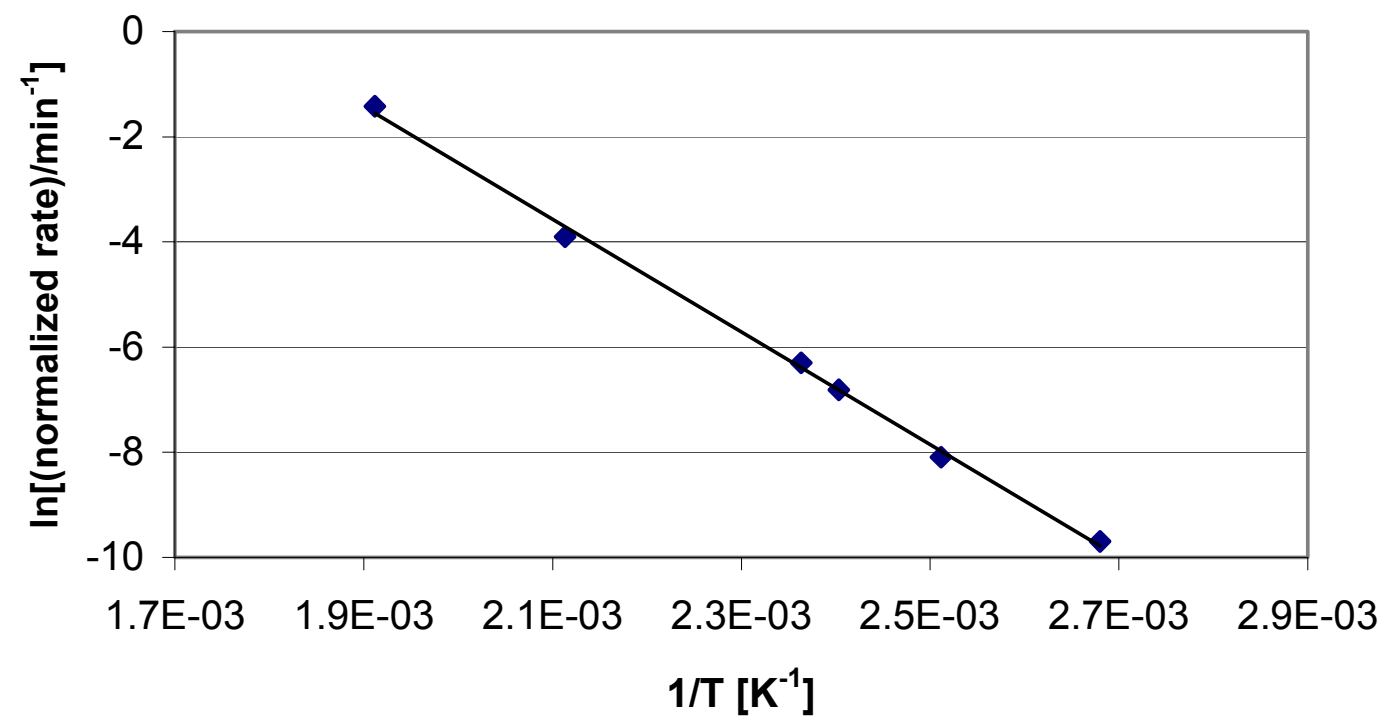

Source: Output DTN: LL050600123121.052.

Figure 6.1-3. Arrhenius Plot for the Decomposition of $\mathrm{NH}_{4} \mathrm{Cl}$, Using Data for Mass Losses Less Than $10 \%$

The lifetime of decomposing particles of $\mathrm{NH}_{4} \mathrm{Cl}$ and $\mathrm{NH}_{4} \mathrm{NO}_{3}$ can be calculated by setting $\alpha\left(t_{s}, T\right)=1$ (complete decomposition) in the rate laws above, and solving for the time $\left(t_{s}\right)$ at which a particle has completely decomposed as a function of temperature $(T)$. For both compounds, the expression for $t_{s}(T)$ is given by:

$$
t_{s}(T)=\frac{1}{A} \cdot e^{E_{a} / R T}
$$

The lifetimes so calculated are tabulated in Table 6.1-1, and shown in Figure 6.1-4. Nominal lifetimes were calculated using the best-fit values of the Arrhenius parameters, while higher and lower error bands were calculated using the nominal parameter values plus or minus the formal 1-sigma errors calculated here for $\mathrm{NH}_{4} \mathrm{Cl}$, and the errors reported by Vyazovkin et al. (2001 [DIRS 172842]) for $\mathrm{NH}_{4} \mathrm{NO}_{3}$ (that reference does not state what level of confidence the reported errors represent). This procedure overestimates the actual uncertainties because it ignores the covariance between the fitted values of the activation energy and pre-exponential factor. Lifetimes for both composition particles vary from several minutes or hours at temperatures above $175^{\circ} \mathrm{C}$ to as much as several years at temperatures below $75^{\circ} \mathrm{C}$. Overall, however, these lifetimes are relatively short, and it is clear that any $\mathrm{NH}_{4} \mathrm{Cl}$ or $\mathrm{NH}_{4} \mathrm{NO}_{3}$ present in dust in the repository will completely decompose during the ventilation and/or high temperature postclosure phases of the repository. 
Table 6.1-1. Calculated Lifetimes of $\mathrm{NH}_{4} \mathrm{Cl}$ and $\mathrm{NH}_{4} \mathrm{NO}_{3}$ as a Function of Temperature

\begin{tabular}{|c|c|c|c|c|c|c|}
\hline \multirow{2}{*}{$\mathbf{T}\left({ }^{\circ} \mathbf{C}\right)$} & \multicolumn{5}{|c|}{$\mathbf{N H}_{\mathbf{4}} \mathbf{C l}$} & \multicolumn{3}{c|}{$\mathbf{N H}_{\mathbf{4}} \mathbf{N O}_{\mathbf{3}}$} \\
\cline { 2 - 7 } & $\mathbf{t}_{\mathbf{s}}$ low & $\mathbf{t}_{\mathbf{s}}$ nominal & $\mathbf{t}_{\mathbf{s}}$ high & $\mathbf{t}_{\mathbf{s}}$ low & $\mathbf{t}_{\mathbf{s}}$ nominal & $\mathbf{t}_{\mathbf{s}} \mathbf{~ h i g h}$ \\
\hline $\mathbf{5 0}$ & 235 days & 861 days & 3,208 days & 11 days & 347 days & 9,188 days \\
\hline $\mathbf{7 5}$ & 23.6 days & 82.1 days & 290 days & 1.1 days & 31.0 days & 707.2 days \\
\hline $\mathbf{1 0 0}$ & 3.2 days & 10.7 days & 36.1 days & $3.8 \mathrm{hr}$ & 3.8 days & 76.6 days \\
\hline $\mathbf{1 2 5}$ & $13.5 \mathrm{hr}$ & 1.8 days & 5.8 days & $40.8 \mathrm{~min}$ & $14.7 \mathrm{hr}$ & $262.9 \mathrm{hr}$ \\
\hline $\mathbf{1 5 0}$ & $2.9 \mathrm{hr}$ & $9.0 \mathrm{hr}$ & $28.0 \mathrm{hr}$ & $8.9 \mathrm{~min}$ & $2.9 \mathrm{hr}$ & $47.3 \mathrm{hr}$ \\
\hline $\mathbf{1 7 5}$ & $44.5 \mathrm{~min}$ & $2.2 \mathrm{hr}$ & $6.7 \mathrm{hr}$ & $2.3 \mathrm{~min}$ & $41.4 \mathrm{~min}$ & $10.3 \mathrm{hr}$ \\
\hline $\mathbf{2 0 0}$ & $13.1 \mathrm{~min}$ & $38.0 \mathrm{~min}$ & $1.9 \mathrm{hr}$ & $0.7 \mathrm{~min}$ & $11.4 \mathrm{~min}$ & $2.6 \mathrm{hr}$ \\
\hline $\mathbf{2 2 5}$ & $4.4 \mathrm{~min}$ & $12.3 \mathrm{~min}$ & $35.4 \mathrm{~min}$ & $0.2 \mathrm{~min}$ & $3.6 \mathrm{~min}$ & $46.1 \mathrm{~min}$ \\
\hline $\mathbf{2 5 0}$ & $1.6 \mathrm{~min}$ & $4.4 \mathrm{~min}$ & $12.5 \mathrm{~min}$ & $0.1 \mathrm{~min}$ & $1.3 \mathrm{~min}$ & $15.2 \mathrm{~min}$ \\
\hline
\end{tabular}

Source: Output DTN: LL050600123121.052.

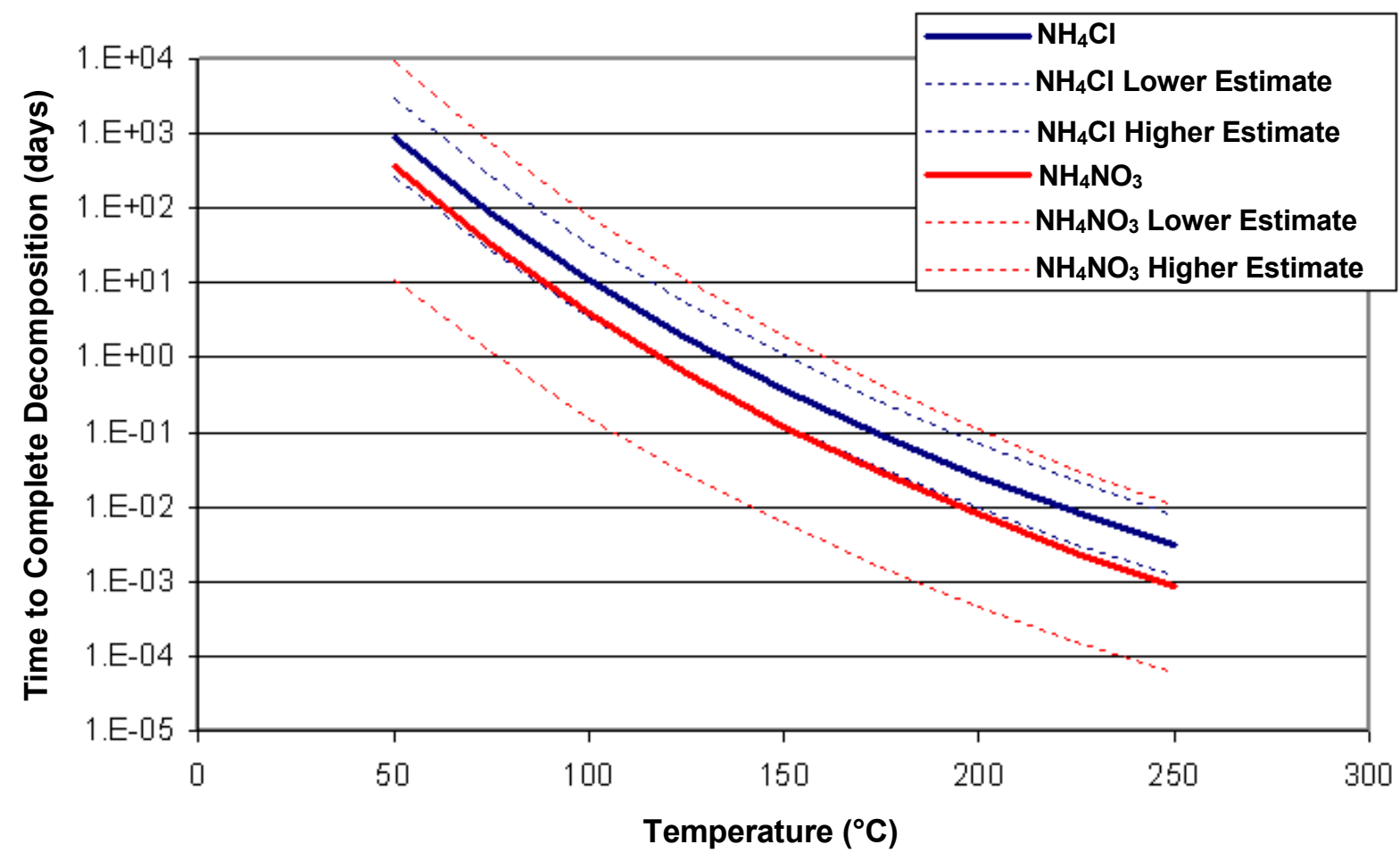

Source: Output DTN: LL050600123121.052.

Figure 6.1-4. Calculated Time for Complete Decomposition of $\mathrm{NH}_{4} \mathrm{Cl}$ and $\mathrm{NH}_{4} \mathrm{NO}_{3}$ Particles as a Function of Temperature

In contrast to ammonium nitrate and ammonium chloride salts, ammonium sulfate salt is more stable and may exhibit stages in the rate of degassing, possibly reflecting changes in surface area or solid phase chemistry (Figure 6.1-2). In general, the rate of decomposition increases with increasing temperature from 100 to $200^{\circ} \mathrm{C}$; however, there is a second stage of slower weight loss observed for the $200^{\circ} \mathrm{C}$ experiment, whereby the rate decreases to approximately $5 \%$ of the 
initial rate. It is possible that the first rate corresponds to the decomposition of ammonium sulfate to ammonium bisulfate $\left(\mathrm{NH}_{4} \mathrm{HSO}_{4}\right)$, while the second, slower rate reflects the decomposition of the bisulfate.

Simple linear extrapolation of the $100^{\circ} \mathrm{C}$ rate data shown in Figure 6.1-2 suggests that ammonium sulfate will completely decompose to its gas components within a year at this temperature $\left(0.5 \%\right.$ decomposition after 1 day at $100^{\circ} \mathrm{C}$ implies complete decomposition after 200 days). However, this may overestimate the loss of $\mathrm{NH}_{3}(\mathrm{~g})$ and $\mathrm{H}_{2} \mathrm{SO}_{4}(\mathrm{~g})$ from salts present in dust if decomposition of ammonium sulfate is limited by a second, slower rate.

There is no adverse consequence if ammonium sulfate does not entirely decompose - the potential change in the deliquescent brine volume calculated in Section 6.4.1, and the potential effect on the nitrate-chloride ratio discussed in Section 6.3, are not significant to the arguments presented in this report. Further, if ammonium sulfate persists as a deliquescent salt, it may promote precipitation of divalent cations (e.g., $\mathrm{Ca}^{2+}$ ) and the additional sulfate may contribute to protection from localized corrosion (BSC 2004 [DIRS 169984], Section 8.3.1).

Thus, ammonium nitrate, ammonium chloride, and probably ammonium sulfate will decompose rapidly, releasing ammonia and a mineral acid $\left(\mathrm{HCl}, \mathrm{HNO}_{3}, \mathrm{or}_{2} \mathrm{H}_{4}\right)$, with the net effect of removing ammonium salts from the dust system prior to deliquescence. The tunnel dust deliquescence modeling carried out to date did not include ammonium, but neither did it account for the anionic component $\left(\mathrm{Cl}^{-}, \mathrm{NO}_{3}{ }^{-}\right.$, or $\left.\mathrm{SO}_{4}{ }^{2-}\right)$ that would be removed along with the ammonium. The net effect of this on the initial dust leachate compositions used in Engineered Barrier System: Physical and Chemical Environment (BSC 2004 [DIRS 169860], Section 6.10) will be to increase the carbonate alkalinity, as some fraction of another anion $\left(\mathrm{Cl}^{-}, \mathrm{NO}_{3}^{-}\right.$, or $\mathrm{SO}_{4}{ }^{2-}$ ) will be removed, but the cation abundance will not change. Some idea of the effect this will have on the evolution of the brines, or predicted eutectic salt assemblages and dryout temperatures, is presented in the following section.

\subsubsection{Analysis of the Effects of Ammonium Mineral Thermal Decomposition on Deliquescent Brine Compositions}

Atmospheric dusts are high in ammonium salts and are expected to constitute much of the dust deposited on the waste packages, and the potential effects of thermal decomposition of ammonium salts are significant. Decomposition makes the salt assemblage less deliquescent by removal of highly deliquescent ammonium salts, and also decreases the salt load of the dust and the volume of brine that will be generated during deliquescence (Section 6.4.1.2). It also changes the predicted deliquescent salt assemblage and eutectic composition. As shown above, both ammonium chloride and ammonium nitrate salts (and to a lesser extent ammonium sulfates) decompose, so both chloride and nitrate are potentially lost from the system by this process. This is of importance with respect to localized corrosion because the nitrate-chloride ratio and the $\mathrm{Cl}^{-}$concentration are parameters in the localized corrosion model (BSC 2004 [DIRS 169984], Section 6.4.4). In this section, the potential effects of ammonium mineral decomposition on the deliquescent salt assemblages in repository dust are evaluated. First, the effects of ammonium decomposition on atmospheric dust compositions are examined because dusts deposited on the waste package are expected to consist largely of atmospheric aerosols and windblown dust brought in by ventilation. Then, the effects are examined for measured 
tunnel-dust compositions, which represent a mixture of the atmospheric component and powdered rock.

Atmospheric Dusts - Chemically representative analyses of local aerosols were obtained from the National Atmospheric Deposition Program/National Trends Network (NADP/NTN), in the form of three average annual precipitation compositions, representing the years 2000 to 2002, from a collection site at Red Rock, Nevada (Table 4.1-8). Precipitation scavenges aerosols from the atmosphere, and is often used to evaluate atmospheric aerosol compositions. The NADP/NTN data provide compositional data for the soluble salts only-mineralogy was not determined. To evaluate the mineralogy of atmospheric aerosols, EQ3/6 was used to simulate evaporation of solutions representing the rain-out chemical analyses to dryness. If the soluble components in the rain-out are in thermodynamic equilibrium, an assumption commonly made in atmospheric aerosol models (e.g., Clegg et al. 1997 [DIRS 172816]; 1998 [DIRS 172807]; 1998 [DIRS 172815]), then the mineral assemblage present at dryout represents the presumed original mineralogy. This assumption is an "end-member" case-the rain-out data may represent mixtures of salts present in atmospheric aerosols and in windblown dust closer to the ground surface, that were not in equilibrium with each other.

The thermodynamic simulations presented in this section use the IDPS model (BSC 2004 [DIRS 169863]), within its range of validation, and data0.ypf.R2 (Output DTN: SN0504T0502205.008), qualified for calculations involving ammonium species at $25^{\circ} \mathrm{C}$. The calculation results are presented in Table 6.1-2. In all three cases, at dryout, chloride is associated solely with ammonium, and hence will be entirely lost during ammonium mineral phase decomposition. Although nitrate is dominantly bound to ammonium, niter, soda niter, and/or calcium nitrate are also present at dryout, and hence would remain after ammonium mineral decomposition. Thus, the net effect of ammonium mineral decomposition on the abundance and composition of soluble salts in atmospheric dusts is to greatly reduce the soluble salt load, and to remove chloride preferentially to nitrate, increasing the $\mathrm{NO}_{3} / \mathrm{Cl}$ ratio. Both are beneficial with respect to corrosion of Alloy 22, as a smaller salt load results is a smaller volume of deliquescent brine (Section 6.4), and increasing the $\mathrm{NO}_{3} / \mathrm{Cl}$ ratio results in a more benign solution.

It should be noted however, that this analysis assumes that the NADP/NTN rain-out compositions represent a salt assemblage in thermodynamic equilibrium. Atmospheric aerosol studies (Section 6.1.3) suggest that ammonium sulfate should be a significant component of atmospheric aerosols. If the NADP/NTN data mixtures of atmospheric aerosols and windblown dust closer to the ground surface, that are not in equilibrium with each other, then it is likely that more sulfate would be associated with ammonium, and less chloride and nitrate. 
Table 6.1-2. Effect of Ammonium Salt Decomposition on Predicted Brine Compositions

\begin{tabular}{|c|c|c|c|c|}
\hline Year at Site NV-00 & 2000 & 2001 & 2002 & Average \\
\hline Analysis Temp $\left({ }^{\circ} \mathrm{C}\right)$ & 25 & 25 & 25 & - \\
\hline Brine pH (Pitzer) & 6.40 & 8.10 & 7.96 & - \\
\hline Brine DRH (\%) & 43.0 & 41.9 & 42.9 & - \\
\hline $\mathrm{NH}_{4}$ ppts formed & $\mathrm{Cl}, \mathrm{NO}_{3}$ & $\mathrm{Cl}, \mathrm{NO}_{3}, \mathrm{SO}_{4}$ & $\mathrm{Cl}, \mathrm{NO}_{3}$ & - \\
\hline$\%$ nitrate bound to $\mathrm{NH}_{4}$ & 64.6 & 96.9 & 87.7 & - \\
\hline$\%$ chloride bound to $\mathrm{NH}_{4}$ & 100 & 100 & 100 & - \\
\hline Initial $\mathrm{Cl} / \mathrm{NO}_{3}$ & 0.138 & 0.130 & 0.194 & - \\
\hline Brine $\mathrm{Cl} / \mathrm{NO}_{3}$ & 0.024 & 0.029 & 0.035 & - \\
\hline $\begin{array}{l}\mathrm{Cl} / \mathrm{NO}_{3} \text { of remainder, after } \\
\text { decomposition of } \mathrm{NH}_{4} \text { phases }\end{array}$ & 0 & 0 & 0 & - \\
\hline$\% \mathrm{NH}_{4}$ bound to chloride & 17.6 & 11.8 & 18.1 & 15.85 \\
\hline$\% \mathrm{NH}_{4}$ bound to nitrate & 82.4 & 87.8 & 81.9 & 84.03 \\
\hline$\% \mathrm{NH}_{4}$ bound to sulfate & 0.0 & $0.4 \%$ & 0.0 & 0.12 \\
\hline
\end{tabular}

Source: Output DTN: SN0506T0502205.014, Atm. dust summary.xls and from files NV00-0\#.6i (\# = 0, 1 and 2).

Tunnel Dusts - As discussed in Section 6.1.2.1, previous analyses of tunnel dust deliquescence are based on tunnel dust chemical analyses for which ammonium data were lacking. A recent data set for tunnel dust leachate analysis that includes ammonium is presented in Table 6.1-3 (DTN: GS050408313000.001 [DIRS 173724]).

Table 6.1-3. Tunnel Dust Analyses That Include Ammonium

\begin{tabular}{|c|c|c|c|c|c|c|c|c|c|c|c|}
\hline $\begin{array}{c}\mathbf{S P C} \\
\mathbf{N u m b e r}\end{array}$ & $\begin{array}{c}\mathbf{N a} \\
(\mathbf{m g} / \mathbf{L})\end{array}$ & $\begin{array}{c}\mathbf{K} \\
(\mathbf{m g} / \mathbf{L})\end{array}$ & $\begin{array}{c}\mathbf{M g} \\
(\mathbf{m g} / \mathbf{L})\end{array}$ & $\begin{array}{c}\mathbf{C a} \\
(\mathbf{m g} / \mathbf{L})\end{array}$ & $\begin{array}{c}\mathbf{N H}_{4} \\
(\mathbf{m g} / \mathbf{L})\end{array}$ & $\begin{array}{c}\mathbf{C l} \\
(\mathbf{m g} / \mathbf{L})\end{array}$ & $\begin{array}{c}\mathbf{S O}_{4} \\
(\mathbf{m g} / \mathbf{L})\end{array}$ & $\begin{array}{c}\mathbf{H C O}_{3} \\
(\mathbf{m g} / \mathbf{L})\end{array}$ & $\begin{array}{c}\mathbf{N O}_{3} \\
(\mathbf{m g} / \mathbf{L})\end{array}$ & $\begin{array}{c}\mathbf{F} \\
(\mathbf{m g} / \mathbf{L})\end{array}$ & $\begin{array}{c}\mathbf{P O}_{4} \\
(\mathbf{m g} / \mathbf{L})\end{array}$ \\
\hline 574979 & 3.0 & 6.4 & 0.6 & 5.7 & 0.2 & 0.26 & 0.9 & 33 & 0.73 & 0.29 & 3.15 \\
\hline 574982 & 29.3 & 13.6 & 6.2 & 47.0 & 6.8 & 9.01 & 47.2 & 73 & 52.9 & 0.61 & 0.29 \\
\hline 574983 & 33.2 & 14.6 & 4.9 & 56.6 & 6.2 & 17.6 & 67.5 & 86 & 38.3 & 1.26 & 0.31 \\
\hline 574984 & 32.0 & 13.1 & 4.4 & 32.5 & $<0.1$ & 12.0 & 49.0 & 68 & 23.9 & 1.22 & $<0.05$ \\
\hline 574985 & 24.7 & 12.9 & 3.4 & 57.8 & 5.9 & 9.24 & 60.0 & 102 & 26.1 & 1.41 & 0.59 \\
\hline 574986 & 22.3 & 13.2 & 3.5 & 61.1 & 5.8 & 11.6 & 66.2 & 93 & 24.9 & 1.24 & 0.61 \\
\hline 574987 & 27.9 & 12.7 & 4.0 & 58.7 & 4.6 & 14.5 & 63.4 & 76 & 22.9 & 1.42 & 0.8 \\
\hline 574990 & 12.8 & 9.0 & 1.3 & 23.6 & 3.0 & 4.57 & 33.7 & 47 & 10.6 & 0.6 & 0.39 \\
\hline 574991 & 10.0 & 8.7 & 3.0 & 29.1 & 7.1 & 3.49 & 35.4 & 72 & 8.87 & 1.12 & 0.30 \\
\hline 574992 & 9.5 & 9.1 & 1.1 & 15.6 & 2.8 & 9.0 & 15.0 & 40 & 7.59 & 0.45 & 0.32 \\
\hline
\end{tabular}

Source: DTN: GS050408313000.001 [DIRS 173724]. 
The effect of ammonium mineral decomposition is to remove ammonium and anions mineralogically bound to it from the soluble salt assemblage. To determine the abundance of the remaining soluble components, it is necessary to apportion the ammonium present in the dust chemical analysis between the different anionic species $\left(\mathrm{NO}_{3}{ }^{-}, \mathrm{Cl}^{-}\right.$, and $\left.\mathrm{SO}_{4}{ }^{2-}\right)$ present, and then to subtract these from the dust leachate total analysis. The modified dust leachate compositions are then evaporated to dryness with $\mathrm{EQ} 3 / 6$ to determine the deliquescent mineral assemblage after ammonium mineral decomposition.

There is no direct mineralogical information on the identity or relative abundance of the ammonium salt phases present in the tunnel dust, so this information must be inferred. Conceptually, tunnel dust can be considered to consist of materials from at least three sources. The largest fraction is powdered rock (Peterman et al. 2003 [DIRS 162819]), generated during tunneling and underground activities. The soluble salt contribution of this fraction represents dried pore water, is minor $(<<1 \%)$, and is relatively chloride-rich and nitrate-poor; no ammonium concentration data exist. A much smaller fraction of the dust represents atmospheric aerosols brought into the tunnel by ventilation. The composition of atmospheric aerosols has been widely studied (Section 6.1.3); this component is high in soluble salts (10 to 20\%) and rich in nitrate, sulfate, and ammonium. The third fraction of the dust comes from anthropologic sources in the tunnel (diesel exhaust, powdered rubber from the conveyer belt, etc.). Little is known about the composition of this component, although ammonia may be present (for instance, it is a contaminant in diesel fuel), and this component will be ignored.

Because the tunnel dust is much more nitrate-rich than measured repository-level pore waters (which constitute the salt load in the powdered rock), it is inferred that most of the soluble salts in the dust are from atmospheric aerosols. Ventilation in the tunnel keeps the relative humidity very low, so ammonium minerals in the dust will not deliquesce and equilibrate, either with other dust salts or with each other. Thus, the mineralogy and relative abundance of the ammonium phases in the tunnel dust should be the same as that present in local atmospheric aerosols, which have been evaluated above using the NADP/NTN rain-out data, and are summarized in Table 6.1-2. At dryout, ammonium nitrate constitutes the majority of the ammonium salts present $(84.03 \%)$, with ammonium chloride present at a lower abundance $(15.85 \%)$. For the year 2001 data, an ammonium sulfate-nitrate double salt is formed, such that a minor amount of ammonium is tied up as sulfate $(0.12 \%)$. Using these ammonium salt proportions, the ammonium salt components were subtracted from 10 new dust leachate analysis data provided by the United States Geological Survey (USGS) (DTN: GS050408313000.001 [DIRS 173724]; see Table 6.1-3). This process lowers the nitrate-chloride ratio of the leachate solutions in each of the 10 cases. For samples SPC574991 and SPC574992, this subtraction resulted in negative values for nitrate concentrations, implying that the excess ammonium was associated with other anions, most likely $\mathrm{Cl}$. In the evaporation calculations, these negative values were artificially set to zero without further adjusting $\mathrm{Cl}$ concentrations.

The adjusted dust leachate compositions were then evaporated to dryness at $25^{\circ} \mathrm{C}$ and atmospheric $\mathrm{CO}_{2}$ partial pressure. The results are shown in Table 6.1-4. Removing all ammonium salt precipitates from the chemical analysis results in brines with neutral to basic $\mathrm{pH}$ and high deliquescence relative humidities, ranging from $64.0 \%$ to $72.4 \%$. In most cases, removal of ammonium phases has little effect on overall brine composition, as ammonium is a minor component, and the final eutectic brine compositions are nitrate-rich $\left(\mathrm{NO}_{3}: \mathrm{Cl}>1\right)$. 
However, for three samples, the nitrate-chloride ratio of the eutectic brine is less than 0.5. Sample SPC574979 evolves into a potassium carbonate/bicarbonate brine with a nitrate-chloride ratio of 0.125 . However, the $\mathrm{pH}$ is high (10.7), and a recent study has shown that carbonate is as effective as nitrate in suppressing localized corrosion (Dunn et al. 2004 [DIRS 173813]). Although the effect of carbonate is not yet incorporated into the YMP corrosion model, it seems unlikely that this brine will be corrosive.

For samples SPC574991 and SPC574992, all nitrate is removed by decomposition and $\mathrm{NaCl}$ brines result. This may be a function of discarding ammonium present in excess of the nitrate available - for instance, the excess ammonium discarded in run SPC574991 would be sufficient to consume all chloride in addition to the nitrate. It may also indicate that the assumption that the NADP/NTN rain-out compositions represent salt assemblages that were in equilibrium is incorrect. As stated earlier, the speciation indicated by the evaporation of the NADP/NTN rain-out samples (Table 6.1-3) of ammonium nitrate plus minor ammonium chloride is at odds with the atmospheric aerosol literature, which suggests that ammonium sulfate should be a significant component. If ammonium sulfate is present, then sulfate instead of nitrate or chloride would be lost by decomposition. While minimizing nitrate loss, sulfate loss could result in corrosive Ca-chloride brine formation, because sulfate is a sink for calcium. To evaluate this, a second set of simulations was run in which the total ammonium in the tunnel dust compositions in Table 6.1-3 was removed as ammonium sulfate, $\left(\mathrm{NH}_{4}\right)_{2} \mathrm{SO}_{4}$ (Output DTN: SN0506T0502205.014, dust with ammonia.xls). The results are shown in Table 6.1-5. In this case, all eutectic brine compositions except for SPC574979 are nitrate-rich. Removal of ammonium as ammonium sulfate has little effect on $\mathrm{Mg}$ and $\mathrm{Ca}$ molalities, which are still on the order of $10^{-3}$ or less. Sample SPC574979 once again forms a potassium carbonate brine.

Summary-This analysis shows that decomposition of ammonium salts from dust deposited on the waste package surface, either during ventilation or in the early postclosure period, has a beneficial effect with respect to brine corrosivity if the dusts are dominantly atmospheric in origin, removing chloride preferentially to nitrate, and reducing soluble salt loads and hence, brine volumes.

For current tunnel dusts, ammonium mineral decomposition generally has little effect. The $\mathrm{Na}-\mathrm{K}_{-} \mathrm{NO}_{3}-\mathrm{Cl}$ monovalent salt assemblages present after decomposition are the same as those predicted by the previous deliquescence modeling studies (BSC 2004 [DIRS 161237], Table 6.7-11). Most brines remain nitrate-rich even though somewhat more nitrate than chloride is generally expected to be removed by ammonium salt decomposition. In a few cases, chloride-rich brines formed. However, the current tunnel dusts are dominantly powdered tuff and contain only a small atmospheric dust component; future dusts will have a larger atmospheric component, and chloride-rich brines will not form. Removal of ammonium salts does not result in formation of $\mathrm{MgCl}_{2}$ or $\mathrm{CaCl}_{2}$ brines. 
Table 6.1-4. Compositions of Brines Formed by Dust Deliquescence after Ammonium Salt Decomposition: NADP/NTN Salts

\begin{tabular}{|c|c|c|c|c|c|c|c|c|c|c|c|}
\hline Sample \# & Pitzer pH & $\begin{array}{c}\text { Water } \\
\text { Activity }\end{array}$ & $\mathbf{K}^{+}$ & $\mathbf{N a}^{+}$ & $\mathbf{C a}^{2+}$ & $\mathbf{M g}^{2+}$ & $\mathbf{C l}^{-}$ & $\mathbf{N O}_{3}{ }^{-}$ & $\mathbf{S O}_{4}{ }^{2-}$ & $\mathbf{H C O}^{-}$ & $\mathbf{C O}_{3}{ }^{2-}$ \\
\hline 574979 & 10.70 & $6.40 \mathrm{E}-01$ & $1.07 \mathrm{E}+01$ & $1.51 \mathrm{E}+00$ & $1.17 \mathrm{E}-07$ & $2.85 \mathrm{E}-05$ & $1.31 \mathrm{E}+00$ & $1.63 \mathrm{E}-01$ & $1.78 \mathrm{E}-02$ & $1.58 \mathrm{E}+00$ & $4.51 \mathrm{E}+00$ \\
\hline 574982 & 8.20 & $6.69 \mathrm{E}-01$ & $2.95 \mathrm{E}+00$ & $9.40 \mathrm{E}+00$ & $7.68 \mathrm{E}-04$ & $4.71 \mathrm{E}-04$ & $3.48 \mathrm{E}+00$ & $5.68 \mathrm{E}+00$ & $1.59 \mathrm{E}+00$ & $1.12 \mathrm{E}-03$ & $2.13 \mathrm{E}-05$ \\
\hline 574983 & 8.20 & $6.69 \mathrm{E}-01$ & $2.95 \mathrm{E}+00$ & $9.40 \mathrm{E}+00$ & $7.69 \mathrm{E}-04$ & $4.72 \mathrm{E}-04$ & $3.48 \mathrm{E}+00$ & $5.68 \mathrm{E}+00$ & $1.59 \mathrm{E}+00$ & $1.12 \mathrm{E}-03$ & $2.13 \mathrm{E}-05$ \\
\hline 574984 & 8.20 & $6.69 \mathrm{E}-01$ & $2.95 \mathrm{E}+00$ & $9.40 \mathrm{E}+00$ & $7.67 \mathrm{E}-04$ & $4.71 \mathrm{E}-04$ & $3.48 \mathrm{E}+00$ & $5.68 \mathrm{E}+00$ & $1.59 \mathrm{E}+00$ & $1.12 \mathrm{E}-03$ & $2.14 \mathrm{E}-05$ \\
\hline 574985 & 8.24 & $6.77 \mathrm{E}-01$ & $2.35 \mathrm{E}+00$ & $9.06 \mathrm{E}+00$ & $8.37 \mathrm{E}-04$ & $6.35 \mathrm{E}-04$ & $3.79 \mathrm{E}+00$ & $4.51 \mathrm{E}+00$ & $1.55 \mathrm{E}+00$ & $1.22 \mathrm{E}-03$ & $4.63 \mathrm{E}-05$ \\
\hline 574986 & 8.20 & $6.69 \mathrm{E}-01$ & $2.95 \mathrm{E}+00$ & $9.40 \mathrm{E}+00$ & $7.68 \mathrm{E}-04$ & $4.72 \mathrm{E}-04$ & $3.48 \mathrm{E}+00$ & $5.68 \mathrm{E}+00$ & $1.59 \mathrm{E}+00$ & $1.12 \mathrm{E}-03$ & $2.13 \mathrm{E}-05$ \\
\hline 574987 & 8.20 & $6.69 \mathrm{E}-01$ & $2.95 \mathrm{E}+00$ & $9.40 \mathrm{E}+00$ & $7.68 \mathrm{E}-04$ & $4.72 \mathrm{E}-04$ & $3.48 \mathrm{E}+00$ & $5.68 \mathrm{E}+00$ & $1.59 \mathrm{E}+00$ & $1.12 \mathrm{E}-03$ & $2.13 \mathrm{E}-05$ \\
\hline 574990 & 8.24 & $6.77 \mathrm{E}-01$ & $2.35 \mathrm{E}+00$ & $9.06 \mathrm{E}+00$ & $8.35 \mathrm{E}-04$ & $6.33 \mathrm{E}-04$ & $3.79 \mathrm{E}+00$ & $4.51 \mathrm{E}+00$ & $1.55 \mathrm{E}+00$ & $1.22 \mathrm{E}-03$ & $4.64 \mathrm{E}-05$ \\
\hline 574991 & 8.20 & $7.24 \mathrm{E}-01$ & $9.86 \mathrm{E}-01$ & $6.60 \mathrm{E}+00$ & $2.92 \mathrm{E}-03$ & $3.85 \mathrm{E}-03$ & $5.97 \mathrm{E}+00$ & 0 & $8.13 \mathrm{E}-01$ & $1.09 \mathrm{E}-03$ & $2.24 \mathrm{E}-04$ \\
\hline 574992 & 9.84 & $7.18 \mathrm{E}-01$ & $9.65 \mathrm{E}-01$ & $7.19 \mathrm{E}+00$ & $1.88 \mathrm{E}-06$ & $3.58 \mathrm{E}-06$ & $5.60 \mathrm{E}+00$ & 0 & $7.85 \mathrm{E}-01$ & $5.30 \mathrm{E}-02$ & $4.52 \mathrm{E}-01$ \\
\hline
\end{tabular}

Source: Output DTN: SN0506T0502205.014, Dust_del.xIs.

NOTE: Units are given in molality.

Table 6.1-5. Compositions of Brines Formed by Dust Deliquescence after Ammonium Salt Decomposition: $\left(\mathrm{NH}_{4}\right)_{2} \mathrm{SO}_{4}$

\begin{tabular}{|c|c|c|c|c|c|c|c|c|c|c|c|}
\hline Sample \# & Pitzer pH & $\begin{array}{c}\text { Water } \\
\text { Activity }\end{array}$ & $\mathbf{K}^{+}$ & $\mathbf{N a}^{+}$ & $\mathbf{C a}^{2+}$ & $\mathbf{M g}^{2+}$ & $\mathbf{C l}^{-}$ & $\mathbf{N O}_{3}{ }^{-}$ & $\mathbf{S O}_{4}{ }^{2-}$ & $\mathbf{H C O}^{-}$ & $\mathbf{C O}_{3}{ }^{2-}$ \\
\hline 574979 & 10.70 & 0.640 & $1.07 \mathrm{E}+01$ & $1.51 \mathrm{E}+00$ & $1.17 \mathrm{E}-07$ & $2.85 \mathrm{E}-05$ & $1.31 \mathrm{E}+00$ & $1.63 \mathrm{E}-01$ & $1.78 \mathrm{E}-02$ & $1.58 \mathrm{E}+00$ & $4.51 \mathrm{E}+00$ \\
\hline 574982 & 7.96 & 0.647 & $2.75 \mathrm{E}+00$ & $1.16 \mathrm{E}+01$ & $1.13 \mathrm{E}-03$ & $2.78 \mathrm{E}-04$ & $2.19 \mathrm{E}+00$ & $9.93 \mathrm{E}+00$ & $1.10 \mathrm{E}+00$ & $6.35 \mathrm{E}-04$ & $1.34 \mathrm{E}-06$ \\
\hline 574983 & 7.96 & 0.647 & $2.75 \mathrm{E}+00$ & $1.16 \mathrm{E}+01$ & $1.13 \mathrm{E}-03$ & $2.78 \mathrm{E}-04$ & $2.19 \mathrm{E}+00$ & $9.93 \mathrm{E}+00$ & $1.10 \mathrm{E}+00$ & $6.35 \mathrm{E}-04$ & $1.34 \mathrm{E}-06$ \\
\hline 574984 & 8.20 & 0.669 & $2.95 \mathrm{E}+00$ & $9.40 \mathrm{E}+00$ & $7.67 \mathrm{E}-04$ & $4.71 \mathrm{E}-04$ & $3.48 \mathrm{E}+00$ & $5.68 \mathrm{E}+00$ & $1.59 \mathrm{E}+00$ & $1.12 \mathrm{E}-03$ & $2.14 \mathrm{E}-05$ \\
\hline 574985 & 8.20 & 0.669 & $2.95 \mathrm{E}+00$ & $9.40 \mathrm{E}+00$ & $7.68 \mathrm{E}-04$ & $4.72 \mathrm{E}-04$ & $3.48 \mathrm{E}+00$ & $5.68 \mathrm{E}+00$ & $1.59 \mathrm{E}+00$ & $1.12 \mathrm{E}-03$ & $2.13 \mathrm{E}-05$ \\
\hline 574986 & 8.20 & 0.669 & $2.95 \mathrm{E}+00$ & $9.40 \mathrm{E}+00$ & $7.68 \mathrm{E}-04$ & $4.72 \mathrm{E}-04$ & $3.48 \mathrm{E}+00$ & $5.68 \mathrm{E}+00$ & $1.59 \mathrm{E}+00$ & $1.12 \mathrm{E}-03$ & $2.13 \mathrm{E}-05$ \\
\hline 574987 & 8.20 & 0.669 & $2.95 \mathrm{E}+00$ & $9.40 \mathrm{E}+00$ & $7.68 \mathrm{E}-04$ & $4.72 \mathrm{E}-04$ & $3.48 \mathrm{E}+00$ & $5.68 \mathrm{E}+00$ & $1.59 \mathrm{E}+00$ & $1.12 \mathrm{E}-03$ & $2.13 \mathrm{E}-05$ \\
\hline 574990 & 8.20 & 0.669 & $2.95 \mathrm{E}+00$ & $9.40 \mathrm{E}+00$ & $7.67 \mathrm{E}-04$ & $4.71 \mathrm{E}-04$ & $3.48 \mathrm{E}+00$ & $5.68 \mathrm{E}+00$ & $1.59 \mathrm{E}+00$ & $1.12 \mathrm{E}-03$ & $2.14 \mathrm{E}-05$ \\
\hline 574991 & 9.95 & 0.668 & $2.77 \mathrm{E}+00$ & $9.36 \mathrm{E}+00$ & $2.64 \mathrm{E}-07$ & $1.89 \mathrm{E}-07$ & $3.53 \mathrm{E}+00$ & $5.34 \mathrm{E}+00$ & $1.51 \mathrm{E}+00$ & $6.36 \mathrm{E}-02$ & $8.11 \mathrm{E}-02$ \\
\hline 574992 & 9.95 & 0.668 & $2.77 \mathrm{E}+00$ & $9.35 \mathrm{E}+00$ & $2.64 \mathrm{E}-07$ & $1.89 \mathrm{E}-07$ & $3.53 \mathrm{E}+00$ & $5.33 \mathrm{E}+00$ & $1.51 \mathrm{E}+00$ & $6.36 \mathrm{E}-02$ & $8.12 \mathrm{E}-02$ \\
\hline
\end{tabular}

Source: Output DTN: SN0506T0502205.014, Dust_del.xls.

NOTE: Units are given in molality. 


\subsubsection{Composition of Atmospheric Aerosols}

A literature review has been carried out to evaluate the composition of atmospheric aerosols that could potentially be deposited on the waste package during ventilation.

Atmospheric aerosols are defined as the condensed-phase particulates dispersed in the atmosphere. Atmospheric aerosols are generally considered to range in size from several nanometers to tens of micrometers in diameter. The particulates involved include solids, liquid solutions ranging from extremely concentrated brines to dilute solutions, and mixtures of solids and liquids. For this review, the main concern is the nature of the aerosols present in the lower portion of the Earth's atmosphere (specifically the lower tropospheric boundary layer). These particles have a number of natural sources, such as windblown surface soils/dust, sea spray, volcanic emissions, biosphere emissions, and the condensation of atmospheric gases. In addition, a significant fraction of the modern aerosol loading of the atmosphere results from anthropogenic activities such as fuel combustion. Common practice distinguishes between primary aerosols, which are particles injected directly into the atmosphere, and secondary aerosols, which are formed directly in the atmosphere by gas-solid or gas-liquid reactions. Common usage also distinguishes between "fine" ( $<2.5$ micrometer diameter) and "coarse" ( $>2.5$ micrometer diameter) particles. The fine fraction is often further subdivided into a "nuclei fraction" or mode ( $>0.1$ micrometer diameter), and an "accumulation fraction" or mode ( 0.1 to 2.5 micrometer diameter). The fine- and coarse-particle fractions, in general, have different origins, transformation mechanisms, chemical properties, and removal mechanisms from the atmosphere (Seinfeld 1986 [DIRS 102180], pp. 24 and 25). Table 6.1-6 summarizes the gross differences among these different size fractions.

Table 6.1-6. Generalized Aerosol Particle Properties as a Function of Size

\begin{tabular}{|c|c|c|c|}
\hline & \multicolumn{2}{|c|}{ Fine particles } & \multirow{2}{*}{$\begin{array}{l}\text { Coarse particles } \\
\text { (>2.5 micrometers) }\end{array}$} \\
\hline & $\begin{array}{c}\text { Nuclei mode } \\
\text { (<0.1 micrometers) }\end{array}$ & $\begin{array}{c}\text { Accumulation mode } \\
\text { (0.1 to } 2.5 \text { micrometers) }\end{array}$ & \\
\hline Origin & $\begin{array}{l}\text { Secondary - mostly } \\
\text { condensation of vapors, } \\
\text { and reaction of gases } \\
\text { on solids }\end{array}$ & $\begin{array}{l}\text { Secondary - mostly aggregation } \\
\text { of nuclei mode particles and } \\
\text { continued condensation } \\
\text { processes }\end{array}$ & $\begin{array}{l}\text { Mostly primary via } \\
\text { mechanical processes }\end{array}$ \\
\hline Composition & $\begin{array}{l}\text { Dominated by sulfates, } \\
\text { nitrates }\end{array}$ & Mixed & Wind-blown dust, sea salt \\
\hline $\begin{array}{l}\text { Dominant } \\
\text { Removal } \\
\text { mechanism }\end{array}$ & Coagulation & Rain-out/wash-out & Sedimentation \\
\hline Abundance & $\begin{array}{l}\text { Dominates particle } \\
\text { number }\end{array}$ & $\begin{array}{l}\text { Usually dominates particulate } \\
\text { surface area; significant fraction } \\
\text { of particulate mass }\end{array}$ & $\begin{array}{l}\text { Dominates particulate } \\
\text { mass }\end{array}$ \\
\hline $\begin{array}{l}\text { Hygroscopic } \\
\text { behavior }\end{array}$ & Hygroscopic & Generally hygroscopic & $\begin{array}{l}\text { Relatively nonhygroscopic } \\
\text { (except over oceans) }\end{array}$ \\
\hline $\begin{array}{l}\text { Atmospheric } \\
\text { residence time }\end{array}$ & Relatively short & Relatively long & Relatively short \\
\hline
\end{tabular}

Source: Seinfeld 1986 [DIRS 102180], Section 1.3. 
The chemical and physical properties of aerosol particles vary globally and with elevation in the atmosphere. Aerosols in the atmosphere over or near the oceans contain a large proportion of sea-spray-derived salt and sulfates derived by the oxidation of dimethyl sulfide $\left(\mathrm{CH}_{3} \mathrm{SCH}_{3}\right)$ emitted by marine plankton. The aerosols over continental landmasses generally contain a larger proportion of terrestrial dusts/soil particles, particles derived from reactions of sea salt with atmospheric gases, and particles (both primary and secondary) that have anthropogenic origins (Seinfeld 1986 [DIRS 102180], pp. 24 and 25).

Because of the significance of the chloride concentration in aerosols to the possibility of deliquescence-induced corrosion of waste packages at Yucca Mountain, it is important to note that although the soluble or "salt" fraction of marine aerosols contains a significant amount of chloride (as might be expected, as sea salt is approximately $55 \%$ by weight $\mathrm{Cl}$ ), chloride is generally a minor constituent of continental aerosols. Even over the oceans, the composition of soluble aerosols has long been recognized to be deficient in chloride relative to sea salt (e.g., Hitchcock et al. 1980 [DIRS 172824]), implying the presence of a mechanism for the removal of chloride (or chlorine) from atmospheric particles. This is generally attributed to reactions of strong inorganic acids with sea salt, such as:

$$
\begin{gathered}
\mathrm{NaCl}(\mathrm{s})+\mathrm{HNO}_{3} \rightarrow \mathrm{NaNO}_{3}(\mathrm{~s})+\mathrm{HCl} \\
2 \mathrm{NaCl}(\mathrm{s})+\mathrm{H}_{2} \mathrm{SO}_{4} \rightarrow \mathrm{Na}_{2} \mathrm{SO}_{4}(\mathrm{~s})+2 \mathrm{HCl}
\end{gathered}
$$

In addition, there are a number of photochemically mediated reactions such as:

$$
\begin{gathered}
\mathrm{N}_{2} \mathrm{O}_{5}+\mathrm{NaCl}(\mathrm{s}) \rightarrow \mathrm{NaNO}_{3}(\mathrm{~s})+\mathrm{ClNO}_{2} \\
2 \mathrm{NO}_{2}\left(\text { or } \mathrm{N}_{2} \mathrm{O}_{4}\right)+\mathrm{NaCl}(\mathrm{s}) \rightarrow \mathrm{NaNO}_{3}(\mathrm{~s})+\mathrm{ClNO} \\
\mathrm{ClONO}_{2}+\mathrm{NaCl}(\mathrm{s}) \rightarrow \mathrm{NaNO}_{3}(\mathrm{~s})+\mathrm{Cl}_{2}
\end{gathered}
$$

that can transfer chloride from the solid to the gas phase. Rossi (2003 [DIRS 172822]) provides a comprehensive review of these and other heterogeneous reactions relevant to the processing of atmospheric aerosols. The relative importance of these various removal mechanisms is a topic of current research in the atmospheric chemistry community. From this discussion, the chloride concentrations in "fine" $(<2.5$ micrometer diameter) atmospheric aerosols in Nevada are, and will continue to be, low relative to sulfate and nitrate. The presence of chloride as a major component of the soluble salts in dust deposited on waste packages in the repository thus depends on windblown dust, such as that which could derive from local sources such as Death Valley or Owens Valley, and on favorable meteorological conditions. Because rain-out data on atmospheric dust compositions (Table 4.1-8) indicate that they are chloride-poor, windblown dust appears to have limited impact on the soluble salt loads of atmospheric dust at Yucca Mountain.

Nitrate and sulfate salts typically dominate the soluble fraction of atmospheric aerosols over continental landmasses, with the most common cations being ammonium and sodium (Seinfeld 1986 [DIRS 102180]; Malm et al. 2003 [DIRS 173674]; Rossi 2003 [DIRS 172822]; Malm et al. 2004 [DIRS 173673]). Ammonia is the third most abundant nitrogen-containing compound in the atmosphere, after $\mathrm{N}_{2}$ and $\mathrm{N}_{2} \mathrm{O}$, and is the most abundant basic gas in the atmosphere (Seinfeld 1986 [DIRS 102180]). Currently, most atmospheric ammonia is anthropogenic in origin, with the single largest global source being the hydrolysis of urea present 
in livestock wastes. The second major anthropogenic source is offgassing of ammonia from fertilizers used in agriculture. Other significant anthropogenic sources include biomass burning, human wastes, chemical and industrial processes, and fossil fuel combustion (Seinfeld 1986 [DIRS 102180]; Aneja et al. 2001 [DIRS 173675]; Anderson et al. 2003 [DIRS 173678]). The primary natural sources are oceanic emissions and emissions from soil and vegetation (Seinfeld 1986 [DIRS 102180]; Aneja et al. 2001 [DIRS 173675]; Anderson et al. 2003 [DIRS 173678]). Like ammonia, atmospheric nitrate and sulfate currently have major anthropogenic sources, but unlike ammonia, their anthropogenic emissions are decreasing, at least in the U.S., owing to pollution prevention programs.

Atmospheric ammonia reacts readily with acid gases in the atmosphere to form solid salts such as $\left(\mathrm{NH}_{4}\right)_{2} \mathrm{SO}_{4},\left(\mathrm{NH}_{4}\right) \mathrm{HSO}_{4}$, and $\mathrm{NH}_{4} \mathrm{NO}_{3}$ (Seinfeld 1986 [DIRS 102180]; Rossi 2003 [DIRS 172822]). As a general rule, ammonia combines preferentially with sulfuric acid rather than nitric acid. In environments of low $\mathrm{NH}_{3}$ availability, sulfate exists as $\mathrm{H}_{2} \mathrm{SO}_{4}$. With increasing $\mathrm{NH}_{3}$, the $\mathrm{H}_{2} \mathrm{SO}_{4}$ is converted first to $\left(\mathrm{NH}_{4}\right) \mathrm{HSO}_{4}$, then to $\left(\mathrm{NH}_{4}\right)_{2} \mathrm{SO}_{4}$. Some conversion of $\mathrm{HNO}_{3}$ to $\mathrm{NH}_{4} \mathrm{NO}_{3}$ occurs simultaneously with conversion of $\left(\mathrm{NH}_{4}\right) \mathrm{HSO}_{4}$ to $\left(\mathrm{NH}_{4}\right)_{2} \mathrm{SO}_{4}$, but complete neutralization of nitric acid only occurs if there is ammonia in excess of the amount required to completely convert $\mathrm{H}_{2} \mathrm{SO}_{4}$ to $\left(\mathrm{NH}_{4}\right)_{2} \mathrm{SO}_{4}$ (Seinfeld 1986 [DIRS 102180]).

Because the ammonia originates almost entirely from the surface, the abundances of ammonium salts are higher in the lower troposphere, are becoming less abundant in the upper troposphere, and are nearly absent in the stratosphere (Rossi 2003 [DIRS 172822]). Near the surface, $\left(\mathrm{NH}_{4}\right)_{2} \mathrm{SO}_{4}$ and $\mathrm{NH}_{4} \mathrm{NO}_{3}$ dominate. At higher altitudes, the more acidic $\left(\mathrm{NH}_{4}\right) \mathrm{HSO}_{4}$ becomes important, while in the stratosphere, sulfate and nitrate exists as sulfuric and nitric acids.

As indicated in Table 6.1-6, fine atmospheric particles (diameters less than 2.5 microns) primarily originate from gas condensation reactions such as those involving ammonia and sulfuric and nitric acids. Thus, one would expect most of the $\left(\mathrm{NH}_{4}\right)_{2} \mathrm{SO}_{4}$ and $\mathrm{NH}_{4} \mathrm{NO}_{3}$ to be present in the fine fraction. In contrast, the coarse fraction should contain particles originating from reactions on primary particles of sea salt and should therefore be dominated by sodium salts of nitrate and/or sulfate. Available studies in both urban (Wall et al. 1988 [DIRS 173676]) and non-urban (Malm et al. 2003 [DIRS 173674]) areas tend to bear out this prediction.

A number of recent review papers provide excellent summaries of the various analytical methods that have been used and are being developed for the analysis of atmospheric particulates (Chow 1995 [DIRS 172846]; McMurry 2000 [DIRS 172818]; Sipin et al. 2003 [DIRS 172823]). Most existing data on the chemical compositions of atmospheric aerosols were derived from the analysis of bulk samples of aerosols collected over some period of time (e.g., by sampling of particles collected on filters through which air had been drawn). The composition of the soluble fraction is generally determined by washing the bulk sample and analysis of the resulting solution. This process destroys any information on the actual phase makeup of the particles as they existed in the atmosphere or on the filters, and the identity of the soluble phases that were present in the original sample must be inferred from basic chemical knowledge. In addition, there are well known problems with the loss of volatile nitrate species from such filters during the sampling process and during handling and storage prior to analysis (Zhang and McMurry 1992 [DIRS 172821]), which complicate the interpretation of filter samples. 
Nevertheless, such information forms the basis for most studies of the effects of atmospheric aerosols.

Another method for inferring the bulk chemical composition of the soluble fraction of atmospheric aerosols involves the measurement of the dissolved constituents in precipitation. This method relies on the fact that precipitation is effective at removing particulate material from the atmosphere, both by rain-out (condensation of water on particulate nuclei) and wash-out (scavenging of particulates by falling rain or snow). This method should be used with caution, however, as the removal processes can introduce a sampling bias because the effectiveness of rain-out and wash-out for removing particulate material depends on the size of the particulates. If the particulate composition varies as a function of particle size (as it normally does), then the composition of the precipitation will not necessarily reflect the composition of the aerosol as it existed in the air mass. In this report, equilibrium among soluble constituents of atmospheric dust is assumed based on airfall and precipitation data. This assumption is commonly used and is addressed in Sections 5.1 and 6.1.2.4.

Organic Material in Dust-It is likely that organic material will be present in repository dust. This material could originate both from repository construction operations (e.g., from machinery exhaust, or abrasion of solid organic materials used in equipment) and from atmospheric particles brought into the repository during the ventilation period. Quantification of the type and number of construction-related organic particles is not possible at this time; however, some information is available on the abundance of organic material in atmospheric particulates. Over the past decade, it has become clear that a significant fraction of the fine particulate material in the atmosphere consists of organic carbon compounds. For example, Malm et al. (2004 [DIRS 173673]) report that at the Interagency Monitoring of Protected Visual Environments (IMPROVE) sites in Death Valley, CA, and Great Basin, NV, approximately 20\% of the atmospheric fine particle ( $<2.5$ micron) mass consists of organic material, and that, in general, 20 to $30 \%$ of the atmospheric fine particle mass in the southwestern U.S. consists of organic material. Organic particulates can originate as primary emissions (both natural and anthropogenic), as well as form by reactions within the atmosphere (Kanakidou et al. 2005 [DIRS 173969]). Atmospheric organic material is present as wholly organic particles, and as internally mixed organic/inorganic particles. Consideration of the volatility of typical constituents of tropospheric organic matter suggests that thermodynamic equilibrium between aerosol particles should be achieved, and that mixed particles should be the rule rather than the exception (Marcolli et al. 2004 [DIRS 173972], Abstract).

The chemistry of atmospheric particulate organic matter is very complex, and remains poorly understood. Typically, studies of the concentrations of individual organic molecules in atmospheric particles are only able to identify a small fraction of the organic material present (Saxena et al. 1995 [DIRS 173976]; McMurry 2000 [DIRS 172818]; Kanakidou et al. 2005 [DIRS 173969]). It is known that the organic fraction contains both hydrophobic, sparingly soluble compounds (high molecular weight alkanes, alkanoic acids, alkenoic acids, aldehydes, and ketones) and soluble hydrophilic compounds (low molecular weight carboxylic acids, dicarboxylic acids, alcohols, aldehydes, and ketones) (Saxena et al. 1995 [DIRS 173976]). In general, addition of a soluble organic compound to an inorganic salt system will lower the relative humidity at which the system will deliquesce (Marcolli et al. 2004 [DIRS 173971]). This is analogous to the lowering of the deliquescence relative humidity in mixtures of inorganic 
salts discussed in Appendix E. Conversely, addition of a hydrophobic organic compound would be expected to inhibit the uptake of water by an inorganic particle (Saxena et al. 1995 [DIRS 173976], Abstract). Field observations in different locations provide evidence for both types of behavior (Saxena et al. 1995 [DIRS 173976]), presumably reflecting the geographically varying composition of the organic fraction of atmospheric aerosols.

In the case of the repository, an analysis of the effects of organics in dust is further complicated by the fact that the composition of the organic fraction of the dust that settles on waste packages will be modified by the elevated temperatures prevailing during the early postclosure period. Some organic species will be volatilized from the dust and recondense in cooler regions of the repository. Other species would be expected to oxidize or otherwise decompose. Finally, some of the original compounds may react with one another, forming new compounds and altering the abundances of the original species. Overall, it is reasonable to expect that the net effect of this thermal treatment would be to reduce the absolute amount of organic material present in the dust layer when the temperature and relative humidity in the repository reached the range at which deliquescence could occur.

Modeling the effects of organic compounds on the deliquescence behavior of soluble particulates is severely hampered by the large number of organic species present, by volatilization and thermal decomposition that will compositionally modify and reduce the organic load over time, and by the paucity of data on organic-inorganic interactions (Ming and Russell 2002 [DIRS 173974], p. 1332). The measurements that exist were obtained at temperatures relevant to atmospheric conditions (i.e., low temperatures), and no data exist for the elevated temperatures relevant to the repository (Cruz and Pandis 2000 [DIRS 173968], Section 2; Lightstone et al. 2000 [DIRS 173970], Section 2; Brooks et al. 2004 [DIRS 173966], Section 2; Parsons et al. 2004 [DIRS 173975], Section 2). In general, these studies found that addition of soluble organic compounds to single inorganic salt systems lowered the relative humidity by 0 to $10 \%$ at ambient temperatures. At the higher temperatures considered in this report, the mixed salt systems expected to be present in repository dust deliquesce at quite low relative humidities, and it is reasonable to expect that the addition of organic components would have only a modest effect on the deliquescence behavior.

In the analyses presented here, the effect of organic materials on conditions of dust deliquescence and brine composition is not considered, but literature data at ambient temperatures suggest that it is small.

\subsubsection{Summary}

Deliquescent brines will form at elevated temperature (e.g., $>120^{\circ} \mathrm{C}$ ) from the deliquescence of multiple-salt assemblages. (The amount of brine produced in this manner from dust deliquescence is small, as discussed in Section 6.4.1; corrosivity is discussed in Section 6.3.)

Boiling points of saturated salt solutions represent the maximum temperature of deliquescence at a given pressure (i.e., $1 \mathrm{~atm}$ at sea level, or approximately $0.90 \mathrm{~atm}$ at repository conditions). For most single-salt solutions (nitrates, chlorides, and carbonates) boiling points at one atmosphere are limited to temperatures below approximately $120^{\circ} \mathrm{C}$ (Table 6.2-1). Divalent-cation salts magnesium and calcium chloride, will deliquesce or boil at higher 
temperatures, but are unstable, converting rapidly to non-deliquescent oxychloride phases (Section 6.2.1). Multi-salt mixtures deliquesce, or mixed-salt brines boil, at higher temperatures than the individual salt components. The boiling points for important salt assemblages predicted to occur on the waste package surface have been investigated experimentally. The two-salt mixture, $\mathrm{NaCl}+\mathrm{KNO}_{3}$, boils at a maximum temperature of $134^{\circ} \mathrm{C}$, and the three-salt mixture, $\mathrm{NaCl}+\mathrm{KNO}_{3}+\mathrm{NaNO}_{3}$, at over $190^{\circ} \mathrm{C}$. By inference the four-salt mixture, $\mathrm{NaCl}+\mathrm{KNO}_{3}+\mathrm{NaNO}_{3}+\mathrm{Ca}\left(\mathrm{NO}_{3}\right)_{2}$, must also deliquesce at temperatures above $190^{\circ} \mathrm{C}$.

Ammonium salts are highly deliquescent, and constitute a significant fraction of the salt load in atmospheric aerosols. They will be present in ventilation-deposited dust on the waste package surface, but will decompose readily into ammonia and mineral acids, and will not persist long enough to contribute to the deliquescent mineral assemblages during the repository cooldown period.

Uncertainty Discussion - Prediction of boiling (dryout) temperatures for multi-salt assemblages depends on experimental data, particularly at temperatures greater than $140^{\circ} \mathrm{C}$, which is the limit of the range of validation for the IDPS model. Boiling-point measurements at temperatures greater than $140^{\circ} \mathrm{C}$ have been performed for only a few multi-salt assemblages. The complete thermal decomposition of ammonium sulfate is subject to uncertainty, but there is no significant, adverse consequence to the nitrate-chloride ratio of deliquescent brine (Section 6.3) or the bounding volume of brine (Section 6.4.1), if ammonium sulfate persists. The effect of organic materials on conditions of dust deliquescence and brine composition is not considered, but literature data at ambient temperatures suggest that it is small.

\subsection{IF BRINES FORM AT ELEVATED TEMPERATURE, WILL THEY PERSIST?}

Modeling results predict that deliquescent brines are likely to form at temperatures below $150^{\circ} \mathrm{C}$. Experimental work indicates that brines can form at even higher temperatures, approaching $200^{\circ} \mathrm{C}$. Once formed, however, such brines may not exist stably for extended periods of time. This section presents the results of simulations and experiments that show the chemical changes caused by acid degassing.

Thermodynamic analysis results presented in this section show that deliquescent brines predicted to form on the waste package surface are not thermodynamically stable at the low acid gas fugacities expected to be maintained by rapid gas exchange in the drift environment. All will undergo acid degassing to some extent, which will change their compositions and if taken to completion will result in precipitation of less-deliquescent salts and, eventually, dryout. One assemblage (Assemblage $\mathrm{C}$ ) contains $\mathrm{Ca}$ and will be buffered to a near-neutral $\mathrm{pH}$ by calcite precipitation (Table 6.2-2). Such a low $\mathrm{pH}$ promotes acid degassing, and although hightemperature simulations are not yet feasible it is likely that this assemblage will dry out. For other salt assemblages, however, lower acid-gas vapor pressures mean that degassing is less likely to go to completion, and brines are not likely to dry out. 
Aqueous acid species are present in all waters in some concentration, and form by protonation of anionic species (e.g., $\mathrm{Cl}^{-}, \mathrm{NO}_{3}{ }^{-}$, and $\mathrm{SO}_{4}{ }^{2-}$ ). For example, in a water containing chloride, the following reaction will take place:

$$
\mathrm{H}^{+}+\mathrm{Cl}^{-} \Leftrightarrow \mathrm{HCl}(\mathrm{aq})
$$

Formation of the aqueous acid species is favored by high anion concentrations (in this example, chloride) and high $\mathrm{H}^{+}$concentrations (low $\mathrm{pH}$ ). There is also an equilibrium between the aqueous acid species and the partial pressure of the acid species in the atmosphere above the solution:

$$
\mathrm{HCl}(\mathrm{aq}) \Leftrightarrow \mathrm{HCl}(\mathrm{g})
$$

Therefore, low $\mathrm{pH}$ and high anion concentrations also cause higher equilibrium partial pressures of acid gas in the atmosphere above the solution.

The dissociation reactions for both $\mathrm{HNO}_{3}$ and $\mathrm{HCl}$ are strongly temperature-dependent, with the undissociated acid species becoming more stable with increasing temperature (see the $\log (K)$ temperature grid for these species in data0.ypf.R0 (DTN: SN0302T0510102.002 [DIRS 162572])). Thus, elevated temperatures also favor higher partial pressures of acid gas species above the solution.

However, it is also clear that degassing of acid gases, in the absence of a buffering reaction, will deplete $\mathrm{H}^{+}$from solution, increasing the $\mathrm{pH}$ of the remaining solution and lowering the equilibrium partial pressure of the acid gas. If it is assumed that the rate of acid degassing is a function of the difference between the equilibrium partial pressure of the degassing species and the actual partial pressure of that species in the environment, then lower partial pressures will generally be associated with slower rates of degassing. Conversely, chemical reactions that buffer the $\mathrm{pH}$ at neutral or acid values will mitigate the effects of acid loss and keep the equilibrium partial pressures of acid gases, and potentially rates of degassing, high.

\subsubsection{Thermogravimetric Studies of Acid-Gas Volatilization}

For some salts, the effects of degassing have been demonstrated experimentally. In thermogravimetric experiments, an Alloy 22 sample surface was coated with an aerosol film of calcium chloride, allowed to deliquesce, and then aged at approximately $22.5 \% \mathrm{RH}$ and temperatures of 100,125 , and $150^{\circ} \mathrm{C}$. Sample weight loss due to acid degassing was observed at $125^{\circ} \mathrm{C}$ and $150^{\circ} \mathrm{C}$, and the samples dried out (BSC 2004 [DIRS 169984], Section 6.4.4.6.6.1). At $100^{\circ} \mathrm{C}$ there was no observed weight loss following the initial increase due to deliquescence, and the specimen surface remained wet and visually unchanged. The precipitate for the $125^{\circ} \mathrm{C}$ and $150^{\circ} \mathrm{C}$ samples was identified by scanning electon microscope energy dispersive spectrometry (EDS) analysis as a calcium chloride hydroxide precipitate, and the reaction was coupled with the loss of chloride as $\mathrm{HCl}$ gas. Subsequent analyses indicated that the precipitates did not contain metal ions from Alloy 22, and no evidence of localized attack was observed.

In the experiments, the calcium chloride brines rapidly degassed to dryness at high temperatures because calcium chloride has a high solubility (corresponding to high chloride concentrations in solution) and because a calcium chloride hydroxide solid phase precipitated, buffering the $\mathrm{pH}$ 
and maintaining the partial pressure of $\mathrm{HCl}$ at a relatively high level. A combined precipitation and degassing reaction could be written (schematically, because the actual stoichiometry of the $\mathrm{Ca}(\mathrm{OH}, \mathrm{Cl})$ phase is not known):

$$
\mathrm{Ca}^{2+}+\mathrm{H}_{2} \mathrm{O}+2 \mathrm{Cl}^{-} \Leftrightarrow \mathrm{HCl}(\mathrm{g})+\mathrm{Ca}(\mathrm{OH}, \mathrm{Cl})(\mathrm{s})
$$

Because $\mathrm{H}^{+}$is neither consumed nor created in this reaction, the $\mathrm{pH}$ remains neutral and the partial pressure of acid gas above the solution remains high, allowing degassing to continue at a rapid rate.

The deliquescent assemblages of mostly monovalent salts that have been identified in tunnel dust (BSC 2004 [DIRS 161237]) are likely to be more stable than the divalent cation salt systems discussed above. First, the divalent cation salts (e.g., $\mathrm{Ca}$ and $\mathrm{Mg}$ chlorides and nitrates) are commonly more soluble than the monovalent salts, and at any given temperature generate a higher acid-gas partial pressure. In addition, monovalent chloride-hydroxide phases do not form, and monovalent hydroxides are highly soluble. Thus, there is no hydroxide-bearing precipitate to buffer the $\mathrm{pH}$ to near-neutral values and maintain high partial pressures of monovalent acid-gas species as degassing progresses. However, as described below, aqueous carbonate complexes and carbonate mineral precipitates will buffer the $\mathrm{pH}$ to higher values where the partial pressure of the acid-gas species, and hence the rate of degassing, is lower.

\subsubsection{Thermodynamic Analysis of Acid Degassing from Deliquescent Brines}

The potential effects of acid degassing were investigated using EQ3/6 V8.0 (BSC 2003 [DIRS 162228]) and the Pitzer database data0.ypf.R0 (DTN: SN0302T0510102.002 [DIRS 162572]). This analysis makes use of the IDPS model (BSC 2004 [DIRS 169863]), with alteration of the gas-phase boundary condition to remove acid-gas species in stepwise equilibrium. Single and multi-salt assemblages were examined to develop an understanding of brine evolution with degassing, and the key salt assemblages described previously were used to represent the deliquescent constituents of dust. Within the drift, temperature-RH conditions are expected to follow the curves presented in Figure 6-2, and in-drift temperatures and RH conditions are relatively stable for decades to hundreds of years. Predicted in-drift $\mathrm{CO}_{2}$ partial pressures also change only slowly with time after the boiling period ends (BSC 2004 [DIRS 169860], Figure 6.7-6). Thus, when analyzing deliquescence and acid degassing, it is a reasonable assumption that conditions of constant temperature, $\mathrm{RH}$, and $p \mathrm{CO}_{2}$ will apply. Note that the actual process of acid degassing does not require this assumption, nor is it assumed that this condition applies to the repository; it is a simplification that allows evaluation of the effects of acid degassing using an equilibrium approach. The EQ3/6 results presented here assume no kinetic limitations on acid degassing, and provide compositional vectors indicating the direction of change in brine chemistry due to acid degassing. The conclusions reached in this section are largely independent of the assumption of constant temperature, $\mathrm{RH}$, and $p \mathrm{CO}_{2}$. An analysis of the kinetics of acid degassing is given in Section 6.2.3.

To analyze the effects of acid degassing, the compositions of saturated solutions of single salts and salt assemblages were calculated at different temperatures and fixed fugacities of $\mathrm{CO}_{2}$, using EQ3. These results were then used as starting values for EQ6 reaction path runs, in which acid gases were titrated out of the brines, while holding constant the activity of water (equivalent to 
the $\mathrm{RH}), p \mathrm{CO}_{2}$, and temperature. For single-salt systems, this involves removing a fixed number of moles of the acid-gas phase from the system at each step and recalculating the equilibrium system composition. For systems containing multiple anions (e.g. chloride and nitrate), the two acids are degassed simultaneously, in proportion to their partial pressure in the gas phase initially in equilibrium with the brine. As degassing occurs, the relative proportion of the acid-gas species in the gas phase changes. If this change is greater than a factor of 5 to 10 , the run is periodically stopped, the relative rate of removal of $\mathrm{HNO}_{3}(\mathrm{~g})$ and $\mathrm{HCl}(\mathrm{g})$ adjusted to match the new ratio of these species in the gas phase. This discretization of the relative removal rate is necessary because there is no method to implement a continuous change in the relative rates in EQ3/6. It results in minor inflections in the predicted solution and gas-phase concentrations, but does not affect general trends in the data.

Four salts that are potentially important components of the dust were examined with single-salt degassing runs: $\mathrm{NaCl}, \mathrm{NaNO}_{3}, \mathrm{KCl}$, and $\mathrm{KNO}_{3}$. In these runs, charge balancing was done on $\mathrm{K}^{+}$ or $\mathrm{Na}^{+}$while holding the $\mathrm{pH}$ constant. This saves a step in the analysis, but results in a slightly different $\mathrm{pH}$ evolution path than if $\mathrm{H}^{+}$were used for charge balancing. However, only the end-point composition resulting from degassing is of interest for the single-salt systems, and that is the same regardless of the method used.

Degassing of brines representing the two-salt assemblage $\mathrm{NaCl}-\mathrm{KNO}_{3}$ (Assemblage A) was also analyzed, as were two other two-salt assemblages, $\mathrm{NaCl}-\mathrm{NaNO}_{3}$ and $\mathrm{NaNO}_{3}-\mathrm{KNO}_{3}$. The simulations representing the latter two assemblages were run for comparison purposes, and are included in the output DTN, but are not discussed here. Finally, degassing of the three- and four-salt assemblages, $\mathrm{NaCl}-\mathrm{KNO}_{3}-\mathrm{NaNO}_{3}$ (Assemblage $\mathrm{B}$ ), and $\mathrm{NaCl}-\mathrm{KNO}_{3}-\mathrm{NaNO}_{3}-$ $\mathrm{Ca}\left(\mathrm{NO}_{3}\right)_{2}$ (Assemblage $\mathrm{C}$ ), were simulated. Because the initial $\mathrm{pH}$ and the evolution of the $\mathrm{pH}$ with time are important results for these calculations, charge balancing was done on $\mathrm{H}^{+}$.

Brine evolution was analyzed at two $\mathrm{pCO}_{2}$ conditions, $10^{-2}$ bar and $10^{-3.5}$ bar, and for several cases, under $\mathrm{CO}_{2}$-free conditions to establish a base case. Total pressure was set to the reference pressure curve in data0.ypf.R0 (DTN: SN0302T0510102.002 [DIRS 162572]), which corresponds to a pressure of 1.0132 bar below $100^{\circ} \mathrm{C}$, and the steam saturation curve for pure water above that temperature. As is appropriate for these concentrated solutions, the "Pitzer $\mathrm{pH}$ " was used in the simulations and is reported throughout this document. The "NBS pH" is appropriate for dilute solutions but is not used here because the activity-composition convention on which it is based is not accurate for high ionic strength solutions. It should be noted that these calculations do not consider reaction kinetics; limitations on the rate of degassing are evaluated later in this report.

\subsubsection{Single-Salt Systems}

Four different single-salt systems were evaluated: $\mathrm{NaCl}, \mathrm{NaNO}_{3}, \mathrm{KCl}$, and $\mathrm{KNO}_{3}$. Degassing an acid component $\left(\mathrm{HCl}\right.$ or $\left.\mathrm{HNO}_{3}\right)$ has differing results depending upon the cation present, the $\mathrm{CO}_{2}$, and the temperature. These results are shown in Table 6.2-1. Degassing of all brines causes increased $\mathrm{pH}$, which is associated with a decrease in corrosion potential of Alloy 22 (BSC 2004 [DIRS 169984], Figure 6-50). Sodium-bearing brines reach an invariant composition when a carbonate phase precipitates, and further degassing results in dryout of the brine. The reactions of interest are: 


$$
\begin{aligned}
2 \mathrm{Na}^{+}+2 \mathrm{Cl}^{-}+\mathrm{CO}_{2}(\mathrm{~g})+\mathrm{H}_{2} \mathrm{O} & =\mathrm{Na}_{2} \mathrm{CO}_{3}(\mathrm{~s})+2 \mathrm{HCl}(\mathrm{g}) \\
2 \mathrm{Na}^{+}+2 \mathrm{NO}_{3}{ }^{-}+\mathrm{CO}_{2}(\mathrm{~g})+\mathrm{H}_{2} \mathrm{O} & =\mathrm{Na}_{2} \mathrm{CO}_{3}(\mathrm{~s})+2 \mathrm{HNO}_{3}(\mathrm{~g})
\end{aligned}
$$

Once saturation is reached with respect to the Na-carbonate phase, the solution composition becomes invariant. The $\mathrm{pH}$ becomes fixed (no hydrogen ions are produced or consumed in the above reaction), and the salt components are removed stoichiometrically from the solution. The solution dries out because degassing and corresponding precipitation of Na-carbonate are removing ions from the solution, and the only way to maintain the same activity of water in the brine (necessary because these degassing simulations are run at fixed $\mathrm{RH}$ ) is to reduce the brine volume. Note that $\mathrm{CO}_{2}(\mathrm{~g})$ must be present; otherwise, the $\mathrm{pH}$ continues to rise and a $\mathrm{NaOH}$ brine forms. $\mathrm{NaOH}$ is more soluble, and more deliquescent, than $\mathrm{NaCl}$ or $\mathrm{NaNO}_{3}$, so the brine does not dry out.

Thus, in the Na-salt systems, the initial Na-salt is converted to a less-deliquescent Na-carbonate phase, the brine composition becomes invariant, and eventually the solution dries out. The $\mathrm{pH}$ of the invariant brine ranges from approximately 8 to 10 (Table 6.2-1) and does not show a clear trend with temperature, as it is dependent on the carbonate phase that forms. The Na-salt systems begin to dry out for these systems as soon as acid degassing starts, and do not dry out completely until the anion supplying the acid-gas component is exhausted.

Potassium nitrate and potassium chloride brines evolve to slightly higher $\mathrm{pH}$ (9.5 to 10.5). Potassium carbonate brines do not dry out because $\mathrm{K}_{2} \mathrm{CO}_{3}$ is highly soluble and more deliquescent over the temperature range examined than either $\mathrm{KNO}_{3}$ or $\mathrm{KCl}$. For both $\mathrm{Na}$ and $\mathrm{K}$ brines, even degassing of very small amounts of acid-less than $1 \%$ of the total-causes rapid increase in $\mathrm{pH}$, generally to values between 9 and 10.5 .

\subsubsection{Deliquescent Salt Assemblages from Dust Leachate Calculations}

The effects of acid degassing on the deliquescent salt assemblages identified in Environment on the Surfaces of the Drip Shield and Waste Package Outer Barrier (BSC 2004 [DIRS 161237]), and described previously as Assemblages A, B, and C, are analyzed in this section. Ideally, the behavior of these assemblages would be examined at high temperatures, corresponding to initial conditions of deliquescence. However, in some cases, numerical convergence was not achieved at the highest temperatures of deliquescence, so simulations were run over a range of temperatures to evaluate trends.

Results from these simulations are summarized in Table 6.2-2. When evaluating these results, it is important to recognize that these calculations include no kinetic limitation on degassing. In all cases, the brines dry out, evolving from a nitrate-chloride salt assemblage to a carbonate-bearing salt assemblage. This is usually a carbonate-nitrate assemblage, and complete dryout requires degassing of all chloride. The carbonate-bearing assemblages are less deliquescent than the initial salt assemblages, and if dryout is achieved, will deliquesce again as the repository cools and the relative humidity increases (but without chloride, which has been volatilized). 
Table 6.2-1. Evolution of Single-Salt Systems by Acid Degassing

\begin{tabular}{|c|c|c|c|c|c|}
\hline Beginning Salt Assemblage & $\mathrm{pCO}_{2}$ & $\mathrm{~T}\left({ }^{\circ} \mathrm{C}\right)$ & End-Point Mineralogy & Final $\mathrm{pH}^{\mathrm{a}}$ & Description \\
\hline \multirow{9}{*}{$\mathrm{NaCl}$} & 0 & 100 & $\mathrm{NaOH}$ brine & 13.16 & Evolves to stable, high-pH brine. \\
\hline & \multirow{4}{*}{$10^{-2}$} & 25 & Nahcolite & 8.44 & \multirow{4}{*}{$\begin{array}{l}\text { Invariant solution composition reached when carbonate } \\
\text { precipitates. Dryout occurs. }\end{array}$} \\
\hline & & 50 & Nahcolite & 8.85 & \\
\hline & & 100 & Natrite & 9.19 & \\
\hline & & $108.7^{b}$ & Natrite & 9.17 & \\
\hline & \multirow{4}{*}{$10^{-3.5}$} & 25 & Nahcolite & 9.91 & \multirow{4}{*}{$\begin{array}{l}\text { Invariant solution composition reached when carbonate } \\
\text { precipitates. Dryout occurs. }\end{array}$} \\
\hline & & 50 & Trona & 8.85 & \\
\hline & & 100 & Natrite & 9.94 & \\
\hline & & $108.7^{b}$ & Natrite & 9.93 & \\
\hline \multirow{9}{*}{$\mathrm{NaNO}_{3}$} & 0 & 100 & $\mathrm{NaOH}$ brine & 13.57 & Evolves to stable, high-pH brine. \\
\hline & \multirow{4}{*}{$10^{-2}$} & 25 & Nahcolite & 8.68 & \multirow{4}{*}{$\begin{array}{l}\text { Invariant solution composition reached when carbonate } \\
\text { precipitates. Dryout occurs. }\end{array}$} \\
\hline & & 50 & Nahcolite & 9.00 & \\
\hline & & 100 & Natrite & 9.17 & \\
\hline & & $120.6^{\mathrm{b}}$ & Thermonatrite & 9.39 & \\
\hline & \multirow{4}{*}{$10^{-3.5}$} & 25 & Nahcolite & 10.08 & \multirow{4}{*}{$\begin{array}{l}\text { Invariant solution composition reached when carbonate } \\
\text { precipitates. Dryout occurs. }\end{array}$} \\
\hline & & 50 & Trona & 10.18 & \\
\hline & & 100 & Natrite & 9.91 & \\
\hline & & $120.6^{\mathrm{b}}$ & Thermonatrite & 10.14 & \\
\hline \multirow{9}{*}{$\mathrm{KCl}$} & 0 & 100 & $\mathrm{KOH}$ brine & 13.07 & Evolves to stable, high-pH brine. ${ }^{c}$ \\
\hline & \multirow{4}{*}{$10^{-2}$} & 25 & K-carb/bicarb brine & 9.59 & \multirow[t]{4}{*}{ Evolves to stable K-carbonate/bicarbonate brine. } \\
\hline & & 50 & K-carb/bicarb brine & 9.63 & \\
\hline & & 100 & K-carb/bicarb brine & 9.76 & \\
\hline & & $108.6^{\mathrm{b}}$ & K-carb/bicarb brine & 9.78 & \\
\hline & \multirow{4}{*}{$10^{-3.5}$} & 25 & K-carb/bicarb brine & 10.41 & \multirow[t]{4}{*}{ Evolves to stable K-carbonate/bicarbonate brine. } \\
\hline & & 50 & K-carb/bicarb brine & 10.44 & \\
\hline & & 100 & K-carb/bicarb brine & 10.54 & \\
\hline & & $108.6^{\mathrm{b}}$ & K-carb/bicarb brine & 10.56 & \\
\hline
\end{tabular}




\begin{tabular}{|c|c|c|c|c|c|}
\hline Beginning Salt Assemblage & $\mathrm{pCO}_{2}$ & $\mathrm{~T}\left({ }^{\circ} \mathrm{C}\right)$ & End-Point Mineralogy & Final $\mathrm{pH}^{\mathrm{a}}$ & Description \\
\hline \multirow{4}{*}{$\mathrm{KNO}_{3}{ }^{\mathrm{d}}$} & \multirow{2}{*}{$10^{-2}$} & 25 & K-carb/bicarb brine & 9.38 & \multirow[t]{2}{*}{ Evolves to stable K-carbonate/bicarbonate brine. } \\
\hline & & 50 & K-carb/bicarb brine & 9.58 & \\
\hline & \multirow{2}{*}{$10^{-3.5}$} & 25 & K-carb/bicarb brine & 10.22 & \multirow[t]{2}{*}{ Evolves to stable K-carbonate/bicarbonate brine. } \\
\hline & & 50 & K-carb/bicarb brine & 10.38 & \\
\hline
\end{tabular}

Source: Output DTN: MO0506SPAEQ36F.002, directory "Degassing_of_Single_Salt_Systems" (see associated readme.doc file for specific file names).

a Pitzer $\mathrm{pH}$.

${ }^{\mathrm{b}}$ Boiling point of saturated solution at $1 \mathrm{~atm}$, see Table 4.1-19, used to represent the maximum temperature for existence of a saturated solution of the single salt, at repository conditions.

c This run ("ct100c0q" in the output DTN) failed to completely degas. There was still chlorine left. The pH value shown is for the last stable degassing step.

${ }^{d} \mathrm{KNO}_{3}$ degassing runs at elevated temperature failed, probably because $\mathrm{K}^{+}-\mathrm{NO}_{3}{ }^{-}, \mathrm{K}^{+}-\mathrm{CO}_{3}{ }^{2-}$, and $\mathrm{K}^{+}-\mathrm{HCO}_{3}{ }^{-}$Pitzer parameters are only available for $25^{\circ} \mathrm{C}$.

Although the dataO.ypf.RO database has been qualified to $140^{\circ} \mathrm{C}$ as part of the IDPS model (Section 4.1.1), the lack of high temperature data for these ion pair interactions causes nonconvergence in some cases.

NOTES: Mineral names and chemical formulas are as follows: halite $-\mathrm{NaCl}$; nahcolite $-\mathrm{NaHCO}_{3} ;$ trona $-\mathrm{Na}_{3} \mathrm{H}\left(\mathrm{CO}_{3}\right)_{2}: 2 \mathrm{H}_{2} \mathrm{O} ;$ natrite $-\mathrm{Na}_{2} \mathrm{CO}_{3}$; soda niter - $\mathrm{NaNO}_{3}$; niter $-\mathrm{KNO}_{3}$; sylvite $-\mathrm{KCl}$; calcite $-\mathrm{CaCO}_{3}$.

The extent of degassing is controlled by kinetics, and may not proceed to complete dryout, but a shift in pH requires relatively small extent of degassing. 


\begin{tabular}{|c|c|c|c|c|c|}
\hline $\begin{array}{l}\text { Beginning Salt } \\
\text { Assemblage }\end{array}$ & $\begin{array}{l}\log \\
\mathrm{pCO}_{2}\end{array}$ & $\mathrm{~T}\left({ }^{\circ} \mathrm{C}\right)$ & End-Point Mineralogy & $\begin{array}{c}\text { Final } \\
\mathrm{pH}^{\mathrm{a}}\end{array}$ & Description \\
\hline \multirow{7}{*}{$\mathrm{NaCl}-\mathrm{KNO}_{3}{ }^{\mathrm{C}}$} & \multirow{3}{*}{-2} & 25 & Nahcolite, niter, sylvite & 8.56 & $\begin{array}{l}\text { Nahcolite and niter precipitate first; an invariant solution composition } \\
\text { is reached when sylvite precipitates. Dryout occurs. }\end{array}$ \\
\hline & & 100 & Natrite, niter & 9.55 & Natrite and niter precipitate. Dryout occurs. \\
\hline & & $126^{b}$ & Natrite, niter & 9.55 & Natrite and niter precipitate. Dryout occurs. \\
\hline & \multirow{4}{*}{-3.5} & 25 & Nahcolite, niter, sylvite & 10.04 & $\begin{array}{l}\text { Niter and nahcolite precipitate first; an invariant solution composition } \\
\text { is reached when sylvite precipitates. Dryout occurs. }\end{array}$ \\
\hline & & 75 & Natrite, niter & 10.33 & \multirow[t]{3}{*}{ Natrite and niter precipitate. Dryout occurs. } \\
\hline & & 100 & Natrite, niter & 10.30 & \\
\hline & & $126^{b}$ & Natrite, niter & 10.29 & \\
\hline \multirow{4}{*}{$\mathrm{NaCl}-\mathrm{KNO}_{3}-\mathrm{NaNO}_{3}$} & \multirow{4}{*}{-3.5} & 25 & Niter, nahcolite, soda niter & 10.06 & $\begin{array}{l}\text { Nahcolite and niter precipitate first; an invariant solution composition } \\
\text { is reached when soda niter precipitates. Dryout occurs. }\end{array}$ \\
\hline & & 50 & Niter, soda niter, trona & 10.33 & $\begin{array}{l}\text { Niter and soda niter precipitate first; an invariant solution composition } \\
\text { is reached when trona precipitates. Dryout occurs. }\end{array}$ \\
\hline & & 75 & Niter, soda niter, natrite & 10.24 & $\begin{array}{l}\text { Niter and soda niter precipitate first; an invariant solution composition } \\
\text { is reached when natrite precipitates. Dryout occurs. }\end{array}$ \\
\hline & & 100 & Niter, soda niter, natrite & 10.16 & $\begin{array}{l}\text { Niter and soda niter precipitate first; an invariant solution composition } \\
\text { is reached when natrite precipitates. Dryout occurs. }\end{array}$ \\
\hline \multirow{2}{*}{$\begin{array}{l}\mathrm{NaCl}-\mathrm{KNO}_{3}-\mathrm{NaNO}_{3}- \\
\mathrm{Ca}\left(\mathrm{NO}_{3}\right)_{2}\end{array}$} & \multirow{2}{*}{-3.5} & 25 & $\begin{array}{l}\text { Calcite, niter, soda niter, } \\
\mathrm{Ca}\left(\mathrm{NO}_{3}\right)_{2}: 4 \mathrm{H}_{2} \mathrm{O}\end{array}$ & 6.44 & $\begin{array}{l}\text { Calcite precipitates first, followed rapidly by niter, soda niter, and } \\
\mathrm{Ca}\left(\mathrm{NO}_{3}\right)_{2}: 4 \mathrm{H}_{2} \mathrm{O} \text {. The solution composition becomes invariant, and } \\
\text { dryout occurs. }\end{array}$ \\
\hline & & 50 & $\begin{array}{l}\text { Calcite, niter, soda niter, } \\
\mathrm{Ca}\left(\mathrm{NO}_{3}\right)_{2}: 4 \mathrm{H}_{2} \mathrm{O}\end{array}$ & 6.47 & $\begin{array}{l}\text { Calcite precipitates first, followed rapidly by niter, soda niter, and } \\
\mathrm{Ca}\left(\mathrm{NO}_{3}\right)_{2}: 4 \mathrm{H}_{2} \mathrm{O} \text {. The solution composition becomes invariant, and } \\
\text { dryout occurs. }\end{array}$ \\
\hline
\end{tabular}

Source: Output DTN: MO0506SPAEQ36F.002, directories "Degassing_of_Binary_Salt_Systems" and "Degassing_of_Three_and_Four_Salt_Systems" (see associated readme.doc file for specific file names).

${ }^{a}$ Pitzer $\mathrm{pH}$.

b Predicted boiling point of saturated solution at 0.9 bar (BSC 2004 [DIRS 161237], Table 6.7-21).

c These runs do not reach an invariant brine composition. Once the chloride concentration dropped to approximately $10^{-5}$ molal, chloride was removed from the system and only nitrate was degassed. This results in a small charge imbalance, that becomes important when brine volumes drop to less than approximately $10^{-6} \mathrm{~kg}$, resulting in run instability. These runs were truncated when they became unstable.

NOTES: Mineral names and chemical formulas are as follows: halite $-\mathrm{NaCl}$; nahcolite $-\mathrm{NaHCO}_{3}$; trona $-\mathrm{Na}_{3} \mathrm{H}\left(\mathrm{CO}_{3}\right)_{2}: 2 \mathrm{H}_{2} \mathrm{O}$; natrite $-\mathrm{Na}_{2} \mathrm{CO}_{3}$; soda niter $-\mathrm{NaNO}_{3}$; niter $-\mathrm{KNO}_{3}$; sylvite $-\mathrm{KCl}$; calcite $-\mathrm{CaCO}_{3}$

The extent of degassing is controlled by kinetics, and may not proceed to complete dryout, but a shift in $\mathrm{pH}$ requires relatively small extent of degassing. 
Assemblage A: The $\mathrm{NaCl}-\mathrm{KNO}_{3}$ simulations at $25^{\circ} \mathrm{C}$ are unusual in that a chloride phase is present in the final salt assemblage following dryout. An assemblage of nahcolite, niter, and sylvite is produced, the more-deliquescent $\mathrm{NaCl}$ being replaced by the less-soluble $\mathrm{KCl}$. At all higher temperatures, the $\mathrm{NaCl}-\mathrm{KNO}_{3}$ brine evolves into a $\mathrm{KNO}_{3}-\mathrm{Na}$-carbonate salt assemblage. Nearly invariant solution compositions are reached at high $\mathrm{pH}\left(>10\right.$ at $p \mathrm{CO}_{2}=10^{-3.5}$ bar). Figure 6.2-1 shows the evolution of this system at $126^{\circ} \mathrm{C}$, the predicted dryout temperature (BSC 2004 [DIRS 161237], Table 6.7-21), and $p \mathrm{CO}_{2}=10^{-3.5}$ bar.

Assemblage B: $\mathrm{NaCl}-\mathrm{KNO}_{3}-\mathrm{NaNO}_{3}$ brines at all temperatures evolve into a $\mathrm{KNO}_{3}-\mathrm{NaNO}_{3}-$ Na-carbonate salt assemblage. An invariant solution composition is reached when all three minerals become saturated, and the $\mathrm{pH}$ becomes fixed (at approximately 10.2 for $p \mathrm{CO}_{2}=10^{-3.5}$ bars). Figure 6.2-2 illustrates the evolution of this system at $100^{\circ} \mathrm{C}$ and $p \mathrm{CO}_{2}=10^{-3.5}$ bar. Runs at the predicted dryout temperature for this salt assemblage of $135^{\circ} \mathrm{C}$ (BSC 2004 [DIRS 161237], Table 6.7-22) failed; the runs were so sensitive to the ratio of chloride to nitrate removed that it was not possible to discretize the ratio finely enough. At some point in the degassing process, when the run was stopped, the ratio adjusted, and the run restarted, the code would not converge to an equilibrium assemblage.

Assemblage $\mathrm{C}$ : $\mathrm{NaCl}-\mathrm{KNO}_{3}-\mathrm{NaNO}_{3}-\mathrm{Ca}\left(\mathrm{NO}_{3}\right)_{2}$ brines are more difficult to analyze at temperatures above approximately 50 to $60^{\circ} \mathrm{C}$ because of uncertainty associated with the Pitzer parameters for $\mathrm{Ca}-\mathrm{NO}_{3}$. Calculations were therefore performed at $25^{\circ} \mathrm{C}$ and $50^{\circ} \mathrm{C}$. At the two temperatures examined, Assemblage $\mathrm{C}$ immediately precipitates calcite, and with slightly more degassing, niter, soda niter, and $\mathrm{Ca}\left(\mathrm{NO}_{3}\right)_{2}: 4 \mathrm{H}_{2} \mathrm{O}$. At this point, the solution composition becomes invariant, with a $\mathrm{pH}$ of approximately 6.5 at $p \mathrm{CO}_{2}$ of $10^{-3.5}$. With continued degassing, the solution dries out when the chloride is consumed. Figure 6.2-3 illustrates the evolution of this system at $50^{\circ} \mathrm{C}$ and $10^{-3.5}$ bar $p \mathrm{CO}_{2}$.

In each of the plots shown, the results are plotted against the amount of nitrate removed. Both $\mathrm{HCl}$ and $\mathrm{HNO}_{3}$ were degassed in each case. In all cases, nitrate was more abundant than chloride in the solution, but the equilibrium partial pressure of $\mathrm{HCl}$ was initially higher than that of $\mathrm{HNO}_{3}$. The higher partial pressure, combined with the lower abundance in solution, resulted in chloride being depleted prior to nitrate in all cases evaluated, except for the two $25^{\circ} \mathrm{C}$ runs for Assemblage A, where the solution dried out before all chloride or nitrate degassed. Although the partial pressure of $\mathrm{HCl}$ can drop below that of $\mathrm{HNO}_{3}$ as degassing continues, the relative proportion of $\mathrm{HCl}$ to $\mathrm{HNO}_{3}$ in the gas phase is greater than that in the liquid phase, so chloride will always be depleted prior to nitrate. It is notable that in all cases, very slight degassing results in a large increase in $\mathrm{pH}$. However, in all cases with $\mathrm{CO}_{2}$ present, the system eventually became buffered to an invariant composition once a carbonate phase became saturated (Assemblages B and $\mathrm{C}$ ), or to a near-invariant composition, as chloride concentrations approached zero (Assemblage A).

The range of predicted $\mathrm{HCl}(\mathrm{g})$ fugacities in the drift wall through time, as calculated in Engineered Barrier System: Physical and Chemical Environment (BSC 2004 [DIRS 169860], Section 6.9) from the output of Drift-Scale THC Seepage Model (BSC 2005 [DIRS 172862]), is also shown in Figures 6.2-1 to 6.2-3. The predicted fugacities of $\mathrm{HNO}_{3}(\mathrm{~g})$ are not shown, but are lower than those for $\mathrm{HCl}(\mathrm{g})$ for each time step, generally by one or more orders of magnitude. In addition, the maximum values shown are achieved for only a short time during the boiling 
period, about 500 years after closure. The range of partial pressures from thermal-hydrologicchemical (THC) simulations using all five waters from the THC seepage model (waters W0, W4, W5, W6, and W7, which are used in TSPA-LA; see BSC 2004 [DIRS 169860], Section 6.6) is shown, as well as the range for all waters except for W0, which develops into a calcium chloride brine and produces higher partial pressures of $\mathrm{HCl}(\mathrm{g})$ than the other four waters. For the deliquescent brine assemblages, the equilibrium partial pressures of the acid-gas species are very dependent upon $\mathrm{pH}$ and temperature, for the reasons discussed at the beginning of Section 6.2. In the elevated temperature runs for Assemblage A (e.g., $100^{\circ} \mathrm{C}$ or higher; see Figure 6.2-1), the equilibrium partial pressures of $\mathrm{HCl}$ and/or $\mathrm{HNO}_{3}$ are initially higher than the predicted fugacities in the drift wall through time. $\mathrm{As} \mathrm{HCl}$ and $\mathrm{HNO}_{3}$ degas from solution, the $p \mathrm{HNO}_{3}$ stabilizes, at a value above the maximum acid-gas partial pressure in the wall rock, as the chloride is depleted, although the solution never reaches a truly invariant composition. The $\mathrm{pHCl}$, in this system with a swept-away boundary condition, continues to decrease and never stabilizes.

For Assemblage B, the run at the predicted dryout temperature of $136^{\circ} \mathrm{C}$ failed to converge, so Figure 6.2-2 shows results at $100^{\circ} \mathrm{C}$, the highest analyzed temperature. Acid-gas partial pressures generated by the Assemblage B deliquescence brines drop quickly as the $\mathrm{pH}$ rises, but stabilize once a carbonate phase precipitates and the solution composition becomes invariant. The $p \mathrm{HNO}_{3}$ never drops below the maximum predicted $p \mathrm{HNO}_{3}$ values in the wall rock, and the $p \mathrm{HCl}$ only drops below the maximum wall rock values for $\mathrm{W} 0$, which are only achieved for a short time during the boiling period. Also, it must be remembered that the Assemblage B results shown are for $100^{\circ} \mathrm{C}$, while the actual brine may deliquesce at temperatures as high as $190^{\circ} \mathrm{C}$. Because higher temperatures correspond to higher acid-gas partial pressures, it is clear that the partial pressures generated when Assemblage B salts deliquesce will significantly exceed those in the wall rocks, and will stabilize as the deliquescent brines degas to values above those in the wall.

Assemblage $\mathrm{C}$ brines cannot be readily analyzed at higher temperatures due to limitations of the data0.ypf.R0 Pitzer database (DTN: SN0302T0510102.002 [DIRS 162572]). Thus, the highest temperature run for this assemblage was done at $50^{\circ} \mathrm{C}$. Even at this temperature, partial pressures of the acid gases when the solution evolves to an invariant composition greatly exceed values in the wall rock. This is because the $\mathrm{pH}$ of the Assemblage $\mathrm{C}$ deliquescent brine is buffered to a value of $\sim 6.5$ by calcite precipitation, keeping the acid-gas partial pressures high. This process should continue to buffer the $\mathrm{pH}$ at higher temperatures, and the acid-gas partial pressure at temperatures of interest with respect to deliquescence (well over $100^{\circ} \mathrm{C}$ ) should be many orders of magnitude higher than the drift wall values.

Note also that the THC seepage model does not incorporate axial transport down the drift. The condensation model (BSC 2004 [DIRS 164327]) calculates that condensation in the amount of hundreds of liters per year per meter of drift will occur in cooler parts of the drifts (e.g., the unheated sections at the ends). This condensate will provide a sink for acid-gas species, suggesting that the drift-wall acid-gas partial pressures calculated from the THC model are upper-bound values, because in reality loss of acid gases via axial transport will occur.

Given these factors, brines that form in small quantities by dust deliquescence are thermodynamically unstable in the drift environment, will degas, and may approach dryness as 
degassing proceeds. Although a long time period (on the order of years) is available, it is possible that the extent of degassing (and dryout) might be limited by kinetics of acid-gas speciation and exsolution, which are not addressed by the calculations that produced Figures 6.2-1 through 6.2-3. A scoping study of the relationship between air volume turnover and degassing rate for acid-gas species is presented in Section 6.2.3.

(a)

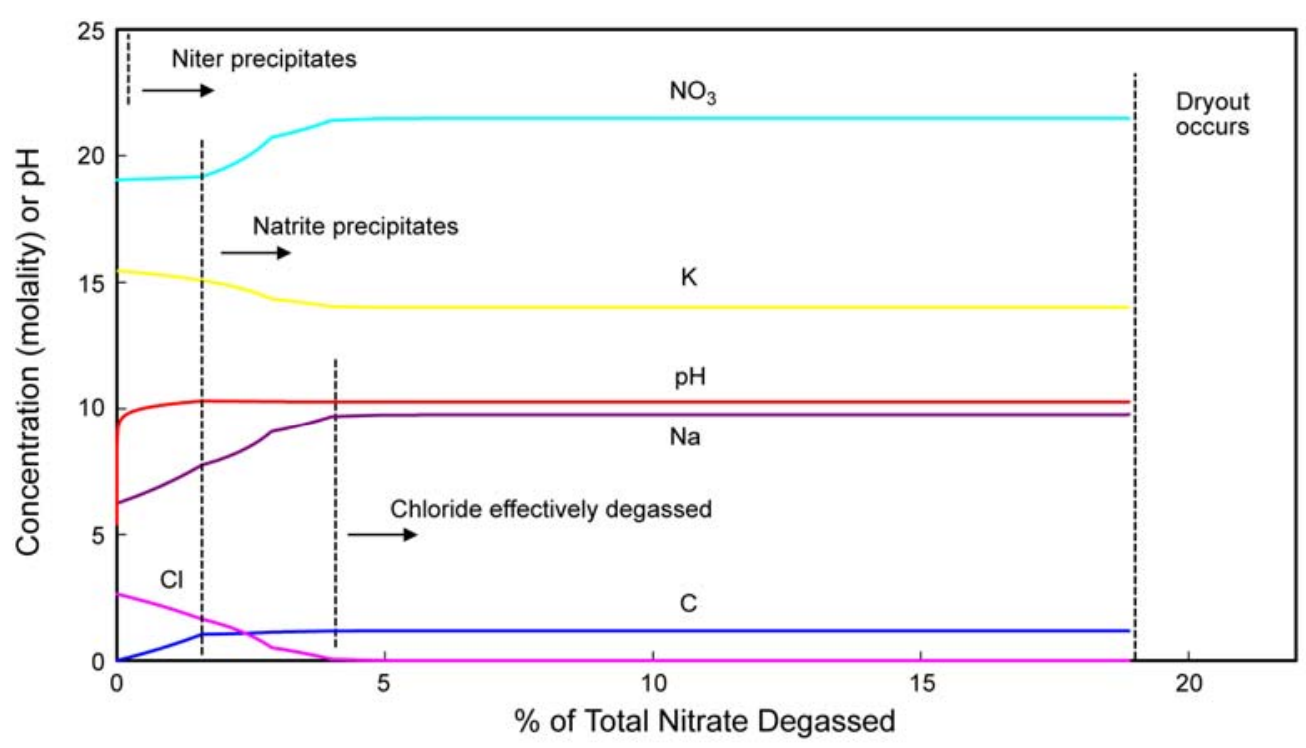

(b)

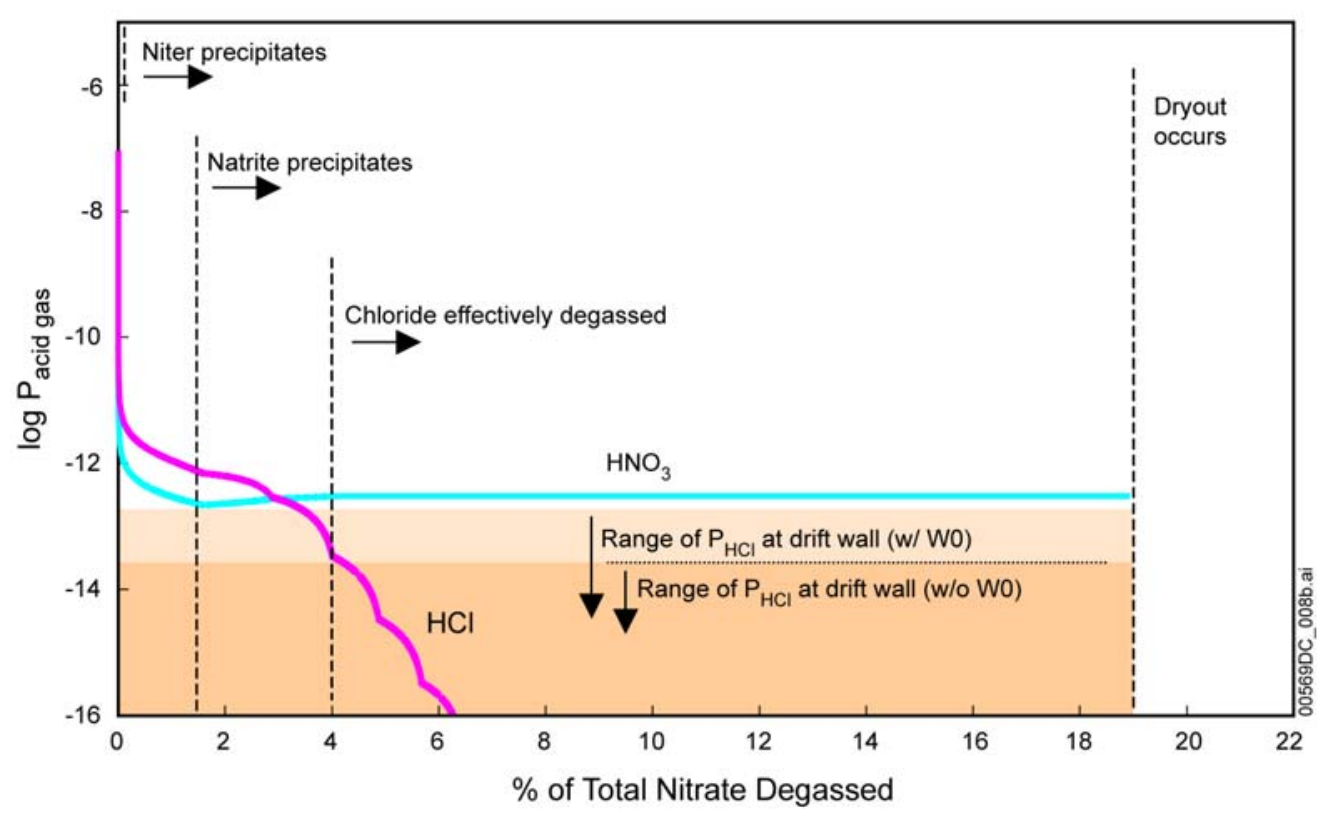

Source: Output DTN: SN0508T0502205.015, Assem. A, 126 C, PCO2 -3.5, graphs for model report.xls.

NOTE: a) Composition of the solution; b) Partial pressure of acid-gas phases. The inflections in the $P_{H C l}$ line are due to stopping the run and adjusting the relative proportion of acid gases being lost. Partial pressures of $\mathrm{HCl}$ in the drift wall are from BSC 2004 [DIRS 161237], Table 4.1-23.

Figure 6.2-1. Evolution of the $\mathrm{NaCl}-\mathrm{KNO}_{3}$ Salt Assemblage ("A") at $126^{\circ} \mathrm{C}$ and $10^{-3.5}$ bar $\mathrm{pCO}$, as $\mathrm{HCl}$ and $\mathrm{HNO}_{3}$ Degas in a Swept-Away Gas Boundary Condition 
(a)

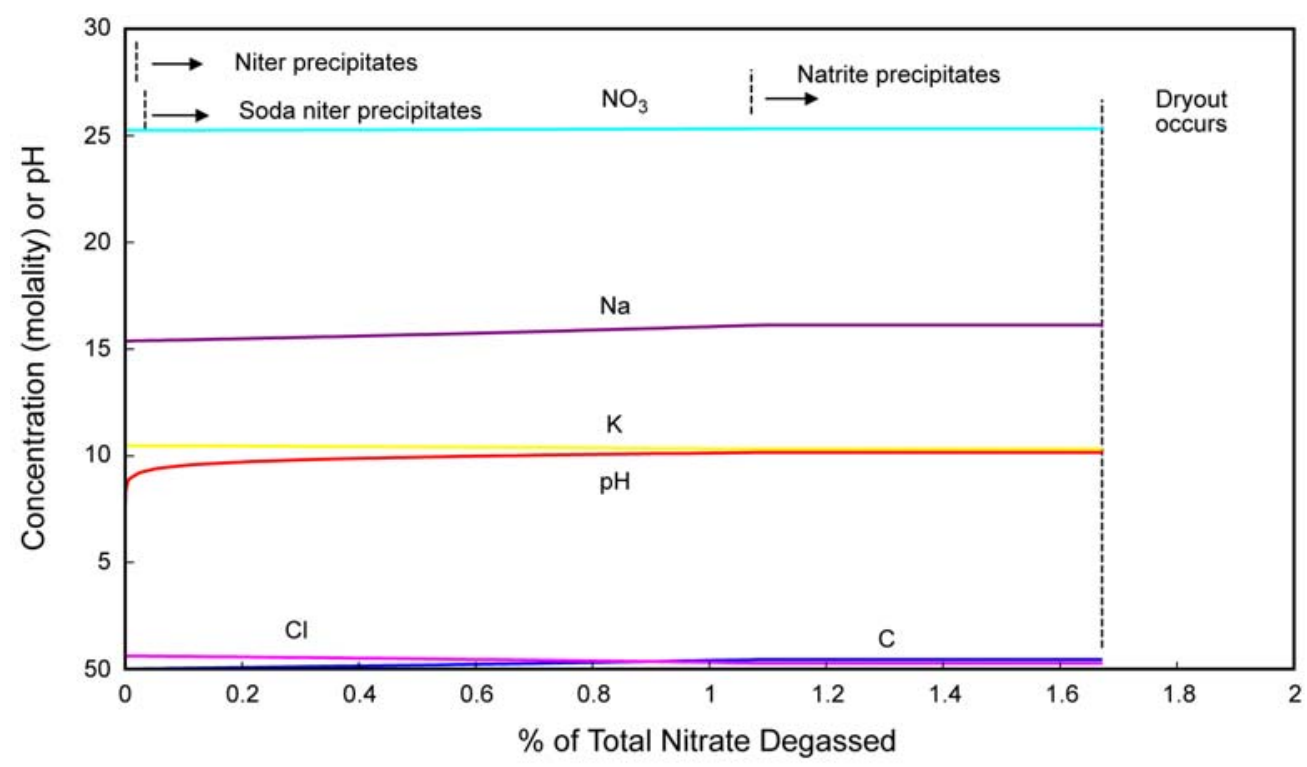

(b)

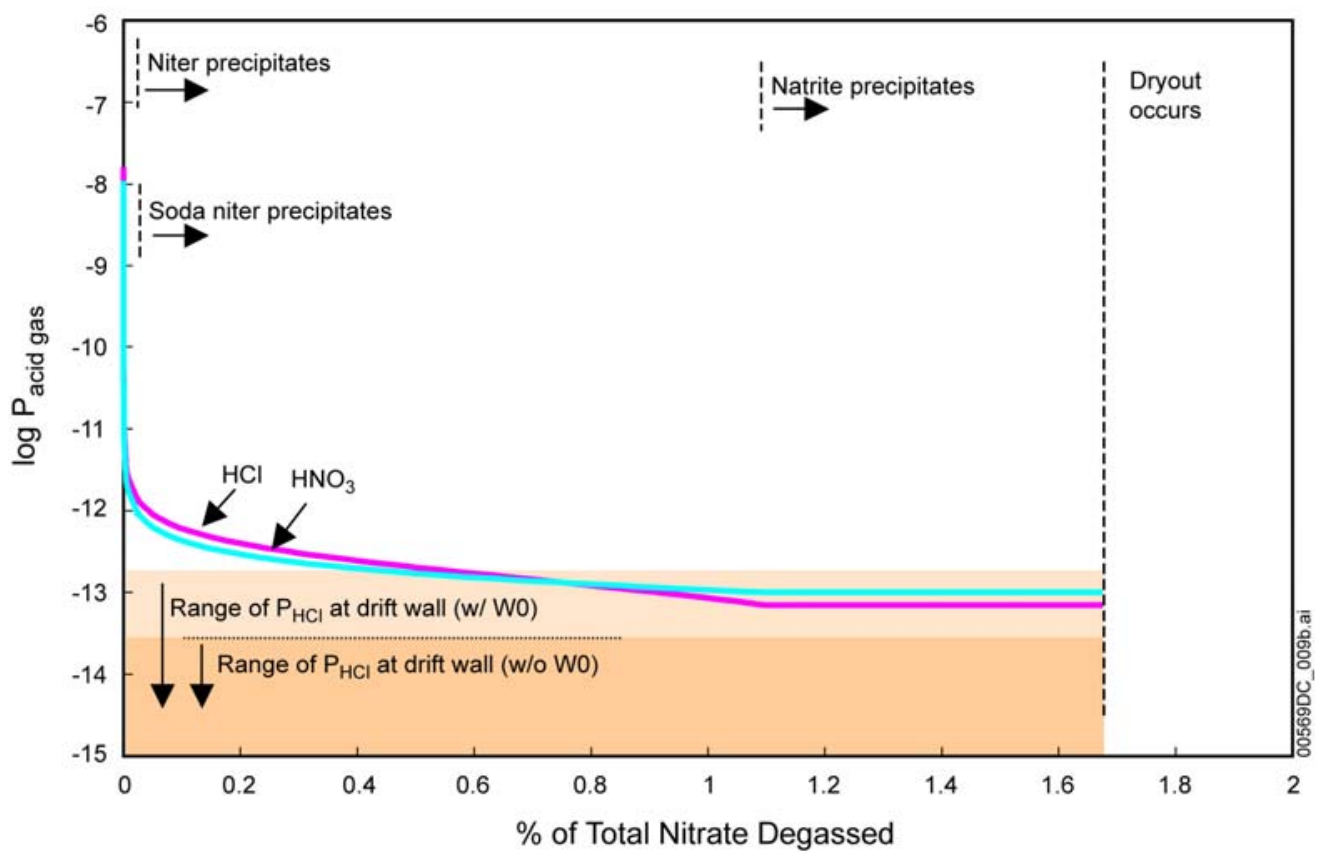

Source: Output DTN: SN0508T0502205.015, Assem. B, 100 C, PCO2 -3.5, graphs for model report.xls.

NOTE: a) Composition of the liquid phase; b) Partial pressures of the acid gases. The solution goes to dryness when all of the chloride and about $1.7 \%$ of the nitrate have been degassed. Partial pressures of $\mathrm{HCl}$ in the drift wall are from BSC 2004 [DIRS 161237], Table 4.1-23.

Figure 6.2-2. Evolution of the $\mathrm{NaCl}-\mathrm{KNO}_{3}-\mathrm{NaNO}_{3}$ Salt Assemblage ("B") at $100^{\circ} \mathrm{C}$ and $10^{-3.5}$ bar $p \mathrm{CO}_{2}$, as $\mathrm{HCl}$ and $\mathrm{HNO}_{3}$ Degas in a Swept-Away Gas Boundary Condition 
(a)

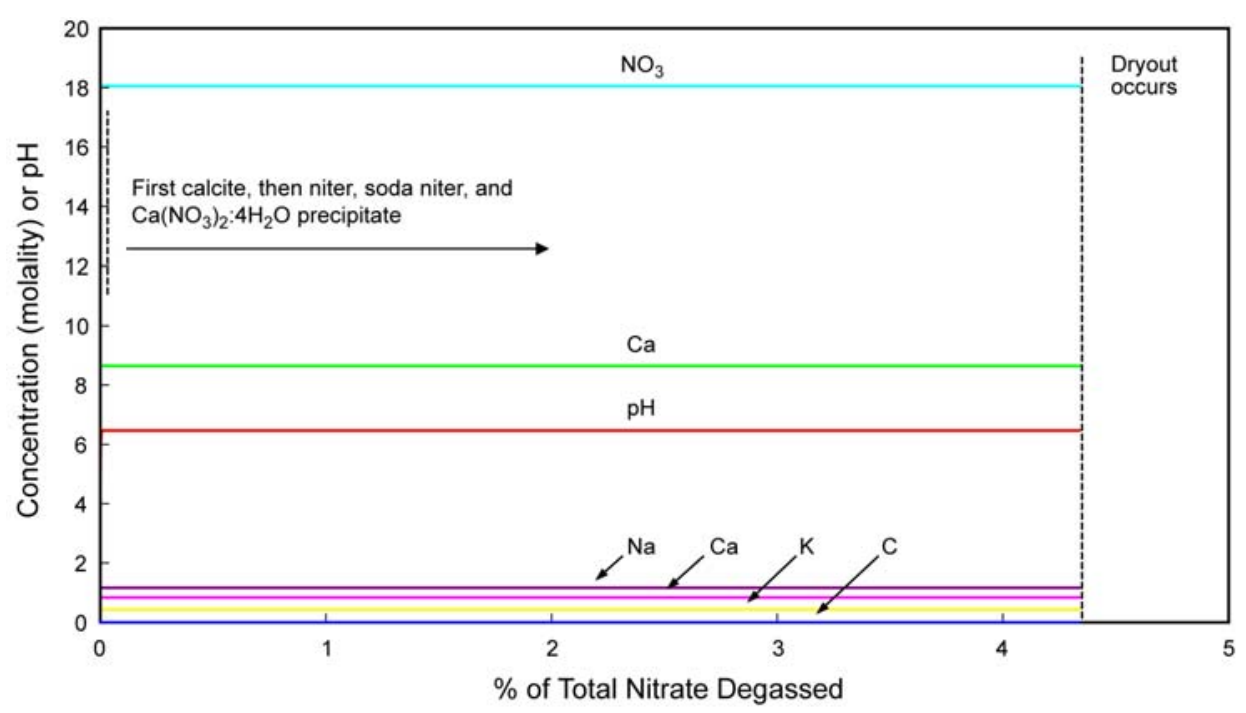

(b)

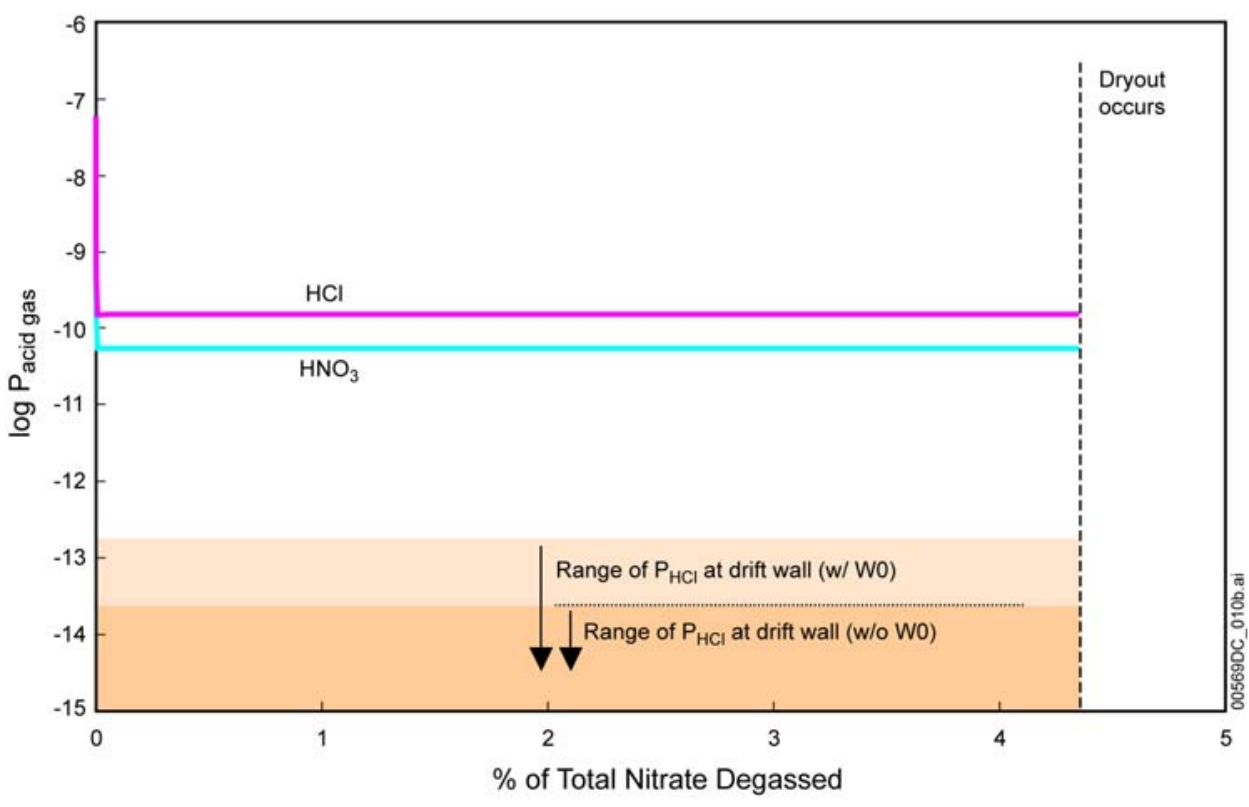

Source: Output DTN: SN0508T0502205.015, Assem. C, 50 C, PCO2 -3.5, graphs for model report.xls.

NOTE: a) Composition of the liquid phase; b) Partial pressures of the acid gases. The solution goes to dryness when all of the chloride and about $11 \%$ of the nitrate have been degassed. Partial pressures of $\mathrm{HCl}$ in the drift wall are from BSC 2004 [DIRS 161237], Table 4.1-23.

Figure 6.2-3. Evolution of the $\mathrm{NaCl}-\mathrm{KNO}_{3}-\mathrm{NaNO}_{3}$ Salt Assemblage (“C”) at $25^{\circ} \mathrm{C}$ and $10^{-3.5}$ bar $p \mathrm{CO}_{2}$, as $\mathrm{HCl}$ and $\mathrm{HNO}_{3}$ Degas in a Swept-Away Gas Boundary Condition

While the brines are thermodynamically unstable, the rate of acid degassing may be very slow, and it is not clear that it will go to completion and dryout. Acid-gas vapor pressures are very low for the high-pH brines that develop from Assemblage A and B brines, and large volumes of air would be required to remove all of the acid. However, the buffering effects of reactions with the silicate components in the dust (discussed later), may keep the $\mathrm{pH}$ lower and enhance degassing. For Assemblage $\mathrm{C}$ brines, which buffer to neutral $\mathrm{pH}$ values by calcite precipitation, acid-gas vapor pressures are relatively high. However, unlike calcium chloride brines, which decompose 
to produce an alkaline precipitate, continued degassing of Assemblage $\mathrm{C}$ requires that $\mathrm{CO}_{2}$ diffuse into the brine, and the rate at which acid degassing can occur may be limited by the rate at which $\mathrm{CO}_{2}$ can be dissolved into the brine.

Should degassing and dryout approach full extent, the final salt assemblages will deliquesce again as the temperature drops and RH increases in the drift. To evaluate the importance of this, deliquescence and further degassing of the carbonate-bearing salt assemblages were analyzed. This was done using exactly the same methods as described in Environment on the Surfaces of the Drip Shield and Waste Package Outer Barrier (BSC 2004 [DIRS 161237], Section 6.7). A single EQ3 input file was created, containing very low concentrations of all species of interest (dilute-a.3i), suppressing the same suite of minerals as in the IDPS model (BSC 2004 [DIRS 169863], Table 6-3) for consistency with other project documents. $\mathrm{O}_{2}(\mathrm{aq})$ and $\mathrm{H}_{2}$ (aq) were also suppressed, as these species are minor, but in some cases can result in nonconvergence. Charge balancing was done on $\mathrm{H}^{+}$. The EQ3 pickup file produced by this simulation was then attached to an EQ6 file that rapidly titrates-in an excess of each of the salts of interest, while ramping up the temperature, starting at $20^{\circ} \mathrm{C}$. The titration rates used are fast enough that saturation with all salt phases of interest is achieved before the temperature reaches $25^{\circ} \mathrm{C}$. Beyond this point, the simulation produces a saturated solution at each temperature step, yielding the deliquescence RH curve. Rather than suppressing minerals during the EQ6 runs, only a particular suite of minerals was allowed to form (this was done to remove the necessity to track the saturations of a multitude of highly undersaturated phases). For consistency, the suite of minerals allowed to form does not include any of those suppressed by the IDPS model (BSC 2004 [DIRS 169863], Table 6-3).

The progressive evolution of Assemblages $\mathrm{A}, \mathrm{B}$, and $\mathrm{C}$ into new deliquescent salt assemblages as degassing occurs is shown below, based on EQ3/6 runs in Output DTN: MO0506SPAEQ36F.002 (folder "Degassing_of_End_Point_Mineralogies_for_Assem_ A,B,C"). The pathways presented below are for elevated temperatures; at temperatures below $100^{\circ} \mathrm{C}$, sodium bicarbonate or hydrated carbonate-bicarbonates may precipitate, and at elevated $p \mathrm{CO}_{2}$ (e.g., $10^{-2}$ bar), potassium bicarbonate (kalicinite) may precipitate.

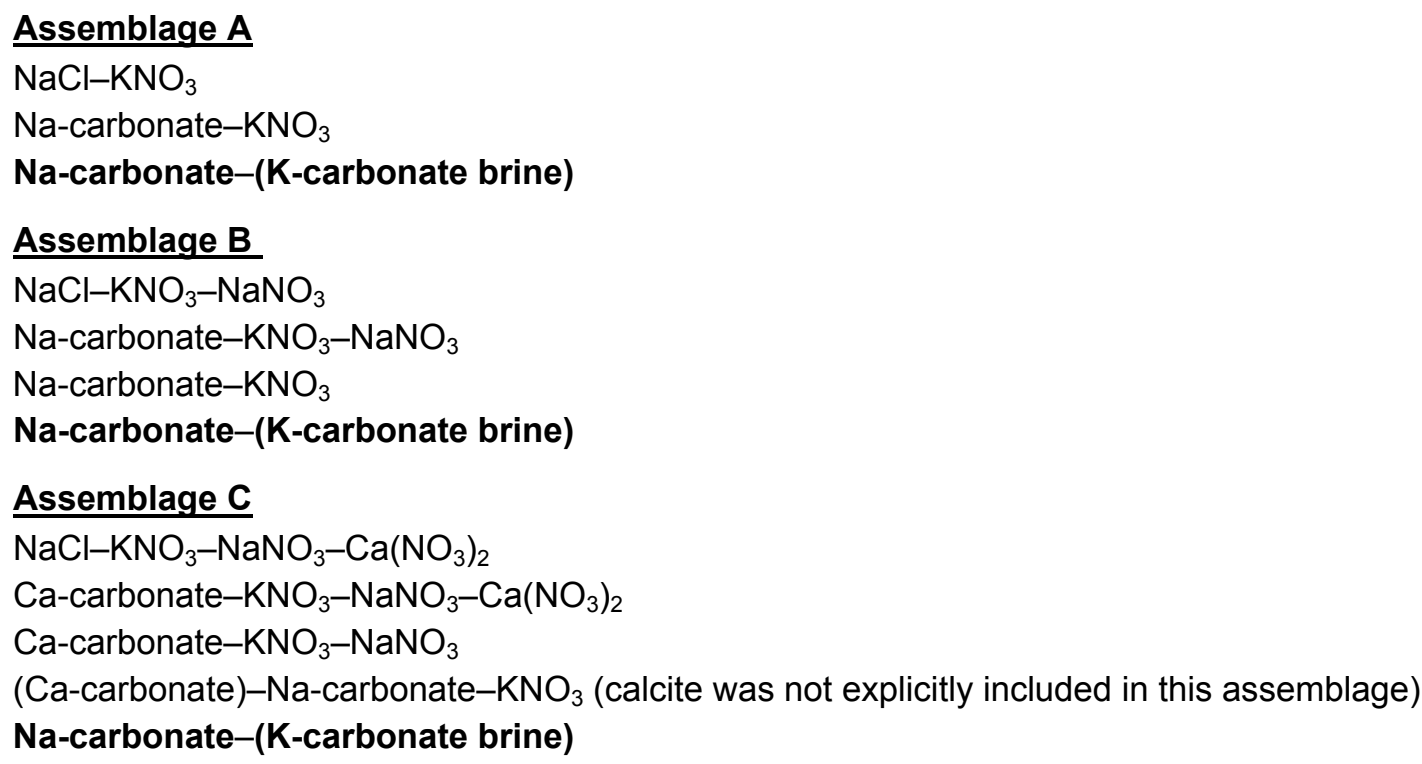


Each successive assemblage dries out as degassing occurs, and chloride is degassed prior to nitrate. In all cases, the final products of degassing are carbonate solid (natrite \pm calcite) and potassium carbonate brine. Potassium carbonate is highly deliquescent and the predicted occurrence of this brine is consistent with observed properties. However, it does not form as long as there is sufficient nitrate in solution to precipitate out all the potassium.

Predicted deliquescence relative humidity as a function of temperature for each of the three salt assemblages and the successive dryout assemblages are shown in Figures 6.2-4, 6.2-5, and 6.2-6. The deliquescence relative humidity versus temperature curves for the initial Assemblages A, B, and $\mathrm{C}$ are from Environment on the Surfaces of the Drip Shield and Waste Package Outer Barrier (BSC 2004 [DIRS 161237], Tables 6.7-21 to 6.7-23). It is important to remember that experimental deliquescence results indicate that the deliquescence temperatures predicted by EQ3/6 are too low. The uncertainties in the IDPS model predictions for deliquescence RH are $\pm 5 \mathrm{RH} \%$ at relative humidities greater than $85 \%$ and $\pm 10 \mathrm{RH} \%$ for the $\mathrm{RH}$ range from $85 \%$ to $40 \%$, and the model is not validated for deliquescence $\mathrm{RH}$ predictions below $40 \%$ or for brines containing calcium nitrate (BSC 2004 [DIRS 169863], Table 7-8). Thus, portions of the deliquescence RH curves in Figures 6.2-4, 6.2-5, and 6.2-6 that are below $40 \% \mathrm{RH}$, and the complete curves for the two calcium nitrate assemblages in Figure 6.2-6, are presented for information only, to allow the reader to assess trends in the predicted results with the evolving mineral assemblages. Uncertainty in predicting deliquescence conditions for multiple-salt assemblages is not significant to the conclusions of this report, because this analysis shows that the consequences of such deliquescence (i.e., localized corrosion, if any) are insignificant.

- Assemblage A (Figure 6.2-4) dries out and the resulting Na-carbonate-niter salt assemblage will re-deliquesce at somewhat higher RH as cooling continues. Comparing the deliquescence curves to the waste package $\mathrm{T}$ and $\mathrm{RH}$ curves suggests that Assemblage A will deliquesce immediately on the "cool" waste packages, in approximately 210 years (at approximately $118^{\circ} \mathrm{C}$ ) on the "median" waste package, and in approximately 1,000 years (at approximately $112^{\circ} \mathrm{C}$ ) on the "hot" waste package (BSC 2005 [DIRS 173944], Figure 6.3-67).

- Assemblage B (Figure 6.2-5) dries out but will re-deliquesce almost immediately as the first dryout assemblage, Na-carbonate-niter-soda niter, has nearly the same deliquescence RH as the initial assemblage. However, once this assemblage dries out, the following Na-carbonate-niter assemblage deliquesces at a significantly higher $\mathrm{RH}$ at any given temperature. Comparing the deliquescence curves to the waste package $\mathrm{T}$ and RH curves suggests that Assemblage B will deliquesce immediately on the "cool" waste packages, in approximately 110 years (at approximately $130^{\circ} \mathrm{C}$ ) on the "median" waste package, and in approximately 610 years (at approximately $123^{\circ} \mathrm{C}$ ) on the "hot" waste package (BSC 2005 [DIRS 173944], Figure 6.3-67).

- Assemblage C (Figure 6.2-6) goes through several steps. The first dryout assemblage is chloride-free, but contains highly deliquescent $\mathrm{Ca}\left(\mathrm{NO}_{3}\right)_{2}$ and deliquesces at nearly the same RH at any given temperature as the initial assemblage. These two assemblages were only analyzed to $60^{\circ} \mathrm{C}$, as the $\mathrm{Ca}-\mathrm{NO}_{3}$ Pitzer calculations fail to converge at higher temperatures. The subsequent assemblage, which only contains $\mathrm{Ca}$ as carbonate, deliquesces at a higher $\mathrm{RH}$, and the final dryout assemblage, Na-carbonate-niter, at even 
higher RH (Ca-carbonate, which is non-deliquescent, was not included). Comparing the deliquescence curves to the waste package $\mathrm{T}$ and $\mathrm{RH}$ curves suggests that Assemblage $\mathrm{C}$ may deliquesce immediately on all waste packages (the inability to simulate assemblages containing $\mathrm{Ca}\left(\mathrm{NO}_{3}\right)_{2}$ at temperatures greater than $50^{\circ} \mathrm{C}$ makes prediction difficult). If degassing and removal of calcium nitrate from the deliquescent assemblage occurs rapidly, as suggested earlier in this section, then the resulting "dryout" assemblage of Ca-carbonate, $\mathrm{NaNO}_{3}$ and $\mathrm{KNO}_{3}$, will remain wet on the "cool" waste packages, and deliquesce in approximately 110 to 130 years (at 126 to $129^{\circ} \mathrm{C}$ ) on the "median" waste package, and in approximately 650 years (at $121^{\circ} \mathrm{C}$ ) on the "hot" waste package (BSC 2005 [DIRS 173944], Figure 6.3-67).

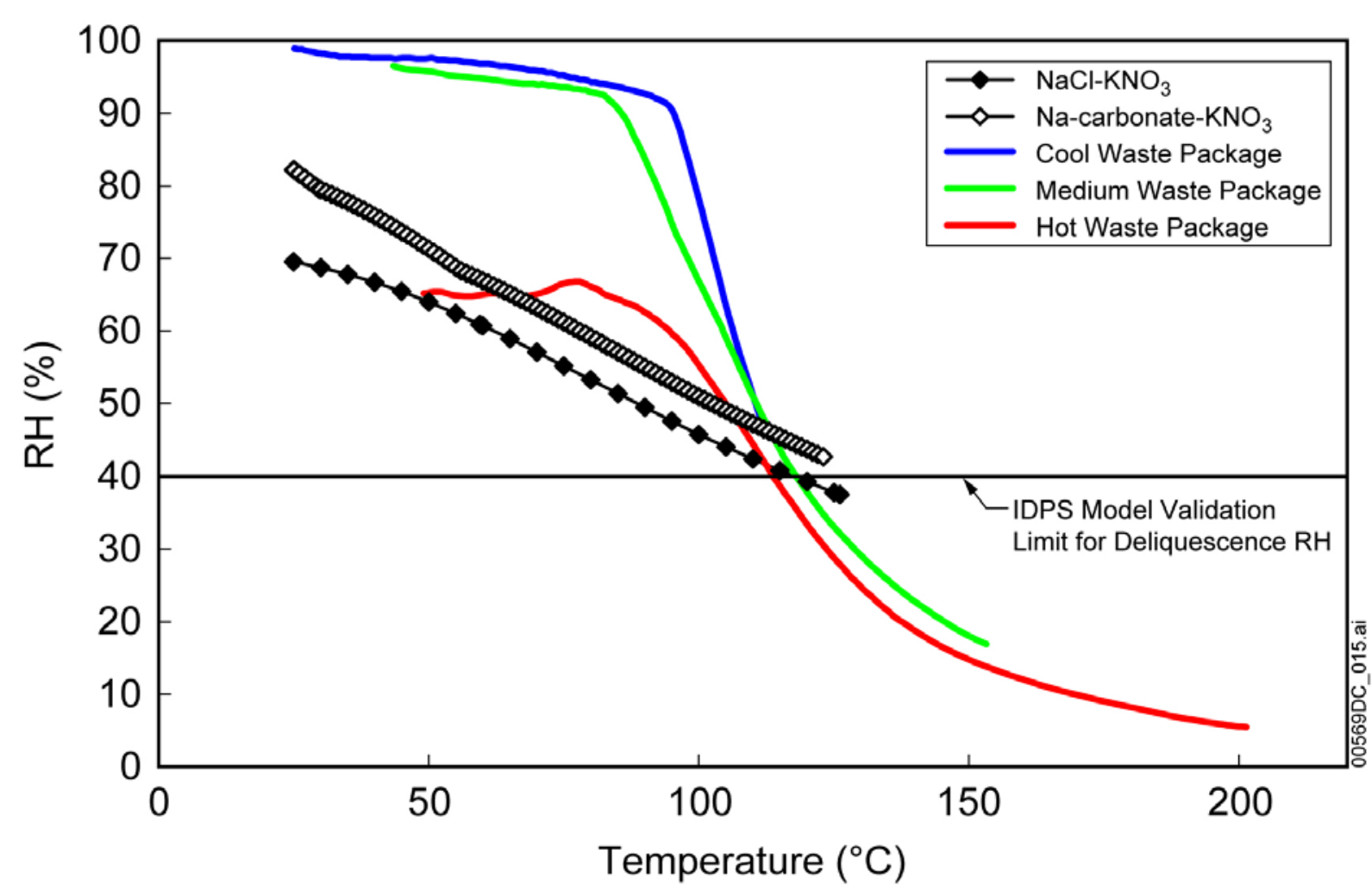

Source: Output DTN: SN0508T0502205.015, Deliquescence_RH_vS_T_curve graphs.xls (deliquescence curve for initial assemblage $\mathrm{NaCl}-\mathrm{KNO}_{3}$ is from BSC 2004 [DIRS 161237], Table 6.7-21; postclosure temperature and $\mathrm{RH}$ data for the waste package are described in Section 4.1.11).

NOTE: The uncertainties in the IDPS model predictions for deliquescence $\mathrm{RH}$ are $\pm 5 \mathrm{RH} \%$ at relative humidities greater than $85 \%$ and $\pm 10 \mathrm{RH} \%$ for the $\mathrm{RH}$ range from $85 \%$ to $40 \%$, and the model is not validated for deliquescence $\mathrm{RH}$ predictions below $40 \%$, or for brines containing calcium nitrate (BSC 2004 [DIRS 169863], Table 7-8). Thus, portions of the deliquescence RH curves that are below $40 \% \mathrm{RH}$ are presented for information only, to allow the reader to assess trends in the predicted results as the mineral assemblages evolve.

Figure 6.2-4. Deliquescence RH as a Function of Temperature for Salt Assemblage A and the Dryout Assemblage That Forms during Acid Degassing 


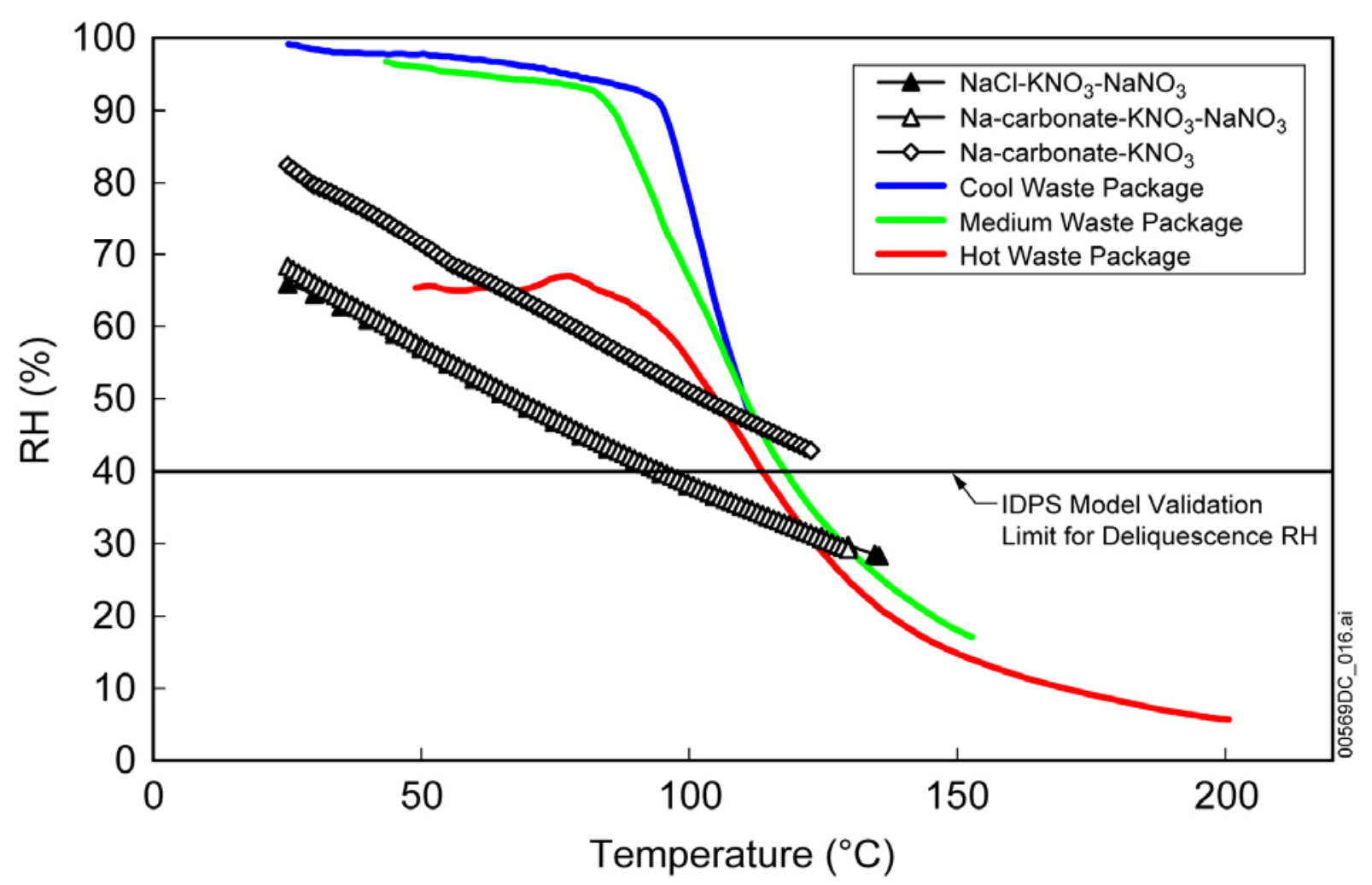

Source: Output DTN: SN0508T0502205.015, Deliquescence_RH_vS_T_curve graphs.xIs (deliquescence curve for initial assemblage $\mathrm{NaCl}-\mathrm{KNO}_{3}-\mathrm{NaNO}_{3}$ is from BSC 2004 [DIRS 161237], Table 6.7-22; postclosure temperature and $\mathrm{RH}$ data for the waste package are described in Section 4.1.11).

NOTE: The uncertainties in the IDPS model predictions for deliquescence $\mathrm{RH}$ are $\pm 5 \mathrm{RH} \%$ at relative humidities greater than $85 \%$ and $\pm 10 \mathrm{RH} \%$ for the $\mathrm{RH}$ range from $85 \%$ to $40 \%$, and the model is not validated for deliquescence RH predictions below 40\%, or for brines containing calcium nitrate (BSC 2004 [DIRS 169863], Table 7-8). Thus, portions of the deliquescence RH curves that are below $40 \% \mathrm{RH}$ are presented for information only, to allow the reader to assess trends in the predicted results as the mineral assemblages evolve.

Figure 6.2-5. Deliquescence RH as a Function of Temperature for Salt Assemblage B and the Dryout Assemblages That Form during Acid Degassing 


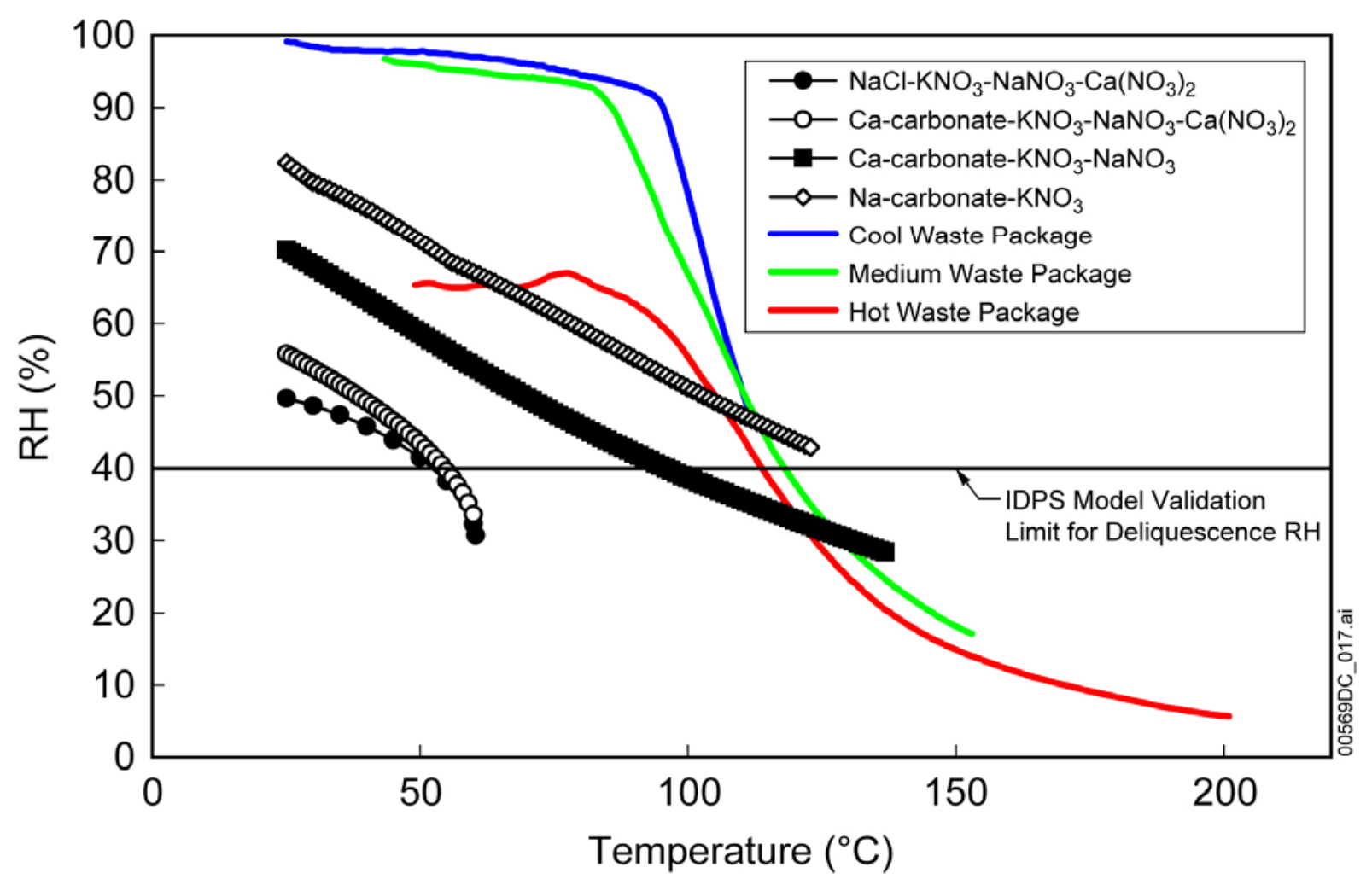

Source: Output DTN: SN0508T0502205.015, Deliquescence_RH_vs_T_curve graphs.xls (deliquescence curve for initial assemblage $\mathrm{NaCl}-\mathrm{KNO}_{3}-\mathrm{NaNO}_{3}-\mathrm{Ca}\left(\mathrm{NO}_{3}\right)_{2}$ is from BSC 2004 [DIRS 161237], Table 6.7-23; postclosure temperature and $\mathrm{RH}$ data for the waste package are described in Section 4.1.11).

NOTE: The uncertainties in the IDPS model predictions for deliquescence $\mathrm{RH}$ are $\pm 5 \mathrm{RH} \%$ at relative humidities greater than $85 \%$ and $\pm 10 \mathrm{RH} \%$ for the $\mathrm{RH}$ range from $85 \%$ to $40 \%$, and the model is not validated for deliquescence RH predictions below 40\%, or for brines containing calcium nitrate (BSC 2004 [DIRS 169863], Table 7-8). Thus, portions of the deliquescence RH curves that are below $40 \% \mathrm{RH}$, and the curves for the two calcium-nitrate bearing assemblages, are presented for information only, to allow the reader to assess trends in the predicted results as the mineral assemblages evolve.

Figure 6.2-6. Deliquescence RH as a Function of Temperature for Salt Assemblage C and the Dryout Assemblages That Form during Acid Degassing

To summarize, most of the deliquescent brine assemblages predicted to occur in the dust are not thermodynamically stable in the drift environment, even given a relatively significant background partial pressure of acid gases controlled by aqueous chemistry in the host rock at the drift wall. Compositional differences and the temperature gradient between the waste package surface and the drift wall are sufficient to ensure that brines formed by dust deliquescence will continue to degas. However, Assemblage A and B brines are buffered by carbonates to $\mathrm{pH}$ values high enough that degassing will occur very slowly. It is not clear that equilibrium assemblages will ever develop; however, even a small amount of degassing can lead to large $\mathrm{pH}$ changes. For Assemblage $\mathrm{C}$ brines, dissolution of $\mathrm{CO}_{2}$ and precipitation of calcite buffer the $\mathrm{pH}$ to near-neutral values, and acid-gas partial pressures may be high enough at elevated temperatures that degassing and dryout will occur readily, limited only by the accessibility of $\mathrm{CO}_{2}$. 


\subsubsection{Scoping Evaluation of Degassing Efficiency}

The foregoing discussion describes the evolution of brine compositions as acid-gas species are exsolved and as $\mathrm{CO}_{2}$ is dissolved from the air. The discussion acknowledges that kinetics may impact the extent to which these processes may drive changes in brine composition, and that the most likely changes involve relatively small mass transfers resulting in an increase in brine $\mathrm{pH}$. This section further develops this point by evaluating controls on mass transfer rates for exsolution/dissolution, and identifying the conditions for which degassing effects are likely to be significant.

The three controls on exsolution/dissolution rates for gas species are: 1) the driving force represented by the maximum gas-phase partial pressure of $\mathrm{CO}_{2}$, or the maximum equilibrium vapor pressure of acid-gas species; 2) the rate at which the gas phase is replenished (i.e., the realistic turnover rate of a "swept-away" boundary condition); and 3) any intrinsic kinetic limitations on mass transfer at the gas-liquid interface. The gas-phase pressures and replenishment of the gas phase are discussed below, while intrinsic kinetics is identified as a possible topic for future analysis.

The driving force for degassing of acid-gas species is a chemical potential gradient across the gas-liquid interface. A "swept-away" condition must exist to some extent in the gas phase, caused by forced ventilation or by natural convection, combined with a sink for the acid-gas species at a location with lower temperature and/or acid-neutralizing chemistry. The magnitude of the driving force is represented by the difference between the equilibrium vapor pressure, which depends on the brine composition, and the ambient partial pressure of the gas in the actual environment. Predicted equilibrium acid-gas vapor pressures for the three salt assemblages $\left(\mathrm{A}, \mathrm{B}\right.$, and C) described in Section 6.2.2.2 are shown in Table 6.2-3, for a $p \mathrm{CO}_{2}$ of $10^{-3.5}$ bar and a range of temperature conditions (Figures 6.2-1 to 6.2-3 show three of these simulations). Both the initial and final partial pressures from the analysis area are shown; the final run conditions correspond to the invariant brine compositions that are reached once all minerals constituting the end mineralogy begin to precipitate. Once this occurs, the brine composition remains constant with further degassing until dryout occurs. Equilibrium vapor pressures for $\mathrm{HCl}$ are higher than those for $\mathrm{HNO}_{3}$ at low temperatures, but at high temperatures predicted brine compositions are increasingly nitrate-rich, and $\mathrm{HNO}_{3}$ may have a higher equilibrium vapor pressure. In all cases, the ratio of $\mathrm{Cl}$ to $\mathrm{NO}_{3}$ in the vapor phase is higher than that in the solution, and degassing results in an increase in the nitrate-chloride ratio of the remaining solution relative to the starting values. Note that data presented here for Assemblages $\mathrm{B}$ and $\mathrm{C}$ do not extend to expected temperatures of deliquescence, which for the average waste package could be as high as $150^{\circ} \mathrm{C}$ (Figure 6.1-1).

For scoping analysis of the gas turnover rate on the waste packages, a parametric range is used to represent the range from postclosure natural convection around the waste package (under the drip shield), through preclosure ventilation. As an example, the preclosure ventilation airflow of $15 \mathrm{~m}^{3} / \mathrm{sec}$ (Table $4.1-6$ ) corresponds to $4.7 \times 10^{8} \mathrm{~m}^{3} / \mathrm{yr}$, or approximately $4.7 \times 10^{6} \mathrm{~m}^{3} / \mathrm{yr}$ per waste package (assuming approximately 100 waste packages per drift).

To estimate the maximum removal of acid-gas species $\dot{n}_{W P}$, in moles/yr per waste package, the following equation, derived from the Ideal Gas Law, is used: 


$$
\dot{n}_{W P}=P_{v} \frac{\dot{V}_{W P}}{R T}
$$

where $P_{v}$ is partial pressure (atm), $\dot{V}_{W P}$ is the gas flow rate $\left(\mathrm{m}^{3} / \mathrm{yr}\right.$ per waste package), $R$ is the gas constant $\left(8.205 \times 10^{-5} \mathrm{~mol} \mathrm{~atm} \mathrm{~m}^{3} / \mathrm{K}\right)$, and $T$ is the absolute temperature $(\mathrm{K})$. The results are plotted in Figure 6.2-7.

The inventory of chloride and nitrate salts on the surface of each waste package is on the order of 0.1 to 1 mole (calculated in Section 6.4.1, assuming $10 \mathrm{~m}^{2}$ area, 16 to $23 \mathrm{mg} / \mathrm{cm}^{2}$ dust, and $10.5 \%$ soluble salts which is the average of values from Table 4.1-9), although a large fraction of the soluble component is likely to be ammonium salts that will be removed by thermal decomposition prior to brine formation. Applying the $P_{v}$ values from Table 6.2-3 in Figure 6.2-7 shows that degassing of the initial compositions is likely to occur, especially at high temperatures. For salt Assemblages A and B, extended degassing that approaches depletion of chloride is unlikely because as the $\mathrm{pH}$ rises to 10, the acid-gas partial pressures become extremely small. This confirms the previous conclusion that the most likely result of degassing is increased $\mathrm{pH}$ (Section 6.2.2). However, for Assemblage C, precipitation of low-solubility calcite buffers the $\mathrm{pH}$ to neutral values, keeping acid-gas vapor pressures 3 to 4 orders of magnitude higher than those for the other assemblages at similar temperatures. At the expected temperatures of deliquescence for this assemblage $\left(140^{\circ} \mathrm{C}\right.$ or higher), the acid-gas vapor pressure above an Assemblage $\mathrm{C}$ brine may be high enough to permit complete dryout.

Table 6.2-3. Predicted Initial and Final $\mathrm{pH}$ Values and Acid-Gas Partial Pressures for Deliquescent Brines, at $p \mathrm{CO}_{2}=10^{-3.5}$ bar

\begin{tabular}{|c|c|c|c|c|c|c|c|c|c|}
\hline $\begin{array}{l}\text { Beginning Salt } \\
\text { Assemblage }\end{array}$ & $\mathrm{T}\left({ }^{\circ} \mathrm{C}\right)$ & $\begin{array}{c}\text { Initial } \\
\mathrm{pH}^{\mathrm{a}}\end{array}$ & $\begin{array}{l}\text { Log } \\
\text { (Initial } \\
p \mathrm{HCl} \text { ) }\end{array}$ & $\begin{array}{c}\text { Log } \\
\text { (Initial } \\
\text { p } \mathrm{HNO}_{3} \text { ) }\end{array}$ & $\begin{array}{l}\text { Initial } \\
\mathrm{NO}_{3} / \mathrm{Cl}\end{array}$ & $\underset{\mathrm{pH}^{\mathrm{a}}}{\text { Final }}$ & $\begin{array}{c}\text { Log } \\
\text { (Final } \\
p \mathrm{HCl} \text { ) }\end{array}$ & $\begin{array}{c}\text { Log } \\
\text { (Final } \\
\text { pHNO }\end{array}$ & $\begin{array}{l}\text { Final } \\
\mathrm{NO}_{3} / \mathrm{Cl}\end{array}$ \\
\hline \multirow{4}{*}{$\begin{array}{c}\text { "A" } \\
\mathrm{NaCl}-\mathrm{KNO}_{3}\end{array}$} & 25 & 5.11 & -10.56 & -11.73 & 0.42 & 10.04 & - & -16.90 & 0.35 \\
\hline & 75 & 5.04 & -8.33 & -9.25 & 2.82 & 10.33 & - & -14.31 & - \\
\hline & 100 & 5.17 & -7.61 & -8.39 & 4.86 & 10.30 & - & -13.35 & - \\
\hline & 126 & 5.40 & -7.08 & -7.72 & 7.22 & 10.29 & - & -12.42 & - \\
\hline \multirow{4}{*}{$\begin{array}{c}\text { "B" } \\
\mathrm{NaCl-KNO}_{3-}- \\
\mathrm{NaNO}_{3}\end{array}$} & 25 & 5.00 & $\begin{array}{l}-10.43 \\
\end{array}$ & $\begin{array}{l}-11.08 \\
\end{array}$ & 2.80 & 10.06 & -15.69 & -16.16 & 5.45 \\
\hline & 50 & 4.95 & -9.31 & -9.75 & 13.1 & 10.33 & -15.29 & -15.18 & 55.9 \\
\hline & 75 & 5.03 & -8.49 & -8.77 & 29.2 & 10.24 & -13.95 & -14.00 & 53.5 \\
\hline & 100 & 5.18 & -7.83 & -8.00 & 41.0 & 10.16 & -13.15 & -13.00 & 94.5 \\
\hline \multirow{2}{*}{$\begin{array}{c}\mathrm{C} " \\
\mathrm{NaCl}-\mathrm{KNO}{ }_{3}- \\
\mathrm{NaNO}_{3}-\mathrm{Ca}\left(\mathrm{NO}_{3}\right)_{2}\end{array}$} & 25 & 3.97 & -8.58 & -9.23 & 2.08 & 6.44 & $\begin{array}{c}-11.05 \\
\end{array}$ & $\begin{array}{l}-11.70 \\
\end{array}$ & 2.09 \\
\hline & 50 & 3.90 & -7.26 & -7.70 & 21.4 & 6.47 & -9.83 & -10.27 & 21.4 \\
\hline
\end{tabular}

Source: Output DTN: MO0506SPAEQ36F.002, directories "Degassing_of_Binary_Salt_Systems" and "Degassing_of_Three_and_Four_Salt_Systems" (see DTN's readme.doc file for specific file names).

a Pitzer $\mathrm{pH}$.

b Predicted boiling point of saturated solution at 0.9 bar (BSC 2004 [DIRS 161237], Table 6.7-21).

NOTE: Dash in cell signifies that no invariant brine composition was reached. $\mathrm{P}_{\mathrm{HCl}}$ will decrease indefinitely (assuming no background vapor pressure). $\mathrm{NO}_{3} / \mathrm{Cl}$ will increase indefinitely; in the simulations, chloride was removed as an input after its concentration had dropped below $\sim 10^{-6}$ molal, corresponding to a nitrate-chloride ratio of $10^{5}$ or larger. 


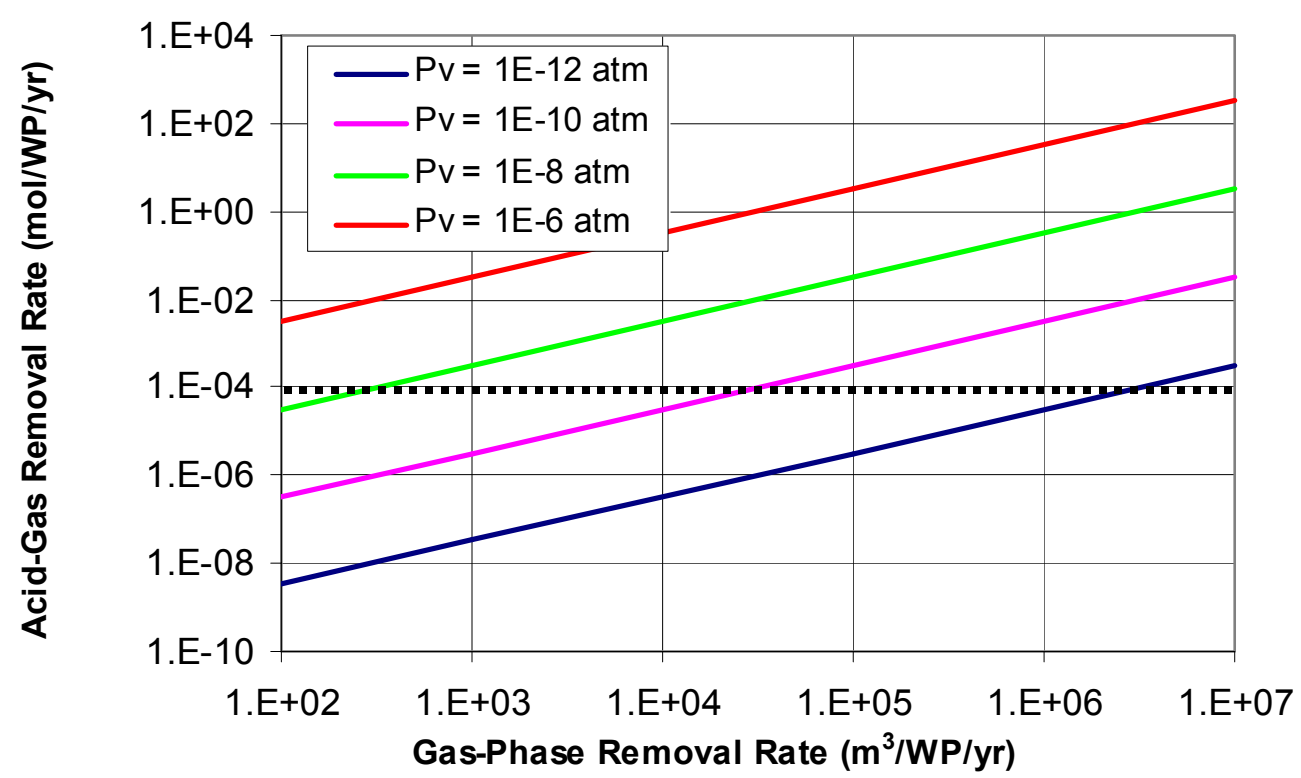

Source: Output DTN: MO0505SPAKINAD.000.

NOTE: $\quad$ WP = waste package. The acid-gas removal rate is assumed to be a function of the acid-gas vapor pressure (a "swept-away" boundary condition). Values are calculated at $100^{\circ} \mathrm{C}$. The dotted line shows the approximate removal rate corresponding to preclosure ventilation $\left(4.7 \times 10^{6} \mathrm{~m}^{3} / \mathrm{yr} / \mathrm{WP}\right.$; see text $)$ and $\mathrm{PV} / \mathrm{P}=1.0 \times 10^{-12}$, the lowest plotted acid gas partial pressure. Less ventilation is represented down and to the left; higher acid gas partial pressures move up.

Figure 6.2-7. Degassing Efficiency as a Function of Gas-Phase and Acid-Gas Removal Rates

\subsubsection{Summary}

Deliquescent brines at elevated temperature (e.g., $\left.>120^{\circ} \mathrm{C}\right)$ may persist. Divalent-cation chloride salts decompose as observed experimentally, converting to less-deliquescent salt minerals with evolution of a gaseous species. For multiple-salt assemblages that deliquesce at elevated temperature (e.g., approaching $190^{\circ} \mathrm{C}$ as discussed in Section 6.1), degassing will lead to changes in brine chemistry, resulting in more benign chemical conditions and possible dryout.

Experimental work has shown that deliquescent $\mathrm{CaCl}_{2}$ brine readily degasses at elevated temperature, producing a less-deliquescent salt. The conversion proceeds rapidly because of the high concentration of chloride (and thus $\mathrm{HCl}$ ), and because a favored precipitate forms, which buffers the $\mathrm{pH}$. Without the precipitate (believed to be Ca-hydroxychloride) the degassing would slow down as the $\mathrm{pH}$ increased. This happens with degassing of $\mathrm{HCl}$ and $\mathrm{HNO}_{3}$ from brines dominated by monovalent salts (e.g., $\mathrm{NaCl}, \mathrm{NaNO}_{3}, \mathrm{KNO}_{3}$ ), but calculations presented in this section show that dissolution of $\mathrm{CO}_{2}$ into the brine prolongs the degassing process and increases the conversion to less-deliquescent salts (e.g., nahcolite or $\mathrm{NaHCO}_{3}$ ). The behavior of $\mathrm{CO}_{2}$ is inherently similar to that of acid-gas species although the direction of mass transfer is reversed: $\mathrm{CO}_{2}$ has essentially unlimited availability in the gas phase, and is generally present in the environment at higher partial pressures than the acid-gas species. 
The immediate result of deliquescent brine degassing is increased $\mathrm{pH}$, and the longer term possibility demonstrated by thermodynamic calculations is the precipitation of less-deliquescent salts. These salts may subsequently deliquesce at lower temperature and higher $\mathrm{RH}$, producing brines of higher $\mathrm{pH}$ than the original assemblage. Higher $\mathrm{pH}$ favors resistance of Alloy 22 to localized corrosion.

A scoping analysis of degassing rates was presented in this section to substantiate that sufficient acid-gas species could be removed from the waste package to affect the deliquescent brine chemistry. The "swept-away" boundary condition was represented as a simple replacement process, and the maximum acid-gas removal rate calculated from the equilibrium partial pressure of the vapor. The results show that initial deliquescence of salt Assemblages $\mathrm{A}, \mathrm{B}$, and $\mathrm{C}$ will result in loss of $\mathrm{HCl}$ and $\mathrm{HNO}_{3}$ and increased $\mathrm{pH}$, but that degassing is unlikely to approach complete depletion of chloride or nitrate. From degassing calculations with EQ3/6, it was noted that significant increase in $\mathrm{pH}$ is obtained from removal of a small proportion of the chloride in solution (e.g., 1\%). Accordingly, $\mathrm{pH}$ increase is likely to occur from degassing. The analysis also shows that Assemblage $\mathrm{C}$, which forms a brine concentrated in $\mathrm{Ca}\left(\mathrm{NO}_{3}\right)_{2}$, is even more likely to degas because the salt is very soluble and deliquesces at higher temperature. In addition, the less-soluble precipitate produced by reaction with $\mathrm{CO}_{2}$ is calcite, which buffers the $\mathrm{pH}$ to near-neutral values.

Uncertainty Discussion-The divalent chloride salts $\left(\mathrm{CaCl}_{2}\right.$ and $\left.\mathrm{MgCl}_{2}\right)$ are likely to decompose at elevated temperature, liberating gaseous $\mathrm{HCl}$ and forming a less-deliquescent hydroxychloride salt as product. This reaction can proceed to completion without inhibition because of the $\mathrm{pH}$-buffering effect of the precipitate, and has been observed in the laboratory for $\mathrm{CaCl}_{2}$. There is comparatively more uncertainty associated with degassing of nitrate and chloride salts for which no such $\mathrm{pH}$ buffering effect exists. Such brines may degas to a great extent if gas-phase $\mathrm{CO}_{2}$ participates, and carbonate precipitates are produced; however, experimental investigation of such reactions is limited and the $\mathrm{CO}_{2}$ step has not been observed experimentally. It is more likely that the effect of degassing for monovalent nitrate and chloride salt assemblages will be limited to increasing the $\mathrm{pH}$ into the near-neutral range, at which point the partial pressure of $\mathrm{HCl}\left(\right.$ or $\left.\mathrm{HNO}_{3}\right)$ will decrease and the rate of degassing will slow.

Low-solubility phases (silicates, carbonates, sulfates) were not included in the thermodynamic calculations of acid degassing, and over the long term will react with brine components to modify the composition of the brine. These interactions are evaluated in Section 6.3.3 with respect to changes in the chemistry and potential corrosivity. These reactions will buffer the $\mathrm{pH}$ and promote degassing to some degree, depending upon the relative rates of degassing and mineral reaction. Independent of degassing, such reactions may result in brine dryout by removal of some brine components (e.g., $\mathrm{Ca}$ ). 


\subsection{IF BRINES PERSIST, WILL THEY BE CORROSIVE?}

This section addresses the corrosivity of brines that may form and persist on the waste package, by first examining the initial brine compositions and then the effect of processes modifying them on the surface of the waste package.

\subsubsection{Predicted Initial Brine Compositions Are Noncorrosive}

The initial composition of brines formed by dust deliquescence has been predicted by geochemical analysis using EQ3/6. The compositional factors affecting the corrosivity of aqueous solutions have been determined experimentally using relatively simple one- and two-component solutions and more complex synthetic groundwater solutions. The relationship of the experimental brines to natural and modeled brines is discussed in the following sections. On the basis of the experimental results, and thermodynamic constraints on the nitrate content of deliquescent brines at elevated temperature, the brines formed by dust deliquescence are likely to be noncorrosive with respect to Alloy 22. At temperatures above $120^{\circ} \mathrm{C}$, the limit of the validated localized corrosion model (BSC 2004 [DIRS 169984], Section 6.4.4), and above $140^{\circ} \mathrm{C}$, the limit of the validated IDPS model (BSC 2004 [DIRS 169863]), deliquescent brines will retain a key characteristic (high nitrate-chloride ratio) of non-corrosive solutions (Section 6.3.1.4).

\subsubsection{Comparison to Corrosion Testing Chemistries}

Geochemical literature (e.g., Drever 1997 [DIRS 147480]) establishes the three types of brines that result from the evaporative concentration of dilute natural waters at the Earth's surface: (1) calcium chloride brine, (2) carbonate brine, and (3) sulfate brine. These brine types are a function of the chemical pathway that the water follows as it evaporates. As minerals precipitate from solution, the relative abundance of ions in solution changes. Each precipitating mineral represents a "chemical divide" (Drever 1997 [DIRS 147480]); once precipitation initiates, either the cationic or anionic component become progressively more enriched in solution, depending upon the initial relative abundance of each species. The three brine designations given above - calcium chloride, carbonate, and sulfate-describe three chemical pathways; all evaporating brines must take one of these.

Deliquescence is fundamentally equivalent to evaporation - that is, assuming thermodynamic equilibrium, at any given $\mathrm{RH}$, the composition of a brine is the same whether it is approached by evaporation of a dilute solution of chemical species or by deliquescence of solid phases containing the same components. Therefore, the same three brine types apply to brines formed by deliquescence. It is important to note that these brine types are not necessarily rich in their namesake components; the compositions of brines are dependent on relative humidity, and the dominant ions in solution can and do change as a function of relative humidity.

The aqueous solutions used in corrosion testing can be related to these three types of natural brines. Initial corrosion test studies focused on carbonate-type brines, because sodium carbonate waters, as typified by J-13 well water from the saturated zone near Yucca Mountain, were the expected types of waters at the repository (Harrar et al. 1990 [DIRS 100814]). A later study (Rosenberg et al. 2001 [DIRS 154862]) showed that evaporative concentration of a Yucca 
Mountain pore water reported by Sonnenthal et al. (1998 [DIRS 118845], Section 7.1) resulted in a calcium-chloride-type brine, so subsequent corrosion experimental work considered other brine types as well as the carbonate brines. The types of aqueous solutions used for corrosion testing are discussed below in the context of the natural brines.

Corrosion Test Chemistries - Two types of waters have been used for Alloy 22 corrosion tests. The first consists of synthetic groundwaters and compositions that represent evaporatively concentrated equivalents of those waters (Table 6.3-1). These solutions are based on the simulated evaporation of J-13 well water, a carbonate-type saturated-zone water from a well near Yucca Mountain. The solution compositions were concentrated by a factor of about 10 times to over 45,000 times to simulate evaporative concentration of the water upon contacting the waste package.

Simple single- and two-component salt solutions with varying nitrate-chloride ratios were also used as test solutions. These included $\mathrm{NaCl}$ test solutions with $\mathrm{NaCl}$ concentrations varying from 0.5 to 4.0 molar, and $\mathrm{CaCl}_{2}$ and $\mathrm{CaCl}_{2}+\mathrm{Ca}\left(\mathrm{NO}_{3}\right)_{2}$ test solutions with $\mathrm{CaCl}_{2}$ concentrations up to 9 molar.

Table 6.3-1. Target Composition of Standard Test Media Based on Evaporative Concentration of a Dilute Carbonate-Type Water

\begin{tabular}{|l|c|c|c|c|c|}
\hline \multicolumn{1}{|c|}{ Ion } & $\begin{array}{c}\text { SDW } \\
\text { (mg/L) }\end{array}$ & $\begin{array}{c}\text { SCW } \\
(\mathbf{m g} / \mathbf{L})\end{array}$ & $\begin{array}{c}\text { SAW } \\
(\mathbf{m g} / \mathbf{L})\end{array}$ & $\begin{array}{c}\text { SSW } \\
\text { (mg/L) }\end{array}$ & $\begin{array}{c}\text { BSW-12 } \\
\text { (mg/L) }\end{array}$ \\
\hline $\mathrm{K}^{+}$ & $3.4 \times 10^{1}$ & $3.4 \times 10^{3}$ & $3.4 \times 10^{3}$ & $1.42 \times 10^{5}$ & $6.71015 \times 10^{4}$ \\
\hline $\mathrm{Na}^{+}$ & $4.09 \times 10^{2}$ & $4.09 \times 10^{4}$ & $3.769 \times 10^{4}$ & $4.87 \times 10^{4}$ & $1.056860 \times 10^{5}$ \\
\hline $\mathrm{Mg}^{2+}$ & 1 & $<1$ & $1.00 \times 10^{3}$ & 0 & 0 \\
\hline $\mathrm{Ca}^{2+}$ & $5 \times 10^{-1}$ & $<1$ & $1.00 \times 10^{3}$ & 0 & 0 \\
\hline $\mathrm{F}^{-}$ & $1.4 \times 10^{1}$ & $1.4 \times 10^{3}$ & 0 & 0 & $1.3308 \times 10^{3}$ \\
\hline $\mathrm{Cl}^{-}$ & $6.7 \times 10^{1}$ & $6.7 \times 10^{3}$ & $2.425 \times 10^{4}$ & $1.28 \times 10^{5}$ & $1.313155 \times 10^{5}$ \\
\hline $\mathrm{NO}_{3}{ }^{-}$ & $6.4 \times 10^{1}$ & $6.4 \times 10^{3}$ & $2.30 \times 10^{4}$ & $1.313 \times 10^{6}$ & $1.394661 \times 10^{6}$ \\
\hline $\mathrm{SO}_{4}{ }^{2-}$ & $1.67 \times 10^{2}$ & $1.67 \times 10^{4}$ & $3.86 \times 10^{4}$ & 0 & $1.39237 \times 10^{4}$ \\
\hline $\mathrm{HCO}_{3}{ }^{-}$ & $9.47 \times 10^{2}$ & $7.0 \times 10^{4}$ & 0 & 0 & 0 \\
\hline $\mathrm{Si}^{2}$ & $27\left(60^{\circ} \mathrm{C}\right), 49\left(90^{\circ} \mathrm{C}\right)$ & $27\left(60^{\circ} \mathrm{C}\right), 49\left(90^{\circ} \mathrm{C}\right)$ & $27\left(60^{\circ} \mathrm{C}\right), 49\left(90^{\circ} \mathrm{C}\right)$ & 0 & 0 \\
\hline $\mathrm{pH}$ & 9.8 to 10.2 & 9.8 to 10.2 & 2.7 & 5.5 to 7 & 12 \\
\hline
\end{tabular}

Source: DTN: LL040803112251.117 [DIRS 171362].

NOTE: The simulated dilute water (SDW), simulated concentrated water (SCW), and basic saturated water (BSW) test solutions correspond to increasing evaporative concentration of $\mathrm{J}-13$ well water. The simulated saturated water (SSW) test solution contains only $\mathrm{Cl}^{-}$and $\mathrm{NO}_{3}{ }^{-}$and represents a very low relative humidity condition, where the other anions have precipitated out of solution. The simulated acidic water (SAW) test solution is moderately acidic (hence, contains no carbonate) with an ionic strength similar to the SCW test solution; fluoride was excluded because of its high vapor pressure at the solution $\mathrm{pH}$. Recorded $\mathrm{pH}$ values are for actual solutions at room temperature.

In-Drift Brine Compared to Test Solutions - The compositions of brines that may form by deliquescence of salt in dust deposited on the waste package were evaluated in Engineered Barrier System: Physical and Chemical Environment (BSC 2004 [DIRS 169860], Sections 6.10 and 6.13). In that document, the evaporative concentration of solutions containing salts leached from tunnel dust samples (see Section 6.1.2 of the present report) was simulated using EQ3/6, and the resulting brines were grouped into six bins based on similar chemical characteristics. 
Table 6.3-2 lists the bins, their relative frequency of occurrence among the dust leachate samples, their dominant constituents at $98 \% \mathrm{RH}$ and at dryout, and classifies the waters in the bins with respect to the natural brine type they represent based on the descriptions of the natural brine types given later in this section. The table also shows the corrosion test solutions that have the corresponding classification. The classification of the corrosion test solutions represents the actual evolutionary pathway required to form them, determined by simulating either dilution or evaporation of the waters with $\mathrm{EQ} 3 / 6$. Solutions of pure $\mathrm{NaCl}$ do not fall directly into any water type, but are broadly similar to either carbonate- or sulfate-type waters during certain periods of their evolution.

Table 6.3-2. Brines Formed by Dust Deliquescence and the Corresponding Corrosion Test Solutions

\begin{tabular}{|c|c|c|c|c|c|}
\hline $\begin{array}{c}\text { Bin } \\
\text { Water }\end{array}$ & $\begin{array}{c}\text { Relative } \\
\text { Frequency }(\%)^{a} \\
\end{array}$ & $\begin{array}{l}\text { Dominant } \\
\text { Constituents in } \\
\text { Bin Water at } \\
\text { 98\% Relative } \\
\text { Humidity }\end{array}$ & $\begin{array}{c}\text { Dominant } \\
\text { Constituents in } \\
\text { End-Point Brines }\end{array}$ & Brine Type & $\begin{array}{l}\text { Corrosion Test } \\
\text { Solutions of the } \\
\text { Same Brine Type } \\
\end{array}$ \\
\hline 1 & 5.77 & $\mathrm{Na}-\mathrm{NO}_{3}$ & $\mathrm{Ca}-\mathrm{NO}_{3}$ & Calcium Chloride & $\begin{array}{c}\mathrm{CaCl}_{2} ; \mathrm{CaCl}_{2}+ \\
\mathrm{Ca}\left(\mathrm{NO}_{3}\right)_{2}\end{array}$ \\
\hline 2 & 7.69 & $\mathrm{Na}-\mathrm{NO}_{3}$ & $\mathrm{~K}-\mathrm{NO} 3 ; \mathrm{Na}-\mathrm{NO}_{3}$ & Sulfate & SSW, SAW, $\mathrm{NaCl}$ \\
\hline 3 & 17.31 & $\mathrm{Na}-\mathrm{SO}_{4}$ & $\mathrm{~K}-\mathrm{NO} 3 ; \mathrm{Na}^{-\mathrm{NO}_{3}}$ & Carbonate & $\begin{array}{c}\text { SDW, SCW, BSW, } \\
\text { SSW, } \mathrm{NaCl}\end{array}$ \\
\hline 4 & 23.08 & $\mathrm{Na}-\mathrm{NO}_{3}$ & $\mathrm{Na}-\mathrm{NO}_{3}$ & Sulfate & SSW, SAW, $\mathrm{NaCl}$ \\
\hline 5 & 44.23 & $\mathrm{Na}-\mathrm{NO}_{3}$ & $\mathrm{~K}-\mathrm{NO} 3 ; \mathrm{Na}-\mathrm{NO}_{3}$ & Sulfate & SSW, SAW, $\mathrm{NaCl}$ \\
\hline 6 & 1.92 & $\mathrm{Na}-\mathrm{Cl}$ & $\mathrm{K}-\mathrm{NO}_{3}$ & Carbonate & $\begin{array}{c}\text { SDW, SCW, BSW, } \\
\text { SSW, } \mathrm{NaCl}\end{array}$ \\
\hline
\end{tabular}

a BSC 2004 [DIRS 169860], Table 6.10-6.

b BSC 2004 [DIRS 169860], Table 6.13-9.

It should be noted that brines formed by dust deliquescence are not expected to exhibit the same range of characteristics as brines formed on the Earth's surface. These differences are mainly due to differences in the chemistry of surface waters relative to the salt components in dust and atmospheric aerosols. Specifically, dust brines are expected to be very nitrate-rich relative to surface waters, and to be magnesium-poor. Nitrate is abundant relative to chloride in dust and atmospheric aerosols because of processes that transfer chloride from the particulate phase to the gas phase in the atmosphere (Section 6.1.3) and the multiple potential sources for nitrate (e.g., atmospheric aerosols, desert soils). Also, because of the high solubility of nitrate minerals (Weast and Astle 1981 [DIRS 100833], pp. B-73 to B-166) at elevated temperature, they dominate most eutectic solutions at deliquescence. Magnesium is not significant because of limited sources for the dust, and multiple removal mechanisms, most of which are enhanced by elevated temperature (BSC 2004 [DIRS 161237], Sections 6.7.2.10 and 6.7.2.11). Table 6.3-3 summarizes the general classification of the brine types that could form by dust deliquescence, and the probabilities of occurrence, based on the number of dust leachates falling in each group. Each of the brine types is discussed below, first in a general sense, and then with specific reference to brines that can form by dust deliquescence. 
Table 6.3-3. General Classification of the Brine Types and the Probabilities of Contact

\begin{tabular}{|l|c|l|}
\hline \multicolumn{1}{|c|}{ Brine Type } & $\begin{array}{c}\text { Relative Frequency of } \\
\text { Occurrence }\end{array}$ & \multicolumn{1}{c|}{ Comments } \\
\hline Calcium chloride & 5.77 & $\begin{array}{l}\text { Solutions are dominated by calcium nitrate. Fluoride, } \\
\text { carbonate, sulfate contents are negligible. }\end{array}$ \\
\hline Sulfate & 75.00 & Near-neutral pH. \\
\hline Carbonate & 19.23 & High pH, no significant calcium or magnesium content. \\
\hline
\end{tabular}

NOTE: $\quad$ Relative frequency of occurrence is tabulated from Table 6.3-2.

Calcium Chloride Brines-Naturally occurring brines may have acidic to near-neutral $\mathrm{pH}$ and no significant bicarbonate, carbonate, fluoride, or sulfate content. These brines may contain other cations such as $\mathrm{Na}^{+}, \mathrm{K}^{+}$, and $\mathrm{Mg}^{2+}$, and other anions such as $\mathrm{NO}_{3}{ }^{-}$. The endpoint of the evaporative concentration of this type of brine would contain $\mathrm{Ca}-\mathrm{Cl} / \mathrm{NO}_{3}$ or a mixture of $\mathrm{Ca} / \mathrm{Mg}-\mathrm{Cl} / \mathrm{NO}_{3}$. The quantity of $\mathrm{Mg}^{2+}$ and $\mathrm{Ca}^{2+}$ in this type of brine is limited due to the precipitation of calcium and magnesium carbonates and sulfates and magnesium silicates. This is consistent with data from saline lakes, where $\mathrm{Na}^{+}$is the dominant cation with the percentage of $\mathrm{Ca}^{2+}$ varying from insignificant to about 20\% (Drever 1997 [DIRS 147480]). In the repository, the concentration of $\mathrm{Mg}^{2+}$ in any type of brine is expected to be insignificant, and magnesium-chloride brines are not expected. Nitrate will be abundant, and the eutectic composition for a brine of this type formed by dust deliquescence is actually expected to be more of a calcium-nitrate-sodium-chloride brine due to the compositional nature of the dust. Calcium chloride-type brines are expected to be rare, if they occur at all in the repository, as indicated in Table 6.3-3 (which is based on tunnel dust analyses).

Corrosion test solutions corresponding to calcium chloride-type brines include: calcium chloride, calcium chloride plus calcium nitrate, SSW (Table 6.3-1), and sodium chloride solutions. The SSW and sodium chloride test solutions represent the moderate relative humidity scenario where calcium is a minor component in the aqueous solution. Numerous electrochemical studies were performed in these test solutions. Thin film studies were also performed using these types of solutions on coupons of Alloy 22 using an environmental thermogravimetric analyzer.

Carbonate Brines-These brines are alkaline and do not contain significant calcium or magnesium. In the early stages of the evaporative concentration, calcium precipitates as carbonate minerals (calcite or aragonite). Magnesium precipitates as magnesium silicate (BSC 2004 [DIRS 161237], Section 6.7.2.11). In the repository, it is expected that magnesium will be removed efficiently, and potassium may be significant in some of these brines. As shown in Table 6.3-3, carbonate-type brines are expected to comprise only a small fraction of those produced by dust deliquescence (based on analyses of tunnel dust).

Corrosion test solutions corresponding to carbonate-type brines include: SDW, SCW, BSW, and under certain circumstances, $\mathrm{SSW}$ and $\mathrm{NaCl}$ aqueous test solutions (Table 6.3-2). The SDW test solution is a dilute alkaline solution; solutions in this concentration range could be expected to form for high relative humidity (greater than 99\%). The SCW test solution is a moderately concentrated alkaline solution; solutions in this concentration range could be expected to form for relative humidity in the range of 90 to $95 \%$. The BSW test solution is a highly concentrated alkaline solution and could be expected under repository conditions where temperatures could be 
at its measured boiling point of nominally $112^{\circ} \mathrm{C}$ to $113^{\circ} \mathrm{C}$, or where the relative humidity is nominally 70 to $75 \%$.

Under conditions of low relative humidity, carbonate-type brines are rich in $\mathrm{Cl}^{-}-\mathrm{NO}_{3}{ }^{-}$with low carbonate content. The SSW test solution has characteristics of this type of brine.

Sulfate Brines - These have near-neutral $\mathrm{pH}$ and no significant carbonate or calcium content. Calcium precipitates as carbonates and possibly sulfates. In addition, brines typically have only a small amount of magnesium, though some surface brines have been observed to have high magnesium (Drever 1997 [DIRS 147480], Table 15-1, p. 333, brines 1 through 3). The dominant cation is typically $\mathrm{Na}^{+}$. In brines formed by dust deliquescence, $\mathrm{K}^{+}$may be more significant than $\mathrm{Na}^{+}$, and $\mathrm{Mg}^{2+}$ is predicted to be insignificant. As shown in Table 6.3-3, the sulfate-type brines are the most common type predicted to form by dust deliquescence.

As with the other brine types, the dominant ions in sulfate brines vary with relative humidity. At low relative humidity, the solutions will be dominated by $\mathrm{Cl}^{-}$and $\mathrm{NO}_{3}{ }^{-}$anions, with $\mathrm{NO}_{3}{ }^{-}$ions dominating at the lowest relative humidity. At moderate relative humidity $(>70 \%), \mathrm{Cl}^{-}$ions may dominate. However, unlike the carbonate brines, these brines are expected to have near-neutral to slightly acidic $\mathrm{pH}$ because of the lack of a carbonate component. Significant amounts of dissolved carbonate and sulfate are not predicted until the relative humidity is greater than $85 \%$.

The corrosion test solutions corresponding to sulfate-type brines include SAW, SSW, and sodium chloride. The SSW has characteristics of water at low relative humidity, where sulfate is not a major brine component. Sodium chloride test solutions simulate the scenario where $\mathrm{Cl}^{-}$is the dominant anion under moderate relative humidity conditions. The SAW test solutions have characteristics of solutions in equilibrium with nominally $90 \%$ relative humidity.

\subsubsection{Experimental Evaluation of the Effect of Nitrate-Chloride Ratio}

Cyclic polarization data were used for developing the localized corrosion initiation model, described in General Corrosion and Localized Corrosion of the Waste Package Outer Barrier (BSC 2004 [DIRS 169984]). The experimental conditions considered include electrolyte composition (including chloride and nitrate ion molal concentrations), nitrate-chloride ion ratio, $\mathrm{pH}$, and temperature (BSC 2004 [DIRS 169984], Table 6-8). The localized corrosion model is parameterized to $120^{\circ} \mathrm{C}$, and shows that predicted deliquescent brine compositions do not initiate localized corrosion below that temperature. In General Corrosion and Localized Corrosion of Waste Package Outer Barrier (BSC 2004 [DIRS 169984], Section 6.4.4.6.6), a conservative nitrate-chloride ratio of 0.5 was selected as a threshold value below which localized corrosion would initiate for exposure temperatures between $120^{\circ} \mathrm{C}$ and $160^{\circ} \mathrm{C}$. Above $160^{\circ} \mathrm{C}$, it was conservatively assumed that crevice corrosion would initiate if a water film was present. The upper temperature limit of $160^{\circ} \mathrm{C}$ was selected due to sparse data above this temperature and not because localized corrosion was observed at higher temperatures.

Results from tests conducted by the Center for Nuclear Waste Regulatory Analyses (CNWRA) (Cragnolino et al. 2002 [DIRS 173552]) in aqueous environments at exposure temperatures of $95^{\circ} \mathrm{C}$ corroborate the nitrate inhibition effect, and indicate that a nitrate-chloride ratio of 0.1 is sufficient to inhibit localized corrosion of welded Alloy 22 in $0.5 \mathrm{M} \mathrm{NaCl-based} \mathrm{solutions.}$ 
The CNWRA has also conducted experiments in aqueous environments at exposure temperatures of $95^{\circ} \mathrm{C}$ and $110^{\circ} \mathrm{C}$ (Dunn et al. 2004 [DIRS 173813]), and these experiments indicate that a nitrate-chloride ratio of 0.2 is sufficient to inhibit localized corrosion of mill-annealed Alloy 22 in $5 \mathrm{M} \mathrm{MgCl}_{2}$-based solutions.

At higher temperatures $\left(\mathrm{T}>160^{\circ} \mathrm{C}\right)$, thermodynamic principles dictate that eutectic brine compositions can only be more nitrate-rich, and available data, although limited, suggest that there is no radical change in corrosion mechanisms (Section 6.3.1.4). Hence, it is likely that nitrate-rich brines will continue to be benign with respect to localized corrosion.

On the basis of this information and because the brines formed by deliquescence will have nitrate-chloride ratios greater than 0.4, and neutral to basic pH (BSC 2004 [DIRS 169860], Table 6.10-4), it is expected that localized corrosion will not initiate on Alloy 22 surfaces exposed to these deliquescent brines.

\subsubsection{Brine Compositions Predicted by Previous Modeling}

Previous models for dust deliquescence on the waste package surface were based on leachate analysis for dust samples collected underground from the Exploratory Studies Facility (BSC 2004 [DIRS 169860], Section 6.10). Brines formed by the deliquescence of salts in these dusts were shown to have nitrate-chloride ratios greater than 0.4, neutral to basic $\mathrm{pH}$ (BSC 2004 [DIRS 169860], Table 6.10-4), and to form by deliquescence at temperatures greater than $120^{\circ} \mathrm{C}$. Experimental data on boiling temperatures of $\mathrm{NaCl}-\mathrm{KNO}_{3}-\mathrm{NaNO}_{3}$ solutions $\left(>190^{\circ} \mathrm{C}\right.$; see Section 6.1.2.2) show that predicted dryout (or boiling) temperatures from the IDPS model (about $136^{\circ} \mathrm{C}$ for this assemblage in BSC 2004 [DIRS 161237], Table 6.7-22) were too low. However, nitrate-chloride ratios predicted at low temperatures can only increase with temperature (BSC 2004 [DIRS 169860], Section 6.15.1.1).

Further, the cited analyses are based on tunnel dusts. Atmospheric aerosols, which are likely to be more prominent in the repository dusts compared to ESF tunnel dust, are relatively depleted in chloride because of various reactions in the upper atmosphere (Section 6.1.3) and have even higher nitrate-chloride ratios. The primary source of chloride is ground-level particulates (e.g., playas, dry lakebeds, sea spray).

Accordingly, the brine compositions predicted to form by previous thermodynamic modeling have sufficient nitrate-chloride ratios that they are not corrosive with respect to Alloy 22. Inclusion of atmospheric aerosols as an important source of repository dust increases the likely nitrate-chloride ratios.

\subsubsection{Experimental Data for Temperatures above the Validation Range of the Localized Corrosion Model}

A series of exposure experiments on boldly exposed foil specimens at temperatures up to $220^{\circ} \mathrm{C}$ showed no evidence of localized corrosion initiation (as pitting) on Alloy 22 specimens. The experiments used autoclaves or Teflon acid digestion bombs and were conducted at exposure temperatures from 120 to $220^{\circ} \mathrm{C}$ with nitrate-chloride ratios from 0.05 to 6.7 for either three to four months $(4 \mathrm{~m})$ or eight to nine months $(9 \mathrm{~m})$ as shown in Table 6.3-4. These tests involved 
both fully immersed samples and samples exposed to vapor only. They were performed in order to obtain the general corrosion rate of Alloy 22 and to evaluate potential initiation of localized corrosion.

The foil weights were measured at three time points: before they were introduced into the autoclave, immediately after removal from the autoclaves (after rinsing briefly with Millipore water to remove excess salts precipitating as the solution dried), and after a more extensive cleaning designed to remove the oxide. Each environment contained three to four foil specimens. Corrosion rates were less than 0.2 microns per year for all temperatures and environments tested and were in agreement with general corrosion rates predicted by the YMP's temperature-dependent Alloy 22 general corrosion model (BSC 2004 [DIRS 169984], Section 6.4.3 and Figure 6-22) at the exposure temperatures considered. No evidence of pitting corrosion was observed. These results indicate that the basic mechanisms for general corrosion and pitting probably do not change with increasing temperature. Thus, the chemical processes (thermodynamic, intrinsic kinetic) that favor nitrate inhibition in solution-solid interactions with Alloy 22 are probably active at higher temperatures.

While these tests were not artificially creviced, they are relevant to the screening of dust deliquescence because they evaluated pitting, a form of localized corrosion. Experimental work with artificially creviced samples has shown that crevices must be very tight in order to restrict chemical transport sufficiently to initiate localized corrosion (Rebak 2005 [DIRS 174186], p. 8; ASM 1987 [DIRS 103753], p. 112). The crevices formed by dust particles in contact with the waste package surface are neither tight enough nor large enough (Section 6.4.4) to initiate localized corrosion, so for most of the waste package surface (excluding engineered crevices), pitting is the only form of localized corrosion that can occur. Thus, the lack of pitting in the elevated temperature experiments (Table 6.3-4) indicates that, for the range of conditions examined, nitrate inhibition of localized corrosion continues to be effective at elevated temperature.

Table 6.3-4. Test Temperatures and Durations Used in Autoclaves and Teflon Acid Digestion Bombs

\begin{tabular}{|c|c|c|c|c|c|c|c|c|}
\hline \multicolumn{5}{|c|}{ Solution } & \multicolumn{4}{|c|}{ Temperature } \\
\hline $\begin{array}{l}\mathrm{NaCl} \\
(\mathrm{m})\end{array}$ & $\begin{array}{c}\mathrm{NaNO}_{3} \\
\text { (m) }\end{array}$ & $\begin{array}{c}\mathrm{KNO}_{3} \\
(\mathrm{~m})\end{array}$ & {$\left[\mathrm{NO}_{3}{ }^{-}\right] /\left[\mathrm{Cl}^{-}\right]$} & $\begin{array}{c}\text { Total } \\
\text { Molality }\end{array}$ & $120^{\circ} \mathrm{C}$ & $140^{\circ} \mathrm{C}$ & $160^{\circ} \mathrm{C}$ & $220^{\circ} \mathrm{C}$ \\
\hline 6.4 & - & 0.3 & 0.05 & 6.7 & - & $4 m, 9 m$ & - & - \\
\hline 6.4 & - & 2.0 & 0.3125 & 8.4 & $4 m$ & $4 m$ & $4 m$ & $4 m, 9 m$ \\
\hline 6.4 & - & 3.2 & 0.5 & 9.6 & - & $4 m, 9 m$ & - & - \\
\hline 2.7 & 3.4 & 15.1 & 6.7 & 21.2 & $4 m$ & $4 m$ & $4 m$ & - \\
\hline
\end{tabular}

Source: DTNs: LL040502512251.099 [DIRS 172589] and LL040907112251.122 [DIRS 172593].

NOTE: The numbers with " $m$ " below the "Temperature" column headers are approximate time lengths of the test performed in months.

\subsubsection{Effects of Acid Degassing}

As discussed in Section 6.2 and reviewed here, acid degassing may result in dryout if sufficient degassing occurs. However, even if dryout does not occur, the effects of acid degassing are beneficial with respect to corrosion. It raises the nitrate-chloride ratio in the remaining solution, because $\mathrm{HCl}$ has a higher vapor pressure than $\mathrm{HNO}_{3}$ and is degassed more readily. Although the predicted vapor pressures of acid gases above the brines are low, especially for Assemblages A 
and $\mathrm{B}$, and degassing to complete dryout is unlikely, even small amounts of degassing ( $1 \%$ or less of the total chloride) result in large increases in $\mathrm{pH}$, to values near 10 for Assemblages $\mathrm{A}$ and $\mathrm{B}$, and to near-neutral conditions for Assemblage $\mathrm{C}$ (Section 6.2). In all cases, acid degassing, regardless of the degree to which it occurs, is beneficial with respect to the corrosivity of the brine.

\subsubsection{Reactions with Low-Solubility Dust Minerals}

In Engineered Barrier System: Physical and Chemical Environment (BSC 2004 [DIRS 169860]), the chemistry of brines that could potentially form on a waste package surface due to dust deliquescence was calculated from dust leachate analyses representing the soluble salts in the dust; the relatively insoluble non-salt minerals (e.g., silicates, and potentially a large fraction of the carbonates and sulfates present) in the dust were not included. However, the non-salt dust particles will remain in close contact with any brine condensed in the dust. Given the high specific surface area of the particles and the time scale of concern for the repository, the insoluble components of the dust are expected to react with brines formed by dust deliquescence.

The non-salt components of the dust will have a significant impact on the chemistry of the deliquesced brine. Peterman et al. (2003 [DIRS 162819], Figure 3) indicate that the major source of the dust collected in the ESF is from the rhyolite of the Topopah Spring tuff. This aluminosilicate component will tend to buffer the $\mathrm{pH}$ of the condensed brine. A similar concept has been proposed by EPRI (2004 [DIRS 172825]), which notes that the same reasoning would apply to atmospheric aerosols, based on the mineralogy of wind-blown dust at the site, which also contained a high load of silicate, carbonate, and sulfate phases. The dissolution or precipitation of silicate minerals (especially clays) will also modify compositional ratios of the brine, thus potentially changing the deliquescent mineral assemblage and the deliquescence RH, causing the brine to dry out. This section summarizes the results of dust deliquescence calculations including both the soluble dust leachate and the less-soluble mineral components. This analysis makes use of the IDPS model (BSC 2004 [DIRS 169863]), using data0.ypf.R0 (DTN: SN0302T0510102.002 [DIRS 162572]). However, the mineral suppressions vary from those in the IDPS model, as the intent here is to evaluate the effect of reactions with low-solubility minerals. Some of these were suppressed in the IDPS model, which was developed to evaluate brine compositions resulting from the relatively rapid processes of evaporation and deliquescence.

The calculations were performed in two steps. First, a chemical composition of each sample was obtained by combining a solid chemical analysis with the corresponding leachate analysis to form a composite dust sample (Output DTN: MO0506SPAEQ36F.002, spreadsheet DUST_Leachate_YW.XLS in "Equilibration_With_Low_Solubility_Phases"). This was done in the following steps:

- For a measurement less than a detection limit $(<\mathrm{n})$, the measurement was set to the half of that limit (i.e., $0.5 \mathrm{n}$ ). This maximized the number of useable dust analyses. A total of 53 samples were included in the calculations (see Tables 4.1-17 and 4.1-18).

- The number of moles of each element in one gram of dust solids was calculated. 
- The number of moles of each element in dust leachates corresponding to one gram of dust solids was calculated.

- The total number of moles of each element in one gram of composite dust was calculated by combining a dust leachate analysis with a dust solid analysis. To minimize the perturbation to the leachate composition, soluble salt components $\left(\mathrm{Cl}, \mathrm{NO}_{3}\right.$, and $\left.\mathrm{SO}_{4}\right)$ were directly taken from the leachate analysis, while other components $(\mathrm{Si}, \mathrm{Al}, \mathrm{Mg}, \mathrm{Ca}$, $\mathrm{Na}, \mathrm{F}$, and $\mathrm{PO}_{4}$ ) were taken from the solid phase analysis.

- $\mathrm{Br}$ was excluded from the calculation because it is probably a contaminant. $\mathrm{LiBr}$ was added as a tracer to waters used for testing and dust suppression, as described by Environment on the Surfaces of the Drip Shield and Waste Package Outer Barrier (BSC 2004 [DIRS 161237], Section 6.7.2.10). The sources of bromide in tunnel dust, and its significance to characterizing the in-drift chemical environment, were evaluated in Engineered Barrier System: Physical and Chemical Environment (BSC 2004 [DIRS 169860], Section 6.12.4.2).

- The input solution compositions for EQ3 runs were calculated by dissolving one gram of the composite dust into one kilogram of deionized water. This specific ratio of dust to water was chosen so that the resulting solutions were close to the upper limit of water activity (approximately 1.0). A low dust/water ratio also helped the convergence of EQ3 calculations. It should be noted that the choice of dust/water ratio does not impact the calculated functional dependence of water chemistry on water activity during evaporation as long as the starting solutions are sufficiently dilute.

Next, the deliquescence calculation was performed by evaporating the initial solution calculated above to complete dryness. The calculation was performed for a temperature of $25^{\circ} \mathrm{C}$ and a $\mathrm{CO}_{2}$ partial pressure of $10^{-3.5} \mathrm{~atm}$. Because no redox reaction was involved, the partial pressure of $\mathrm{O}_{2}$ was arbitrarily set to $0.6732 \mathrm{~atm}$. Precipitation of dolomite and magnesite were suppressed while silicates, especially clays, were allowed to precipitate or dissolve. Given the sizes of dust particles (on the order of microns) and the time scale of interest (many years), the assumption that brines will react with silicate components is reasonable. The calculation results are documented in Output DTN: MO0506SPAEQ36F.002 and are shown in Figure 6.3-1.

As shown in Figure 6.3-1a, the inclusion of dust solids in the calculations results in a somewhat narrower $\mathrm{pH}$ range than predicted for the leachate only. Even two leachate samples that were phosphate-rich and generated highly acidic brines when evaporated (charge balancing was done on $\mathrm{H}^{+}$) plotted in the same $\mathrm{pH}$ range as the other samples when equilibrated with the insoluble phases. This demonstrates that dissolution and formation of silicate minerals is an effective $\mathrm{pH}$ buffering mechanism for brines formed by dust deliquescence. These reactions may also promote acid degassing by preventing the $\mathrm{pH}$ from rising as high, but this was not analyzed because the relative rates of the two processes are not known.

An added dividend of this approach is that the predicted brine $\mathrm{pH}$ vales are insensitive to the $\mathrm{pH}$ of the initial solution; therefore, initial $\mathrm{pH}$ measurements in leachate samples (which were not measured) are not required for brine $\mathrm{pH}$ predictions as long as dust solid components are 
included in the calculations, and the silicate components are sufficiently reactive to allow substantial reaction with the brine on the time scale of interest.

The silicate minerals that formed during these simulations include quartz, albite, maximum microcline, celadonite (a muscovite-group clay, given in data0.ypf.R1 as $\mathrm{KMgAlSi}_{4} \mathrm{O}_{10}(\mathrm{OH})_{2}$ ), and erionite (a zeolite, given in data0.ypf.R1 as $\mathrm{K}_{1.5} \mathrm{Na}_{0.9} \mathrm{Ca}_{0.9} \mathrm{Al}_{4.2} \mathrm{Si}_{13.8} \mathrm{O}_{36}: 13 \mathrm{H}_{2} \mathrm{O}$ ). These phases are the predicted stable mineral assemblage at dryout, indicating that deliquescent brines will react with the dust minerals to form this suite of minerals. While quartz and feldspars are present in the rock dust already, celadonite and erionite are secondary minerals, which will form as the primary minerals react with the brine. They contain potassium, and magnesium or calcium, and are sinks for these elements. As these mineral species precipitate, the brines will evolve towards Na-rich compositions. The corresponding predicted deliquescent mineral assemblages are sodium-rich and deliquesce from around 40 to $70 \% \mathrm{RH}$ at $25^{\circ} \mathrm{C}$ (Figure $6.3-1 \mathrm{~b}$ ). Of the total of 53 samples (Section 4.1.9), 52 of them have deliquescence relative humidities greater than $67 \%$ at $25^{\circ} \mathrm{C}$, controlled largely by the formation of either halite or soda niter. This indicates that reaction with less-soluble components in the dust, if taken to equilibrium, will cause dryout of brines formed by dust deliquescence.

The effect of including low solubility components of the dust on other important parameters is shown in Figures 6.3-1c and 6.3-1d. Chloride concentrations (Figure 6.3-1c) cluster tightly into two groups, which are, on average, slightly higher than the concentrations in the leachate-only samples. However, nitrate-chloride ratios (Figure 6.3-1d) change little. In both cases, the phosphate-rich samples cluster with the other samples in the "leachate + solid" cases, testifying to the buffering capacity of the solution:solid system with respect to chemistry. The nitrate-chloride ratios of several of the dust-equilibrated end-point brines are 0.46 , close to the conservative threshold value for crevice-induced localized corrosion of 0.5 (Section 6.3.1.2). However, it should be noted that these simulations were run at $25^{\circ} \mathrm{C}$, and that nitrate-chloride ratios at dryout would be higher at higher temperatures, because the solubility of $\mathrm{Na}$ and $\mathrm{K}$ nitrate phases increases more rapidly with temperature than that of the corresponding chloride phases. Also, it should be remembered that these are tunnel dusts, containing only a tiny fraction of nitrate-rich atmospheric dusts, while future repository dusts are expected to be much more nitrate-rich (Section 6.1.3).

Although not examined quantitatively here, secondary silicate phases that form as brine and dust minerals react may also consume brine components. Chloride substitution for hydroxides in mica-group minerals, including biotite, muscovite, and phlogophite, is well documented (Chen and Sverjensky 1991 [DIRS 173233]); similar substitution may occur in celadonite. However, the degree of substitution in micas is strongly temperature dependent, and even if it should occur in celadonite, it is likely limited to several tens of parts per million at temperatures relevant to Yucca Mountain. Similarly, chloride may be removed from solution by exchange with surface hydroxyl groups on minerals in the dust or secondary minerals that form by dust-brine reactions. Vassilev et al. (2000 [DIRS 173232]) found that chloride in coal was associated with clays, and postulated that substitution for hydroxyl groups on the clay surface was important. Relatively few of the many possible silicate minerals that might form by brine-dust interactions are in data0.ypf.R0 (DTN: SN0302T0510102.002 [DIRS 162572]). Some of the missing phases contain stoichiometric chloride (e.g., scapolite-, sodalite-, cancriniteand prehnite-group minerals, amphiboles); however, some of these (the feldspathoids) are 
unlikely to form in the silica-rich environment of the dust, and some (the scapolite and amphibole groups) form only at high temperatures or pressures. A great many other minerals, including many clay species, contain hydroxyl groups for which varying amounts of chloride can substitute. Sequestration of chloride into silicate phases is very likely to occur; however, thermodynamic data are lacking to evaluate this quantitatively, and the degree to which this process could consume chloride in the brine is unknown.

a)

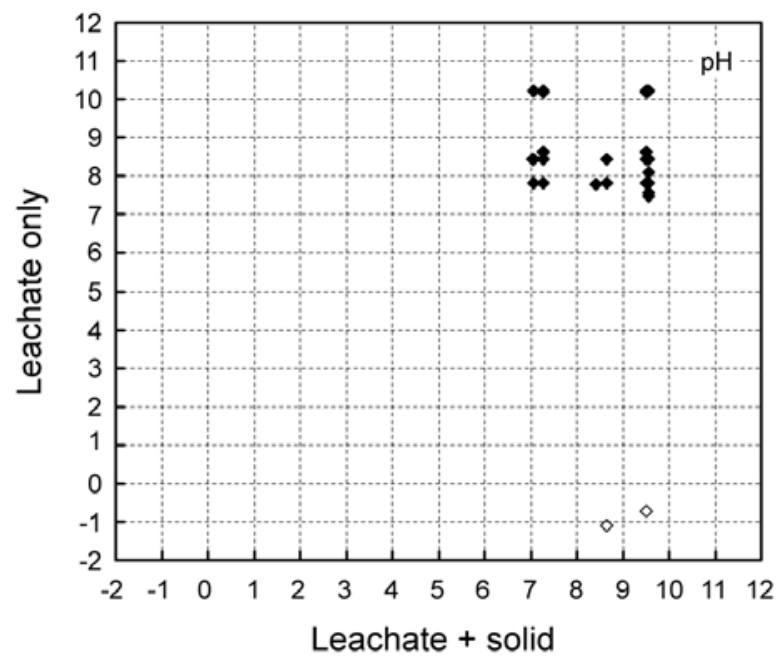

c)

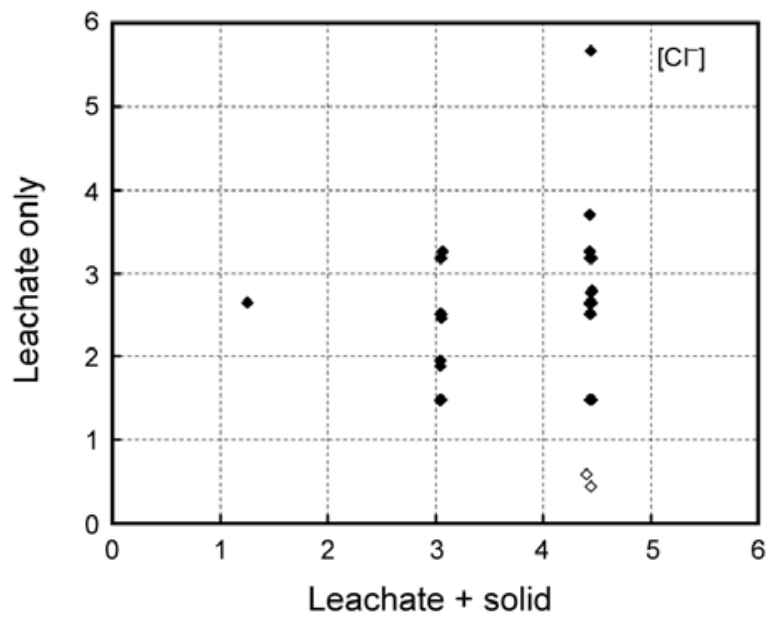

b)

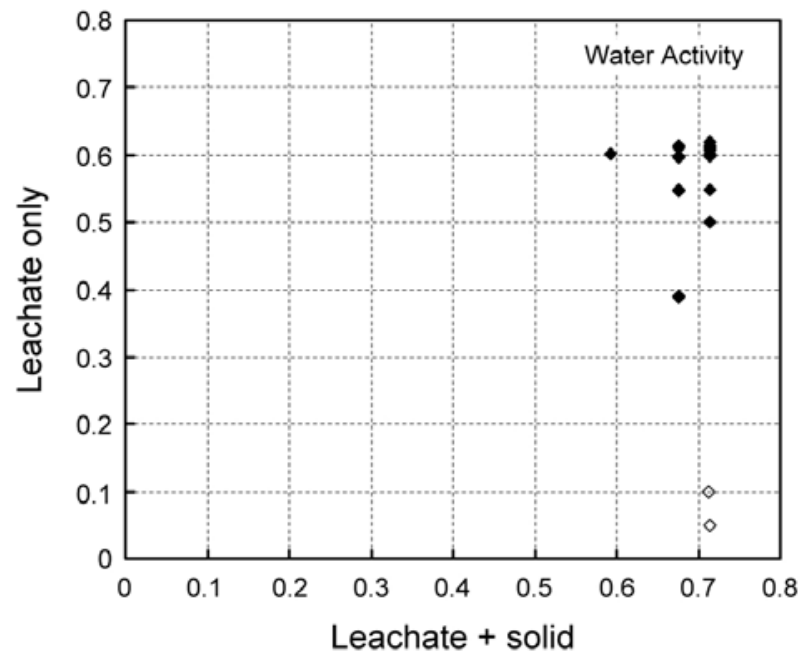

d)

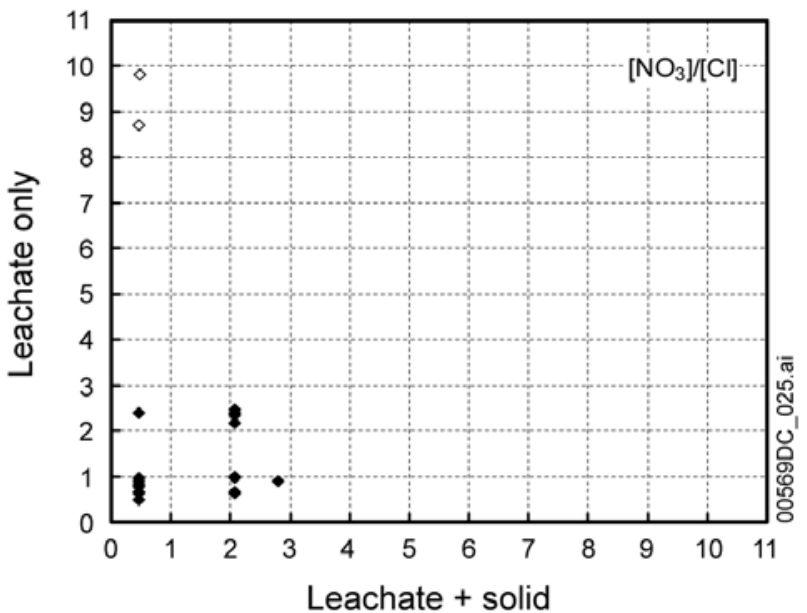

Source: Output DTN: MO0506SPAEQ36F.002.

NOTE: The data shown here correspond to the end point of the evaporation. The points shown as open symbols in each graph represent phosphate-rich samples that are not included in the BSC 2004 [DIRS 161237] analysis. Chloride concentration in part c) is given in molality.

Figure 6.3-1. Comparison of Analysis Results with Dust Leachate Residues Included (Labeled as "Leachate + solid") with Calculations Using Only Leachate (Labeled as "Leachate only") 


\subsubsection{Summary}

Initial brines formed by deliquescence are expected to be near-neutral $\mathrm{pH}$, nitrate-rich, and chloride-poor (BSC 2004 [DIRS 169860], Section 6.10), and therefore to be benign with respect to localized corrosion. Experimental corrosion studies used to develop the localized corrosion model have verified that corrosion will not be initiated by brines high in nitrate, such as those formed by dust deliquescence, at temperatures below $120^{\circ} \mathrm{C}$. Newer, higher-temperature data have verified that nitrate inhibition of corrosion can continue to be effective at temperatures up to $220^{\circ} \mathrm{C}$.

Based on thermodynamic principles, brines potentially forming at temperatures above $140^{\circ} \mathrm{C}$, the validation limit of the IDPS model, can only be more nitrate-rich (BSC 2004 [DIRS 169863], Section 7; BSC 2004 [DIRS 169860], Section 6.15.1.1) than brines that form at lower temperatures, within the range of validation. Analyses presented here show that processes occurring after deliquescence, acid degassing and reactions with silicate minerals, cannot result in brines that are corrosive with respect to localized corrosion. Acid degassing will raise the nitrate-chloride ratio of the remaining solution, and even small degrees of degassing will result in increases in the brine $\mathrm{pH}$, to values ranging from near neutral to as high as approximately 10.3. Brine interactions with silicate minerals may buffer the $\mathrm{pH}$ to near-neutral values, and may lead to dryout and precipitation of a less-deliquescent salt assemblage. Initiation of localized corrosion is unlikely in these exposure environments (BSC 2004 [DIRS 169984], Section 6.4.4).

Uncertainty Discussion-The corrosivity part of the screening arguments for dust deliquescence emphasizes the inhibiting effect of the nitrate-chloride ratio on initiation and extent of localized corrosion in Alloy 22. However, other anionic species including carbonate and sulfate also provide some inhibition (BSC 2004 [DIRS 169984], Section 8.3.1) that is not considered quantitatively.

Nitrate in repository dust will be contributed by atmospheric aerosols, from host rock pore waters, from fossil-fuel operated equipment upstream of the emplacement areas, and other sources (Section 6.1.3). The chemical form of that nitrate is uncertain and may include $\mathrm{NH}_{4} \mathrm{NO}_{3}$, $\mathrm{NaNO}_{3}$, and $\mathrm{KNO}_{3}$. To the extent that nitrate exists as $\mathrm{NH}_{4} \mathrm{NO}_{3}$, it may volatilize from the waste package surface (e.g., as $\mathrm{N}_{2} \mathrm{O}(\mathrm{g})$ ). This behavior is taken into account in the qualitative description of dust (Section 6.1.2.3), and this report includes an analysis of the effects of ammonium salts on deliquescent brine (Section 6.1.2.4). However, lacking direct observations of the soluble salts present in dust, the partitioning of nitrate to ammonium and other salts remains an uncertainty in the analysis of corrosivity.

Finally, the representation of the undissociated $\mathrm{HCl}$ and $\mathrm{HNO}_{3}$ species in concentrated brines, upon which the calculated gas-phase partial pressures depend directly, may be subject to effects that are not represented in the EQ3/6 Pitzer calculations. In other words, whereas the partial pressure of $\mathrm{HCl}$ is predicted to be greater than that of $\mathrm{HNO}_{3}$, this has not been observed directly. The impact of this uncertainty is minor if the extent of degassing is minor, and the effects are limited to buffering the $\mathrm{pH}$ (Section 6.2). 


\subsection{IF POTENTIALLY CORROSIVE BRINES FORM, WILL THEY INITIATE LOCALIZED CORROSION?}

Even if brines do persist, and are potentially corrosive (i.e., concentrated $\mathrm{Cl}^{-}$, low $\mathrm{pH}$, or low nitrate-chloride ratio; see Sections 6.2 and 6.3), they will not initiate localized corrosion for several reasons. The volumes of brine that form are very small, and much of what forms will be suspended in the dust by capillarity. Not all of the brine will contact the waste package surface, and what does contact will likely not form a continuous layer on the surface. Brine layer thickness or individual droplet sizes may be too small to maintain oxygen potential gradients necessary for cathodic and anodic regions to form and initiate localized corrosion.

Brine volume (or a liquid-solid ratio) is not included as a parameter of the localized corrosion model used for TSPA-LA (BSC 2004 [DIRS 169984], Section 6.4.4). The abstraction used for TSPA-LA is based mainly on data collected from immersed samples, and therefore closely represents the corrosion initiation response in environments with an abundant liquid phase, such as may occur if seepage contacts the waste package directly. For dust deliquescence, the liquid-phase volume has an important role because aspects of the brine volume (film thickness and continuity, access of air to the metal surface, and chloride inventory) are strongly limiting. Accordingly, while the localized corrosion model developed for TSPA-LA captures key chemical processes (e.g., nitrate inhibition), it does not capture the physico-chemical processes that depend on brine volume, and limit the initiation and propagation of localized corrosion.

\subsubsection{Brine Volume Estimates from Deliquescence of Salts Originating as Atmospheric Aerosols}

To estimate the volumes of brine that may form on the waste packages by deliquescence, it is necessary to evaluate the dust load that will be brought in by ventilation, and the amount and composition of salts in the dust.

\subsubsection{Quantity of Dust on the Waste Package Surface}

A quantitative analysis of the amount of dust that will be deposited upon waste packages during the ventilation period is summarized below. This quantity is of interest, as it will directly limit the quantity of potential brine that can form from the salts within the dust.

Direct inputs for this analysis are presented in Section 4.1.5 and reiterated briefly here. The following is a list of the information used in this analysis:

- Airborne particulate matter measurements (1996 to 2001) in $\mu \mathrm{g} / \mathrm{m}^{3}$ (Table 4.1-7)

- The nominal preclosure emplacement drift ventilation duration (50 years) and airflow volume $\left(15 \mathrm{~m}^{3} / \mathrm{sec}\right)(\mathrm{BSC} 2004$ [DIRS 168489], Table 1)

- Emplacement drift diameter, average lengths of emplacement and turnout drifts (BSC 2003 [DIRS 165572], Table 8 and Figure 5) 
- Turnout drift cross-sectional configuration (BSC 2004 [DIRS 172801] and its sources)

- 21-PWR waste package diameter (BSC 2004 [DIRS 169062]).

The particle mass distribution is calculated for two size fractions, based on the mean of the airborne particulate measurement average annual values (Table 4.1-7). Using the airborne particulate matter measurements that report both total suspended particle mass loading (average of $21.8 \mu \mathrm{g} / \mathrm{m}^{3}$ ) in air as well as $\mathrm{PM}_{10}$ (mass loading in air for particles that are equal to or less than $10 \mu \mathrm{m}$ in diameter, average $9.2 \mu \mathrm{g} / \mathrm{m}^{3}$ ), the mass-density of particles greater than $10 \mu \mathrm{m}$ in diameter was determined by difference. The resulting two fractions then have mass loading 9.2 and $12.6 \mu \mathrm{g} / \mathrm{m}^{3}$ for the sub-10- $\mu \mathrm{m}$ and $>10-\mu \mathrm{m}$-diameter particles, respectively (Output DTN: SN0508T0502205.016, Deposition.xls, tab "Dust particle"). To complete this analysis, the size distribution of the dust particles needs to be defined. Lacking any direct measurements of particle size distribution, a conservative modeling approach is adopted that determines and uses the particle sizes (above and below $10 \mu \mathrm{m}$ ) resulting in maximum deposition, and therefore maximum deliquescence brine volume.

The amount of atmospheric dust deposited during ventilation requires a dust particle density and particle size. Dust deposition velocities are calculated assuming atmospheric dust densities of both 1 and $2 \mathrm{~g} / \mathrm{cm}^{3}$. These densities are consistent with dust derived from common silicate minerals. A dust with particle density of $1 \mathrm{~g} / \mathrm{cm}^{3}$ can be considered highly porous, representing particles with mineral density of $2.6 \mathrm{~g} / \mathrm{cm}^{3}$ and porosity of approximately $60 \%$. This low value is reasonably close to the $1.26 \mathrm{~g} / \mathrm{cm}^{3}$ given by Quinn et al. (2001 [DIRS 173007], Table 4) for eastern North American 1.1 to $10 \mu \mathrm{m}$ "Super- $\mu \mathrm{m}$ " density measurements at $55 \% \mathrm{RH}$. The value of $1 \mathrm{~g} / \mathrm{cm}^{3}$ also corresponds to one of the density value lines $\left(1,4\right.$, and $\left.11.5 \mathrm{~g} / \mathrm{cm}^{3}\right)$ on the deposition velocity plot from Sehmel (1980 [DIRS 172607], Figure 6), which is used here to estimate deposition velocities (see Figure 4-1). An alternate density of $2 \mathrm{~g} / \mathrm{cm}^{3}$ is suggested by data from Handbook on Aerosols (Dennis 1976 [DIRS 158805], p. 20), which lists two applicable materials: "Air Filter Institute, standard test dust" with density approximately $2.0 \mathrm{~g} / \mathrm{cm}^{3}$; and "Atmospheric dust" with density 1.2 to $2.0 \mathrm{~g} / \mathrm{cm}^{3}$. Although no deposition velocity curve for $2 \mathrm{~g} / \mathrm{cm}^{3}$ particle density is shown in the figure provided by Sehmel (1980 [DIRS 172607], Figure 6), it is reasonable to estimate that the settling behavior is between that for $1 \mathrm{~g} / \mathrm{cm}^{3}$ and $4 \mathrm{~g} / \mathrm{cm}^{3}$.

The principal analysis here uses a mathematical model for particle and gas dry deposition described in the journal article "Particle and Gas Dry Deposition: A Review" (Sehmel 1980 [DIRS 172607]). Simply put, the deposition velocity, $v_{d}$, is defined as the negative of the deposition flux, $F$, divided by an airborne concentration, $\chi$. This is Equation 1 in the article by Sehmel (1980 [DIRS 172607]) and reproduced as input Equation 4-4.

One parameter to determine is the deposition velocity $\left(v_{d}\right)$. This is determined from Figure 4-1 (Figure 6 in Sehmel 1980 [DIRS 172607]) for the two particle sizes with a surface roughness height of $0.1 \mathrm{~cm}$. Surface roughness was estimated from the values in Table 6 of the article by Sehmel (1980 [DIRS 172607]), capturing a value between the invert roughness and the relatively smooth, but periodically broken, waste package surface. For $1 \mathrm{~g} / \mathrm{cm}^{3}$ dust density, the resulting 
deposition velocity range for particles from 5 to $40 \mu \mathrm{m}$ diameter is from 0.2 to $5 \mathrm{~cm} / \mathrm{sec}$; for approximately $2 \mathrm{~g} / \mathrm{cm}^{3}$, this range increases to 0.25 up to $8.5 \mathrm{~cm} / \mathrm{sec}$ (tabulated in DTN: SN0508T0502205.016, Deposition2.xls, sheet “dust particle"). These values fall within the range of $10^{-3}$ to $40 \mathrm{~cm} / \mathrm{sec}$ for particles of diameters 0.03 to $30 \mu \mathrm{m}$, as indicated at the top of Table 3 in Sehmel's (1980 [DIRS 172607]) article.

These deposition velocities allow for the numerical determination of the deposition flux, $F$, as a function of position along an average drift, including both the turnout and emplacement portions. Each successive meter of drift has the particle density adjusted for deposition occurring in the previous meter, which is consistent with turbulent mixing in the ventilation air flow, and results in slightly more deposition than might otherwise occur.

The average ventilated drift used as the baseline analysis here consists of $105 \mathrm{~m}$ of turnout drift proceeded by $627 \mathrm{~m}$ of emplacement drift. This is determined from the total repository lengths for turnout and emplacement drifts (BSC 2003 [DIRS 165572], Table 8) divided by the total number (106) of these drifts (BSC 2003 [DIRS 165572], Figure 5).

Also considered for the bounding case is a shorter turnout drift, which will result in a slightly higher dust loading relative to the average turnout. From current designs, the short turnout consists of $238 \mathrm{ft}$ of curved drift and $80 \mathrm{ft}$ of straight, prior to the start of the emplacement drift (see BSC 2004 [DIRS 167736], detail Panel 1, Turnout 1-8). The first $100 \mathrm{ft}$ of the curved section occurs before the ventilation door and can be subtracted from the total. The $100-\mathrm{ft}$ value is determined by hand-calculating the angle of the triangle which goes from the access main where the turnout begins, to where the turnout has fully separated from the main. With a 200-ft radius, and drift widths of 26 and $25 \mathrm{ft}$ for turnout and main, respectively, as input (Table 4.1-6), a value of 28.4 degrees is determined. This translates into an arc distance for the turnout drift of $99 \mathrm{ft}$, or approximately $100 \mathrm{ft}$. Removing the turnout deflection distance results in a ventilated turnout length of approximately $66 \mathrm{~m}$.

Within the turnout drift, deposition is considered to be proportional to the horizontal footprint area (i.e., width) of the invert. This assessment is conservative in that it will overestimate the dust carried into the emplacement drifts because some dust will settle upon the vertical walls of the turnout drift. Within the emplacement drift, the deposition is considered upon the waste package horizontal footprint and upon the invert horizontal footprint minus the shadow cast by the waste package. This decreases the deposition upon the emplacement invert, creating a conservative result with more dust accumulating on the downstream waste packages.

The numerical method results are also found to be consistent with the analytically integrated equation derived by Fuchs (1964 [DIRS 173852], Equation 46.2) for deposition of aerosols in turbulent flow, from which he concludes that "The rate of deposition of the aerosol...decays exponentially in the direction of the flow" (Fuchs 1964 [DIRS 173852], p. 264). Therefore, for any particle size or size distribution, the largest deposition, given constant flow and deposition area parameters, will occur at the closest point to the source of flow. This becomes the basis for considering the deposition in the first meter of flow in the emplacement drift as the upper bound.

A range of dust particle sizes is first investigated on a normalized (by mass) basis in order to determine what size particles will result in maximal deposition. The resulting relative values, 
scaled to the largest deposition in the 66-m case, are examined for three cases. Figure 6.4-1 shows the different depositions along the drift for different sized particles for: (a) 66-m turnout, $1 \mathrm{~g} / \mathrm{cm}^{3}$ particle density; (b) $105-\mathrm{m}$ turnout, $1 \mathrm{~g} / \mathrm{cm}^{3}$ particle density; and (c) $105-\mathrm{m}$ turnout, $2 \mathrm{~g} / \mathrm{cm}^{3}$ particle density. Note that, for clarity, not all particle sizes calculated in the DTN (SN0508T0502205.016, Deposition2.xls) are shown in this figure.

The conclusion from Figure 6.4-1a is that, for the 66-m turnout, the greatest deposition will occur at the beginning of the emplacement drift with a particle size of $30 \mu \mathrm{m}$. For the average $105-\mathrm{m}$ turnout and a particle density of $1 \mathrm{~g} / \mathrm{cm}^{3}$ (Figure $6.4-1 \mathrm{~b}$ ), the $23 \mu \mathrm{m}$ diameter particle is the size that will have the maximum relative deposition $(0.7$ percent greater than the $25 \mu \mathrm{m}$ case), $63 \%$ of that deposited in the 66-m turnout case. The same maximum relative deposition is seen for the $2 \mathrm{~g} / \mathrm{cm}^{3}$ case in Figure 6.4-1c, but with a smaller particle size of $18 \mu \mathrm{m}$ diameter. The uncertainty on the particle sizes determined to give maximum deposition is approximately $\pm 2 \mu \mathrm{m}$.

From this information, the particle sizes that will maximize deposition can be selected for the greater and less than $10 \mu \mathrm{m}$ size fractions. In every case, for the sub-10 $\mu \mathrm{m}$ size fraction, the diameter of $10 \mu \mathrm{m}$ results in the greatest deposition at the beginning of the emplacement drift. For the particle fraction greater than $10 \mu \mathrm{m}$, the diameter becomes case-dependent: for the 66-m turnout $\left(1 \mathrm{~g} / \mathrm{cm}^{3}\right)$, it is $30 \mu \mathrm{m}$; for the $105-\mathrm{m}$ turnout $\left(1 \mathrm{~g} / \mathrm{cm}^{3}\right)$, it is $23 \mu \mathrm{m}$; for the $105-\mathrm{m}$ turnout $\left(2 \mathrm{~g} / \mathrm{cm}^{3}\right)$, it is $18 \mu \mathrm{m}$.

By using these particle sizes to maximize dust deposition, the reasonable upper mass limits to dust deposition from ventilation can be determined for these three cases. This result, also as a function of length along the emplacement drift, is shown in Figure 6.4-2. 

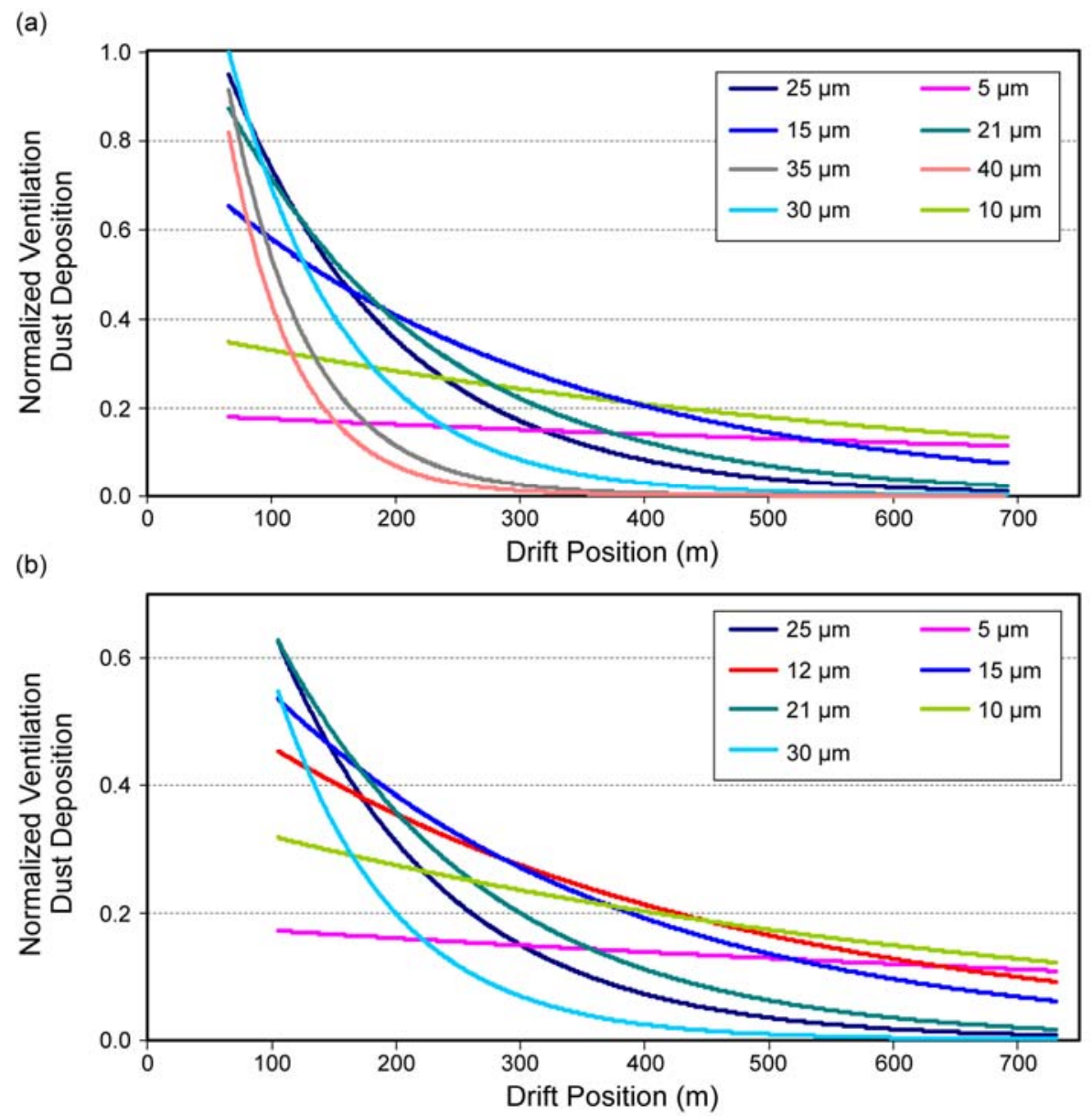

(c)

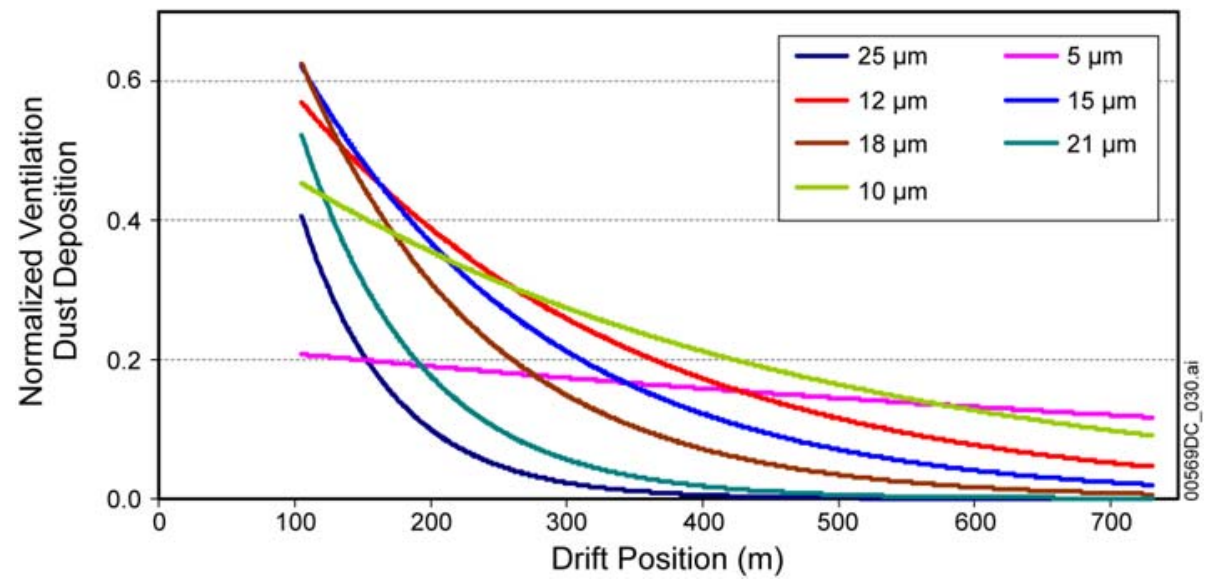

Source: Output DTN: SN0508T0502205.016, Deposition2.xls, sheets "Plot WP Dep 66m", "Plot WP Dep 105m_1" and "Plot WP Dep 105m_2."

Figure 6.4-1. Normalized Dust Deposition Quantity at Waste Package Position in Emplacement Drift: (a) $66-\mathrm{m}$ Turnout, $1 \mathrm{~g} / \mathrm{cm}^{3}$; (b) $105-\mathrm{m}$ Turnout, $1 \mathrm{~g} / \mathrm{cm}^{3}$; (c) $105-\mathrm{m}$ Turnout $2 \mathrm{~g} / \mathrm{cm}^{3}$ Density 

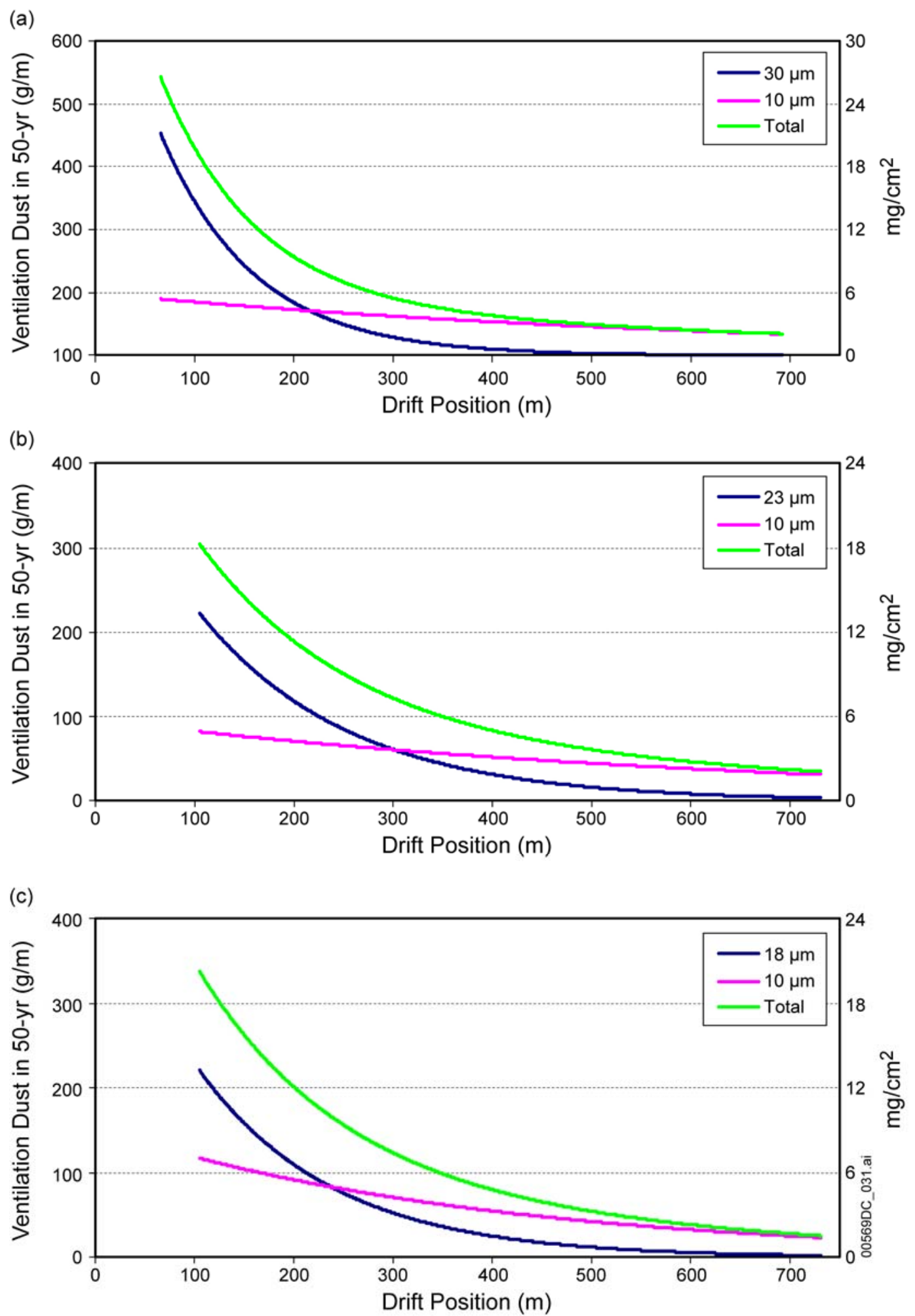

Source: Output DTN: SN0508T0502205.016, Deposition.xls, sheets "Plot WP Dep 105m_1", "Plot WP Dep 105m_2" and "Plot WP Dep 66m."

NOTE: Second y-axis is only an approximate conversion to $\mathrm{mg} / \mathrm{cm}^{2}$.

Figure 6.4-2. Dust Deposition Quantity on the Waste Package with: (a) 66-m Turnout, $1 \mathrm{~g} / \mathrm{cm}^{3}$; (b) $105-\mathrm{m}$ Turnout, $1 \mathrm{~g} / \mathrm{cm}^{3}$; (c) $105-\mathrm{m}$ Turnout $2 \mathrm{~g} / \mathrm{cm}^{3}$ Density 
Results showing both particle sizes and total deposition on the waste package are expressed on a gram per meter basis, and also converted to $\mathrm{mg} / \mathrm{cm}^{2}$ for the top of the waste package. The maximum quantity for average drift geometry ( $105 \mathrm{~m}$ of turnout drift before emplacement drift) is about $18 \mathrm{mg} / \mathrm{cm}^{2}$, using the dust density of $1 \mathrm{~g} / \mathrm{cm}^{3}$. The $2 \mathrm{~g} / \mathrm{cm}^{3}$ dust results in $10 \%$ more deposition on the waste package-about $20 \mathrm{mg} / \mathrm{cm}^{2}$. The reasonable upper bound result obtained for the $66-\mathrm{m}$ turnout case is $26 \mathrm{mg} / \mathrm{cm}^{2}$ of dust coverage on the waste package at the entrance to the emplacement drift. A summary of the integrated dust deposition at various locations (total mass) and the percentage of the total mass ventilated through and out of the drift over 50 years is presented in Table 6.4-1.

In comparison, these results fall between the lower and upper estimates of dust accumulation calculated in Total Dust Settling on Naval Long Waste Packages in 100 Years (BSC 2004 [DIRS 171462], Section 7). Those estimates were developed to bound the amount of dust present on the waste package exterior, for the purpose of modeling in-package criticality. The upper estimate considers the total dust introduced to an emplacement drift to be deposited on one waste package (Naval Long, length $5.98 \mathrm{~m}$ ), yielding a value of $3.04 \mathrm{~kg}$ dust per meter of waste package, or $18.2 \mathrm{~kg}$ per waste package. Using a plan waste package area of approximately $12 \mathrm{~m}^{2}$, this gives $150 \mathrm{mg} / \mathrm{cm}^{2}$ accumulation on the waste package surface. Similarly, the lower estimate considers the dust to be distributed throughout the length of the emplacement drift, at a rate of $0.03 \mathrm{~kg}$ dust per meter of waste package, or $0.18 \mathrm{~kg}$ per waste package. With a plan area of $12 \mathrm{~m}^{2}$, this gives $1.5 \mathrm{mg} / \mathrm{cm}^{2}$ accumulation.

Table 6.4-1. Disposition of Representative Ventilation Dust in Average and Short Drifts

\begin{tabular}{|c|c|c|c|c|c|}
\hline $\begin{array}{c}\text { Particle } \\
\text { Size }(\mu \mathrm{m}) / \\
\text { Density }\left(\mathrm{g} / \mathrm{cm}^{3}\right)\end{array}$ & $\begin{array}{c}\text { Total Ventilated } \\
\text { Through Drift }\end{array}$ & Turnout & $\begin{array}{c}\text { Emplacement } \\
\text { Invert }\end{array}$ & $\begin{array}{c}\text { Waste } \\
\text { Packages }\end{array}$ & Exhausted \\
\hline \multicolumn{6}{|c|}{ Average Drift, kg (Relative Percentage) } \\
\hline $23 / 1$ & $297(100)$ & $188.1(63.3)$ & $74.1(24.9)$ & $33.1(11.2)$ & $(0.6)$ \\
\hline $10 / 1$ & $218(100)$ & $45.3(20.8)$ & $73.8(33.9)$ & $33.0(15.2)$ & $(30.1)$ \\
\hline $18 / 2$ & $297(100)$ & $199.7(67.2)$ & $66.6(22.4)$ & $29.8(10.0)$ & $(0.3)$ \\
\hline $10 / 2$ & $218(100)$ & $70.2(32.2)$ & $81.6(37.5)$ & $36.5(16.8)$ & $(13.5)$ \\
\hline \multicolumn{6}{|c|}{ Short Drift, kg (Relative Percentage) } \\
\hline $30 / 1$ & $297(100)$ & $189.8(63.9)$ & $74.0(24.9)$ & $33.1(11.1)$ & $(0.0)$ \\
\hline $10 / 1$ & $218(100)$ & $29.7(13.6)$ & $80.5(37.0)$ & $36.0(16.5)$ & $(32.9)$ \\
\hline
\end{tabular}

Source: Output DTN: SN0508T0502205.016, Deposition.xls, sheets "23+10 um 105m_1", "18+10 um 105m_2" and " $30+10$ um $66 \mathrm{~m} . "$

NOTE: Percentages may not total $100 \%$ due to rounding off of values to nearest tenth of a percent.

Because the smallest size fraction is likely to contain a disproportionate amount of the soluble salts (Section 6.1.3), smaller particle size depositions were also examined with the 105-m average turnout. The results (Table 6.4-2) are presented as relative percentages that would be deposited; no specific mass is attributed. These dust particles are assigned a density of $4 \mathrm{~g} / \mathrm{cm}^{3}$ on the basis that if they do contain a higher salt density they should be less porous, and this higher density results in a higher deposition velocity. It is still found that a quantity less than $2 \%$ of this very small size dust is deposited upon waste packages, and more than $90 \%$ is still contained within the ventilation exhaust flow. Also, this small degree of deposition results in an even smaller relative mass contribution due to particle size; e.g., the $1 \mu \mathrm{m}$ particles, even with 
four times the density, have a mass less than $1 / 30$ of the mass of a $5 \mu \mathrm{m}$ particle. For these reasons, very small particulates are not considered further.

Table 6.4-2. Consideration of Smaller Particle Deposition in Average Drift

\begin{tabular}{|c|c|c|c|c|c|}
\cline { 3 - 6 } \multicolumn{2}{c|}{} & \multicolumn{4}{c|}{ Dust Deposition Location (Relative Percentage) } \\
\hline Particle Size $(\mu \mathrm{m})$ & $v_{d}(\mathbf{c m} / \mathbf{s})$ & Turnout & Emplacement Drift & Waste Packages & Exhausted \\
\hline 1 & 0.025 & 1.4 & 3.8 & 1.7 & 93.1 \\
\hline 0.2 & 0.01 & 0.55 & 1.6 & 0.7 & 97.2 \\
\hline
\end{tabular}

Source: Output DTN: SN0508T0502205.016, Deposition.xIs, sheet "<1 um particles."

\subsubsection{Volume of Brine Generated by Dust Deliquescence}

Direct inputs for this analysis are presented in Section 4.1.3 and reiterated briefly here. The following is a list of the input information used in this analysis:

- Soluble salt content in local dust (Reheis and Kihl 1995 [DIRS 106653])

- Potential soluble salt composition results for site NV00 (NADP/NTN 2000 [DIRS 172977], Part 2; 2001 [DIRS 172976], Part 2; 2003 [DIRS 173141], Part 2)

- Total pressure at the elevation of the repository (BSC 2004 [DIRS 169862]).

The first part of this analysis starts with the measured soluble salt content within ambient dust near Yucca Mountain. Ambient atmospheric dust will represent the predominant source of salt, which will be deposited on the waste packages during ventilation. Reheis and Kihl (1995 [DIRS 106653], Table 2) present data from six sample sites near Fortymile Wash (Table 4.1-9). These six sites, with four samples each, have an average soluble salt content of $10.5 \mathrm{wt} \%$, with a $2.8 \%$ standard deviation as calculated in Output DTN: SN0508T0502205.016 (NV00-dust.xls, sheet “Ambient Soluble Salt"). This value does not include the less-soluble constituents of carbonate and gypsum.

Next, the composition of the soluble salt within the dust needs to be considered. Precipitation chemistries from the National Atmospheric Deposition Program/National Trends Network are available, and annual concentration data from the years 2000 through 2002 for the NV00 site, located in Red Rock, Nevada (see NADP/NTN data in Table 4.1-8), have been selected. These precipitation chemistries have entrained the soluble components from atmospheric dust. Notable is the high ammonium concentration, which if considered as composed primarily of $\mathrm{NH}_{4} \mathrm{NO}_{3}$ and $\mathrm{NH}_{4} \mathrm{Cl}$ salts, represents 45 to $60 \%$ of the total sample composition by mass; if considered as composed of $\left(\mathrm{NH}_{4}\right)_{2} \mathrm{SO}_{4}$ and $\mathrm{NH}_{4} \mathrm{NO}_{3}$, it represents from 40 to $57 \%$ by mass (Output DTN: SN0508T0502205.016, NV00-dust.xls, sheet "NV00 Data”).

EQ3/6 V8.0 (BSC 2003 [DIRS 162228]) was used to perform evaporation on these NADP/NTN chemistries. This analysis makes use of the IDPS model (BSC 2004 [DIRS 169863]) within its range of validation, using data0.ypf.R0 (DTN: SN0504T0502404.011 [DIRS 173493]) or data0.ypf.R2 (Output DTN: SN0504T0502205.008) for simulations not including ammonium and including ammonium, respectively. As discussed below, the ammonium salts were first 
removed from the assemblage prior to calculating brine volume, and hence the ammonium Pitzer data were not used in the analysis.

First, the evaporation of the NADP/NTN precipitation chemistries for the year 2000 composition (NADP/NTN 2000 [DIRS 172977], Part 2) was performed at 70, 100 and $140^{\circ} \mathrm{C}$ (Output DTN: SN0508T0502205.016, NV00-dust.xls, sheet "NADP NV00"). As the ionic strength of these solutions exceeds 50 molal, the activity model begins to break down, as seen by a rising water activity with further evaporation. For this reason these runs were halted prior to that point and the data presented are therefore not to complete dryout. Reaching dryout conditions is not necessary for estimation of brine volume, once the terminal dryout value of the water activity is approached in the simulation. Comparison of the three solute and solvent mass quantities as a function of temperature in Figure 6.4-3 for this composition indicates that minimal temperature effects exist. For this reason, further calculations on other precipitation chemistries are done only at $70^{\circ} \mathrm{C}$ and can then be extrapolated to higher temperature.

The comparison of the latest three years of precipitation chemistry at the NV00 site is performed at $70^{\circ} \mathrm{C}$ and those results are shown in Figure 6.4-4. Note that evaporation results from years 2001 and 2002 do not proceed to as low a water activity. This is due to their higher sulfate concentrations yielding less-soluble compositions. Nevertheless, they evaporate to similar water concentration levels, expressed here as solute to solvent mass ratios, with 2001 and 2002 at about a ratio of 2, and 2000 at a ratio of 3 . The three samples have differing amounts of initial solute content, yet at the point where solvent mass equals solute mass they have nearly the same mass percentage of very soluble salts, averaging $65.5 \%$ with a standard deviation of $1.1 \%$ (Output DTN: SN0508T0502205.016, NV00-dust.xls, sheet "VSF in dust").

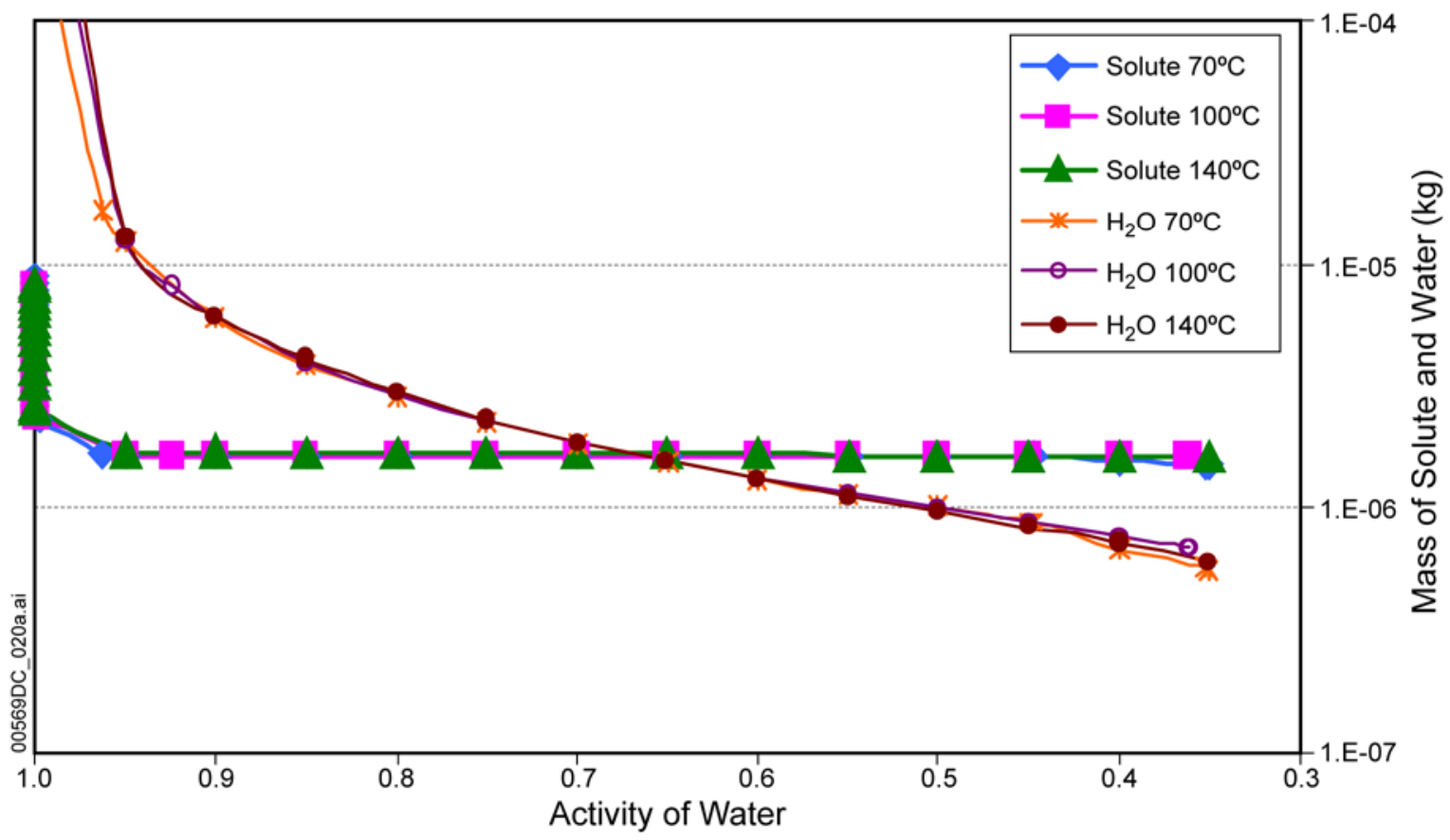

Source: Output DTN: SN0508T0502205.016, NV00-dust.xls, sheet "NADP NV00."

Figure 6.4-3. NV00-2000 Solute and Water Mass during Evaporation at Various Temperatures 


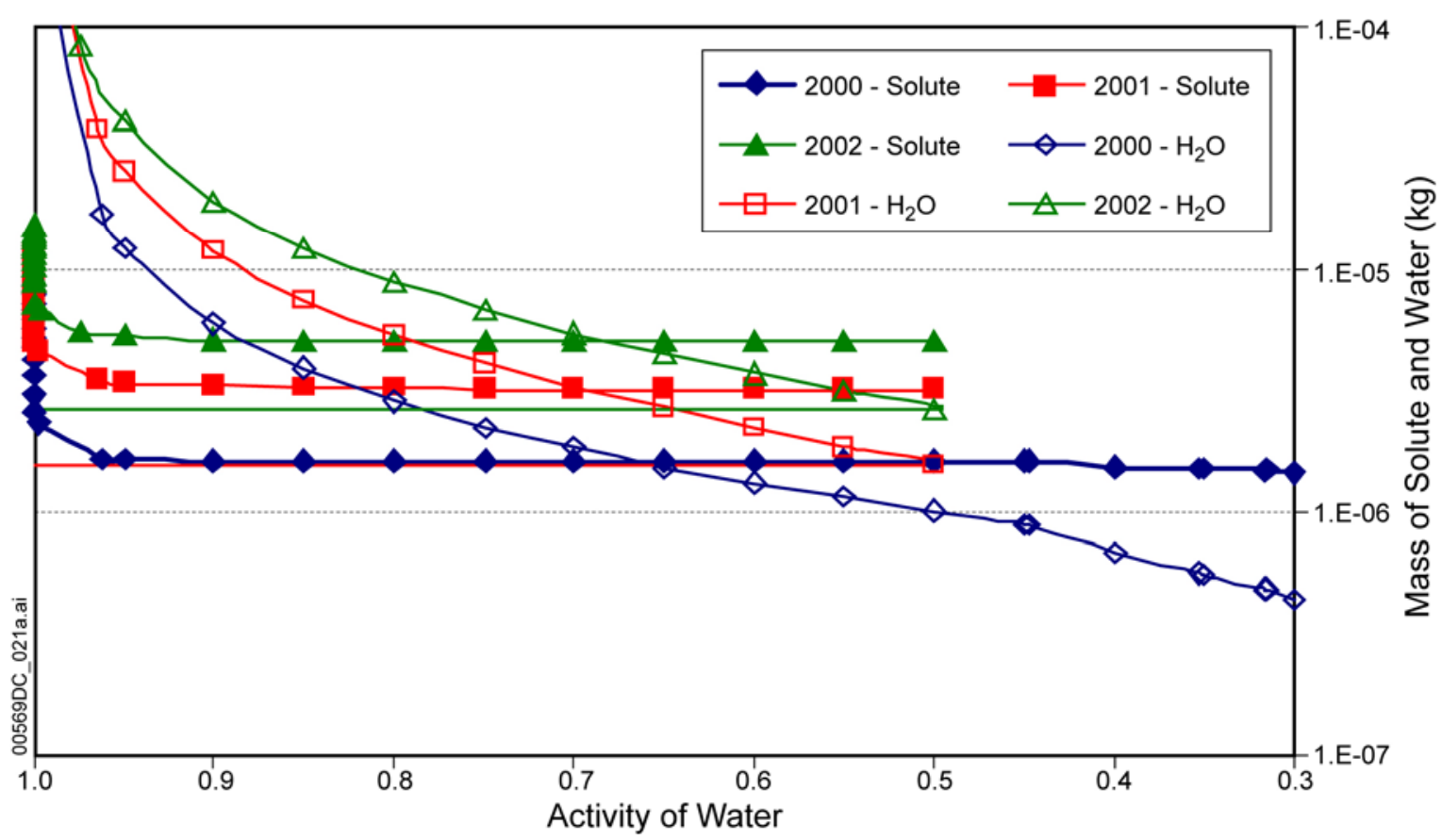

Source: Output DTN: SN0508T0502205.016, NV00-dust.xls, sheet "NADP NV00."

Figure 6.4-4. NV00 Solute and Water Mass during Evaporation at $70^{\circ} \mathrm{C}$

The analysis then centered on the NV00-2000 data (NADP/NTN 2000 [DIRS 172977], Part 2) as these are both more soluble/deliquescent and the associated evaporative calculations are able to proceed to lower relative humidity, enabling better comparison with the maximum relative humidities attainable at elevated temperatures in the repository.

Given the appreciable ammonium content measured in atmospheric dusts, the analysis considered the fate of the ammonium salts present. As shown in Section 6.1, the likely ammonium salts $\left(\mathrm{NH}_{4} \mathrm{Cl}, \mathrm{NH}_{4} \mathrm{NO}_{3}\right.$, and $\left.\left(\mathrm{NH}_{4}\right)_{2} \mathrm{SO}_{4}\right)$ will mostly decompose during the preclosure ventilation period (or early in the postclosure period). This will have the effect of lowering the soluble salt content of the remaining deposited dust. This analysis therefore allows complete removal of ammonium from the system. As the exact partitioning of ammonium among possible salts (represented by $\mathrm{NH}_{4} \mathrm{NO}_{3}, \mathrm{NH}_{4} \mathrm{Cl},\left(\mathrm{NH}_{4}\right)_{2} \mathrm{SO}_{4}$ ) is not well established, for purposes of analysis the least soluble ammonium sulfate is removed first, and the excess ammonium is then taken out with nitrate, thus maximizing the resulting bounding brine volume estimate.

Brine volume resulting from deliquescence of the residual atmospheric dust after thermal decomposition of ammonium phases is analyzed as a function of relative humidity. Taking the calculated results of solvent and solute mass, together with an approximate brine density (ranging from 1.05 to $1.25 \mathrm{~g} / \mathrm{mL}$, representing the range of values given in Table $4.1-10$ ), the volume of brine per mass of dust-salt is calculated. This is then converted to volume of brine per mass of dust using the soluble dust content given in Table 4.1-9. Results are determined at every 5\% RH and presented in Table 6.4-3. 
Table 6.4-3. Analysis Values and Results for Atmospheric Dust Brine Volume

\begin{tabular}{|c|c|c|c|c|c|}
\hline $\mathbf{R H}$ & $\begin{array}{c}\text { Solvent/Solute } \\
\text { (mass ratio) }\end{array}$ & $\begin{array}{c}\text { Approximate } \\
\text { Density } \\
(\mathbf{g} / \mathbf{m L})\end{array}$ & $\begin{array}{c}\text { Soluble } \\
\text { Salts (\%) }\end{array}$ & $\begin{array}{c}\mu \mathbf{L} \text { Brine per } \\
\text { mg Dust }\end{array}$ & $\begin{array}{c}\text { Maximum Temperature } \\
\text { at Which RH can be } \\
\text { Achieved }\end{array}$ \\
\hline 95 & 6.76 & 1.05 & 48.6 & 0.377 & - \\
\hline 90 & 3.67 & 1.10 & 48.6 & 0.217 & - \\
\hline 85 & 2.64 & 1.10 & 48.6 & 0.169 & - \\
\hline 80 & 2.11 & 1.15 & 48.6 & 0.138 & - \\
\hline 75 & 1.74 & 1.15 & 48.8 & 0.122 & - \\
\hline 70 & 1.46 & 1.20 & 49.1 & 0.106 & - \\
\hline 65 & 1.26 & 1.20 & 49.4 & 0.098 & - \\
\hline 60 & 1.10 & 1.20 & 49.5 & 0.091 & - \\
\hline 55 & 0.98 & 1.25 & 49.6 & 0.083 & - \\
\hline 50 & 0.88 & 1.25 & 49.7 & 0.079 & - \\
\hline 45 & 0.73 & 1.25 & 46.9 & 0.068 & $130^{\circ} \mathrm{C}$ \\
\hline 40 & 0.62 & 1.25 & 45.5 & 0.062 & - \\
\hline 35 & 0.53 & 1.25 & 44.4 & 0.057 & - \\
\hline 30 & 0.41 & 1.25 & 43.0 & 0.051 & - \\
\hline
\end{tabular}

Source: Output DTN: SN0508T0502205.016, NV0O-dust.xIs, sheet "Volume vs. RH."

NOTE: $\quad$ "Soluble salts (\%)" refers to the fraction of dissolved solids corresponding to highly deliquescent salts.

By combining this analysis result with the dust deposition quantity per surface area of waste package from Section 6.4.1.1, the brine volume per surface area of waste package is determined. These results are shown in Table $6.4-4$ considering both the average $18 \mathrm{mg} / \mathrm{cm}^{2}$ of maximum dust in the $105-\mathrm{m}$ turnout drift length as well as the $26 \mathrm{mg} / \mathrm{cm}^{2}$ maximum in the shorter $66-\mathrm{m}$ turnout. The "Maximum RH and Volume at Temperature" column in Tables 6.4-3 and 6.4-4 gives an approximate upper bound for the temperature on the waste package at which each $\mathrm{RH}$ is possible, due to the atmospheric pressure limit in the repository. For example, at $120^{\circ} \mathrm{C}$ in the short turnout, the maximum RH achievable is $\sim 45 \%$, so the first packages can have at most about $1.8 \mu \mathrm{L} / \mathrm{cm}^{2}$ of deliquescent brine; a higher $\mathrm{RH}$ is not supportable at this temperature in the repository.

The brine volume of $1.8 \mu \mathrm{L} / \mathrm{cm}^{2}$ at $120^{\circ} \mathrm{C}$ is adopted for this report to represent a maximum brine volume for use in physico-chemical screening arguments based on brine volume (i.e., supporting Sections 6.4.2, 6.4.4, 6.5.3, and 6.5.4). This value does not represent the global maximum of possible brine volume estimates at temperatures lower than $120^{\circ} \mathrm{C}$; hence the brine volume screening arguments are targeted to the temperature range above $120^{\circ} \mathrm{C}$. The "maximum brine volume" of $1.8 \mu \mathrm{L} / \mathrm{cm}^{2}$ does not necessarily have access to the waste package surface, given that brine can be retained within the dust layer (Section 6.4.3). 
Table 6.4-4. Maximum Brine Developed from Atmospheric Dust on Waste Package

\begin{tabular}{|c|c|c|c|}
\hline \multirow[b]{2}{*}{ RH } & \multicolumn{2}{|c|}{$\mu \mathrm{L}$ Brine per $\mathrm{cm}^{2}$ of Waste Package, Maximum } & \multirow{2}{*}{$\begin{array}{c}\text { Maximum Temperature } \\
\text { at Which RH Can Be } \\
\text { Achieved }\end{array}$} \\
\hline & Average Turnout $\left(18 \mathrm{mg} / \mathrm{cm}^{2}\right)$ & Short Turnout $\left(26 \mathrm{mg} / \mathrm{cm}^{2}\right)$ & \\
\hline 95 & 6.8 & 9.8 & - \\
\hline 90 & 3.9 & 5.6 & - \\
\hline 85 & 3.0 & 4.4 & - \\
\hline 80 & 2.5 & 3.6 & - \\
\hline 75 & 2.2 & 3.2 & $105^{\circ} \mathrm{C}$ \\
\hline 70 & 1.9 & 2.8 & - \\
\hline 65 & 1.8 & 2.5 & $110^{\circ} \mathrm{C}$ \\
\hline 60 & 1.6 & 2.4 & - \\
\hline 55 & 1.49 & 2.1 & - \\
\hline 50 & 1.41 & 2.0 & - \\
\hline 45 & 1.23 & 1.8 & $120^{\circ} \mathrm{C}$ \\
\hline 40 & 1.11 & 1.6 & - \\
\hline 35 & 1.02 & 1.48 & $130^{\circ} \mathrm{C}$ \\
\hline 30 & 0.92 & 1.32 & - \\
\hline
\end{tabular}

Source: Output DTN: SN0508T0502205.016, NVOO-dust.xls, sheet "Volume vs. RH."

These brine volumes, if they were able to combine at the surface of the waste package, would be equivalent to a thickness of $10 \mu \mathrm{m}$ for every one $\mu \mathrm{L} / \mathrm{cm}^{2}$ of fluid. Therefore, at temperatures above $105^{\circ} \mathrm{C}$, it is unlikely that a deliquesced-salt film thicker than $30 \mu \mathrm{m}(0.03 \mathrm{~mm})$ can form.

Assuming a dust porosity of 0.5 (Section 4.1.6), the maximum brine volume of $1.8 \mu \mathrm{L} / \mathrm{cm}^{2}$ and dust mass of $26 \mathrm{mg} / \mathrm{cm}^{2}$ corresponds to a liquid saturation of about $15 \%$. Previous modeling in support of TSPA-LA, documented in Engineered Barrier System: Physical and Chemical Environment (BSC 2004 [DIRS 169860], Section 6-10), used dust compositions measured from tunnel dusts only, which contained at most approximately $0.5 \%$ soluble salts, or about $5 \%$ of the amount in atmospheric dusts. The brine volumes would therefore be about $5 \%$ as much as calculated here, corresponding to less than $0.1 \mu \mathrm{L} / \mathrm{cm}^{2}$, and a maximum liquid saturation of approximately $1 \%$.

\subsubsection{Summary of Brine Volume Estimates}

The analyses presented in this section show that the amount of dust that will enter the drifts and settle on the waste packages is small- $18 \mathrm{mg} / \mathrm{cm}^{2}$ typical to $26 \mathrm{mg} / \mathrm{cm}^{2}$ maximal — and the volume of brine generated at $120^{\circ} \mathrm{C}$ will be, at a maximum, $1.8 \mu \mathrm{L} / \mathrm{cm}^{2}$. This value is conservative, as it represents the dust as composed entirely of atmospheric aerosols with a relatively high salt content. Addition of ammonium sulfate to the calculation would produce only a minor change in the estimated maximum brine volume, or the temperature adopted for specification of the maximum brine volume.

Note that the brine volume estimate of $1.8 \mu \mathrm{L} / \mathrm{cm}^{2}$, if integrated over the footprint area of a waste package (approximately $10 \mathrm{~m}^{2}$ ), gives a total volume of a fraction of a liter. Compared to seep strength as represented by BSC (2004 [DIRS 169131], Section 6.8) it is clear that if seepage 
contacts the waste package surface that the resulting liquid volume and its composition will be dominated by seepage characteristics.

\subsubsection{Geometrical Analysis of Grain-Grain Contact}

The previous calculations are dependent upon the assumption that the different salt grains in the dust are in chemical communication with each other - that is, all grains are in contact, so that eutectic brines can develop. This is consistent with atmospheric aerosol models, which commonly assume that all components of atmospheric aerosols are in thermodynamic equilibrium (e.g., Clegg et al. 1997 [DIRS 172816]; 1998 [DIRS 172807]; 1998 [DIRS 172815]; Wexler and Clegg 2002 [DIRS 172826]); however, those models are directed mostly towards upper atmospheric processes. It is probable that atmospheric aerosols brought into the repository during ventilation will include both aerosols generated high in the atmosphere and coarser materials, carried by the wind as bedload near the ground surface. Thus, individual salt phases may not be in contact with each other in a dust deposit. Eutectic deliquescence of multiple salts requires contact between salt grains for initiation. The salts involved represent small fractions of the total mass of dust, and therefore the grain-grain contacts required for eutectic behavior may be statistically rare. The soluble salt grains in the dust, which total approximately $10 \%$ of the total mass (see Section 6.4.1), are diluted by relatively inert grains (e.g., comprising carbonate, silicate, or sulfate minerals). Only a fraction of the soluble salts can exist with the grain-grain contacts required for deliquescence, and the amount of brine that can form is thus limited. Starting from first principles, this section develops a formalism to describe grain-grain contacts, and solves for the ratio of the mass of potentially deliquescent salts in grain-grain contact to the total mass of the salts in dust.

A number density function $N_{i}(r)$ is defined that represents the abundances of particles of each species $i$ (salt or inert dust) as a function of particle size $r$, per unit total mass of dust. The function is defined as:

$$
d N_{i}=N_{i}(r) \cdot d r
$$

where $N_{i}(r)$ is the number of particles of type (species) $i$ in a given size range from $r$ to $r+d r$. The total number of particles of type $i$, per unit total mass of dust, is then:

$$
T_{i}=\int_{R_{i}} N_{i}(r) \cdot d r
$$

where the integration is carried out over all sizes of particles of type $i$. The total number of dust particles is:

$$
T_{T}=\sum_{i=1}^{n} T_{i}
$$

where the summation is over all $n$ types of particles. The probability of encountering a particle of type $i$ is: 


$$
p\{i\}=\frac{T_{i}}{T_{T}}
$$

The coordination number $k$ is the number of other particles touching a given particle. Then the number of particles of type $j$ touching a given particle of type $i$, per unit total mass of dust, is:

$$
c_{j}=\frac{T_{j}}{T_{T}} \cdot \bar{k}(r)
$$

where $\bar{k}(r)$ is the average coordination number for particles of radius $r$ (assuming that coordination behavior in the dust depends on particle size only and not type). The number density for all contacts of particles of type $j$ with particles of type $i$ is written by integrating the product of Equation 6.4-5 and the number density $N_{i}(r)$ for particles of type $i$, over the entire range of particle sizes:

$$
K_{i, j}=\int_{R_{i}} N_{i}(r) \cdot \frac{T_{j}}{T_{T}} \cdot \bar{k}(r) \cdot d r
$$

The function $K_{i, j}$ is the number density for type $i-j$ contacts per unit mass of dust. Double-counting of $i-j$ contacts is negligible because the relative abundances for both types are small (i.e., mass fractions $m_{i}<<1$ and $m_{j}<<1$ ), which implies the reciprocity relationship:

$$
\int_{R_{i}} N_{i}(r) \cdot \frac{T_{j}}{T_{T}} \cdot \bar{k}(r) \cdot d r=\int_{R_{j}} N_{j}(r) \cdot \frac{T_{i}}{T_{T}} \cdot \bar{k}(r) \cdot d r
$$

The objective of this analysis is to derive an expression for the total mass of particles of types $i$ and $j$ that is involved in $i-j$ contacts, as a fraction of the total mass for all particles of both types. Each of the contacts represented by the left-hand side of Equation 6.4-7 is associated with one particle of type $j$, and each of the contacts represented by the right-hand side is associated with one particle of type $i$. Together the right-hand and left-hand sides of Equation 6.4-7 represent all the particles of both types involved in $i$-j contacts. For the involved particles of each type, say type $i$, the mass fraction of involved particles per unit total mass is:

$$
M_{i, j}=\int_{R_{i}} N_{i}(r) \frac{T_{j}}{T_{T}} \bar{k}(r)\left[\bar{v}_{i}(r) \rho_{i}+\bar{v}_{j}(r) \rho_{j}\right] \cdot d r
$$

where $\bar{v}_{i}(r)$ represents the average volume of particles of type $i$, as a function of size $r$, and $\rho_{i}$ is the density for type $i$. Because of reciprocity, this expression (Equation 6.4-8) represents the mass fraction of involved particles of both types, per unit total mass. This is shown by substituting the reciprocity relation (Equation 6.4-7):

$$
M_{i, j}=M_{j, i}=\int_{R_{i}} \bar{k}(r) N_{i}(r) \frac{T_{j}}{T_{T}} \cdot\left[\bar{v}_{i}(r) \rho_{i}+\bar{v}_{j}(r) \rho_{j}\right] \cdot d r
$$




$$
=\int_{R_{j}} \bar{k}(r) N_{j}(r) \frac{T_{i}}{T_{T}} \cdot\left[\bar{v}_{i}(r) \rho_{i}+\bar{v}_{j}(r) \rho_{j}\right] \cdot d r
$$

Comparing the mass fraction $M_{i, j}$ (or $M_{j, i}$ ) with the combined total mass fraction for both salts gives the proportion of soluble salt that can potentially deliquesce for a two-salt system:

$$
f_{i, j}=\frac{M_{i, j}}{m_{i}+m_{j}}
$$

This result is an over-estimate because it does not take into account eutectic behavior whereby deliquescence initiates but one salt is completely dissolved, and thus depleted, while the other salt is more abundant and does not completely dissolve. Also, as temperature and relative humidity change, the composition follows a peritectic curve, which further changes the molar ratios of dissolved species.

Estimating the coordination function $\bar{k}(r)$ and the functions $N_{i}(r)$ and $\bar{v}_{i}(r)$ for the different dust components would be formidable for real dust samples. For expository purposes the remainder of this section discusses a system representing all particles in dust as spheres of equal size ("billiard balls"). This simplifies the functions described above, so that the influence of coordination number and salt abundance on the frequency of occurrence for $i-j$ contacts can be graphically presented. For uniform spheres of radius $R$ (all particles of all types are the same size), the number density function and the total number of particles of each species per unit total mass reduce to, respectively:

$$
N_{i}=\delta(r-R) \frac{3 m_{i}}{4 \pi r^{3} \rho_{i}}, T_{i}=\frac{3 m_{i}}{4 \pi R^{3} \rho_{i}}, \text { and } T_{T}=\frac{3}{4 \pi R^{3}}\left(\frac{m_{i}}{\rho_{i}}+\frac{m_{j}}{\rho_{j}}+\cdots+\frac{m_{n}}{\rho_{n}}\right)
$$

where $\delta(r-R)$ is the Kronecker delta function, and the $n$ particle types include those which are inert (non-deliquescent). The volume function $v(r)$ reduces to $4 \pi R^{3} / 3$ for all particle types. For two-salt particle association the total number of particles is:

$$
T_{T 2-\text { salt }}=\frac{3}{4 \pi R^{3}}\left(\frac{m_{i}}{\rho_{i}}+\frac{m_{j}}{\rho_{j}}+\frac{\left(1-m_{i}-m_{j}\right)}{\rho_{\text {inert }}}\right)
$$

where $\rho_{\text {inert }}$ is the average or effective density of the inert (non-deliquescent) particles. Substituting these simplifications into Equations 6.4-2, 6.4-3, 6.4-10, and 6.4-11 gives for two-salt particle association:

$$
f_{i, j}=\frac{M_{i, j}}{m_{i}+m_{j}}=\frac{\bar{k} m_{i} m_{j} \rho_{\text {inert }}\left(\rho_{i}+\rho_{j}\right)}{\left[m_{i}\left(\rho_{j} \rho_{\text {inert }}-\rho_{i} \rho_{j}\right)+m_{j}\left(\rho_{i} \rho_{\text {inert }}-\rho_{i} \rho_{j}\right)+\rho_{i} \rho_{j}\right]\left(m_{i}+m_{j}\right)}
$$


The coordination number is treated parametrically in this discussion. For equal-sized spheres the maximum coordination number is 12 in cubic-closest packing (Section 4.1.6; Klein and Hurlbut 1993 [DIRS 153700], p. 191), and the minimum coordination number for a rigid (self-supporting) packing is 4 (Gardner 1995 [DIRS 173894], p. 88). Dust generally has a porosity on the order of $50 \%$, and thus a smaller packing density than cubic closest packing. Dust may therefore have a smaller coordination number. For this discussion the coordination number is varied in the range from 2 to 12 .

For the two-salt system, calculations are performed using handbook densities for $\mathrm{NaCl}$ and $\mathrm{KNO}_{3}$ (Section 4.1), rounded to 3 significant figures. Although other salts such as $\mathrm{NaNO}_{3}$ may be present instead, the differences in densities among such salts are not significant to the conclusions of the analysis.

Equation 6.4-13 is plotted in Figure 6.4-5 (upper), which shows that when two salt species are present in low abundance, on the order of $1 \%$ of total mass, only a small fraction of the salts (approximately one tenth or less) exists in grain-grain contact relationships that allow eutectic deliquescence behavior. This conclusion is extended to three-salt (and multi-salt) association in Section 6.4.2.3.

\subsubsection{Conceptualization of Multi-Salt Deliquescent Brine Development}

At the onset of deliquescence, a tiny drop of brine forms where grains of the different salts are in contact. The proportions of the different salts in solution are determined by the eutectic composition. Because there is essentially unlimited water available from the gas phase, the drop must continue to grow if the necessary salts are available for dissolution. That is, so long as the drop is in physical contact with solid grains of each salt in the assemblage, the drop will grow until one of the salt grains is exhausted or is no longer in contact. As the relative humidity increases, salt dissolution proceeds and the brine composition evolves along a peritectic curve (or more accurately, a surface, which becomes more difficult to visualize for three-salt assemblages). During this evolution the drop will grow in volume until one of the salt grains is depleted or no longer in contact with the solution.

For higher temperature conditions, deliquescent brines of eutectic compositions are very concentrated and have densities comparable to the constituent solid salts. To a first approximation, the drop grows to assume the volume of the contacting salt grains (actually smaller because one or more salts must eventually be limiting). The effect of the inert (non-deliquescing) matrix is now clear: it limits drop growth by separating a drop from the next adjacent solid grain of the limiting salt in the eutectic brine composition.

This leads to a question of the flow behavior of the drop: does it wet the inert solids and spread, bringing more salt grains into contact with a contiguous aqueous phase, or is such connection impeded because the loci of deliquescence are too far apart? Spreading behavior would be strongly affected by surface forces and therefore isotropic and not gravity-dominated. Dust has high specific surface area, so the brine would be spread too thin to support effective mass transfer connections between adjacent salt grains. 
To the extent that spreading does link all deliquescent salt grains to form a contiguous aqueous phase, the "billiard ball" analysis developed above can be used to estimate the thickness of brine that would result if spreading links all the deliquescent salt grains in a contiguous aqueous phase. This thickness can then be compared with water film behavior, to infer the potential for a contiguous brine phase to form.

a)

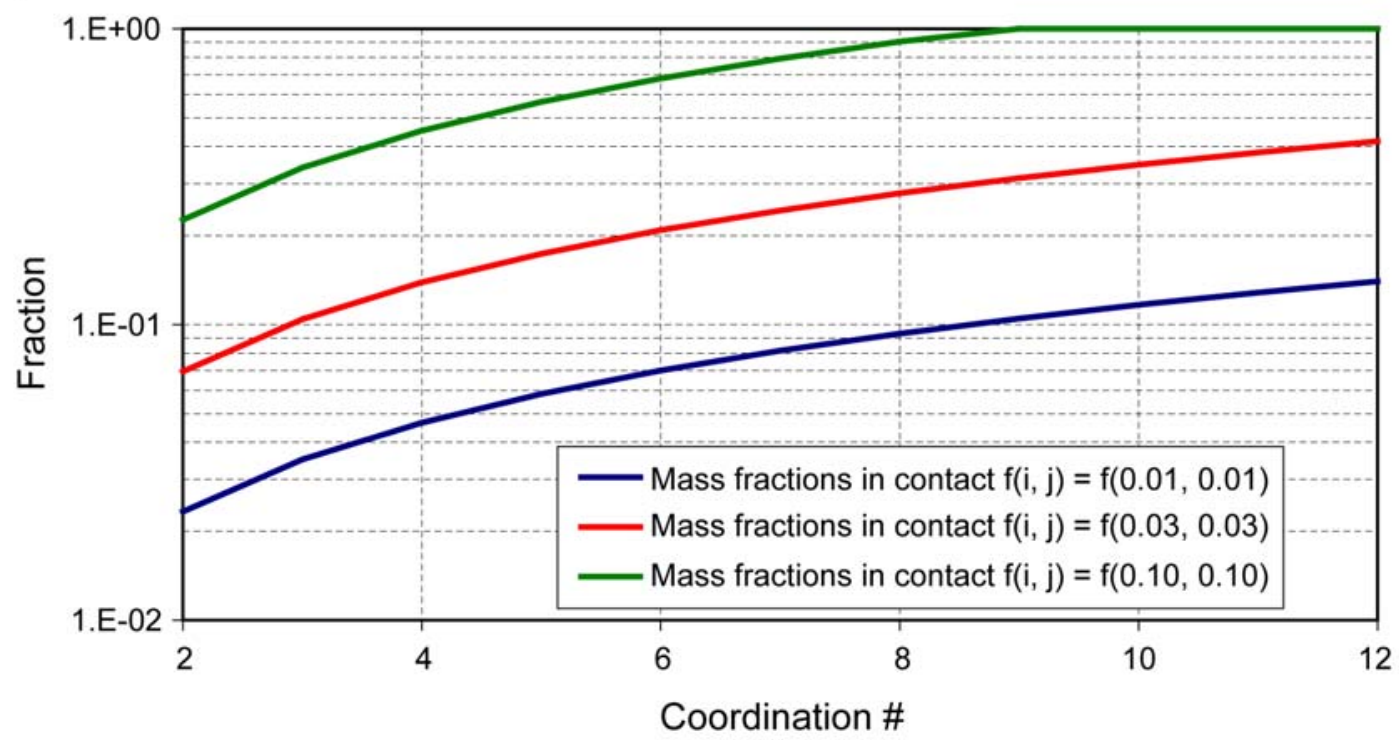

b)

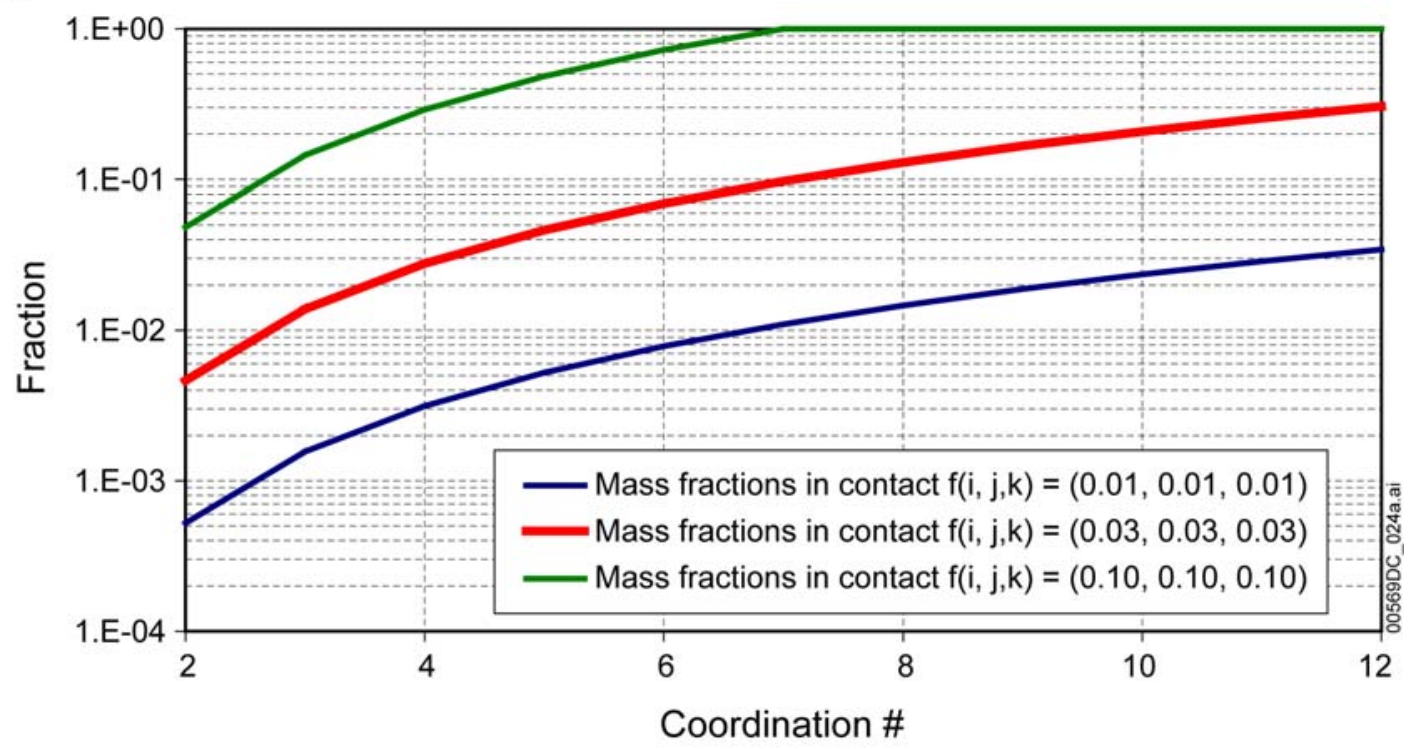

Source: Output DTN: MO0508SPAGEOME.003, billiard ball analysis 24May05.xls.

NOTE: Equal-sized spherical grains are assumed.

Figure 6.4-5. Mass Fraction of Salts Associated with Contacting Grains, for the Two-Salt System (upper) and the Three-Salt System (lower) 


\subsubsection{Brine Film Thickness Analysis for Two-Salt Deliquescence}

The analysis presented in this section uses the results described above (Equation 6.4-13) for the fraction of salts involved in two-salt deliquescence to evaluate the thickness of a contiguous film containing the brine resulting from that deliquescence. The purpose is qualitative evaluation of transport mobility in such a brine film. If the estimated brine film thickness is extremely thin, so that transport mobility is obviously restricted, then there is little likelihood that spreading could envelope all the deliquescent salt in dust. This analysis therefore supports the conclusion reached in Section 6.4.2.1 that the frequency of grain-grain contacts limits the fraction of salts present that can participate in two-salt (or multi-salt) deliquescence.

For each deliquescent salt $i$ or $j$ the volume of the solid salt $\left(V_{i}\right)$, per unit total mass of dust, is given by:

$$
V_{i}=\frac{m_{i}}{\rho_{i}}
$$

where $\rho_{i}$ is salt density and $m_{i}$ is the mass fraction of salt $i$ in the dust. The total volume of the solid salts, per unit total mass of dust, is $V_{\text {salt }}=V_{1}+V_{2}+\ldots$. The volume of brine that can form, per unit total mass of dust, is bounded by a factor, $\alpha$, of the total volume of salt:

$$
V_{\text {brine }} \approx \alpha V_{\text {salt }}=\alpha\left(\frac{m_{i}}{\rho_{i}}+\frac{m_{j}}{\rho_{j}}+\cdots\right)
$$

(this is intended as a simple upper bound; brine volume is discussed in more detail in Section 6.4.1.2). The mass fraction of salt species of types $i$ and $j$ involved in $i$-j contacts is $f_{i, j}$, so that the estimated volume of brine for a two-salt system is (substituting Equations 6.4-13 and 6.4-14):

$$
\begin{aligned}
V_{2-\text { salt brine }} \approx \alpha f_{i, j} \cdot\left(V_{i}+V_{j}\right)=\alpha f_{i, j} \frac{\left(m_{i} \rho_{j}+m_{j} \rho_{i}\right)}{\rho_{i} \rho_{j}} \\
=\frac{\alpha \bar{k} m_{i} m_{j} \rho_{\text {inert }}\left(\rho_{i}+\rho_{j}\right)\left(m_{i} \rho_{j}+m_{j} \rho_{i}\right)}{\rho_{i} \rho_{j}\left[m_{i}\left(\rho_{j} \rho_{\text {inert }}-\rho_{i} \rho_{j}\right)+m_{j}\left(\rho_{i} \rho_{\text {inert }}-\rho_{i} \rho_{j}\right)+\rho_{i} \rho_{j}\right]\left(m_{i}+m_{j}\right)}
\end{aligned}
$$

Spreading this volume over the surfaces of all grains in the dust requires an estimate of total number of particles and their total surface area. The following discussion is based on an assumption of equal-size spheres, which gives a lower bound on the surface area and an upper bound on the resulting brine film thickness. For a dust mixture containing two co-deliquescent salts and an inert phase, this analysis is concerned with spreading of the brine film over the inert grains. Salt grains that have not deliquesced are not included in the surface area calculation because the intent is to evaluate the thickness of a brine film that bridges from loci of deliquescence to envelope all the other grains of the same salts which have not deliquesced. The 
approximation taken here is that spreading of the film over all the inert grains is necessary and sufficient to envelope all of the salt.

The mass fraction of inert particles, per unit total mass of a two-salt dust mixture, is:

$$
m_{\text {inert }}=\left(1-m_{i}-m_{j}\right)
$$

and the number of inert particles of radius $R$, per unit total mass of dust, is then:

$$
n_{\text {inert }}=\frac{m_{\text {inert }}}{\rho_{\text {inert }} \cdot 4 \pi R^{3} / 3}=\frac{3\left(1-m_{i}-m_{j}\right)}{\rho_{\text {inert }} 4 \pi R^{3}}
$$

The total surface area of these inert, spherical particles is:

$$
A_{\text {inert }}=4 \pi R^{2} n_{\text {inert }}=\frac{3\left(1-m_{i}-m_{j}\right)}{\rho_{\text {inert }} R}
$$

and the brine film thickness is:

$$
\begin{aligned}
t_{\text {brine }} & \approx \frac{V_{2-\text { saltbrine }}}{A_{\text {inert }}} \\
& =\frac{\alpha \bar{k} m_{i} m_{j} \rho_{\text {inert }}\left(\rho_{i}+\rho_{j}\right)\left(m_{i} \rho_{j}+m_{j} \rho_{i}\right) \rho_{\text {inert }} R}{3 \rho_{i} \rho_{j}\left[m_{i}\left(\rho_{j} \rho_{\text {inert }}-\rho_{i} \rho_{j}\right)+m_{j}\left(\rho_{i} \rho_{\text {inert }}-\rho_{i} \rho_{j}\right)+\rho_{i} \rho_{j}\right]\left(m_{i}+m_{j}\right)\left(1-m_{i}-m_{j}\right)}
\end{aligned}
$$

In order to estimate the brine thickness for either the two-salt system or the three-salt system presented above, an estimate of the volume multiplier $\alpha$ is required. Section 6.4.1.2 develops a bounding estimate that $1.8 \mu \mathrm{L} / \mathrm{cm}^{2}$ of brine may form on the waste package surface, in response to deliquescence of $26 \mathrm{mg} / \mathrm{cm}^{2}$ of total deposited dust, of which approximately $5 \%$ is deliquescent and persists on the waste package surface (the other $5 \%$ consists of ammonium salts that will decompose prior to deliquescence). Choosing a reasonable lower bound of $2.0 \mathrm{~g} / \mathrm{cm}^{3}$ for the density of soluble salts, the ratio of brine volume to deliquescent salt volume is:

$$
\alpha=\frac{1.8 \cdot 10^{-6} \mathrm{~L} / \mathrm{cm}^{2} \cdot 2.0 \mathrm{~g} / \mathrm{cm}^{3}}{(5 \%) 26 \cdot 10^{-3} \mathrm{~g} / \mathrm{cm}^{2}} \cdot \frac{10^{3} \mathrm{~cm}^{3}}{L}=2.8
$$

The other parameter that is assumed for evaluation of brine thickness is $\rho_{\text {inert }}$, the average density of the inert (non-deliquescent) grains in the dust. As stated previously, these grains comprise relatively insoluble carbonate, silicate, or sulfate minerals, for which a representative density of $2.5 \mathrm{~g} / \mathrm{cm}^{3}$ (Section 4.1.6) is used in this analysis. This mineralogical density estimate is suitable for evaluating surface area at the scale of individual grains. 
The application of Equation 6.4-20 evaluates the effect when the brine volume represented (calculated from the volume of salt involved, multiplied by 2.8 for the presence of water) is spread throughout the inert particle surface area. The film thickness estimated in this manner is shown in Figure 6.4-6. For dust with a particle size (radius) of 10 microns or smaller, and soluble salt abundances on the order of $10 \%$ or less, the concentrated brine formed from two-salt mixtures would form a film with a maximum thickness on the order of approximately 0.01 micron or less. For smaller particles, the layer thickness is proportionately smaller. The approximate diameter of a water molecule is 2.6 angstroms (Hillel 1998 [DIRS 165404] p. 23), and therefore the calculated brine film thickness corresponds to a layer of approximately 40 or fewer water molecules (for particles of 10 microns or smaller). Such layers tend to be strongly influenced by surface interactions, such that movement of ions is strongly impeded (particularly proximal to a charged liquid-solid interface). The immobility of such films is supported also because this result was calculated for spheres of equal size, whereas actual dust has more surface area that would further reduce film thickness. For greater salt abundance represented by the 3\% and $10 \%$ curves on Figure 6.4-6, smaller particles on the order of 1 micron or less are required to infer transport immobility.

\subsubsection{Analysis of Three-Salt Mixtures}

When a third salt is required for deliquescence to occur (e.g., $\mathrm{NaCl}-\mathrm{NaNO}_{3}-\mathrm{KNO}_{3}$ ), an even smaller fraction (relative to the two-salt case) of the soluble salt will participate in deliquescence because the probability of occurrence of three-grain contacts is less than that of two-grain contacts. The following derivation develops an estimate for the proportion of the total mass of three deliquescent salts that are in grain-grain contact, analogous to the two-salt result of Equation 6.4-13.

The approach begins with the two-salt result, then treats the two-particle assemblage as a single (composite) particle, and then calculates the frequency of contacts between the third particle type and the composite particles. The coordination number of the composite particle is the sum of the coordination numbers for its two constituents, minus 2 (to account for the two-salt contact). Conceptually this approach includes three-salt particle assemblages that are in serial contact, but not necessarily in mutual contact such that each involved salt particle touches salt grains of the two other types. Thus, the approach overestimates the quantity of salt that could deliquesce.

Starting with Equation 6.4-5, the probability of a particle of type $k$ contacting the two-salt $(i, j)$ composite particle, is:

$$
c_{j}=\frac{T_{j}}{T_{T}} \bar{k}(r) \cdot \frac{T_{k}}{T_{T}}[2 \bar{k}(r)-2]
$$

The number density of three-salt contacts is written by incorporating Equation 6.4-22 into Equation 6.4-6:

$$
K_{i, j}=\int_{R_{i}} N_{i}(r) \frac{T_{j}}{T_{T}} \bar{k}(r)\left[\frac{T_{k}}{T_{T}}(2 \bar{k}(r)-2)\right] \cdot d r=\int_{R_{i}} N_{i}(r) \frac{T_{j} T_{k}}{T_{T}^{2}} \bar{k}(r)[(2 \bar{k}(r)-2)] \cdot d r
$$


(Eq. 6.4-23)

The reciprocity relation for the two-salt system (Equation 6.4-7) also holds for the contact relationship between two-salt composite particles and the third (type $k$ ) particle type, but is not repeated here. The mass density for type $i, j$, and $k$ particles involved in three-salt assemblages is analogous to Equation 6.4-9:

$$
M_{i, j, k}=\int_{R_{i}} N_{i}(r) \frac{T_{j} T_{k}}{T_{T}^{2}} \bar{k}(r)[2 \bar{k}(r)-2]\left[\bar{v}_{i}(r) \rho_{i}+\bar{v}_{j}(r) \rho_{j}+\bar{v}_{k}(r) \rho_{k}\right] \cdot d r
$$

Analogous to Equation 6.4-10, the proportion of the three soluble salts that are in mutual contact is given by:

$$
f_{i, j, k}=\frac{M_{i, j, k}}{m_{i}+m_{j}+m_{k}}
$$

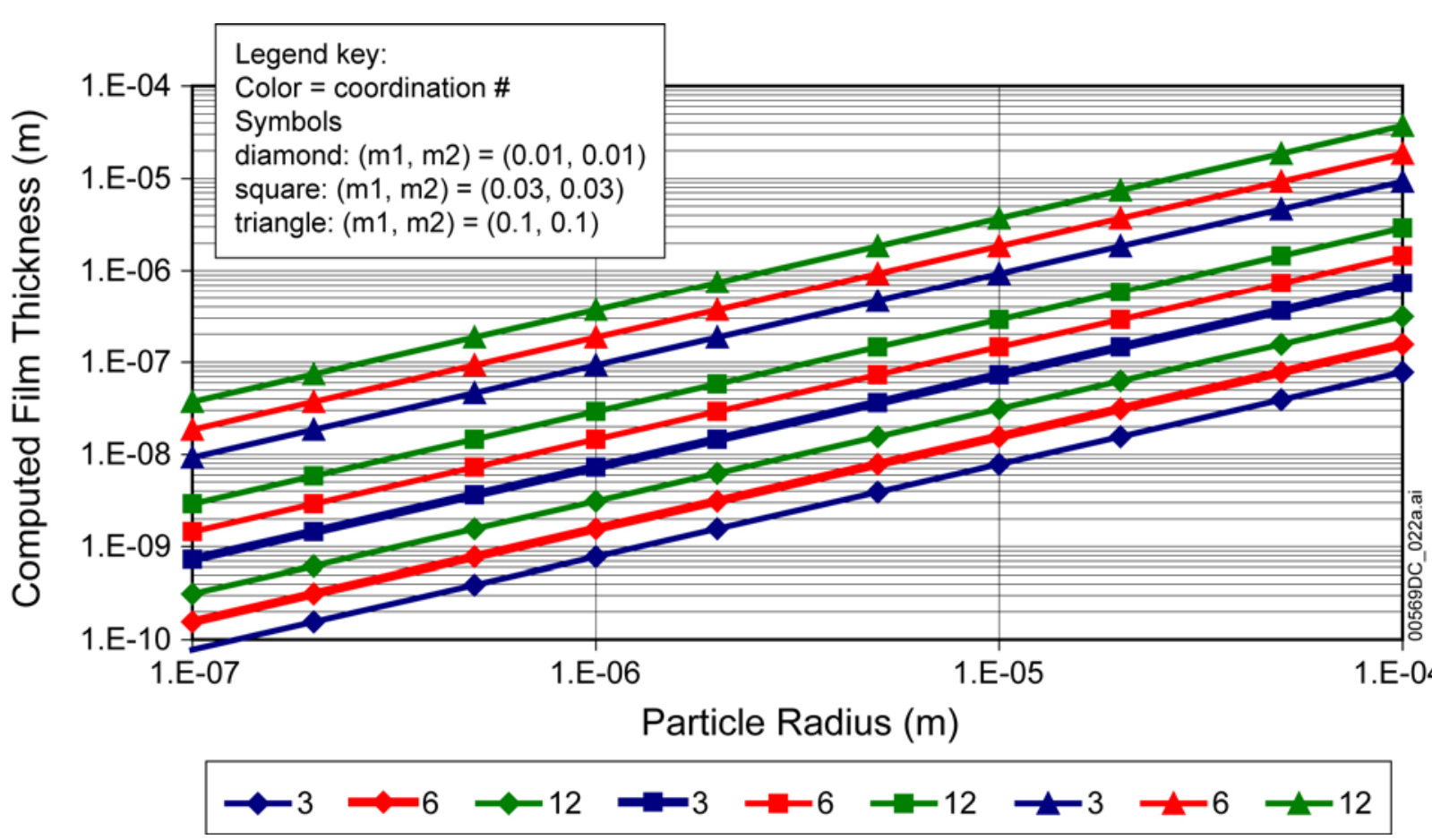

Source: Output DTN: MO0508SPAGEOME.003.

NOTE: Equal-sized spherical grains are assumed.

Figure 6.4-6. Calculated Film Thickness When the Brine Formed by Two Salts in Contact Is Spread throughout the Dust, Coating All Grains

Equation 6.4-25 is conservative (i.e., it overestimates the abundance of three-salt contacts) for the reason described in the conceptual discussion above. 
For equal-size spheres, the "billiard ball" analysis is extended to the three-salt system using Equation 6.4-11, and writing the total number of particles as:

$$
T_{T 3-\text { salt }}=\frac{3}{4 \pi R^{3}}\left(\frac{m_{i}}{\rho_{i}}+\frac{m_{j}}{\rho_{j}}+\frac{m_{k}}{\rho_{k}}+\frac{\left(1-m_{i}-m_{j}-m_{k}\right)}{\rho_{\text {inert }}}\right)
$$

and substituting, which yields:

$$
f_{i, j}=\frac{M_{i, j, k}}{m_{i}+m_{j}+m_{k}}=\frac{\bar{k}(\bar{k}-1) m_{i} m_{j} m_{k}\left(\rho_{i}+\rho_{j}+\rho_{k}\right)}{\left(m_{i}+m_{j}+m_{k}\right)\left[\frac{m_{i}}{\rho_{i}}+\frac{m_{j}}{\rho_{j}}+\frac{m_{k}}{\rho_{k}}+\frac{\left(1-m_{i}-m_{j}-m_{k}\right)}{\rho_{\text {inert }}}\right]^{2}} \frac{1}{\rho_{i} \rho_{j} \rho_{k}}
$$

Equation 6.4-27 is plotted in Figure 6.4-5 (lower), which shows that for the three-salt system the extent of grain-grain contact that facilitates multi-salt deliquescence is decreased compared to the two-salt system, particularly for low salt abundances on the order of $3 \%$ or less. At higher abundances $(10 \%)$ the extent of potentially deliquescent grain-grain contacts is comparable for the three-salt and two-salt system, according to this analysis. With less brine, the corresponding brine film thickness is reduced, so that by inference from the results of Section 6.4.2.2, the possibility of brine spreading to encompass all the grains of deliquescent salt present in the dust is unlikely.

\subsubsection{Summary of Geometrical Analysis}

These derivations and example calculations using equally sized spherical particles show that for two-salt deliquescent systems a deliquescent aqueous phase will incorporate only a small fraction (e.g., approximately $10 \%$ or less) of the salt present, if the relative abundances of the salts are on the order of $1 \%$ or less. The film thickness analysis shows also that the resulting brine will not migrate and grow if the particle size is less than approximately 10 microns. To the extent that soluble salts in atmospheric aerosols favor smaller particle sizes (see Section 6.1.3), on the order of 1 micron or smaller, the particle size result could be extended to higher salt abundances.

For three-salt systems this analysis shows that a deliquescent aqueous phase will incorporate only a small fraction (e.g., approximately $10 \%$ or less) of the salt present, if the relative abundances of the salts are on the order of $3 \%$ or less.

The effects of coordination number on the results are comparable in magnitude to the effects of salt abundance. The two-salt brine film thickness result is more sensitive to particle size, in the range examined (Figure 6.4-6), than coordination number or salt abundances. The coordination calculations for spherical grains are scale invariant and do not depend on particle size.

It should be noted that the "billiard ball" analysis relies on simplifying geometrical assumptions, and the results are therefore scoping in nature. The use of equal-sized spherical particles tends to underestimate surface area and may underestimate the numbers of particles, both of which would 
lead to a conservative prediction of thicker brine films and greater mobility. This analysis also conservatively ignores surface tension effects, which would cause the brine to preferentially accumulate at grain-grain contacts, limiting brine connectivity and mobility. The formalism developed for three-salt mixtures is conservative in the sense that for each set of three contacting salt grains $(i-j-k)$, all arrangements are included without the additional complexity of which arrangements produce all-around mutual contacts between the three salt grains. It should also be noted that atmospheric aerosols may not contain different salts as discrete particles, but certain salts may be attached together, which would lead to three-salt behavior resembling that of two-salt mixtures. The analyses described in Section 6.4 .2 are documented in Output DTN: MO0508SPAGEOME.003.

\subsubsection{Retention of Brine in the Dust by Capillary Forces}

Because the predicted volumes of brine in the dust are so small, it is likely that the brine will be retained by capillarity within the dust, thus limiting brine contact with the waste package surface. To evaluate this, dust samples collected from the ESF underground were evaluated to characterize grain and pore sizes and capillary properties.

The dust-characterization activities are as follows:

(1) Microtomography imaging of dust collected from the repository horizon in the ESF and the Enhanced Characterization of the Repository Block (ECRB)

(2) Estimating the capillary properties of dust, based on pore-space analysis of the images

(3) Comparing the capillary strength of dust in retaining the brine solution to that of an idealized crack/crevice on the waste package.

Imaging was performed on dust collected from the lower lithophysal (Tptpll) repository unit of the Topopah Spring welded tuff. Several complementary imaging methods were employed to increase confidence in the conclusions drawn from the imaging results based on a limited number of images.

The results of this analysis are presented here, and show that both the particle and pore linear dimensions range from a fraction of a micron to tens of microns, with the distribution skewed toward smaller values. This indicates that if the corrosion crevices on waste packages were to compete with the dust in attracting brine, the crevice dimension needs to be on the order of, or smaller than, a micron.

\subsubsection{Complementary Imaging Approaches}

To gain an initial idea of the dimensions of the relevant structures (intergrain pore size, intragrain features, etc.) of the repository dust, different imaging techniques have been employed: focused ion beam (FIB), scanning electron microscope (SEM), and confocal microscope.

FIB Imaging - The FIB contains both a $\mathrm{Ga}^{+}$ion beam and a field-emission scanning electron column. The field emission SEM offers nanometer-scale resolution, higher than the standard tungsten filament SEM, and is ideally suited for identifying intragrain porosity, if pores exist. 
This is highly relevant to the screening argument, since intragrain pores will likely be the smallest and supply the highest capillary suction to retain brine in the dust.

Cross-sectioned dust grains were examined using the FIB, and exhibit little intragrain porosity. One such grain, a 5-micron dust particle, is presented in Figure 6.4-7. This particle is typical of the size range expected to be deposited on the waste package (Section 6.4.1), and is virtually nonporous. On the basis of this analysis, it is assumed that intergrain porosity is primarily responsible for the capillary response of the dust.

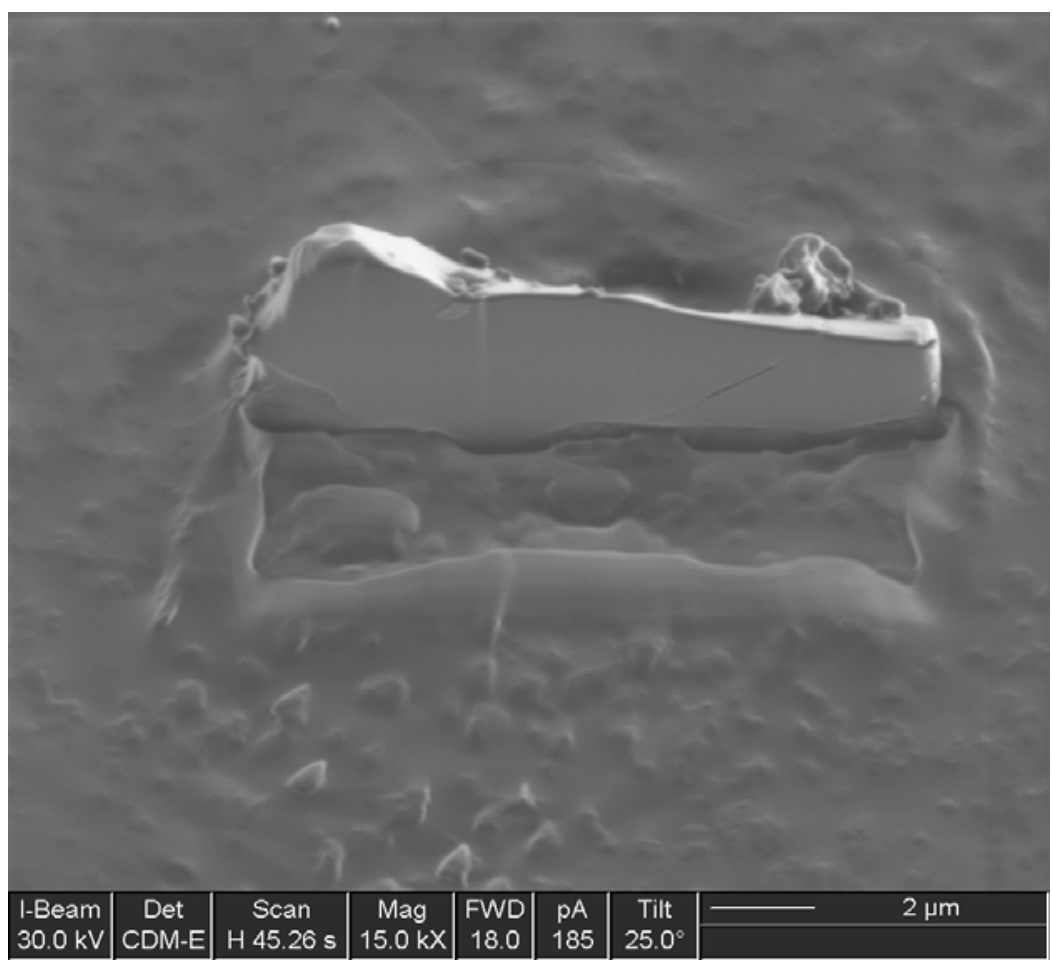

Source: DTN: LB0503DUSTIMAG.001 [DIRS 173258], 24.tif.

Figure 6.4-7. FIB Image Showing the Freshly Exposed Cross-Section of a Dust Particle with an Average Dimension of $\sim 5$ Microns

SEM Imaging - SEM imaging was conducted on two dust samples from Niche 5 of the ECRB in the Tptpll unit and from Niche 3 in the main tunnel, in the Tptpmn unit. Sample preparation involved infusion of liquid epoxy under pressure and hand polishing with abrasive grit to $0.1 \mu \mathrm{m}$.

The prepared sample of dust collected in Niche 5 of the ECRB drift was selected for imaging; typical two-dimensional backscattered electron SEM images are shown in Figures 6.4-8 and 6.49 , with dark areas representing pores and bright areas representing dust particles. The images show that both the dust particles and the dust pores have linear dimensions ranging from a fraction of a micron to tens of microns. 


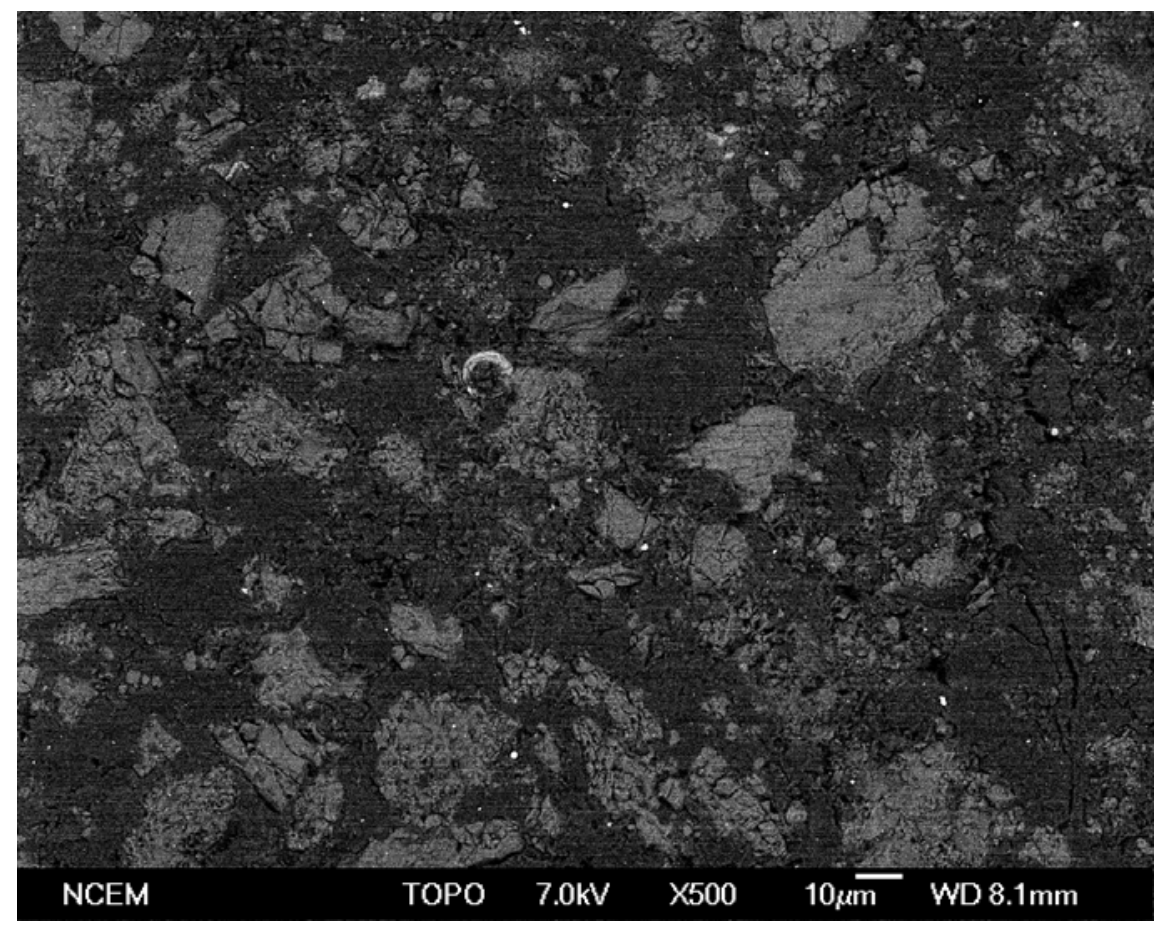

Source: DTN: LB0503DUSTIMAG.001 [DIRS 173258], 1.tif.

Figure 6.4-8. Backscattered Electron SEM Image of Epoxy-Impregnated Dust (Image A)

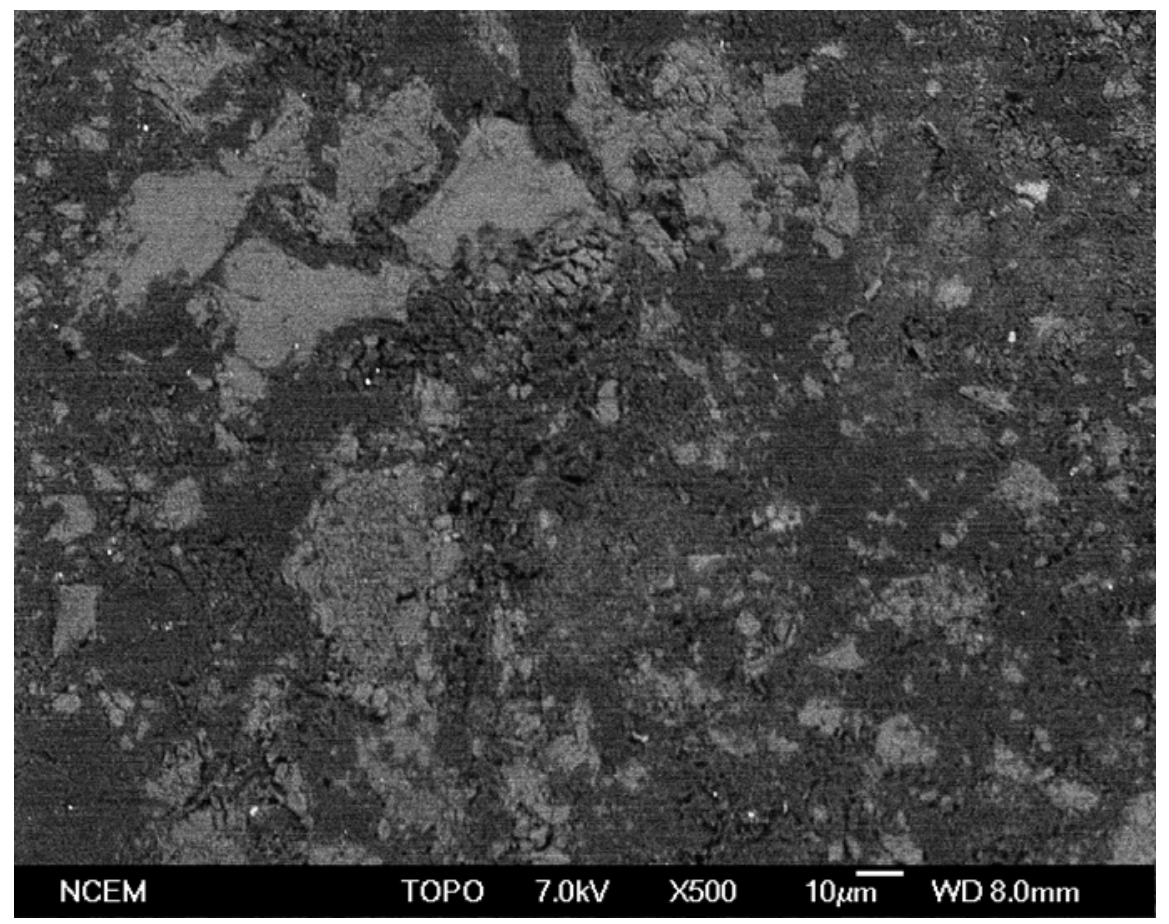

Source: DTN: LB0503DUSTIMAG.001 [DIRS 173258], 10.tif.

Figure 6.4-9. Backscattered Electron SEM Image of Epoxy-Impregnated Dust (Image B) 
Confocal Microscope Three-Dimensional Imaging-To address the concern that the sample preparation disturbed packing structure, three-dimensional imaging was carried out using a confocal microscope. For this, dust from Niche 5 was air-deposited from a height of $50 \mathrm{~cm}$ onto the microscope slide. Typical confocal three-dimensional images are shown in Figure 6.4-10.
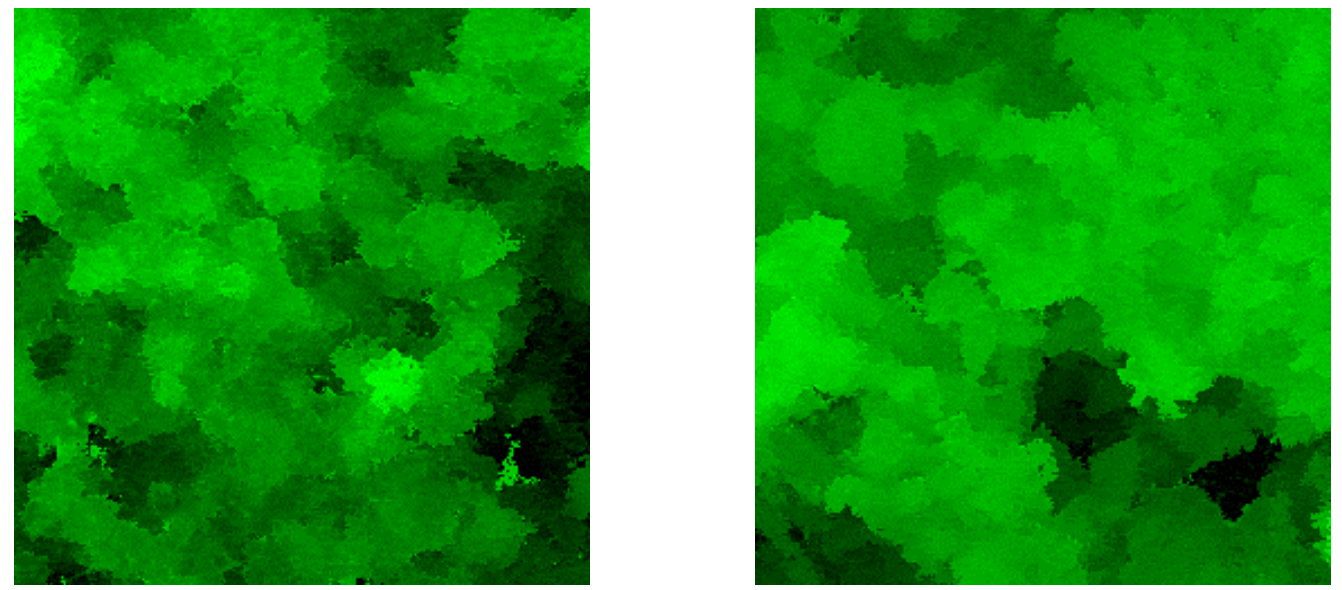

Source: DTN: LB0503DUSTIMAG.001 [DIRS 173258], s10_3d.tif, s13_3d.tif.

NOTE: Images are $250 \mu \mathrm{m} \times 250 \mu \mathrm{m}$ in linear dimension.

Figure 6.4-10. Confocal Three-Dimensional Images of Air-Deposited Dust

Bright areas in Figure 6.4-10 signify grains and dark signify pores. The three-dimensional reconstruction is for a depth of approximately 120 to 200 microns. The approach is limited to a depth of one to two dust grains, and after three-dimensional rendering the top surface topography can be observed.

Figure 6.4-10 shows the delicate structure of the dust packing. This differs from the more defined contrast between grain and pores of the polished surface imaged in two dimensions with SEM. The images in Figure 6.4-10 also indicate that the pore dimensions range from less than a micron to tens of microns.

\subsubsection{Pore Space Analysis and Capillary Suction}

To obtain a quantitative measure of the pore size distribution, standard image postprocessing functions such as thresholding, drawing, and counting areas and perimeters are applied to the SEM image in Figure 6.4-9. The image was initially segmented in pore/grain areas by applying a simple threshold function. Next, circles were fitted within the pores starting with the largest circle that could be fitted in the pore and continuing with smaller circles (or irregular shapes) fitting in the rough pore walls. The image postprocessing tools return the area, perimeter, and location for each such measured feature. A label and outline is provided for each feature measured. An outline representing the largest pores is shown in Figure 6.4-11a, and an outline representing both the large circular pores and the irregular small pores is shown in Figure 6.4-11b. 
By assuming the formula for circular pores, dividing the area of each counted pore by its perimeter, and multiplying by 4 , a pore diameter is obtained for each pore, and a distribution of the pore diameters for over 800 pores is shown in Figure 6.4-11.

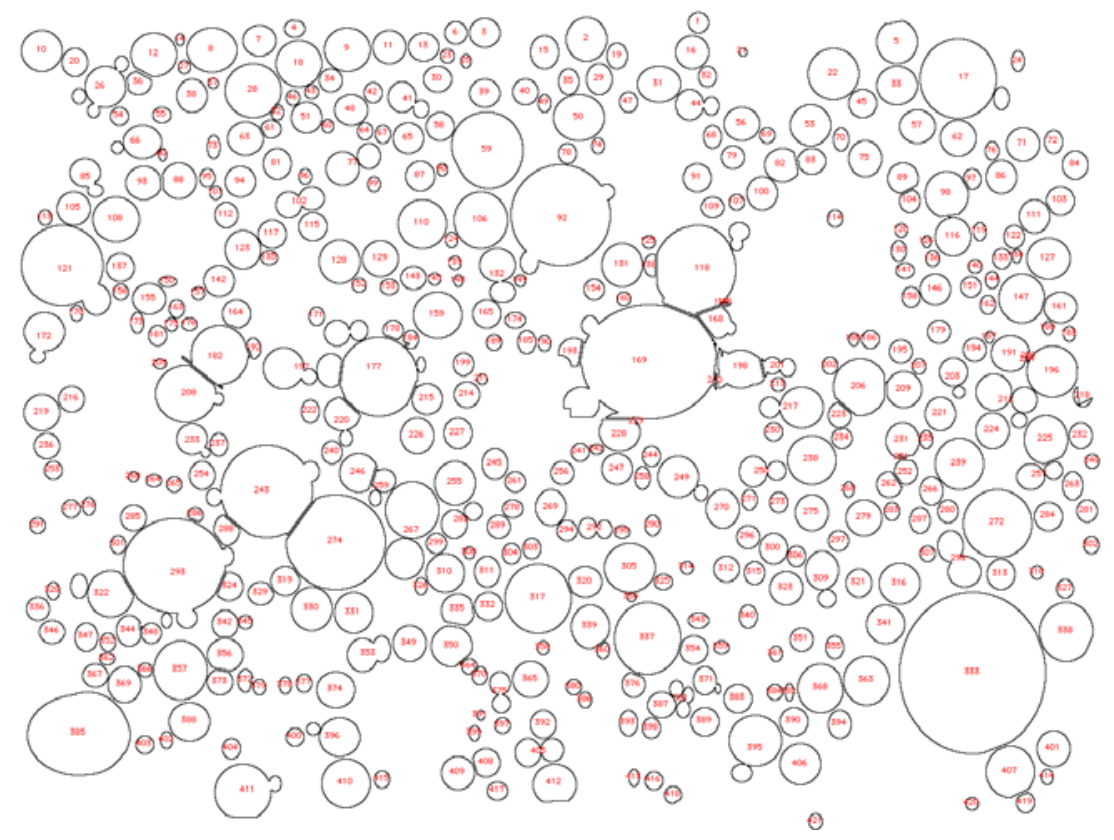

(b)

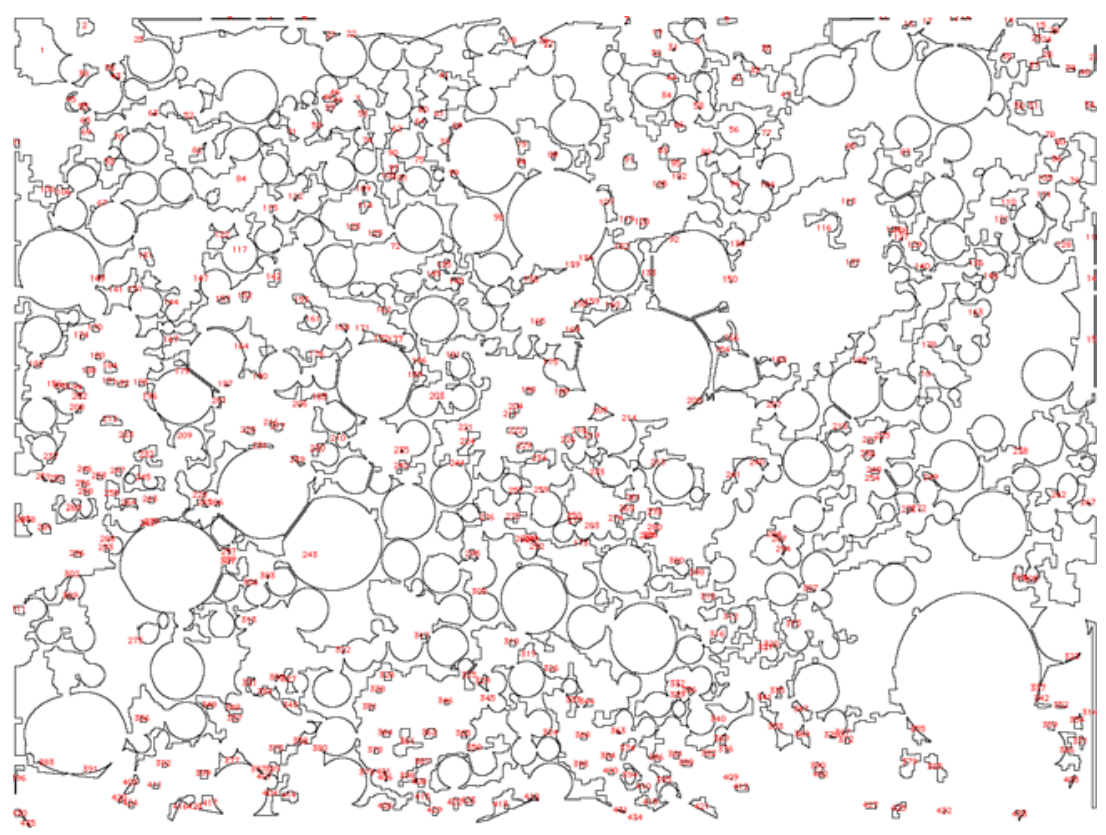

Source: DTN: LB0503DUSTIMAG.001 [DIRS 173258], Drawing with labels of big pore areas.tif and Drawing with labels of small pore areas.tif.

NOTE: $\quad(a)=$ large pores; $(b)=$ small pores. Pore labels (numbers) are not pertinent to this discussion, and are legible in the DTN if required.

Figure 6.4-11. Drawing of Pore Areas and Perimeters for Over 800 Pores, Based on the SEM Image Presented in Figure 6.4-8 


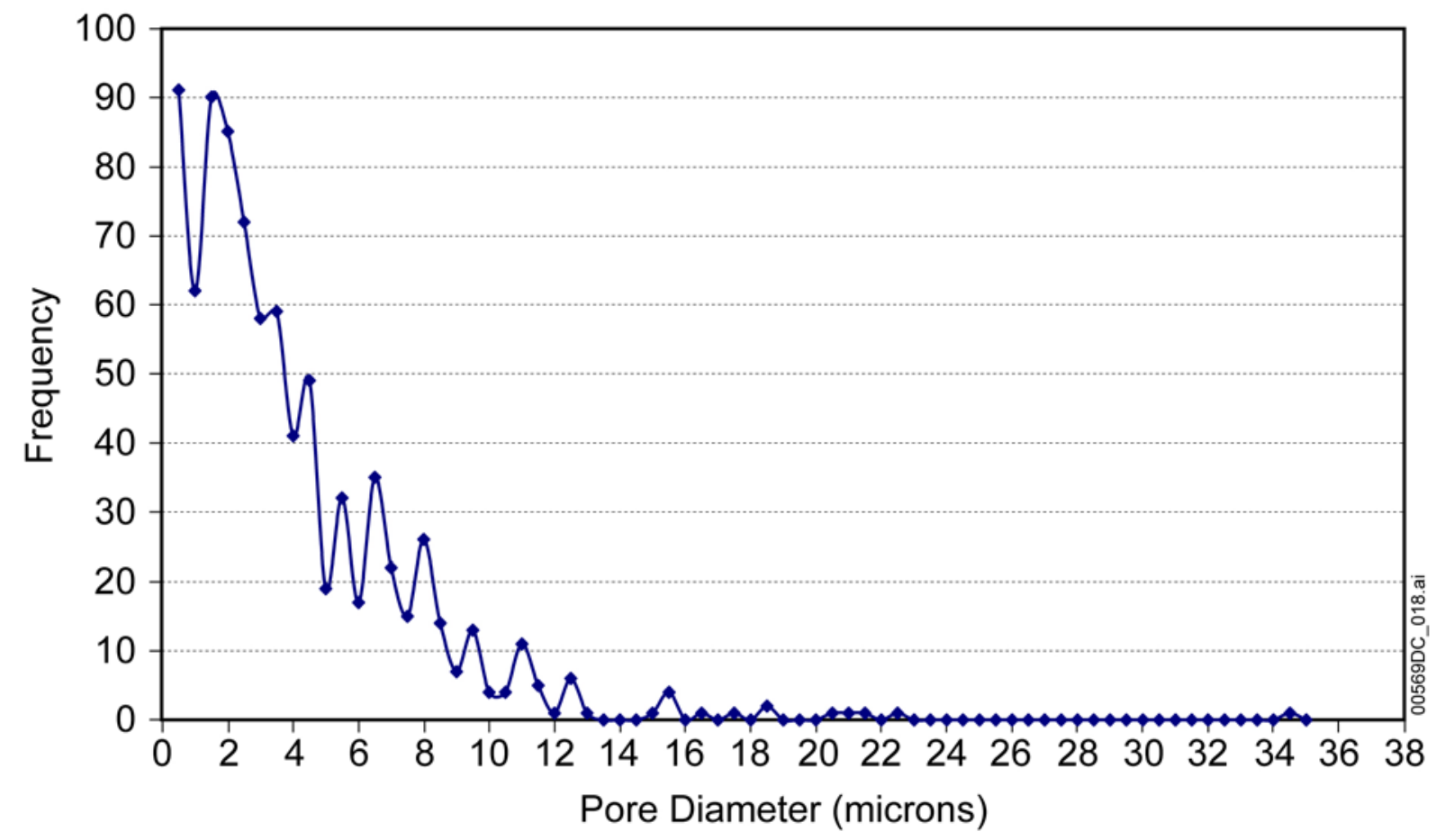

Source: DTN: LB0503DUSTPCAP.001 [DIRS 173259].

NOTE: $\quad$ Since the diameter of pores was not presented in the DTN, the pore diameters for all 853 pores were calculated from the area and perimeter of the pores (see Section 6.4.3.2). The pore diameter distribution was determined with the calculated pore diameters using the histogram function of Excel in 0.5 micron intervals. The distribution plot was also created with Excel.

Figure 6.4-12. Pore Diameter Distribution Based on the Pore Analysis in Figure 6.4-11

Using a capillary bundle approximation, the local capillary pressure associated with each pore of diameter, $d$, is expressed as (Jury et al. 1991 [DIRS 102010], p. 41):

$$
\left|\mathrm{P}_{\text {cap }}\right|=4 \sigma \cos \theta / d
$$

where $\sigma$ is the interfacial tension, which ranges from $0.0755 \mathrm{Newton} / \mathrm{m}$ at $273.15^{\circ} \mathrm{K}$ to 0.0589 Newton/m at $373.15 \mathrm{~K}$ for water (Incropera and DeWitt 1996 [DIRS 108184], Table A.6), and $\theta$ is the contact angle. In the simplest approximation, the contact angle is concluded to be zero for a perfectly wetting fluid, accessibility to large pore bodies behind small pore throat is not taken into account, and the slight temperature dependence of surface tension is neglected. Figure 6.4-12 shows that, according to the two-dimensional SEM image, the capillary response at low liquid saturation conditions likely for dust at elevated temperature is characterized by a typical dimension of about 1 micron, so that to compete for brine, the waste package crevice due to localized corrosion needs to be on the order of 1 micron. In addition, hydraulic communication must exist between the tiny brine droplets or films in the dust and the crevice or pore in the metal surface. Such conditions limit the availability of aqueous brine to support localized corrosion. 


\subsubsection{Scale Limitations on Diffusion as Part of the Localized Corrosion Process}

This section presents an argument that excludes initiation of localized corrosion (e.g., of Alloy 22) on boldly exposed surfaces, or surfaces which have small irregularities, or are in contact with dust particles. The argument is a bounding one, in that brine retention as discussed in the previous section is ignored and the total amount of the estimated maximum brine volume (for temperature of $120^{\circ} \mathrm{C}$ or greater; see Section 6.4.1) is brought in contact with the metal surface.

As pointed out by EPRI (2004 [DIRS 172825]), the thickness of a brine film formed from deliquescence of soluble constituents in dust will be small, so that dissolved oxygen will readily diffuse throughout. Thus, the anodic and cathodic regions of a potential localized corrosion cell will coincide, and "neither the differential $\mathrm{O}_{2}$ concentration conditions nor the local acidification required for the initiation of localized corrosion will be established" (EPRI 2004 [DIRS 172825], p. 5-9). The EPRI report offers an example calculation of the dissolved oxygen concentration at the metal interface, as a function of the maximum dissolved concentration and the passive current density (representing the consumption rate prior to initiation of localized corrosion).

The following discussion uses a similar derivation, along with brine film thickness parameters developed elsewhere in this report, to support this conclusion. The derivation begins with a temperature-dependent function for passive current density for Alloy 22:

$$
i_{\text {pass }}=i_{\text {pass }}(T)
$$

This function represents the uniform, oxidative corrosion behavior of Alloy 22, based on measured uniform corrosion rates as discussed below.

Diffusion of $\mathrm{O}_{2}$ in a layer of brine is represented by the one-dimensional form:

$$
i_{O 2 f l u x}=D_{\text {corr }}\left(C_{\text {bulk }}-C_{0}\right) / d
$$

where $D_{\text {corr }}$ is an effective diffusion coefficient corrected for temperature and viscosity effects (see below), $C_{\text {bulk }}$ represents the maximum concentration of dissolved $\mathrm{O}_{2}$ in the brine at the air-brine interface, $C_{0}$ is the dissolved $\mathrm{O}_{2}$ concentration at the site of active corrosion, and $d$ is the fluid layer thickness. In this analysis the chemical activity of dissolved $\mathrm{O}_{2}$ is not used directly, but instead the maximum concentration is modified by a salting-out coefficient (see below) and a diffusion coefficient for more dilute solutions is used, modified by the brine viscosity. This is conservative because the maximum chemical activity in solution is actually unchanged by salting-out behavior, so the activity gradient that drives diffusion is under-predicted. The approach is subject to uncertainty in the estimates of salting-out and viscosity effects, as discussed at the end of this section.

The reduction of oxygen at the brine-metal interface is represented by:

$$
\mathrm{O}_{2}+2 \mathrm{H}_{2} \mathrm{O}+4 e^{-} \rightarrow 4 \mathrm{OH}^{-}
$$


which is justified because 1) the product of anodic attack is soluble metal-hydroxyl complexes and 2) the reaction maximizes the utilization of oxygen to produce hydroxyl ions. Use of Equation 6.4-31 is corroborated by Apted et al. (2004 [DIRS 172858], Equation 2). For each mole of electrons transferred at the metal surface, 0.25 moles of $\mathrm{O}_{2}$ are consumed. In other words, the steady-state flux of $\mathrm{O}_{2}$ is one fourth of the passivation current (expressed in equivalent units, for example using Faraday's constant).

Equating $i_{\text {pass }}$ with $4 \times i_{O 2 f l u x}$ and solving for $C_{0} / C_{\text {bulk }}$ gives a measure of the range of $\mathrm{O}_{2}$ concentration present in the brine layer.

The effective diffusion coefficient is represented by:

$$
D=D_{0} \tau \varepsilon
$$

where $D_{0}$ is a representative diffusion coefficient in concentrated brine, $\tau$ is the tortuosity factor, and $\varepsilon$ is porosity. A representative value of $D_{0}=1.8 \times 10^{-5} \mathrm{~cm}^{2} / \mathrm{sec}$ at $25^{\circ} \mathrm{C}$ is used, corresponding to a sodium chloride solution (approximately the average value given by Kear et al. 2004 [DIRS 172833], Table 6). The tortuosity is set to 1, which bounds the effective diffusion, consistent with conceptualization of the dust as an open, loose, highly porous agglomeration of very fine particles. Also, the brine layer thickness (and not tortuosity) is used in this analysis to represent path-length effects associated with brine film geometry proximal to dust grain contacts with the Alloy 22 surface.

The value used for dust porosity in the analysis is 0.5. As described in Section 4.1.6, this is based on a bulk dust density of $70 \mathrm{lb} / \mathrm{ft}^{3}$, or $1.12 \mathrm{~g} / \mathrm{cm}^{3}$, and on typical silicate, carbonate, and sulfate mineral densities ranging from approximately 2.1 to $2.7 \mathrm{~g} / \mathrm{cm}^{3}$.

Corrections to the effective diffusivity to represent the effects of temperature, and solution viscosity, combined with Equation 6.4-32, are of the form:

$$
D_{\text {corr }}=\frac{D T}{T_{r e f} C_{v i s}}=\frac{D_{0} \tau \varepsilon T}{T_{r e f} C_{v i s}}
$$

where $T$ is absolute temperature, $T_{\text {ref }}$ is the reference temperature corresponding to $D_{0}$ (i.e., $25^{\circ} \mathrm{C}$ ), and $C_{v i s}$ captures the effect of increased viscosity in concentrated deliquescent brines. By setting $C_{v i s}=10$, the diffusion coefficient is reduced one order of magnitude at all temperatures to represent tenfold greater brine viscosity than the concentrated salt solution that is the basis for $D_{0}$. The temperature and viscosity corrections in Equation 6.4-33 are consistent with the functional form of the Stokes-Einstein equation (Atkins 1990 [DIRS 111464], p. 765).

The maximum dissolved $\mathrm{O}_{2}$ concentration at the air-brine interface, $C_{b u l k}$, is described by the polynomial expression provided by EPRI (2004 [DIRS 172825]), which is based on the reference data of Battino et al. (1983 [DIRS 172817]) modified by a salting-out factor ranging from 0.05 to 0.5 (Section 4.1.6). 
Equating $i_{\text {pass }}$ with $i_{O 2 f l u x}$, substituting for parameters, and solving for $C_{0} / C_{\text {bulk }}$ gives:

$$
\begin{aligned}
\frac{C_{0}}{C_{\text {bulk }}} & =1-\frac{i_{\text {pass }} d}{4 D_{\text {corr }} C_{\text {bulk }}} \\
& =1-\frac{i_{\text {pass }} d T_{r e f} C_{v i s}}{4 D_{0} \tau \varepsilon T C_{\text {bulk }}}
\end{aligned}
$$

The derivation of $i_{\text {pass }}$ is presented below.

General or uniform corrosion of Alloy 22 is governed by the transport properties of reacting species in the passive film and the dissolution rate of the passive film (BSC 2004 [DIRS 169984], Section 6.4.3.4). Prior to initiation of localized corrosion, uniform corrosion occurs slowly, described by the passive current density. Combining Equations 6-28 and I-3 of General Corrosion and Localized Corrosion of Waste Package Outer Barrier (BSC 2004 [DIRS 169984]), an equation for the general corrosion rate, in terms of the passive current density $\left(i_{\text {pass }}\right)$, is derived as:

$$
i_{\text {pass }}=\exp \left\{\frac{C}{T}-\frac{C}{333.15}\right\} \frac{r_{0} \rho}{k \cdot E W}
$$

Applying unit corrections, $i_{\text {pass }}$ is expressed in units of $\mathrm{nA} / \mathrm{cm}^{2}$. The parameters of Equation 6.4-35 are defined in Section 4.1.6.

Figure 6.4-13 compares the current density-temperature curves for different percentiles of the general corrosion model (BSC 2004 [DIRS 169984], Section 6.4.3.4) with that generated from Equation 3 of the study by Apted et al. (2005 [DIRS 172858]):

$$
\mathrm{i}_{\text {pass }}=\mathrm{i}_{0} \cdot \exp [-\Delta \mathrm{E} / \mathrm{RT}]
$$

where $\mathrm{R}$ is the universal gas constant, the pre-exponential factor $\mathrm{i}_{0}$ has a value of $0.023 \mathrm{~A} / \mathrm{cm}^{2}$, and the activation energy $\Delta \mathrm{E}$ has a value of $44.7 \mathrm{~kJ} / \mathrm{mol}$. The curve from the study by Apted et al. (2005 [DIRS 172858]) compares with the upper-percentile curves (see Figure 6.4-13 with respect to range). Detailed calculations are presented in Output DTN: MO0508SPAOXYGE.004.

The 99th percentile curve for $i_{\text {pass }}$ was used in Equation 6.4-34. The results are plotted in Figure 6.4-13. This curve is also used in the analysis shown in Figures 6.4-14 through 6.4-16 for three values of film thickness: $1.8 \mu \mathrm{m}, 18 \mu \mathrm{m}$ (the estimated average brine layer thickness from this report), and $180 \mu \mathrm{m}$; three values of salting-out factor; and three sets of viscosity values (versus temperatures). Note that the $18 \mu \mathrm{m}$ brine film thickness value corresponds to the estimated maximum elevated temperature $\left(120^{\circ} \mathrm{C}\right.$ or greater) brine volume from Section 6.4.1. The $180-\mu \mathrm{m}$ value, combined with the porosity $\varepsilon$, is intended to represent the remote possibility of a large, pendular brine drop present at the contact between dust grains and the metal surface, and adhering to both. Alternatively, this thickness can represent a brine film containing a fraction of relatively insoluble dust particles. The scale of this approximation is supported by 
laboratory tests of artificially creviced samples, which have shown that localized corrosion does not initiate in boldly exposed regions of the metal surface, and imagery which suggests that localized corrosion does not initiate within roughly $100 \mu \mathrm{m}$ of the opening of an artificial crevice (Figure 6.4-17).

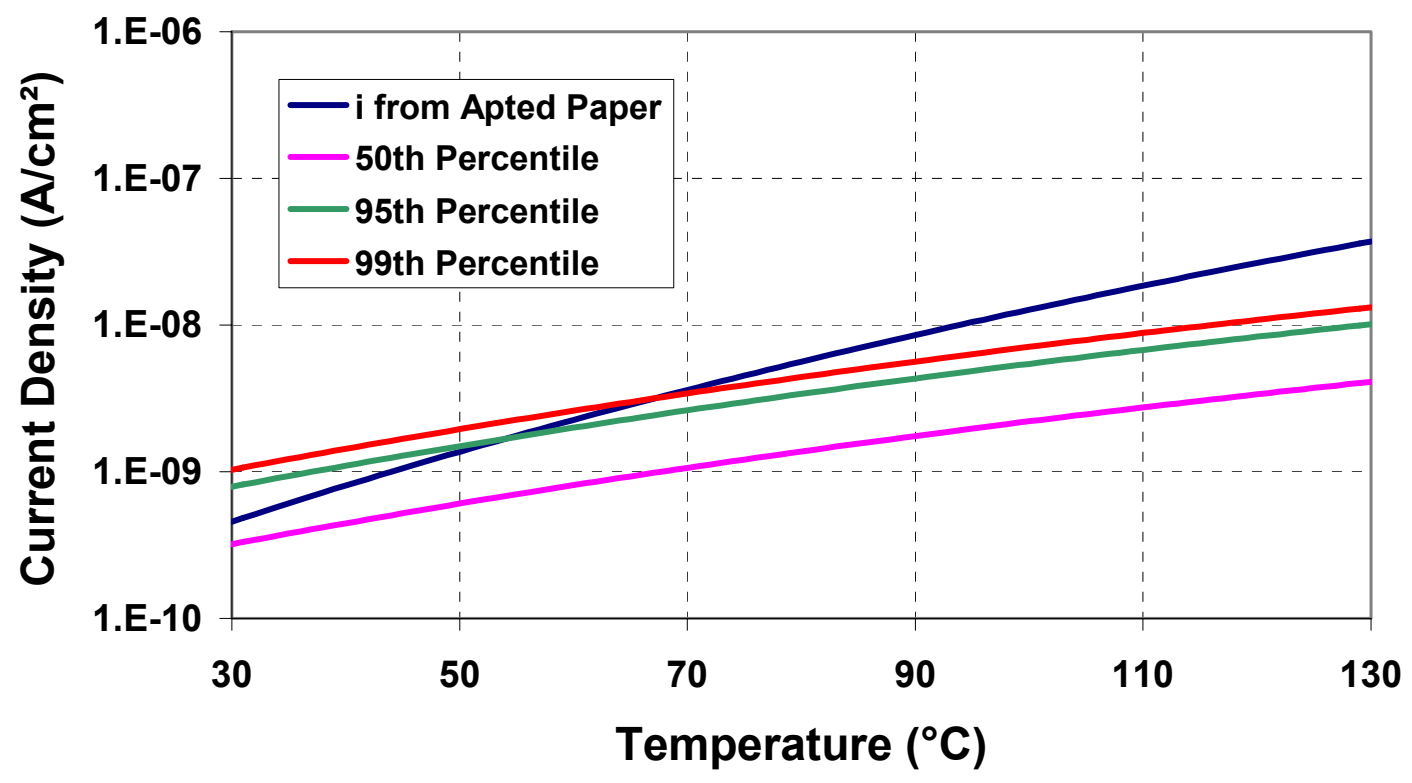

Source: Output DTN: MO0508SPAOXYGE.004, AptediRev.xls.

NOTE: "Apted paper" refers to the study by Apted et al. (2005 [DIRS 172858]).

Figure 6.4-13. Passivation Current $\left(i_{\text {pass }}\right)$ as a Function of Temperature

The calculated results show that the $\mathrm{O}_{2}$ concentration will be nearly uniform throughout the brine layer (or drop), corroborating the conclusion in the EPRI report (2004 [DIRS 172825]), as stated above, that the scale of brine occurrence due to dust deliquescence is so small that molecular diffusion will inhibit corrosion reactions within the cell. Note that this conclusion applies anywhere that dust may be found; because the dust has an open structure and is highly permeable to air, even dust within a contact crevice will be subject to limited brine volume and access by $\mathrm{O}_{2}$ in air. In addition to oxygen solubility, the limited amount of chloride and the presence of nitrate ions will act to inhibit the initiation of localized corrosion. The analyses described in this section can be found in Output DTN: MO0508SPAOXYGE.004. Finally, it is noted that other chemical oxidants may be present in deliquescent brine as dissolved species, but that these are also uniformly distributed, and that $\mathrm{O}_{2}$ is the only such species that can be replenished from the gas phase. 


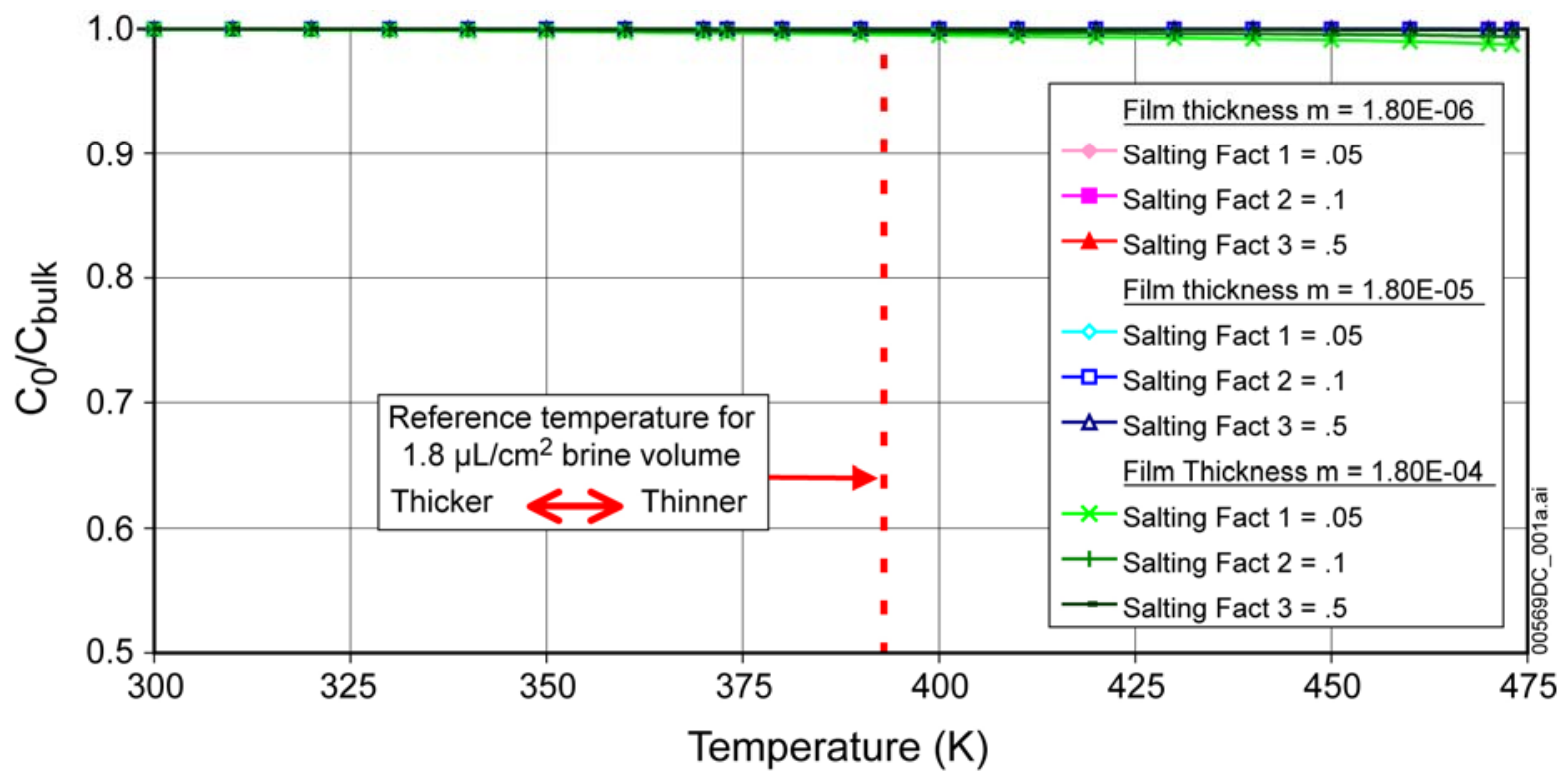

Source: Output DTN: MO0508SPAOXYGE.004, O2 flux calculation Rev3.xls.

Figure 6.4-14. Predicted Change in Dissolved $\mathrm{O}_{2}$ Concentration with Brine Layer Thickness (1x Viscosity)

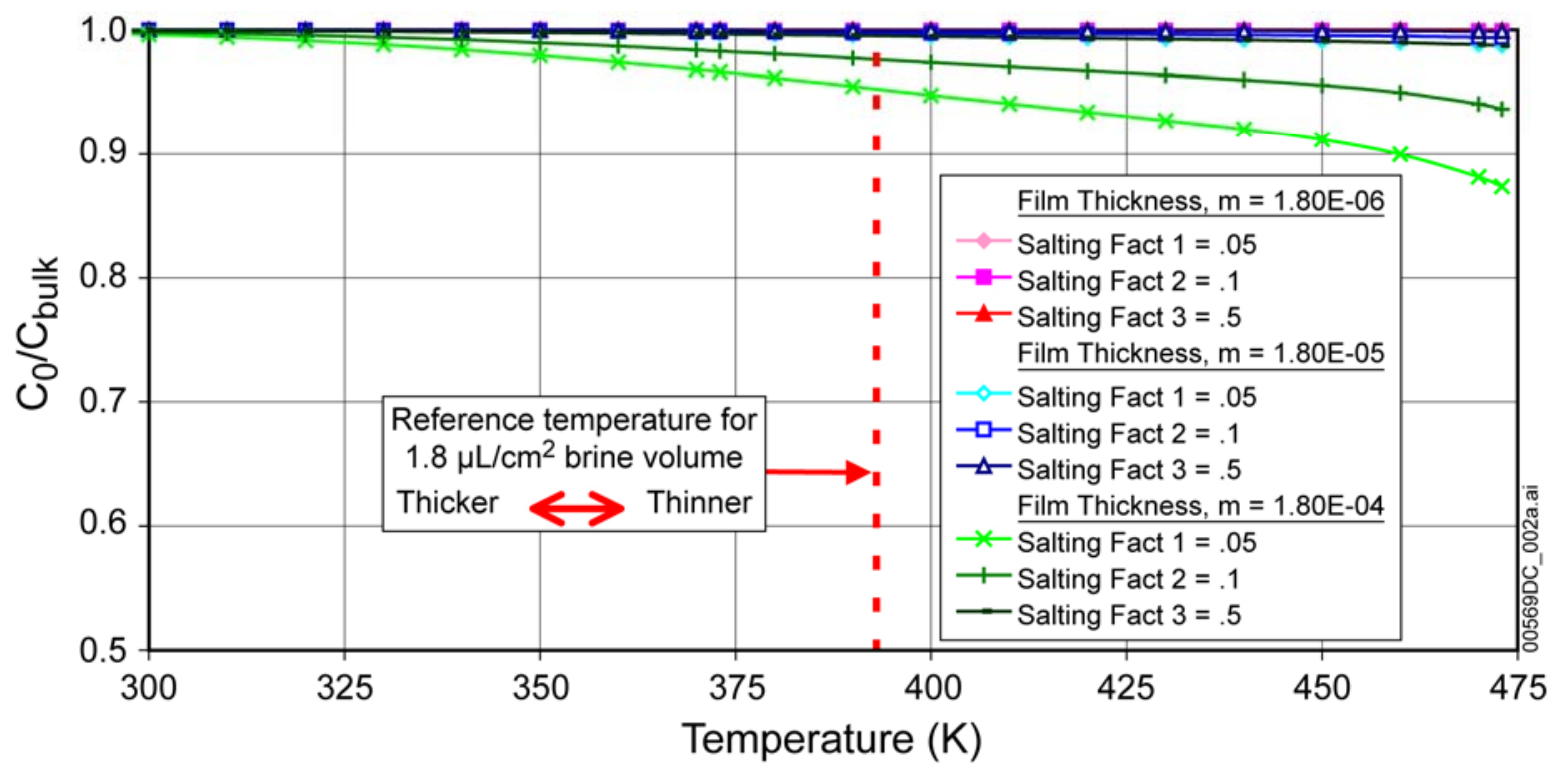

Source: Output DTN: MO0508SPAOXYGE.004, O2 flux calculation Rev3.xls.

Figure 6.4-15. Predicted Change in Dissolved $\mathrm{O}_{2}$ Concentration with Brine Layer Thickness (10x Viscosity) 


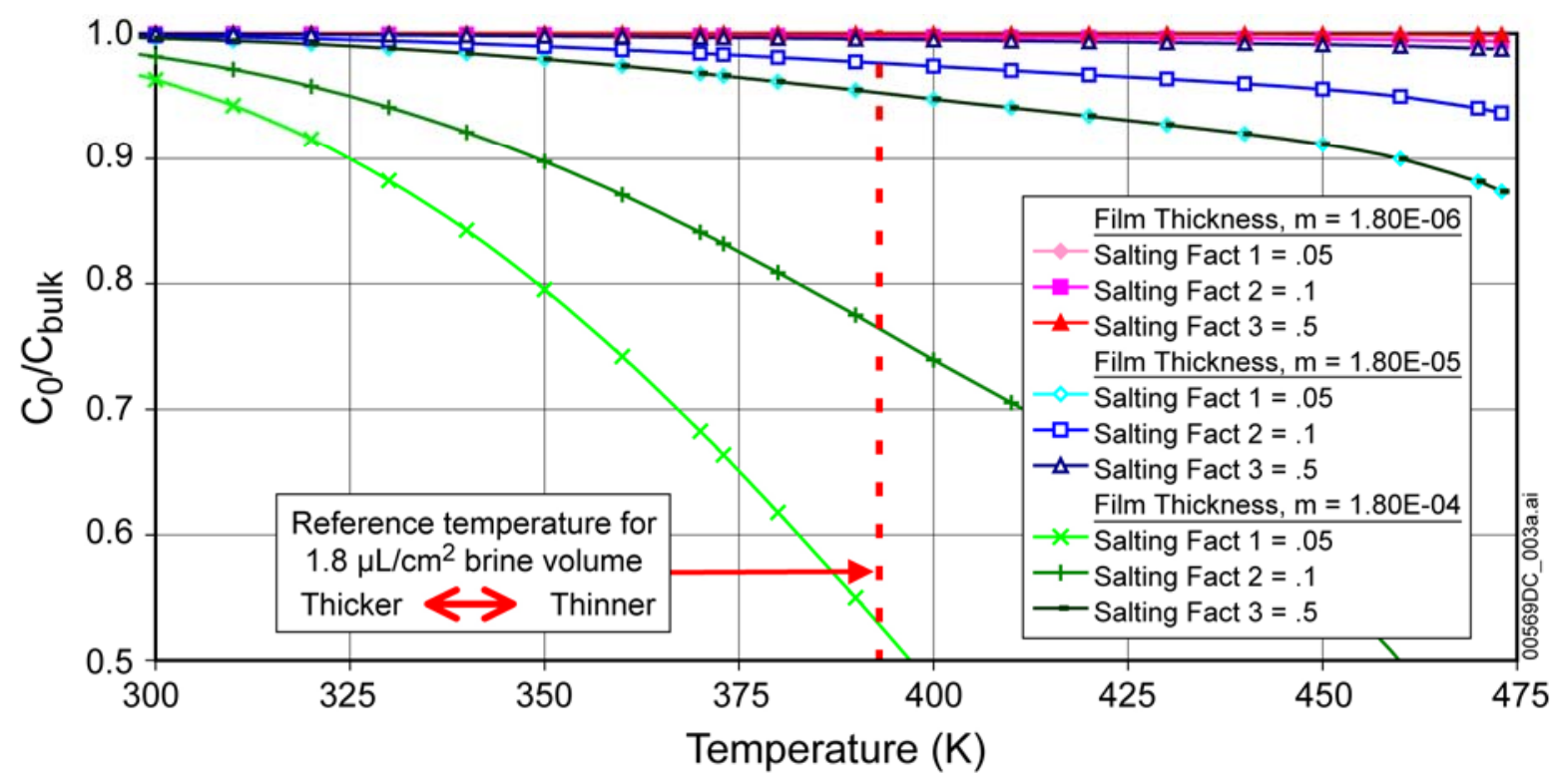

Source: Output DTN: MO0508SPAOXYGE.004, O2 flux calculation Rev3.xls.

Figure 6.4-16. Predicted Change in Dissolved $\mathrm{O}_{2}$ Concentration with Brine Layer Thickness (100x Viscosity)

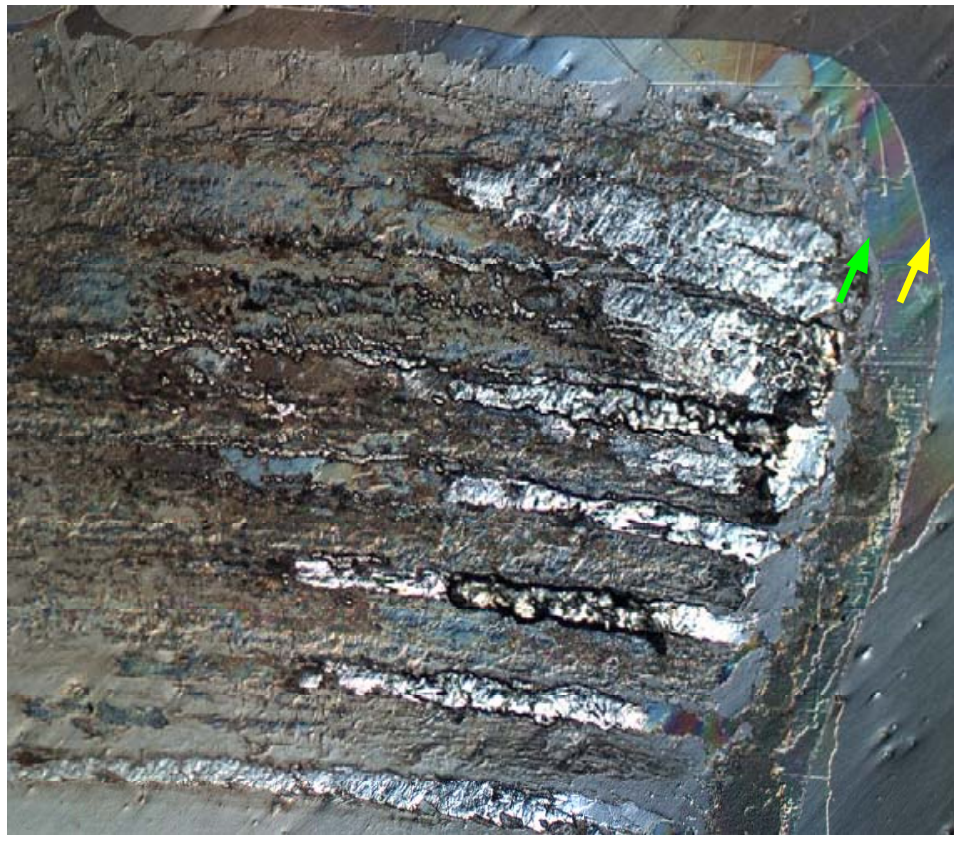

Source: DTN: LL040702112251.112 [DIRS 173822], ECIC-C22-NaCl-OCP-33Ohrs-image.ppt.

NOTE: A gap of approximately 100 microns exists between the original edge of the crevice former (yellow arrow) and the edge of the corroded zone (green arrow).

Figure 6.4-17. Optical Microscopic Images of Crevice Corrosion on an Alloy 22 Sample under a Pseudo Thin Film $(\sim 5 \mathrm{~mm})$ of Saturated $\mathrm{NaCl}$ Solution after 330 Hours at $105^{\circ} \mathrm{C}$ and $78 \%$ Relative Humidity 


\subsubsection{Summary}

Localized corrosion will not initiate on Alloy 22 surfaces because the deliquescent brine composition will be benign (Section 6.3). In addition, the brine volume available on the alloy surface to potentially support corrosion at elevated temperature (here defined as $\mathrm{T}>120^{\circ} \mathrm{C}$ ) is very small because of the limited quantity of deposited soluble salts, the statistical rarity of mutual deliquescence when soluble salts exist in separate grains, and because the brine will tend to be retained within the dust layer (which will consist mostly of non-deliquescent minerals). With such small brine volume the brine film dimensions will be small, and diffusion of oxygen throughout the aqueous phase will inhibit the creation of separate anodic and cathodic regions for localized corrosion. This will occur on boldly exposed surfaces, and under a dust layer of small dust grains (on the scale of microns).

Calculations presented here show that the amount of dust deposited on the waste package during ventilation will be small, and brines generated by dust deliquescence will be limited in volume. Assuming that the soluble salt content of dust is derived entirely from atmospheric aerosols, and making reasonable assumptions regarding the effects of ammonium salt decomposition, the maximum deliquescent brine volume is estimated to be $1.8 \mu \mathrm{L} / \mathrm{cm}^{2}$ at $120^{\circ} \mathrm{C}$ (and approximately twice this amount at $105^{\circ} \mathrm{C}$ ). This value assumes that all salt components in the dust are in contact with each other, so that mutual deliquescence (eutectic behavior) occurs to maximum extent. A sensitivity calculation is presented evaluating the effects of salt mineral isolation in the dust, and indicates that salt mineral isolation will result in lower brine volumes if overall salt abundances constitute less than a few percent of the dust, but has no effect at higher concentrations.

Tunnel dust samples have been characterized to evaluate the potential for capillary retention of the brine to reduce surface contact or inhibit brine flow into pores or crevices. Results indicate that the capillary response of the dust is characterized by a typical dimension of about one micron. This dimension suggests that liquid brine will be strongly retained in the dust, and that pores or cervices on the metal surface would need to have similar (or smaller) dimensions in order to compete successfully for the brine.

Scoping calculations presented here verify the conclusions of EPRI (2004 [DIRS 172825]), which predicted that deliquescent brine volumes, represented as layer thicknesses or droplets on the waste package, are too small to support the $\mathrm{O}_{2}$ concentration gradients necessary to develop the separate anodic and cathodic zones required for initiation of localized corrosion.

Uncertainty Discussion-The screening arguments pertaining to initiation have associated uncertainties which are addressed using bounding approximations and parametric analysis. The estimated brine volume estimates (Section 6.4.1.1 and 6.4.1.2) are based on collected data for dust abundance and for soluble-salt composition of rain-out, representing precipitated soluble salts available for suspension in air at or near the ground surface. In the calculation of dust deposition on the waste packages (Section 6.4.1.1), the uncertainty in dust particle size distribution and associated deposition rate is addressed by assigning the soluble constituents of dust to particle sizes that are more likely to be deposited on the waste packages during preclosure ventilation. This is confirmed by a parametric study of smaller particle deposition behavior (Table 6.4-2). Dust deposition may also be affected by electrostatic effects or ionizing radiation, 
which could either enhance or inhibit deposition, or result in deposition on all sides of the waste package instead of just the upper surface. The potential effects of eddies, which could result in uneven dust deposition, are also not considered. The analysis of brine volume (but not its composition) is bounding because it considers the dust as originating entirely from atmospheric aerosols (which have relatively high salt content) and not from within the tunnels (as represented by tunnel dust samples).

The analysis of grain-grain contact probabilities (Section 6.4.2) is based on a formalism for arbitrary particles, which is simplified for expository purposes by the assumption of equal size spheres. Various particle characteristics may contribute to the uncertainty associated with this assumption, including disparate particle size, shape, and salt coatings. The contact analysis (Figure 6.4-5) is scale invariant (independent of particle size) but may underestimate grain-grain contact between mutually deliquescent salts if smaller particles containing soluble salts are arranged together in the interstices between larger, non-deliquescent particles. Particle shape effects could cause the contact coordination behavior to be underestimated, especially for filamentous structures that could coordinate with many other particles. Microscopic analysis of tunnel dust did not reveal the presence of such filamentous structures (Section 6.4.3), and the particles of most soluble salts are believed to be relatively small, on the order of 2.5 microns or smaller (Section 6.1.3). Therefore, the uncertainty associated with particle shape may be minor. Salt coatings could form on otherwise non-deliquescent particles, from deliquescence and subsequent re-drying. The effect of such coatings would be to increase the effective particle size without increasing the total abundance of the coating salts. In a dust mixture of disparately sized particles this would increase the effective coordination with other grains. Also, the soluble salts in atmospheric aerosols may be "internally mixed" whereby the smallest discrete particles contain mixtures of mutually deliquescent salts, in which case the grain-grain contact scoping analyses would not be applicable.

An analysis of the potential for brine retention in dust based on laboratory observations of the geometrical characteristics of dust deposits is affected by the uncertainty associated with physical changes from sampling, handling, and redepositing the dust. Some aggregation of the particles may have occurred, decreasing the sizes of pores. Alternatively, the process of sampling (e.g., by vacuuming) and redeposition on a slide for examination may have increased the porosity. The conclusion of this part of the analysis is based on the association of observed pore size with particle size, which is not changed by handling. Hence the dust contains an abundance of fine particles and pores, for which the general retention behavior may be inferred.

The final part of the analysis considers the diffusion of oxygen throughout an occurrence of deliquescent brine, establishing that the scale of occurrence as a brine film or pendular droplet promotes uniform $\mathrm{O}_{2}$ concentrations throughout. Thus, for boldly exposed metal surfaces, the potential to develop separate anodic and cathodic regions necessary for localized corrosion is inhibited by $\mathrm{O}_{2}$ diffusion. This mechanism may not be effective in artificial crevices such as the waste package-pallet contact. The effective path length for diffusion of $\mathrm{O}_{2}$ into a crevice through a continuous aqueous phase (if one exists) may exceed that considered in the analysis. This explanation is consistent with the conditions required for occurrence of localized corrosion (Section 6.5.1). This uncertainty does not apply to contacts between dust grains and the metal surface, and the analysis does consider path lengths that greatly exceed the size of the dust particles. 


\subsection{ONCE INITIATED, WILL LOCALIZED CORROSION PENETRATE THE WASTE PACKAGE OUTER BARRIER?}

This section describes the localized or crevice corrosion process and identifies factors that will inhibit progress in a deliquescent dust environment. A power-law expression for localized corrosion is then presented which limits the rate and extent of localized corrosion propagation. Available data pertaining to the applicability of the power law are discussed. Finally, a scoping analysis is presented which compares the available brine volume with the volume of corrosion products produced as localized corrosion occurs, to show that sequestration of the brine in the corrosion products will limit localized corrosion propagation and prevent penetration.

\subsubsection{Crevice Corrosion}

Crevice corrosion occurs within shielded or occluded regions on a metal surface (Fontana 1986 [DIRS 100890]) and requires the presence of a continuous liquid film connecting the anodic and cathodic regions. Occluded regions, which can act as anodes, could be formed at the interfaces between the waste packages and the pallets or other close contact areas on the waste package surface (contact crevices). Within this region, a volume of stagnant liquid must form in order for crevice corrosion to occur. The crevice geometry must be wide enough to permit liquid entry but narrow enough to maintain the stagnant layer (Fontana 1986 [DIRS 100890]). Crevice corrosion initiation involves: 1) local depletion of oxygen in the crevice; 2) formation of an anodic region, where electrons are produced (the crevice), and cathodic regions, where electrons are consumed (typically outside the crevice); 3) metal dissolution within the crevice; and 4) hydrolysis of dissolved metal ions and the accompanying acidification of the creviced region (Fontana 1986 [DIRS 100890]). Metal ion hydrolysis also leads to a charge imbalance within the crevice and migration of anions such as chloride into the creviced region (Fontana 1986 [DIRS 100890]). The crevice grows by anodic processes (metal dissolution) within the crevice balanced by cathodic reduction and, to a lesser extent, by reduction of $\mathrm{H}^{+}$within the crevice (Fontana 1986 [DIRS 100890]). Although metal-ion and oxygen-concentration differences do exist between solutions inside and outside the crevice during crevice corrosion, these are not the direct causes of crevice corrosion. Oxygen depletion within the crevice coupled with metal dissolution leads to an excess of positive charge in the crevice solution, which is balanced by migration of chloride ions (Fontana 1986 [DIRS 100890]). Hydroxide ions may also migrate into the crevice, but they are less mobile than chloride ions and thus migrate more slowly (Fontana 1986 [DIRS 100890]). It is this build-up of chloride ions which leads to breakdown of the passive film and crevice corrosion initiation.

A number of characteristics of crevice corrosion will tend to deplete the limited supply of water available in the brine formed by dust deliquescence. Hydrolysis of dissolved metal ions consumes water through reactions of the form:

$$
\mathrm{M}^{\mathrm{x}+}+\mathrm{y} \mathrm{H} \mathrm{H}_{2} \mathrm{O} \rightarrow \mathrm{M}(\mathrm{OH})_{\mathrm{y}}^{(\mathrm{x}-\mathrm{y})+}+\mathrm{y} \mathrm{H}^{+}
$$

Reactions at the cathode also consume water. The cathode and anode, although spatially separated (by a distance that may be as short as $100 \mu \mathrm{m}$, as suggested by Figure 6.4-17), must have a continuous solution path between them (the deliquescent film or brine droplet) as well as a continuous electrical path (the alloy itself). In order for growth to continue, the solution must 
maintain contact with the crevice tip (the site of metal ion dissolution). As the crevice grows, more solution volume is required to fill the new volume of crevice not occupied by corrosion products. As noted, water in the solution is being consumed at the anode and the cathode, so this water must be replaced by condensation from the gas phase for the corrosion process to continue.

Progress of crevice or localized corrosion requires precipitation of solid phases in the cathodic region, which for fine crevices (e.g., contact crevices) would then impede the transport processes necessary for the corrosion cell to function. The required transport includes transport of ionic species and $\mathrm{O}_{2}$ in the aqueous phase, and transport of $\mathrm{H}_{2} \mathrm{O}$ and $\mathrm{O}_{2}$ through the gas phase to reach the aqueous phase. Any decrease of the cathodic area available to support the dissolution reaction (e.g., from solid precipitates) would lead to cathodic limitation of the crevice corrosion process. Any blockage of the gas-phase pathway for replenishment of reactants would similarly impede corrosion progress.

The effect of high temperatures on the mechanism of crevice corrosion also tends to impede corrosion. At higher temperatures, the diffusion rate of oxygen increases, promoting homogenization of the oxygen concentration profile, thereby decreasing the possibility of crevice corrosion initiation as discussed in Section 6.4. Similarly, increased temperatures enhance the diffusion of all species in solution, thereby promoting uniform solution conditions, and decreasing the stability of crevice chemistry.

\subsubsection{The Power Law for Propagation of Localized Corrosion}

An alternative conceptual model for the rate of localized corrosion propagation is discussed in General Corrosion and Localized Corrosion of the Waste Package Outer Barrier (BSC 2004 [DIRS 169984], Section 6.4.4.8.2). This alternative conceptual model was based on the observation that, for a number of alloy/exposure environment combinations, the rate of localized corrosion propagation has been observed to decrease with time (CRWMS M\&O 1998 [DIRS 100349], Table 3-2; Hunkeler and Boehni 1983 [DIRS 162221]; McGuire et al. 1998 [DIRS 152193], Section 5.2.8; EPRI 2002 [DIRS 158069], Section 5.3.1; Frankel 1998 [DIRS 162216]; Newman and Franz 1984 [DIRS 162250]). A simple time-dependent model used in the literature for this behavior is based on growth of hemispherical pits and yields a propagation law of the form (CRWMS M\&O 1998 [DIRS 100349], Table 3-2; Hunkeler and Boehni 1983 [DIRS 162221]; McGuire et al. 1998 [DIRS 152193], Section 5.2.8):

$$
D=k t^{n}
$$

where $D$ is the depth of propagation, $t$ is time, and $k$ is a growth constant. The growth constant depends on the properties of the material, particularly its susceptibility to anodic dissolution in the acidic environment prevailing at a propagating site of localized corrosion. The time exponent, $n$, would be about 0.5 (and always less than 1) for both diffusion-controlled (i.e., diffusion of metal ions out of the pit) and ohmically controlled (i.e., rate determined by the ohmic potential drop that develops in the electrolyte in the pit) pit growth (McGuire et al. 1998 [DIRS 152193], Section 5.2.8; Vetter and Strehblow 1974 [DIRS 162245]). This growth law is followed in the pitting and crevice corrosion of stainless steels (Hunkeler and Boehni 1983 [DIRS 162221]; Newman and Franz 1984 [DIRS 162250]) and was used in a separate analysis of Alloy 22 by EPRI (2002 [DIRS 158069], Section 5.3.1). A key point of this growth law is that 
the rate of propagation is proportional to $t^{n-1}\left(d D / d t \propto k t^{n-1}\right)$, meaning that the rate of propagation decreases with increasing time, particularly over repository time scales. This behavior is schematically illustrated in Figure 6.5-1.

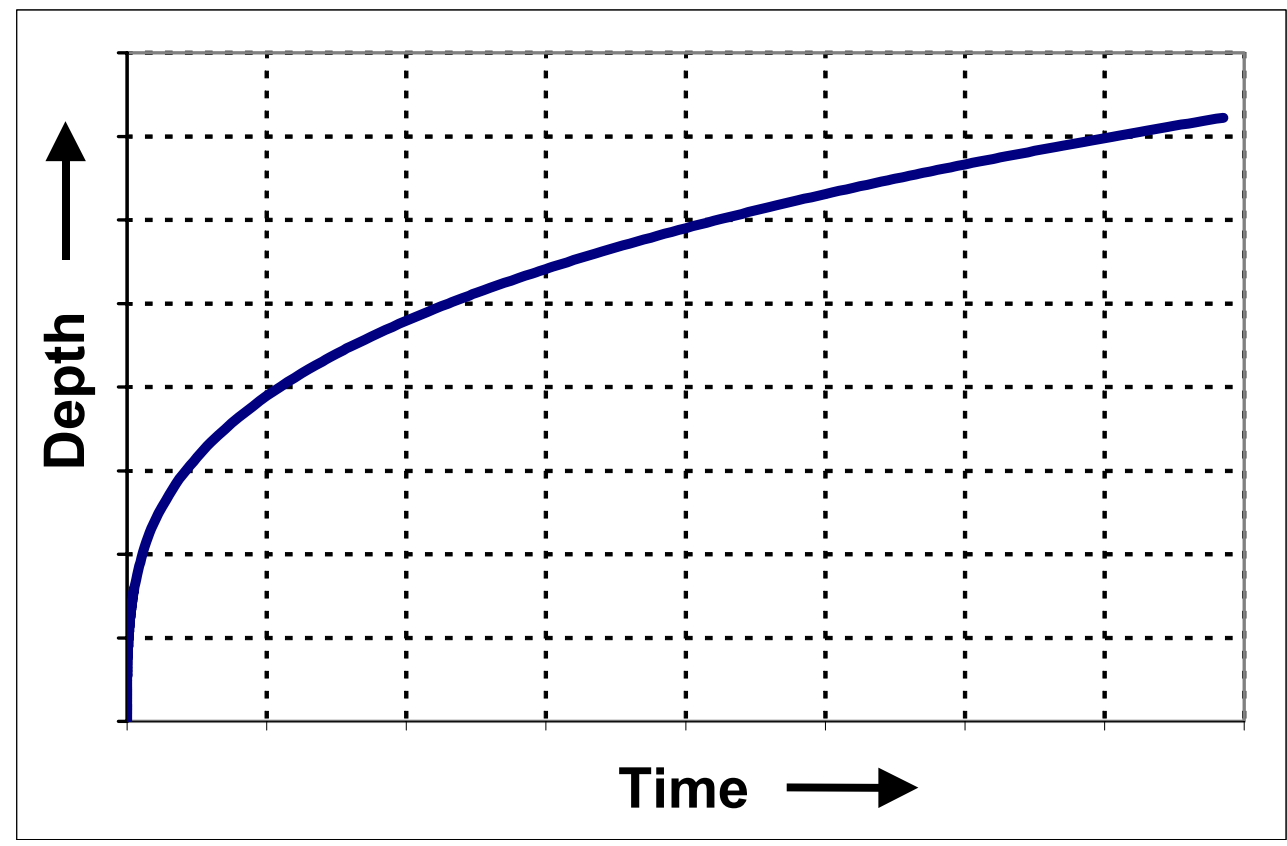

Figure 6.5-1. Schematic Plot of Depth versus Time for Power Law Growth with Exponent Less Than One

The literature data available for less-corrosion-resistant materials (e.g., iron, copper, Titanium Grade 2) (Hunkeler and Boehni 1983 [DIRS 162221]; Marsh et al. 1991 [DIRS 162234]; Mughabghab and Sullivan 1989 [DIRS 162235]; Sharland et al. 1991 [DIRS 162238]; Ishikawa et al. 1991 [DIRS 162222]) clearly show that a propagation rate law of the form of Equation 6.5-2 is appropriate, and that a value of $n=0.5$ is justifiable. A key point with the materials discussed above (e.g., iron, carbon steel, copper, and Titanium Grade 2) is that they are materials that would be expected to undergo rapid propagation. Providing it is not stifled by the accumulation of corrosion product deposits or slow cathodic kinetics, propagation would be limited only by diffusive or ohmic effects, leading to a value of $n$ approaching 0.5. By contrast, for highly corrosion-resistant materials such as Alloy 22, which is designed to resist localized corrosion, additional metallurgical features such as the ability of molybdenum to decrease the pitting current densities (Frankel 1998 [DIRS 162216]; Newman 1985 [DIRS 162251]) could decrease $n$ well below 0.5 . Molybdenum reduces the active dissolution rate within the pit or crevice, preventing the maintenance of the critical chemistry necessary to sustain propagation and leading to repassivation and a cessation of crevice growth. Kehler et al. (2001 [DIRS 162231]) showed that the depth of crevice penetration for Alloy 22 in electrochemically driven studies (i.e., no possibility of cathodic limitation) using extremely saline $(5 \mathrm{M} \mathrm{LiCl})$ solutions at $85^{\circ} \mathrm{C}$ was limited to less than $0.1 \mathrm{~mm}$, well below the $20-\mathrm{mm}$ waste package outer barrier wall thickness. 
In General Corrosion and Localized Corrosion of the Waste Package Outer Barrier (BSC 2004 [DIRS 169984], Section 6.4.4.8.2), it was determined that not enough data was currently available to evaluate the model parameters for use in TSPA-LA. The remainder of this section is devoted to an evaluation of data made available since General Corrosion and Localized Corrosion of the Waste Package Outer Barrier (BSC 2004 [DIRS 169984]) was issued, data which show that stifling of localized corrosion occurs on Alloy 22. Although the data show that stifling occurs, they are not sufficient to develop a power law model for propagation of localized corrosion for use in TSPA-LA.

\subsubsection{Data Supporting Stifling of Localized Corrosion}

Even if localized corrosion initiates on Alloy 22, propagation rates will slow or even cease with time because of stifling due to either cathodic or ohmic limitations (as typified by the power rate law for corrosion discussed above). In this section, a semi-quantitative discussion of data relevant to stifling of crevice corrosion is undertaken. The results presented in this section serve to illustrate that stifling of localized corrosion of Alloy 22 occurs, and to evaluate the degree to which stifling may slow localized corrosion propagation rates. However, the constant potential experiments described here force corrosion to occur, and the rates of corrosion and stifling that are observed are not directly applicable to repository conditions.

Although not initially implemented to obtain stifling rate parameters, constant potential experiments (in which there are effectively no cathodic current limitations) were conducted in a variety of de-aerated electrolytes with nitrate-chloride ratios between zero and 100 (DTN: LL050200212251.125 [DIRS 173131]) at exposure temperatures between $80^{\circ} \mathrm{C}$ and $155^{\circ} \mathrm{C}$. These experiments were originally undertaken to test the validity of the use of the repassivation potential as a critical potential for crevice corrosion initiation. The data consist of measurements of current versus exposure time for specimens held at constant potentials (usually slightly above the repassivation potential for the material under the exposure conditions used). The specimens used were as-welded prism crevice assembly specimens with a total area of $14.06 \mathrm{~cm}^{2}$ with 24 creviced regions of equal area and a total creviced area of $1.50 \mathrm{~cm}^{2}$ (i.e., each crevice had an area of $1.50 \mathrm{~cm}^{2} / 24=6.25 \times 10^{-2} \mathrm{~cm}^{2}$ ). Table $6.5-1$ is a summary of the constant potential data reported in DTN: LL050200212251.125 [DIRS 173131]. The sample identities, exposure temperatures, solution compositions, approximate nitrate-chloride ion ratios, applied potentials versus the saturated silver chloride reference electrode (SSC), and duration of the test are reported along with brief comments including whether crevice corrosion was observed and if it stifled.

Eleven tests were of sufficient duration and were obtained in solutions where crevice corrosion initiated and stifled. The data from these tests, summarized in the first 11 rows of Table 6.5-1, were used for further analysis. Figure 6.5-2 shows a plot of these data. After crevice corrosion initiates (the initial increase of the current density to a peak seen in the figure), the current density decreases to passive levels with increasing exposure time, indicating that crevice corrosion has stifled. 
Table 6.5-1. Summary of Data from Constant Potential Experiments

\begin{tabular}{|c|c|c|c|c|c|c|c|c|}
\hline $\begin{array}{l}\text { Specimen } \\
\text { Identity }\end{array}$ & $\begin{array}{l}\text { Temperature } \\
\left({ }^{\circ} \mathrm{C}\right)\end{array}$ & Solution Composition & $\mathrm{NO}_{3} / \mathrm{Cl}$ & $\begin{array}{l}\text { Applied } \\
\text { Potential } \\
\text { (mV SSC) }\end{array}$ & $\begin{array}{c}\text { Duration } \\
\text { (hr) }\end{array}$ & $\begin{array}{l}\text { Crevice } \\
\text { Corrosion } \\
(\mathrm{Y} / \mathrm{N})\end{array}$ & $\begin{array}{l}\text { Stifling? (Y/N) or } \\
\text { Current Drop? } \\
\text { (CD) }\end{array}$ & Comments \\
\hline KE0106 & 100 & $3.5 \mathrm{~m} \mathrm{NaCl}+0.175 \mathrm{~m} \mathrm{KNO}_{3}$ & 0.05 & 100 & $168^{\mathrm{a}}$ & $\mathrm{Y}$ & $\mathrm{Y}$ & Used in further analysis \\
\hline KE0108 & 100 & $3.5 \mathrm{~m} \mathrm{NaCl}+0.175 \mathrm{~m} \mathrm{KNO}_{3}$ & 0.05 & 100 & 168 & $\mathrm{Y}$ & $\bar{Y}$ & Used in further analysis \\
\hline KE0104 & 100 & $3.5 \mathrm{~m} \mathrm{NaCl}+0.525 \mathrm{~m} \mathrm{KNO}_{3}$ & 0.15 & 100 & 168 & $\bar{Y}$ & $\bar{Y}$ & Used in further analysis \\
\hline KE0166 & 100 & $3.5 \mathrm{~m} \mathrm{NaCl}+0.525 \mathrm{~m} \mathrm{KNO}_{3}$ & 0.15 & 100 & $194^{b}$ & $\mathrm{Y}$ & $\bar{Y}$ & Used in further analysis \\
\hline KE0105 & 100 & $6 \mathrm{~m} \mathrm{NaCl}+0.3 \mathrm{~m} \mathrm{KNO}_{3}$ & 0.05 & 100 & 168 & $\mathrm{Y}$ & $\bar{Y}$ & Used in further analysis \\
\hline KE0164 & 100 & $6 \mathrm{~m} \mathrm{NaCl}+0.3 \mathrm{~m} \mathrm{KNO}_{3}$ & 0.05 & 0 & 168 & $\bar{Y}$ & $\bar{Y}$ & Used in further analysis \\
\hline KE0170 & 100 & $6 \mathrm{~m} \mathrm{NaCl}+0.9 \mathrm{~m} \mathrm{KNO}_{3}$ & 0.15 & 0 & 194 & $\bar{Y}$ & $\bar{Y}$ & Used in further analysis \\
\hline KE0103 & 100 & $6 \mathrm{~m} \mathrm{NaCl}+0.9 \mathrm{~m} \mathrm{KNO}_{3}$ & 0.15 & 100 & 168 & $\mathrm{Y}$ & $\mathrm{Y}$ & Used in further analysis \\
\hline KE0165 & 100 & $6 \mathrm{~m} \mathrm{NaCl}+0.9 \mathrm{~m} \mathrm{KNO}_{3}$ & 0.15 & 0 & 168 & $\bar{Y}$ & $\bar{Y}$ & Used in further analysis \\
\hline KE0102 & 120 & $5 \mathrm{M} \mathrm{CaCl}_{2}+0.5 \mathrm{M}\left(\mathrm{CaNO}_{3}\right)_{2}$ & $\sim 0.1$ & 100 & 168 & $\bar{Y}$ & $\bar{Y}$ & Used in further analysis \\
\hline KE0109 & 155 & $18 \mathrm{~m} \mathrm{CaCl}_{2}+0.9 \mathrm{~m} \mathrm{Ca}\left(\mathrm{NO}_{3}\right)_{2}$ & 0.1 & 50 & $117^{\mathrm{C}}$ & $\mathrm{N}(\mathrm{LC})$ & $\mathrm{Y}$ & Used in further analysis \\
\hline KE0101 & 120 & $5 \mathrm{M} \mathrm{CaCl}_{2}$ & 0 & -200 & 168 & $\mathrm{~N}$ & $C D$ & Not used in further analysis \\
\hline KE0107 & 120 & $5 \mathrm{M} \mathrm{CaCl}_{2}$ & 0 & -150 & 189 & $\mathrm{~N}$ & CD & Not used in further analysis \\
\hline KE0154 & 120 & $5 \mathrm{M} \mathrm{CaCl}_{2}$ & 0 & -100 & 53 & $\mathrm{Y}$ & $\mathrm{N}$ & $\begin{array}{l}\text { Duration may have been too short } \\
\text { to observe stifling. Crevice } \\
\text { corrosion may not readily stifle in } \\
\text { non-relevant pure chloride } \\
\text { solutions. Not used in further } \\
\text { analysis. }\end{array}$ \\
\hline KE0502 & 100 & $6 \mathrm{~m} \mathrm{NaCl}+0.3 \mathrm{~m} \mathrm{KNO}_{3}$ & 0.05 & -150 & 194 & $\mathrm{~N}$ & CD & Not used in further analysis \\
\hline KE0501 & 100 & $6 \mathrm{~m} \mathrm{NaCl}+0.3 \mathrm{~m} \mathrm{KNO}_{3}$ & 0.05 & -50 & 194 & $\mathrm{Y}$ & $\mathrm{N}$ & $\begin{array}{l}\text { Duration may have been too short } \\
\text { to observe stifling. Not used in } \\
\text { further analysis. }\end{array}$ \\
\hline KE0505 & 80 & $\begin{array}{c}3.5 \mathrm{~m} \mathrm{NaCl}+0.175 \mathrm{~m} \mathrm{NaNO}_{3}+ \\
0.7 \mathrm{~m} \mathrm{Mg}\left(\mathrm{SO}_{4}\right)\end{array}$ & 0.05 & 400 & 141 & $\bar{Y}$ & $\bar{Y}$ & $\begin{array}{l}\text { Not used in further analysis. } \\
\text { Applied potential too high. } \\
\text { Multiple initiation events evident. }\end{array}$ \\
\hline KE0506 & 80 & $\begin{array}{c}3.5 \mathrm{~m} \mathrm{NaCl}+0.175 \mathrm{~m} \mathrm{NaNO}_{3}+ \\
0.7 \mathrm{~m} \mathrm{Mg}\left(\mathrm{SO}_{4}\right)\end{array}$ & 0.05 & 500 & 141 & $\bar{Y}$ & $\mathrm{~N}$ & $\begin{array}{l}\text { Not used in further analysis. } \\
\text { Applied potential too high. } \\
\text { Multiple initiation events evident. }\end{array}$ \\
\hline
\end{tabular}


Table 6.5-1. Summary of Data from Constant Potential Experiments (Continued)

\begin{tabular}{|c|c|c|c|c|c|c|c|c|}
\hline $\begin{array}{l}\text { Specimen } \\
\text { Identity }\end{array}$ & $\begin{array}{l}\text { Temperature } \\
\left({ }^{\circ} \mathrm{C}\right)\end{array}$ & Solution Composition & $\mathrm{NO}_{3} / \mathrm{Cl}$ & $\begin{array}{l}\text { Applied } \\
\text { Potential } \\
\text { (mV SSC) }\end{array}$ & $\begin{array}{l}\text { Duration } \\
\text { (hr) }\end{array}$ & $\begin{array}{l}\text { Crevice } \\
\text { Corrosion } \\
\text { (Y/N) }\end{array}$ & \begin{tabular}{|c|} 
Stifling? $(\mathrm{Y} / \mathrm{N})$ or \\
Current Drop? \\
(CD)
\end{tabular} & Comments \\
\hline KE0153 & 100 & $5 \mathrm{M} \mathrm{CaCl}_{2}+0.5 \mathrm{M}\left(\mathrm{CaNO}_{3}\right)_{2}$ & $\sim 0.1$ & 100 & 167 & $\bar{Y}$ & $\mathrm{~N}$ & $\begin{array}{l}\text { Duration may have been too short } \\
\text { to observe stifling. Not used in } \\
\text { further analysis. }\end{array}$ \\
\hline KE0171 & 100 & $6 \mathrm{~m} \mathrm{NaCl}+0.9 \mathrm{~m} \mathrm{KNO}_{3}$ & 0.15 & -100 & 194 & $\mid \bar{Y}(\mathrm{TP}$ or LC) & NA & $\begin{array}{l}\text { Not used in further analysis. } \\
\text { Negative currents }\end{array}$ \\
\hline KE0110 & 100 & $6 \mathrm{~m} \mathrm{NaCl}+0.9 \mathrm{~m} \mathrm{KNO}_{3}$ & 0.15 & 100 & 168 & $\bar{Y}$ & $\bar{Y}$ & $\begin{array}{l}\text { Not used in further analysis. Data } \\
\text { had negative values after stifling. }\end{array}$ \\
\hline KE0503 & 100 & $6 \mathrm{~m} \mathrm{NaCl}+3 \mathrm{~m} \mathrm{KNO}_{3}$ & 0.5 & 350 & 168 & $\bar{Y}$ & $\mathrm{CD}-\mathrm{AA}$ & Not used in further analysis \\
\hline KE0504 & 100 & $6 \mathrm{~m} \mathrm{NaCl}+3 \mathrm{~m} \mathrm{KNO}_{3}$ & 0.5 & 250 & 168 & $\bar{Y}$ & $C D-A A$ & Not used in further analysis \\
\hline KE0509 & 100 & $5 \mathrm{~m}\left(\mathrm{CaNO}_{3}\right)_{2}+5 \mathrm{~m} \mathrm{CaCl} 2$ & 1 & 850 & 121 & $\mathrm{~N}(\mathrm{TP})$ & $\mathrm{CD}-\mathrm{AA}$ & $\begin{array}{l}\text { Applied potential too high. No } \\
\text { crevice corrosion initiated. Likely } \\
\text { enhanced general corrosion }\end{array}$ \\
\hline KE0510 & 100 & $5 \mathrm{~m}\left(\mathrm{CaNO}_{3}\right)_{2}+5 \mathrm{~m} \mathrm{CaCl}_{2}$ & 1 & 900 & 98 & $\mathrm{~N}(\mathrm{TP})$ & $C D-A A$ & $\begin{array}{l}\text { Applied potential too high. No } \\
\text { crevice corrosion initiated. Likely } \\
\text { enhanced general corrosion }\end{array}$ \\
\hline KE0163 & 145 & $22.5 \mathrm{~m}\left(\mathrm{CaNO}_{3}\right)_{2}+0.225 \mathrm{MgCl}_{2}$ & 100 & 850 & 191 & $\mathrm{~N}(\mathrm{TP})$ & CD & Not used in further analysis \\
\hline KE0511 & 145 & $22.5 \mathrm{~m}\left(\mathrm{CaNO}_{3}\right)_{2}+0.225 \mathrm{~m} \mathrm{MgCl}_{2}$ & 100 & 940 & 13 & $\mathrm{~N}(\mathrm{TP}$ or LC) & NA-1 & Not used in further analysis \\
\hline KE0512 & 145 & $\begin{array}{c}22.5 \mathrm{~m}\left(\mathrm{CaNO}_{3}\right)_{2}+0.225 \mathrm{~m} \\
\mathrm{MgCl}_{2}\end{array}$ & 100 & 840 & 168 & $\mathrm{~N}(\mathrm{TP})$ & $\begin{array}{l}\text { Noisy Anodic } \\
\text { Current }\end{array}$ & Not used in further analysis \\
\hline
\end{tabular}

Source: DTN: LL050200212251.125 [DIRS 173131].

${ }^{\text {a }}$ Data for sample KE0106 up to 79 hours used. Subsequent current data had negative values.

${ }^{b}$ Data for sample KE0166 up to 119 hours used. Subsequent current data had negative values.

${ }^{c}$ Data for sample KE0109 up to 72 hours used. Subsequent current data had negative values.

NOTE: $\quad C D=$ current drop (the specimen remained passive); $A A=$ shows subsequent anodic activity; $L C=$ localized corrosion outside the crevice formers; $\mathrm{TP}=$ transpassivity, iridescent, yellow or black; NA = not available (data not clear); NA-1 = high spikes of anodic current. 


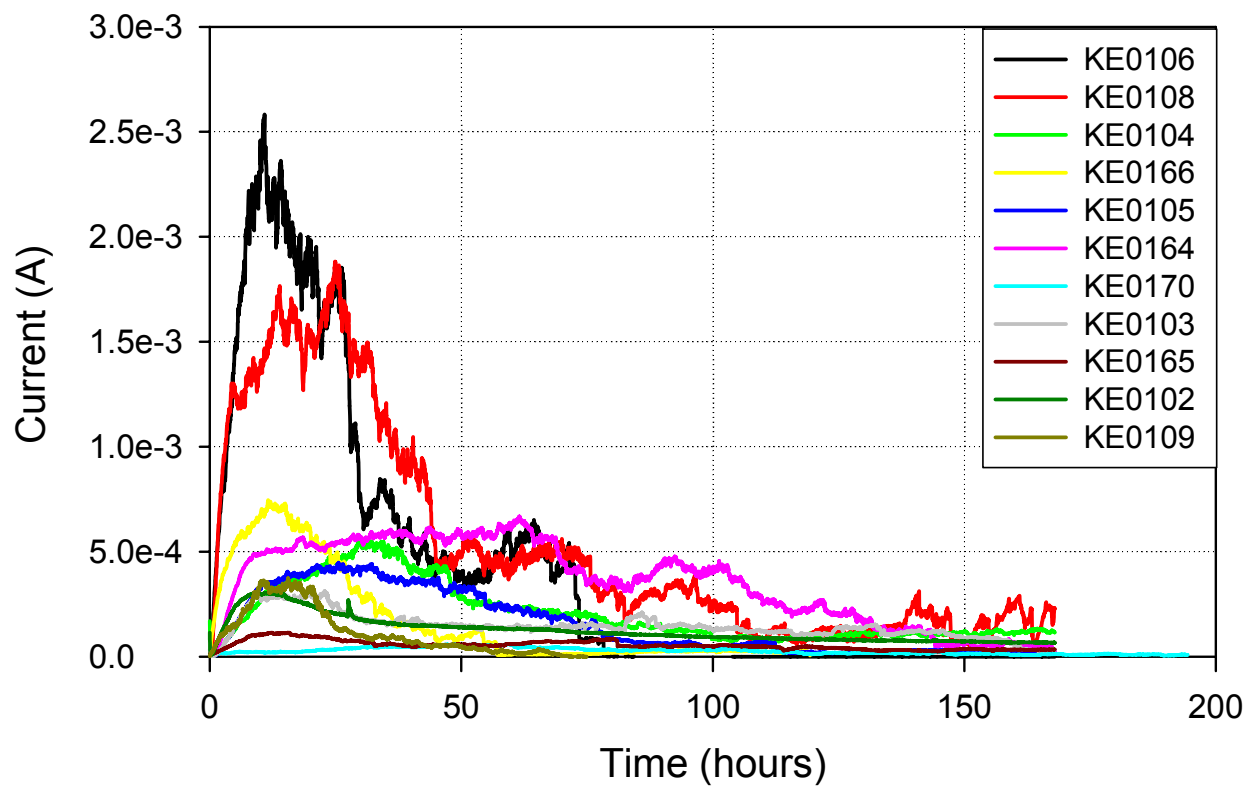

Source: DTN: LL050200212251.125 [DIRS 173131]; Output DTN: MO0505SPASTIFL.001, StiflingDTN3.zip.

Figure 6.5-2. Plot of Current versus Time during Constant Potential Testing of As-Welded Alloy 22 Prism Crevice Assembly Specimens

In general, the data are not suitable for detailed quantitative analysis (i.e., unequivocal evaluation of parameters for use in the power law) because:

1. There are 24 potential locations ( 24 crevices) where crevice corrosion can initiate during the exposure time. Each crevice may initiate crevice corrosion at different times during the exposure (or not initiate crevice corrosion during the exposure). If crevice corrosion initiates at one location, then stifles just as another location initiates crevice corrosion, quantitative interpretation of the data is difficult. Data collected from a sample with only one creviced region could alleviate this issue.

2. As shown in General Corrosion and Localized Corrosion of the Waste Package Outer Barrier (BSC 2004 [DIRS 169984], Figure 7-1), the general corrosion rate (which corresponds to the passive current density) decreases with time. Therefore, the passive current density value to which the curves should decay after stifling decreases with time. Also, the cathodic current density capable of being generated on a more perfectly formed and less-defective (i.e., older) passive film would be less than that capable of being generated on a more-defective (i.e., younger) passive film. Data from samples exposed to the environment for longer periods of time before potential is applied could alleviate this issue.

Furthermore, because the original purpose of the testing was not to obtain stifling rate parameters, many of the observations were not suitable for use in the semi-qualitative analysis undertaken in this section. The reasons for including or excluding the results for a particular sample are given in the "Comments" column of Table 6.5-1. For example, samples KE0101 and 
KE0107 did not initiate crevice corrosion and displayed a decreasing current-with-time profile. Sample KE0154 was exposed to the same solution $(5 \mathrm{M} \mathrm{CaCl} 2)$ and temperature $\left(120^{\circ} \mathrm{C}\right)$ as samples KE0101 and KE0107, but at a higher potential, and showed evidence of crevice corrosion initiation and did not show evidence of stifling. This indicates that the critical potential for crevice corrosion initiation is between -150 and $-100 \mathrm{mV} \mathrm{SSC}$ in this solution and may indicate that the presence of at least some nitrate ion in solution is necessary for stifling (at least over the time frames investigated in this data set). Sample KE0502 did not initiate crevice corrosion and displayed a decreasing current-with-time profile. Sample KE0501 showed evidence of crevice corrosion initiation and did not show evidence of stifling even though the exposure time was about 194 hours and samples with similar exposures (e.g., KE0105 and KE0164) show evidence of stifling. It is likely that stifling would have occurred had the duration of the experiment been longer. Samples KE0505 and KE0506 showed evidence of initiation of crevice corrosion at multiple locations during the testing period, but the duration of the testing period was likely not long enough, and the potentials applied were likely too high, for complete stifling to occur. Sample KE0153 showed evidence of crevice corrosion initiation and did not show evidence of stifling even though the exposure time was about 167 hours and sample KE0102, exposed under similar exposure conditions, showed evidence of stifling. It is likely sample KE0153 would have shown evidence of stifling if the duration of the experiment had been longer. Sample KE0171 showed large cathodic (negative) currents during the exposure time. It is probable that an experimental error occurred in testing of this sample. Sample KE0110 underwent crevice corrosion initiation and showed stifling behavior but displayed negative currents immediately after stifling, rendering this data unusable for quantitative analysis (without the using a subjective treatment, e.g., removing the negative values and keeping the positive values). Samples KE0503 and KE0504 did show some limited crevice corrosion initiation behavior but overall showed a predominant passive behavior (i.e., current decreasing with exposure time) and were therefore not used for quantitative analysis. Like samples KE0503 and KE0504, samples KE0509, KE0510, KE0163, KE0511, and KE0512 did not display the peaked response indicative of crevice corrosion initiation and stifling. It is likely that the large amounts of nitrate present in solution (these samples have nitrate-chloride ratios of 1 or more) do not allow crevice corrosion to initiate (BSC 2004 [DIRS 169984], Section 6.4.4), although for these samples it is also probable that the applied potentials were high enough for enhanced general corrosion (e.g., transpassive dissolution) to occur.

The remainder of this section is devoted to a very conservative quantitative analysis of the data in the first 11 rows of Table 6.5-1 involving fitting a power law (with an extra constant relative to the power law discussed previously) of the form:

$$
D=A+k t^{n}
$$

where $D$ is the depth of propagation, $t$ is time, $k$ is a growth constant, and $A$ is a fitting constant (which may be interpreted as a minimum pit or crevice depth for which stifling begins to occur). The primary intent of this exercise is to estimate $n$, the time exponent, which, as noted earlier, should be about 0.5 for both diffusion-controlled (i.e., diffusion of metal ions out of the pit) and ohmically controlled (i.e., rate determined by the ohmic potential drop which develops in the electrolyte in the pit) pit growth. While $A$ does not have a physical interpretation in this context (i.e., the depth at time zero should be zero), its inclusion allows for better fitting of the time exponent. The reader should again take note of the reasons given above as to why the data are 
not suitable for detailed quantitative analysis (i.e., unequivocal evaluation of parameters for use in the power law).

The corrosion rate, $C R$ in $\mathrm{mm} / \mathrm{yr}$, can be calculated from the corrosion current density, $i_{\text {corr }}$, using the following relation (ASTM G 102-89 [DIRS 163908], Section 4.7):

$$
C R=K_{1} \frac{i_{\text {corr }} \cdot E W}{\rho}
$$

where $K_{l}=3.27 \times 10^{-3} \mathrm{~mm} \mathrm{~g} / \mu \mathrm{A} \mathrm{cm} \mathrm{yr}, E W$ is the equivalent weight of Alloy 22 (23.28) (ASTM G 102-89 [DIRS 163908], Table 1), and $\rho$ is the density of Alloy $22\left(8.69 \mathrm{~g} / \mathrm{cm}^{3}\right.$ for N06022) (Haynes International 1997 [DIRS 100896], p. 13). Table 1 of ASTM G 102-89 [DIRS 163908] presents several choices for the Alloy 22 equivalent weight ranging from 17.88 to 26.04, depending on the valences assumed for the metal ions resulting from the corrosion reactions. The actual choice of which equivalent weight to use has minor impact on the analysis results presented in this report because the primary intent of this exercise is to estimate $n$, the time exponent, and the equivalent weight affects the value of the growth constant, $k$. The current density, $i$, was obtained by dividing the current provided in DTN: LL050200212251.125 [DIRS 173131] by the area of one creviced region (there were 24 creviced regions on each sample with a total area of $1.50 \mathrm{~cm}^{2}$; therefore, the area of one creviced region is about $0.0625 \mathrm{~cm}^{2}$ ). This treatment is very conservative because it is likely that the measured current resulted from more than one creviced region (i.e., the actual corrosion rate was lower than is being estimated here).

The corrosion rates obtained using Equation $6.5-4$ were converted to $\mathrm{mm} / \mathrm{hr}$ by dividing by $8,766 \mathrm{hrs} / \mathrm{yr}$. The corrosion rates were then integrated over time through a simple sum of rectangles (sum over all time steps of length of time step multiplied by corrosion rate) to get profiles of depth, $D$, versus time, $t$. The length of each time step was the same as the length of the time steps used to report the measured current data in DTN: LL050200212251.125 [DIRS 173131]. Plots of depth versus time for all samples analyzed in this way are presented in Figure 6.5-3. Even using this conservative treatment, no calculated crevice depth exceeds $1.4 \mathrm{~mm}$ over the length of the experiment. 


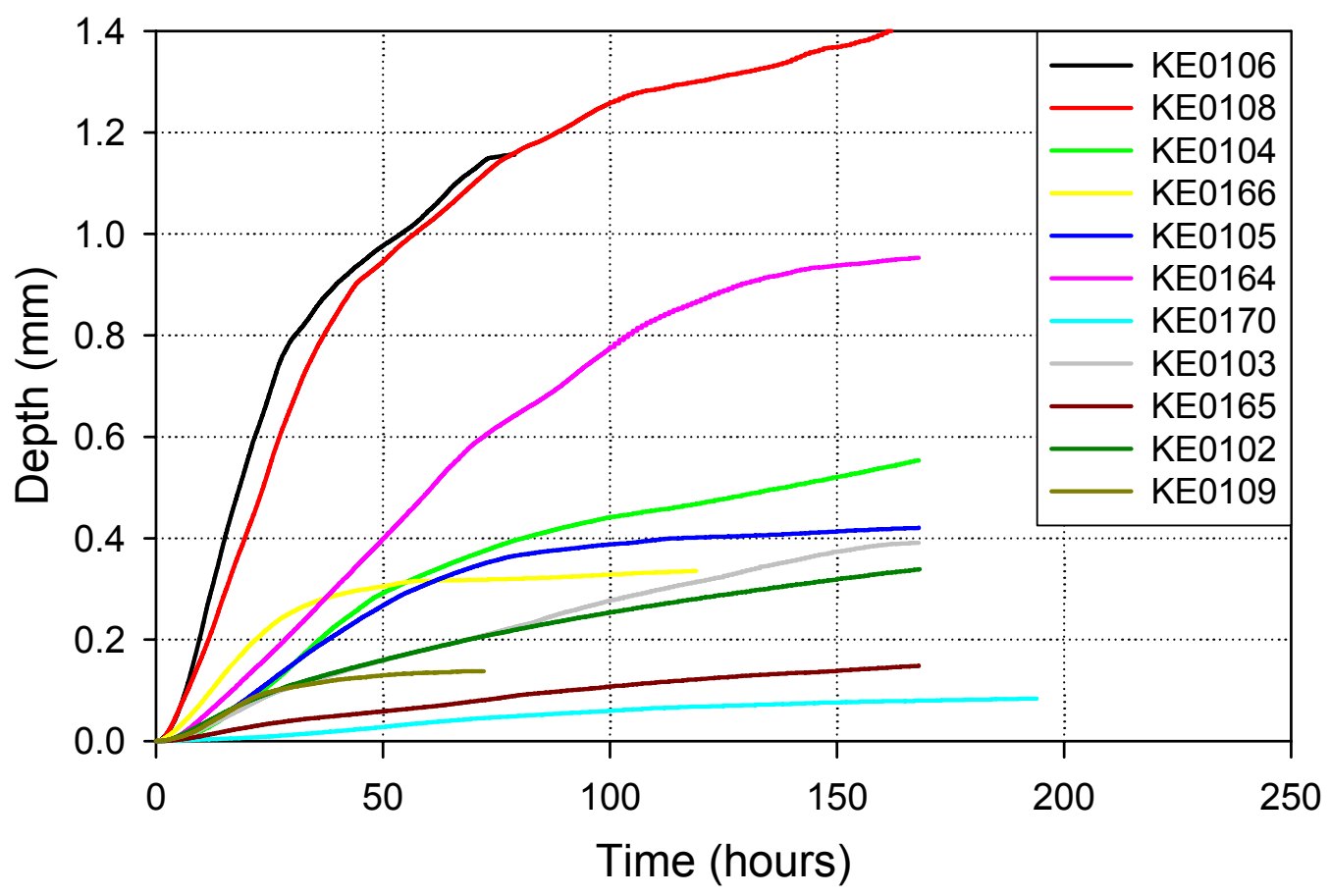

Source: Output DTN: MO0505SPASTIFL.001, StiflingDTN3.zip.

Figure 6.5-3. Plot of Depth versus Time during Constant Potential Testing of As-Welded Alloy 22 Prism Crevice Assembly Specimens

Fitting these depth versus time profiles to Equation 6.5-3 yields estimates for $A, k$, and $n$ as shown in Table 6.5-2. The $\mathrm{R}^{2}$ values obtained indicate that Equation 6.5-3 fits the data very well $\left(\mathrm{R}^{2}\right.$ is close to 1$)$. The fitting parameter, $A$, is always negative for this data set, indicating that, if this fit were to be used to estimate crevice depths, it would be conservative to ignore it. The growth constant, $k$, varies from about 0.005 to 0.758 and averages about $0.2 \mathrm{~mm} / \mathrm{hr}^{n}$. The time exponent, $n$, varies from about 0.094 to 0.690 and averages about 0.439 . Using the average values, the power law would predict penetration by crevice corrosion in about 4 years. There are several caveats to direct application of these estimates:

1. As mentioned earlier, there are 24 potential locations (crevices) where crevice corrosion can initiate during the exposure time. Each crevice may initiate crevice corrosion at different times during the exposure (or not initiate crevice corrosion during the exposure). If crevice corrosion initiates at one location, then stifles just as another location initiates crevice corrosion, quantitative interpretation of the data is difficult. Data collected from a sample with only one creviced region could alleviate this issue.

2. Despite the possibility that multiple loci of localized corrosion could have been active, the rates calculated are based on all current measured originating from just one of the creviced regions or about $1 / 225$ th of the total sample area or $1 / 24$ th of the total creviced area.

3. As mentioned earlier, the general corrosion rate (which corresponds to the passive current density) decreases with time. Therefore, the passive current density value to which the 
curves should decay after stifling decreases with time. Furthermore, the cathodic current density capable of being generated on a more perfectly formed and less-defective (i.e., older) passive film would be less than that capable of being generated on a more-defective (i.e., younger) passive film. Data from samples exposed to the environment for longer periods of time before potential is applied could address this issue.

4. The results may be conservative because corrosion is forced through use of a constant potential. There is no cathodic limitation in these tests because the forcing potential overwhelms ohmic and mass transport limitations. In the repository environment, the reaction will be cathode-limited, which would likely enhance the stifling effect.

Because of these caveats, especially the final one, these rates are not applicable to the repository environment. Rather, the data here serve to illustrate that stifling does occur, and that it significantly slows localized corrosion propagation rates in Alloy 22 . With no stifling $(\mathrm{n}=1)$, the value of $k$ represents the initial corrosion rate, averaging $0.2 \mathrm{~mm} / \mathrm{hr}$. This would result in penetration of the outer barrier $(2 \mathrm{~cm})$ in 100 hours. However, because of stifling, localized corrosion propagation rates slow markedly $(n=0.439)$ and the mean predicted penetration time is 4 years. Thus, even in these experiments where corrosion is forced, stifling serves to increase the penetration time by a factor of about 350 .

The calculation described in this section can be found in Output DTN: MO0505SPASTIFL.001 (StiflingDTN3.zip).

Table 6.5-2. Summary of Power Law Fit to Corrosion Stifling Data

\begin{tabular}{|c|c|c|c|c|c|}
\hline $\begin{array}{c}\text { Sample } \\
\text { Identity }\end{array}$ & $\begin{array}{c}\mathbf{m v ~ S S C} \\
\text { Applied }\end{array}$ & $\begin{array}{c}\mathbf{A} \\
\mathbf{m m}\end{array}$ & $\begin{array}{c}\mathbf{k} \\
\mathbf{m m} / \mathbf{h r}^{\mathbf{n}}\end{array}$ & $\boldsymbol{n}$ & $\mathbf{R}^{\mathbf{2}}$ \\
\hline KE0106 & 100 & -0.432 & 0.309 & 0.385 & 0.973 \\
\hline KE0108 & 100 & -0.983 & 0.758 & 0.231 & 0.967 \\
\hline KE0104 & 100 & -0.173 & 0.083 & 0.428 & 0.975 \\
\hline KE0166 & 100 & -0.760 & 0.718 & 0.094 & 0.911 \\
\hline KE0105 & 100 & -0.261 & 0.168 & 0.285 & 0.942 \\
\hline KE0164 & 0 & -0.181 & 0.061 & 0.588 & 0.981 \\
\hline KE0170 & -150 & -0.016 & 0.005 & 0.597 & 0.978 \\
\hline KE0103 & 100 & -0.030 & 0.013 & 0.690 & 0.999 \\
\hline KE0165 & 0 & -0.013 & 0.006 & 0.663 & 0.997 \\
\hline KE0102 & 100 & -0.048 & 0.027 & 0.523 & 0.998 \\
\hline KE0109 & 100 & -0.068 & 0.051 & 0.343 & 0.948 \\
\hline Averages & & $-\mathbf{0 . 2 7 0}$ & $\mathbf{0 . 2 0 0}$ & $\mathbf{0 . 4 3 9}$ & $\mathbf{0 . 9 7 0}$ \\
\hline
\end{tabular}

Source: Output DTN: MO0505SPASTIFL.001, StiflingDTN3.zip.

\subsubsection{Will Corrosion Products Physically Sequester Brine?}

If localized or crevice corrosion occurs, the elemental constituents of the removed alloy will be redeposited in the cathodic region of the corrosion cell as corrosion products consisting primarily of metal oxides or hydroxides. The corrosion products will be polycrystalline, or amorphous, 
and will have porosity. They will be precipitated from the aqueous phase, because transport is required. The aqueous phase must form a contiguous circuit to the anodic region where metal dissolution occurs. After precipitation of the corrosion products, the pore structure of the corrosion products will have a capillary response that could retain the aqueous phase. The result would be gradual incorporation of brine into the physical structure of the corrosion product material. Brine volume is limited as discussed in Section 6.4.1; this section will show that at elevated temperature $\left(120^{\circ} \mathrm{C}\right.$ or greater) the brine volume available on the waste package surface is far less than the pore volume of corrosion products potentially produced by corrosion and development of a penetration in the outer barrier. Thus, any cumulative loss of brine volume will arrest the corrosion process. This section provides a parametric analysis of this effect, which establishes the conditions that must exist in order for localized corrosion to cause penetration of the waste package outer barrier.

Two types of parametric analysis are described here: 1) the limiting (maximum) brine content possible for corrosion products from a penetration of assumed size and shape; and 2) the maximum size of a patch failure in the outer barrier if formed by all the brine available on the waste package surface, as a function of the brine content of the corrosion products.

For the first parametric analysis two simple geometries for fully penetrating breaches in a $2-\mathrm{cm}$ thick layer of Alloy 22 are considered: 1) a hemispherical penetration with a radius of $2 \mathrm{~cm}$ (corresponding to the waste package outer barrier thickness); and 2) a conical penetration with a base area of $1 \mathrm{~cm}^{2}$ (base radius of $0.56 \mathrm{~cm}$ ). The basal area value is chosen for convenience: the ratio of the volume of a cone $\left(1 / 3 \pi r^{2} h\right)$ to the basal area $\left(\pi r^{2}\right)$ is constant, with a value of $h / 3$, where $h$ is the thickness of the outer barrier $(2 \mathrm{~cm})$. Hence, any basal area and corresponding brine volume value would yield the same ratio of brine volume to corrosion product volume. The brine volume associated with each of these features is calculated from the breach area at the outer surface, and the estimate of the maximum brine volume at elevated temperature $\left(1.8 \mu \mathrm{L} / \mathrm{cm}^{2}\right.$ for temperatures of $120^{\circ} \mathrm{C}$ or greater; see Section 6.4 .1$)$. As these features grow, the aqueous phase (brine) will be trapped in the corrosion products by capillary and adsorptive forces, or by overgrowth and encapsulation as fluid inclusions. Brine redistribution causes interruption of the contiguous aqueous pathway from the anodic to cathodic region that is required for localized corrosion. Alternatively, as the brine film thins, its diffusive resistance increases, slowing the corrosion cell. The parametric analysis (Table 6.5-3) calculates how small the aqueous volumetric fraction of the corrosion products would have to be for penetration to occur without being arrested by these effects.

The derivation for this analysis begins with the relationship between the volume of associated brine, volume of the breach, and the porosity of the corrosion products:

$$
V_{c p}=f V_{h}+V_{c p} \phi
$$

where $V_{c p}$ is the bulk volume of corrosion products, $V_{h}$ is the volume of the breach or hole, and $\phi$ is the porosity of the corrosion products. The parameter $f$ is a multiplier representing the increase in molar volume of the corrosion products compared to the density of Alloy 22. The density of Alloy 22 is $8.69 \mathrm{~g} / \mathrm{cm}^{3}$ (Haynes International 1997 [DIRS 100896], p.13, listed as Alloy N06022), whereas the grain densities of some possible corrosion products are: 
- Hematite $\left(\mathrm{Fe}_{2} \mathrm{O}_{3} ; 5.24 \mathrm{~g} / \mathrm{cm}^{3}\right.$; Weast and Astle 1981 [DIRS 100833], p. B-109)

- Goethite (FeOOH; $4.37 \mathrm{~g} / \mathrm{cm}^{3}$; Klein and Hurlbut 1993 [DIRS 153700], p. 659)

- Eskolaite $\left(\mathrm{Cr}_{2} \mathrm{O}_{3} ; 5.21 \mathrm{~g} / \mathrm{cm}^{3}\right.$; Weast and Astle 1981 [DIRS 100833], p. B-93)

- Theophrastite $\left(\mathrm{Ni}(\mathrm{OH})_{2} ; 3.93 \mathrm{~g} / \mathrm{cm}^{3}\right.$; Barthelmy 2004 [DIRS 173796]).

The corrosion product grain densities are approximately half that of the original alloy; accordingly, a value of $f=2$ is used in the analysis. Rearranging Equation 6.5-5:

$$
V_{c p}=f V_{h} /(1-\phi)
$$

If the volume of brine (Section 6.4.1) is represented by $V_{\text {brine, }}$, then the volume fraction of liquid in the corrosion products, $\theta$, is:

$$
\theta=V_{b r i n e} / V_{c p}
$$

Using the relationship between volumetric water content, liquid saturation, and porosity $\left(\theta=S_{l i q} \phi\right)$, and substituting Equation 6.5-6, the equivalent liquid saturation is:

$$
S_{\text {liq }}=(1-\phi) V_{\text {brine }} /\left(\phi f V_{h}\right)
$$

The results for both of the breach geometries are given in Table 6.5-3. They show that the volumetric liquid content of the corrosion products must be approximately 0.001 or less to allow penetration. This corresponds to liquid saturation of less than $1 \%$, for a wide range of porosity encompassing typical values for secondary minerals. Such low liquid content is not likely to exist for common porosity values of geologic materials, which are on the order of $10 \%$ or greater (see the speleothem geological analogue described by Baker et al. 1998 [DIRS 141249]). The porosity of Alloy 22 corrosion products has not been measured, but they would have to be nearly nonporous for this sequestering mechanism not to be effective.

While porosity data for Alloy 22 corrosion products are not available, porosity data for steel and iron corrosion products formed under atmospheric conditions have been gathered. Dillmann et al. (2004 [DIRS 171480], Table 7) characterized the porosity of corrosion products on ferrous metals ranging in age from 800 years to modern using both mercury porosimetry and small-angle X-ray scattering techniques. The porosity ranged from a few percent to 10 to $15 \%$ in the samples analyzed, and in all cases, a significant fraction of the porosity (approximately $50 \%$ ) consisted of nano-scale pores, with a diameter of $<50$ nanometers. Because of the small pore size, these materials would have high capillarity. If Alloy 22 corrosion products have similar porosity characteristics, then the potential for brine retention is high.

The aqueous phase could also be trapped within corrosion products during crystal growth as fluid inclusions, also referred to as occlusions. These always form in growing crystals, and vary in size from microscopic features representing water trapped by crystal growth and encapsulation, to submicroscopic dislocations in the crystal structure. Impurities in the liquid phase promote the formation of occlusions, and they generally constitute $0.1 \%$ to $0.5 \%$ by volume in crystalline 
phases grown in impure systems (Perry et al. 1984 [DIRS 125806], p. 19-28). This would be sufficient to consume most or all of the brine expected to be present on the corroded area, even in the absence of capillary retention in the corrosion product porosity.

A parametric analysis on values for porosity $(\phi)$ and liquid saturation $\left(S_{l i q}\right)$ is presented in Table 6.5-3. This table includes corrosion product bulk porosity values of $10 \%$ and $50 \%$, reasonable lower- and upper-bound estimates in comparison to granular geologic materials. The calculated volumetric liquid contents and saturations represent the maximum possible values for the brine volumes given; in order for the brine not to be consumed prior to penetration, the amount of brine retained in the corrosion products would have to be less than these values. The calculated upper-bound value for liquid brine content of corrosion products, consistent with corrosion penetration of the outer barrier, is approximately $0.1 \%$. This is highly unlikely, since the combined effects from fluid inclusions and residual saturation are likely to be greater than $0.5 \%$.

Table 6.5-3. Calculations Illustrating Brine Sequestration in the Porosity of Corrosion Products Using | Hemispherical and Conical Breaches, and a Maximum Total Breach Area

\begin{tabular}{|c|c|c|c|c|c|c|}
\hline $\begin{array}{c}\text { Outer } \\
\text { Surface Area } \\
\left(\mathrm{cm}^{2}\right)\end{array}$ & $\begin{array}{l}\text { Breach } \\
\text { Volume } \\
\left(\mathrm{cm}^{3}\right)\end{array}$ & $\begin{array}{c}\text { Brine } \\
\text { Volume } \\
(\mu L)\end{array}$ & $\begin{array}{c}\text { Corrosion } \\
\text { Product } \\
\text { Porosity }\end{array}$ & $\begin{array}{c}\text { Corrosion } \\
\text { Product } \\
\text { Volume } \\
\left(\mathrm{cm}^{3}\right)\end{array}$ & $\begin{array}{c}\text { Volumetric } \\
\text { Liquid Content } \\
\text { Required for } \\
\text { Penetration }^{\mathrm{a}}\end{array}$ & $\begin{array}{c}\text { Liquid } \\
\text { Saturation } \\
\text { Required for } \\
\text { Penetration }^{\mathrm{a}}\end{array}$ \\
\hline \multicolumn{7}{|c|}{ Breach Type: Hemisphere } \\
\hline \multirow[t]{2}{*}{12.57} & \multirow[t]{2}{*}{16.76} & \multirow[t]{2}{*}{22.63} & 0.10 & 37.23 & $<6.08 \mathrm{E}-04$ & $<6.08 \mathrm{E}-03$ \\
\hline & & & 0.50 & 67.02 & $<3.38 \mathrm{E}-04$ & $<6.75 \mathrm{E}-04$ \\
\hline \multicolumn{7}{|c|}{ Breach Type: Cone } \\
\hline \multirow[t]{2}{*}{$1.00^{\mathrm{b}}$} & \multirow[t]{2}{*}{0.67} & \multirow[t]{2}{*}{1.80} & 0.10 & 1.48 & $<1.21 \mathrm{E}-03$ & $<1.21 \mathrm{E}-02$ \\
\hline & & & 0.50 & 2.67 & $<6.75 \mathrm{E}-04$ & $<1.35 \mathrm{E}-03$ \\
\hline
\end{tabular}

Source: Surface area and volume values for cone and hemispherical breaches are based on 2-cm thickness of Alloy 22; brine volumes are based on $1.8 \mu \mathrm{l} / \mathrm{cm}^{2}$ on the waste package surface (see Section 6.4.1); corrosion product volumes, volumetric liquid contents, and liquid saturations are calculated using Equations 6.5-6, 6.5-7, and 6.5-8, respectively.

a These values represent the maximum volumetric liquid contents and liquid saturations that could occur in the corrosion products, for the given brine volumes. For penetration of the outer barrier to occur, the amount of brine retained in the corrosion products would have to be less than these values.

b This is a reference value for the basal area, used for convenience. Because the ratio of basal surface area to volume is constant for a cone of a given height, any value would yield identical results for volumetric liquid content and liquid saturation.

\subsubsection{Will Corrosion Products Consume Brine Components (Cl)?}

The small amounts of brine that form by deliquescence of dust on the waste package surface will be sequestered physically in corrosion product porosity, as discussed in the preceding section, but may also be sequestered chemically, by incorporation into corrosion product minerals that either contain brine components, especially chloride, stoichiometrically within their ideal chemical composition, or that contain hydroxide and have a structure that permits chloride substitution for that species. Corrosion product minerals that may form depend on the composition of Alloy 22, which is given in Table 4.1-3. Several oxide, oxyhydroxide, silicate, molybdate, and tungstate phases may form by corrosion of Alloy 22 in the presence of 
deliquescence brines, and many of these potentially contain chloride. However, thermodynamic data is mostly lacking for these phases, and, unless directly observed in corrosion experiments, evaluating the stability of most of these phases in relevant brine compositions is not possible. Despite this, several chloride-bearing phases that are commonly observed as products of metal corrosion deserve consideration. One such mineral is akaganeite: $\mathrm{FeO}(\mathrm{OH}, \mathrm{Cl})$. A polymorph of $\mathrm{FeOOH}$, it forms preferentially to goethite in chloride-rich solutions and contains up to several weight percent $\mathrm{Cl}$ (Cornell and Schwertmann 2003 [DIRS 173037], pp. 21 and 499).

Another type of corrosion product that may form is one or more members of a family of materials known as layered double hydroxide (LDH) materials. Of the general formula $\mathrm{M}(\mathrm{II})_{1-\mathrm{x}} \mathrm{M}(\mathrm{III})_{\mathrm{x}}(\mathrm{OH})_{2} \mathrm{Y}_{\mathrm{x} / \mathrm{n}}$, these materials consist of positively charged metal hydroxide layers, whose surplus positive charge, arising from substitution of the trivalent cation $\mathrm{M}$ (III) for the divalent cation M(II), is neutralized by an exchangeable interlayer anion Y. A wide variety of anionic species, including carbonate, chloride, nitrate, or sulfate, may be present as interlayer anions. Metal oxyanions such as molybdate or tungstate may also substitute into the interlayer site. Although carbonate is favored in the exchange site, high concentrations of nitrate or chloride in solution will result in incorporation of these species into the LDH interlayer. Hence, formation of LDH phases by corrosion of Alloy 22 could consume brine components on the waste package surface.

LDH minerals are common in nature and are easily synthesized in the laboratory. Divalent metal cations that readily form $\mathrm{LDH}$ species are $\mathrm{Mg}, \mathrm{Mn}, \mathrm{Fe}, \mathrm{Ni}$, and $\mathrm{Co}$, while trivalent metal cations include $\mathrm{Al}, \mathrm{Fe}(\mathrm{III}), \mathrm{Co}(\mathrm{III})$, and $\mathrm{Cr}(\mathrm{III})$. Naturally occurring minerals belong to the hydrotalcite structural group, and include hydrotalcite (Mg:Al), pyroaurite $(\mathrm{Mg}: \mathrm{Fe})$, sitchtite $(\mathrm{Mg}: \mathrm{Cr})$, reevesite $(\mathrm{Ni}: \mathrm{Fe})$, and comblainite $(\mathrm{Ni}: \mathrm{Co})$, among others. $\mathrm{Ni} \mathrm{Cr} \mathrm{LDH}$ is not known to occur naturally, but is readily synthesized in the laboratory, and is among the stablest of LDH materials (Boclair et al. 1999 [DIRS 172929]; Boclair and Braterman 1999 [DIRS 172930]).

LDH materials are common metal corrosion products. "Green rust," or Fe(II):Fe(III) LDH, is a widely recognized intermediate in the corrosion of metallic iron under low-oxygen conditions (Refait et al. 1998 [DIRS 173015]; 1999 [DIRS 173014]); the previously mentioned reevesite (Ni:Fe LDH) forms naturally in the corrosion rinds of nickel-iron meteorites (Lee and Bland 2004 [DIRS 173241], p. 910; Koch and Buchwald 1994 [DIRS 173242]); and several Al-bearing $\mathrm{LDH}$ materials have been identified as products of $\mathrm{Al}$ metal corrosion by natural waters. In a recent experiment to evaluate corrosion of Alloy 22, an LDH phase was identified by X-ray diffraction (XRD), confirming that these materials are potentially relevant to corrosion of Alloy 22 in brines formed by dust deliquescence. This experimental work is discussed in detail below.

Because Ni, Cr, and Fe are abundant elements in Alloy 22, likely LDH minerals to form include $\mathrm{Ni}: \mathrm{Cr}(\mathrm{III})$ and Ni:Fe(III) LDH; it is likely that the observed phase was one of these. Fortunately, there are thermodynamic data available for these two phases, allowing a general evaluation of their stability in relevant dust deliquescence brine compositions. The results of these EQ3/6 calculations are also discussed below. Note that thermodynamic data are only available for the chloride-containing versions of these phases. There is no explicit modeling of types with other anions (e.g., carbonate, sulfate, molybdate, tungstate) in the exchangeable interlayer site, as thermodynamic data are unavailable. While these more highly charged complexes will be 
favored over chloride in the exchangeable site, the high concentrations of chloride in solution will favor some incorporation of chloride, even if ion exchange selectivity coefficients for chloride are low.

Other LDH species may possibly form, for instance, containing Co, but as this is a relatively minor component of Alloy 22, it was not considered here. "Green rust," containing Fe(II), was also not considered, as is would not form under oxidizing conditions.

\subsubsection{Results of Experimental Work to Determine Alloy 22 Corrosion Products}

Experiments were carried out by Lawrence Livermore National Laboratories personnel to identify potential Alloy 22 corrosion products. In these experiments, Alloy 22 specimens were prepared with polytetraflouroethylene-wrapped crevice formers, immersed in $5 \mathrm{M} \mathrm{CaCl}_{2}$ or $4 \mathrm{M} \mathrm{NaCl}$ brines at $90^{\circ} \mathrm{C}$, and aged at $90^{\circ} \mathrm{C}$. Some samples were polarized potentiostatically at $100 \mathrm{mV}$; others were not polarized. In all cases, severe crevice corrosion occurred. The corrosion products, present as loose material in the sample containers, were collected by filtering the test solutions, and the collected material was split into two aliquots, one of which was rinsed with deionized water and dried at $40^{\circ} \mathrm{C}$ for one week, and the other of which was dried without rinsing.

Samples have not yet been chemically analyzed, but have been ground and analyzed by XRD. Each pattern differed, with the unrinsed samples providing little useful information. The diffraction patterns for the unrinsed and rinsed samples from the $\mathrm{NaCl}$ brine experiments were dominated by halite peaks. Several broad, unidentified peaks were also present, most prominently in the rinsed sample. The unrinsed $\mathrm{CaCl}_{2}$ samples had a flat pattern with only a few very broad diffraction peaks; however, the rinsed samples displayed several distinct peaks. The rinsed and unrinsed patterns for the $\mathrm{CaCl}_{2}$ system that was run with a potential of $100 \mathrm{mV}$ are shown in Figure 6.5-4 (the system run at a potential of $0 \mathrm{mV}$ shows similar patterns). The diffraction pattern for the rinsed sample, smoothed and background subtracted, is shown in Figure 6.5-5, along with diagnostic peak patterns for two phases: the LDH phase hydrotalcite $\left(\mathrm{Mg}_{6} \mathrm{Al}_{2}\left(\mathrm{CO}_{3}\right)(\mathrm{OH})_{16}: 4 \mathrm{H}_{2} \mathrm{O}\right.$, JCPDF card \#41-1428), and a calcium-chloride hydroxide phase $\left(\mathrm{CaCl}_{2}: \mathrm{Ca}(\mathrm{OH})_{2}: \mathrm{H}_{2} \mathrm{O}\right.$, JCPDF card \#02-1099). Hydrotalcite cannot be present in the experimental system because no magnesium is present, but XRD data for LDH materials are limited in the Joint Committee Powder Diffraction File (JCPDF) database, and hydrotalcite is presented here as an analogue for other LDH phases. All possess similar structures, and have similar X-ray diffraction patterns. It is clear from the diffraction pattern that an LDH phase is probably present - the hydrotalcite pattern clearly matches several broad peaks in the pattern. Several sharper peaks are also present and represent an unidentified mineral. A Ca-hydroxidechloride phase, $\mathrm{CaCl}_{2}: \mathrm{Ca}(\mathrm{OH})_{2}: \mathrm{H}_{2} \mathrm{O}$, matches a few of the peaks, but is a poor match in general.

The composition of the LDH phase is not known, as no analysis has been performed on the corrosion products yet, but given the composition of Alloy 22 (Table 4.1-3), Ni:Cr LDH is a likely candidate. Although no such phase is present in the JCPDF database, diffraction patterns for such a phase have been published by Clause et al. (1991 [DIRS 173016]), and are presented in Figure 6.5-6. The patterns are clearly similar to that of the LDH phase in the corrosion products, although LDH phases of other compositions cannot be excluded. 


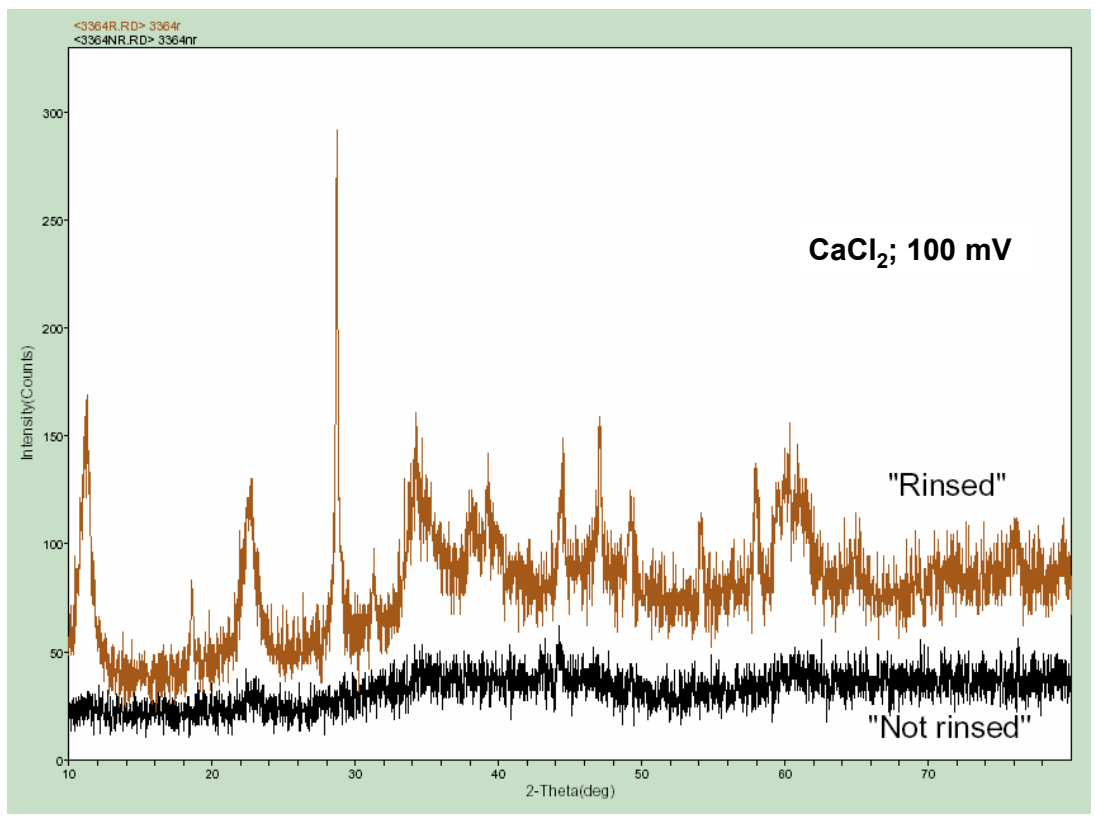

Source: DTN: LL050302823121.051 [DIRS 173608], 3364R and 3364NR.

Figure 6.5-4. X-Ray Diffraction Patterns of "Rinsed" and "Unrinsed" Corrosion Products from the $\mathrm{CaCl}_{2}$ Brine Systems Aged with an Applied Polarizing Potential of $100 \mathrm{mV}$

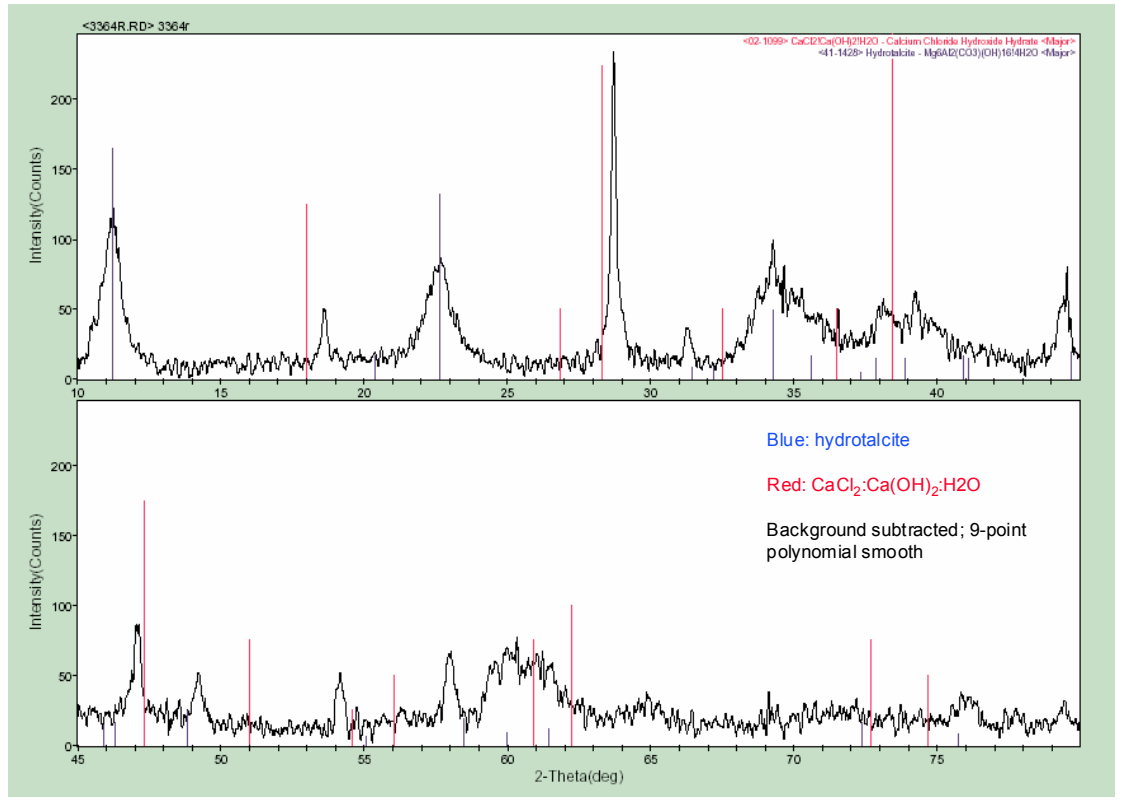

Source: DTN: LL050302823121.051 [DIRS 173608], 3364R.

NOTE: Also shown are the diagnostic peak patterns for two phases, hydrotalcite $\left(\mathrm{Mg}_{6} \mathrm{Al}_{2}\left(\mathrm{CO}_{3}\right)(\mathrm{OH})_{16}: 4 \mathrm{H}_{2} \mathrm{O}\right.$, JCPDF card \#41-1428), and a calcium chloride hydroxide ( $\mathrm{CaCl}_{2}: \mathrm{Ca}(\mathrm{OH})_{2}: \mathrm{H}_{2} \mathrm{O}$, JCPDF card \#02-1099).

Figure 6.5-5. Smoothed and Background Subtracted Diffraction Pattern of the "Rinsed" Sample Shown in Figure 6.5-4 


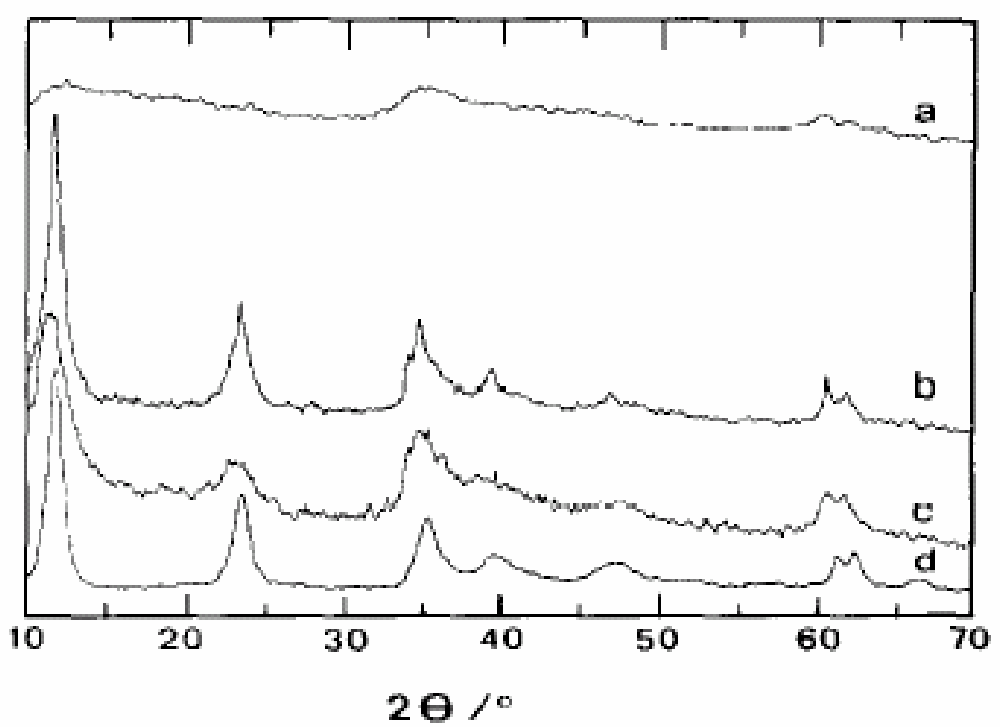

Source: Clause et al. 1991 [DIRS 173016].

NOTE: Pattern $(d)$ is from a similar Ni:Al phase.

Figure 6.5-6. Published X-Ray Diffraction Peaks for a Ni:Cr LDH Phase, Formed at (a) High Supersaturation, (b) Low Supersaturation, and (c) after Hydrothermal Treatment

\subsubsection{EQ3/6 Analysis of Ni:Cr and Ni:Fe LDH Stability in Experimental Systems and Brines Formed by Dust Deliquescence}

Because an LDH phase has been observed in experimental corrosion studies, thermodynamic data were obtained from the literature for two likely phases, $\mathrm{Ni}-\mathrm{Cr}$ and $\mathrm{Ni}-\mathrm{Fe} \mathrm{LDH}$, and were added to data0.ypf.R2. EQ3/6 simulations have been run, in which a hypothetical solid phase corresponding to the composition of Alloy 22 has been titrated into eutectic brines for the binary, ternary, and quaternary salt assemblages, designated A, B, and C (from BSC 2004 [DIRS 161237]), and corrosion phases predicted to precipitate have been noted.

To perform these simulations, thermodynamic data for three phases were added to the data0.ypf.R2 database, two LDH phases (Ni-Cr and $\mathrm{Ni}-\mathrm{Fe}$ ), and a hypothetical solid phase representing Alloy 22. The LDH-phase thermodynamic data are taken from two papers by Boclair et al. (1999 [DIRS 172929]) and Boclair and Braterman (1999 [DIRS 172930]) and are justified for intended use in Section 4.1.4. The data are presented again below for convenience.

Table 6.5-4. Thermodynamic Data for Ni:Cr and Ni:Fe LDH Phases

\begin{tabular}{|l|c|c|c|}
\hline $\begin{array}{c}\text { Name in } \\
\text { data0.ypf.R2 }\end{array}$ & $\begin{array}{c}\text { Chemical } \\
\text { Formula }\end{array}$ & \multicolumn{1}{c|}{ Dissociation Reaction } & log $(K)$ \\
\hline $\mathrm{Cr}-\mathrm{Ni} \_\mathrm{LDH}$ & $\mathrm{CrNi}_{2}(\mathrm{OH})_{6} \mathrm{Cl}$ & $\mathrm{CrNi}_{2}(\mathrm{OH})_{6} \mathrm{Cl} \rightarrow \mathrm{Cr}^{3+}+2 \mathrm{Ni}^{2+}+6 \mathrm{OH}^{-}+\mathrm{Cl}^{-}$ & -61.83 \\
\hline $\mathrm{Fe}-\mathrm{Ni}$ LDH & $\mathrm{FeNi}_{2}(\mathrm{OH})_{6} \mathrm{Cl}$ & $\mathrm{FeNi}_{2}(\mathrm{OH})_{6} \mathrm{Cl} \rightarrow \mathrm{Fe}^{3+}+2 \mathrm{Ni}^{2+}+6 \mathrm{OH}^{-}+\mathrm{Cl}^{-}$ & -59.49 \\
\hline
\end{tabular}

Source: Table 4.1-4. 
In order to insert these into data0.ypf.R2, the dissociation reactions in Table 6.5-2 have to be rewritten to correspond to the format used in that database, and the $\log (K)$ values modified appropriately. Rewriting these two equations yields:

$$
\mathrm{CrNi}_{2}(\mathrm{OH})_{6} \mathrm{Cl}+6 \mathrm{H}^{+} \rightarrow \mathrm{Cr}^{3+}+2 \mathrm{Ni}^{2+}+6 \mathrm{H}_{2} \mathrm{O}+\mathrm{Cl}^{-} \quad \log (K)=22.14 \quad \text { (Eq. 6.5-5) }
$$

and:

$$
\mathrm{FeNi}_{2}(\mathrm{OH})_{6} \mathrm{Cl}+6 \mathrm{H}^{+} \rightarrow \mathrm{Fe}^{3+}+2 \mathrm{Ni}^{2+}+6 \mathrm{H}_{2} \mathrm{O}+\mathrm{Cl}^{-} \quad \log (K)=24.28 \quad \text { (Eq. 6.5-6) }
$$

The $\log (K)$ values for Equations 6.5-5 and 6.5-6 were derived from the literature values by subtracting off 6 times $\log \left(K_{w}\right)$, the dissociation constant for water, -13.9951 at $25^{\circ} \mathrm{C}$ (from data0.ypf.Rl). In addition, the $\log (K)$ for the Fe-bearing phase had to be adjusted to make it consistent with $\mathrm{Fe}(\mathrm{OH})_{3}$ solubility data in data0.ypf.R1, yielding a $\log (K)$ of 23.84. These calculations are documented in LDH titration calcs.xls in Output DTN: SN0504T0502205.009. These two LDH phases, the dissociation reactions in Equations 6.5-5 and 6.5-6 and their associated $\log (K)$ values, have been inserted into the data0.ypf.R2 database used in many calculations in this report. Thermodynamic data are not available to populate a $\log (K)$ temperature grid, so values were only put into the database for $25^{\circ} \mathrm{C}$.

The Alloy 22 solid phase has a simplified composition relative to that given in Table 4.1-3. Because the number of Mo and $\mathrm{W}$ phases in data0.ypf.R2 is limited, and because these components are not incorporated into the LDH phases of interest, these components were left out of the hypothetical solid phase. In addition, Co was not included (although it can form LDH phases), because it is a relatively minor component, and is not a component in the specific phases that were added to the database. The composition of the Alloy 22 "mineral" is derived in Table 6.5-3. An arbitrarily $\operatorname{large} \log (K)$ of 499 is used to guarantee that the dissociation reaction proceeds in the forward direction only.

\begin{tabular}{|c|c|c|c|c|c|c|}
\hline Element & Mass & $\begin{array}{c}\text { wt \% in } \\
\text { Alloy }\end{array}$ & $\begin{array}{c}\text { \# moles, } \\
\text { assuming } \\
100 \mathrm{~g} / \mathrm{mole} \\
\text { Alloy } 22 \\
\end{array}$ & $\begin{array}{c}\text { Proportioned } \\
\text { to } \mathrm{Fe}\end{array}$ & $\begin{array}{c}\text { Rounded } \\
\text { off }\end{array}$ & $\begin{array}{c}\text { Milli- } \\
\text { equivalents } \\
\end{array}$ \\
\hline $\mathrm{Ni}$ & 58.6934 & 50.02 & 0.8522 & 7.9321 & 8 & 16 \\
\hline $\mathrm{Cr}$ & 51.9961 & 22.5 & 0.4327 & 4.0276 & 4 & 12 \\
\hline $\mathrm{Fe}$ & 55.845 & 6.0 & 0.1074 & 1.0000 & 1 & 3 \\
\hline \multicolumn{7}{|c|}{ Dissociation equation: Alloy $22\left(\mathrm{FeNi}_{8} \mathrm{Cr}_{4}\right)+31 \mathrm{H}^{+}+7.75 \mathrm{O}_{2}(\mathrm{~g}) \rightarrow$} \\
\hline \multicolumn{7}{|c|}{$\mathrm{Fe}^{3+}+8 \mathrm{Ni}^{2+}+4 \mathrm{Cr}^{3+}+15.5 \mathrm{H}_{2} \mathrm{O}$} \\
\hline
\end{tabular}

Table 6.5-5. Composition of Hypothetical Alloy 22 Solid Phase Added to data0.ypf.R2

Source: Table 4.1-3 and LDH titration calcs.xls in Output DTN: SN0504T0502205.009.

Analysis Results - In corrosion experiments at $90^{\circ} \mathrm{C}$, a layered double hydroxide phase was identified by XRD in the corrosion products from a $5 \mathrm{M} \mathrm{CaCl}_{2}$ brine experiment, but not in the corrosion products that formed in an experiment with $4 \mathrm{M} \mathrm{NaCl}$ brine. In order to understand why this might be the case, these two experimental systems were analyzed. However, high temperature $\log (K)$ data for LDH phases are not available, so the systems have been analyzed 
at $25^{\circ} \mathrm{C}$. In the EQ3/6 simulations, 0.1 moles of the Alloy 22 mineral are titrated into the system while the $p \mathrm{O}_{2}$ is held constant at $10^{-0.7}$ bars and the $p \mathrm{CO}_{2}$ is held at zero (it is assumed that the degree of corrosion was too small to consume a significant amount of the oxygen from the atmosphere in the test chamber, but that $\mathrm{CO}_{2}$ is limited to the starting amount present, and might have been consumed). Charge balancing is done on $\mathrm{H}^{+}$. All $\mathrm{Cr}(\mathrm{VI})$ species are suppressed.

Additional simulations have been run using brine Assemblages $\mathrm{A}, \mathrm{B}$, and $\mathrm{C}$, assuming $p \mathrm{CO}_{2}=10^{-3.5}$, at $25^{\circ} \mathrm{C}$ to evaluate the stability of $\mathrm{LDH}$ in deliquescent brines. $\mathrm{EQ} 3 / 6$ runs for the experimental simulations and the deliquescent brine assemblages are listed in Table 6.5-6, and are contained in Output DTN: SN0505T0502205.011.

The results of the corrosion experiment simulations are summarized in Table 6.5-7. In neither the $\mathrm{NaCl}$ nor the $\mathrm{CaCl}_{2}$ simulations is an $\mathrm{LDH}$ phase predicted to precipitate. Chrome solubilities are very low, due to precipitation of eskolaite, $\mathrm{Cr}_{2} \mathrm{O}_{3}$. Because such oxide phases are often kinetically inhibited, the simulations were repeated with this phase suppressed. This had little effect on the solution composition, other than raising the Cr solubility by several orders of magnitude. In these runs, $\mathrm{NiCr}_{2} \mathrm{O}_{4}$, a spinel phase, is the solubility-limiting phase for chromium. In a third pair of runs, both eskolaite and $\mathrm{NiCr}_{2} \mathrm{O}_{4}$ were suppressed. In these runs, Cr solubilities were several orders of magnitude higher than the previous runs, and $\mathrm{Ni}$ concentrations several orders of magnitude lower. In both brines, when eskolaite and the $\mathrm{Ni}-\mathrm{Cr}$ spinel phase are suppressed, $\mathrm{Ni}$ :Cr layered double hydroxide is predicted to precipitate, but it is more abundant in the $\mathrm{CaCl}_{2}$ brine relative to the $\mathrm{NaCl}$ brine.

Because an LDH phase has been observed experimentally, eskolaite and the $\mathrm{NiCr}_{2} \mathrm{O}_{4} \mathrm{spinel}$ phase may be the most stable phases thermodynamically but kinetically inhibited from forming. This is not unreasonable. The iron system displays analogous behavior-while hematite is the most thermodynamically stable Fe(III) phase, other oxyhydroxide phases (ferrihydrite, goethite, lepidocrocite) are common in nature, and can persist for hundreds of millions of years without converting to hematite.

Similar calculations have been performed with salt Assemblages A, B, and $\mathrm{C}$, at $25^{\circ} \mathrm{C}$, and a $p \mathrm{CO}_{2}$ of $10^{-3.5}$, and yield slightly different results (Table 6.5-8). Ni-carbonate is an important solid phase in the Assemblage $\mathrm{A}$ and $\mathrm{B}$ runs, but not in the Assemblage $\mathrm{C}$ runs, which have a somewhat lower $\mathrm{pH}$. As with the simulations of the $\mathrm{CaCl}_{2}$ and $\mathrm{NaCl}$ experimental systems, the $\mathrm{Ni}: \mathrm{Cr} \mathrm{LDH}$ phase is only predicted to precipitate when both eskolaite and $\mathrm{NiCr}_{2} \mathrm{O}_{4}$ are suppressed. It is a minor precipitate in the Assemblage A and B systems, but the most abundant one in the Assemblage $\mathrm{C}$ system.

The Ni:Fe layered double hydroxide was not predicted to form in any simulation. Akaganeite was also never predicted to form-hematite was the iron oxide/oxyhydroxide closest to saturation, and goethite only slightly less saturated. Akaganeite was well below saturation, even in the $5 \mathrm{M} \mathrm{CaCl}_{2}$ brine, which contains 10 molal chloride. This is inconsistent with observed stability of akaganeite in high-chloride brines; it may be that the particular composition of akaganeite that was placed in data0.ypf.R2 was not appropriate for brines of this composition (akaganeite can accept widely varying amounts of chloride and water in its channel structure, and the most stable composition varies with brine concentration). 
It is difficult to evaluate the effects of temperature on the stability of layered double hydroxides in Assemblage A, B, and C brines. First, there are no thermodynamic data available to generate a $\log (K)$ temperature grid for the two phases. Second, data are only available for the chloride forms of the materials, although the nitrate forms are also easily synthesized. The nitrate forms are likely to become relatively more stable at high temperatures, where nitrate concentrations and nitrate-chloride ratios in the brines are very high. Because chloride and nitrate are stoichiometric components in LDH phases, and chloride and/or nitrate concentrations in eutectic brines increase with temperature, LDH materials should be more stable at higher temperatures.

As an LDH phase forms, anionic components in the brine will be incorporated into the interlayer site. These include carbonate, sulfate, chromate, and molybdate, as well as chloride and nitrate. Although carbonate and many of the other oxyanions have a higher site affinity than chloride, and chloride is preferred over nitrate, the interlayer site is an exchangeable site, and the relative proportions of the anions populating in the site will be a function of the brine composition. Because the concentrations of nitrate and chloride are high in the brines with respect to carbonate and other oxyanions, they will be incorporated, at least to some degree, into the LDH, even though their ion exchange selectivity coefficients are low.

Thus, if an LDH phase forms, it is likely to consume chloride and/or nitrate from the brines. It may be that the amount of consumption is small, but because the volume of brine predicted to form by dust deliquescence is very small (Section 6.3), only a small amount of chemical sequestration by layered double hydroxides and other corrosion products is necessary to result in brine dryout and cessation of corrosion. Because chloride is preferred over nitrate, exchange into LDH phases, if present, will raise the nitrate-chloride ratio in the remaining brine, rendering it even less corrosive.

Table 6.5-6. EQ3/6 Files Used in Evaluating the Stability of LDH in Deliquescent Brines

\begin{tabular}{|c|c|}
\hline File name & Description \\
\hline \multicolumn{2}{|r|}{ Calculations with Assemblage $\mathrm{A}, 25^{\circ} \mathrm{C}$} \\
\hline ad25/dh.3i, 3o, 3p & $\begin{array}{l}\text { Creates an unsaturated Assemblage A brine with small amounts of transition metals. The } \\
\text { pickup file is used as the bottom half of the ad25/dh.6i file listed below. }\end{array}$ \\
\hline ad25ldh.6i, 6o, $6 p$ & $\begin{array}{l}\text { Titrates in } \mathrm{NaCl} \text { and } \mathrm{KNO}_{3} \text { until the brine is saturated with both. The pickup file is used as } \\
\text { the bottom half of the files listed below. }\end{array}$ \\
\hline Idh-ad1.6i, 60 & Titrates in hypothetical solid phase Alloy 22. No $\mathrm{Cr}(\mathrm{III})$ phases suppressed. \\
\hline Idh-ad2.6i, 60 & Titrates in hypothetical solid phase Alloy 22. Eskolaite $\left(\mathrm{Cr}_{2} \mathrm{O}_{3}\right)$ suppressed. \\
\hline Idh-ad3.6i, 60 & Titrates in hypothetical solid phase Alloy 22. Eskolaite $\left(\mathrm{Cr}_{2} \mathrm{O}_{3}\right)$ and $\mathrm{NiCr}_{2} \mathrm{O}_{4}$ suppressed. \\
\hline \multicolumn{2}{|r|}{ Calculations with Assemblage $\mathrm{B}, 25^{\circ} \mathrm{C}$} \\
\hline$a b d 25 / d h .3 i, 3 o, 3 p$ & $\begin{array}{l}\text { Creates an unsaturated Assemblage B brine with small amounts of transition metals. The } \\
\text { pickup file is used as the bottom half of the abd25/dh.6i file listed below. }\end{array}$ \\
\hline$a b d 25 / d h .6 i, 6 o, 6 p$ & $\begin{array}{l}\text { Titrates in } \mathrm{NaCl} \text { and } \mathrm{KNO}_{3} \text { until the brine is saturated with both. The pickup file is used as } \\
\text { the bottom half of the files listed below. }\end{array}$ \\
\hline ldh-abd1.6i, 60 & Titrates in hypothetical solid phase Alloy 22. No $\mathrm{Cr}(\mathrm{III})$ phases suppressed. \\
\hline ldh-abd2.6i, 60 & Titrates in hypothetical solid phase Alloy 22. Eskolaite $\left(\mathrm{Cr}_{2} \mathrm{O}_{3}\right)$ suppressed. \\
\hline Idh-abd3.6i, 60 & Titrates in hypothetical solid phase Alloy 22. Eskolaite $\left(\mathrm{Cr}_{2} \mathrm{O}_{3}\right)$ and $\mathrm{NiCr}_{2} \mathrm{O}_{4}$ suppressed. \\
\hline
\end{tabular}


Table 6.5-6. EQ3/6 Files Used in Evaluating the Stability of LDH in Deliquescent Brines (Continued)

\begin{tabular}{|c|c|}
\hline File name & Description \\
\hline \multicolumn{2}{|r|}{ Calculations with Assemblage $\mathrm{C}, 25^{\circ} \mathrm{C}$} \\
\hline a-d25/dh.3i, 3o, 3p & $\begin{array}{l}\text { Creates an unsaturated Assemblage A brine with small amounts of transition metals. The } \\
\text { pickup file is used as the bottom half of the a-d25/dh.6i file listed below. }\end{array}$ \\
\hline a-d25/dh.6i, $60,6 p$ & $\begin{array}{l}\text { Titrates in } \mathrm{NaCl} \text { and } \mathrm{KNO}_{3} \text { until the brine is saturated with both. The pickup file is used as } \\
\text { the bottom half of the files listed below. }\end{array}$ \\
\hline Idh-a-d1.6i, 60 & Titrates in hypothetical solid phase Alloy 22. No $\mathrm{Cr}(\mathrm{III})$ phases suppressed. \\
\hline$I d h-a-d 2.6 i, 6 o$ & Titrates in hypothetical solid phase Alloy 22. Eskolaite $\left(\mathrm{Cr}_{2} \mathrm{O}_{3}\right)$ suppressed. \\
\hline Idh-a-d3.6i, 60 & Titrates in hypothetical solid phase Alloy 22. Eskolaite $\left(\mathrm{Cr}_{2} \mathrm{O}_{3}\right)$ and $\mathrm{NiCr}_{2} \mathrm{O}_{4}$ suppressed. \\
\hline \multicolumn{2}{|r|}{ Calculations in $5 \mathrm{M} \mathrm{CaCl}_{2}$ brine at $25^{\circ} \mathrm{C}$} \\
\hline cacl-Idh.3i, 3o, 3p & $\begin{array}{l}\text { Creates a } 5 \mathrm{M} \mathrm{CaCl}_{2} \text { brine with small amounts of transition metals. The pickup file is used } \\
\text { as the bottom half of the files listed below. }\end{array}$ \\
\hline Idh-ca1.6i, 60 & Titrates in hypothetical solid phase Alloy 22. No $\mathrm{Cr}(\mathrm{III})$ phases suppressed. \\
\hline Idh-ca2.6i, 6o & Titrates in hypothetical solid phase Alloy $22 . \mathrm{NiCr}_{2} \mathrm{O}_{4}$ suppressed. \\
\hline Idh-ca3.6i, 60 & Titrates in hypothetical solid phase Alloy 22. Eskolaite $\left(\mathrm{Cr}_{2} \mathrm{O}_{3}\right)$ and $\mathrm{NiCr}_{2} \mathrm{O}_{4}$ suppressed. \\
\hline \multicolumn{2}{|r|}{ Calculations in $4 \mathrm{M} \mathrm{NaCl}$ brine at $25^{\circ} \mathrm{C}$} \\
\hline nacl-Idh.3i, 3o, 3p & $\begin{array}{l}\text { Creates a } 4 \mathrm{M} \mathrm{NaCl} \text { brine with small amounts of transition metals. The pickup file is used as } \\
\text { the bottom half of the files listed below. }\end{array}$ \\
\hline Idh-na1.6i, 60 & Titrates in hypothetical solid phase Alloy 22. No $\mathrm{Cr}(\mathrm{III})$ phases suppressed. \\
\hline Idh-na2.6i, 60 & Titrates in hypothetical solid phase Alloy $22 . \mathrm{NiCr}_{2} \mathrm{O}_{4}$ suppressed. \\
\hline Idh-na3.6i, 60 & Titrates in hypothetical solid phase Alloy 22. Eskolaite $\left(\mathrm{Cr}_{2} \mathrm{O}_{3}\right)$ and $\mathrm{NiCr}_{2} \mathrm{O}_{4}$ suppressed. \\
\hline
\end{tabular}

Source: Output DTN: SN0505T0502205.011.

Table 6.5-7. Results of Simulations of Experimental Corrosion Studies

\begin{tabular}{|c|c|c|c|c|c|}
\hline $\begin{array}{l}\text { Run } \\
\text { Condition: }\end{array}$ & $\begin{array}{c}\text { Suppressed } \\
\text { Minerals }\end{array}$ & $\begin{array}{c}\text { Final } \\
\text { pH }\end{array}$ & $\mathrm{Ni}(\mathrm{m})$ & $\mathrm{Cr}(\mathrm{m})$ & $\begin{array}{c}\text { Precipitated Phases (in Order of } \\
\text { Abundance) }\end{array}$ \\
\hline \multirow{3}{*}{$\begin{array}{l}5 \mathrm{M} \mathrm{CaCl} \\
25^{\circ} \mathrm{C} \\
p \mathrm{CO}_{2}=0\end{array}$} & None & 7.13 & 4.37E-05 & $6.10 \mathrm{E}-12$ & $\mathrm{Ni}(\mathrm{OH})_{2}$, Eskolaite, Ferrite-Ni $\left(\mathrm{NiFe}_{2} \mathrm{O}_{4}\right)$ \\
\hline & Eskolaite & 7.14 & $4.34 \mathrm{E}-05$ & $8.60 \mathrm{E}-10$ & $\mathrm{Ni}(\mathrm{OH})_{2}, \mathrm{NiCr}_{2} \mathrm{O}_{4}$, Ferrite-Ni \\
\hline & $\begin{array}{l}\text { Eskolaite + } \\
\mathrm{NiCr}_{2} \mathrm{O}_{4}\end{array}$ & 10.34 & 4.04E-08 & 1.63E-07 & $\mathrm{Ni}(\mathrm{OH})_{2}, \mathrm{Cr}(\mathrm{OH})_{3(\mathrm{am})}, \mathrm{LDH} \_\mathrm{Cr}-\mathrm{Ni}$, Ferrite-N \\
\hline \multirow{3}{*}{$\begin{array}{l}4 \mathrm{M} \mathrm{NaCl} \\
25^{\circ} \mathrm{C} \\
p \mathrm{CO}_{2}=0\end{array}$} & None & 8.39 & $2.10 \mathrm{E}-06$ & $9.66 \mathrm{E}-13$ & $\mathrm{Ni}(\mathrm{OH})_{2}$, Eskolaite, Ferrite-Ni \\
\hline & Eskolaite & 8.39 & $2.10 \mathrm{E}-06$ & $1.84 \mathrm{E}-10$ & $\mathrm{Ni}(\mathrm{OH})_{2}, \mathrm{NiCr}_{2} \mathrm{O}_{4}$, Ferrite-Ni \\
\hline & $\begin{array}{l}\text { Eskolaite + } \\
\mathrm{NiCr}_{2} \mathrm{O}_{4}\end{array}$ & 8.83 & $3.43 \mathrm{E}-07$ & 1.47E-07 & $\mathrm{Ni}(\mathrm{OH})_{2}, \mathrm{Cr}(\mathrm{OH})_{3(\mathrm{am})}$, Ferrite-Ni, LDH_Cr-Ni \\
\hline
\end{tabular}

Source: Output DTN: SN0505T0502205.011, CaCl-Idh.xls and NaCl-Idh.xls. 
Table 6.5-8. Results of Simulations of Deliquescent Brine Assemblages

\begin{tabular}{|c|c|c|c|c|c|}
\hline $\begin{array}{c}\text { Run } \\
\text { Condition: }\end{array}$ & $\begin{array}{c}\text { Suppressed } \\
\text { Minerals }\end{array}$ & $\begin{array}{c}\text { Final } \\
\mathrm{pH}\end{array}$ & $\mathrm{Ni}(\mathrm{m})$ & $\operatorname{Cr}(\mathrm{m})$ & $\begin{array}{c}\text { Precipitated Phases (in Order of } \\
\text { Abundance) }\end{array}$ \\
\hline \multirow{3}{*}{$\begin{array}{l}\text { Assemblage A } \\
25^{\circ} \mathrm{C} \\
p \mathrm{CO}_{2}=10^{-3.5}\end{array}$} & None & 7.28 & 5.94E-05 & $9.65 \mathrm{E}-12$ & $\mathrm{NiCO}_{3}$, Eskolaite, Ferrite-Ni \\
\hline & Eskolaite & 7.28 & $5.94 \mathrm{E}-05$ & 2.17E-09 & $\mathrm{NiCO}_{3}, \mathrm{NiCr}_{2} \mathrm{O}_{4}$, Ferrite-Ni \\
\hline & $\begin{array}{l}\text { Eskolaite + } \\
\mathrm{NiCr}_{2} \mathrm{O}_{4}\end{array}$ & 8.80 & 1.97E-07 & $1.49 \mathrm{E}-07$ & $\mathrm{NiCO}_{3}, \mathrm{Cr}(\mathrm{OH})_{3(\mathrm{am})}$, Ferrite-Ni, LDH_Cr-Ni \\
\hline \multirow{3}{*}{$\begin{array}{l}\text { Assemblage B } \\
25^{\circ} \mathrm{C} \\
p \mathrm{CO}_{2}=10^{-3.5}\end{array}$} & None & 7.04 & 3.37E-05 & $4.48 \mathrm{E}-11$ & $\mathrm{NiCO}_{3}$, Eskolaite, Ferrite-Ni \\
\hline & Eskolaite & 7.04 & 3.37E-05 & $1.01 \mathrm{E}-08$ & $\mathrm{NiCO}_{3}, \mathrm{NiCr}_{2} \mathrm{O}_{4}$, Ferrite-Ni \\
\hline & $\begin{array}{l}\text { Eskolaite + } \\
\mathrm{NiCr}_{2} \mathrm{O}_{4}\end{array}$ & 8.79 & 1.60E-07 & $1.51 \mathrm{E}-07$ & $\mathrm{NiCO}_{3}, \mathrm{Cr}(\mathrm{OH})_{3(\mathrm{am})}$, Ferrite-Ni, LDH_Cr-Ni \\
\hline \multirow{3}{*}{$\begin{array}{l}\text { Assemblage } \mathrm{C} \\
25^{\circ} \mathrm{C} \\
\mathrm{pCO}_{2}=10^{-3.5}\end{array}$} & None & 6.31 & 7.62E-04 & 1.00E-09 & $\mathrm{NiCO}_{3}$, Eskolaite, Ferrite-Ni \\
\hline & Eskolaite & 6.31 & 7.62E-04 & $2.25 \mathrm{E}-07$ & $\mathrm{NiCO}_{3}, \mathrm{NiCr}_{2} \mathrm{O}_{4}$, Ferrite-Ni \\
\hline & $\begin{array}{l}\text { Eskolaite + } \\
\mathrm{NiCr}_{2} \mathrm{O}_{4}\end{array}$ & 6.45 & 3.99E-05 & 1.99E-05 & LDH_Cr-Ni, Hematite \\
\hline
\end{tabular}

Source: Output DTN: SN0505T0502205.011, Assemblage A-LDH.xls, Assemblage B-LDH.xls, and Assemblage C-LDH.XIs.

\subsubsection{Summary}

Analysis presented in this section shows that localized corrosion will not penetrate the waste package outer barrier, because the corrosion process is subject to stifling, and the limited volume of available brine will be readily taken up physically and chemically in the precipitated corrosion products.

A chemical description of the crevice corrosion process shows that water is consumed by redox reactions in both the anodic and cathodic regions of the corrosion cell. This water must be replaced by condensation of moisture from the gas phase for corrosion to continue. As corrosion products accumulate in the cell, cathodic limitation will occur from decreased availability of reaction sites, and potentially from decreased availability of oxygen and replenishing moisture if these pathways are restricted. Elevated temperature decreases the aqueous solubility of oxygen, which will contribute to cathodic limitation, while at the same time increasing the diffusivity of oxygen and other species which degrades the differential chemical conditions required to continue localized corrosion. The power-law description of localized or crevice corrosion propagation is applicable to Alloy 22 as well as many other materials. Laboratory data clearly show that stifling of the localized corrosion propagation rate in Alloy 22 occurs.

A scoping analysis shows that corrosion products formed by localized or crevice corrosion would have to be nearly nonporous not to exhaust the aqueous brine phase by incorporation and physical sequestration. Finally, corrosion products have been identified experimentally that contain brine components; thermodynamic analysis with EQ3/6 indicates that these phases may form in brines formed by dust deliquescence as well, and potentially represent a sink for brine components.

Uncertainty Discussion-The analysis of potential for stifling of localized corrosion of Alloy 22 is subject to several uncertainties which are addressed in Section 6.5.2.1, and are generally the result of data limitations. Importantly, measurements of localized corrosion that is forced through use of an applied potential are not applicable to the repository environment 
because there is no cathodic limitation, which inhibits corrosion. Accordingly, the stated purpose of the discussion is to show that stifling does occur, and significantly impedes localized corrosion propagation in Alloy 22.

There are other uncertainties associated with the solution chemistry and corrosion reactions at high temperatures or within the confines of a crevice. Under some circumstances, nitrate instead of oxygen might act as the oxidant and be consumed by the corrosion reaction, or even promote passive layer breakdown by enhancing conversion of $\mathrm{Cr}(\mathrm{III})$ to $\mathrm{Cr}(\mathrm{VI})$. However, the very limited brine volumes in the dust-crevice system should mitigate this effect.

The arguments presented in Section 6.5.3 for brine sequestration have associated uncertainties, which have been addressed using parametric analysis. The porosity and liquid saturation of corrosion products are the principal uncertainties, and critical values for the volumetric liquid content (product of porosity and saturation) are identified. Sequestration might be less effective if the corrosion products exhibited hydrophobicity, but this is not likely for aqueous mineral precipitates.

Section 6.5.4 presents current information on the formation of LDH minerals in the corrosion products, and the potential for chemical uptake of chloride. Uncertainties associated with identification of the phases by X-ray diffraction, and with the uptake of chloride, are discussed. Additional sources of uncertainty are the sparsity of data on corrosion products of Alloy 22, and the lack of chemical analysis for chloride in the experimentally produced corrosion products that would confirm the inferred uptake. Finally, there are uncertainties associated with the suppression of the oxide phases eskolaite and $\mathrm{NiCr}_{2} \mathrm{O}_{4}$; even if such phases are kinetically inhibited in the short-term experimental systems, as suggested by the presence of LDH, the LDH phase may convert back to them over longer times, liberating the anions. 


\section{INTENTIONALLY LEFT BLANK}




\section{CONCLUSIONS}

This section summarizes the arguments for screening out localized corrosion caused by deliquescence of dust on the waste package, using a logical framework similar to that described in Section 1.1 and Appendix E, and that proposed by EPRI (2004 [DIRS 172825]). The recommended screening decision is to exclude localized corrosion due to dust deliquescence from the TSPA-LA. It is noted that this evaluation is based on qualitative, parametric, and bounding analyses (see the run-in section headings at the end of Sections 6.1 through 6.5), and any uncertainty or variation in the input parameter values, within a reasonably expected range, will not change the conclusions drawn in this report. There are no restrictions for subsequent use of the analysis results in this report.

\subsection{SUMMARY OF SCREENING ARGUMENTS}

To evaluate the potential for localized corrosion caused by dust deliquescence to result in penetration of the Alloy 22 waste package outer barrier, five propositions are addressed. These propositions are listed in Table 7.1-1, along with the data sources used to evaluate each.

Table 7.1-1. Decision Tree Propositions and Data Sources Considered

\begin{tabular}{|c|c|}
\hline Decision Tree Item & Data Sources Considered \\
\hline $\begin{array}{l}\text { 1. Can multiple-salt deliquescent } \\
\text { brines form at elevated } \\
\text { temperature? Yes }\end{array}$ & $\begin{array}{l}\text { - } \quad \text { Tunnel dust and atmospheric aerosol compositions } \\
\text { - } \mathrm{NH}_{4} \text { salt decomposition } \\
\text { - } \quad \text { Experimental data on salt dryout }\end{array}$ \\
\hline $\begin{array}{l}\text { 2. If brines form at elevated } \\
\text { temperature, will they persist? } \\
\text { Sometimes }\end{array}$ & $\begin{array}{l}\text { - } \quad \text { Tunnel dust and atmospheric aerosol composition } \\
\text { - } \mathrm{NH}_{4} \text { salt decomposition } \\
\text { - } \quad \text { Experimental data on salt dryout } \\
\text { - } \quad \text { Brines degas acid-gas species and react with } \mathrm{CO}_{2} \\
\text { - } \\
\text { Brine reacts with minerals in dust }\end{array}$ \\
\hline $\begin{array}{l}\text { 3. If deliquescent brines persist, } \\
\text { will they be corrosive? No }\end{array}$ & $\begin{array}{l}\text { - } \quad \text { Tunnel dust and atmospheric aerosol composition } \\
\text { - } \mathrm{NH}_{4} \text { salt decomposition } \\
\text { - } \quad \text { Experimental data on salt dryout } \\
\text { - } \quad \text { Brines degas acid-gas species and react with } \mathrm{CO}_{2} \\
\text { - } \quad \text { Brine reacts with minerals in dust } \\
\text { - } \quad \text { Nitrate inhibition of localized corrosion (nitrate-chloride ratio) }\end{array}$ \\
\hline $\begin{array}{l}\text { 4. If deliquescent brines are } \\
\text { potentially corrosive, will they } \\
\text { initiate localized corrosion? } \\
\text { No }\end{array}$ & $\begin{array}{l}\text { - } \quad \text { Small quantity of dust and brine volume } \\
\text { - } \quad \text { Limited grain-grain contact and brine film thickness } \\
\text { - } \quad \text { Capillary retention of brine in dust } \\
\text { - } \mathrm{O}_{2} \text { diffusion and scale limits } \\
\text { - } \quad \text { Nitrate inhibition of localized corrosion (nitrate-chloride ratio) }\end{array}$ \\
\hline $\begin{array}{l}\text { 5. Once initiated, will localized } \\
\text { corrosion penetrate the waste } \\
\text { package outer barrier? No }\end{array}$ & $\begin{array}{l}\text { - Small brine volume insufficient to support penetration } \\
\text { - } \quad \text { Power-law stifling of localized corrosion } \\
\text { - } \quad \text { Brine sequestration by corrosion products }\end{array}$ \\
\hline
\end{tabular}


For localized corrosion caused by dust deliquescence to result in penetration of the waste package outer barrier, and the resulting dose consequence, to occur, each of the propositions in the following sections must be true.

\subsubsection{Can Multi-Salt Deliquescent Brines Form at Elevated Temperature? (Section 6.1)}

Boiling points of saturated salt solutions represent the maximum temperature of deliquescence at a given pressure. The one-atmosphere boiling points of solutions saturated with a single salt (nitrates, chlorides, and carbonates) are generally below $120^{\circ} \mathrm{C}$. This temperature is used as a transition point in this report; localized corrosion has been more intensively investigated below this temperature, the boiling points of prevalent single-salt brines $\left(\mathrm{NaCl}, \mathrm{KCl}, \mathrm{NaNO}_{3}, \mathrm{KNO}_{3}\right)$ are below this temperature, and capabilities for predicting brine chemistry generally produce more certain results. Saturated multi-salt mixtures always boil at higher temperatures than the individual salt components. The boiling points for important salt assemblages predicted to occur on the waste package surface have been investigated experimentally. The two-salt mixture $\mathrm{NaCl}+\mathrm{KNO}_{3}$ (Assemblage A) boils at a maximum temperature of $134^{\circ} \mathrm{C}$ and the three-salt mixture, $\mathrm{NaCl}+\mathrm{KNO}_{3}+\mathrm{NaNO}_{3}$ (Assemblage B), at over $190^{\circ} \mathrm{C}$. By inference, the four-salt mixture, $\mathrm{NaCl}+\mathrm{KNO}_{3}+\mathrm{NaNO}_{3}+\mathrm{Ca}\left(\mathrm{NO}_{3}\right)_{2}$ (Assemblage $\mathrm{C}$ ), must also deliquesce at temperatures above $190^{\circ} \mathrm{C}$.

Ammonium salts are highly deliquescent, and will be present in ventilation-deposited dust on the waste package surface. However, they thermally decompose readily into ammonia and mineral acids, and will not persist long enough to contribute to the deliquescent mineral assemblages.

Multi-salt deliquescent brines can form at elevated temperature (above $120^{\circ} \mathrm{C}$ ). Ammonium salts will comprise a significant fraction of the salts in the dust, but readily decompose, and will not persist long enough to contribute to deliquescent mineral assemblages, thus significantly decreasing the salt load present for deliquescence.

\subsubsection{If Brines Form at Elevated Temperature, Will They Persist? (Section 6.2)}

Experimental work has shown that deliquescent $\mathrm{CaCl}_{2}$ brine readily degasses at elevated temperature, producing a less-deliquescent salt. The conversion proceeds rapidly because of the high concentration of chloride, and because a calcium-hydroxide-chloride precipitate forms, which buffers the $\mathrm{pH}$, keeping $\mathrm{HCl}$ gas pressures high. For degassing of $\mathrm{HCl}$ and $\mathrm{HNO}_{3}$ from brines dominated by monovalent salts (e.g., $\mathrm{NaCl}, \mathrm{NaNO}_{3}, \mathrm{KNO}_{3}$ ), dissolution of $\mathrm{CO}_{2}$ into the brine prolongs the degassing process and increases the conversion to less-deliquescent salts (e.g., $\mathrm{NaHCO}_{3}$ ). The immediate result of degassing is increased $\mathrm{pH}$, and the long-term result is precipitation of the less-deliquescent salts. These salts may subsequently deliquesce at lower temperature and higher $\mathrm{RH}$, producing brines with higher $\mathrm{pH}$ than the original assemblage. Higher-pH brines are more benign with respect to localized corrosion of Alloy 22. Scoping analysis of degassing rates substantiates that sufficient acid-gas species could be removed from the waste package to affect the deliquescent brine chemistry. The "swept-away" boundary condition was represented as a simple replacement process, and the maximum acid-gas removal rate calculated from the equilibrium partial pressure of the vapor. The results show that initial degassing of salt Assemblages $\mathrm{A}$ and $\mathrm{B}$ will result in a loss of $\mathrm{HCl}$ and an increase in $\mathrm{pH}$ to values around 10. However, as the $\mathrm{pH}$ rises, the partial pressures of acid-gas phases decrease, 
resulting in slower removal. Thus, complete depletion of chloride or nitrate, resulting in dryout, is unlikely. The analysis also shows that Assemblage $\mathrm{C}$, which forms a brine concentrated in $\mathrm{Ca}\left(\mathrm{NO}_{3}\right)_{2}$, is even more likely to degas because it deliquesces at high temperature, and because precipitation of calcite buffers the $\mathrm{pH}$ to near-neutral values, maintaining high acid-gas partial pressures. A scoping study shows that reactions with silicate minerals can also result in the precipitation of a less-deliquescent salt assemblage and dryout of high-temperature brines.

Multi-salt brines can persist on the waste package surface but are not stable. Acid degassing will occur rapidly at first, increasing the $\mathrm{pH}$ to near-neutral or alkaline conditions. Further degassing results in dryout, producing an assemblage of less-deliquescent salts that yield a higher $\mathrm{pH}$ solution when they redeliquesce.

\subsubsection{If Brines Persist, Will They Be Corrosive? (Section 6.3)}

Nitrate is a significant moderator of localized corrosion, and the various salt and brine evolution processes investigated in this report cause the nitrate-chloride ratio to increase. Nitrate is a major component of the soluble fraction of tunnel dusts and atmospheric airfall or rainfall analyses. Initial brines formed by deliquescence of multi-salt assemblages will have near-neutral $\mathrm{pH}$, and they will be nitrate-rich and chloride-poor. Experimental corrosion studies, used to develop the localized corrosion model, have verified that localized corrosion will not be initiated by nitrate-rich brines (nitrate-chloride ratio at 0.5 or greater) at temperatures below $120^{\circ} \mathrm{C}$. Based on thermodynamic principles, brines potentially forming at higher temperatures can only be more nitrate-rich than at lower temperatures because the chloride salts are relatively less soluble. New, higher-temperature data indicate that general corrosion mechanisms do not change up to temperatures of $220^{\circ} \mathrm{C}$, suggesting that nitrate inhibition of localized corrosion may continue to be effective at elevated temperatures. Analyses presented in this report show that processes occurring after deliquescence, including acid degassing and reactions with silicate minerals, do not result in brines that are corrosive with respect to localized corrosion. Acid degassing will raise the nitrate-chloride ratio of the remaining solution, and even small degrees of degassing will result in increases in the brine $\mathrm{pH}$, to values ranging from near neutral to alkaline. Brine interactions with silicate minerals may buffer the $\mathrm{pH}$ to near-neutral values, and may lead to dryout and precipitation of a less-deliquescent salt assemblage.

Brines formed by deliquescence of tunnel dusts or atmospheric aerosols are benign, and will remain so as they are modified by processes that occur on the waste package surface.

\subsubsection{If Potentially Corrosive Brines Form, Will They Initiate Localized Corrosion? (Section 6.4)}

The amount of dust that will be deposited on the waste package during ventilation will be small, and brines generated by dust deliquescence will be limited in volume. Conservatively considering the short turnout drift configuration, and assuming that dusts are entirely high-salt atmospheric aerosols, and the ammonium phase lost by thermal decomposition is low-solubility ammonium sulfate, the maximum deliquescence brine volume is estimated to be $1.8 \mu \mathrm{L} / \mathrm{cm}^{2}$ at $120^{\circ} \mathrm{C}$, and about twice this volume at $105^{\circ} \mathrm{C}$. This value also assumes that all salt components in the dust are in contact with each other, so that equilibrium conditions exist. The effects of salt mineral isolation in the dust were evaluated by calculating the probability of 
salt-salt contacts, and indicate lower brine volumes would form if overall salt abundances constitute less than a few percent of the dust. However, salt mineral isolation has no effect at higher salt loadings. Capillary retention of the brine is likely to reduce surface contact or inhibit brine flow into pores or crevices. Results indicate that the capillary response of the dust is characterized by a typical dimension of about one micron. This dimension suggests that brine flow through the dust will be inhibited, and that pores or crevices on the metal surface would have to have similar dimension in order to compete successfully for the brine. The analysis presented here confirms the conclusions drawn by EPRI (2004 [DIRS 172825]), which predicted that deliquescent brine volume, represented as brine film thickness, is too small to support the $\mathrm{O}_{2}$ concentration gradients necessary to develop the separate anodic and cathodic zones required for initiation of localized corrosion on the flat surface. However, this inhibiting action may not be effective in deep crevices, even for unsaturated (non-immersion) conditions, depending on the accessibility of the Alloy 22 surface to air. Importantly, the amount and composition of dust accumulated on waste packages at repository closure is subject to confirmation and control (BSC 2004 [DIRS 172452], Section 3.3.1.10).

Even if potentially corrosive, brines formed by dust deliquescence are of small volume and will be retained by capillary forces in the dust. Brine droplet volumes or layer thicknesses are too small to maintain chemical environments necessary for localized corrosion on the flat surface (e.g., pitting), but this inhibiting process may not apply to crevice corrosion.

\subsubsection{Once Initiated, Will Localized Corrosion Penetrate the Waste Package Outer Barrier? (Section 6.5)}

A chemical description of the crevice corrosion process shows that water is consumed by redox reactions in both the anodic and cathodic regions of the corrosion cell. This water must be replaced by condensation of moisture from the gas phase for corrosion to continue. As corrosion products accumulate in the cell, cathodic limitation will occur as secondary products precipitate and coat the metal surface, limiting brine contact and potentially decreasing availability of oxygen and moisture if transport pathways through the corrosion products are limited.

The power-law description of localized or crevice corrosion propagation is applicable to Alloy 22, as well as to many other materials. Laboratory data clearly show that stifling of crevice corrosion in Alloy 22 occurs with time. Although experimental data for unforced localized corrosion of Alloy 22 are unavailable, stifling represents diffusion control of reaction rate, with limitation from precipitated material and transport losses in the brine film that will occur.

A scoping analysis shows that corrosion products formed by localized or crevice corrosion would have to be nearly nonporous not to volumetrically deplete the aqueous brine phase by physical incorporation. In addition, corrosion products have been identified experimentally that contain brine components $\left(\mathrm{Cl}^{-}\right)$, and thermodynamic analysis indicates that these phases may also form in deliquescent brines. Thus, the small volumes of brine available at elevated temperature (above $120^{\circ} \mathrm{C}$ ) will limit the progress of localized corrosion on the waste package, compared with laboratory experiments performed with far greater brine volumes (e.g., immersion conditions) or forced polarization. 
Importantly, the amount and composition of dust accumulated on waste packages at repository closure is subject to confirmation and control (BSC 2004 [DIRS 172452], Section 3.3.1.10).

Localized or crevice corrosion will not penetrate the 2-cm waste package outer barrier because of corrosion product precipitation in a small liquid volume, brine incorporation in corrosion products, and diffusion-limited power-law behavior substantiated by testing results for Alloy 22 and other materials.

Recommended Screening Decision: The physiochemical characteristics of the brines produced from dust deposited on the Alloy 22 waste package outer barrier will not generate a favorable environment for localized corrosion initiation and growth. If brine exists at elevated temperatures $\left(>120^{\circ} \mathrm{C}\right)$, it will be benign rather than corrosive, so initiation of localized corrosion and subsequent penetration of the waste package outer barrier is not expected. The quantity of brine at elevated temperatures is small, which hinders corrosion initiation and extent. Thus, the overall consequence of dust deliquescence on the localized corrosion of the waste package outer barrier will be insignificant. Therefore, localized corrosion of Alloy 22 due to dust deliquescence is excluded based on low consequence and will not be considered in TSPA-LA.

This recommendation applies to FEP 2.1.09.28.0A (Localized Corrosion on Waste Package Outer Surface due to Deliquescence), which is analyzed in Engineered Barrier System Features, Events, and Processes (BSC 2005 [DIRS 173781], Section 6.2.61) and Screening of Features, Events, and Processes in Drip Shield and Waste Package Degradation (BSC 2005 [DIRS 174995], Section 6.2.18). (Note that the FEP name and description have been slightly modified from that presented in those two documents, as described in Technical Management Review Board (TMRB) Decision Proposal (BSC 2005 [DIRS 174965])).

\subsection{Addressing Acceptance Criteria}

The subcriteria identified in Section 4.2 are addressed by this report, as explained in the following paragraphs.

YMRP Section 2.2.1.2.1.3, Acceptance Criterion 2, Subcriterion 2-The U.S. Department of Energy has provided justification for those features, events, and processes that have been excluded. An acceptable justification for excluding features, events, and processes is that either the feature, event, and process is specifically excluded by regulation; probability of the feature, event, and process (generally an event) falls below the regulatory criterion; or omission of the feature, event, and process does not significantly change the magnitude and time of the resulting radiological exposures to the reasonably maximally exposed individual, or radionuclide releases to the accessible environment.

This report provides justification for exclusion of FEP 2.1.09.28.0A, as summarized in Section 7.1. The screening recommendation is based on a finding that there is no expectation that localized corrosion due to deliquescence of dust on the waste packages will result in penetration of the outer (Alloy 22) barrier. With such low consequence from dust deliquescence, there is no significant change to the magnitude or timing of radionuclide releases from the waste package. 
YMRP Section 2.2.1.2.1.3, Acceptance Criterion 2, Subcriterion 3-The U.S. Department of Energy has provided an adequate technical basis for each feature, event, and process, excluded from the performance assessment, to support the conclusion that either the feature, event, or process is specifically excluded by regulation; the probability of the feature, event, and process falls below the regulatory criterion; or omission of the feature, event, and process does not significantly change the magnitude and time of the resulting radiological exposures to the reasonably maximally exposed individual, or radionuclide releases to the accessible environment.

The technical basis for the screening decision summarized above is developed in this report. The screening arguments consider a range of data on dust composition (Section 6.1), including evaluation of atmospheric dust sources, and ammonium salts not considered in previous analyses. Appropriate basis has been developed for FEP exclusion, using multiple lines of reasoning (particularly Sections 6.3 through 6.5). The analysis has considered the degradation mode with the greatest potential for dose consequence, that is, penetration of the waste package outer barrier. It has addressed existing data and models describing localized corrosion. The analysis has emphasized key differences between the corrosion environment produced from seepage (if the drip shield is disrupted, seepage may lead to outer barrier penetration by localized corrosion) and from dust deliquescence (for which the limited brine composition and volume do not lead to penetration).

YMRP Section 2.2.1.3.3.3, Acceptance Criterion 1, Subcriterion 1-Total system performance assessment adequately incorporates important design features, physical phenomena, and couplings, and uses consistent and appropriate assumptions throughout the quantity and chemistry of water contacting engineered barriers and waste forms abstraction process.

This report provides the technical basis for screening of localized corrosion due to dust deliquescence, summarized in Section 7. Important features of the waste package environment are considered, including contact crevices (Section 6.4), dust accumulation during preclosure ventilation (Sections 6.1 and 6.4), the history of temperature and relative humidity during both preclosure and postclosure periods (Section 6), and the potential for thermal decomposition of salt minerals, degassing, and reaction with non-deliquescent solids (Sections 6.1 through 6.3). The assumptions used in this analysis are consistent with other analyses and models that support TSPA-LA, with exceptions noted and explained (e.g., the range of preclosure temperature and relative humidity, the inventory of soluble salts expected on the waste packages, and use of the stifling alternative conceptual model to support the screening arguments).

YMRP Section 2.2.1.3.3.3, Acceptance Criterion 1, Subcriterion 6-The expected ranges of environmental conditions within the waste package emplacement drifts, inside of breached waste packages, and contacting the waste forms and their evolution with time are identified. These ranges may be developed to include: (i) the effects of the drip shield and backfill on the quantity and chemistry of water (e.g., the potential for condensate formation and dripping from the underside of the shield); (ii) conditions that promote corrosion of engineered barriers and degradation of waste forms; (iii) irregular wet and dry cycles; (iv) gamma-radiolysis; and (v) size and distribution of penetrations of engineered barriers; 
This analysis considers an appropriate range of environmental conditions, at a level of detail sufficient for the screening arguments. The range of preclosure temperature and relative humidity conditions is extended to include seasonal and package-to-package variability (Section 6 and Appendix A). The range of postclosure temperature and humidity conditions is addressed with respect to dryout temperatures for multiple-salt assemblages (Sections 6.1 and 6.2). Repeated cycles of deliquescence and dryout due to acid degassing are considered in Section 6.2. Radiolysis effects are not evaluated in this report. The relative effects from seepage and dust deliquescence (representing the influence of the drip shield) on the corrosion environment are addressed in Section 6.4.1, and bounding relationships that address the size of waste package outer barrier penetrations from localized corrosion due to dust deliquescence are presented in Section 6.5.3.

YMRP Section 2.2.1.3.3.3, Acceptance Criterion 1, Subcriterion 10-Likely modes for container corrosion (Section 2.2.1.3.1 of the Yucca Mountain Review Plan) are identified and considered in determining the quantity and chemistry of water entering the engineered barriers and contacting waste forms. For example, the model abstractions consistently address the role of parameters, such as $\mathrm{pH}$, carbonate concentration, and the effect of corrosion on the quantity and chemistry of water contacting engineered barriers and waste forms.

This analysis addresses localized corrosion as the potential mode of container failure, and considers the key chemical environment parameters that are used in TSPA-LA (BSC 2004 [DIRS 169984], Section 6.4.4) to describe the potential for initiation (i.e., pH, chloride, and nitrate-chloride ratio), as well as those parameters affecting them (e.g., atmospheric $\mathrm{CO}_{2}$ and acid-gas concentrations, and concentrations of carbonate and other aqueous species).

\subsection{Product Output DTNs}

Product output DTNs produced in the preparation of this report are listed in Table 7.3-1.

Table 7.3-1. Product Output DTNs

\begin{tabular}{|l|l|}
\hline \multicolumn{1}{|c|}{ DTN } & \multicolumn{1}{|c|}{ Title } \\
\hline LL050205323121.049 & $\begin{array}{l}\text { Temperature Dependent Pitzer Parameters for Aqueous Ammonium Nitrate } \\
\left(\mathrm{NH}_{4} \mathrm{NO}_{3}\right)\end{array}$ \\
\hline LL050600123121.052 & Kinetic Analysis of $\mathrm{NH}_{4} \mathrm{Cl}$ and $\mathrm{NH}_{4} \mathrm{NO}_{3}$ Thermal Decomposition Rate Data \\
\hline M00506SPAEQ36F.002 & $\begin{array}{l}\text { EQ3/6 Input/Output Files and Summary Spreadsheets Modeling Dust } \\
\text { Deliquescence and Evolution of Brine in Dust }\end{array}$ \\
\hline M00505MWDPRECL.001 & Preclosure Temperature and Relative Humidity Analysis \\
\hline M00508SPAGEOME.003 & Geometrical Analysis of Grain-Grain Contact \\
\hline M00505SPAKINAD.000 & Kinetics of Acid Degassing \\
\hline M00508SPAOXYGE.004 & Oxygen Diffusion as Part of the Localized Corrosion Process \\
\hline M00505SPASTIFL.001 & Stifling of Localized Corrosion \\
\hline SN0504T0502205.008 & Ammonium Pitzer Database Additions (data0.ypf.R2) and Binary File (data1.yp2) \\
\hline SN0504T0502205.009 & Supporting Files for data0.ypf.R2 Pitzer Database \\
\hline SN0508T0502205.016 & Deposition of Atmospheric Dust from Ventilation and Resulting Brine Volume \\
\hline
\end{tabular}


Table 7.3-1. Product Output DTNs (Continued)

\begin{tabular}{|l|l|}
\hline \multicolumn{1}{|c|}{ DTN } & \multicolumn{1}{c|}{ Title } \\
\hline SN0505T0502205.011 & $\begin{array}{l}\text { EQ3/6 Input/Output Files and Summary Spreadsheets Evaluating Layered Double } \\
\text { Hydroxide (LDH) Stability in Dust Brines }\end{array}$ \\
\hline SN0506T0502205.014 & $\begin{array}{l}\text { Data Supporting Analysis of the Effect of Ammonium Mineral Thermal } \\
\text { Decomposition on the Composition of Brines Formed by Dust Deliquescence }\end{array}$ \\
\hline SN0508T0502205.015 & $\begin{array}{l}\text { Graphs and Supporting Data Used in ANL-EBS-MD-000074, REV 01, "Analysis of } \\
\text { Dust Deliquescence for FEPS Screening" }\end{array}$ \\
\hline
\end{tabular}




\section{INPUTS AND REFERENCES}

\subsection{DOCUMENTS CITED}

173678 Anderson, N.; Strader, R.; and Davidson, C. 2003. "Airborne Reduced Nitrogen: Ammonia Emissions from Agriculture and Other Sources." Environmental International, 29, 277-286. New York, New York: Elsevier. TIC: 257288.

173675 Aneja, V.P.; Roelle, P.A.; Murray, G.C.; Southerland, J.; Erisman, J.W.; Fowler, D.; Asman, W.A.H.; and Patni, N. 2001. "Atmospheric Nitrogen Compounds II: Emissions, Transport, Transformation, Deposition and Assessment." Atmospheric Environment, 35, 1903-1911. New York, New York: Elsevier. TIC: 257290.

172858 Apted, M.; King, F.; Langmuir, D.; Arthur, R.; and Kessler, J. 2005. “The Unlikelihood of Localized Corrosion of Nuclear Waste Packages Arising from Deliquescent Brine Formation.” Journal of Metals, 57, (1), 43-48. Warrendale, Pennsylvania: The Minerals, Metals \& Materials Society. TIC: 257253.

111464 Atkins, P.W. 1990. Physical Chemistry. 4th Edition. New York, New York: W.H. Freeman and Company. TIC: 245483.

103753 ASM International. 1987. Corrosion. Volume 13 of Metals Handbook. 9th Edition. Metals Park, Ohio: ASM International. TIC: 209807.

141249 Baker, A.; Genty, D.; Dreybrodt, W.; Barnes, W.L.; Mockler, N.J.; and Grapes, J. 1998. "Testing Theoretically Predicted Stalagmite Growth Rate with Recent Annually Laminated Samples: Implications for Past Stalagmite Deposition." Geochimica et Cosmochimica Acta, 62, (3), 393-404. New York, New York: Pergamon Press. TIC: 247408.

173796 Barthelmy, D. 2004. “Theophrastite Mineral Data.” Spring, Texas: David Barthelmy. Accessed 05/19/2005. URL: http://webmineral.com/data/ Theophrastite.shtml

172817 Battino, R.; Rettich, T.R.; and Tominaga, T. 1983. "The Solubility of Oxygen and Ozone in Liquids." Journal of Physical Chemistry Reference Data, 12, (2), 163-178. Washington, D.C.: American Chemical Society. TIC: 256916.

173269 Biedermann, G. and Chow, J.T. 1966. "Studies on Hydrolysis of Metal Ions. Part 57. The Hydrolysis of Iron (III) Ion and Solubility Product of $\mathrm{Fe}(\mathrm{OH})_{2.70} \mathrm{Cl}_{0.30}$ in $0.5 \mathrm{M}\left(\mathrm{NA}^{+}\right) \mathrm{CL}^{-}$Medium." Acta Chemica Scandinavica, 20, (5), 1376-1388. Copenhagen, Denmark: Munksgaard. TIC: 257128.

172930 Boclair, J.W. and Braterman, P.S. 1999. "Layered Double Stability. 1. Relative Stabilities of Layered Double Hydroxides and Their Simple Counterparts." Chemical Materials, 11, (2), 298-302. Washington, D.C.: American Chemical Society. TIC: 257016. 
172929 Boclair, J.W.; Braterman, P.S.; Jiang, J.; Lou, S.; and Yarberry, F. 1999. "Layered Double Hydroxide Stability. 2. Formation of Cr(III)-Containing Layered Double Hydroxides Directly from Solution.” Chemical Materials, 11, (2), 303-307. Washington, D.C.: American Chemical Society. TIC: 257015.

173966 Brooks, S.D.; DeMott, P.J.; and Kreidenweis, S.M. 2004. "Water Uptake by Particles Containing Humic Materials and Mixtures of Humic Materials with Ammonium Sulfate." Atmospheric Environment, 38, 1859-1868. New York, New York: Elsevier. TIC: 257365.

156276 BSC (Bechtel SAIC Company) 2001. Repository Multiple Waste Package Thermal Calculation. CAL-WIS-TH-000010 REV 00. Las Vegas, Nevada: Bechtel SAIC Company. ACC: MOL.20010814.0330.

165425 BSC 2003. Longevity of Emplacement Drift Ground Support Materials for LA. 800-K0C-TEG0-01200-000-00A. Las Vegas, Nevada: Bechtel SAIC Company. ACC: ENG.20030922.0004.

165572 BSC 2003. Underground Layout Configuration. 800-P0C-MGR0-00100-000-00E. Las Vegas, Nevada: Bechtel SAIC Company. ACC: ENG.20031002.0007.

169131 BSC 2004. Abstraction of Drift Seepage. MDL-NBS-HS-000019 REV 01. Las Vegas, Nevada: Bechtel SAIC Company. ACC: DOC.20041103.0003.

168489 BSC 2004. D\&E / PA/C IED Emplacement Drift Configuration and Environment. 800-IED-MGR0-00201-000-00B. Las Vegas, Nevada: Bechtel SAIC Company. ACC: ENG.20040326.0001.

172801 BSC 2004. D\&E/RIT IED Subsurface Facilities [Sheet 1 of 4]. 800-IED-WIS0-00101-000-00B. Las Vegas, Nevada: Bechtel SAIC Company. ACC: ENG.20041130.0002.

169860 BSC 2004. Engineered Barrier System: Physical and Chemical Environment. ANL-EBS-MD-000033 REV 03. Las Vegas, Nevada: Bechtel SAIC Company. ACC: DOC.20041201.0001; DOC.20050411.0004.

161237 BSC 2004. Environment on the Surfaces of the Drip Shield and Waste Package Outer Barrier. ANL-EBS-MD-000001 REV 01. Las Vegas, Nevada: Bechtel SAIC Company. ACC: DOC.20041116.0005.

169845 BSC 2004. General Corrosion and Localized Corrosion of the Drip Shield. ANL-EBS-MD-000004 REV 02. Las Vegas, Nevada: Bechtel SAIC Company. ACC: DOC.20040921.0002.

169984 BSC 2004. General Corrosion and Localized Corrosion of Waste Package Outer Barrier. ANL-EBS-MD-000003 REV 02. Las Vegas, Nevada: Bechtel SAIC Company. ACC: DOC.20041004.0001. 
170292 BSC 2004. Ground Control for Emplacement Drifts for LA. 800-K0C-SSE0-00100-000-00A. Las Vegas, Nevada: Bechtel SAIC Company. ACC: ENG.20040712.0019.

164327 BSC 2004. In-Drift Natural Convection and Condensation. MDL-EBS-MD-000001 REV 00. Las Vegas, Nevada: Bechtel SAIC Company. ACC: DOC.20041025.0006; DOC.20050330.0001.

169863 BSC 2004. In-Drift Precipitates/Salts Model. ANL-EBS-MD-000045 REV 02. Las Vegas, Nevada: Bechtel SAIC Company. ACC: DOC.20041111.0002.

172452 BSC 2004. Performance Confirmation Plan. TDR-PCS-SE-000001 REV 05. Las Vegas, Nevada: Bechtel SAIC Company. ACC: DOC.20041122.0002.

167736 BSC 2004. Repository Subsurface Turnout Drift 1-8 Interface. 800-KM0-SSD0-00301-000-00A. Las Vegas, Nevada: Bechtel SAIC Company. ACC: ENG.20040220.0009.

172804 BSC 2004. Technical Work Plan for Screening Evaluation for Dust Deliquescence and Localized Corrosion. TWP-MGR-PA-000030 REV 00. Las Vegas, Nevada: Bechtel SAIC Company. ACC: DOC.20041220.0006.

171462 BSC 2004. Total Dust Settling on Naval Long Waste Packages in 100 Years. 800-M0C-VU00-00900-000-00A. Las Vegas, Nevada: Bechtel SAIC Company. ACC: ENG.20040913.0001.

169862 BSC 2004. Ventilation Model and Analysis Report. ANL-EBS-MD-000030 REV 04. Las Vegas, Nevada: Bechtel SAIC Company.

ACC: DOC.20041025.0002.

169062 BSC 2004. Waste Package Envelope Dimensions for Facilities \& Handling. 000-B20-MGR0-00101-000-00A. Las Vegas, Nevada: Bechtel SAIC Company. ACC: ENG.20040423.0004.

172862 BSC 2005. Drift-Scale THC Seepage Model. MDL-NBS-HS-000001 REV 04. Las Vegas, Nevada: Bechtel SAIC Company. ACC: DOC.20050218.0001.

173781 BSC 2005. Engineered Barrier System Features, Events, and Processes. ANL-WIS-PA-000002 REV 04. Las Vegas, Nevada: Bechtel SAIC Company.

173501 BSC 2005. IED Waste Package Configuration [Sheet 1 of 1]. 800-IED-WIS0-00601-000-00A. Las Vegas, Nevada: Bechtel SAIC Company. ACC: ENG.20050406.0005.

173705 BSC 2005. IED Waste Package Decay Heat Generation [Sheet 1 of 1]. 800-IED-WIS0-00701-000-00A. Las Vegas, Nevada: Bechtel SAIC Company. ACC: ENG.20050406.0006. 
173944 BSC 2005. Multiscale Thermohydrologic Model. ANL-EBS-MD-000049 REV 03. Las Vegas, Nevada: Bechtel SAIC Company.

174269 BSC 2005. Q-List. 000-30R-MGR0-00500-000-002. Las Vegas, Nevada: Bechtel SAIC Company. ACC: ENG.20050805.0006.

174995 BSC 2005. Screening of Features, Events, and Processes in Drip Shield and Waste Package Degradation. ANL-EBS-PA-000002 REV 05. Las Vegas, Nevada: Bechtel SAIC Company. ACC: DOC.20050817.0003.

174965 BSC 2005. Technical Management Review Board (TMRB) Decision Proposal. TMRB-2005-047. Las Vegas, Nevada: Bechtel SAIC Company. ACC: MOL.20050809.0101.

173255 Byrne, R.H. and Luo, Y.-R. 2000. "Direct Observations of Nonintegral Hydrous Ferric Oxide Solubility Products: $\mathrm{K}_{\mathrm{S} 0}=\left[\mathrm{Fe}^{3+}\right]\left[\mathrm{H}^{+}\right]^{-2.86}$." Geochimica et Cosmochimica Acta, 64, (11), 1873-1877. New York, New York: Elsevier. TIC: 257121.

168006 Byrne, R.H.; Luo, Y.-R.; and Young, R.W. 2000. "Iron Hydrolysis and Solubility Revisited: Observations and Comments on Iron Hydrolysis Characterizations." Marine Chemistry, 70, (1-3), 23-35. New York, New York: Elsevier. TIC: 255717.

163817 Campbell, A.N. and Smith, N.O. 1951. The Phase Rule and its Applications. $9^{\text {th }}$ Edition. New York, New York: Dover Publications. TIC: 254360.

166275 Canori, G.F. and Leitner, M.M. 2003. Project Requirements Document. TER-MGR-MD-000001 REV 02. Las Vegas, Nevada: Bechtel SAIC Company. ACC: DOC.20031222.0006.

173681 Chaiken, R.F.; Sibbett, D.J.; Sutherland, J.E.; Van De Mark, D.K.; and Wheeler, A. 1962. "Rate of Sublimation of Ammonium Halides." The Journal of Chemical Physics, 37, (10), 2311-2318. College Park, Maryland: American Institute of Physics. ACC: 257269.

173233 Chen, Z. and Sverjensky, D.A. 1991. "Partitioning of F-Cl-OH between Minerals and Hydrothermal Fluids." Geochimica et Cosmochimica Acta, 55, 1837-1848. Elmsford, New York: Pergamon Press. TIC: 257103.

172846 Chow, J.C. 1995. "Measurement Methods to Determine Compliance with Ambient Air Quality Standards for Suspended Particles." Journal of Air \& Waste Management Association, 45, (5), 320-382. Pittsburgh, Pennsylvania: Air and Waste Management Association. TIC: 256900. 
173016 Clause, O.; Gazzano, M.; Trifiró, F.; Vaccari, A.; and Zatorski, L. 1991. "Preparation and Thermal Reactivity of Nickel/Chromium and Nickel/Aluminum Hydrotalcite-Type Precursors." Applied Catalysis, 73, 217-236. Amsterdam, The Netherlands: Elsevier. TIC: 257093.

174184 Clegg, S.L. 2004. "Re: Our Paper and NH4NO3.” E-mail from S.L. Clegg (University of East Anglia) to J.A. Rard, December 28, 2004.

ACC: MOL.20050607.0261.

172803 Clegg, S.L. and Brimblecombe, P. 1989. "Solubility of Ammonia in Pure Aqueous and Multicomponent Solutions." Journal of Physical Chemistry, 93, (20), 7237-7248. Washington, D.C.: American Chemical Society. TIC: 253631.

173820 Clegg, S.L. and Brimblecombe, P. 1995. "Application of a Multicomponent Thermodynamic Model to Activities and Thermal Properties of $0-40 \mathrm{~mol} \mathrm{~kg}^{-1}$ Aqueous Sulfuric Acid from $<200$ to 328 K." Journal of Chemical Engineering Data, 40, (1), 43-64. Washington, D.C.: American Chemical Society.

TIC: 257021.

172806 Clegg, S.L. and Whitfield, M. 1995. "A Chemical Model of Seawater Including Dissolved Ammonia and the Stoichiometric Dissociation Constant of Ammonia in Estuarine Water and Seawater from -2 to $40^{\circ} \mathrm{C}$." Geochimica et Cosmochimica Acta, 59, (12), 2403-2421. New York, New York: Pergamon. TIC: 256913.

172815 Clegg, S.L.; Brimblecombe, P.; and Wexler, A.S. 1998. "A Thermodynamic Model of the System $\mathrm{H}^{+}-\mathrm{NH}_{4}{ }^{+}-\mathrm{SO}_{4}{ }^{2-}-\mathrm{NO}_{3}{ }^{-}-\mathrm{H}_{2} \mathrm{O}$ at Tropospheric Temperatures." Journal of Physical Chemistry A, 102, (12), 2137-2154. Washington, D.C.: American Chemical Society. TIC: 251467.

172807 Clegg, S.L.; Brimblecombe, P.; and Wexler, A.S. 1998. "Thermodynamic Model of the System $\mathrm{H}^{+}-\mathrm{NH}_{4}{ }^{+}-\mathrm{Na}^{+}-\mathrm{SO}_{4}{ }^{2-}-\mathrm{NO}_{3}{ }^{-}-\mathrm{Cl}^{-}-\mathrm{H}_{2} \mathrm{O}$ at $298.15 \mathrm{~K}$." Journal of Physical Chemistry A, 102, (12), 2155-2171. Washington, D.C.: American Chemical Society. TIC: 251468.

172816 Clegg, S.L.; Brimblecombe, P.; Liang, Z.; and Chan, C.K. 1997. "Thermodynamic Properties of Aqueous Aerosols to High Supersaturation: II-A Model of the System $\mathrm{Na}^{+}-\mathrm{Cl}^{-}-\mathrm{NO}_{3}{ }^{-} \mathrm{SO}_{4}^{2-}-\mathrm{H}_{2} \mathrm{O}$ at $298.15 \mathrm{~K}$." Aerosol Science and Technology, 27, (3), 345-366. New York, New York: Elsevier. TIC: 256876.

173037 Cornell, R.M. and Schwertmann, U. 2003. The Iron Oxides, Structure, Properties, Reactions, Occurrences and Uses. 2nd Edition. Weinheim, Germany: Wiley-VCH Verlagsgesellschaft. TIC: 257034. 
173552 Cragnolino, G.A.; Dunn, D.S.; and Pan, Y.-M. 2002. "Localized Corrosion Susceptibility of Alloy 22 as a Waste Package Container Material." Scientific Basis for Nuclear Waste Management XXV, Symposium held November 26-29, 2001, Boston, Massachusetts. McGrail, B.P. and Cragnolino, G.A., eds. 713, 53-60. Warrendale, Pennsylvania: Materials Research Society. TIC: 248663.

173968 Cruz, C.N. and Pandis, S.N. 2000. "Deliquescence and Hygroscopic Growth of Mixed Inorganic-Organic Atmospheric Aerosol.” Environmental Science Technology, 34, (20), 4313-4319. Washington, D.C.: American Chemical Society. TIC: 257383.

100349 CRWMS (Civilian Radioactive Waste Management System) M\&O (Management and Operating Contractor) 1998. Waste Package Degradation Expert Elicitation Project. Rev. 1. Las Vegas, Nevada: CRWMS M\&O.

ACC: MOL.19980727.0002.

160626 CRWMS M\&O 2000. Data Qualification Report, Air Particulate Matter Data 1989-1997. Las Vegas, Nevada: CRWMS M\&O. ACC: MOL.20000307.0805.

100722 Dean, J.A. 1992. Lange's Handbook of Chemistry. 14th Edition. New York, New York: McGraw-Hill. TIC: 240690.

158805 Dennis, R., ed. 1976. Handbook on Aerosols. TID-26608. Oak Ridge, Tennessee: Energy Research and Development Administration, Technical Information Center. TIC: 242478.

171480 Dillmann, Ph.; Mazaudier, F.; and Hœrlé, S. 2004. “Advances in Understanding Atmospheric Corrosion of Iron. I. Rust Characterisation of Ancient Ferrous Artefacts Exposed to Indoor Atmospheric Corrosion." Corrosion Science, 46, 1401 - 1429. New York, New York: Elsevier. TIC: 256483.

168842 DOE (U.S. Department of Energy) 2003. Site Environmental Report for the Yucca Mountain Project Calendar Year 2002. PGM-MGR-EC-000004 REV 00. Las Vegas, Nevada: U.S. Department of Energy, Office of Repository Development. ACC: MOL.20040413.0145.

171539 DOE 2004. Quality Assurance Requirements and Description. DOE/RW-0333P, Rev. 16. Washington, D.C.: U.S. Department of Energy, Office of Civilian Radioactive Waste Management. ACC: DOC.20040907.0002.

147480 Drever, J.I. 1997. "Evaporation and Saline Waters.” Chapter 15 of The Geochemistry of Natural Waters: Surface and Groundwater Environments. 3rd Edition. Upper Saddle River, New Jersey: Prentice Hall. TIC: 246732. 
173813 Dunn, D.S.; Yang, L.; Wu, C.; and Cragnolino, G.A. 2004. "Effect of Inhibiting Oxyanions on the Localized Corrosion Susceptibility of Waste Package Container Materials." Scientific Basis for Nuclear Waste Management XXVIII, Symposium held April 13-16, 2004, San Francisco, California, U.S.A. Hanchar, J.M.; Stroes-Gascoyne, S.; and Browning, L.; eds. 824, 33-38. Warrendale, Pennsylvania: Materials Research Society. TIC: 256855.

158069 EPRI (Electric Power Research Institute) 2002. Evaluation of the Proposed High-Level Radioactive Waste Repository at Yucca Mountain Using Total System Performance Assessment, Phase 6. EPRI TR-1003031. Palo Alto, California: Electric Power Research Institute. TIC: 252239.

172825 EPRI 2004. Comments regarding in-drift chemistry related to corrosion of containment barriers. 1010941. Palo Alto, California: EPRI. On Order.

173253 Flynn, C.M., Jr. 1984. "Hydrolysis of Inorganic Iron(III) Salts.” Chemical Reviews, 84, (1), 31-41. Washington, D.C.: American Chemical Society. TIC: 257116.

100890 Fontana, M.G. 1986. Corrosion Engineering. 3rd Edition. New York, New York: McGraw-Hill. TIC: 240700.

162216 Frankel, G.S. 1998. "Pitting Corrosion of Metals, A Review of the Critical Factors." Journal of the Electrochemical Society, 145, (6), 2186-2198. Pennington, New Jersey: Electrochemical Society. TIC: 254587.

173852 Fuchs, N.A. 1964. The Mechanics of Aerosols. New York, New York: Peragmon Press. TIC: 241094.

173894 Gardner M. 1995. New Mathematical Diversions. Washington, D.C.: Mathematical Association of America. TIC: 257370.

100814 Harrar, J.E.; Carley, J.F.; Isherwood, W.F.; and Raber, E. 1990. Report of the Committee to Review the Use of J-13 Well Water in Nevada Nuclear Waste Storage Investigations. UCID-21867. Livermore, California: Lawrence Livermore National Laboratory. ACC: NNA.19910131.0274.

101970 Hartman, H.L., ed. 1992. SME Mining Engineering Handbook. 2nd Edition. Volume 2. Littleton, Colorado: Society for Mining, Metallurgy and Exploration. TIC: 206894.

118163 Harvie, C.E.; Moller, N.; and Weare, J.H. 1984. “The Prediction of Mineral Solubilities in Natural Waters: The Na-K-Mg-Ca-H-Cl-SO ${ }_{4}-\mathrm{OH}-\mathrm{HCO}_{3}-\mathrm{CO}_{3}-\mathrm{CO}_{2}-$ $\mathrm{H}_{2} \mathrm{O}$ System to High Ionic Strengths at $25^{\circ} \mathrm{C}$." Geochimica et Cosmochimica Acta, 48, (4), 723-751. New York, New York: Pergamon Press. TIC: 239849. 
100896 Haynes International. 1997. Hastelloy C-22 Alloy. Kokomo, Indiana: Haynes International. TIC: 238121.

165404 Hillel, D. 1998. Environmental Soil Physics. San Diego, California: Academic Press. TIC: 254422.

172824 Hitchcock, D.R.; Spiller, L.L.; and Wilson, W.E. 1980. "Sulfuric Acid Aerosols and $\mathrm{HCl}$ Release in Coastal Atmospheres: Evidence of Rapid Formation of Sulfuric Acid Particulates." Atmospheric Environment, 14, 165-182. New York, New York: Pergamon. TIC: 256889.

162221 Hunkeler, F. and Boehni, H. 1983. "Pit Growth Measurements on Stainless Steels." Passivity of Metals and Semiconductors, Proceedings of the Fifth International Symposium on Passivity, Bombannes, France, May 30-June 3, 1983. Froment, M., ed. Pages 655-660. New York, New York: Elsevier. TIC: 236283.

108184 Incropera, F.P. and DeWitt, D.P. 1996. Fundamentals of Heat and Mass Transfer. 4th Edition. New York, New York: John Wiley \& Sons. TIC: 243950.

163337 Incropera, F.P. and DeWitt, D.P. 2002. Fundamentals of Heat and Mass Transfer. 5th Edition. New York, New York: John Wiley \& Sons. TIC: 254280.

162222 Ishikawa, H.; Honda, A.; and Sasaki, N. 1994. "Long Life Prediction of Carbon Steel Overpacks for Geological Isolation of High-Level Radioactive Waste.” Life Prediction of Corrodible Structures. Parkins, R.N., ed. Volume 1. Pages 454-483. Houston, Texas: NACE International. TIC: 254834.

169567 Jarek, R.L. 2002. GetEQData Version 1.0.1, Software Management Report. Software Document Number: 10809-SMR-1.0.1-00. Albuquerque, New Mexico: Sandia National Laboratories. ACC: MOL.20030127.0064.

102010 Jury, W.A.; Gardner, W.R.; and Gardner, W.H. 1991. Soil Physics. 5th Edition. New York, New York: John Wiley \& Sons. TIC: 241000.

173969 Kanakidou, M.; Seinfeld, J.H.; Pandis, S.N.; Barnes, I.; Dentener, F.J.; Facchini, M.C.; Van Dingenen, R.; Ervens, B.; Nenes, A.; Nielsen, C.J.; Swietlicki, E.; Putaud, J.P.; Balkanski, Y.; Fuzzi, S.; Horth, J.; Moortgat, G.K.; Winterhalter, R.; Myhre, C.E.L.; Tsigaridis, K.; Vignati, E.; Stephanou, E.G.; and Wilson, J. 2005. "Organic aerosol and global climate modelling: a review." Atmospheric Chemistry and Physics, 5, 1053-1123. European Geosciences Union.

160782 Kays, W.M. and Perkins, H.C. 1973. "Forced Convection, Internal Flow in Ducts." Section 7 of Handbook of Heat Transfer. Rohsenow, W.M. and Hartnett, J.P., eds. New York, New York: McGraw-Hill. TIC: 253611. 
172833 Kear, G.; Barker, B.D.; and Walsh, F.C. 2004. "Electrochemical Corrosion of Unalloyed Copper in Chloride Media - A Critical Review." Corrosion Science, 46, 109-135. New York, New York: Elsevier. TIC: 256911.

162231 Kehler, B.A.; Ilevbare, G.O.; and Scully, J.R. 2001. "Crevice Corrosion Stabilization and Repassivation Behavior of Alloy 625 and Alloy 22." Corrosion, 57, (12), 1042-1065. Houston, Texas: NACE International. TIC: 254305.

173256 Khoe, G.H. and Robins, R.G. 1989. "Polymerization Reactions in Hydrolyzed Iron(III) Solutions." Journal of Colloid and Interface Science, 133, (1), 244-252. New York, New York: Academic Press. TIC: 257118.

172836 King, F.; Quinn, M.J.; and Litke, C.D. 1995. "Oxygen Reduction on Copper in Neutral NaCl Solution.” Journal of Electroanalytical Chemistry, 385, 45-55. New York, New York: Elsevier. TIC: 256912.

$153700 \quad$ Klein, C. and Hurlbut, C.S., Jr. 1993. Manual of Mineralogy. 21st Edition. New York, New York: John Wiley \& Sons. TIC: 249368.

173242 Koch, C.B. and Buchwald, V.F. 1994. "Weathering of Iron Meteorites from Monturaqui, Chile." Meteoritics, 29, (4), 443. Albuquerque, New Mexico: Meteoritical Society. TIC: 257101.

$122125 \quad$ Kracek, F.C. 1928. "P-T-X Relations for Systems of Two or More Components and Containing Two or More Phases (L-V, $\mathrm{L}_{\mathrm{I}}-\mathrm{L}_{\mathrm{II}^{-}}-\mathrm{V}$ and S-L-V Systems)." International Critical Tables of Numerical Data, Physics, Chemistry and Technology. Washburn, E.W., ed. Volume III. 1st Edition. New York, New York: McGraw-Hill. TIC: 243268.

173254 Laberty C. and Navrotsky, A. 1998. "Energetics of Stable and Metastable Low-Temperature Iron Oxides and Oxyhydroxides." Geochimica et Cosmochimica Acta, 62, (17), 2905-2913. New York, New York: Elsevier. TIC: 257120.

173067 Lamb, D. and Bowersox V. 2000. "The National Atmospheric Deposition Program: An Overview." Atmospheric Environment, 34, 1661-1663. New York, New York: Pergamon. TIC: 257050.

100051 Langmuir, D. 1997. Aqueous Environmental Geochemistry. Upper Saddle River, New Jersey: Prentice Hall. TIC: 237107.

173241 Lee, M.R. and Bland, P.A. 2003. "Mechanisms of Weathering of Meteorites Recovered from Hot and Cold Deserts and the Formation of Phyllosilicates." Geochemica et Cosmochimica Acta, 68, (4), 893-916. New York, New York: Pergamon. TIC: 257084.

162229 Lide, D.R., ed. 2000. CRC Handbook of Chemistry and Physics. 81st Edition. Boca Raton, Florida: CRC Press. TIC: 253056. 
173970 Lightstone, J.M.; Onasch, T.B.; Imre, D.; and Oatis, S. 2000. "Deliquescence, Efflorescence, and Water Activity in Ammonium Nitrate and Mixed Ammonium Nitrate/Succinic Acid Microparticles." Journal of Physical Chemistry, 104, (41), 9337-9346. Washington, D.C.: American Chemical Society. TIC: 257382.

166191 Linke, W.F. 1965. Solubilities, Inorganic and Metal-Organic Compounds. 4th Edition. Volume II, K-Z. Washington, D.C.: American Chemical Society. TIC: 222176.

168023 Liu, X. and Millero, F.J. 1999. "The Solubility of Iron Hydroxide in Sodium Chloride Solutions." Geochimica et Cosmochimica Acta, 63, (19/20), 3487-3497. New York, New York: Pergamon. TIC: 255724.

173257 Liu, X. and Millero, F.J. 2002. “The Solubility of Iron in Seawater." Marine Chemistry, 77, 43-54. New York, New York: Elsevier. TIC: 257117.

173674 Malm, W.C.; Day, D.E.; Kreidenweis, S.M.; Collett, J.L.; and Lee, T. 2003. "Humidity-Dependent Optical Properties of Fine Particles during the Big Bend Regional Aerosol and Visibility Observational Study." Journal of Geophysical Research, 108, (D9), 13-1 - 13-16. Washington, D.C.: American Geophysical Union. TIC: 257270.

173673 Malm, W.C.; Schichtel, B.A.; Pitchford, M.L.; Ashbaugh, L.L.; and Eldred, R.A. 2004. "Spatial and Month Trends in Speciated Fine Particle Concentration in the United States." Journal of Geophysical Research, 109, 1-22. Washington, D.C.: American Geophysical Union. TIC: 257291.

173971 Marcolli, C.; Luo, B.; and Peter, T. 2004. "Mixing of the Organic Aerosol Fractions: Liquids as the Thermodynamically Stable Phases." Journal of Physical Chemistry, 108, (12), 2216-2224. Washington, D.C.: American Chemical Society. TIC: 257381.

173972 Marcolli, C.; Luo, B.P.; Peter, T.; and Wienhold, F.G. 2004. "Internal Mixing of the Organic Aerosol by Gas Phase Diffusion of Semivolatile Organic Compounds." Atmospheric Chemistry and Physics, 4, 2593-2599. European Geosciences Union.

162234 Marsh, G.P.; Taylor, K.J.; and Harker, A.H. 1991. The Kinetics of Pitting Corrosion of Carbon Steel Applied to Evaluating Containers for Nuclear Waste Disposal. SKB TR-91-62. Stockholm, Sweden: Svensk Kärnbränsleförsörjning AB. TIC: 206582.

161435 McAdams, W.H. 1954. Heat Transmission. 3rd Edition. New York, New York: McGraw-Hill. TIC: 242359. 
152193 McGuire, R.; Vlasity, J.; Kessler, J.; Long, A.; Childs, S.; Ross, B.; Schwartz, F.; Shoesmith, D.; Kolar, M.; Apted, M.; Zhou, W.; Sudicky, E.; Smith, G.; Kozak, M.; Salter, P.; Klos, R.; Venter, A.; Stenhouse, M.; Watkins, B.; and Little, R. 1998. Alternative Approaches to Assessing the Performance and Suitability of Yucca Mountain for Spent Fuel Disposal. EPRI TR-108732. Palo Alto, California: Electric Power Research Institute. TIC: 248813.

172818 McMurry, P.H. 2000. "A Review of Atmospheric Aerosol Measurements." Atmospheric Environment, 34, 1959-1999. New York, New York: Pergamon. TIC: 256891.

172808 Meng, Z.; Seinfeld, J.H.; Saxena, P.; and Kim, Y.P. 1995. “Atmospheric Gas-Aerosol Equilibrium: IV. Thermodynamics of Carbonates." Aerosol Science and Technology, 23, 131-154. New York, New York: Elsevier. TIC: 256915.

163054 Michel, H. 1999. "Bernold Sheets.” Letter from H. Michel (Bernold AG) to M. Grigore (MK), July 2, 1999, with enclosures. ACC: MOL.20030506.0321.

173974 Ming, Y. and Russell, L.M. 2002. "Thermodynamic Equilibrium of Organic-Electrolyte Mixtures in Aerosol Particles.” AIChE Journal, 48, (6), 1331-1348. New York, New York: American Institute of Chemical Engineers. TIC: 257360. Copyright Requested

162235 Mughabghab, S.F. and Sullivan, T.M. 1989. "Evaluation of the Pitting Corrosion of Carbon Steels and Other Ferrous Metals in Soil Systems." Waste Management, 9, (4), 239-251. Elmsford, New York: Pergamon Press. TIC: 254591.

173260 Murray, J.W. 1979. "Iron Oxides." In Marine Minerals, Volume 6, Chapter 2 of Reviews in Mineralogy. Chelsea, Michigan: Mineralogical Society of America. TIC: 257035.

173628 NADP (National Atmospheric Deposition Program) 2002. Quality Assurance Plan. NADP CAL QA Plan 2002-01. Champaign, Illinois: National Atmospheric Deposition Program, Illinois State Water Survey. TIC: 257264.

173625 NADP 2005. "Quality Assurance Support for the NADP.” Champaign, Illinois: National Atmospheric Deposition Program, Illinois State Water Survey. Accessed May 6, 2005. TIC: 257265. URL: http://nadp.sws.uiuc.edu/QA/

172977 NADP/NTN (National Atmospheric Deposition Program/National Trends Network) 2000. 2000 Annual \& Seasonal Data Summary for Site NV00. Champaign, Illinois: National Atmospheric Deposition Program Office, Illinois State Water Survey. TIC: 256983.

172976 NADP/NTN 2001. 2001 Annual \& Seasonal Data Summary for Site NV00. Champaign, Illinois: National Atmospheric Deposition Program Office, Illinois State Water Survey. TIC: 256984. 
173141 NADP/NTN 2003. 2002 Annual \& Seasonal Data Summary for Site NV00. Champaign, Illinois: National Atmospheric Deposition Program Office, Illinois State Water Survey. TIC: 256214.

162251 Newman, R.C. 1985. "The Dissolution and Passivation Kinetics of Stainless Alloys Containing Molybdenum-I. Coulometric Studies of $\mathrm{Fe}-\mathrm{Cr}$ and $\mathrm{Fe}-\mathrm{Cr}-\mathrm{Mo}$ Alloys.” Corrosion Science, 25, (5), 331-339. New York, New York: Elsevier. TIC: 254590.

162250 Newman, R.C. and Franz, E.M. 1984. "Growth and Repassivation of Single Corrosion Pits in Stainless Steel." Corrosion, 40, (7), 325-330. Houston, Texas: National Association of Corrosion Engineers. TIC: 254580.

163274 NRC (U.S. Nuclear Regulatory Commission) 2003. Yucca Mountain Review Plan, Final Report. NUREG-1804, Rev. 2. Washington, D.C.: U.S. Nuclear Regulatory Commission, Office of Nuclear Material Safety and Safeguards. TIC: 254568.

173975 Parsons, M.T.; Knopf, D.A.; and Bertram, A.K. 2004. "Deliquescence and Crystallization of Ammonium Sulfate Particles Internally Mixed with Water-Soluble Organic Compounds." Journal of Physical Chemistry, 108, (52), 11600-11608. Washington, D.C.: American Chemical Society. TIC: 257380.

173672 Payer, J.H. 2004. Corrosion Resistance of Alloy 22. Presented to: Nuclear Waste Technical Review Board, May 18-19, 2004. Washington, D.C.: U.S. Department of Energy, Office of Civilian Radioactive Waste Management. ACC: MOL.20040629.0421.

125806 Perry, R.H.; Green, D.W.; and Maloney, J.O., eds. 1984. Perry's Chemical Engineers' Handbook. 6th Edition. New York, New York: McGraw-Hill. TIC: 246473.

174140 Peterman, Z. 2005. Intended Use for Scoping Analyses for Water-Soluble ions in ESF, ECRB, and Surface Dust Samples Memorandum date 05/06/2005 ACC: MOL.20050517.0362.

162819 Peterman, Z.E.; Paces, J.B.; Neymark, L.A.; and Hudson, D. 2003. "Geochemistry of Dust in the Exploratory Studies Facility, Yucca Mountain, Nevada." Proceedings of the 10th International High-Level Radioactive Waste Management Conference (IHLRWM), March 30-April 2, 2003, Las Vegas, Nevada. Pages 637-645. La Grange Park, Illinois: American Nuclear Society. TIC: 254559.

169631 Pulvirenti, A.L.; Needham, K.M.; Adel-Hadadi, M.A.; Barkatt, A.; Marks, C.R.; and Gorman, J.A. 2004. "Multi-Phase Corrosion of Engineered Barrier Materials." Corrosion/2004, 59th Annual Conference \& Exposition, March 28-April 1, 2004, New Orleans. Paper No. 04694. Houston, Texas: NACE International. TIC: 255943. 
155798 Pye, J.H. 2000. "Planning Guidance for Underground Dust Sampling." Interoffice correspondence from J.H. Pye (CRWMS M\&O) to Distribution, December 13, 2000, LV.SSPTS.JHP.12/00.019, with attachment. ACC: MOL.20010228.0517.

173007 Quinn, P.K.; Coffman, D.J.; Bates, T.S.; Miller, T.L.; Johnson, J.E.; Voss, K.; Welton, E.J.; and Neusüss, C. 2001. "Dominant Aerosol Chemical Components and Their Contribution to Extinction During the Aerosols99 Cruise Across the Atlantic." Journal of Geophysical Research, 106, (D18), 20,783-20,809. Washington, D.C.: American Geophysical Union. TIC: 257023.

162105 Rard, J.A.; Clegg, S.L.; and Palmer, D.A. 2000. "Isopiestic Determination of the Osmotic Coefficients of $\mathrm{Na}_{2} \mathrm{SO}_{4}(\mathrm{aq})$ at 25 and $50^{\circ} \mathrm{C}$, and Representation with Ion-Interaction (Pitzer) and Mole Fraction Thermodynamic Models." Journal of Solution Chemistry, 29, (1), 1-49. New York, New York: Plenum. TIC: 253942.

173816 Rard, J.A.; Wijesinghe, A.M.; and Wolery, T.J. 2004. "Review of the Thermodynamic Properties of $\mathrm{Mg}\left(\mathrm{NO}_{3}\right)_{2}(\mathrm{aq})$ and Their Representation with the Standard and Extended Ion-Interaction (Pitzer) Models at 298.15 K." Journal of Chemical Engineering Data, 49, (5), 1127-1140. Washington, D.C.: American Chemical Society. TIC: 257020.

174186 Rebak, R.B. 2005. "Factors Affecting the Crevice Corrosion Susceptibility of Alloy 22." Corrosion/2005, 60th Annual Conference \& Exposition, 1945-2005, April 3-7, 2005, George R. Brown Convention Center, Houston, Texas. Paper No. 05610. Houston, TX: NACE International. TIC: 257165.

173015 Refait, Ph.; Abdelmoula, M.; and Génin, J.-M.R. 1998. "Mechanisms of Formation and Structure of Green Rust One in Aqueous Corrosion of Iron in the Presence of Chloride Ions." Corrosion Science, 40, (9), 1547-1560. New York, New York: Pergamon. TIC: 257092.

173014 Refait, Ph.; Drissi, S.H.; Pytkiewicz, J.; and Génin, J.-M.R 1997. “The Anionic Species Competition in Iron Aqueous Corrosion: Role of Various Green Rust Compounds." Corrosion Science, 39, (9), 1699-1710. New York, New York: Pergamon. TIC: 257091.

106653 Reheis, M.C. and Kihl, R. 1995. "Dust Deposition in Southern Nevada and California, 1984-1989: Relations to Climate, Source Area, and Source Lithology." Journal of Geophysical Research, 100, (D5), 8893-8918. Washington, D.C.: American Geophysical Union. TIC: 234886.

107105 Roberts, W.L.; Campbell, T.J.; and Rapp, G.R., Jr. 1990. Encyclopedia of Minerals. 2nd Edition. New York, New York: Van Nostrand Reinhold. TIC: 242976.

169241 Rohsenow, W.M.; Hartnett, J.P.; and Cho, Y.I. 1998. Handbook of Heat Transfer. 3rd Edition. New York, New York: McGraw-Hill. TIC: 253612. 
154862 Rosenberg, N.D.; Gdowski, G.E.; and Knauss, K.G. 2001. "Evaporative Chemical Evolution of Natural Waters at Yucca Mountain, Nevada." Applied Geochemistry, 16, (9-10), 1231-1240. New York, New York: Pergamon. TIC: 249879.

172822 Rossi, M.J. 2003. "Heterogeneous Reactions on Salts." Chemistry Reviews, 103, (12), 4823-4882. Washington, D.C.: American Chemical Society. TIC: 256893.

174143 Safley, G. 2005. Memo to File from G. Safley, Re: Memo of Documentation for Qualification of Water Soluble Ion Concentrations- ANL-EBS-MD-000074 REV 00 Memorandum dated 06/15/2005. ACC: MOL.20050622.0144.

173976 Saxena, P.; Hildemann, L.M.; McMurry, P.H.; and Seinfeld, J.H. 1995. “Organics Alter Hygroscopic Behavior of Atmospheric Particles." Journal of Geophysical Research, 100, (D9), 18,755-18,770. Washington, D.C.: American Geophysical Union. TIC: 257361. Copyright Requested

173682 Schultz, R.D. and Dekker, A.O. 1956. "The Effect of Physical Adsorption on the Absolute Decomposition Rates of Crystalline Ammonium Chloride and Cupric Sulfate Trihydrate." Linear Decomposition Rates of Ammonium Chloride, 60, 1095-1100. Washington, D.C.: American Chemical Society.

172607 Sehmel, G. 1980. "Particle and Gas Dry Deposition: A Review." Atmospheric Environment, 14, 983-1011. New York, New York: Pergamon Press.

TIC: 256898.

102180 Seinfeld, J.H. 1986. Atmospheric Chemistry and Physics of Air Pollution. New York, New York: John Wiley \& Sons. TIC: 243754.

162238 Sharland, S.M.; Naish, C.C.; Taylor, K.J.; and Marsh, G.P. 1994. “An Experimental and Modelling Study of the Localized Corrosion of Carbon Steel Overpacks for the Geological Disposal of Radioactive Waste." Life Prediction of Corrodible Structures. Parkins, R.N., ed. Volume 1. Pages 402-418. Houston, Texas: NACE International. TIC: 254835.

172823 Sipin, M.F.; Guazzotti, S.A.; and Prather, K.A. 2003. "Recent Advances and Some Remaining Challenges in Analytical Chemistry of the Atmosphere." Analytical Chemistry, 75, (12), 2929-2940. Washington, D.C.: American Chemical Society. TIC: 256888.

118845 Sonnenthal, E.; Spycher, N.; Apps, J.; and Simmons, A. 1998. Thermo-HydroChemical Predictive Analysis for the Drift-Scale Heater Test. Milestone SPY289M4. Version 1.0. Berkeley, California: Lawrence Berkeley National Laboratory. ACC: MOL.19980812.0268. 
173671 Steefel, C.I. 2004. The In-Drift Chemical Environment During the Above-Ground Boiling Period. Presented to: Nuclear Waste Technical Review Board, May 19, 2004. Washington, D.C.: U.S. Department of Energy, Office of Civilian Radioactive Waste Management. ACC: MOL.20040629.0419.

173232 Vassilev, S.V.; Eskenazy, G.M.; and Vassileva, C.G. 2000. "Contents, Modes of Occurrence and Origin of Chlorine and Bromine in Coal." Fuel, 79, 903-921. New York, New York: Elsevier. TIC: 257102.

162245 Vetter, K.J. and Strehblow, H.H. 1974. "Pitting Corrosion in an Early Stage and its Theoretical Implications." Localized Corrosion, U.R. Evans Conference on Localized Corrosion, December 6-10, 1971, Williamsburg, Virginia. International Corrosion Conference Series, NACE-3. Pages 240-251. Houston, Texas: National Association of Corrosion Engineers. TIC: 254803.

172842 Vyazovkin, S.; Clawson, J.S.; and Wight, C.A. 2001. "Thermal Dissociation Kinetics of Solid and Liquid Ammonium Nitrate." Chemistry of Materials, 13, (3), 960-966. Washington, D.C.: American Chemical Society. TIC: 256892.

173676 Wall, S.M.; John, W.; and Ondo, J.L. 1988. "Measurement of Aerosol Size Distributions for Nitrate and Major Ionic Species." Atmospheric Environment, 22, (8), 1649-1656. New York, New York: Pergamon. TIC: 257292.

100833 Weast, R.C. and Astle, M.J., eds. 1981. CRC Handbook of Chemistry and Physics. 62nd Edition. Boca Raton, Florida: CRC Press. TIC: 240722.

172826 Wexler, A.S. and Clegg, S.L. 2002. "Atmospheric Aerosol Models for Systems Including the Ions $\mathrm{H}^{+}, \mathrm{NH}^{+}, \mathrm{Na}^{+}, \mathrm{SO}^{2-}{ }_{4}, \mathrm{NO}^{-}{ }_{3}, \mathrm{Cl}^{-}, \mathrm{Br}^{-}$, and $\mathrm{H}_{2} \mathrm{O}$." Journal of Geophysical Research-Atmosphere, 107, (D14), ACH-14-1-ACH-14-14. Washington, D.C.: American Geophysical Union. TIC: 251464.

172821 Zhang, X. and McMurry, P.H. 1992. "Evaporative Losses of Fine Particulate Nitrates during Sampling." Atmospheric Environment, 26A, (18), 3305-3312. New York, New York: Pergamon. TIC: 256890.

\subsection{CODES, STANDARDS, REGULATIONS, AND PROCEDURES}

173273 10 CFR 63. 2005 Energy: Disposal of High-Level Radioactive Wastes in a Geologic Repository at Yucca Mountain, Nevada. ACC: MOL.20050405.0118.

15182840 CFR 50. 1999 Protection of Environment: National Primary and Secondary Ambient Air Quality Standards. ACC: MOL.20050518.0088.

AP-2.22Q, Rev. 1, ICN 1. Classification Analyses and Maintenance of the Q-List. Washington, D.C.: U.S. Department of Energy, Office of Civilian Radioactive Waste Management. ACC: DOC.20040714.0002. 
AP-SIII.3Q, Rev. 2, ICN 1. Submittal and Incorporation of Data to the Technical Data Management System. Washington, D.C.: U.S. Department of Energy, Office of Civilian Radioactive Waste Management. ACC: DOC.20040226.0001.

147465 ASTM B 575-99a. 1999. Standard Specification for Low-Carbon NickelMolybdenum-Chromium, Low-Carbon Nickel-Chromium-Molybdenum, LowCarbon Nickel-Chromium-Molybdenum-Copper, Low-Carbon Nickel-ChromiumMolybdenum-Tantalum, and Low-Carbon Nickel-Chromium-Molybdenum-Tungsten Alloy Plate, Sheet, and Strip. West Conshohocken, Pennsylvania: American Society for Testing and Materials. TIC: 247534.

163908 ASTM G 102-89 (Reapproved 1999). 1989. Standard Practice for Calculation of Corrosion Rates and Related Information from Electrochemical Measurements. West Conshohocken, Pennsylvania: American Society for Testing and Materials. TIC: 249897.

138917 ASTM G 48-99a. 1999. Standard Test Methods for Pitting and Crevice Corrosion Resistance of Stainless Steels and Related Alloys by Use of Ferric Chloride Solution. West Conshohocken, Pennsylvania: American Society for Testing and Materials. TIC: 247546.

117479 ASTM G 5-94. 1994. Standard Reference Test Method for Making Potentiostatic and Potentiodynamic Anodic Polarization Measurements. Philadelphia, Pennsylvania: American Society for Testing and Materials. TIC: 231902.

LP-2.14Q, Rev. 0, ICN 1. Document Review. Washington, D.C.: U.S. Department of Energy, Office of Civilian Radioactive Waste Management.

ACC: DOC.20050727.0005.

LP-3.15Q-BSC, Rev. 0, ICN 2. Managing Technical Product Inputs. Washington, D.C.: U.S. Department of Energy, Office of Civilian Radioactive Waste Management. ACC: DOC.20050801.0010.

LP-SI.11Q-BSC, Rev. 0, ICN 1. Software Management. Washington, D.C.: U.S. Department of Energy, Office of Civilian Radioactive Waste Management. ACC: DOC.20041005.0008.

LP-SII.3Q-BSC, Rev. 0 ICN 0. Collection, Submission, Return, and Documentation of Non-Core and Non-Cuttings Samples/Specimens to the Sample Management Facility. Washington, D.C.: U.S. Department of Energy, Office of Civilian Radioactive Waste Management. ACC: DOC.20040610.0002.

LP-SIII.2Q-BSC, Rev. 0 ICN 0. Qualification of Unqualified Data. Washington, D.C.: U.S. Department of Energy, Office of Civilian Radioactive Waste Management. ACC: DOC.20050119.0002. 
LP-SIII.9Q-BSC, Rev. 0 ICN 1. Scientific Analyses. Washington, D.C.:

U.S. Department of Energy, Office of Civilian Radioactive Waste Management.

ACC: DOC.20050622.0004.

NMW-USGS-GP-22 Rev 01. Dust Trap Sampling. Denver, CO: U.S. Geological Survey. ACC: NNA.19880217.0042.

NNWSI-USGS-GP-22 Rev 00. Dust Trap Sampling and Analysis. Denver, CO: U.S. Geological Survey. ACC: NNA.19870924.0068.

NWM-USGS-GCP-02 R2. Labeling, Identification, and Control of Samples for Geochemistry and Isotope Geology. Denver, CO.: U.S. Geological Survey.

ACC: NNA.19901206.0069.

NWM-USGS-GP-27 R2. Trench Wall and Natural Outcrop Sampling for Coordinated Studies. Denver, CO.: U.S. Geological Survey.

ACC: NNA.19901206.0066.

YMP-USGS-GCP-03 R4. Uranium-Thorium Disequilibrium Studies. Denver, CO: U.S. Geological Survey. ACC: MOL.19990723.0011.

YMP-USGS-GCP-42 R0. Calibration of Laboratory Scales and Analytical Balances. Denver, CO.: U.S. Geological Survey. ACC: MOL.20050616.0263.

YMP-USGS-GCP-43 R0. Leaching of Dust and Rock Samples: Denver, CO.: U.S. Geological Survey. ACC: MOL.20050616.0264.

YMP-USGS HP-202 R1-M1. Analysis of Water Samples for Anion, Cation, Silica Concentrations by Ion Chromatography. Denver, CO: U.S. Geological Survey. ACC: MOL.20050215.0011.

YMP-USGS-HP-300, R0-M5. Extraction of Pore Water by High Water Centrifuge Methods. Denver, CO: U.S. Geological Survey. ACC: MOL.20030707.0322.

YMP-USGS-QMP-8.01 R4-M1. Identification and Control of Samples. Denver, CO: U.S. Geological Survey. ACC: MOL.19980203.0379.

\subsection{SOURCE DATA, LISTED BY DATA TRACKING NUMBER}

173724 GS050408313000.001. Scoping Analyses for Water-Soluble Ions in ESF, ECRB, and Surface Dust Samples. Submittal date: 04/07/2005.

173258 LB0503DUSTIMAG.001. ECRB Dust Characterization (Imaging). Submittal date: $03 / 25 / 2005$.

173259 LB0503DUSTPCAP.001. ECRB Dust Pore Diameter Distribution and Capillary Pressure Characteristic Curves. Submittal date: 3/25/2005. 
166419 LL030808523122.035. Input and Output Files Supporting MSTHM Micro-Abstractions for LA Multi-Scale Analyses. Submittal date: 09/11/2003.

168767 LL030905931032.001. Sensitivity Studies for Evaluating the Impact of Thermal Conductivity and Percolation Rate on LA Multi-Scale Analyses. Lower Percolation Case, Low Thermal Conductivity in Hostrock. Submittal date: 09/16/2003.

168768 LL030906331032.004. Sensitivity Studies for Evaluating the Impact of Thermal Conductivity and Percolation Rate on LA Multi-Scale Analyses. Upper Percolation Case, High Thermal Conductivity in Hostrock. Submittal date: 09/16/2003.

172589 LL040502512251.099. Weight Loss Measurements and Weight Loss Corrosion Rates from Alloy 22 Foil Specimens. Submittal date: 06/11/2004.

173822 LL040702112251.112. Open Circuit Electrochemical Studies of Alloy 22 with High Temperature Pseudo Thin-Film (5MM) NACL Brine and PVDF (Polyvinylidene Fluoride) Crevice Formers. Submittal date: 11/17/2004 .

171362 LL040803112251.117. Target Compositions of Aqueous Solutions Used for Corrosion Testing. Submittal date: 08/14/2004.

173659 LL040901831032.008. Results from Boiling Temperature Measurements for Saturated Solutions in the Systems NACL $+\mathrm{KNO} 3+\mathrm{H} 2 \mathrm{O}, \mathrm{NaNO} 3+\mathrm{KNO} 3+$ $\mathrm{H} 2 \mathrm{O}$, and NACL + NANO3 + KNO3 + H2O. Submittal date: 02/17/2005.

172593 LL040907112251.122. Weight Loss Measurements and Weight Loss Corrosion Rates from Alloy 22 Foil Specimens. Submittal date: 12/16/2004.

173688 LL041001423121.046. Deliquescence of Na-K-Cl-NO3 Salt Mixtures Using Resistivity Techniques. Submittal date: 11/18/2004.

173131 LL050200212251.125. Constant Potential Tests for Alloy 22 in Chloride Plus Nitrate Brines. Submittal date: 03/09/2005.

174025 LL050205223121.048. Thermal Analysis of Ammonium Chloride and Ammonium Sulfate. Submittal date: 05/26/2005.

173175 LL050301723121.050. Thermal Analysis of Ammonium Chloride and Ammonium Sulfate. Submittal date: 03/15/2005.

173608 LL050302823121.051. X-Ray Diffraction Data of Alloy 22 Corrosion Products from Electrochemically Induced Localized Corrosion in 4M NACL and 5M CACL2. Submittal date: 04/14/2005.

173790 MO0104SEPAMARQ.001. Ambient Air Quality - 1998 Particulate matter Concentration. Submittal date: 04/23/2001. 
173791 MO0104SEPAMARQ.002. Ambient Air Quality - 1999 Particulate Matter Concentration. Submittal date: 04/23/2001.

173792 MO0104SEPAMARQ.003. Ambient Air Quality - 2000 Particulate Matter Concentration. Submittal date: 04/23/2001.

162556 MO0207EBSDUSTS.020. Geochemical Composition of Dust Samples. Submittal date: $07 / 11 / 2002$.

162557 MO0209EBSDUST2.030. Geochemical Composition of Dust Samples (Phase II). Submittal date: 09/30/2002.

161756 MO0302SPATHDYN.000. Thermodynamic Data Input Files - Data0.YMP.R2. Submittal date: 02/05/2003.

166207 MO03119MET9397.000. Meteorological Monitoring Data, Site 9, 1993-1997. Submittal date: 11/10/2003.

167054 MO04019SUM9397.000. Summary of 1993-1997 Site 9 Meteorological Data. Submittal date: 01/20/2004.

172601 MO0501SEPFEPLA.001. LA FEP List and Screening. Submittal date: 01/17/2005.

173795 MO0505SEPAMARQ.004. Ambient Air Quality - 2001 Particulate Matter Concentration. Submittal date: 05/19/2005.

119501 MO98PSDALOG111.000. Particulate Sampler Data Records and Filter Weight Logs, Oct. - Dec. 97. Submittal date: 01/29/1998.

162572 SN0302T0510102.002. Pitzer Thermodynamic Database (data0.ypf.r0, Formerly data0.ypf, Revision 1). Submittal date: 02/06/2003.

164196 SN0307T0510902.003. Updated Heat Capacity of Yucca Mountain Stratigraphic Units. Submittal date: 07/15/2003.

169129 SN0404T0503102.011. Thermal Conductivity of the Potential Repository Horizon Rev 3. Submittal date: 04/27/2004.

173493 SN0504T0502404.011. Pitzer Thermodynamic Database for Some Actinide and Transition Metal Species (Data0.ypf.R1). Submittal date: 04/19/2005.

121386 TM000000000001.039. Particulate Matter Air Quality Data - January 1992 through September 1992. Submittal date: 07/27/1993.

121396 TM000000000001.041. Particulate Air Quality Data Forms, January thru June 1991. Submittal date: 07/27/1993. 
121405 TM000000000001.042. Particulate Air Quality Forms, July thru September 1991. Submittal date: 01/23/1992.

121408 TM000000000001.043. Particulate Air Quality Forms, October thru December 1991. Submittal date: 03/09/1992.

121410 TM000000000001.079. Particulate Sampler Data Records and Filter Weight Logs for 1992 through 1995. Submittal date: 03/11/1996.

121416 TM000000000001.082. Particulate Air Quality Data Forms, April 1989 thru December 1990. Submittal date: 03/12/1996.

121419 TM000000000001.084. Particulate Sampler Data Records and Filter Weight Logs, January - March 1996. Submittal date: 05/07/1996.

121421 TM000000000001.096. Particulate Sampler Data Records and Filter Weight Logs, April - June 1996. Submittal date: 01/18/1997.

121426 TM000000000001.097. Particulate Sampler Data Records and Filter Weight Logs, July - September 1996. Submittal date: 04/18/1997.

121429 TM000000000001.098. Particulate Sampler Data Records and Filter Weight Logs, October - December 1996. Submittal date: 04/18/1997.

121435 TM000000000001.099. Particulate Sampler Data Records and Filter Weight Logs, January - March 1997. Submittal date: 04/18/1997.

121440 TM000000000001.105. Particulate Sampler Data Records and Filter Weight Logs, April - June 1997. Submittal date: 07/21/1997.

121442 TM000000000001.108. Particulate Sampler Data Records and Filter Weight Logs, July - September 1997. Submittal date: 10/22/1997.

\subsection{SOFTWARE CODES}

173680 BSC 2002. GetEQData. 1.0.1. PC w/ Windows 2000. STN: 10809-1.0.1-00.

162228 BSC 2003. Software Code: EQ3/6. V8.0. PC w/ Windows 95/98/2000/NT 4.0. 10813-8.0-00.

173862 LBNL (Lawrence Berkeley National Laboratory) 2005. Software Code: TOUGHREACT. V3.2. Alpha System OSF1.V5.1. 10396-3.2-00.

148638 LLNL (Lawrence Livermore National Laboratory) 2000. Software Routine:

XTOOL V10.1. V10.1. Sun Ultra10. 10208-10.1-00. 
APPENDIX A

PRECLOSURE TEMPERATURE AND RELATIVE HUMIDITY ANALYSIS 
This appendix describes the calculations performed to estimate reasonable bounds on the preclosure waste package temperature and relative humidity. The technical product output is incorporated into Output DTN: MO0505MWDPRECL.001.

The input data used as direct input to the preclosure analyses of waste package temperature and relative humidity are described in Section 4.1.8. Most of the inputs to the calculations are identical to the inputs to calculations documented in Ventilation Model and Analysis Report (BSC 2004 [DIRS 169862], Section 4.1).

Preclosure temperature and relative humidity are not predicted by the multiscale model that describes postclosure conditions for TSPA-LA (BSC 2005 [DIRS 173944]); the analysis in this appendix is an application of the validated analytical version of the ventilation model (BSC 2004 [DIRS 169862], Section 6.4.2) with the objective to describe a wider range of spatial and temporal variability than the original ventilation model output.

\section{A.1 ANALYSIS METHOD}

The calculations were performed with the analytical version of the ventilation model (BSC 2004 [DIRS 169862], Section 6.4.2). The analytical model is used with developed information for the inlet air temperature and the average line load for waste packages for the winter and summer months. The ventilation model results are then scaled according to the power of a pressurized water reactor (PWR) waste package and a defense high-level waste (DHLW) waste package, and the maximum and minimum waste package temperatures are estimated using the following process:

- Perform a ventilation analysis using the inlet air temperature. The analysis produces the average waste package temperature based upon the average waste package line load (BSC 2005 [DIRS 173705]) during the 50-year ventilation period, for the winter and summer months.

- The analytical ventilation model calculates the waste package temperatures at $100-\mathrm{m}$ intervals down the drift. Temperature extremes at the inlet and exhaust ends of the drift are estimated using linear extrapolation to the ends of the drift.

- The temperature of a "hot" PWR waste package is obtained from the scaling relationship:

$$
P W R T(t)=\frac{P W R(t)}{\text { Average_Line_Load }(t)} \cdot\left(T_{-} \text {Array }(t)-T W P S A V E\right)+T W P S A V E
$$

where

$$
\begin{array}{ll}
\operatorname{PWRT}(t) & =\text { Scaled temperature of the PWR waste package }\left({ }^{\circ} \mathrm{C}\right) \\
P W R(t) & =
\end{array}
$$




$$
\begin{array}{lll}
T_{-} \text {Array }(t) & \begin{array}{l}
\text { Average waste package temperature during the } \\
\text { ventilation period }\left({ }^{\circ} \mathrm{C}\right)
\end{array} \\
\text { Average_Line_Load }(t)= & \text { Average Line Load as a function of } t(\mathrm{~kW} / \mathrm{m}) \\
\text { TWPSAVE } & \left.=\text { Temperature at Emplacement (Assumed as } 25^{\circ} \mathrm{C}\right) \\
t & = & \text { Preclosure time }(\mathrm{yrs}) .
\end{array}
$$

- The temperature of a "cool" DHLW waste package is obtained from the scaling relationship:

$$
D H L W T(t)=\frac{D H L W(t)}{\text { Average_Line_Load }(t)} \cdot\left(T_{-} \text {Array }(t)-T W P S A V E\right)+T W P S A V E
$$

where

$$
\begin{aligned}
& \operatorname{DHLWT}(t)=\text { Scaled temperature of the PWR waste package }\left({ }^{\circ} \mathrm{C}\right) \\
& D H L W(t)=\text { Defense High Level Waste Power }(\mathrm{kW} / \mathrm{m}) \\
& T \_\operatorname{Array}(t)=\text { Average waste package temperature during the ventilation } \\
& \text { period }\left({ }^{\circ} \mathrm{C}\right) \\
& \text { TWPSAVE }=\text { Temperature at Emplacement (Assumed as } 25^{\circ} \mathrm{C} \text { ) } \\
& t \quad=\quad \text { Preclosure time (yrs). }
\end{aligned}
$$

- For the estimated waste package temperatures, the waste package relative humidity (Jury et al. 1991 [DIRS 102010], p. 60) is calculated as:

$$
W P_{-} R H(T)=\frac{P_{\text {vapor }}}{P_{\text {sat }}(T)}
$$

where

$$
\begin{array}{ll}
W P_{-} R H(T) & =\text { Waste package relative humidity } \\
P_{\text {vapor }} & =\text { Partial pressure of water }(\mathrm{Pa}) \\
P_{\text {sat }}(T) & =\text { Saturated vapor pressure of water at absolute temperature }(T) \\
T & =\text { Absolute temperature }(\mathrm{K}) .
\end{array}
$$

These results are then used with relative humidity measurements to estimate the mean and maximum partial pressure and mole fraction of water during the winter and summer months. These partial pressures are then used with the waste package temperatures to estimate the associated range of waste package $\mathrm{RH}$. 
The analytical ventilation model used for calculation of the average waste package temperatures, with the changes to input data as discussed above for points in space down the emplacement drift and at different times, is used within its range of validation. The analytical ventilation model solves the thermal energy balance accounting for radiant and convective heat transfer within the drift, and heat conduction in the surrounding rock using radiant, convective, and conductive heat transfer relations that are appropriate for the intended application of estimating waste package temperatures. The basic processes for assessing waste package temperatures scale linearly, and thus superposition applies. Therefore, the scaling relationships used to estimate the waste package temperatures for PWR and DHLW waste packages are appropriate for the intended application of estimating preclosure waste package temperature and relative humidity.

\section{A.2 ANALYSIS RESULTS}

Preclosure inlet air temperature and relative humidity will vary due to seasonal and daily meteorological effects. The principal variation with regards to waste package temperature is seasonal in nature, with the minimum inlet air temperature occurring during the winter months and the maximum inlet air temperature occurring during the summer months. Daily fluctuations occur, but these are of less consequence than seasonal variations because of energy and mass storage effects in the emplacement drifts and upstream in the underground facility. As seasonal temperatures rise and fall, the heat transferred to the rock will change due to an increase and decrease in the ventilation efficiency. This will result in changes in the seasonal-average waste package temperatures.

The partial pressure of each component in the ventilation gas flow $\left(\mathrm{p}_{\mathrm{i}}\right)$ equals the product of the mole fraction of each component $\left(\mathrm{y}_{\mathrm{i}}\right)$ times the total pressure $\left(\mathrm{P}_{\text {total }}\right)$ (Dean 1992 [DIRS 100722], p. 5.155). For an open system in which the total pressure is constant, the partial pressures are constant.

Note that the partial pressure of water vapor could change due to flux of water vapor from the rock into the ventilation air. The flux of water vapor into the ventilation air stream was addressed in Ventilation Model and Analysis Report (BSC 2004 [DIRS 169862], Section 6.9.1). If the length of the average emplacement drift is considered (627 m, including 600-m and 800-m drifts) with an emplacement drift diameter of $5.5 \mathrm{~m}$, the total surface area of the drift is $10,830 \mathrm{~m}^{2}$. A reasonable bound flux of water vapor from the rock, for quasi-steady conditions, is calculated to be approximately $3 \mathrm{~m}^{3} / \mathrm{yr}$, equivalent to $0.8 \mathrm{lbm} / \mathrm{hr}$. Considering the density of air at $300 \mathrm{~K}$ (Incropera and DeWitt 1996 [DIRS 108184], Table A.4) of $1.16 \mathrm{~kg} / \mathrm{m}^{3}$ and the volumetric air flow rate of $15 \mathrm{~m}^{3} / \mathrm{sec}$ (see Section 4.1.8.1), the mass flow rate of air equals $17.4 \mathrm{~kg} / \mathrm{sec}$. Converting this mass flow rate to the English system of units, the air mass flow rate for ventilation is approximately $138,000 \mathrm{lbm} / \mathrm{hr}$. The flux of water vapor is therefore small compared to the air flux rate, and would not significantly affect the partial pressure of water vapor.

In addition to variations in inlet air temperature, there will be variations in waste package relative humidity, as determined from the ratio of the partial vapor pressure of water vapor to the saturated vapor pressure at the waste package temperature. Since waste package temperatures depend on the heat evolution, which in turn depends on the type of waste package, the 
temperature and relative humidity environment during preclosure will be different for commercial spent fuel versus defense high level waste.

The following steps provide additional detail on the method used to estimate the variations in waste package temperature and $\mathrm{RH}$ :

- An analysis of meteorological temperature and $\mathrm{RH}$ data recorded at Site 9 during the period from 1993 to 1997 was performed to estimate seasonal variations in the partial pressure of water. This was done by considering a thirty day period during each season, and calculating the partial pressure of water vapor from the temperature based upon temperature and relative humidity, and the saturated vapor pressure, as a function of temperature (Incropera and DeWitt 2002 [DIRS 163337], Table A.6, pp. 924 to 925). The mean and maximum partial pressures of water vapor were determined for the four seasons, and the winter and summer seasons were found to be bounding (Output DTN: MO0505MWDPRECL.001, MathCad file Analysis of Temperature and RH Measurements.mcd).

- For the given mean inlet air temperature, the analytical ventilation model was used with the average waste package line-load to estimate the average waste package temperature during the preclosure period. An 800-m emplacement drift was considered in the analysis because this drift produces a broader range of temperatures than the $600-\mathrm{m}$ drift (Output DTN: MO0505MWDPRECL.001, Ventilation Analysis.xls and Summer Ventilation Analysis.xls).

- To estimate the range of the actual waste package temperature during ventilation, the 21-PWR and the DHLW Short waste packages were considered. The estimated waste package temperature was calculated on the basis of the ratio of the waste package power to the average line loading, including effects of time-dependent decay, and the average waste package temperature rise during ventilation. Note that since the analytical ventilation model uses eight lumped segments each $100 \mathrm{~m}$ in length, the values for waste package temperature are extrapolated to the inlet and outlet points for the emplacement drift (Output DTN: MO0505MWDPRECL.001, MathCad file DUST CALCULATION TEMPERATURE AND RH CLOUD REV02.MCD).

The analysis of the data from Site 9 shows the average inlet temperature to be $7^{\circ} \mathrm{C}$ in the winter and $31.2^{\circ} \mathrm{C}$ in the summer. The mean and upper-bound partial pressures of water vapor were obtained from the relative humidity measurements and the corresponding temperature. During winter, the mean and maximum partial pressures of water vapor are from .0057 bar to .014 bar, respectively. During summer, the mean and upper-bound partial pressures of water were .0052 bar and .023 bar respectively (Output DTN: MO0505MWDPRECL.001, MathCad file Analysis of Temperature and RH Measurements.mcd).

Table A-1 is a summary of the analysis of the estimated peak preclosure temperature and relative humidities for the mean and upper-bound cases during the winter and summer months. Figure A-1 presents the range of preclosure waste package temperatures versus relative humidities for various conditions. 
Table A-1. Summary of Preclosure Maximum Temperature and Relative Humidity Results

\begin{tabular}{|c|c|c|c|c|c|c|c|}
\hline \multirow{3}{*}{ Season } & \multicolumn{2}{|c|}{ PWR } & \multicolumn{2}{c|}{ DHLW } & \multicolumn{2}{c|}{ Average } \\
\cline { 2 - 8 } & $\begin{array}{c}\text { Mole Fraction } \\
\text { Bound }\end{array}$ & $\begin{array}{c}\text { Temperature } \\
\left({ }^{\circ} \mathbf{C}\right)\end{array}$ & $\mathbf{R H}(\%)$ & $\begin{array}{c}\text { Temperature } \\
\left({ }^{\circ} \mathbf{C}\right)\end{array}$ & $\mathbf{R H}(\%)$ & $\begin{array}{c}\text { Temperature } \\
\left({ }^{\circ} \mathbf{C}\right)\end{array}$ & $\mathbf{R H}(\%)$ \\
\hline \multirow{2}{*}{ Winter } & Mean & 127.4 & 20.6 & 59.7 & 18.5 & 90.9 & 19.5 \\
\cline { 2 - 8 } & Upper & 127.4 & 50.6 & 59.7 & 45.4 & 90.9 & 47.8 \\
\hline \multirow{2}{*}{ Summer } & Mean & 156.8 & 2.7 & 71.0 & 9.6 & 109.8 & 5.0 \\
\cline { 2 - 8 } & Upper & 156.8 & 11.7 & 71.0 & 42.3 & 109.8 & 22.0 \\
\hline
\end{tabular}

Source: Output DTN: MO0505MWDPRECL.001, Dust Results Rev03.xls, worksheet "Summary Sorted."

\section{A.3 UNCERTAINTY ANALYSIS}

The analysis presented above considers a range of partial pressures of water vapor based on collected data for temperature and relative humidity, and therefore accounts for this principal uncertainty. Additional uncertainties in the preclosure waste package temperature include the variation in the inlet air temperature during the winter month or summer months and the variation in rock mass thermal conductivity.

Ventilation Model and Analysis Report (BSC 2004 [DIRS 169862], Section 6.11) identifies uncertainties in the calculation of the ventilation efficiency. Note that while preclosure waste package temperatures are not explicitly calculated in that report, the calculation sequence and model parameters apply here. As shown in Ventilation Model and Analysis Report (BSC 2004 [DIRS 169862], Figure 6-12), the most significant parameters include the inlet air temperature and the rock mass thermal conductivity.

To estimate the uncertainty in waste package temperature and relative humidity due to an uncertainty in the inlet air temperature, the following steps are followed. An estimate of the uncertainty of the inlet air temperature is made on the basis of the monthly average maximum and minimum temperatures for the winter months (DTN: MO04019SUM9397.000 [DIRS 167054], develdata_s9_9397.doc). The variation in temperature for the average waste package is approximately equal to the variation in inlet air temperature. The variation in the PWR and DHLW temperatures scales to the approximate line average line load for these packages. The variation in relative humidity scales to the variation in PWR and DHLW saturated vapor pressure according to the equation presented above from Jury et al. (1991 [DIRS 102010], p. 60).

The approximate uncertainty analysis does not account for the change in temperature through heat exchange through inlet shafts and perimeter drifts. As air moves through these entries, heat is transferred to the air, which would result in the inlet air temperatures being in closer agreement with the rock temperature at the repository horizon. The estimates presented in the following discussion are therefore bounding in that the uncertainty in waste package temperature and relative humidity is overestimated. The estimates are appropriate for the intended use of FEPs screening analysis presented in this report.

No specific analyses have been conducted that would simulate the preclosure ventilation subject to daily variations in temperature. Daily variations in inlet air temperature would likely not alter heat transfer within the surrounding rock mass to a significant degree. The uncertainty on 
preclosure waste package relative humidity due to the inlet air temperature is also expected to be small in comparison to the uncertainty in the partial pressure of water that is considered in the analysis.

In order to evaluate the uncertainty in rock mass thermal conductivity, the ventilation model was run over the range representing the dry value, minus one standard deviation $(1.30 \mathrm{~W} /(\mathrm{m} \cdot \mathrm{K}))$, to the saturated value plus one standard deviation $(2.14 \mathrm{~W} /(\mathrm{m} \cdot \mathrm{K}))$, for both the winter and summer conditions. These results are presented in Output DTN: MO0505MWDPRECL.001 (MathCad file DUST CALCULATION TEMPERATURE AND RH CLOUD REV02.MCD). The results of the analysis show that waste package temperature varies by only several degrees due to uncertainty in host-rock thermal conductivity. This is a consequence of the high ventilation efficiency during the preclosure period.

Table A-2. Range of Rock Mass Thermal Conductivity

\begin{tabular}{|c|c|c|c|}
\hline $\begin{array}{c}\text { Saturation } \\
\text { State }\end{array}$ & $\begin{array}{c}\text { Mean Values } \\
\mathbf{( W / m} \cdot \mathbf{K})\end{array}$ & $\begin{array}{c}\text { Mean plus Std } \\
\mathbf{( W / m} \cdot \mathbf{K})\end{array}$ & $\begin{array}{c}\text { Mean minus Std } \\
\mathbf{( W / m} \cdot \mathbf{K})\end{array}$ \\
\hline Dry & 1.28 & 1.03 & 1.53 \\
\hline Saturated & 1.89 & 1.64 & 2.14 \\
\hline
\end{tabular}

Source: DTN: SN0404T0503102.011 [DIRS 169129], ReadMe Summary.Doc, Tables 7-10 and 7-11.

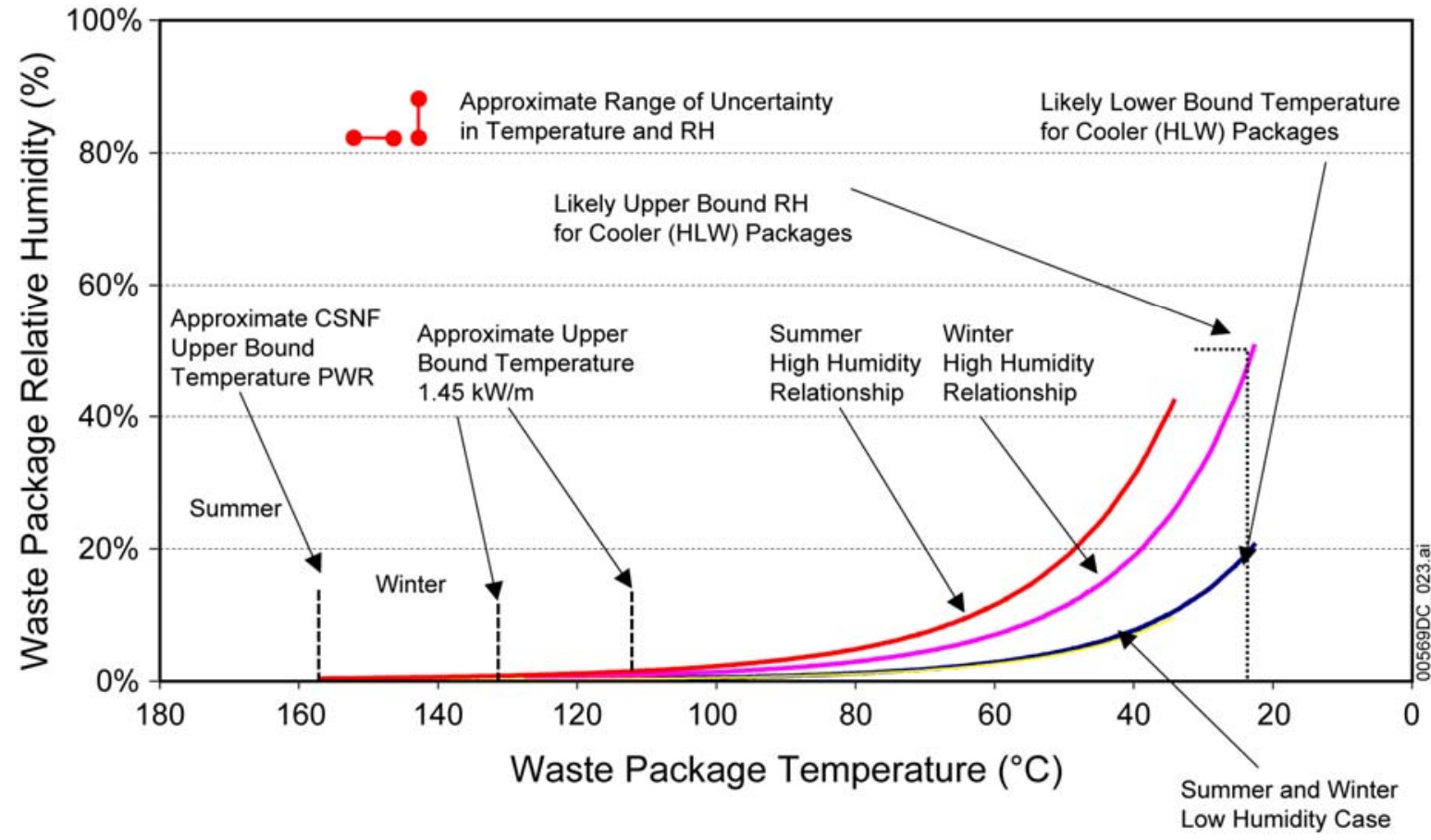

Source: Output DTN: MO0505MWDPRECL.001, Dust Results Rev03.xls, Chart 3.

NOTE: $\quad$ Average inlet air temperature of $7^{\circ} \mathrm{C}$ and partial pressure of water ranging from 0.0057 bar to 0.014 bar during the winter months. Average inlet air temperature of $31.2^{\circ} \mathrm{C}$ and partial pressure of water ranging from 0.0052 bar to 0.023 bar.

Figure A-1. Range of Preclosure Waste Package Temperatures versus Relative Humidities for Various Conditions 


\section{APPENDIX B}

CALCULATIONS FOR AMMONIUM PITZER DATABASE PARAMETERS 


\section{B.1 AMMONIUM-NITRATE INTERACTION PARAMETER}

The work by Clegg et al. (1998 [DIRS 172815]) critically assesses thermodynamic data for $\mathrm{NH}_{4} \mathrm{NO}_{3}(\mathrm{aq})$ solutions, and represents these data with a mole-fraction based thermodynamic model valid from freezing temperatures to $100^{\circ} \mathrm{C}$. However, the $\mathrm{EQ} 3 / 6$ code and database use Pitzer's standard model, so a conversion was performed. The basic method was to evaluate the temperature coefficients for the Pitzer ion-interaction model parameters $\beta^{(0)}, \beta^{(1)}$, and $C^{\phi}$ using the methodology described by Rard et al. (2004 [DIRS 173816]).

The source information for this analysis consisted of a synthetic grid of osmotic coefficients for aqueous $\mathrm{NH}_{4} \mathrm{NO}_{3}$ calculated using the mole-fraction approach of Clegg et al. (1998 [DIRS 172815]). This grid was calculated for closely spaced intervals of ionic strength and temperature. Also required for this calculation were the Debye-Hückel limiting law slopes used by Clegg et al. (1998 [DIRS 172815]), which are those reported by Clegg and Brimblecombe (1995 [DIRS 173820]). The parameters of the mole-fraction-based method of Clegg et al. (1998 [DIRS 172815]) are based on use of a critically assessed database of literature values, and represent the best available parameterized model for this system.

The method of Clegg et al. (1998 [DIRS 172815]) was used to calculate values of the osmotic coefficient $\phi$ to high molalities at intervals of $0.2 \mathrm{~mol}-\mathrm{kg}^{-1}$, and temperatures from 0 to $100^{\circ} \mathrm{C}$ at $10^{\circ} \mathrm{C}$ intervals and also at $25^{\circ} \mathrm{C}$. The generated synthetic data grid was then used to evaluate the temperature coefficients for the three Pitzer parameters $\beta^{(0)}, \beta^{(1)}$, and $C^{\phi}$ (for more information on these Pitzer parameters, see BSC 2004 [DIRS 169863], Appendix I, Sections I.3 through I.3.1.3). The maximum molality used to constrain the model at each temperature was the molality closest to the saturated solution molalities tabulated by Linke (1965 [DIRS 166191], p. 709), which differ from the solubilities by $\leq 0.2 \mathrm{~mol}-\mathrm{kg}^{-1}$. The value of Pitzer's $\alpha_{1}$ exponential coefficient was optimized over the full temperature range to yield $\alpha_{1}=1.15 \mathrm{~mol}^{1 / 2}-\mathrm{kg}^{-1 / 2}$. This value reduced the root mean square model error by about $40 \%$ compared to the alternative choice of $\alpha_{1}=2.0 \mathrm{~mol}^{1 / 2}-\mathrm{kg}^{-1 / 2}$ (see spreadsheet DataMF2PitzerNC_MX_NH4NO3_2.xls in Output DTN: LL050205323121.049).

The accuracy of the Pitzer parameters fitted to the osmotic coefficients was verified by first calculating the Pitzer parameters corresponding to the optimum value of the "alphal" parameter from the fitted temperature coefficients for $273.15 \mathrm{~K}\left(0^{\circ} \mathrm{C}\right)$ and $373.15 \mathrm{~K}\left(100^{\circ} \mathrm{C}\right)$, which are the lower and upper limits of the fitted temperature range. These parameters were then used to calculate the osmotic coefficient at several ionic strengths and exact agreement was obtained with the values calculated using Clegg's original mole fraction parameters. The maximum deviation in osmotic coefficient between the two methods over this temperature and ionic strength range is less than 0.015 and the RMS deviation is only 0.00434. Again, the spreadsheet calculations along with details to obtain the optimized $\alpha_{1}$ value are given in Output DTN: LL050205323121.049. Note that the derivation was constrained to the approximate solubility limits, and the representation is not suitable for extrapolation to supersaturated solution molalities. The obtained Pitzer parameters are listed in Table B-1.

Several inconsistencies or errors were identified in the study by Clegg et al. (1998 [DIRS 172815]) and corrected in this analysis: 1) the parameters $\mathrm{U}_{1}, \mathrm{~V}_{1}$, and $\mathrm{W}_{1}$ (labeled in the spreadsheet as $\mathrm{U}(1), \mathrm{V}(1)$, and $\mathrm{W}(1)$, respectively) in Table 1 of the source are given in the 
wrong order; 2) the term $\mathrm{B}^{1}{ }_{\mathrm{NH} 4 \cdot \mathrm{NO} 3}$ in Table 1 is duplicated into another parameter thus indicating a missing value; and 3) the third and fourth terms on the right-hand side of Equation (13) should have a negative sign. The correct form of Equation 13 with a slightly different notation can be found in the study by Rard et al. (2000 [DIRS 162105], Equation (30), p. 35). Use of the erroneous expression resulted in incorrect values for the osmotic coefficient. Upon correction of Equation (30) of the source, the incorrect parameter values listed in Table 1 for $\mathrm{NH}_{4} \mathrm{NO}_{3}$ still produced incorrect values of osmotic coefficient. The three incorrect parameter values for $U_{l}, V_{l}$, and $\mathrm{W}_{1}$ were then identified by direct comparison of values in Table 1 of the source and the email correspondence (Clegg 2004 [DIRS 174184]) between the senior author (Dr. Simon L. Clegg) and Dr. Joseph A. Rard (LLNL). Moreover, this email correspondence also provided the missing parameter value from Table 1 of the source. The corrected values for the parameters $U_{1}$, $\mathrm{V}_{1}$, and $\mathrm{W}_{1}$ are given in Table B-2. After all these corrections, an exact correspondence was obtained between the osmotic coefficient values given by the senior author in the email correspondence (Clegg 2004 [DIRS 174184]) and those acquired from the corrected equation and parameters used in the spreadsheet calculations (Output DTN: LL050205323121.049.) The corrections described above - the correct ordering of the $U_{1}, V_{l}$, and $W_{1}$ parameters, the parameter value missing from Table 1 of the source, and the correct signs on the terms of Equation 13-are all explained in Output DTN: LL050205323121.049. The value of the parameter used in the mole-fraction model of Clegg et al. (1998 [DIRS 172815]) is not given in this source but is listed by Rard et al. (2000 [DIRS 162105], Table IX). The value of this parameter constant is 13.0 .

The resulting Pitzer parameter temperature-dependent representations for $\mathrm{NH}_{4}{ }^{+}-\mathrm{NO}_{3}{ }^{-}$in data0.ypf.R2 (Output DTN: SN0504T0502205.008) are given below. Note that the $\alpha_{2}$ value (12.0) is not from the source described above, but is the default value used in the cited Pitzer database and is only changed if the source data specify a different value. The upper bounding value for ionic strength at each temperature for the osmotic coefficient data obtained from Clegg et al. (1998 [DIRS 172815]) were set to those equal or greater than the solubility limits (within $0.2 \mathrm{~mol} / \mathrm{kg}$ ) of the solid $\mathrm{NH}_{4} \mathrm{NO}_{3}$. The solubility for this phase in its various crystalline forms as a function of temperature were obtained from Linke (1965 [DIRS 166191], p. 709).

For the temperature extrapolation of the model parameters named in Table 1 of the source as B, $\mathrm{B}^{1}, \mathrm{U}_{1}, \mathrm{~V}_{1}$, and $\mathrm{W}_{1}$ (labeled in the spreadsheet as $\mathrm{B}(1), \mathrm{B}(2), \mathrm{U}(1), \mathrm{V}(1)$ and $\mathrm{W}(1)$, respectively), the following equation is used:

$$
P(T)=P(298.15)+a_{1} *\left(T-T_{r e f}\right)+0.5 * a_{2}\left(T^{2}-T_{r e f}^{2}\right)
$$

where $P$ is the model parameter (for $\mathrm{B}, \mathrm{B}^{1}, \mathrm{U}_{1}, \mathrm{~V}_{1}$, and $\left.\mathrm{W}_{1}\right), P(298.15$ ) is the value of the parameter $P$ at $298.15 \mathrm{~K}, T$ stands for temperature (degrees Kelvin), and $T_{r e f}$ corresponds to the reference temperature of $298.15 \mathrm{~K}$. For the parameter $P$, in this case represented by B (listed as $\mathrm{B}(1)$ in the spreadsheet), $\mathrm{U}_{1}, \mathrm{~V}_{1}$, and $\mathrm{W}_{1}$, the coefficients $a_{1}$ and $a_{2}$ in Equation B-1, are defined as (Clegg 2004 [DIRS 174184]): 


$$
\begin{aligned}
& a_{1}=P_{1}^{L}-T_{r e f} * \frac{\partial^{2} P}{\partial T^{2}} \\
& a_{2}=\frac{\partial^{2} P}{\partial T^{2}}=P_{1}^{J}-\left(\frac{2}{T_{r e f}}\right) * P_{1}^{L}
\end{aligned}
$$

where the values for the parameters $P_{1}^{L}$ and $P_{1}^{J}$ are given by Clegg et al. (1998 [DIRS 172815], Table 1). Similarly, for the parameter $\mathrm{B}^{1}$ (listed as $\mathrm{B}(2)$ in the spreadsheet), $a_{1}$ and $a_{2}$ are given by:

$$
\begin{aligned}
& a_{1}=P^{1, L}-T_{r e f} * \frac{\partial^{2} P^{1}}{\partial T^{2}} \\
& a_{2}=\frac{\partial^{2} P^{1}}{\partial T^{2}}=P^{1, J}-\left(\frac{2}{T_{r e f}}\right) * P^{1, L}
\end{aligned}
$$

where $P^{1, L}$ and $P^{1, J}$ are also listed in Table 1 of the study by Clegg et al. (1998 [DIRS 172815]). Notice that $P^{1}$ refers only to the parameter designated as $B^{1}$ by Clegg et al. (1998 [DIRS 172815]). Values for $P(298.15), a_{1}$ and $a_{2}$ coefficients of the temperature function described above, are given in Table B-3; Equations B-1 through B-3 are given by Clegg (2004 [DIRS 174184]).

Table B-1. Calculated Coefficients for the Molality-Based Pitzer Parameters Based on the Mole-Fraction Model of Clegg et al. (1998 [DIRS 172815])

\begin{tabular}{|c|c|}
\hline Parameter & Value \\
\hline alpha(1) & 1.15 \\
\hline alpha(2) & 12.0 \\
\hline \multicolumn{2}{|c|}{ beta(0) } \\
\hline a1 & -0.01478300 \\
\hline a2 & -161.3624 \\
\hline a3 & 0.4766337 \\
\hline a4 & 0.0001253472 \\
\hline \multicolumn{2}{|c|}{ beta(1) } \\
\hline a1 & -488.3983 \\
\hline a2 & -0.4048236 \\
\hline a3 & -0.001386780 \\
\hline a4 & 0 \\
\hline \multicolumn{2}{|c|}{} \\
\hline a1 & 0 \\
\hline a2 & 0 \\
\hline a3 & 0 \\
\hline a4 & \\
\hline
\end{tabular}


Table B-1. Calculated Coefficients for the Molality-Based Pitzer Parameters Based on the Mole-Fraction Model of Clegg et al. (1998 [DIRS 172815]) (Continued)

\begin{tabular}{|c|c|}
\hline Parameter & Value \\
\hline \multicolumn{2}{|c|}{ C(phi) } \\
\hline a1 & 0.0002739639 \\
\hline a2 & 24.20412 \\
\hline a3 & 0.1286081 \\
\hline a4 & -0.0001707604 \\
\hline
\end{tabular}

Source: Output DTN: LL050205323121.049.

Table B-2. Corrected $\mathrm{NH}_{4} \mathrm{NO}_{3}$ Parameters at $298.15 \mathrm{~K}$ for Clegg et al. (1998 [DIRS 172815]) Mole Fraction Model

\begin{tabular}{|c|c|}
\hline Parameter & Value \\
\hline$U_{1}$ & $-4.035640 \mathrm{E}-02$ \\
\hline$V_{1}$ & $-6.805070 \mathrm{E}-01$ \\
\hline$W_{1}$ & $6.161360 \mathrm{E}-01$ \\
\hline
\end{tabular}

Source: Output DTN: LL050205323121.049.

Table B-3. Fitting Coefficients for Temperature Function of the Clegg et al. (1998 [DIRS 172815]) Mole Fraction Model

\begin{tabular}{|c|c|c|c|}
\hline Parameter & $\mathbf{P ( 2 9 8 . 1 5 )}$ & a1 Value & $\mathbf{0 . 5} \times$ a2 Value \\
\hline$B$ & $1.304660 \mathrm{E}+01$ & $1.899294 \mathrm{E}+00$ & $-2.710216 \mathrm{E}-03$ \\
\hline$B^{\prime}$ & $-1.622540 \mathrm{E}+01$ & $-2.149881 \mathrm{E}-01$ & $2.403579 \mathrm{E}-04$ \\
\hline $\mathrm{U}_{1}$ & $-4.035640 \mathrm{E}-02$ & $5.152080 \mathrm{E}-03$ & $-5.760054 \mathrm{E}-06$ \\
\hline$V_{1}$ & $-6.805070 \mathrm{E}-01$ & $1.736687 \mathrm{E}-02$ & $-2.540636 \mathrm{E}-05$ \\
\hline$W_{1}$ & $6.161360 \mathrm{E}-01$ & $-2.236243 \mathrm{E}-02$ & $2.581787 \mathrm{E}-05$ \\
\hline
\end{tabular}

Source: Output DTN: LL050205323121.049.

\section{B.2 AMMONIA-AMMONIA INTERACTION PARAMETER}

The refitting of the original ternary Pitzer parameter of ammonia to ammonia (termed $\lambda_{\mathrm{NH}_{3}, \mathrm{NH}_{3}}$ ) is in the spreadsheet NH3-Temp_Regress.xls, within Output DTN: SN0504T0502205.009. The original equation of Clegg and Brimblecombe (1989 [DIR 172803], footnote $a$ in Table VI), shown as input Equation 4-1 in the current report, was fit for a range of temperatures from 0 to $40^{\circ} \mathrm{C}$. The objective of this calculation was to recast the original temperature dependence from its absolute Kelvin scaling to the EQ3/6 compatible scaling based on $25^{\circ} \mathrm{C}$ (input Equation 4-2).

First, the $\lambda_{\mathrm{NH}_{3}, \mathrm{NH}_{3}}$ was calculated at every integer temperature from 0 to $40^{\circ} \mathrm{C}$ from the original source Equation 4-1. Then each of the three temperature-dependent fitting terms in Equation 4-2 were calculated at each of these temperatures as well. The last step used the built-in data analysis Excel tool called "Regression" to fit the $\lambda_{\mathrm{NH}_{3}, \mathrm{NH}_{3}}$ parameters to the new temperature terms and generate the coefficients $a 1$ through $a 4$ for Equation 4-2, which were then directly put into the database (Output DTN: SN0504T0502205.008). 
The quality of the new fit was also compared with the original data for verification. The largest deviation, at $40^{\circ} \mathrm{C}$, is an insignificant $-0.001 \%$. Values were also calculated using the new fit up to $100^{\circ} \mathrm{C}$ to check that they remain stable and do not begin increasing or decreasing rapidly. The values are well behaved up to $100^{\circ} \mathrm{C}$ and are reasonable to use up to this temperature.

\section{B.3 AMMONIUM SALT SOLID SOLUBILITY PARAMETERS}

The refitting of ammonia salt solids from the mole fraction scale used by Clegg et al. (1998 [DIRS 172815]) to an EQ3/6-compatible molality scale is performed in the spreadsheet AmmoniumSalts.xls, within Output DTN: SN0504T0502205.009. The conversion simply uses Equation 4 from the article by Clegg et al. (1998 [DIRS 172815]; input shown in Equation 4-3). The only term requiring description is $v_{i, p}-v_{i, r}$ : this is the stoichiometric difference of the aqueous components for dissolution of the salt solid from reactant to product, and therefore all the differences are positive.

Confidence building in the quality of the data, as well as the conversion itself, is included by comparison of seven ammonium salts that are already contained within the existing Pitzer database. In all but one case, the differences in $\log (K)$ values are less than 0.1 , confirming the new estimates and the method used. For the one other salt, $\left(\mathrm{NH}_{4}\right)_{2} \mathrm{SO}_{4}$, the $\log (K)$ value differed by approximately 0.3 , which is within the typical range of predictive uncertainty for key analytes in the in-drift precipitates/salts model (BSC 2004 [DIRS 169863], Table 7-8) and suitable for the analysis presented in this report. 


\section{INTENTIONALLY LEFT BLANK}


APPENDIX C

QUALIFICATION OF AIR PARTICULATE MATTER DATA IN TABLE 4.1-7 
Airborne particulate measurement results from Site 5 for the years 1998 through 2001 are being qualified (per LP-SIII.2Q-BSC, Qualification of Unqualified Data) as part of this analysis (Table C-1). Site 5 is in Jackass Flats along Fortymile Wash near Well J-12, 5 to $10 \mathrm{~km}$ south of most surface-disturbing activities. It was selected to measure remote background concentrations within the most likely air pathway for dispersal of pollutants from Midway Valley to populated areas to the south. Airborne particulate matter data are presented in Site Environmental Report for the Yucca Mountain Project Calendar Year 2002 (DOE 2003 [DIRS 168842], Table 2, p. 44). This qualification summary follows the requirements presented in the Data Qualification Plan, a facsimile of which is provided at the end of this appendix.

Table C-1. Unqualified Airborne Particulate Matter Data Tracking Numbers

\begin{tabular}{|c|c|c|}
\hline Data Tracking Number & Year & DIRS Number \\
\hline MO0104SEPAMARQ.001 & 1998 & 173790 \\
\hline MO0104SEPAMARQ.002 & 1999 & 173791 \\
\hline MO0104SEPAMARQ.003 & 2000 & 173792 \\
\hline MO0505SEPAMARQ.004 & 2001 & 173795 \\
\hline
\end{tabular}

An air-quality monitoring program at Yucca Mountain has been conducted by the Radiological and Environmental Programs Department and its predecessors. Ambient airborne particulate matter has been sampled as part of the environmental monitoring program since 1989 using standard regulatory methods of the Environmental Protection Agency (EPA). From 1991 to 1999, the State of Nevada air quality operating permits for the YMP stipulated that the U.S. Department of Energy must measure $\mathrm{PM}_{10}$ inhalable particulate matter 10 micrometers or less in aerodynamic diameter. Total suspended particulate matter less than 25 to 50 micrometers in aerodynamic diameter were also collected to comply with previous Nevada standards. $\mathrm{PM}_{10}$ inhalable particulate matter monitoring has continued since 1999 to demonstrate continued compliance with EPA (40 CFR Part 50 [DIRS 151828]) and Nevada Division of Environmental Protection (NAC 445B) ambient air quality standards.

A previous data qualification evaluation (CRWMS M\&O 2000 [DIRS 160626]) was conducted on 14 data sets containing air particulate matter measurements, which included Site 5, collected during 1989 through 1997 (Table C-2). The data qualification used the technical assessment method (per LP-SIII.2Q-BSC) because data collection had not been controlled in accordance with the Office of Civilian Radioactive Waste Management's quality assurance program. Qualification was conducted by evaluating that appropriate equipment were used, the data were traceable to the Technical Data Management System (TDMS) and the YMP Records Information System, the calculations were repeatable, the precision of the data verified, and trends and outlying values reviewed. The data collection methods were also compared to the EPA standards for air-quality monitoring. The qualification team recommended that the status of the 14 data sets evaluated be changed to "Qualified." The qualified data were used to estimate parameters required as inputs in the biosphere dose conversion factors. 
Table C-2. Qualified Airborne Particulate Matter Data Tracking Numbers

\begin{tabular}{|l|l|c|}
\hline \multicolumn{1}{|c|}{ Data Tracking Number } & \multicolumn{1}{|c|}{ Time Period } & DIRS Number \\
\hline TM000000000001.082 & April 1989 to December 1990 & 121416 \\
\hline TM000000000001.041 & January 1991 to June 1991 & 121396 \\
\hline TM000000000001.042 & July 1991 to September 1991 & 121405 \\
\hline TM000000000001.043 & October 1991 to December 1991 & 121408 \\
\hline TM000000000001.039 & January 1992 to September 1992 & 121386 \\
\hline TM000000000001.079 & October 1992 to December 1995 & 121410 \\
\hline TM000000000001.084 & January 1996 to March 1996 & 121419 \\
\hline TM000000000001.096 & April 1996 to June 1996 & 121421 \\
\hline TM000000000001.097 & July 1996 to September 1996 & 121426 \\
\hline TM000000000001.098 & October 1996 to December 1996 & 121429 \\
\hline TM000000000001.099 & January 1997 to March 1997 & 121435 \\
\hline TM000000000001.105 & April 1997 to June 1997 & 121440 \\
\hline TM000000000001.108 & July 1997 to September 1997 & 121442 \\
\hline MO98PSDALOG111.000 & October 1997 to December 1997 & 119501 \\
\hline
\end{tabular}

In this data qualification, the corroboration method (per LP-SIII.2Q-BSC) is used for qualification of the data from 1998 through 2001. The unqualified data from Site 5 (Table C-3) are compared with the previously qualified data sets collected from 1989 through 1997 from Site 5 (Table C-4). The annual averages (rounded to whole numbers) are determined in this qualification analysis from the individual measurements conducted during a 24-hour period every six days during the specified time periods. The same organization, using the same equipment, data collection and calibration methods, and following the same EPA standard monitoring procedures, was used to collect the qualified data sets from 1989 through 1997.

Table C-3. Unqualified Airborne Particulate Matter Annual Averages from Site 5

\begin{tabular}{|c|c|c|c|}
\hline Year & $\mathbf{P M}_{\mathbf{1 0}}\left(\mu \mathbf{g} / \mathbf{m}^{\mathbf{3}}\right)$ & $\begin{array}{c}\text { Total Suspended } \\
\text { Particles }\left(\mu \mathbf{g} / \mathbf{m}^{\mathbf{3}}\right)\end{array}$ & Qualification Status \\
\hline 1998 & 7 & 18 & Unqualified \\
\hline 1999 & 8 & 23 & Unqualified \\
\hline 2000 & 12 & NR & Unqualified \\
\hline 2001 & 10 & NR & Unqualified \\
\hline
\end{tabular}

NOTES: $\quad$ NR = not reported; total suspended particles (TSP) sampling had been discontinued.

See Table C-1 for the source DTN for airborne particulate data. 
Table C-4. Qualified Airborne Particulate Matter Annual Averages from Site 5

\begin{tabular}{|c|c|c|c|}
\hline Year & $\mathbf{P M}_{\mathbf{1 0}}\left(\boldsymbol{\mu} \mathbf{g} / \mathbf{m}^{\mathbf{3}}\right)$ & $\begin{array}{c}\text { Total Suspended } \\
\text { Particles }\left(\mu \mathbf{g} / \mathbf{m}^{\mathbf{3}}\right)\end{array}$ & Qualification Status \\
\hline 1989 & N/A & N/A & N/A \\
\hline 1990 & 11 & 23 & Qualified \\
\hline 1991 & 10 & 27 & Qualified \\
\hline 1992 & 12 & 30 & Qualified \\
\hline 1993 & 9 & 21 & Qualified \\
\hline 1994 & 9 & 19 & Qualified \\
\hline 1995 & 10 & 27 & Qualified \\
\hline 1996 & 10 & 26 & Qualified \\
\hline 1997 & 9 & 20 & Qualified \\
\hline
\end{tabular}

NOTES: $\quad N / A=$ not available. Sampling began in April. Insufficient data for annual averages.

See Table C-2 for the source DTN for airborne particulate data.

Descriptive statistics were performed in this qualification using an Excel spreadsheet on the two groups of data sets for airborne $\mathrm{PM}_{10}$ annual averages (Table $\mathrm{C}-5$ ) and TSP annual averages (Table C-6) to determine the mean, standard deviation, and range of values. The mean and range of values from the data sets are compared to determine if the data results calculated from the unqualified data are within one standard deviation of the mean and closely resemble the range of the qualified data.

Table C-5. Airborne $\mathrm{PM}_{10}$ Measurement Descriptive Statistics

\begin{tabular}{|l|c|c|c|}
\hline \multicolumn{1}{|c|}{ Statistics } & 1989 through 1997 & 1998 through 2001 & Difference \\
\hline Mean $\left(\mu \mathrm{g} / \mathrm{m}^{\mathbf{3}}\right)$ & 10.00 & 9.25 & -0.75 \\
\hline Standard Deviation & 1.07 & 2.22 & +1.15 \\
\hline Minimum $\left(\mu \mathrm{g} / \mathrm{m}^{3}\right)$ & 9 & 7 & -2 \\
\hline Maximum $\left(\mu \mathrm{g} / \mathrm{m}^{3}\right)$ & 12 & 12 & 0 \\
\hline Count & 8 & 4 & -4 \\
\hline
\end{tabular}

The annual $\mathrm{PM}_{10}$ mean of the unqualified data sets $\left(9.25 \mu \mathrm{g} / \mathrm{m}^{3}\right)$ falls within one standard deviation of the annual $\mathrm{PM}_{10}$ mean from the qualified data sets $\left(10.00 \mu \mathrm{g} / \mathrm{m}^{3}\right)$ (Table C-5). The minimum $\mathrm{PM}_{10}$ value for the unqualified data sets $\left(7 \mu \mathrm{g} / \mathrm{m}^{3}\right)$ is slightly less than the minimum $\mathrm{PM}_{10}$ value of the qualified data sets $\left(9 \mu \mathrm{g} / \mathrm{m}^{3}\right)$. The maximum $\mathrm{PM}_{10}$ value $\left(12 \mu \mathrm{g} / \mathrm{m}^{3}\right)$ is the same for both data sets. The smaller number of unqualified data sets adds to the uncertainty in determining the mean and range of values, but does not impact the results. 
Table C-6. Airborne TSP Measurement Descriptive Statistics

\begin{tabular}{|l|c|c|c|}
\hline \multicolumn{1}{|c|}{ Statistics } & 1989 through 1997 & 1998 through 2001 & Difference \\
\hline Mean $\left(\mu \mathrm{g} / \mathrm{m}^{3}\right)$ & 24.13 & 20.5 & -3.63 \\
\hline Standard Deviation & 3.94 & 3.54 & -0.40 \\
\hline Minimum $\left(\mu \mathrm{g} / \mathrm{m}^{3}\right)$ & 19 & 18 & -1 \\
\hline Maximum $\left(\mu \mathrm{g} / \mathrm{m}^{3}\right)$ & 30 & 23 & -7 \\
\hline Count & 8 & 2 & -6 \\
\hline
\end{tabular}

The mean annual TSP value of the unqualified data sets $\left(20.5 \mu \mathrm{g} / \mathrm{m}^{3}\right)$ falls within one standard deviation of the mean annual TSP value from the qualified data sets $\left(24.13 \mu \mathrm{g} / \mathrm{m}^{3}\right)$ (Table C-6). The minimum TSP value for the unqualified data sets $\left(18 \mu \mathrm{g} / \mathrm{m}^{3}\right)$ correlates with the minimum value of the qualified data sets $\left(19 \mu \mathrm{g} / \mathrm{m}^{3}\right)$. The maximum TSP value $\left(23 \mu \mathrm{g} / \mathrm{m}^{3}\right)$ from the unqualified data sets is slightly less than the maximum value for the qualified data set $\left(30 \mu \mathrm{g} / \mathrm{m}^{3}\right)$. There were only two unqualified data sets since TSP data collection was discontinued in 1999. The limited number of unqualified data sets adds to the uncertainty in determining the mean and range of values, but does not significantly impact the results.

The qualification team concluded that the values of $\mathrm{PM}_{10}$ and TSP collected from Site 5 during 1998 though 2001 agree with the mean value and correlate to the range of values collected from Site 5 during 1989 though 1997. The organization, equipment, measurement systems, calculations, and procedures followed during 1998 through 2001 were consistent with those used to collect the previous qualified data. The $\mathrm{PM}_{10}$ and TSP properties in the cited data correlate to the expected material properties addressed in this analysis of dust deliquescence for FEP screening. The data are available in the TDMS and cited in the Records Information System. The qualification team recommends that the airborne particulate data sets from Site 5 for 1998 through 2001 be considered "Qualified for Intended Use" in this analysis. 


\section{\begin{tabular}{l|l} 
BSC & Data Qualification Plan
\end{tabular}}

Complete only applicable items.

\begin{tabular}{|l}
\hline Section I. Organizational Information \\
\hline Qualification Title \\
QUALIFICATION OF AIRBORNE PARTICULATE MEASUREMENTS FROM SITE 5 FOR 1998 \\
\hline Requesting Organization \\
PCA - NEAR FIELD ENVIRONMENT \\
\hline Section II. Process Planning Requirements \\
\hline 1. List of Unqualified Data to be Evaluated \\
MO0104SEPAMARQ.001 - Ambient Air Quality - 1998 Particulate Matter Concentration \\
MO0104SEPAMARQ.002 - Ambient Air Quality - 1999 Particulate Matter Concentration \\
MO0104SEPAMARQ.003 - Ambient Air Quality - 2000 Particulate Matter Concentration \\
MO0505SEPAMARQ.004 - Ambient Air Quality - 2001 Particulate Matter Concentration
\end{tabular}

2. Type of Data Qualification Method(s) [Including rationale for selection of method(s) (Attachment 3) and qualification attributes (Attachment 4)]

Corroborating Method is used by comparing unqualified data sets with qualified airborne particulate matter data sets from Site 5 collected from 1989 through 1997. The primary qualification attribute is to determine the extent and quality of corroborating data. Additional attributes include evaluation of the organization generating the data, the technical adequacy of equipment and procedures used to collect and analyze data, the extent to which the data demonstrate the properties of interest, prior uses of the data, prior professional reviews of the data and their results, and extent and reliability of documentation associated with the data.

3. Data Qualification Team and Additional Support Staff Required

Charles Bryan - Qualification Chairperson

Gene Safley - Team Member

Ernest Hardin - Responsible Manager

\section{Data Evaluation Criteria}

Mean and range of $\mathrm{PM}_{10}$ and TSP data results calculated from the unqualified data sets will be compared with the mean and range of results from qualified data sets conducted under the same collection methods, environmental conditions, and procedural requirements. If the mean of the unqualified data sets is within one standard deviation of the mean from the qualified data sets, and the range of values correlate between the unqualified and qualified data sets, the data will be considered Qualified for Intended Use within Analysis Report ANL-EBS-MD-000074 REV 01.

\section{Identification of Procedures Used \\ LP-SIII.2Q-BSC \\ LP-SIII.9Q-BSC}

Section III. Approval

\begin{tabular}{|l|l|l|}
\hline $\begin{array}{l}\text { Qualification Chairperson Printed Name } \\
\text { Charles Bryan }\end{array}$ & Qualification Chairperson Signature & Date \\
\hline $\begin{array}{l}\text { Responsible Manager Printed Name } \\
\text { Ernest Hardin }\end{array}$ & Responsible Manager Signature & Date \\
\hline
\end{tabular}

LP-SIII.2Q-BSC 


\section{INTENTIONALLY LEFT BLANK}


APPENDIX D

CORROBORATION OF THE SOLUBILITY OF OXYGEN IN WATER FROM EPRI REPORT 


\section{D.1 CORROBORATION OF THE SOLUBILITY OF OXYGEN IN WATER USING PERRY ET AL. 1984 [DIRS 125806]}

The solubility of oxygen in water is given by EPRI (2004 [DIRS 172825], Figure 5.5) as a 5 th-order polynomial in temperature. The reference given for this solubility polynomial does not provide the details on how the polynomial is derived. Therefore, the solubility of oxygen as predicted by this EPRI 5th-order polynomial is corroborated by comparing the prediction with that obtained from a handbook (Perry et al. 1984 [DIRS 125806]) as follows.

Perry et al. (1984 [DIRS 125806]) present the Henry's Law coefficient, designated as H, for oxygen in water in Table 3-140, p. 3-103, according to the definition of Henry's Law on p. 3-101. Henry's Law as used here is the expression $p=H x$, where $x$ is the mole fraction of the solute (oxygen in this case) in the liquid phase (water), $p$ is the partial pressure of the solute in the gas phase expressed in atmospheres, and $\mathrm{H}$ is a proportionality constant and is in units of atmospheres of solute pressure in the gas phase per unit concentration in the liquid phase.

The solute (dissolved oxygen) is taken to be in equilibrium with the gas phase, which is air. The composition of air must be taken into account in order to obtain the partial pressure (or pressure) of oxygen in the water. The composition of air with respect to oxygen is 0.20946 moles per mole of air (Perry et al. 1984 [DIRS 125806], caption for Figure 3-16, p. 3-160); for calculations, a value of 0.21 is adopted. Therefore, the partial pressure of oxygen is the total atmospheric pressure multiplied by 0.21 .

The total atmospheric pressure at the elevation of the repository is 0.88 atmosphere, as discussed in Ventilation Model and Analysis Report (BSC 2004 [DIRS 169862], Appendix XIX). Therefore, the partial pressure of oxygen of interest at the elevation of the repository is $0.88 \times 0.21=0.1848$ atmosphere.

The prediction of the solubility of oxygen in water from the 5 th order polynomial in temperature from the EPRI (2004 [DIRS 172825]) report appears to be based on one atmosphere total pressure. The reason for this conclusion is based on the observation that 0.88 times the EPRI (2004 [DIRS 172825]) prediction yields the same result (and curve shape) using the information from Perry et al. (1984 [DIRS 125806]) utilizing a total pressure of 0.88 atmosphere as described here. This comparison, and hence corroboration, is presented in Table D-1 and illustrated in Figure D-1.

It is concluded, based on the comparison described here, that the prediction of the solubility of oxygen in the EPRI (2004 [DIRS 172825]) report is corroborated with data (in the form of Henry's Law constants) obtained from a reliable source (Perry et al. 1984 [DIRS 125806]). Therefore, the prediction of the solubility of oxygen in the EPRI (2004 [DIRS 172825]) report is suitable for the intended use. 
Table D-1. Corroboration of EPRI Oxygen Solubility Prediction

\begin{tabular}{|c|c|c|c|}
\hline Input Variables: & $\begin{array}{l}\mathrm{x}\left(\mathrm{O}_{2}\right)=0.21 \text { in air } \\
\mathrm{P}_{\text {total }}=0.88 \text { atmosphere } \\
\mathrm{H}_{2} \mathrm{O} \mathrm{m} / \mathrm{l}=55 \text { moles } / \text { liter } \\
\mathrm{O}_{2} \mathrm{mw}=32 \mathrm{grams} / \mathrm{mole}\end{array}$ & EPRI Oxygen Solubility Coefficients: ${ }^{\mathrm{a}}$ & $\begin{array}{r}-1.48 \mathrm{E}-14 \times \mathrm{T}^{\wedge} 5 \\
2.83 \mathrm{E}-11 \times \mathrm{T}^{\wedge} 4 \\
-2.16 \mathrm{E}-08 \times \mathrm{T}^{\wedge} 3 \\
8.25 \mathrm{E}-06 \times \mathrm{T}^{\wedge} 2 \\
-1.58 \mathrm{E}-03 \times \mathrm{T}^{\wedge} 1 \\
1.21 \mathrm{E}-01 \times \mathrm{T}^{\wedge} 0\end{array}$ \\
\hline
\end{tabular}

\begin{tabular}{|c|c|c|c|c|c|c|c|}
\hline $\begin{array}{l}\text { Temp. } \\
\left({ }^{\circ} \mathrm{C}\right)\end{array}$ & H Values ${ }^{\text {b }}$ & $\begin{array}{c}\text { Henry's H in } \\
P=\text { Hx }^{c}\end{array}$ & $\begin{array}{l}\text { Oxygen mole fraction } \\
\text { in water at } 0.88 \mathrm{~atm}^{\mathrm{d}}\end{array}$ & $\begin{array}{c}\text { Oxygen moles per liter } \\
\text { in } \mathrm{H}_{2} \mathrm{O} \text { at } 0.88 \mathrm{~atm}^{\mathrm{e}}\end{array}$ & $\begin{array}{l}\text { Oxygen ppm } \\
\text { at } 0.88 \mathrm{~atm}\end{array}$ & $\begin{array}{c}\mathrm{O}_{2} \text { Solubility in } \mathrm{H}_{2} \mathrm{O}, \\
\mathrm{mol} / \mathrm{L} \text { at } 1 \mathrm{~atm}^{\mathrm{a}}\end{array}$ & $\begin{array}{c}\mathrm{O}_{2} \text { Solubility in } \mathrm{H}_{2} \mathrm{O}, \mathrm{mol} / \mathrm{L} \\
\text { at } 0.88 \mathrm{~atm}^{\mathrm{a}}\end{array}$ \\
\hline 0 & 2.55 & 25,500 & $7.25 E-06$ & 3.99E-04 & 12.8 & $4.58 \mathrm{E}-04$ & 4.03E-04 \\
\hline 5 & 2.91 & 29,100 & $6.35 \mathrm{E}-06$ & 3.49E-04 & 11.2 & 4.06E-04 & 3.57E-04 \\
\hline 10 & 3.27 & 32,700 & $5.65 \mathrm{E}-06$ & $3.11 \mathrm{E}-04$ & 9.9 & $3.62 \mathrm{E}-04$ & $3.18 \mathrm{E}-04$ \\
\hline 15 & 3.64 & 36,400 & $5.08 \mathrm{E}-06$ & $2.79 \mathrm{E}-04$ & 8.9 & $3.25 E-04$ & $2.86 \mathrm{E}-04$ \\
\hline 20 & 4.01 & 40,100 & $4.61 \mathrm{E}-06$ & $2.53 \mathrm{E}-04$ & 8.1 & 2.94E-04 & $2.59 \mathrm{E}-04$ \\
\hline 25 & 4.38 & 43,800 & 4.22E-06 & 2.32E-04 & 7.4 & 2.69E-04 & $2.37 \mathrm{E}-04$ \\
\hline 30 & 4.75 & 47,500 & 3.89E-06 & $2.14 \mathrm{E}-04$ & 6.8 & $2.49 \mathrm{E}-04$ & $2.19 \mathrm{E}-04$ \\
\hline 35 & 5.07 & 50,700 & $3.64 \mathrm{E}-06$ & $2.00 \mathrm{E}-04$ & 6.4 & $2.32 \mathrm{E}-04$ & 2.04E-04 \\
\hline 40 & 5.35 & 53,500 & $3.45 \mathrm{E}-06$ & 1.90E-04 & 6.1 & $2.19 \mathrm{E}-04$ & 1.92E-04 \\
\hline 45 & 5.63 & 56,300 & $3.28 \mathrm{E}-06$ & 1.81E-04 & 5.8 & $2.08 \mathrm{E}-04$ & 1.83E-04 \\
\hline 50 & 5.88 & 58,800 & $3.14 \mathrm{E}-06$ & 1.73E-04 & 5.5 & 1.99E-04 & 1.75E-04 \\
\hline 60 & 6.29 & 62,900 & 2.94E-06 & 1.62E-04 & 5.2 & 1.87E-04 & 1.65E-04 \\
\hline 70 & 6.63 & 66,300 & $2.79 \mathrm{E}-06$ & $1.53 \mathrm{E}-04$ & 4.9 & 1.80E-04 & $1.58 \mathrm{E}-04$ \\
\hline 80 & 6.87 & 68,700 & 2.69E-06 & $1.48 \mathrm{E}-04$ & 4.7 & 1.76E-04 & 1.55E-04 \\
\hline 90 & 6.99 & 69,900 & $2.64 \mathrm{E}-06$ & $1.45 \mathrm{E}-04$ & 4.7 & 1.74E-04 & 1.53E-04 \\
\hline 100 & 7.01 & 70,100 & 2.64E-06 & $1.45 \mathrm{E}-04$ & 4.6 & 1.75E-04 & 1.54E-04 \\
\hline
\end{tabular}

${ }^{a}$ From EPRI 2004 [DIRS 172825], Figure 5.5.

${ }^{\mathrm{b}}$ From Perry et al. 1984 [DIRS 125806].

c Values multiplied by 10,000 , per instructions.

d Calculated from $0.21 \times 0.88 /($ Henry's $\mathrm{H})$.

e Oxygen mole fraction $\times 55$.

NOTES: The solubilities presented above pertain to oxygen in air at the total pressure indicated; the results can be reproduced by "hand calculations."

Henry's Law coefficient from Perry et al. 1984 [DIRS 125806], Table 3-140, p. 3-103. Definition: $p=H x$ where $p$ is the partial pressure of the gas in atmospheres, $x$ is mole fraction of the solute in the liquid phase (see Perry et al. 1984 [DIRS 125806], p. 3-101).

The partial pressure of oxygen in air is based on the composition of "air," oxygen mole fraction is 0.20946 (see Perry et al. 1984 [DIRS 125806], caption for Figure 3-16, p. 3-169). Use 0.21. Atmospheric pressure is $0.88 \mathrm{~atm}$ at the elevation of the repository (see BSC 2004 [DIRS 169862], Appendix XIX).

For one (1) liter of water, use 55 moles per liter (from 1,000 g/liter divided by $18 \mathrm{~g} / \mathrm{mole}=55.5$; use 55). See Perry et al. 1984 [DIRS 125806], Table 3-1, p. 4-24, for specific gravity = 1; Table 3-1, p. 3-18, for the molecular weight of water $=18.016$. Use 18 . 


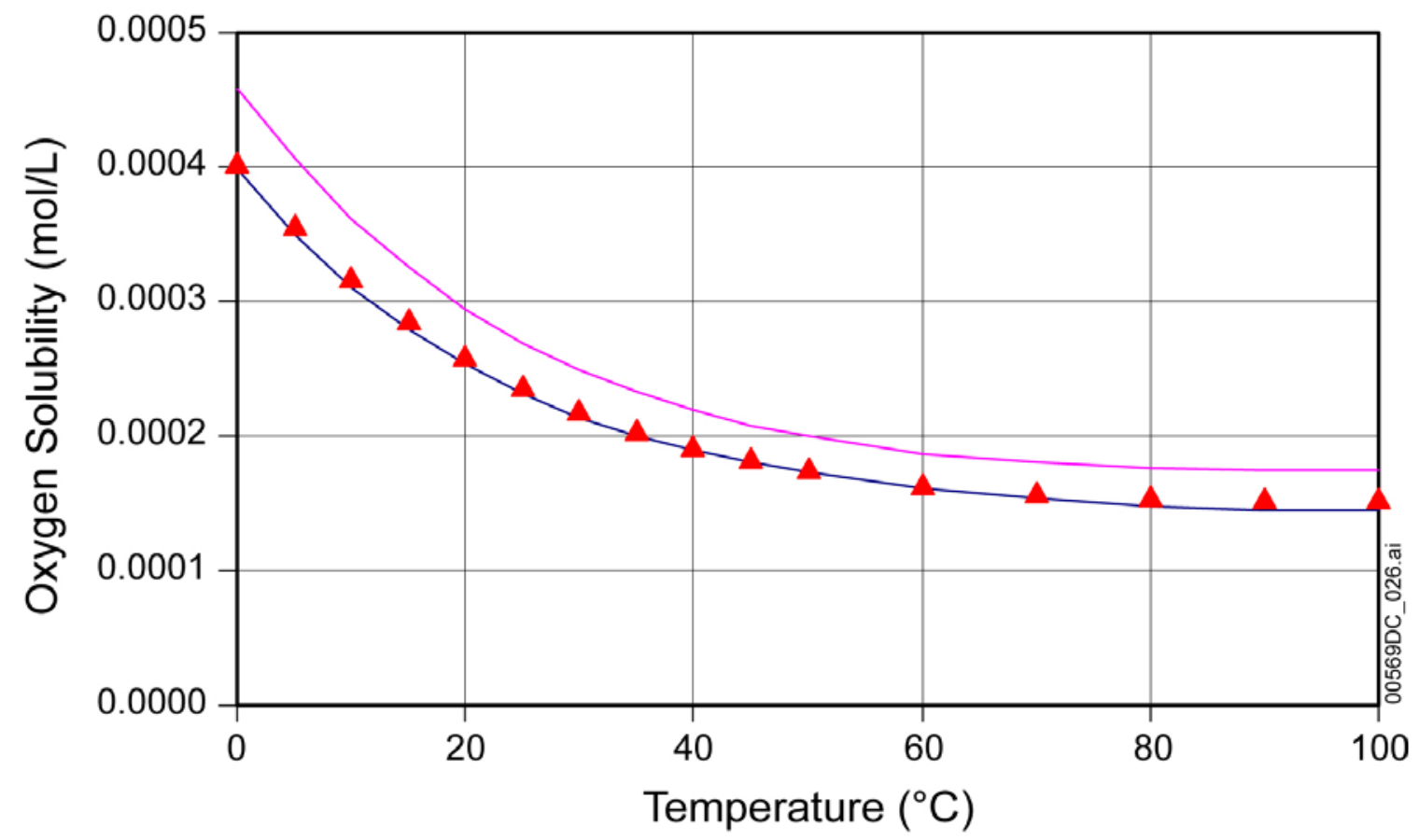

NOTE: Upper solid curve $\left(P_{\text {total }}=1 \mathrm{~atm}\right)$ is from EPRI 2004 [DIRS 172825]; lower solid curve $\left(P_{\text {total }}=0.88\right.$ atm $)$ is from Perry et al. 1984 [DIRS 125806]. Triangles are EPRI curve multiplied by 0.88 . Therefore, the EPRI oxygen solubility is corroborated.

Figure D-1. Corroboration of Polynomial Fit for Temperature-Dependent Oxygen Solubility in Water

\section{D.2 CORROBORATION OF THE SOLUBILITY OF OXYGEN IN WATER USING DATAO.YMP.R2}

Additional corroboration for the use of the predicted solubility of oxygen in water given by the EPRI (2004 [DIRS 172825], Figure 5.5) report is provided here. Specifically, hand calculations are performed to compare oxygen solubility in water using the $\log (K)$ constants at given temperatures $\left(0,25,60\right.$, and $100^{\circ} \mathrm{C}$ ) from data0.ymp.R2 (DTN: MO0302SPATHDYN.000 [DIRS 161756]), against oxygen solubility predicted by the EPRI 5th order polynomial. First, the data0.ymp.R2 oxygen (aq) $\log \left(K_{e q}\right)$ constants at the specified temperatures in Table D-2 are converted to $K_{e q}$. The associated data0.ymp.R2 oxygen solubilities (Table D-2, column 3) are then calculated by dividing the $\mathrm{pO}_{2}$ of oxygen in air $(0.21)$ by $K_{e q}$ for each temperature, following the equation:

$$
K_{e q}=\left[p O_{2}(g) / c O_{2}(a q)\right]
$$

Where $p$ is partial pressure (atmospheres) and $c$ is concentration. 
The EPRI oxygen solubilities in Table D-2 (column 4) are then calculated by solving the 5th-order polynomial given by EPRI (2004 [DIRS 172825], Figure 5.5), where $T$ is temperature in degrees Kelvin $(\mathrm{K})$. The polynomial is also given in Section 4.1.6 and repeated here for convenience.

- Oxygen solubility $(\mathrm{mol} / \mathrm{L})=-1.4842 \mathrm{E}-14 \mathrm{~T}^{5}+2.8347 \mathrm{E}-11 \mathrm{~T}^{4}-2.1630 \mathrm{E}-08 \mathrm{~T}^{3}+$ $8.2524 \mathrm{E}-06 \mathrm{~T}^{2}-1.5759 \mathrm{E}-03 \mathrm{~T}+1.2078 \mathrm{E}-01$

The results given in Table D-2 show that the calculated oxygen solubility (at the four various temperatures) given by data0.ymp.R2 is very similar to that predicted by the EPRI polynomial, and thus the solubility of oxygen predicted by EPRI (2004 [DIRS 172825]) is further justified for the intended use.

Table D-2. Comparison of Oxygen Solubility at $1 \mathrm{~atm}$

\begin{tabular}{|c|c|c|c|c|}
\hline $\begin{array}{c}\text { Temperature } \\
(\text { K) }\end{array}$ & $\begin{array}{c}\text { data0.ymp.R2 } \\
\left.\text { Oxygen log( } \boldsymbol{K}_{\text {eq }}\right)\end{array}$ & $\begin{array}{c}\text { data0.ymp.R2 } \\
\text { Oxygen Solubility } \\
\text { (mol/L) }^{\mathbf{a}}\end{array}$ & $\begin{array}{c}\text { EPRI Oxygen } \\
\text { Solubility } \\
(\mathbf{m o l} / \mathbf{L})^{\mathbf{a}}\end{array}$ & \% Difference \\
\hline 273.15 & 2.657 & $4.63 \mathrm{E}-04$ & $4.57 \mathrm{E}-04$ & 1.34 \\
\hline 298.15 & 2.898 & $2.66 \mathrm{E}-04$ & $2.69 \mathrm{E}-04$ & 1.22 \\
\hline 333.15 & 3.063 & $1.82 \mathrm{E}-04$ & $1.87 \mathrm{E}-04$ & 3.06 \\
\hline 373.15 & 3.108 & $1.64 \mathrm{E}-04$ & $1.75 \mathrm{E}-04$ & 6.30 \\
\hline
\end{tabular}

a Partial pressure $(0.21)$ divided by $K_{\text {eq. }}$. Rounded to three significant figures. 
APPENDIX E

SUMMARY OF MAY 2004 PRESENTATIONS TO THE

NUCLEAR WASTE TECHNICAL REVIEW BOARD 
This appendix summarizes two presentations to the NWTRB in May of 2004. The first, by Dr. Carl I. Steefel of Lawrence Berkeley National Laboratory, summarizes the in-drift chemical environment during the above-boiling period, a period during which only dust deliquescence can potentially result in aqueous conditions on the waste package surface (Steefel 2004 [DIRS 173671]). The second, by Professor Joe H. Payer of Case Western Reserve University, discusses corrosion of Alloy 22 (Payer 2004 [DIRS 173672]). Much of the information in these presentations is directly relevant to the screening analysis presented here. The presentations are summarized below as background information to this analysis. It should be noted that these presentations reflect the state of knowledge at the time they were given.

\section{E.1 DR. CARL I. STEEFEL: IN-DRIFT CHEMICAL ENVIRONMENT DURING THE ABOVE-BOILING PERIOD}

This section summarizes the presentation by Steefel (2004 [DIRS 173671]). The chemical behavior of dust constituents depend on the thermal-hydrologic environment (temperature, humidity), as well as the dust composition. Temperature and humidity are controlled by the waste heat output, and the heat- and mass-transfer processes in the near-field host rock. The thermal evolution of the repository can be described by the following time periods (Figure E-1):

I. Emplacement of waste packages and preclosure ventilation

II. Heat-up after closure

III. Cooldown/thermal barrier (waste package surface and drift wall above boiling temperature)

IV. Cooldown/dripping and seepage possible (waste package surface above boiling; drift wall below boiling)

V. Waste package environment evolves beyond critical conditions for corrosion.

Of these periods, only II through IV involve waste package or drift wall temperatures above the boiling point of water (approximately $96^{\circ} \mathrm{C}$ throughout the repository). These periods can be described as a relatively short period of heating that dries out the drift and the host rock, followed by a longer period of cooling during which no seepage into drifts occurs because the drift wall temperature is above boiling (i.e., above a temperature of $100^{\circ} \mathrm{C}$ as given by $\mathrm{BSC} 2004$ [DIRS 169131], Section 6.5.2.2). During this interval, the only aqueous phase that could potentially contact the waste package (even if the drip shields do not perform their function) is brine that originates by deliquescence of soluble salts in dust deposited on the waste package during emplacement and ventilation. Note that each waste package will progress through these stages, but cooler packages will do so sooner than hotter ones. The waste package surface is always warmer than the drift wall, but the difference diminishes with time. 


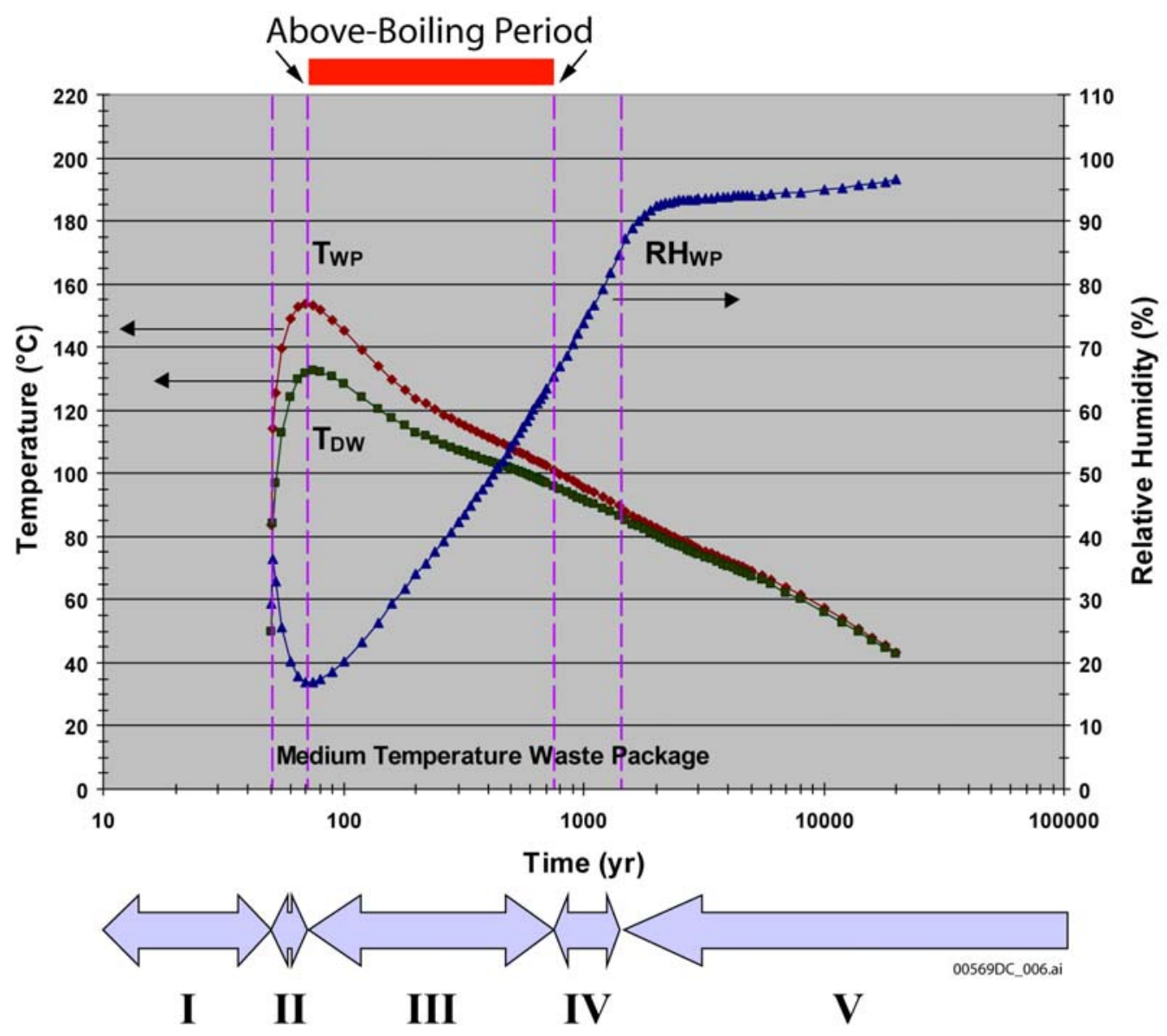

Source: Steefel 2004 [DIRS 173671], p. 6.

Figure E-1. Periods in the Thermal Evolution of the Repository

Overview of Salt Deliquescence - Salt deliquescence is a natural process inherent to soluble solids that exist in an environment containing water vapor. Dust that either originates in the repository or is blown in by forced ventilation contains salts such as $\mathrm{NaCl}$ or $\mathrm{NaNO}_{3}$ that deliquesce at relative humidity values less than $100 \%$. In a brine, the water activity (equivalent to $\mathrm{RH}$ ) is always less than $100 \%$, and when the water activity in a brine is less than the relative humidity in the air, moisture is absorbed into the liquid, thus diluting the brine. For highly deliquescent salts (e.g., $\mathrm{CaCl}_{2}$ ), the resulting brine can exist as a liquid at temperatures significantly above the boiling point of pure water. General deliquescence behavior of single salts and salt assemblages is described in Environment on the Surfaces of the Drip Shield and Waste Package Outer Barrier (BSC 2004 [DIRS 161237], Section 6.4.1).

Brine in the repository may form by the deliquescence of two or more salts together, and exhibit a eutectic composition (Figure E-2). This composition is specific to the particular combination of salts, and is associated with the lowest RH at which a multicomponent solution can form. The eutectic RH for a particular combination of salts generally decreases with increasing temperature for salts that become more soluble with increasing temperature. The most soluble salt in a combination may dominate the eutectic composition, but the eutectic RH is always lower than the deliquescence RH for any pure end-member salt by itself. When the RH in the environment 
increases, one of the salts must completely dissolve, and the brine composition evolves along a defined path (solvus). Finally, at higher RH, sufficient water is adsorbed from the atmosphere that all salts dissolve, and the brine composition leaves the solvus. It is only at this point that the relative proportion of salts in the brine matches the initial salt mixture.

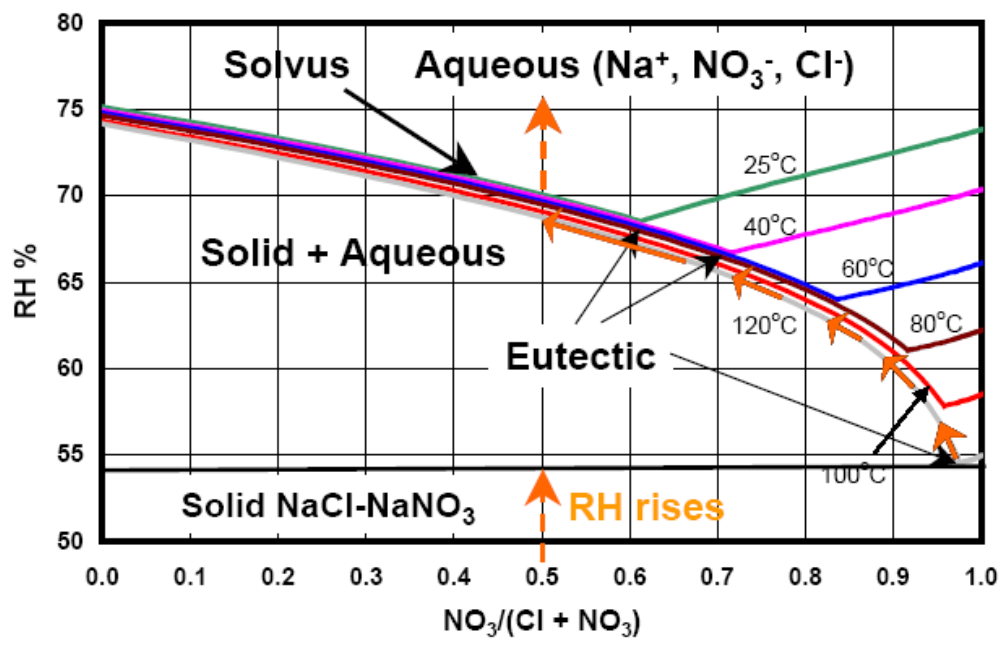

Source: Steefel 2004 [DIRS 173671], p. 12.

Figure E-2. $\mathrm{RH}$ versus Mole-Fraction $\mathrm{NO}_{3}$ for $\mathrm{NaCl}-\mathrm{NaNO}_{3}$ System

Salts Present in Dust-During the above-boiling period in the repository, deliquescence of salt-bearing dusts is the only mechanism for aqueous conditions to occur on the waste package. To date, only small amounts of soluble salts have been found in repository dusts, though these amounts could increase as a result of atmospheric dust introduced during repository operation.

In tests conducted by the USGS, dust was collected by vacuuming sample surfaces in the Exploratory Studies Facility. The amount of dust accumulation registered in these tests ranged from 0.012 to $0.023 \mathrm{~g} / \mathrm{cm}^{2}$. The soluble mineral content of dust samples was determined by leaching with deionized water and analyzing the leachate. However, this process does not provide mineralogical information. Two methods were used to evaluate the mineralogy of the salts in the dust. In the first, the dust leachates were evaporated to dryness and analyzed by $\mathrm{X}$-ray diffraction. This process concentrates the salts, present in only fractions of a percent in the dust, to the point where salt minerals can be identified. The results are shown in Table E-1, and are largely consistent with chemical analysis, which indicates that sodium, chloride, and sulfate are major soluble components in the dust. However, the results are not quantitative; salts have to be present in concentrations of several percent relative abundance to be inferred. Nitrate, which is a significant component of the leachates as determined from ion chromatography, was not detected because the abundance of each nitrate salt (e.g., $\mathrm{NaNO}_{3}, \mathrm{KNO}_{3}$ ) was less than the detection limit. 
Table E-1. X-Ray Diffraction Analysis of Salts Precipitated from Evaporated Dust Leachate

\begin{tabular}{|l|c|c|c|c|c|}
\hline \multicolumn{1}{|c|}{ Salt } & Sample 1 & Sample 2 & Sample 3 & Sample 4 & Sample 5 \\
\hline $\mathrm{NaCl}$ & $\mathrm{X}$ & $\mathrm{XX}$ & $\mathrm{XX}$ & $\mathrm{XX}$ & $\mathrm{XX}$ \\
\hline $\mathrm{KCl}$ & & & & & \\
\hline $\mathrm{NH}_{4} \mathrm{Cl}$ & $\mathrm{X}$ & $\mathrm{X}$ & $\mathrm{X}$ & & \\
\hline $\mathrm{CaCO}_{3}$ & $\mathrm{XX}$ & $\mathrm{X}$ & & $\mathrm{X}$ & \\
\hline $\mathrm{CaSO}_{4} 2 \mathrm{H}_{2} \mathrm{O}$ & & & $\mathrm{XX}$ & $\mathrm{X}$ & \\
\hline $\mathrm{CaSO}_{4} 5 \mathrm{H}_{2} \mathrm{O}$ & $\mathrm{X}$ & & & & \\
\hline$\left(\mathrm{NH}_{4}\right)_{2} \mathrm{SO}_{4}$ & $\mathrm{X}$ & & & & \\
\hline$\left(\mathrm{NH}_{4}, \mathrm{~K}_{2} \mathrm{H}_{2} \mathrm{PO}_{4}\right.$ & & $\mathrm{X}$ & $\mathrm{X}$ & & \\
\hline $\mathrm{CaC}_{2} \mathrm{O}_{4} 2 \mathrm{H}_{2} \mathrm{O}$ & & & & \\
\hline
\end{tabular}

Source: Steefel 2004 [DIRS 173671], p. 18.

NOTE: $\quad \mathrm{XX}=$ major component; $\mathrm{X}=$ minor component. Analysis conducted at the USGS.

Another method of analysis involves computationally "evaporating" dust leachate solutions with the computer code EQ3/6 to yield a primary assemblage of deliquescent salts. This has been done for the entire suite of dust leachate compositions, and the salts contributing to deliquescence behavior have been identified (Table E-2). They fall in three suites, consisting largely of sodium and potassium chlorides and nitrates. Potassium bromide is also present in each assemblage, but the bromide is probably an artifact of the lithium bromide tracer added to construction water used in underground activities at the site.

Table E-2. Salt Mineralogy Calculated with EQ3/6

\begin{tabular}{|l|c|}
\hline \multicolumn{1}{|c|}{ Main Predicted Salts } & Occurrence (\%) \\
\hline $\mathrm{NaCl}-\mathrm{NaNO}_{3}-\mathrm{KNO}_{3}-\mathrm{KBr}$ & 28 \\
\hline $\mathrm{NaCl}-\mathrm{KNO}_{3}-\mathrm{KBr}$ & 68 \\
\hline $\mathrm{Ca}\left(\mathrm{NO}_{3}\right)_{2}-\mathrm{NaCl}-\mathrm{NaNO}_{3}-\mathrm{KNO}_{3}-\mathrm{KBr}$ & 4 \\
\hline
\end{tabular}

Source: Steefel 2004 [DIRS 173671], p. 19.

Both of these analyses provide an equilibrium salt assemblage - the soluble minerals present in the dust if all were in chemical or thermodynamic equilibrium. However, to some extent the dust may contain a mechanical mixture of dry salts that have not chemically equilibrated, so these analyses are an approximation to the actual salt mineralogy in the dust.

Generation of $\mathrm{CaCl}_{2}$ or $\mathbf{M g C l}_{2}$ Brines by Salt in Repository Dust-The divalent-cation chloride salts $\mathrm{CaCl}_{2}$ and $\mathrm{MgCl}_{2}$ are potentially corrosive, and their importance to waste package corrosion has been investigated as described below. The thermodynamic calculations described above provide a description of the equilibrium salt assemblages present in the dust, and indicate that $\mathrm{CaCl}_{2}$ or $\mathrm{MgCl}_{2}$ salts are not part of the eutectic salt assemblages. (Such calculations are performed for the analysis presented in Sections 6.1, 6.2, and 6.3 of this report.) 
As background information, a geochemical description of the conditions necessary to generate $\mathrm{CaCl}_{2}$ or $\mathrm{MgCl}_{2}$ brines by salt deliquescence follows, providing insight into why these brines do not form. The formation of $\mathrm{CaCl}_{2}$ brines is possible only if the following conditions are met in the aqueous phase:

- $\mathrm{Ca}>\mathrm{SO}_{4}+\mathrm{CO}_{3}$

- $\mathrm{Cl}>\mathrm{Na}+\mathrm{K}$

using molar concentrations. $\mathrm{CaSO}_{4}$ and $\mathrm{CaCO}_{3}$ are relatively insoluble and will therefore form first, so the amount of $\mathrm{Ca}$ present must exceed the amount of $\mathrm{SO}_{4}$ and $\mathrm{CO}_{3}$ available for $\mathrm{CaCl}_{2}$ to precipitate. Similarly, the chloride molar concentration must exceed that of $\mathrm{Na}+\mathrm{K}$, as $\mathrm{NaCl}$ and $\mathrm{KCl}$ are less soluble than $\mathrm{CaCl}_{2}$.

Similarly for $\mathrm{MgCl}_{2}$, the following three conditions must be met:

- $\mathrm{Mg}>\mathrm{CO}_{3}$

- $\mathrm{Cl}>\mathrm{Na}+\mathrm{K}$

- Insufficient availability of silica.

A "low-silica" environment must exist, since $\mathrm{Mg}$ will readily precipitate as sepiolite and/or other low-solubility Mg-aluminosilicates, and will be removed from solution if soluble silica exceeds $\mathrm{Mg}$ in the soluble fraction. This condition is never met for the dust leachates, as they contain abundant soluble silica (BSC 2004 [DIRS 161237], Section 6.7.2.10).

Considering that the bulk composition of leachates from tunnel dust does not result in precipitation of $\mathrm{CaCl}_{2}$ or $\mathrm{MgCl}_{2}$, the only other potential source for these salts would be from atmospheric dust introduced by operational activities (e.g., tunneling, construction) or inducted by forced ventilation during the repository preclosure phase (50-year ventilation period). However, these are unlikely sources. The divalent chloride salt minerals are known to exist on the earth's surface at only a few locations (for example, $\mathrm{CaCl}_{2}: 6 \mathrm{H}_{2} \mathrm{O}$, or antarcticite, in Antarctica). Such occurrences appear to be ephemeral and require low RH conditions (e.g., less than approximately $25 \% \mathrm{RH}$ and $30^{\circ} \mathrm{C}$; see BSC 2004 [DIRS 161237], Section 6.7.2) to preserve the salts in situ, conditions which are unlikely to be maintained during atmospheric transport. Should antarcticite or related salts be transported into the repository as solid salt grains or brine aerosols in dust and settle on waste package surfaces, they will be present in the form of a mechanical mixture, and will not be in thermodynamic equilibrium. Any such disequilibrium salt assemblage would almost immediately equilibrate upon initial deliquescence, leading back to a dry state via a reaction such as:

$$
\mathrm{CaCl}_{2}(\mathrm{aq})+\mathrm{Na}_{2} \mathrm{SO}_{4}(\mathrm{c})=\mathrm{CaSO}_{4}(\mathrm{c})+2 \mathrm{NaCl}(\mathrm{c})
$$

The reaction products here have higher deliquescence $\mathrm{RH}$ points than do the original $\mathrm{Ca}$ and $\mathrm{Mg}$ chloride salts (if they existed), causing the salt mixture to dry out. 
(It is noted that a similar reaction with $\mathrm{NaNO}_{3}$ produces a highly deliquescent nitrate-rich brine that is noncorrosive with respect to Alloy 22:

$$
\mathrm{CaCl}_{2}(\mathrm{aq})+2 \mathrm{NaNO}_{3}(\mathrm{c})=\mathrm{Ca}\left(\mathrm{NO}_{3}\right)_{2}(\mathrm{aq})+2 \mathrm{NaCl}(\mathrm{c})
$$

Potassium nitrate behaves similarly. These reactions are important because the soluble fraction of the dusts is nitrate-rich.)

In summary, the likelihood of $\mathrm{CaCl}_{2}$ or $\mathrm{MgCl}_{2}$ being introduced into the repository environment by way of atmospheric or aerosol transport is low, as are the consequences of its arrival in the form of a mechanical mixture. The soluble components in atmospheric aerosols, as determined by rainfall analyses performed as part of the National Atmospheric Deposition Program, indicate that salts in atmospheric dusts are relatively similar to those in the tunnel dusts already analyzed (Table E-3).

Table E-3. Comparison of Soluble lonic Ratios (mol/mol): Tunnel Dusts versus Nevada Rainfall

\begin{tabular}{|c|c|c|c|c|c|c|}
\hline & \multicolumn{3}{|c|}{ Tunnel Dusts ${ }^{a}$} & \multicolumn{3}{|c|}{ Nevada Rainfall $^{b}$} \\
\hline & P07 & P14 & P10 & CA95 & NV00 & NV05 \\
\hline $\mathrm{Na} / \mathrm{Cl}$ & 2.699 & 4.069 & 2.894 & 2.070 & 1.127 & 1.828 \\
\hline $\mathrm{K} / \mathrm{Cl}$ & 1.221 & 1.528 & 1.237 & 0.158 & 0.139 & 0.207 \\
\hline $\mathrm{NH}_{4} / \mathrm{Cl}$ & $\mathrm{N} / \mathrm{A}$ & $\mathrm{N} / \mathrm{A}$ & N/A & 2.605 & 5.514 & 4.633 \\
\hline $\mathrm{Mg} / \mathrm{Cl}$ & 0.072 & 0.305 & 0.175 & 0.336 & 0.555 & 0.417 \\
\hline $\mathrm{Ca} / \mathrm{Cl}$ & 8.472 & 6.389 & 2.348 & 3.101 & 2.973 & 2.907 \\
\hline $\mathrm{NO}_{3} / \mathrm{Cl}$ & 4.002 & 1.671 & 0.776 & 2.969 & 5.146 & 3.839 \\
\hline $\mathrm{SO}_{4} / \mathrm{Cl}$ & 3.123 & 3.293 & 1.458 & 1.009 & 1.384 & 1.555 \\
\hline $\mathrm{CO}_{3} / \mathrm{Cl}$ & 4.839 & 4.737 & 2.057 & 2.860 & 2.461 & 2.683 \\
\hline
\end{tabular}

Source: Steefel 2004 [DIRS 173671], p. 26.

a Three Phase I samples, each representing a different key salt assemblage.

b National Atmospheric Deposition Program, 2002 Annual Mean Data.

NOTE: $\quad$ CA95 $=$ Death Valley; NV00 $=$ Red Rock; NV05 = Great Basin.

The likelihood of $\mathrm{CaCl}_{2}$ or $\mathrm{MgCl}_{2}$ brines forming on the waste package is low for reasons discussed above, and such brines, if formed, are likely to react with other salts to form a dry rather than deliquescent assemblage. Despite their unlikely occurrence, however, the stability of these brines has been examined experimentally to evaluate the potential existence of deliquescent brines at different conditions of temperature and relative humidity in the drift.

In tests conducted at LLNL, thermogravimetric analysis was used to study deliquescent brines under different temperature and $\mathrm{RH}$ conditions under conditions of fixed gas flow through the reactor (Figure E-3). The results for $\mathrm{CaCl}_{2}$ show that at $100^{\circ} \mathrm{C}$, aqueous films are stable for the duration of the test. At $125^{\circ} \mathrm{C}$, the $\mathrm{CaCl}_{2}$ solution evolves slowly, degassing $\mathrm{HCl}$ and forming insoluble precipitates, while at $150^{\circ} \mathrm{C}$ the solution evolves more rapidly, forming non-deliquescent precipitates and acid gas. $\mathrm{MgCl}_{2}$ brines transform within hours at all temperatures, degassing $\mathrm{HCl}$ and forming non-deliquescent precipitates. The relative instability of these brines with respect to acid degassing is due to the hydroxide-chloride precipitate that 
forms. As it precipitates, it buffers the solution $\mathrm{pH}$, thus maintaining a high partial pressure of acid gas, which is then lost via volatilization.

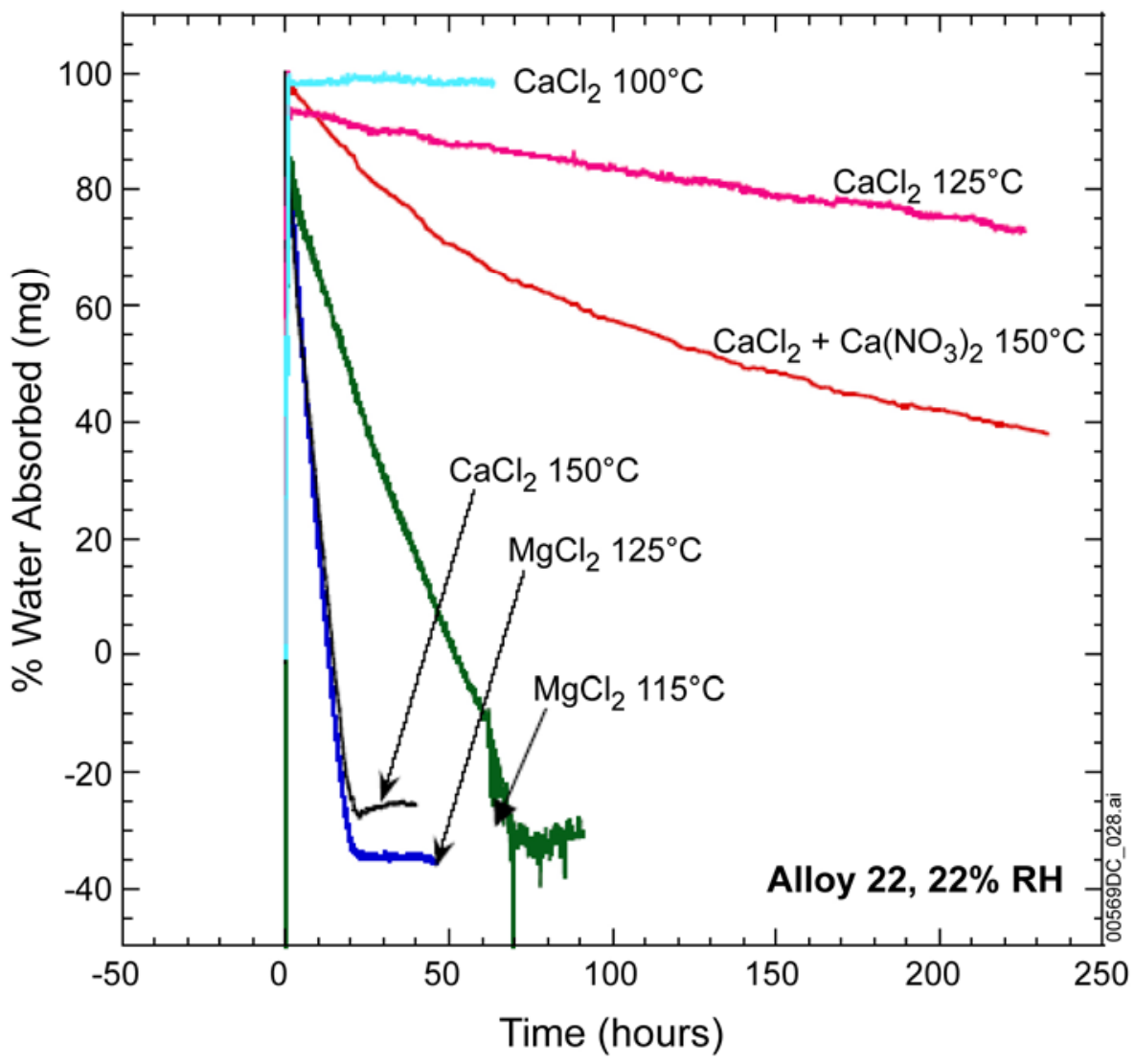

Source: Steefel 2004 [DIRS 173671], p. 29.

Figure E-3. Deliquescence and Stability of $\mathrm{CaCl}_{2}$ and $\mathrm{MgCl}_{2}$ Brines in TGA Experiments

Volatilization of Acid Gases in the Drift Environment - The relative instability of $\mathrm{CaCl}_{2}$ and $\mathrm{MgCl}_{2}$ brines is largely due to degassing of $\mathrm{HCl}$ (see Section 6.2.1). Under open-system conditions, acid degassing results in eventual dryout of the residual brine, which has been demonstrated experimentally. $\mathrm{HCl}$ gas generated as a result of salt deliquescence will disperse in the drift and migrate along fractures in the rock until moisture is encountered (Figure E-4). Because of the Henry's Law constant for $\mathrm{HCl}$ (and for other acid gases), it will partition readily into the aqueous phase. The waste packages are the hottest part of the drift environment, so they are unlikely places for any liquid water to form that could absorb the acid gases. The thermal gradients in the environment, therefore, require that any acid gases that are generated be dispersed in the cooler rock mass. The ability of gases to migrate along fractures away from the drift was documented for the drift-scale heater test (BSC 2005 [DIRS 172862], Section 7.1.10). 


\section{Dust and Salt Deliquescence \\ During the Thermal Period}

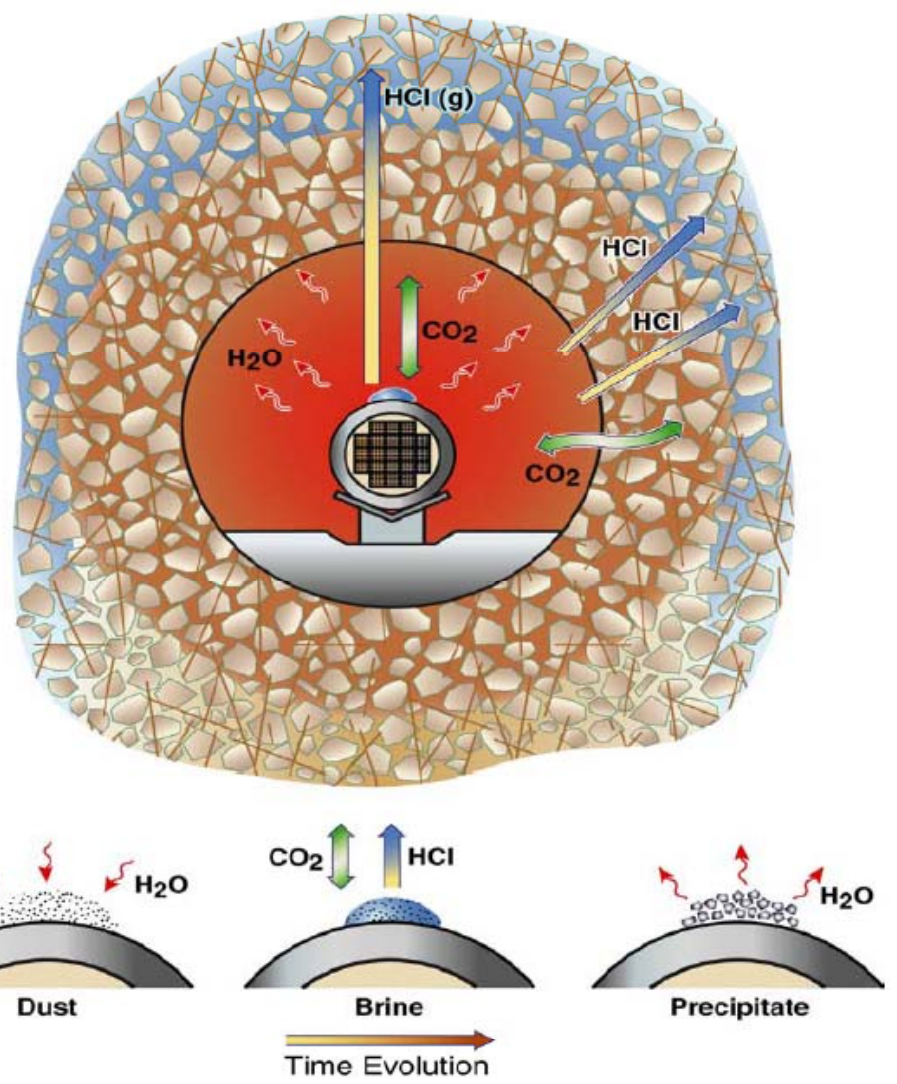

Source: Steefel 2004 [DIRS 173671], p. 35.

Figure E-4. Fate of Acid Gas in the Drift Environment

To demonstrate the processes of acid-gas volatilization, dispersal, and reaction with the rock, two THC simulations were conducted at LBNL. (These simulations used a version of the TOUGHREACT code modified to include the Pitzer activity model, similar to TOUGHREACT V3.2 (LBNL 2005 [DIRS 173862]), but this version was not controlled by YMP Software Configuration Management at the time the simulations were performed.) The following sample-based parameters were used: 1) the amount of dust deposited on a waste package, estimated from dust coatings collected by the USGS in the underground, and 2) the measured chloride content of the dusts. Using a conservative simplification that all available chloride in the dust volatizes immediately as $\mathrm{HCl}, \mathrm{HCl}$ gas was injected above a representative waste package in a drift. In the first simulation, the drift wall is just below boiling, and the wetting front has just intersected it. But the waste package surface is still above boiling, so it remains dry. Under these conditions, condensation of moisture or $\mathrm{HCl}$ on the waste package does not occur. The simulation shows that $\mathrm{HCl}$ gas disperses rapidly (within a day) in the drift environment due to dispersion and diffusion (Figure E-5). The $\mathrm{HCl}$ gas readily dissolves into the aqueous phase in the rock matrix, decreasing its concentration in the drift atmosphere. Any aqueous phase in the near field represents a significant sink for acid gases, and this process operates within a short time period. 

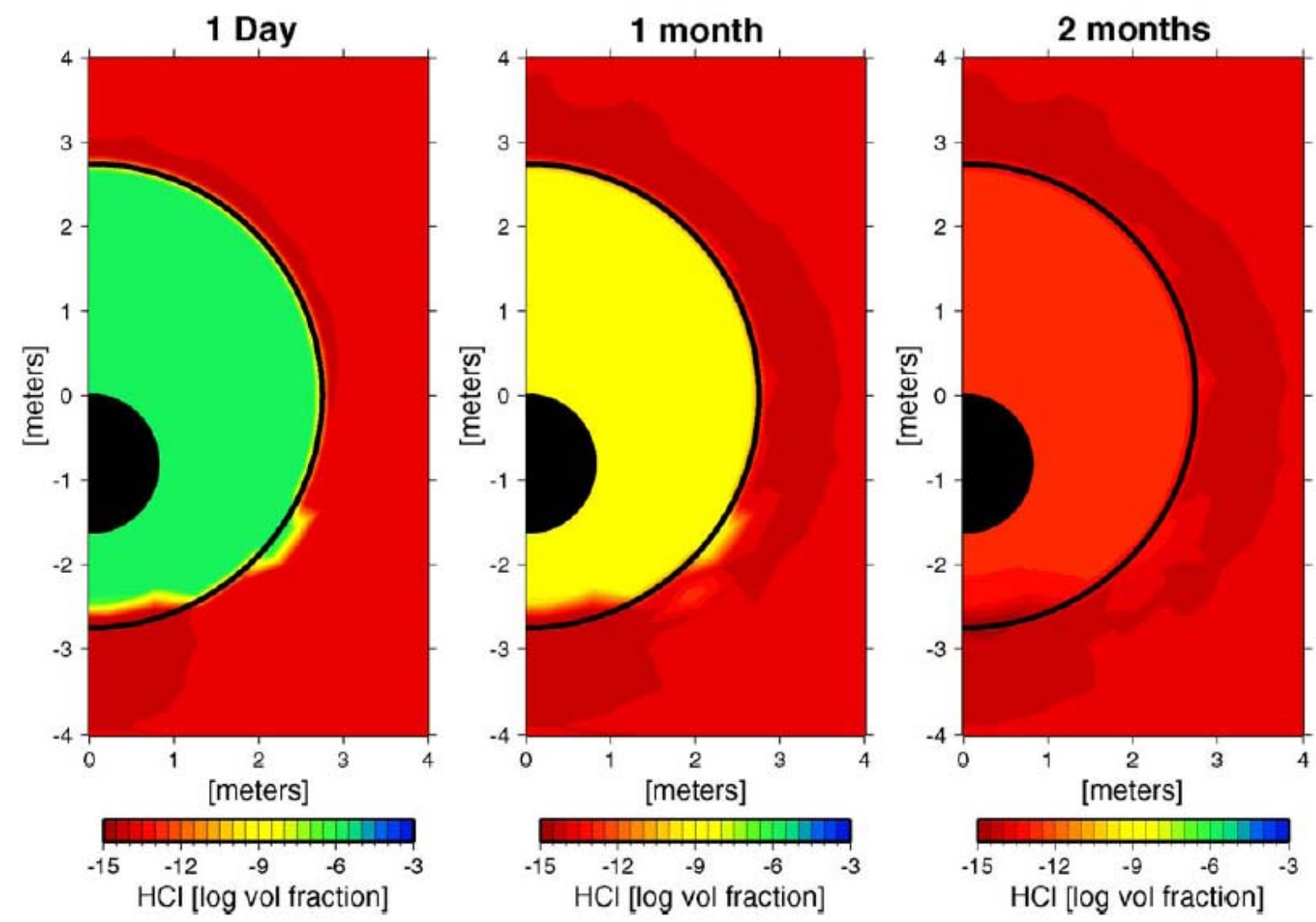

Source: Steefel 2004 [DIRS 173671], p. 37.

Figure E-5. THC Simulation of Acid-Gas Transport in the Drift and Near-Field: Waste Package above Boiling, Drift Wall below Boiling (No Condensation in the Drift)

In the second simulation, both the waste package and drift-wall temperatures were set below boiling. In addition to $\mathrm{HCl}$, water vapor was injected into the drift, simulating axial transport of water vapor from hotter to cooler locations in the drift, and associated condensation. The waste package is hotter than the drift wall, with the result that the relative humidity on the waste package surface is lower, so condensation occurs preferentially on the cooler drift wall rather than the waste package. Because acid gases partition strongly into the aqueous phase, the initial condensate is very acidic (Figure E-6). However, within a day, further condensation occurs and the $\mathrm{pH}$ increases from dilution to values of 4 to 5. At longer time intervals, the $\mathrm{pH}$ signal moves into the rock and is further attenuated by mineral buffering that eliminates the low-pH effect entirely. 

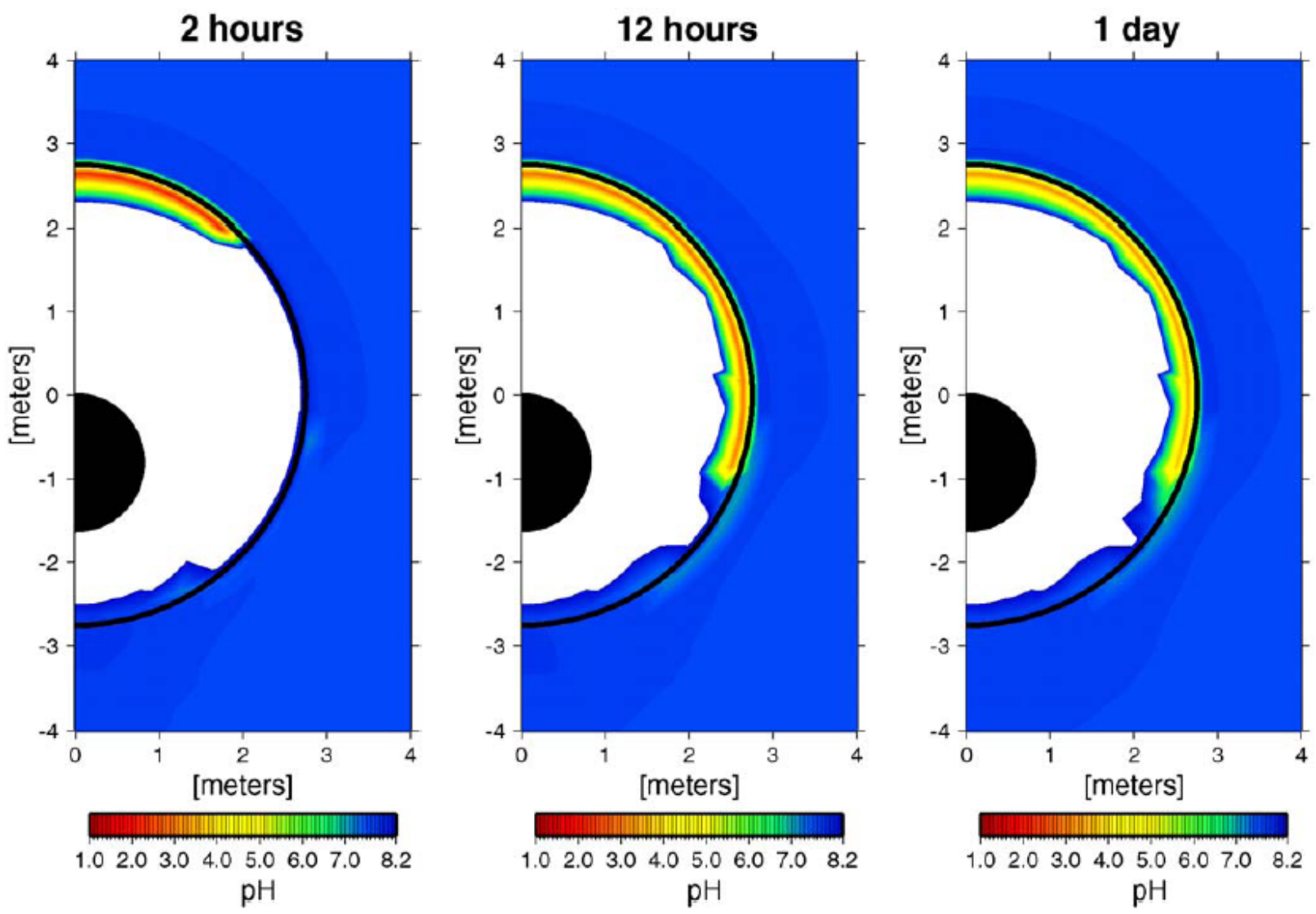

Source: Steefel 2004 [DIRS 173671], p. 38.

Figure E-6. THC Simulation of Acid-Gas Transport: Waste Package and Drift Wall below Boiling, Water Vapor Axially Transported from a Hotter Region (Condensation Occurs)

In summary, in the unlikely case that chloride-bearing salts are present in the drift environment and deliquesce to form potentially corrosive brines during the above-boiling period, acid gases will be generated and rapidly diffuse into the rock, where they will be absorbed by the aqueous phase present in the rock matrix and eventually neutralized by mineral buffering reactions. Should below-boiling conditions apply, then condensation may scavenge the acid gases generated by this process, but this will occur in the coolest parts of the drift (e.g., the drift wall) and not on the waste packages. The acid component eventually diffuses into the rock matrix and is neutralized by reaction with minerals.

Formation of Multi-Component Brines-Thermodynamic modeling based on the leachable components in the dust (see Sections 6.1, 6.2, and 6.3) indicates that nitrates and chlorides of potassium and sodium are the major salt components in the dust controlling the deliquescence behavior. The fundamental behavior of multicomponent mixtures of these salts is typified by the example in Figure E-2. Deliquescence RH values drop with increasing temperature, and the composition of the eutectic brine evolves towards the most soluble component in the salt assemblage. Because the nitrates of potassium and sodium are much more soluble than the chlorides, the eutectic composition is nitrate-rich, particularly at elevated temperatures. In the 
dust leachates, representing the bulk composition of soluble salts in the dust, the ratio of nitrate to chloride is favorable with respect to corrosion, generally greater than 0.5 . Predicted eutectic brine compositions all have higher nitrate-chloride ratios. Therefore, the nitrate-chloride ratio in the brine will be greater than the bulk value of the dust leachate until the brine leaves the solvus, and can never be less than the bulk value.

An additional point is that the soluble salt load in the dust is small, less than $0.5 \%$ by mass for measured tunnel dust samples (see Section 6.1.1), and predicted deliquescence brine volumes are correspondingly small, on the order of microliters per square centimeter (or less; see Section 6.4.1).

Summary-Based on the discussion above, the following conclusions are drawn about the indrift chemical environment during the above-boiling period and the potential for corrosive brines to form and persist:

- Due to lack of seepage during the above-boiling period, the deliquescence of salts in dust is the only mechanism for development of aqueous conditions in the drift.

- Potentially corrosive $\mathrm{CaCl}_{2}$ and $\mathrm{MgCl}_{2}$ brines are unlikely to form in the repository. Solid phases of these salts are unlikely to be present in dusts that originate within the drifts or in dusts introduced by atmospheric transport, and any brines that form from deliquescence of these salts will not persist because of reactions with other salt phases present in the dust. Even if present, these salts are unstable and will rapidly transform to non-deliquescent phases due to acid degassing.

- Any acid gases generated as a result of salt deliquescence will be dispersed in the drift environment and readily dissolve into moisture in the host rock.

- Condensation of liquid water may scavenge acid gases such as $\mathrm{HCl}$, but it will take place in the coolest parts of the drift, not on the waste packages.

Other conclusions that mitigate against the possibility of corrosion due to salt deliquescence during the above-boiling period include the following:

- Only $\mathrm{NO}_{3}$-dominant brines will form during the above-boiling period due to the thermodynamics of deliquescence in the $\mathrm{Na}-\mathrm{K}-\mathrm{Cl}-\mathrm{NO}_{3}$ system.

- Total deliquescent brine volumes are expected to be very small, on the order of microliters or less.

Catholic University Experiments - In spite of these conclusions, certain experiments have suggested that, when subjected to above-boiling temperatures for an extended period of time, multiple-salt systems similar to those expected in the repository can produce condensation of low pH water, which in turn can lead to metal corrosion (Pulvirenti et al. 2004 [DIRS 169631]). Such experiments, however, in their nature and design, actually demonstrate by contrast the extent to which the in-drift environment works to limit potentially corrosive processes such as dust deliquescence. 
For example, a distillation experiment conducted by Catholic University (Pulvirenti et al. 2004 [DIRS 169631]) caused corrosion on metal coupon samples, but only under conditions that are not relevant to the repository environment (see Figure E-7). To begin with, the experiment involved highly localized condensation in a system closed to the escape of acid-gas species, with condensed acids continually refluxed back into the boiling solution. The repository environment, by contrast, is an open system in which potentially corrosive substances such as $\mathrm{HCl}$ gas disperse along pathways (e.g., toward water in the host rock), where typically they are neutralized. This behavior of acid gases (mainly $\mathrm{CO}_{2}$ ) migrating away from emplacement drifts has been observed in the drift-scale heater test as noted above. Second, the metal coupons in the experiment were at lower temperatures than the boiling solution and hence represented loci for condensation, whereas in the repository environment the higher temperature of waste package surfaces will effectively keep them dry and promote condensation in other areas of the drift (e.g., the drift wall). Finally, the Catholic University experiment involved the equivalent of about 14,000 liters of dilute seepage water subjected to temperature gradients which were unrealistically large for the repository environment (the maximum difference between the waste package and drift wall temperature is on the order of $10^{\circ} \mathrm{C}$ or less, especially after the waste package has cooled through the boiling temperature; see BSC 2005 [DIRS 173944], Section 7.6).

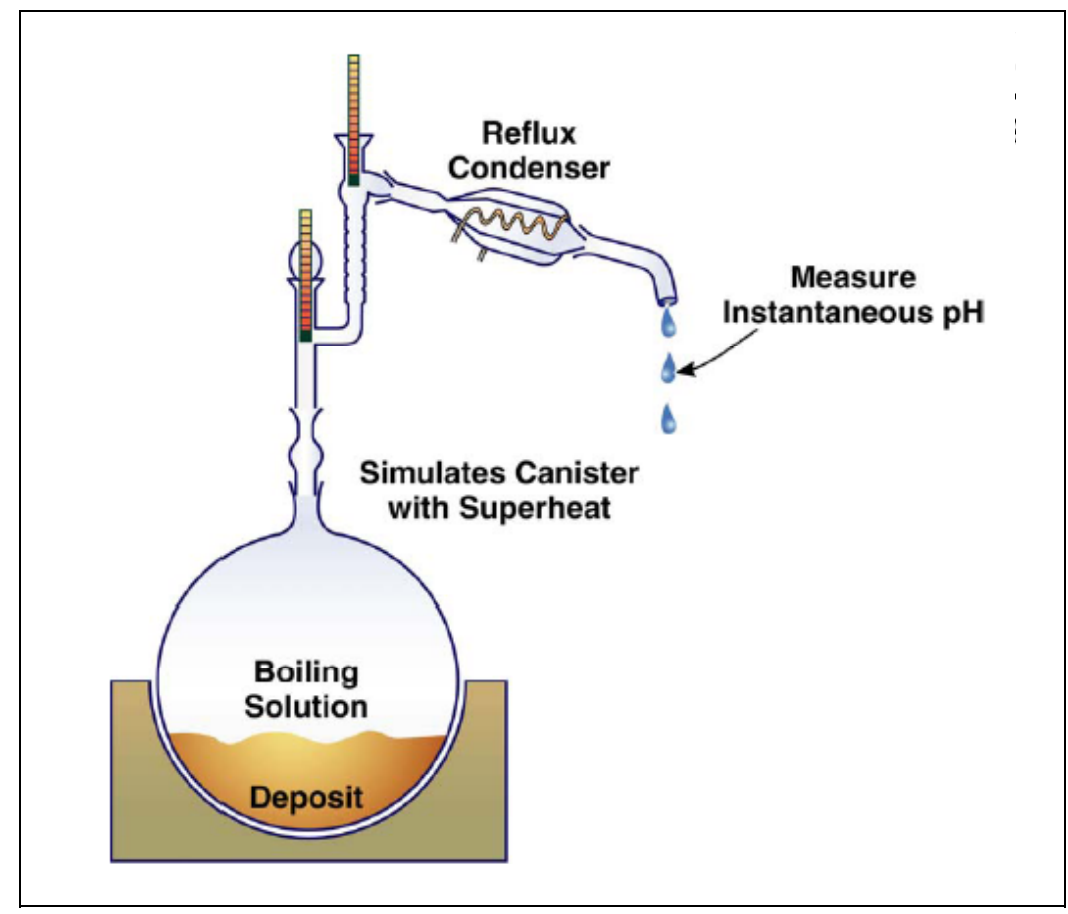

Source: Steefel 2004 [DIRS 173671], p. 51.

Figure E-7. Catholic University Distillation Experiment

Thus, experiments such as the Catholic University distillation experiment are irrelevant to the in-drift environment at Yucca Mountain and, beyond that, actually illustrate by contrast important repository mechanisms that work to limit the potential for corrosion due to processes such as dust deliquescence. 


\section{E.2 DR. JOE H. PAYER: CORROSION RESISTANCE OF ALLOY 22}

This subsection summarizes the presentation by Payer (2004 [DIRS 173672]). Corrosion resistance is an important factor in evaluating waste package performance under repository conditions. As a rule, radionuclides are fully isolated if there are no penetrations to the waste package, and corrosion is a principal mechanism by which penetrations could potentially occur. Thus, as one of a number of features, events, or processes that could affect waste package integrity, corrosion has been the subject of extensive study at Yucca Mountain. The following questions have been addressed:

- Can corrosive environments form and persist at Yucca Mountain?

- Will localized corrosion start and persist?

- What damage could result from such corrosion?

With respect to waste package performance, the answers to these questions depend on a range of factors including the properties of the host rock, climate conditions, repository temperature and relative humidity, the volume and composition of waters, and the availability of dust and dust components.

\section{E.2.1 Background on Alloy 22}

The material chosen for the outer barrier of waste packages at Yucca Mountain is Alloy 22. Alloy 22 belongs to a family of Ni-Cr-Mo alloys that includes Inconel 686, Alloy 59, Hastelloy C-2000, and MAT-21. In addition to its toughness and plastic qualities (50\% elongation before failure), Alloy 22 is known for its high resistance to corrosion, and has been used in a wide range of harsh (high temperature, highly corrosive) industrial environments. Extensive laboratory testing has also shown Alloy 22 to possess high resistance to general and pitting corrosion, comparable to that of Inconel 686, Alloy 59, and C-2000. For example, when subjected to a boiling "Green Death Solution" $\left(11.5 \% \mathrm{H}_{2} \mathrm{SO}_{4}, 1.2 \% \mathrm{HCl}, 1 \% \mathrm{FeCl}_{2}, 1 \% \mathrm{CuCl}_{2}\right)$, an industrial standard for corrosion tests, Alloy 22 was found to corrode at a rate of $0.1 \mu \mathrm{m} / \mathrm{yr}$, or over 10,000 years per mm. Alloy 22 also offers high resistance to pitting corrosion, again comparable to that of Inconel 686 or Alloy 59, as demonstrated in threshold tests using the Green Death Solution. Alloy 22 resists pitting corrosion up to a critical pitting temperature of $120^{\circ} \mathrm{C}$, beyond which the solution decomposes (Haynes International 1997 [DIRS 100896]).

The layer of Alloy 22 on a typical waste package is $2 \mathrm{~cm}$ thick. Given that realistic passive corrosion-rate estimates for Alloy 22 range from approximately 1 to $0.01 \mu \mathrm{m} / \mathrm{yr}$ (one-millionth of a meter per year; see Section 6.4 .4 of this report for additional discussion of the passive corrosion rate), it would take 2,000 to 200,000 years for passive corrosion to penetrate Alloy 22 to the thickness of two millimeters.

\section{E.2.2 Passive Corrosion Rates in Brines Relevant to Yucca Mountain}

General passive corrosion rates of Alloy 22 have been measured in simple salt solutions and simulated groundwater and evaporated groundwater solutions, covering a large range of temperatures and compositional variables, including $\mathrm{pH}$, ionic strength, chloride content, and 
nitrate-chloride ratio. These tests typically fall into two categories, immersion testing or electrochemical testing, and include:

- Long-term open circuit potential tests

- Cyclic polarization tests

- Weight loss tests

- Linear polarization tests.

Immersion testing methods are accepted broadly in industrial applications. Electrochemical testing provides a quick and efficient means to determine the effect of environmental variables such as temperature and nitrate levels, but often yields corrosion rates higher than the actual values for longer exposures.

The following provides a sampling of corrosion rates determined by immersion tests:

- In a solution of $1000 \mathrm{x}$ ambient water $\left(\sim 0.8 \mathrm{M} \mathrm{Cl}, \sim 0.4 \mathrm{M} \mathrm{NO}_{3}\right.$, acidified to $\left.\mathrm{pH} 2.8\right)$ at $90^{\circ} \mathrm{C}$, Alloy 22 registered a corrosion rate of $1.5 \mu \mathrm{m} / \mathrm{yr}$ following one hour of immersion (solution deaerated and samples freshly polished). After one week in aerated solution, this rate had fallen to $0.1 \mu \mathrm{m} / \mathrm{yr}$.

- In an aerated $1 \mathrm{M} \mathrm{NaCl}, \mathrm{pH} 2$ solution at $95^{\circ} \mathrm{C}$, Alloy 22 registered a corrosion rate of $2.1 \mu \mathrm{m} / \mathrm{yr}$ following one hour of immersion. After 30 hours of immersion, this rate had fallen to $0.2 \mu \mathrm{m} / \mathrm{yr}$.

- In a boiling $3.5 \% \mathrm{NaCl}$ solution, Alloy 22 registered a corrosion rate of less than $2.5 \mu \mathrm{m} / \mathrm{yr}$ following 96 hours of immersion.

In longer immersion tests $(5+$ years $)$ using simulated acidified water, simulated concentrated water, and basic saturated water, Alloy 22 registered corrosion rates of approximately $0.01 \mu \mathrm{m} / \mathrm{yr}$, regardless of temperature and solution composition, as illustrated in Figure E-8. Additional discussion of the passive corrosion rate is provided in Section 6.4.4, with reference to the abstraction model used for TSPA-LA. 


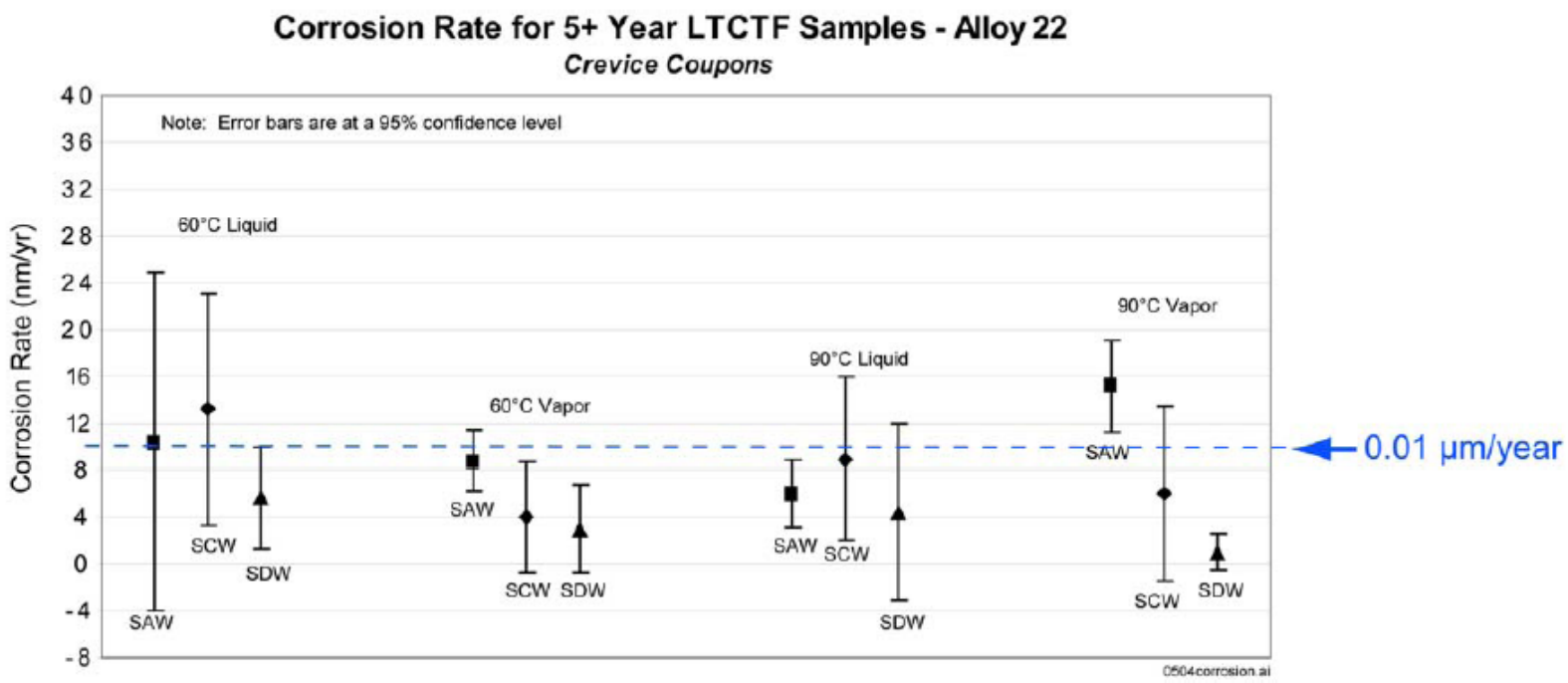

Source: Payer 2004 [DIRS 173672], p. 20.

NOTE: $\quad \mathrm{SAW}=1000 \mathrm{x}$ ambient water, $\sim 0.8 \mathrm{M} \mathrm{Cl}, 0.4 \mathrm{M} \mathrm{NO}_{3}$, acidified to $\mathrm{pH} 2.8$; $\mathrm{SCW}=1000 \mathrm{x}$ ambient water, $\sim 0.2 \mathrm{M} \mathrm{Cl}, 0.1 \mathrm{M} \mathrm{NO}_{3}, \mathrm{pH} 10 ; \mathrm{BSW}=18,000 \mathrm{x}$ ambient water, $\sim 3.7 \mathrm{M} \mathrm{Cl}, 2.4 \mathrm{M} \mathrm{NO}_{3}, \mathrm{pH} 11$ to 13 .

Figure E-8. Long-Term Passive Corrosion Rates of Alloy 22 in Liquid and Vapor, to $90^{\circ} \mathrm{C}$

The presence of nitrate inhibits corrosion. Experiments with mixed-salt systems $\left(\mathrm{NaCl}: \mathrm{KNO}_{3}\right.$ and $\left.\mathrm{CaCl}_{2}: \mathrm{Ca}\left(\mathrm{NO}_{3}\right)_{2}\right)$ at nitrate-chloride ratios of 0.05 to 0.5 indicate that nitrates are effective inhibitors up to temperatures of at least $160^{\circ} \mathrm{C}$ (Figure E-9).
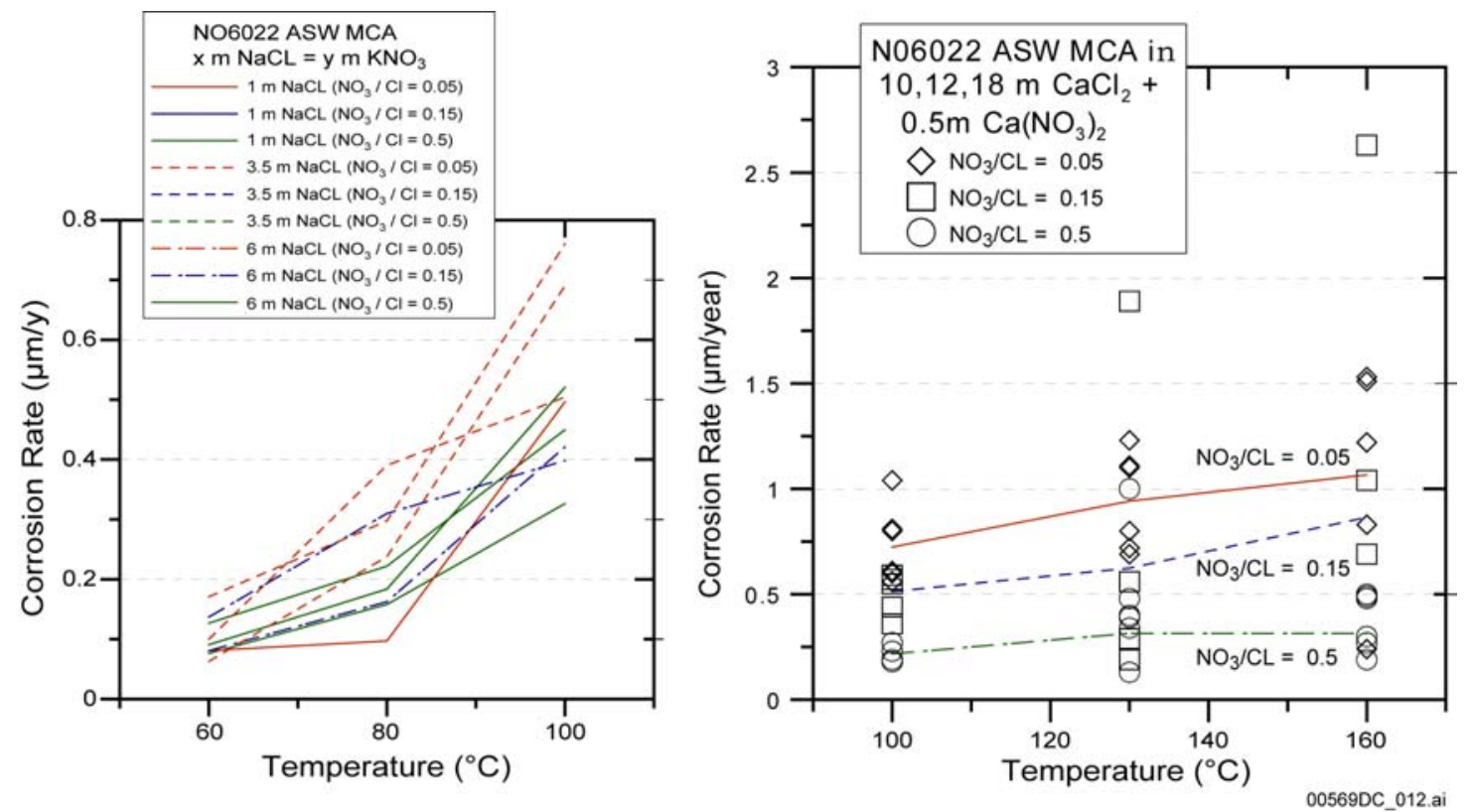

Source: Payer 2004 [DIRS 173672, p. 21.

Figure E-9. Passive Corrosion Rates of Alloy 22 in the Presence of Nitrate in (a) Sodium-Chloride Brines and (b) Calcium-Chloride Brines 
Finally, as illustrated in Table E-4, autoclave testing to measure corrosion rates in terms of weight loss found no significant corrosion of Alloy 22 in concentrated $\mathrm{NaCl}-\mathrm{KNO}_{3}$ brines with nitrate-chloride ratios of 0.05 to 6.7 , at temperatures between 120 and $220^{\circ} \mathrm{C}$.

Table E-4. Alloy 22 Corrosion Rates in Concentrated Salt Brines at Elevated Temperatures, Determined by Weight Loss in Autoclave Tests

\begin{tabular}{|c|c|c|c|c|c|}
\hline \multicolumn{2}{|c|}{ Solution } & \multicolumn{4}{|c|}{ Corrosion Rate $(\mu \mathrm{m} / \mathrm{yr})$} \\
\hline \multirow{2}{*}{$\mathrm{NO}_{3} / \mathrm{Cl}$} & \multirow{2}{*}{$\begin{array}{c}\text { Total } \\
\text { Molality }\end{array}$} & \multicolumn{4}{|c|}{ Temperature $\left({ }^{\circ} \mathrm{C}\right)$} \\
\hline & & 120 & 140 & 160 & 220 \\
\hline 0.05 & 6.7 & - & $<0.02^{\mathrm{a}}$ & - & - \\
\hline 0.31 & 8.4 & $<0.02^{b}$ & $<0.02^{b}$ & $<0.02^{b}$ & $<0.02^{\mathrm{a}}$ \\
\hline 0.5 & 9.6 & - & $0.06^{a}$ & - & - \\
\hline 6.7 & 21.2 & $<0.02^{b}$ & $0.13^{b}$ & $0.13^{b}$ & - \\
\hline
\end{tabular}

Source: Payer 2004 [DIRS 173672], p. 22.

a Exposure time: 130 days.

b Exposure time: 157 days.

NOTE: $\quad$ Values in the column labeled "Total Molality" were incorrectly ordered in the source (Payer 2004 [DIRS 173672], p.22) and have been placed in the correct order here (see Table 6.3.4).

Taken together, these test results demonstrate that Alloy 22 has a high level of resistance to corrosion under a wide range of temperatures (to $160^{\circ} \mathrm{C}$ and above) and solution compositions (including concentrated brines). The short-term passive corrosion rate of Alloy 22 is $2 \mu \mathrm{m} / \mathrm{yr}$ or significantly less. Over time, passive corrosion rates decrease to the order of $0.01 \mu \mathrm{m} / \mathrm{yr}$ or less.

\section{E.2.3 Fundamentals of Localized Corrosion}

Localized corrosion is a complex process requiring several conditions in order to occur. In general, and in the context of the repository at Yucca Mountain, the potential for localized corrosion can be conceptualized in the form of an "overlap" diagram (Figure E-10). The two major "spheres" in this diagram represent the range of environmental conditions that could occur in the repository, and the range of environments in which the material in question (Alloy 22) is susceptible to corrosion. The area of overlap designated by a question mark in Figure E-10 is called the "zone of susceptibility."

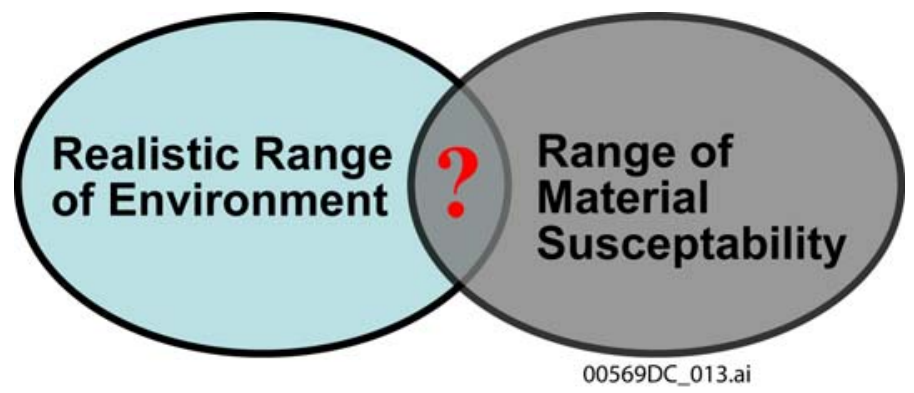

Source: Payer 2004 [DIRS 173672], p. 38.

Figure E-10. Interaction Diagram 
Certain conditions are required for corrosion to take place. First, water must come in contact with the waste package, and second, it must persist there. Next, corrosive species must be present to form electrolytes, and the material itself must be susceptible to corrosion under these conditions. Finally, the conditions must persist over a sufficiently long period of time to have an appreciable effect on the waste package.

At high temperatures, the waste packages are likely to be dry. In the absence of an aqueous solution contacting the surface, significant corrosion cannot occur. Thus, the environmental conditions do not intersect the range of conditions of material susceptibility, and corrosion does not occur. (Note: further discussion of high-temperature multi-salt deliquescence is provided in Section 6.1.) Conversely, at lower temperatures (e.g., below $90^{\circ} \mathrm{C}$ ), Alloy 22 is more resistant to localized corrosion, such that there is a smaller range of environmental conditions for which the material is susceptible (consistent with the abstraction described in BSC 2004 [DIRS 169984], Section 6.4.4). Therefore it is only at intermediate temperatures that Alloy 22 is susceptible to localized corrosion.

In general, the range of material susceptibility is a function of several environmental and intrinsic factors. Alloy 22 susceptibility to crevice corrosion depends most strongly on the following variables:

1. Chloride concentration $\left(\mathrm{Cl}^{-}\right)$

2. Temperature $(\mathrm{T})$

3. Potential (E)

4. Acidity $(\mathrm{pH})$

5. Crevice geometry (tightness).

As a general rule, the higher the $\mathrm{Cl}^{-}, \mathrm{T}$, and $\mathrm{E}$, the lower the $\mathrm{pH}$, and the tighter the crevice geometry, the lower the resistance of Alloy 22 to crevice corrosion. However, many other parameters, including gas-phase composition, the presence of inhibiting ions such as nitrate and sulfate, and even the character of the crevice-former, are also of importance with respect to both initiation and propagation of crevice corrosion.

Experimental crevice corrosion tests have shown that extremely tight crevices are necessary for crevice corrosion of Alloy 22. Teflon-coated washers, able to deform and conform to the metal surface, tend to promote corrosion, while highly polished metal washers, unable to conform to slight surface irregularities, do not. Thus, dust or rock particles on the waste package surface are unlikely to create crevices tight enough to promote or sustain corrosion (Sections 6.4.3 and 6.4.4 of this report discuss crevice characteristics for corrosion, and representation of brine behavior at the dust-alloy interface).

Even should localized corrosion occur, the rate of corrosion will slow with time (see Section 6.5 .2 of this report for more discussion of stifling). This effect is widely documented in corrosion literature. Penetration by localized corrosion decreases with time according to a power-law relationship:

$$
P=k t^{n}
$$


where $P$ is the maximum depth of penetration; $k$ is a constant dependent on material characteristics; and $n$ is a time exponent with typical values of 0.5 to 0.1 , with 0.5 representing a diffusion-controlled process, and lower values indicating the effect of corrosion product plugging, cathodic area limitations, limited brine solution availability, or inability to maintain critical crevice chemistry with increasing depth. Although Alloy 22 data are limited, a wide range of alloys has been shown to exhibit similar behavior (see Section 6.5.2.1 for further discussion).

\section{E.2.4 Localized Corrosion Logic/Fault Tree}

To evaluate the potential occurrence and magnitude of waste package damage by localized corrosion, the following questions must be considered:

- Do conditions for corrosion exist?

- Will corrosion occur?

- Will corrosion persist?

- What damage results?

The following logic/fault tree provides a framework for evaluating these:

\section{Define the zone of Susceptibility (Figure E-10):}

A) Determine corrosion behavior in types of waters

B) Determine types of waters during relevant periods

- T-RH controls on solution formation over time

- Seepage and deliquescence waters

- Evolution of water composition and corrosivity with time.

- Water in dusts, deposits, crevices.

If A) and B) allow localized corrosion:

C) Is $\mathrm{E}_{\text {corr }}$ positive enough to initiate and support localized corrosion?

If A), B), and C) allow localized corrosion:

D) Are crevices present of sufficient severity?

If A), B), C), and D) support localized corrosion:

E) Will localized corrosion persist?

- Consider propagation, stifling, and arrest.

\section{If from E) corrosion persists:}

What is the evolution of damage?

- Rate of corrosion and penetration

- Damage size, shape, distribution. 
In the sections below, this logic tree is applied to evaluate the potential for localized corrosion of Alloy 22 in a Yucca Mountain repository. (A similar logic framework for screening of localized corrosion from dust deliquescence is developed in Sections 6.1 through 6.5 of this report.)

\section{E.2.5 Localized Corrosion Experimental Data}

The first step in this logic requires determining what water compositions initiate localized corrosion of Alloy 22. An extensive experimental program has been carried out to evaluate this. Both immersion testing and electrochemical techniques including cyclic polarization and Tsujikawa Hisamatsu electrochemical experiments have been used. Samples are artificially creviced using Teflon-coated ceramic washers, or are Alloy 22 weld samples. The expected water types at Yucca mountain include ambient waters-dilute, near-neutral solutions of the $\mathrm{Na}-\mathrm{K}-\mathrm{Ca}-\mathrm{Mg}-\mathrm{HCO}_{3}-\mathrm{CO}_{3}-\mathrm{Cl}-\mathrm{NO}_{3}-\mathrm{SO}_{4}$ system - and their more concentrated equivalents, modified by water-rock interactions and evaporatively concentrated (Figure E-11). In experiments with dilute waters and their evaporatively concentrated neutral- to high-pH equivalents, no localized corrosion was observed. Nitrate in these waters, at nitrate-chloride ratios of 0.05 or greater, is effective at inhibiting localized corrosion. In chloride-containing waters with no nitrate, crevice corrosion was observed, although once initiated, it was rapidly stifled. Nitrate also inhibited corrosion of Alloy 22 welds. Calcium chloride brines are more corrosive with respect to localized corrosion, and nitrate-chloride values of 0.5 or higher are required for inhibition.

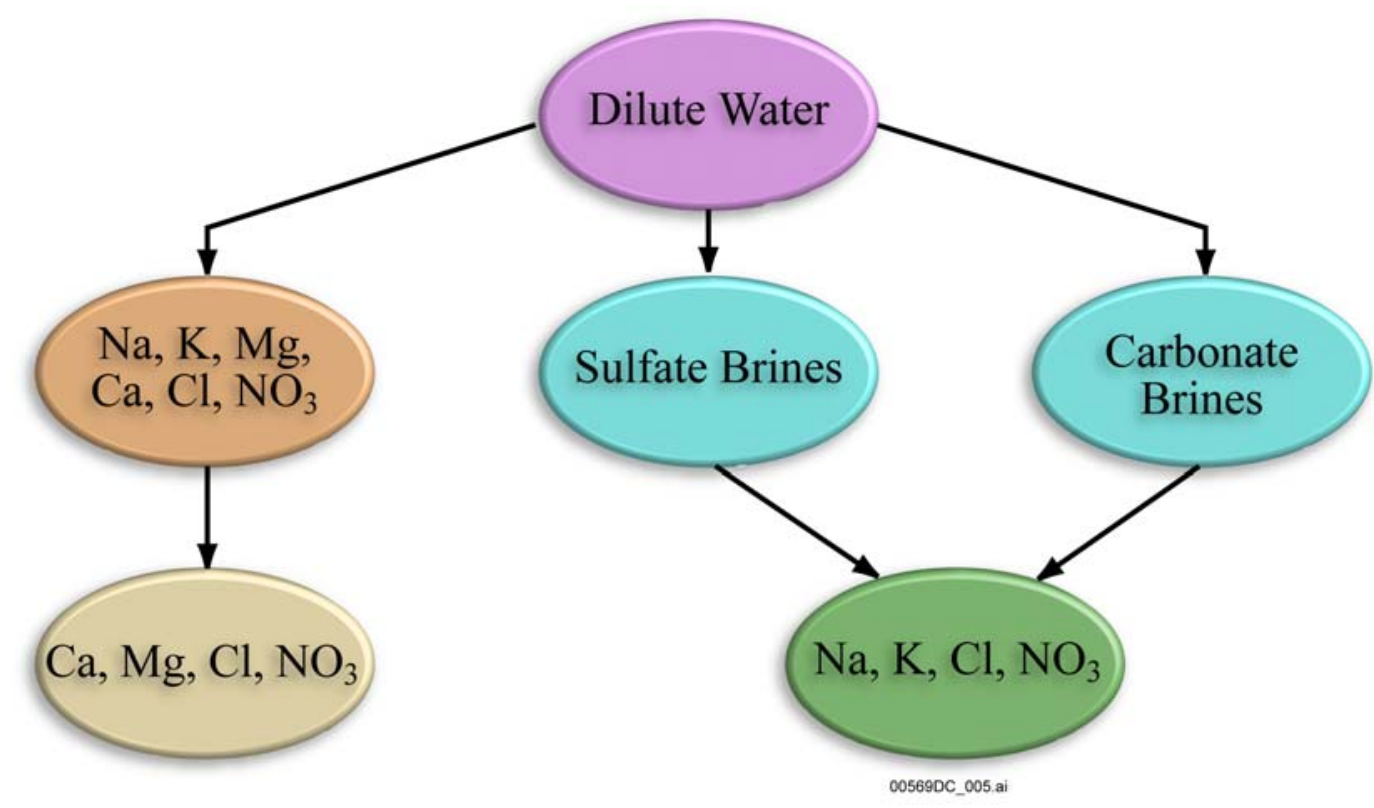

Source: Payer 2004 [DIRS 173672], p. 52.

NOTE: Dilute waters are transformed to different types of brines, depending on their composition, through the processes of evaporation and mineral precipitation. The component assemblages shown are the dominant ones produced by evaporation.

Figure E-11. Expected Aqueous Solution Types 


\section{E.2.6 The Yucca Mountain Environment}

In contrast to the harsh industrial or test environments in which Alloy 22 has demonstrated high resistance to corrosion, the repository environment at Yucca Mountain is expected to be comparatively benign, both in terms of natural properties and engineered factors that protect against corrosion. At ambient conditions, Yucca Mountain waters are dilute and have near-neutral $\mathrm{pH}$, but under repository elevated-temperature conditions (e.g., $96^{\circ} \mathrm{C}$ or greater) more concentrated waters can form. In principle, these highly concentrated waters can increase the potential for corrosion, but their likelihood of contacting a waste package is mitigated by a number of repository design features.

The heating cycle itself protects against corrosion in two ways. First, as opposed to the frequent and rapid thermal cycles associated with typical industrial applications of Alloy 22, the repository at Yucca Mountain will subject Alloy 22 to a single long and slow cycle of heating to relatively modest temperature, followed by a period of cooling to ambient. Because heat fluxes will be low and thermal gradients modest during this cycle, the Alloy 22 will not be subjected to the stress of rapid thermal expansion and contraction. Second, during the phase of the heating cycle when temperatures are at their highest (above boiling), a vaporization barrier to seepage forms in the host rock when temperatures at the drift wall are high enough to evaporate percolating water on contact, which combined with the capillary response of the rock effectively prevents water from dripping onto drip shields or waste packages.

Additional design features that prevent water contact are the drip shields, which prevent dripping onto waste packages, and the emplacement pallets, which hold the packages off the invert and enhance air circulation around the packages. Also, no external or functional loads are imposed on the waste packages: they are not subjected to added internal pressure, and there are no moving parts to generate stresses or additional heat.

Localized Corrosion Processes by Key Time Period-A challenge for the analysis of potential corrosion of Alloy 22 at Yucca Mountain is the long time period required for repository performance. The performance period of the repository can be divided into five phases, with specific temperature and $\mathrm{RH}$ characteristics. The relevant periods are as follows (see Figure E-1):

Period I. Emplacement of Waste Packages and Preclosure

Period II. Heat-Up after Closure

Period III. Cooldown/Thermal Barrier (drift wall above boiling temperature)

Period IV. Cooldown/Dripping and Seepage Possible

Period V. Waste Packages below Critical Temperature for Corrosion.

Period I: Comprises the first 50 years after waste emplacement, during which the drifts are being ventilated. During this time, waste packages are kept relatively cool by the ventilation system (which removes most of the generated heat). Dust from tunneling and emplacement activities, and dust brought in by ventilation, will accumulate on waste packages. Waste package temperatures are generally below boiling, the drift walls are dried out by ventilation, and metal surfaces remain dry (thus deliquescence is limited or does not occur); thus there is no corrosion. 
Period II: The heat-up period begins after ventilation ceases and lasts for approximately 10 to 15 years. A thermal vaporization barrier forms when rock surrounding the emplacement tunnels reaches above-boiling temperatures. The thermal barrier works in conjunction with the capillary barrier effect and the drip shield to prevent seepage from dripping onto waste packages. Dust from external sources is no longer entering the drift, and only minor amounts of dust can be generated by drift degradation. Thus, the dust present on the waste package at cessation of ventilation represents the total amount present for deliquescence. Relative humidity also decreases during this heat-up period. Dust deliquescence is unlikely, and corrosion is negligible.

Period III: In this period, the thermal vaporization barrier is also effective. Drift wall temperatures exceed boiling, and seepage onto the waste package will not occur. The drift wall stays above boiling until approximately 750 years after closure (a median value; see Figure 6.1-1). Condensation on the waste package will not generally occur because it is hotter than the drift wall. Dust deliquescence can occur, but deliquescence brines are nitrate-rich (calcium chloride brines are unlikely, and if present, unstable), and there is no significant corrosion (Figure E-12).

Period IV: Begins at approximately year 750 and lasts until the waste package surface has fallen below the critical temperature for corrosion-about year 1375 for a median waste package (Figure E-12). Drift wall temperatures are below boiling, and dripping onto waste packages could occur, although other barrier effects, capillary diversion and the drip shield, are still operative. Nevertheless, it is conceivable that seepage could contact the waste package (if the drip shield does not perform its function) and should the seepage be corrosive, localized corrosion could occur. The end of this time period is not well constrained, but corresponds to the condition that contacting solutions are sufficiently dilute, and other environmental factors (such as temperature) sufficiently benign, that localized corrosion is no longer a significant process.

Period V: The waste package surface has now fallen below the localized corrosion cutoff temperature. The localized corrosion cutoff temperature is a function of brine composition, and is not known exactly; however, expected repository brine compositions would not be corrosive below $90^{\circ} \mathrm{C}$, the value assumed here. Passive corrosion rates (on the order of 1.0 to $0.01 \mu \mathrm{m} / \mathrm{yr}$; see Section 6.4.4 for additional discussion and reference to the abstraction for TSPA-LA) apply. 


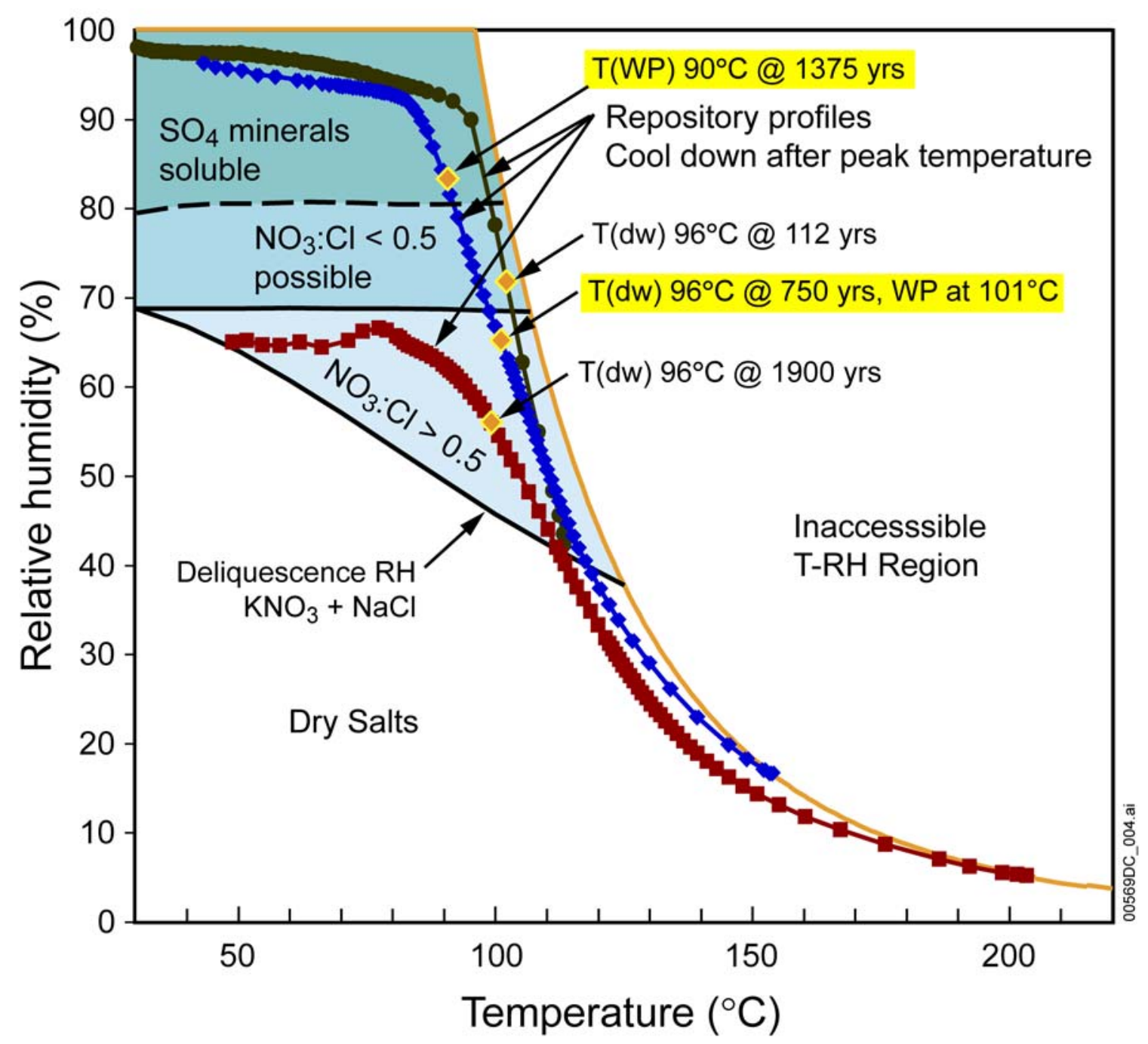

Source: Payer 2004 [DIRS 173672], p. 67.

Figure E-12. Possible Brine Composition Zones Related to Temperature and Relative Humidity during Cooldown after the Peak Temperature

Summary-The potential for corrosion due to seepage or dust deliquescence is negligible for Periods I and II. In Period III, seepage is still inhibited, but dust deliquescence can occur; however, deliquescence brine compositions are nitrate-rich, and benign with respect to corrosion. During Period IV, localized corrosion due to seepage and dripping onto the waste package is possible if nitrate-poor waters contact the waste package. However, the capillary barrier and drip shield are still effective barriers, and the likelihood of seepage contacting the waste package is small. During Period V, thermal conditions have dropped below the critical corrosion temperature for Alloy 22 , and only extremely slow passive corrosion rates $(\sim 0.01 \mu \mathrm{m} / \mathrm{yr})$ apply. 


\section{APPENDIX F}

QUALIFICATION OF WATER-SOLUBLE CONCENTRATIONS OF DUST SAMPLES 
In this appendix, water-soluble anion and cation concentrations of ESF dust sample leachates are being qualified per LP-SIII.2Q-BSC. The data to be qualified are cited in Table 6.1-3 of the current report and reproduced below in Table F-1. The anion and cation concentration values were obtained as part of development and testing of the methodology for leaching water-soluble salts from rock and dust samples. The leaching analyses were originally done on a scoping basis and did not meet all QA requirements. The results were submitted to the TDMS under unqualified DTN: GS050408313000.001 [DIRS 173724]. This technical assessment qualification method follows the requirements presented in the data qualification plan, a facsimile of which is provided at the end of this appendix.

Table F-1. Tunnel Dust Analyses That Include Ammonium

\begin{tabular}{|c|c|c|c|c|c|c|c|c|c|c|c|}
\hline $\begin{array}{c}\mathbf{S P C} \\
\mathbf{N u m b e r}\end{array}$ & $\begin{array}{c}\mathbf{N a} \\
(\mathbf{m g} / \mathbf{L})\end{array}$ & $\begin{array}{c}\mathbf{K} \\
(\mathbf{m g} / \mathbf{L})\end{array}$ & $\begin{array}{c}\mathbf{M g} \\
(\mathbf{m g} / \mathbf{L})\end{array}$ & $\begin{array}{c}\mathbf{C a} \\
(\mathbf{m g} / \mathbf{L})\end{array}$ & $\begin{array}{c}\mathbf{N H}_{4} \\
(\mathbf{m g} / \mathbf{L})\end{array}$ & $\begin{array}{c}\mathbf{C l} \\
(\mathbf{m g} / \mathbf{L})\end{array}$ & $\begin{array}{c}\mathbf{S O}_{4} \\
(\mathbf{m g} / \mathbf{L})\end{array}$ & $\begin{array}{c}\mathbf{H C O}_{3} \\
(\mathbf{m g} / \mathbf{L})\end{array}$ & $\begin{array}{c}\mathbf{N O}_{3} \\
(\mathbf{m g} / \mathbf{L})\end{array}$ & $\begin{array}{c}\mathbf{F} \\
(\mathbf{m g} / \mathbf{L})\end{array}$ & $\begin{array}{c}\mathbf{P O}_{4} \\
(\mathbf{m g} / \mathbf{L})\end{array}$ \\
\hline 574979 & 3.0 & 6.4 & 0.6 & 5.7 & 0.2 & 0.26 & 0.9 & 33 & 0.73 & 0.29 & 3.15 \\
\hline 574982 & 29.3 & 13.6 & 6.2 & 47.0 & 6.8 & 9.01 & 47.2 & 73 & 52.9 & 0.61 & 0.29 \\
\hline 574983 & 33.2 & 14.6 & 4.9 & 56.6 & 6.2 & 17.6 & 67.5 & 86 & 38.3 & 1.26 & 0.31 \\
\hline 574984 & 32.0 & 13.1 & 4.4 & 32.5 & $<0.1$ & 12.0 & 49.0 & 68 & 23.9 & 1.22 & $<0.05$ \\
\hline 574985 & 24.7 & 12.9 & 3.4 & 57.8 & 5.9 & 9.24 & 60.0 & 102 & 26.1 & 1.41 & 0.59 \\
\hline 574986 & 22.3 & 13.2 & 3.5 & 61.1 & 5.8 & 11.6 & 66.2 & 93 & 24.9 & 1.24 & 0.61 \\
\hline 574987 & 27.9 & 12.7 & 4.0 & 58.7 & 4.6 & 14.5 & 63.4 & 76 & 22.9 & 1.42 & 0.8 \\
\hline 574990 & 12.8 & 9.0 & 1.3 & 23.6 & 3.0 & 4.57 & 33.7 & 47 & 10.6 & 0.6 & 0.39 \\
\hline 574991 & 10.0 & 8.7 & 3.0 & 29.1 & 7.1 & 3.49 & 35.4 & 72 & 8.87 & 1.12 & 0.30 \\
\hline 574992 & 9.5 & 9.1 & 1.1 & 15.6 & 2.8 & 9.0 & 15.0 & 40 & 7.59 & 0.45 & 0.32 \\
\hline
\end{tabular}

Source: GS050408313000.001 [DIRS 173724].

According to "Planning Guidance for Underground Dust Sampling" (Pye 2000 [DIRS 155798]), the primary objective of the sampling and analysis program was to determine the physical and chemical composition of dust, from both natural and anthropogenic sources. Sampling focused on dust that tends to accumulate on metallic surfaces that could be analogous to the waste package or drip shield in the repository. Sample collection and handling followed existing QA-approved procedures. Sampling followed USGS technical procedure NWM-USGS-GP-27 R2, Trench Wall and Natural Outcrop Sampling for Coordinated Studies (effective 10/22/90). Sample handling followed USGS technical procedure NWM-USGS-GCP-02 R2, Labeling, Identification, and Control of Samples for Geochemistry and Isotope Geology (effective 10/22/90). Results of prior geochemical analyses of dust samples have been submitted under the qualified DTNs: MO0207EBSDUSTS.020 [DIRS 162556] and MO0209EBSDUST2.030 [DIRS 162557].

As part of this data qualification, Gene Safley met in Denver with USGS personnel (Zell Peterman, Tom Oliver, and Kevin Scofield) who were involved with the leaching analyses, to gather additional supporting information and to view laboratory equipment in order to qualify the results of the analyses (the supporting laboratory notebook pages and equipment calibrations are located in Safley 2005 [DIRS 174143]).

Three size distributions were prepared for chemical analysis: 60-200 mesh, 200-325 mesh, and less than 325 mesh. Samples were identified in compliance with QA-approved quality 
management procedure YMP-USGS-QMP-8.01 R4-M1, Identification and Control of Samples (effective 6/27/97). The dust samples from the ESF were collected on 2/12/02. Ten sample splits were prepared for leachate analysis, and listed in Table F-1 (excerpts from the USGS laboratory notebooks to document the sample names, weights and mesh size are provided in Safley 2005 [DIRS 174143], p. 2). The Sample Collection Reports (per LP-SII.3Q-BSC, Collection, Submission, Return, and Documentation of Non-Core and Non-Cuttings Samples/Specimens to the Sample Management Facility) and Curatorial Sample Inventory and Tracking System verifications were found in the YMP Records Information System. The leachate analyses were performed on 11/29/04.

Table F-2. Sample Splits for Leachate Analyses

\begin{tabular}{|c|c|c|}
\hline SPC Number & Weight & Mesh \\
\hline SPC00574979 & $0.5 \mathrm{~g}$ & $<200$ \\
\hline SPC00574982 & $0.5 \mathrm{~g}$ & -325 \\
\hline SPC00574983 & $0.5 \mathrm{~g}$ & -325 \\
\hline SPC00574984 & $0.5 \mathrm{~g}$ & -325 \\
\hline SPC00574985 & $0.5 \mathrm{~g}$ & $-200+325$ \\
\hline SPC00574986 & $0.5 \mathrm{~g}$ & -325 \\
\hline SPC00574987 & $0.5 \mathrm{~g}$ & -325 \\
\hline SPC00574990 & $0.5 \mathrm{~g}$ & -325 \\
\hline SPC00574991 & $0.5 \mathrm{~g}$ & -325 \\
\hline SPC00574992 & $0.5 \mathrm{~g}$ & -325 \\
\hline
\end{tabular}

Source: Safley 2005 [DIRS 174143], p. 2.

NOTE: $\quad$ All samples taken from the "Dust II" location of the ESF.

While YMP-USGS-GCP-43 R0, Leaching of Dust and Rock Samples, was not effective until $6 / 2 / 05$, sample leaching methods followed in the scoping analyses were consistent with the procedure. The samples were weighed and the result recorded in the laboratory logbook. A measured volume of water was added and the dust sample was shaken to ensure thorough mixing. A centrifuge was used to separate the suspended material from the leachate sample. The leachate was then filtered into a clean sample bottle. Table F-2 presents the results of the leaching of dust and rock samples.

Daily operational checks of the analytical balance were performed per USGS technical procedure YMP-USGS-GCP-03 R4, Uranium-Thorium Disequilibrium Studies (effective 6/28/99). The balance used was a Mettler AX205 (SN 1121230542). A Troemner weight set (SN 27627), traceable by the National Institute of Standards and Technology, was used in the range representative of samples being analyzed. The check results were in the acceptable range for use for YMP quality-affecting work and noted in the laboratory logbook (Safley 2005 [DIRS 174143], p. 5) and on the balance. Use of the centrifuge followed YMP-USGS-HP-300 R0-M5, Extraction of Pore Water by High Water Centrifuge Methods (effective 4/17/03). 
Table F-3. Results of Leaching of Dust and Rock Samples from the ESF

\begin{tabular}{|c|c|c|c|c|c|c|c|}
\hline $\begin{array}{c}\text { Sample } \\
\text { Number }\end{array}$ & $\begin{array}{c}\text { Weight } \\
\text { Sample (g) }\end{array}$ & $\begin{array}{c}\text { Total Water } \\
\text { Added (ml) }\end{array}$ & $\begin{array}{c}\text { Total } \\
\text { Weight (g) }\end{array}$ & $\begin{array}{c}\mathbf{H}_{2} \mathbf{O} / \text { Sample } \\
\text { Ratio }\end{array}$ & $\begin{array}{c}\text { Weight } \\
\text { Leachate (g) }\end{array}$ & $\begin{array}{c}\text { Weight } \\
\mathbf{H}_{\mathbf{2}} \mathbf{O}(\mathbf{g})\end{array}$ & Dilution \\
\hline SPC00574979 & 0.52069 & 10.4 & 10.92069 & 19.97 & 0.14892 & 1.48384 & 9.964 \\
\hline SPC00574982 & 0.52454 & 10.5 & 11.02454 & 20.02 & 0.15154 & 1.47981 & 9.765 \\
\hline SPC00574983 & 0.53774 & 10.7 & 11.23774 & 19.90 & 0.14405 & 1.46478 & 10.169 \\
\hline SPC00574984 & 0.48179 & 9.6 & 10.08179 & 19.93 & 0.14810 & 1.47324 & 9.948 \\
\hline SPC00574985 & 0.45190 & 9.0 & 9.45190 & 19.92 & 0.14342 & 1.47242 & 10.266 \\
\hline SPC00574986 & 0.56698 & 11.3 & 11.86698 & 19.93 & 0.14939 & 1.45234 & 9.722 \\
\hline SPC00574987 & 0.53687 & 10.7 & 11.23687 & 19.93 & 0.14845 & 1.52118 & 10.247 \\
\hline SPC00574990 & 0.45033 & 9.0 & 9.45033 & 19.99 & 0.14461 & 1.46387 & 10.123 \\
\hline SPC00574991 & 0.47963 & 9.5 & 9.97963 & 19.81 & 0.15064 & 1.56705 & 10.403 \\
\hline SPC00574992 & 0.53101 & 10.6 & 11.13101 & 19.96 & 0.14811 & 1.47530 & 9.961 \\
\hline
\end{tabular}

Source: Safley 2005 [DIRS 174143], p. 6.

Scoping sample analyses deviated from the approved procedure in the use of the dust SPC barcode numbers for the leachate samples instead of separate SPC barcode numbers for each water leachate. In addition to operational checks of the balance, calibration of the balance is also required according to USGS technical procedure YMP-USGS-GCP-42, Calibration of Laboratory Scales and Analytical Balances (effective 6/2/05). These deviations did not affect the results of the analyses.

The leachate samples were provided for determination of anion and cation concentrations by ion chromatography. This analysis followed YMP-USGS-HP-202 R1-M1, Analysis of Water Samples for Anion, Cation, and Silica Concentrations by Ion Chromatography (effective 11/30/04). Anions were measured using Dionex ICS 2000 (SN 0409377) and cations were measured using Dionex ICS 2000 (SN 04090430). Calibration of the equipment was performed using standards prepared prior to running each set of samples. Deionized water blanks were occasionally alternated with the samples being analyzed in order to clean the fluid lines (calibration records and supporting documentation for ion chromatography analysis are available in Safley 2005 [DIRS 174143], pp. 7 to 25). The results of the ion chromatography for the ESF were submitted as part of DTN: GS050408313000.001 [DIRS 173724]. The data being qualified for intended use are a subset of the data in this DTN.

Individuals involved with the sample collection, sample handling, and laboratory analyses have been trained to the various procedures and are technically competent to perform the required tasks. The personnel have performed prior qualified geochemical analyses of dust samples using existing QA-approved sample handling, equipment calibration, measurement system, and ion chromatography analyses techniques. Their development plans and training records are available in the YMP Records Information System and on the training server.

A statement of intended use by the principal investigator of the scoping analyses was submitted to the YMP Records Information System (Peterman 2005 [DIRS 174140]). It states that there is no reason to suspect the technical accuracy of the data as representing in situ conditions, and the data could be used to give a preliminary indication of the dust chemistry. In the current report, 
the composition of the dust leachates is used to calculate the chemical analysis with respect to the corrosivity of brines that might form by dust deliquescence.

The qualification team, with assistance from the USGS personnel, performed the technical assessment and concluded that the leaching analyses followed the appropriate methods consistent with the subsequently QA-approved leaching procedure. Sample collection and handling, and ion chromatography analysis techniques, followed existing QA-approved procedures. The organization, equipment calibrations, measurement systems, calculations, and procedures followed were consistent with those used to collect other qualified geochemical compositions of dust data. The data are available in the Records Processing Center package for DTN: GS050408313000.001 [DIRS 173724], and in sample collection reports cited in Curatorial Sample Inventory and Tracking System and the Records Information System. The qualification team recommends that the water-soluble ion concentrations from dust samples be considered "Qualified for Intended Use" in this analysis for evaluating the effects of ammonium mineral decomposition on deliquescence of tunnel dusts. 
BSC

\section{Data Qualification Plan}

Complete only applicable items.
QA: QA

Page 1 of 1

Section I. Organizational Information

Qualification Title

QUALIFICATION OF WATER-SOLUBLE IONS IN DUST SAMPLES

Requesting Organization

PCA - NEAR FIELD ENVIRONMENT

Section II. Process Planning Requirements

1. List of Unqualified Data to be Evaluated

GS050408313000.001 Scoping Analysis for Water-Soluble Ions in ESF, ECRB, and Surface Dust Samples

(Only the water-soluble ion concentrations from leaching of ESF dust samples are being qualified for intended use).

2. Type of Data Qualification Method(s) [Including rationale for selection of method(s) (Attachment 3 ) and qualification attributes (Attachment 4)]

Technical Assessment is used since the data were collected as a scoping analysis and do not meet all QA requirements. An independent evaluation of the data and available documentation from leaching analyses of ESF dust samples will be performed to justify that the data acquisition was appropriate and traceable to the original source of the data, analysis methods are consistent with QA-approved procedures, conducted by qualified individuals, collected under proper environmental conditions, and that the collected results are appropriate, reasonable, and suitable for their intended use. Gene Safley will meet in Denver with USGS personnel to collect additional supporting information and present the documentation to the Qualification Team to justify the qualification. The qualification attributes include evaluation of the technical adequacy of equipment and procedures used to collect and analyze data, extent and reliability of documentation associated with the data, the extent to which the data demonstrate the properties of interest, the personnel and organization generating the data, prior professional reviews of the data and their results, and prior uses of the data.

3. Data Qualification Team and Additional Support Staff Required

Charles Bryan - Qualification Chairperson

Gene Safley - Team Member

Ernest Hardin - Responsible Manager

\section{Data Evaluation Criteria}

Data and documentation will be evaluated to determine that the data acquisition method followed proper technical procedures, that sample numbers can be tracked to the Sample Tracking System, that all calibration records for the equipment used are available, that personnel performing the analysis were properly trained, and that the data results be reviewed for their intended use. Documentation collected from the USGS in Denver will be submitted to the YMP Records Processing Center and the TDIF will be updated. If the data and documentation meet these requirements, the data will be considered Qualified for Intended Use within Analysis Report ANL-EBS-MD-000074 REV 01.

\section{Identification of Procedures Used}

LP-SIII.2Q-BSC

LP-SIII.9Q-BSC

\section{Section III. Approval}

\begin{tabular}{l|l|l}
\hline $\begin{array}{l}\text { Qualification Chairperson Printed Name } \\
\text { Charles Bryan }\end{array}$ & Qualification Chairperson Signature & Date \\
\hline $\begin{array}{l}\text { Responsible Manager Printed Name } \\
\text { Ernest Hardin }\end{array}$ & Responsible Manager Signature & Date $8 / 175$ \\
\hline
\end{tabular}


INTENTIONALLY LEFT BLANK 


\begin{abstract}
APPENDIX G
QUALIFICATION OF THE SOLUBLE SALT CONTENT IN ATMOSPHERIC DUST SAMPLES COLLECTED IN FORTYMILE WASH FROM 1985 TO 1989, REPORTED IN REHEIS AND KIHL 1995 [DIRS 106653]
\end{abstract}


In this appendix, the soluble salt contents in dust samples taken at six Fortymile Wash locations are being qualified per LP-SIII.2Q-BSC. The data to be qualified are cited in Table 4.1-9 of the current report and are used as input in Output DTN: SN0508T0502205.016. This technical assessment qualification method follows the requirements presented in the Data Qualification Plan, a facsimile of which is provided at the end of this appendix.

The source, a study by Reheis and Kihl (1995 [DIRS 106653]), presents project data from years of sample collection and analysis of dust in southern Nevada and California. Analyses of these samples was simple, involving quantification of the percent of soluble salts present. However, it was extensive, with multiple samples collected from multiple collectors at the same general location. Six such sites for dust collection were located in Fortymile Wash, very close to Yucca Mountain. The data from these locations appropriately represent the property of interest to this report, which is the soluble salt content of atmospheric dust from all sources in the Yucca Mountain area.

The data to be qualified are soluble salt concentrations in atmospheric dust. The dust samples were collected by USGS personnel from the years 1985 through 1989, on an annual basis. The analyses are not found in any Yucca Mountain Project DTN; they are presented only in the cited journal article. These data are qualified here by technical assessment, through review of the technical adequacy of the equipment and procedures used to collect and analyze the data, the qualifications of the personnel involved, and quality and consistency of the data themselves.

The technical adequacy of equipment and procedures was evaluated through the descriptions given in the source document, and additional procedural information derived from the Yucca Mountain Project records system. As described within the source article, dust samples were collected using traps suspended at least 1.5 meters above ground to limit collection of locally derived coarse wind-blown particulates. Dust samples were collected from the traps annually, and the soluble salt content was determined by extraction with water and gravimetric measurement. This straightforward method is easily implemented and produces reliable results.

Initial dust sampling was performed without a governing procedure. In 1987, USGS technical procedure NNWSI-USGS-GP-22 R0, Dust Trap Sampling and Analysis (effective 1/8/87) was implemented; a revised version was issued later that year: USGS Technical Procedure NMW-USGS-GP-22, R1, Dust Trap Sampling (effective 12/3/87). Review of these procedures indicates that they are appropriate and are consistent with generally accepted scientific practices.

This study was directed by the USGS, and involved both personnel from the USGS and the University of Colorado, Boulder. The principal investigator and first author of the source article, Marith C. Reheis of the U.S. Geological Survey, has published more than 20 articles on soil properties and dust deposition in the Western United States. The principal investigator is widely recognized in source studies of the chemical components in desert soils, and was competent to direct this study.

These data were published in the Journal of Geophysical Research, which is a respected journal with a long record of publication. Its articles are peer-reviewed, i.e., reviewed by other experts in the pertinent technical field, including individuals with experience in the subject matter who typically use such information in the course of their work. Technical problems identified by the 
review process are either resolved prior to publication or the article is rejected. This process provides a high level of confidence that the information is suitable for use in the types of analyses for which it was intended. This source article has been cited over 50 times in the open scientific literature.

The data being qualified are each based upon four independent measurements, with their mean values and standard deviations presented in Table G-1. They are a subset of sixty analyses presented in the source document, and are corroborated by the remaining data. The six Fortymile Wash analyses (Table G-1) fall near the center of the range of the entire data set (3.6\% to $18.3 \%)$. The data are self-consistent and contain no outliers, with all values falling within two standard deviations of the mean value $(10.5 \%)$.

Table G-1. Fortymile Wash Dust Data

\begin{tabular}{|c|c|c|c|}
\hline Site (T) & Soluble Salt (\%) & $\begin{array}{c}\text { Number of } \\
\text { Samples }\end{array}$ & $\begin{array}{c}\text { Standard } \\
\text { Deviation (\%) }\end{array}$ \\
\hline 1 & 12.2 & 4 & 3.7 \\
\hline 2 & 11.1 & 4 & 3.0 \\
\hline $3 a$ & 6.3 & 4 & 2.7 \\
\hline 4 & 12.4 & 4 & 3.4 \\
\hline 5 & 13.1 & 4 & 2.4 \\
\hline 6 & 7.9 & 4 & 3.2 \\
\hline a This column contains the input data being qualified in this appendix, \\
as presented in Table 4.1-9.
\end{tabular}

Source: Reheis and Kihl 1995 [DIRS 106653], Table 2.

The organization, equipment, measurement methods, and procedures followed were consistent with generally accepted scientific practices. Personnel were qualified to direct and perform this dust collection and analysis. The data are self-consistent and corroborated by data from other dust collection sites presented in the source document. The qualification team recommends that the soluble salt contents for atmospheric dust from Fortymile Wash be considered "Qualified for Intended Use" for estimating deliquescent brine quantities in this report (Section 6.4.1.2). 


\section{BSC}

\section{Data Qualification Plan}

Complete only applicable items.
QA: QA

Page 1 of 1

\begin{tabular}{|c|c|c|}
\hline \multicolumn{3}{|c|}{$\begin{array}{l}\text { Qualification Title } \\
\text { QUALIFICATION OF THE SOLUBLE SALT CONTENT IN ATMOSPHERIC DUST SAMPLES COLLECTED IN FORTYMILE } \\
\text { WASH FROM } 1985 \text { TO 1989, REPORTED IN REHEIS AND KIHL, } 1995 \text { [DIRS 106653] }\end{array}$} \\
\hline \multicolumn{3}{|l|}{$\begin{array}{l}\text { Requesting Organization } \\
\text { PCA - NEAR FIELD ENVIRONMENT }\end{array}$} \\
\hline \multicolumn{3}{|c|}{ Section II. Process Planning Requirements } \\
\hline \multicolumn{3}{|c|}{$\begin{array}{l}\text { 1. List of Unqualified Data to be Evaluated } \\
\text { The data to be qualified consist of soluble salt contents for dust samples collected in } 6 \text { atmospheric dust samplers in } \\
\text { Fortymile Wash, over the period from } 1985 \text { to } 1989 \text {. These data are summarized in Table } 2 \text { of Reheis and Kihl (1995 } \\
\text { [DIRS 106653], Sites 1-6). }\end{array}$} \\
\hline \multicolumn{3}{|c|}{$\begin{array}{l}\text { 2. Type of Data Qualification Method(s) [Including rationale for selection of method(s) (Attachment 3) and qualification attributes } \\
\text { (Attachment 4)] } \\
\text { Technical Assessment is used by reviewing the methods used to collect and analyze the dust samples, as described in the } \\
\text { Reheis and Kihl journal article, and the USGS procedures in use at the time. The primary qualification attribute is to } \\
\text { determine the technical adequacy of the equipment and procedures used to collect and analyze the data. Additional } \\
\text { attributes include evaluation of the organization generating the data, the extent to which the data demonstrate the } \\
\text { properties of interest, prior professional reviews of the data and their results, extent and quality of corroborating data and } \\
\text { confirmatory results, and extent and reliability of documentation associated with the data. }\end{array}$} \\
\hline \multicolumn{3}{|c|}{$\begin{array}{l}\text { 3. Data Qualification Team and Additional Support Staff Required } \\
\text { Charles Bryan - Qualification Chairperson } \\
\text { Russell Jarek - Qualification Team Member } \\
\text { Ernest Hardin - Responsible Manager }\end{array}$} \\
\hline \multicolumn{3}{|c|}{$\begin{array}{l}\text { 4. Data Evaluation Criteria } \\
\text { Documentation of sample collection and analysis procedures will be evaluated for clarity and completeness with } \\
\text { generally accepted dust collection and laboratory analysis procedures. In addition, the data from the } 6 \text { Fortymile Wash } \\
\text { sites will be evaluated for consistency. If documentation of the sampling and analysis procedures is adequate, and the } \\
\text { procedures follow accepted scientific practices, and the data from Fortymile Wash are consistent to within two standard } \\
\text { deviations, the data will be considered Qualified for Intended Use within Analysis Report ANL-EBS-MD-000074 } \\
\text { REV } 01 \text {. }\end{array}$} \\
\hline \multicolumn{3}{|l|}{$\begin{array}{l}\text { 5. Identification of Procedures Used } \\
\text { LP-SIII.2Q-BSC } \\
\text { LP-SIII.9Q-BSC }\end{array}$} \\
\hline \multicolumn{3}{|l|}{ Section III. Approval } \\
\hline $\begin{array}{l}\text { Qualification Chairperson Printed Name } \\
\text { Charles Bryan }\end{array}$ & Qualification Chairperson Signature & $\begin{array}{l}\text { Date } \\
\quad 8 / 17 / 05\end{array}$ \\
\hline $\begin{array}{l}\text { Responsible Manager Printed Name } \\
\text { Ernest Hardin }\end{array}$ & Respónsible Manager Signature & Date $8 / 18 / 05$ \\
\hline \multicolumn{3}{|c|}{-3} \\
\hline
\end{tabular}




\section{INTENTIONALLY LEFT BLANK}

